\title{
Tätigkeitsbericht 2002/2003
}

- Konzeption

- Planung

- Schwerpunkte

- Ergebnisse

\section{Impressum}

\section{Herausgeber:}

Direktoren des Max-Planck-Instituts für ausländisches und internationales Strafrecht

Freiburg im Breisgau

Günterstalstr. 73

79100 Freiburg im Breisgau

\section{Redaktion}

Jörg Arnold

Michael Kilchling

Irene Kortel

Beate Lickert

Christa Wimmer

Internet-Adresse: www.iuscrim.mpg.de 


\section{VORBEMERKUNG}

\section{ALLGEMEINE FORSCHUNGSKONZEPTION DES INSTITUTS}

1. Forschungsaufgaben des Instituts 13

2. Überblick über die bisherigen Forschungsfelder des Instituts 13

3. Zukünftige Forschungsschwerpunkte 14

II. SCHWERPUNKTE DER WISSENSCHAFTLICHEN ARBEIT 2002/2003 16

1. Gemeinsame Projekte beider Forschungsgruppen 16

The Punishment of Serious Crimes - A Comparative Analysis of Sentencing Law and Practice

2. Forschungsvorhaben und Referatsbereiche auf dem Gebiet des Strafrechts

2.1 Überblick über die Arbeitsschwerpunkte der strafrechtlichen $\begin{array}{lr}\text { Forschungsgruppe } & 18\end{array}$

2.2 Gemeinschaftliche Projekte innerhalb der strafrechtlichen Forschungsgruppe 20

2.2.1 Allgemeiner strafrechtlicher Strukturvergleich 20

2.2.2 Strafrecht in Reaktion auf Systemunrecht - Vergleichende Einblicke in Transitionsprozesse

2.2.3 Nationale Strafverfolgung völkerrechtlicher Verbrechen im internationalen Vergleich

2.2.4 Die Rolle der Ehre im Strafrecht

2.2.5 Private Commercial Bribery Laws in Major OECD Country Groups

2.2.6 Freiburg Proposal on Concurrent Jurisdictions and the Prohibition of Multiple Prosecutions in the European Union

2.3 Einzelvorhaben 36

2.3.1 Schwerpunkt: Deutsches Straf- und Strafverfahrensrecht 36

NS-Fortsetzungspropaganda zwischen Versammlungsrecht und Internet Ein Beitrag zum strafrechtlichen Umgang der Bundesrepublik Deutschland mit NS-bezogenen Delikten 
2.3.2.3 Strafrechtliche Reaktion auf Systemunrecht in Rumänien nach 1989 im Vergleich zu anderen osteuropäischen Staaten

2.3.3 Schwerpunkt: Rechtsvergleichung

2.3.3.1 Wiedergutmachungsansätze für Kriminalitätsopfer im deutschen und amerikanischen Recht

2.3.3.2 Grenzüberschreitende Auswirkungen von ne bis in idem in horizontaler und vertikaler Richtung

2.3.4 Schwerpunkt: Europäische Zusammenarbeit in Strafsachen

Beweisrechtsgrundsätze für eine grenzüberschreitende Strafverfolgung

2.3.5 Schwerpunkt: Internationales Strafrecht, Völkerstrafrecht sowie Menschenrechte

2.3.5.1 Völkerrechtliche Exemtionen von strafrechtlicher Verantwortlichkeit

2.3.5.2 Die Rolle des Anklägers eines Internationalen Strafgerichtshofs

2.3.5.3 Sexuelle Gewalt als verbotenes Mittel der Kriegsführung

2.3.5.4 Völkerstrafrechtliche Verbrechen und ihre Erfassung durch die rumänische Strafgewalt - Ein Vergleich des rumänischen Strafgesetzbuchs mit dem Römischen Statut und dem deutschen Völkerstrafgesetzbuch

2.3.5.5 Strafrecht in Postkonfliktsituationen - eine komparative Untersuchung zum Einsatz von Strafrecht in der Internationalen Gemeinschaft

2.3.6 Schwerpunkt: Recht und Medizin

2.3.6.1 Medizinrechtliche Aspekte des Klonens

2.3.6.2 Der Status des extrakorporalen Embryos in interdisziplinärer Perspektive

2.3.6.3 Der Schutz des Menschen in der biomedizinischen Forschung. Ein Vergleich der Bioethik-Konvention mit dem deutschen und dem griechischen Recht

2.4 Länder- und Sachbereiche

2.4.1 Allgemeine Aufgaben 
2.4.3 Länderbereich Schweiz und Österreich 57

2.4.4 Länderbereich Frankreich $\quad 58$

$\begin{array}{lll}\text { 2.4.5 Länderbereich Italien } & 60\end{array}$

2.4.6 Länderbereich Portugal, Spanien, Belgien und Brasilien 61

2.4.7 Länderbereich Common-Law-Länder (Schwerpunkt Großbritannien) 63

2.4.8 Länderbereich Vereinigte Staaten von Amerika 64

$\begin{array}{ll}\text { 2.4.9 Länderbereich Nordische Länder } & 65\end{array}$

2.4.10 Länderbereich Osteuropa - Schwerpunkt ehemalige sowjetische Republiken 67

2.4.11 Länderbereich Osteuropa - Schwerpunkt Polen 67

2.4.12 Länderbereich Türkei, Iran, arabische Staaten 69

2.4.13 Länderbereich Ostasien 70

2.4.14 Länderbereich Hispanoamerika 71

2.4.15 Länderbereich Afrika (südlich der Sahara) 72

$\begin{array}{lll}2.5 & \text { Sachbereiche } & 73\end{array}$

$\begin{array}{lll}\text { 2.5.1 Sachbereich Internationales Strafrecht } & 73\end{array}$

$\begin{array}{lll}\text { 2.5.2 Sachbereich Europarecht } & 74\end{array}$

$\begin{array}{lll}\text { 2.5.3 Sachbereich Recht und Medizin } & 75\end{array}$

$\begin{array}{lll}\text { 2.5.4 Gutachtenreferat } & 77\end{array}$

2.5.5 Veröffentlichungsreferat (Strafrechtliche Abteilung) 79

2.5.6 Übersetzungsreferat (Deutsch-Englisch) 80

3. Forschungsschwerpunkte und Forschungsplanung auf dem
Gebiet der Kriminologie

3.1 Arbeitsschwerpunkte und Forschungsplanung 81

$\begin{array}{lll}3.1 .1 & \text { Arbeitsschwerpunkte } & 81\end{array}$

$\begin{array}{lll}3.1 .2 & \text { Forschungsplanung } & 82\end{array}$

3.2 Schwerpunkt "Sanktions- und Vollzugsforschung" $\quad 84$

3.2.1 Die Implementation von Sanktionen 84 
3.2.1.1 Berücksichtigung von Angehörigen bei der Auswahl und Vollstreckung von Sanktionen

3.2.1.2 Evaluation eines Modellprojekts zum Einsatz der elektronischen Fußfessel (Hessen)

3.2.1.3 Die Implementation der Fußfessel in Hessen - Eine Evaluation des

Einführungsprozesses anhand empirischer Analyse der Rechtswirklichkeit und Effizienz des elektronisch überwachten Hausarrests

3.2.1.4 Untersuchungshaftvermeidung bei Jugendlichen und Heranwachsenden in Baden-Württemberg aus Sicht der Praxis

3.2.2 "Gefährliche Straftäter": Rückfall und Behandlung

3.2.2.1 Sexuelle Gewalt im Lebenslängsschnitt

3.2.2.2 Legalbewährung von Sicherungsverwahrten und gefährlichen Straftätern eine Nachuntersuchung

3.2.2.3 Opfer von Sexualstraftaten

3.2.2.4 Sexualstraftäter in sozialtherapeutischen Anstalten des Freistaates Sachsen

3.2.2.5 Jugendliche Sexualstraftäter in sozialtherapeutischen Abteilungen des Freistaates Sachsen

3.2.2.6 Die Entwicklung eines empirisch begründeten, differentialdiagnostischen Modells zur Typisierung von Sexualstraftätern nach therapie- und prognoserelevanten psychometrischen Daten

3.3 Schwerpunkt "Organisierte Kriminalität und Innere Sicherheit"

3.3.1 Rechtsberatungs- und Wirtschaftsprüfungsberufe aus der Perspektive von Geldwäsche und Geldwäschekontrolle

3.3.2 Strafverfolgung von Menschenhandel

3.3.3 Die rechtliche Bewältigung von Erscheinungsformen organisierter Kriminalität

3.3.4 Organisierte Kriminalität im internationalen Kontext

3.3.5 The Double Construction of Crime. Patterns of Definition and of Organization of Crime in Two European Cities (Milan and Frankfurt)

3.3.6 Organized Crime in Europe: Manifestations and Policies in the European Union and Beyond 
3.3.8 Modelling the World Heroin Market: Assessing the Consequences of Changes in Afghanistan Production

3.4 Schwerpunkt "Normanwendung im Strafverfahrensrecht"

3.4.1 Rechtswirklichkeit und Effizienz der Überwachung der Telekommunikation nach den $\S \S 100 \mathrm{a}, 100 \mathrm{~b}$ StPO und anderer verdeckter Ermittlungsmaßnahmen

3.4.1.1 Rechtswirklichkeit der Überwachung der Telekommunikation nach $\S \S 100 \mathrm{a}, 100 \mathrm{~b}$ StPO

3.4.1.2 Effizienz der Überwachung der Telekommunikation nach den $\S \S 100 \mathrm{a}, 100 \mathrm{~b}$ StPO

3.4.1.3 Rechtswirklichkeit und Effizienz der akustischen Wohnraumüberwachung ("großer Lauschangriff") nach $\S 100$ c I Nr. 3 StPO

3.4.1.4 Möglichkeiten und Praxis elektronischer Überwachungsmaßnahmen in Europa

3.4.2 Cannabis Non-Prosecution Policies in Germany

3.4.3 Implementations- und Evaluationsprojekt zu Täter-Opfer-Ausgleich und Wiedergutmachung im allgemeinen Strafrecht im deutschösterreichischen Vergleich

3.4.4 Drogenkonsum und Strafverfolgungspraxis

3.5 Schwerpunkt "Opferforschung"

3.5.1 Viktimisierung und Viktimisierungsverarbeitung in den Bürgerkriegsregionen des ehemaligen Jugoslawien

3.5.2 Methoden und Diskurse empirischer Beschreibung von MassenViktimisierungen. Eine Untersuchung am Beispiel der Opferwerdung im ehemaligen Jugoslawien und an EU-Außengrenzen

3.5.3 Viktimisierung und Verbrechensangst in den alten und neuen Bundesländern Deutschlands - Vergleich Jena - Freiburg I und II

3.6 Schwerpunkt "LEA - Laboratoire Européen Associé"

3.6.1 Die Entwicklung der Staatsgrenzen in den Ländern Ex-Jugoslawiens und in Albanien

3.6.2 Grenzüberschreitende polizeiliche Kooperation - Praktiken, Institutionen und Strukturen entlang der deutsch-französischen Grenze

3.6.3 Arbeit und Strafvollzug: eine rechtsvergleichende Studie der Aufgaben und Ausgestaltung der Gefangenenarbeit in Frankreich, Deutschland und England 
3.6.4 Strafrechts-Mediation: das Paradox eines außergerichtlichen Verfahrens im strafrechtlichen Rahmen. Eine rechtssoziologische Untersuchung am Beispiel des deutschen Täter-Opfer-Ausgleichs und der französischen médiation pénale

3.6.5 Rechtliche und tatsächliche Kriterien der Strafzumessung im deutschfranzösischen Vergleich

3.6.6 Abschiebungshaft in Deutschland und in Frankreich

3.7 Schwerpunkt "Sozialer Wandel, Veränderung von Lebenslagen, Kriminalität und Kriminalitätskontrolle"

3.7.1 Freiburger Kohortenstudie

3.7.1.1 Kohortenstudie zur Entwicklung polizeilich registrierter Kriminalität und strafrechtlicher Sanktionierung

3.7.1.2 Sanktion und Legalbewährung im Jugendstrafverfahren in BadenWürttemberg - Eine Analyse der Legalbewährung von jugendlichen Straftätern nach einer formellen bzw. informellen Erledigung des Verfahrens anhand der Freiburger Kohortenstudie

3.7.1.3 Analyse von Deliktsähnlichkeiten auf der Basis von Individualdaten

3.7.1.4 Gewaltkriminalität im Lebenslauf - Eine Längsschnittanalyse von jugendlichen Gewalttätern anhand der Daten der Freiburger Kohortenstudie

3.7.2 Subjektive Kriminalitätstheorien - Alltagswissen und Vorstellungen über Kriminalität in der Bevölkerung

3.7.3 Kriminalitätswahrnehmung und die Schwereeinschätzung von Delikten

3.7.4 "Punitivität" - ein konzeptioneller und empirischer Ansatz

3.7.5 Gewalt- und Jugenddelinquenz im sozialökologischen Kontext

3.7.6 Individuelle und strukturelle Determinanten von Anzeigeverhalten und Entdeckungsrisiko delinquenter Jugendlicher 
IV. WISSENSCHAFTLICHE VERANSTALTUNGEN DES INSTITUTS 298

1. Tagungen am oder in Zusammenarbeit mit dem Institut 298

2. Kolloquien am Institut 300

2.1 Allgemeine Kolloquien am Institut 300

2.2 Wissenschaftliche Kolloquien der strafrechtlichen Forschungsgruppe 300

2.3 Wissenschaftliche Kolloquien der kriminologischen Forschungsgruppe 301

3. Doktorandensprecher/Doktorandentreffen 302

V. WISSENSCHAFTLICHE VORTRÄGE 303

VI. BETEILIGUNG AN DER LEHRE 333

VII. STUDIENAUFENTHALTE, VORTRAGSREISEN, KONTAKT- UND INFORMATIONSREISEN 336

VIII. ZUSAMMENARBEIT MIT ANDEREN FORSCHUNGSEINRICHTUNGEN DES IN- UND AUSLANDS

IX. BEZIEHUNGEN ZU WIRTSCHAFT, POLITIK UND GESELLSCHAFT

X. ÖFFENTLICHKEITSARBEIT 342

XI. SONSTIGE WISSENSCHAFTLICHE TÄTIGKEITEN 343

XII. RUFE UND WISSENSCHAFTLICHE AUSZEICHNUNGEN 345

XIII. AUSLÄNDISCHE WISSENSCHAFTLER AM INSTITUT UND ENTWICKLUNGEN IM BEREICH DES WISSENSCHAFTLICHEN NACHWUCHSES 346

1. Ausländische Wissenschaftler am Institut 346 
2. Entwicklungen im Bereich des wissenschaftlichen Nachwuchses (Doktoranden/Habilitanden)

$\begin{array}{lll}2.1 & \text { Strafrechtliche Forschungsgruppe } & 347\end{array}$

2.2 Kriminologische Forschungsgruppe $\quad 348$

XIV. EDV UND BIBLIOTHEK

$\begin{array}{lll}\text { 1. } & \text { EDV } & 351\end{array}$

1.1 Interne und externe Informationsdienste, Internet-Repräsentation, Angebote, Informationsmanagement 351

1.2 Beschaffung, Umbau 353

$1.3 \quad$ Konsolidierung und Umstrukturierung 353

$\begin{array}{lll}1.4 & \text { Sicherheit } & 354\end{array}$

$\begin{array}{lll}1.5 & \text { Sonstiges } & 354\end{array}$

$\begin{array}{lll}1.6 & \text { Planung } & 355\end{array}$

2. Bibliothek 356

$2.1 \quad$ Überblick 356

$\begin{array}{lll}2.2 & \text { Personal } & 356\end{array}$

2.3 Etat und Verteilung der Mittel 356

$\begin{array}{lll}2.4 & \text { Bestand und Zuwachs } & 357\end{array}$

2.5 Digitale Informationsversorgung und Internet 357

$\begin{array}{lll}2.6 & \text { Benutzung } & 358\end{array}$

$\begin{array}{lll}2.7 & \text { Projekte } & 359\end{array}$

2.7.1 Umstellung auf ein neues EDV-System der Bibliothek (Aleph) 359

$\begin{array}{lll}\text { 2.7.2 Retrospektive Katalogisierung } & 359\end{array}$

2.7.3 Zusammenführung des Sonderbestandes "Recht und Medizin" 360

2.7.4 Bibliographie "New Criminological Literature in Europe" 360 


\section{Vorbemerkung}

Der vorliegende Tätigkeitsbericht 2002/2003 des Max-Planck-Instituts für ausländisches und internationales Strafrecht betrifft eine Zeit des Übergangs: Am 31.1.2003 wurde der langjährige Direktor des Instituts, Prof. Dr. Dr. h.c. mult. Albin Eser, emeritiert. Am 1.10.2003 wurde als sein Nachfolger Prof. Dr. Ulrich Sieber von der Ludwig-Maximilians-Universität München zum hauptamtlichen Institutsdirektor und Leiter der strafrechtlichen Forschungsgruppe ernannt.

Der Tätigkeitsbericht 2002/2003 ist deswegen, soweit er die strafrechtliche Forschungsgruppe betrifft, vor allem durch die von dem früheren Direktor Prof. Dr. Eser initiierten Projekte geprägt, welche die Tätigkeit des Instituts auch im Jahr 2003 noch wesentlich bestimmt haben. Aktivitäten von Prof. Dr. Sieber sind insoweit aufgenommen, als sie in den letzten drei Monaten des Jahres 2003 am Institut erfolgten.

Der Tradition der bisherigen Berichte folgend wird das neue Programm von Prof. Dr. Sieber zusammen mit den Planungen des Leiters der kriminologischen Forschungsgruppe und Direktors des MaxPlanck-Instituts Prof. Dr. Hans-Jörg Albrecht im Rahmen der allgemeinen Forschungskonzeption des Instituts kurz skizziert. Eine ausführlichere Darstellung des Forschungsprogramms von Prof. Dr. Sieber erfolgt bei der Feier aus Anlass der Amtsübergabe am 2. März 2004. 





\section{Allgemeine Forschungskonzeption des Instituts}

\section{Forschungsaufgaben des Instituts}

Die Forschungen des Max-Planck-Instituts für ausländisches und internationales Strafrecht sind rechtsvergleichend, internationalrechtlich, interdisziplinär und auf empirische Untersuchungen der Kriminalität, der Kriminalitätskontrolle sowie des Opfers der Straftat ausgerichtet. Im rechtsvergleichenden Zugang werden ausländische Rechtsordnungen und Rechtspraktiken untersucht und mit dem deutschen Strafrechtssystem kontrastiert. Dabei geht es gleichermaßen um Erkenntnisse über den bereits existierenden Bestand an rechtlichen Lösungen für bestimmte soziale Probleme, funktionale rechtliche und außerstrafrechtliche Alternativen sowie daraus zu ziehende Konsequenzen für die Fortentwicklung des Strafrechts. Untersuchungen zur Implementation des Rechts, zu den tatsächlich eingetretenen Folgen kriminellen Verhaltens sowie zu Entwicklungen von Kriminalitätsphänomenen stellen in diesem Zusammenhang wichtige Grundlagen für die Beurteilung der Wirksamkeit des Rechts zur Verfügung. Von hervorragender Bedeutung für die wissenschaftliche Tätigkeit des Instituts sind weiterhin Fragen der europäischen Integration und hierbei bedeutsamer Ziele wie Harmonisierung und Angleichung des Straf- und Strafverfahrensrechts der Mitgliedstaaten der Europäischen Union.

Das Max-Planck-Institut arbeitet insoweit an Grundlagenfragen zu den Strukturen des Strafrechts und dessen Rolle und Funktionen in einer sozial und wirtschaftlich vernetzten Welt, die einem rapiden sozialen Wandel unterworfen ist. Im Vordergrund steht dabei die - durchaus auch kritisch zu beleuchtende - Frage nach dem in modernen und komplexen Gesellschaften vorhandenen Potential an Steuerung und Lenkung durch Strafrecht mit den ihm eigenen und in einem Spannungsverhältnis stehenden Zielsetzungen des Schutzes von Rechtsgütern sowie der Gewährleistung von Sicherheit, Freiheit, Vorhersehbarkeit und Gerechtigkeit in sozialen und wirtschaftlichen Austauschprozessen. Drastische Zuwächse von grenzüberschreitenden kriminellen Aktivitäten, Mobilität, Migration und Verlagerungspotentiale stellen die Politik der Steuerung durch national gesetztes Strafrecht vor neue Probleme, aber auch vor Schranken.

Die Bearbeitung strafrechtsvergleichender, internationalrechtlicher und empirischer Fragestellungen der angesprochenen Art führt die Tätigkeit des Max-Planck-Instituts auch in die wissenschaftliche Beratung über in- und ausländische Gesetzgebung sowie zur Anfertigung von Gutachten für Gerichte, Behörden, Kanzleien und sonstigen einschlägig tätigen Organisationen. Die Aufgaben der Grundlagenforschung im Bereich der Rechtsvergleichung und des internationalen Rechts sind ferner mit der Einrichtung und Unterhaltung einer Schwerpunktbibliothek für die Bereiche des Strafrechts, des Strafverfahrensrechts und der Kriminologie verbunden.

\section{2. Überblick über die bisherigen Forschungsfelder des Instituts}

Wichtige laufende Tätigkeitsfelder der strafrechtlichen Forschungsgruppe waren im Jahr 2002/2003 neben der kontinuierlichen Beobachtung der Fortentwicklung des ausländischen und internationalen Strafrechts - exemplarisch: Strukturvergleich des Strafrechts, Strafrechtsangleichung in Europa, Möglichkeiten und Grenzen der Auslieferung in rechtsvergleichender Sicht und dabei insbesondere die Rechtsstellung des betroffenen Individuums bei der Internationalen Rechtshilfe, Strafrecht in Reaktion auf Systemunrecht, Völkerstrafrecht (d.h. sowohl die Arbeit der internationalen Tribunale als auch die nationale Strafverfolgung völkerrechtlicher Verbrechen) sowie allgemein der strafrechtliche Schutz von Menschenrechten. Ferner ist auf die zweisprachige Herausgabe von Übersetzungen ausländischer Strafgesetzbücher hinzuweisen. 
Die laufenden Arbeiten der kriminologischen Forschungsgruppe lassen sich insgesamt sechs Schwerpunkten zuordnen. Dabei handelt es sich um die Sanktions- und Vollzugsforschung, die Themenkomplexe "organisierte Kriminalität und Innere Sicherheit" sowie "Normanwendung im Strafverfahrensrecht", die Opferforschung und das LEA - Laboratoire Européen Associé, schließlich das Gebiet "Sozialer Wandel, Veränderung von Lebenslagen, Kriminalität und Kriminalitätskontrolle". Damit werden einerseits Fragestellungen aufgegriffen, die - wie etwa die Viktimologie - schon länger zum Forschungsprogramm des Instituts gehören und in verschiedenen Vertiefungen von ungebrochener Aktualität sind, andererseits Phänomene bearbeitet, die - wie beispielsweise die organisierte Kriminalität oder die Transaktionskriminalität- neue methodische und theoretische Zugänge erfordern und erst im letzten Jahrzehnt in die kriminologische Forschung Eingang gefunden haben.

\section{Zukünftige Forschungsschwerpunkte}

Die zukünftigen Planungen des Instituts betreffen insbesondere die folgenden Punkte:

a) In der strafrechtlichen Forschungsgruppe sollen nach der Neuberufung von Prof. Dr. Ulrich Sieber zunächst die bisher laufenden Projekte der strafrechtlichen Forschungsgruppe fortgesetzt und abgeschlossen werden. Dies betrifft sowohl die größeren gemeinsamen Projekte der Forschungsgruppe als auch die Einzelprojekte der Wissenschaftler.Die Fertigstellung dieser Arbeiten wird die Ressourcen des Instituts in den nächsten ein bis zwei Jahren noch in erheblichem Umfang in Anspruch nehmen. Die parallel dazu beginnenden weiterführenden und neuen Forschungen sollen dann zunehmend auch neue Schwerpunkte setzen, die vor allem durch eine verstärkte Zusammenarbeit zwischen der strafrechtlichen und der kriminologischen Forschungsgruppe geprägt sein werden.

Die neuen Schwerpunkte der strafrechtlichen Forschungsgruppe werden dabei vor allem die drei zentralen Herausforderungen im Bereich der Kriminalität und der Kriminalitätsbekämpfung betreffen, die mit den Begriffen "Weltgesellschaft", "Informationsgesellschaft" und "neue Risikogesellschaft" schlagwortartig umschrieben werden: Kriminalität wird globaler; sie nutzt dabei internationale Datennetze; ihre Auswirkungen können - durch Technik und Organisation - schon im Einzelfall gesamtgesellschaftliche Bedeutung erlangen und zu neuen Formen der Makrokriminalität führen. Diese drei Entwicklungen der Welt-, Informations- und Risikogesellschaft hängen eng miteinander zusammen, verstärken sich gegenseitig und führen auch zu teilweise gleichen Problemstellungen.

Ein wichtiger Aspekt dieser Entwicklungen ist ein häufiges Scheitern des klassischen, auf der territorialen Souveränität beruhenden rein nationalen Strafrechts: In der Weltgesellschaft lassen sich global agierende Täter nicht mehr durch ein Strafrecht kontrollieren, dessen Entscheidungen in ihrer Wirksamkeit auf ein nationales Territorium begrenzt sind und die im Falle ihrer Erstreckung auf ein anderes Staatsgebiet erst langwierige Mechanismen der Amts- oder Rechtshilfe durchlaufen müssen. In der modernen Informationsgesellschaft kann die Vielzahl der Datenpakete des Internet mit ihren oft verschlüsselten Inhalten an den Außengrenzen eines Staates nicht mehr flächendeckend überprüft werden, so dass der virtuelle Raum des Internet durch ein territorial begrenztes Strafrecht nur noch begrenzt kontrollierbar ist. Auch in der durch Technik und Organisation gekennzeichneten neuen Risikogesellschaft scheitert das klassische Strafrecht häufig an - vor allem international vernetzten - Fällen der Wirtschaftskriminalität, der organisierten Kriminalität, des Terrorismus, der Kriminalität in gewalttätigen Konflikten mit internationaler Bedeutung oder anderen Formen der Makrokriminalität.

Eine der zentralen Herausforderungen des beginnenden neuen Jahrtausends wird daher die Erforschung von internationalen und supranationalen Strafrechtssystemen und Kooperationsformen sowie von alternativen Präventionsmodellen sein, die zwar mit dem klassischen, territorial begrenzten nationalen Strafrecht zusammenwirken, jedoch in ihrer Effektivität darüber hinausgehen. Neue Formen der 
Amts- und Rechtshilfe, die unmittelbare Geltung von strafrechtlichen Entscheidungen in anderen Rechtssystemen, supranationales Strafrecht sowie europäische oder gar universelle Modellstrafgesetze gehören daher ebenso zum zukünftigen Forschungsschwerpunkt des Instituts wie die internationale Selbstregulierung der Wirtschaft, neue Formen der staatlich-privaten "Ko-Regulierung" oder der Umgang mit Post-Konfliktsituationen auf regionaler, nationaler und internationaler Ebene. In diesem Rahmen sollen auch Fragestellungen aus bisherigen Forschungsprojekten des Instituts (wie zum Projekt "Strafrecht in Reaktion auf Systemunrecht") weiterentwickelt werden.

b) Die Forschungsgruppe Kriminologie wird der wachsenden Bedeutung der Internationalität von gesellschaftlichen wie Verbrechens-Phänomenen durch einen weiteren Ausbau international vergleichend angelegter Projekte Rechnung tragen, bei denen zudem nach Bedarf eine Vernetzung mit anderen europäischen wie außereuropäischen Forschungseinrichtungen stattfindet, wie dies beispielsweise durch (komparative) Untersuchungen zum Phänomen der organisierten Kriminalität und insbesondere zu der Rolle und Funktion von (Drogen-)Märkten geschieht. 


\title{
II. Schwerpunkte der wissenschaftlichen Arbeit 2002/2003
}

1. Gemeinsame Projekte beider Forschungsgruppen

\author{
The Punishment of Serious Crimes - A Comparative Analysis of Sentencing \\ Law and Practice
}

- $\quad$ Projektleitung und -koordination: Ulrich Sieber

- $\quad$ Bearbeiter(innen): Jörg Arnold, Phillip Brunst, Karin Cornils, Helmut Gropengießer, Sven Höfer, Barbara Huber, Konstanze Jarvers, Michael Kilchling, Irini Kiriakaki, Ernesto Kiza, Roland Kniebühler, Hans-Georg Koch, Adome Blaise Kouassi, Helmut Kreicker, Verena Krenberger; Juliette Lelieur-Fischer, Jorge Ezequiel Malarino, Teresa Manso, Tilmann Mohr, Clivia Namgalies, Thomas Richter, Ulrich Sieber, Emily Silverman, Jan-Michael Simon, Silvia Tellenbach, Ingeborg Zerbes sowie externe Mitarbeiterinnen und Mitarbeiter

- Zeitrahmen: September bis Oktober 2003

- $\quad$ Projektstatus: abgeschlossen

- $\quad$ Projektbeschreibung:

Gegenstand dieses Projekts war die Erstellung eines Gutachtens für den Internationalen Strafgerichtshof für das ehemalige Jugoslawien (ICTY) zu Fragen der Rechtsfolgen bestimmter völkerrechtlicher Verbrechen und der Strafzumessungspraxis in verschiedenen Ländern. Das Gutachten ging auf eine Entscheidung des Gerichts vom 25. September 2003 zurück, mit der Prof. Dr. Sieber im Verfahren gegen Dragan Nicolić als expert witness um die Erstellung eines Gutachtens gebeten wurde. In diesem Verfahren hatte sich der Angeklagte Nicolić für schuldig bekannt, im Jahr 1992 als Leiter eines Gefangenenlagers in dem Gebiet des früheren Jugoslawien diverse Verbrechen gegen die Menschlichkeit begangen zu haben, namentlich murder (Art. 5 (a) ICTY-Statut), torture (Art. 5 (f) ICTY-Statut), rape (Art. 5 (g) ICTY-Statut) und persecutions on political, racial and religious grounds (Art. 5 (h) ICTYStatut). Zur Vorbereitung einer Strafzumessungsentscheidung des ICTY sollte das Gutachten Auskunft vor allem über zwei Fragen geben. Zum einen sollte dargelegt werden, welche Strafrahmen für diese Taten in den Rechtsordnungen der Staaten des früheren Jugoslawien und der Mitgliedsstaaten des Europarats sowie in anderen wichtigen Rechtsordnungen vorgesehen sind. Zum anderen sollte die Strafzumessungspraxis der nationalen Gerichte im Gebiet des ehemaligen Jugoslawien bei solchen Straftaten untersucht werden.

Zur Vorbereitung des Gutachtens wurden Landesberichte zu insgesamt 22 Ländern erstellt, die Auskunft über die Strafrahmen für die angeklagten Taten sowie über Grundfragen der Strafbemessung in den einzelnen Ländern geben. Im Einzelnen wurden anhand eines zuvor ausgearbeiteten einheitlichen Fragenkatalogs Landesberichte zu folgenden Staaten angefertigt:

Länder des Europarats: Belgien (Kniebühler), Deutschland (Gropengießer/Kreicker), England (Huber), Finnland (Frände, Mohr), Frankreich (Lelieur-Fischer), Griechenland (Kiriakaki), Italien (Jarvers), Österreich (Zerbes), Polen (Szeroczyńska), Russland (Shestakova), Spanien (Manso), Schweden (Cornils, Mohr), Türkei (Tellenbach).

Nord-Amerika: Kanada (Wolpert), USA (Silverman).

Südamerika: Argentinien (Malarino), Brasilien (IBCCRIM), Chile (Simon), Mexiko (Neri Guajardo).

Afrika: Côte d'Ivoire (Kouassi), Südafrika (Namgalies).

Asien: China (Richter/Yang).

Ozeanien: Australien (Warner). 
Auf der Grundlage dieser Landesberichte wurden dann in einem rechtsvergleichenden Querschnitt die vom ICTY gestellten Fragen insbesondere zu Strafrahmen, zur Strafzumessung und zur Strafaussetzung beantwortet (Arnold, Koch, Kreicker, Namgalies, Sieber, Simon).

Darüber hinaus wurden spezielle Landesberichte für die folgenden Länder des ehemaligen Jugoslawien erarbeitet: Bosnien-Herzegowina, Kroatien, Frühere Jugoslawische Republik Mazedonien, Serbien und Montenegro (Kiza/Krenberger/Sieber/Simon).

Parallel dazu wurde in einem zweiten Schritt auf der Grundlage eines speziellen Fragebogens (Kiza/Sieber) eine Befragung von Richterinnen und Richtern zu ihrer Strafzumessungspraxis in Bosnien-Herzegowina, Kroatien, Mazedonien und Montenegro durchgeführt (Kiza zusammen mit Mijatovic, Maljevic, Ivicevic, Getos, Perunicic und Bacanovic). Die Befragung musste aufgrund des vom Gericht gesetzten engen Zeitplanes innerhalb von zwei Wochen durchgeführt werden. Die übersetzten Transkripte dieser Befragungen bildeten dann die Basis für die Beantwortung der Fragen zur Strafzumessungspraxis (Höfer, Kilchling, Kiza, Sieber).

Die Gutachtenerstellung war vor allem deswegen schwierig, weil aufgrund der Scheduling Order des Gerichts vom 25. September 2003 für die Arbeit nur wenige Wochen Zeit zur Verfügung standen. Die Gutachtenerstellung war aus diesem Grund durch eine enge Teamarbeit zahlreicher Mitarbeiter geprägt, die besondere Herausforderung an die Koordinierung des Projekts stellte. Das Gutachten konnte dem ICTY am 23. Oktober übersandt werden. Prof. Dr. Sieber stellte es dann dem ICTY in Den Haag im Rahmen des Sentencing Hearings am 5. November 2003 vor und beantwortete anschließend die Fragen der Verfahrensbeteiligten. Für die interne Intitutsarbeit zeigte das Gutachten, dass bei einer entsprechenden engen Koordination selbst komplexe forschungsgruppenübergreifende Projekte in begrenzen Zeiträumen abgeschlossen werden können.

Der Gutachtenauftrag wurde von Herrn Prof. Dr. Sieber vor allem deswegen angenommen, weil mit ihm wissenschaftliches Neuland betreten werden konnte. Eine strafrechtlich-kriminologische Untersuchung, die sowohl rechtsvergleichend Strafrahmen für bestimmte Taten, die der Jurisdiktion eines internationalen Tribunals unterliegen, als auch die entsprechende Strafzumessungspraxis untersucht, wurde zuvor - soweit ersichtlich - noch nicht durchgeführt. Die Ergebnisse dieser normativ-empirischen Studie sind deswegen nicht nur für den ICTY im zu entscheidenden Fall und in anderen Fällen von Bedeutung, sondern von allgemeinem wissenschaftlichem Interesse. Das kurzfristig zu erstellende Gutachten bot dem Institut vor allem auch die Chancen, die einschlägigen Forschungskapazitäten des Instituts in wirkungsvoller Weise einem internationalen Forum zu demonstrieren und dabei auch das internationale Strafzumessungsrecht mit zu gestalten. Dass diese Ziele erreicht wurden, macht vor allem das inzwischen vom Gericht abgesetzte Nicolić-Urteil deutlich, in dem das Gericht das schriftliche Gutachten einschließlich der ihm beigefügten 22 Landesberichte vielfach zitiert. Die Entscheidung dürfte das bisher ausführlichste Urteil eines Internationalen Gerichtshofs zur Strafzumessung sein. Es zeichnet sich insbesondere dadurch aus, dass es auf eine wissenschaftlich fundierte und breite Rechtsvergleichung gestützt ist.

Die häufige Bezugnahme des Urteils auf das Gutachten und die Landesberichte führte dazu, dass das Gutachten in der Folgezeit vielfach angefordert wurde. Das Institut veröffentlicht das Gutachten deswegen in der Originalfassung in der Reihe Arbeitsberichte des Max-Planck-Instituts für ausländisches und internationales Strafrecht. Die Publikation erscheint im März 2004.

Die Erforschung von Grundlagen der völkerstrafrechtlichen Strafzumessung wird in weiteren - ebenfalls wiederum gemeinsam von der strafrechtlichen und der kriminologischen Forschungsgruppe betriebenen - Nachfolgeprojekten weitergeführt werden. Es ist beabsichtigt, die Untersuchung in $\mathrm{Zu}-$ sammenarbeit mit dem ICTY und möglicherweise auch des Office of the High Representative in Bosnien und Herzegovina (Interimsverwaltung) der Vereinten fortzuführen. Im Rahmen dieses Projekts sollen Grundlagen der Strafzumessung im Völkerstrafrecht entwickelt, weitere rechtsvergleichende Untersuchungen durchgeführt und auch die bisher ergangenen Urteile internationaler Gerichte analysiert werden. 


\section{Forschungsvorhaben und Referatsbereiche auf dem Gebiet des Strafrechts}

\section{1 Überblick über die Arbeitsschwerpunkte der strafrechtlichen Forschungsgruppe}

Im Berichtszeitraum ging es im Hinblick auf den bevorstehenden Direktorenwechsel vor allem darum, die laufenden Projekte weiter voranzutreiben. Dabei wurden die Empfehlungen des Fachbeirates zur Weiterführung bestimmter Projekte bzw. zur Vertiefung neuer Fragestellungen aufgegriffen.

Als weitgehend abgeschlossen können die Projekte "Wiedergutmachung im Strafrecht" sowie "Rechtsvergleichende und empirische Untersuchungen zu Umweltschutz und Strafrecht" betrachtet werden. Die bei beiden Projekten noch ausstehenden rechtsvergleichenden Querschnitte werden von den Projektverantwortlichen Frau Prof. Dr. Walther für das Wiedergutmachungsprojekt und Herrn Prof. Dr. Heine für das Umweltprojekt fertig gestellt. Ähnliches lässt sich berichten von den Projekten "Systematisches Völkerstrafrecht" sowie "Die Polizei im lateinamerikanischen Rechtsstaat". Diese beiden unter der Leitung von Herrn Prof. Dr. Ambos stehenden Projekte werden an dessen Lehrstuhl in Göttingen endgültig fertiggestellt. Im Berichtszeitraum beendet wurde das Projekt "Private Commercial Bribery Laws in Major OECD Countries", das in der Verantwortung von Herrn Prof. Dr. Heine und Frau Dr. Huber stand. Abgeschlossen wurde auch das Projekt "Strafrechtsentwicklung in Euro$p a^{\prime \prime}$, jedenfalls in seiner bisherigen Form.

Erfolgreich beendet wurden die folgenden Promotionsvorhaben:

- Der Verband als Straftäter und Strafprozesssubjekt (Haeusermann);

- Informationsrechte des Beschuldigten im Vorverfahren. Eine rechtsvergleichende Studie strafprozessualer Garantien im Verfahrensrecht Deutschlands und der nordischen Länder unter Berücksichtigung der Europäischen Menschenrechtskonvention (Tallroth);

- Der Straftatbestand des zwangsweisen Verschwindenlassens von Personen (Grammer);

- Täterschaft und Teilnahme im südafrikanischen Recht. Eine rechtsvergleichende Studie unter besonderer Berücksichtigung der common purpose rule (Günther);

- Die Unterlassungshaftung im Völkerstrafrecht aus dem Blickwinkel des französischen, USamerikanischen und deutschen Recht (Weltz).

Was die Fortführung von Projekten entsprechend der Empfehlungen des Fachbeirates betrifft, so standen besonders die Projekte "Strukturvergleich", "Systemunrecht", "Nationale Strafverfolgung völkerrechtlicher Verbrechen" sowie "Ehrenschutz im Strafrecht" im Mittelpunkt der Betrachtungen.

Beim Projekt "Strukturvergleich" ging es um das Vorantreiben des Abschlusses auf der bisherigen Grundlage der Tötungsdelikte. Dafür leistet Herr Prof. Dr. Perron die notwendigen Arbeiten, indem er die rechtsvergleichende Auswertung vornimmt, die im Jahr 2004 abgeschlossen sein soll.

Planmäßig fortgesetzt wurden die Arbeiten am Projekt "Systemunrecht". Nachdem im vergangenen Berichtszeitraum 2 Länderberichte veröffentlicht wurden, ist die Zahl der publizierten Landesberichte auf mittlerweile 12 angewachsen. Damit liegt insgesamt die Hälfte der in das Projekt einbezogenen Landesberichte vor. Klar ist damit aber auch, dass dieses Projekt noch einige Zeit der Bearbeitung in Anspruch nehmen wird. Hinsichtlich des rechtsvergleichenden Querschnitts ist dazu übergangen worden, verstärkt Promotionen dafür zu nutzen, regionale Vergleiche von Ländergruppen vorzunehmen (Simon für Lateinamerika, Trappe für Osteuropa). Fortgesetzt wurde die Erweiterung des Projekts um interdisziplinäre Aspekte. Denn die Frage nach "Erfolgsmodellen" des juristischen Umgangs mit Systemunrecht nach politischen Systemwechseln lässt sich nicht in erster Linie und schon gar nicht allein 
allein normativ beantworten. Vor diesem Hintergrund gewinnt die Zusammenarbeit mit der kriminologischen Forschungsgruppe eine besondere Bedeutung wie auch die Einbeziehung anderer Wissenschaftsdisziplinen. Zu diesem Zweck wurde das Projekt in vergleichende historische Untersuchungen über die Schuld eingeführt (Oslo 19./20.12.2003). Ferner erfolgt die Vorbereitung einer Tagung mit der Evangelischen Akademie Berlin-Brandenburg, die die Thematik der Verarbeitung von Systemunrecht neben den strafrechtlichen Gesichtspunkten gerade auch unter sozio-kulturellen, soziopsychologischen sowie historischen Aspekten zu beleuchten sucht.

Der Forschungsschwerpunkt des Völkerstrafrechts wurde vor allem durch das Projekt "Nationale Strafverfolgung völkerrechtlicher Verbrechen" repräsentiert. Die Fragestellung des Projekts, wie und in welcher Weise die Strafrechtsordnungen verschiedener Staaten die Ahndung von Völkerstraftaten durch eigene nationale Gerichte vorsehen bzw. ermöglichen, weist deutliche Bezüge zu dem Projekt "Systemunrecht" auf. Während beim Projekt Systemunrecht" der Schwerpunkt bei der Aufarbeitung von Systemunrecht in politischen Transformationsprozessen liegt, geht es beim völkerstrafrechtlichen Projekt um die Rolle des nationalen Strafrechts in Reaktion auf Völkerrechtsverbrechen, unabhängig von Systemwechseln. Insofern kann das völkerstrafrechtliche Projekt als eine notwendige Ergänzung der Gesamtthematik eines wirkungsvollen Menschenrechtsschutzes durch Strafrecht angesehen werden. Ein großer Teil der insgesamt 35 Landesberichte zum völkerstrafrechtlichen Projekt wurde verfasst und liegt der Projektgruppe zur weiteren Bearbeitung vor. Veröffentlicht wurden die Landesberichte zu Deutschland, Finnland, Polen, Schweden und einigen Ländern Lateinamerikas. Für das Jahr 2004 ist die Fertigstellung und Publikation von weiteren Landesberichten vorgesehen. Hierfür ist allerdings ein erheblicher Überarbeitungsbedarf erforderlich. Mit einem rechtsvergleichenden Querschnitt wurde noch nicht begonnen.

Fortgesetzt werden soll auch das Projekt "Ehre und Strafrecht". Zu diesem Projekt liegen - teilweise allerdings erst in Rohfassungen - bereits 11 Landesberichte vor. Insoweit besteht noch erheblicher Fertigstellungsaufwand.

Schließlich ist als besonderer Sachbereich noch das Referat "Recht und Medizin" zu nennen. Obgleich für diesbezügliche Grenzfragen, die nicht selten über das Strafrecht hinausweisen, eingerichtet, steht es nicht für sich allein, sondern befindet sich im Rahmen einschlägiger rechtsvergleichender Projekte in enger Kooperation mit den Länderreferaten. Auch fungiert dieses Referat als wichtiges Bindeglied zur Universität in Form der Mitträgerschaft des "Zentrums für Ethik und Recht in der Medizin (ZERM)". Inhaltlich werden neben klassischen medizinrechtlichen Themen wie der Forschung am Menschen insbesondere auch höchst aktuelle und außerordentlich kontrovers diskutierte Themen der Biomedizin wie Fortpflanzungsmedizin einschließlich Stammzellforschung oder Klonen behandelt. 


\subsection{Gemeinschaftliche Projekte innerhalb der strafrechtlichen Forschungsgruppe}

\subsubsection{Allgemeiner strafrechtlicher Strukturvergleich}

- Mitarbeiter(innen): Walter Perron (Projektkoordinator, Universitäten Mainz/Freiburg), Holger Barth (Frankreich), Karin Cornils (Schweden), Helmut Gropengießer (Deutschland), Susanne Hein/Konstanze Jarvers (Italien), Barbara Huber (England), Peter Hünerfeld (Portugal), Josef Kürzinger (empirische Fragestellungen), Ursula Medigovic (Österreich, Universität Wien), Hans Vest (Schweiz, Universitäten Basel/St. Gallen)

- $\quad$ Zeitrahmen: 1995 bis 2004

- $\quad$ Projektstatus: in Bearbeitung

- $\quad$ Projektbeschreibung:

(vgl. dazu bereits die Tätigkeitsberichte 1994/1995, S. 15-19, 1996/1997, S. 10-14, 1998/ 1999, S. 16-18, 2000/2001, S. 15-17)

\section{Projektziel und -methode}

Ziel des Projektes ist es, Regelmäßigkeiten - und zwar sowohl Übereinstimmungen als auch Abweichungen - herauszufinden, nach denen die zu untersuchenden Rechtsordnungen im Bereich des materiellen Strafrechts organisiert sind. Dabei soll das Strafrecht im spezifischen Zusammenspiel von normativer Regelung und faktischer Anwendung adäquat erfasst werden.

Die Untersuchungsmethode trägt sowohl der rechtstatsächlichen als auch der normativ-dogmatischen Seite Rechnung. Zu einem konkreten Thema wurde jeweils ein Satz von praktischen Fällen gebildet, für die in jedem Land untersucht wurde, mit welchen materiell-rechtlichen Kategorien die Fälle jeweils erfasst und wie sie in der Praxis durch das Strafverfolgungssystem transportiert werden.

Die Ausgangsfälle sind so gebildet, dass sie einerseits den tatsächlich vorkommenden Phänomenen in dem gewählten Themenbereich entsprechen, andererseits aber auch die Differenzierungen der materiell-rechtlichen Institutionen und Kategorien möglichst deutlich werden lassen. Sie wurden für jede Rechtsordnung zunächst auf der normativ-dogmatischen Ebene gelöst, um die Differenzierungen des materiellen Rechts in den verschiedenen Ländern transparent und vergleichbar zu machen.

Ein besonders wichtiger Teil des Projekts ist sodann die Untersuchung des Transports der Ausgangsfälle durch das jeweilige Strafverfolgungssystem. Die grundlegende Hypothese ist, dass die Differenzierungen des materiellen Rechts nicht ausschließlich aus sich bzw. aus normativ-dogmatischen Erwägungen heraus verstanden werden können, sondern auch maßgeblich von den praktischen Konsequenzen der Rechtsanwendung bestimmt werden. Um diese rechtstatsächliche Seite zu erfassen, wurden für jedes Land Juristen aus verschiedenen Berufsgruppen (Richter, Staatsanwälte, Verteidiger, Hochschullehrer) zu der materiellrechtlichen Lösung, prozessualen Behandlung und konkreten Sanktionierung der einzelnen Fälle befragt. Die dabei gewählte Methode war die des Intensivinterviews mit vorgefertigtem Interviewleitfaden, aber ohne vorgegebene Antwortmöglichkeiten. Die einzelnen Gespräche wurden auf Tonband aufgezeichnet, in der Originalsprache transkribiert und sodann anhand eines für alle Länder einheitlichen Auswertungsbogens einer Inhaltsanalyse unterzogen.

\section{Konkretes Untersuchungsthema}

Die Untersuchung konzentriert sich zunächst auf die Tötungsdelikte als denjenigen Bereich, in welchem sich die "klassischen" dogmatischen Fragen (einschließlich Rechtfertigung und Entschuldigung) besonders zuspitzen. Dabei wurde als konkretes Thema die Tötung des tyrannischen Ehegatten durch die Ehefrau ausgewählt und in vier Fallvarianten aufgefächert (geplante Tötung nach längerem Heran- 
reifen des Tatentschlusses - spontane Tötung aufgrund plötzlicher Gefühlsaufwallung - Tötung nach kurz zuvor erlittener Misshandlung - Tötung in einer Notwehrsituation).

\section{In die Untersuchung einbezogene Länder}

Die Untersuchung wurde auf folgende europäische Länder beschränkt: Deutschland, England und Wales, Frankreich, Italien, Österreich, Portugal, Schweden, Schweiz.

\section{- $\quad$ Vorarbeiten bis 2001:}

Von 1995 bis 2002 wurde das Projekt entwickelt und durchgeführt. Die Ergebnisse der Befragungen wurden ausgewertet und teilweise in Landesberichten dargestellt.

- $\quad$ Arbeitsbericht 2002/2003:

Die noch ausstehenden Landesberichte wurden fertig gestellt und in mehreren Arbeitssitzungen diskutiert. Die rechtsvergleichende Auswertung wurde begonnen und unter den Projektmitarbeitern diskutiert; sie ist inzwischen zu etwa $60 \%$ durchgeführt.

Dabei zeichnet sich als eher überraschendes Ergebnis ab, dass die nationalen Rechtsordnungen bei der Lösung der vier Fälle zwar zu deutlich unterschiedlichen Ergebnissen gelangen, diese Unterschiede aber fast ausschließlich mit den konkreten gesetzlichen Vorgaben zu erklären sind. Wo immer das Gesetz bzw. in England das Common Law dem Rechtsanwender dagegen Entscheidungsspielräume gewährt, werden diese Spielräume über alle untersuchten Länder hinweg weitgehend übereinstimmend ausgefüllt. Offensichtlich besteht - jedenfalls für die untersuchten Sachverhalte - ein europäischer Common Sense, der von den Besonderheiten des nationalen Rechts nur wenig beeinflusst wird. Für die europäische Rechtsangleichung und Rechtsvereinheitlichung könnte das bedeuten, dass bei Beseitigung der legislativen Unterschiede auch die praktischen Ergebnisse in deutlich stärkerem Maß übereinstimmen könnten als bislang angenommen.

- $\quad$ Arbeitsplanung 2004:

Der Strukturvergleich der Tötungsdelikte soll Ende 2004 mit der betreffenden Veröffentlichung abgeschlossen werden.

- Zum Projekt vorliegende Veröffentlichungen:

ESER, A., Einführung aus deutscher Sicht, sowie Justification and Excuse: A Key Issue in the Concept of Crime. In: Rechtfertigung und Entschuldigung. Rechtsvergleichende Perspektiven. Hrsg. A. Eser, G.P. Fletcher, Freiburg 1987, 1-8 bzw. 17-65.

PERRON, W., Rechtfertigung und Entschuldigung im deutschen und spanischen Recht. Ein Strukturvergleich strafrechtlicher Zurechnungssysteme. Nomos Verlagsgesellschaft Baden-Baden 1988, $251 \mathrm{~S}$. Veröffentlichung in japanischer Sprache (Übersetzung: Norio Takahashi) im Seibundo-Verlag, Tokyo 1992.

ESER, A., Eröffnungsansprache. In: Rechtfertigung und Entschuldigung IV. Hrsg. A. Eser, H. Nishihara, Freiburg 1995, 3-7.

PERRON, W., Überlegungen zum Erkenntnisziel und Untersuchungsgegenstand des Forschungsprojektes "Allgemeiner Strafrechtlicher Strukturvergleich". In: Grenzüberschreitungen Beiträge zum 60. Geburtstag von Albin Eser. Hrsg. J. Arnold, B. Burkhardt, W. Gropp, H.-G. Koch, Freiburg i.Br. 1996, 127-136. 
PERron, W., Sind die nationalen Grenzen des Strafrechts überwindbar? Überlegungen zu den strukturellen Voraussetzungen der Angleichung und Vereinheitlichung unterschiedlicher Strafrechtssysteme. In: Zeitschrift für die gesamte Strafrechtswissenschaft, 109 (1997), 281-301. Japanische Übersetzung in: The Journal of the Faculty of Law, Universität Aichi, Japan, Nr. 145, 1-25 (1997).

PERRON, W., Strafrechtsvereinheitlichung in Europa. In: Europa als Rechtsgemeinschaft. Hrsg. D. Dörr, M. Dreher, Baden-Baden 1997, 135-154.

PERRON, W., Hat die deutsche Straftatsystematik eine europäische Zukunft? In: Festschrift für Theodor Lenckner. Hrsg. A. Eser, U. Schittenhelm, H. Schumann, München 1998, 227-247.

PERRON, W., Strukturen der strafrechtlichen Verantwortlichmachung und Tatbewertung im europäischen Vergleich. In: Waseda Proceedings of Comparative Law, Vol. 4 (2001), 2002, 233-247.

ESER, A., Von der Konkurrenz zur Kongruenz nationaler Strafrechtsordnungen: Wege zur Rechtsangleichung in Europa. In: Poinikos Logos 5/2002, 2158-2170.

\subsubsection{Strafrecht in Reaktion auf Systemunrecht - Vergleichende Einblicke in Transitionsprozesse}

- $\quad$ Projektkoordinator: Jörg Arnold

- $\quad$ Mitarbeiter(innen): Jan-Michael Simon (Koordination Lateinamerika), Julie Trappe (Koordination Osteuropa), Kumelio Koffi A. Afanđe, Peter Hünerfeld, Barbara Huber, Nora Karsten, Helmut Kreicker, Siegfried Lammich, Clivia Namgalies, Thomas Richter, Ewa Weigend sowie zahlreiche externe Mitarbeiterinnen und Mitarbeiter

- Zeitrahmen: 1996 bis voraussichtlich 2005

- $\quad$ Projektstatus: in Bearbeitung

- $\quad$ Projektbeschreibung:

(vgl. dazu bereits die Tätigkeitsberichte 1998/1999, S. 21, 1996/1997, S. 16, 1994 1995, S. 20, 2000/2001, S. 18)

\section{Forschungsthema:}

"Strafrecht in Reaktion auf Systemunrecht" beschäftigt sich mit der für Wissenschaft und Praxis gleichermaßen wichtigen und aktuellen Frage des Umgangs mit systemtypischem Unrecht nach dem Beginn der Ablösung eines politischen Systems.

Nach Ablösung eines politischen Systems stehen der Post-Konfliktgesellschaft viele Formen des Umgangs mit diesem System zur Verfügung. Wird das abgelöste politische System als Unrechtssystem bezeichnet, dann steht der Umgang mit Unrechtstaten dieses Systems im Vordergrund. Reaktionen auf diese Unrechtstaten können die Form des Strafrechts annehmen. Andere Reaktionsformen auf Systemunrecht sind vor allem die Entschädigung, Rehabilitierung und der Einsatz von Wahrheitskommissionen. Der Vergleich dieser unterschiedlichen Reaktionsformen ist Gegenstand der Forschungen in dem internationalen Projekt "Strafrecht in Reaktion auf Systemunrecht".

Für den Vergleich unterschiedlicher Reaktionsformen auf Systemunrecht sind bereits 24 Länder einbezogen: Argentinien, Brasilien, Chile, China, Deutschland (DDR), Estland, Georgien, Ghana, Griechenland, Guatemala, Litauen, Mali, Polen, Portugal, Ruanda, Rumänien, Russland, Spanien, Südafrika, Südkorea, Tschechien, Ungarn, Uruguay, Weißrussland.

Zunächst werden zu den Ländern Berichte erstellt. Diese Landesberichte erschließen das abgelöste politische System, seine Klassifizierung als Unrechtssystem und beschreiben systemtypische Unrechtstaten. Anschließend wird geprüft, ob diese Unrechtstaten zum Tatzeitpunkt von dem materiellen Strafrecht erfasst sind und was erst nach der Ablösung des Systems erfassbar wird. Schließlich wird 
beschrieben, ob strafbares Unrecht verfolgt wird, und zwar sowohl vor wie nach der Ablösung des politischen Systems.

Anschließend werden die Berichte zu den einzelnen Ländern regional miteinander verglichen. In diesen Forschungsarbeiten werden Unterschiede und regionale Gemeinsamkeiten herausgearbeitet. Im Fall Lateinamerikas wird auch der Einfluss strafrechtlicher Reaktionsformen durch Drittstaaten auf den Umgang mit dem Systemunrecht in der Region untersucht. Darüber hinaus wird der Befund aus der lateinamerikanischen Region mit der Praxis in Südafrika verglichen.

Aufbauend auf den vergleichenden Regionalberichten wird ein vergleichender Querschnitt erfolgen. In diesen Querschnitten werden Modelle für den Umgang mit systemtypischem Unrecht gebildet. Darüber hinaus werden die Möglichkeiten und Grenzen für ein (internationales) Strafrecht diskutiert und rechtspolitische Schlussfolgerungen formuliert.

\section{Selbstverständnis:}

"Strafrecht in Reaktion auf Systemunrecht" schließt mit seiner Fragestellung an ein wichtiges Forschungsthema des Instituts an. Es setzt das im Anschluss an die Nürnberger Kriegsverbrecherprozesse vor einem halben Jahrhundert von Herrn Prof. Dr. Jescheck begonnene Forschungsthema "Internationales Strafrecht" fort. Dieses Forschungsthema wurde nach der Einrichtung der ad hoc-Tribunale für das ehemalige Jugoslawien und für Ruanda sowie einer internationalen Strafgerichtsbarkeit in Den Haag von Herrn Prof. Dr. Eser weitergeführt.

Anschließend an diese, die Außenwahrnehmung des Instituts seit seiner Gründung prägende Forschung, formuliert "Strafrecht in Reaktion auf Systemunrecht" die übergreifende Grundlagenfrage nach Funktion und Grenzen von Strafrecht bei der Ablösung politischer Systeme. Die Fragestellung wird über einen internationalen Vergleich erforscht. Diese Form der Grundlagenforschung erfordert lange Beobachtungszeiträume und eine über das übliche Maß internationaler vergleichender Forschung hinausgehende Tiefe und Untersuchungsbreite.

Das Thema "Strafrecht in Reaktion auf Systemunrecht" ist für Wissenschaft und Praxis international von wachsendem Interesse. Die in Deutschland entwickelten Fragestellungen sind für viele andere Rechtskulturen in unterschiedlicher Form von zunehmend praktischer und theoretischer Bedeutung. Diese Entwicklung spiegelt sich in dem international steigenden Forschungsinteresse an dem Thema von "Strafrecht in Reaktion auf Systemunrecht" sowie den Agenden nationaler und internationaler Organisationen wider.

\section{Forschungsmethode:}

Die Forschungsmethode ist auf der Zeitachse abhängig vom jeweiligen Ablauf der Reaktionen auf systemtypisches Unrecht. Dieser Ablauf der Reaktionen auf Systemunrecht wird von der Wandlungsgeschwindigkeit des neuen politischen Systems und der Varianz in den Reaktionen auf das Unrecht des abgelösten Systems beeinflusst. Methodisch erfordert die Prozesshaftigkeit dieser Reaktionen auf Systemunrecht deshalb eine Längsschnittstudie.

Das Forschungsinteresse von "Strafrecht in Reaktion auf Systemunrecht" richtet sich auf die Ablösung nicht-demokratischer Systeme durch demokratische. Diese demokratischen Systeme werden durch den aus der US-amerikanischen vergleichenden Politikwissenschaft (sog. Transitionsforschung) stammenden, empirischen "governance" Begriff zugleich definiert und hinterfragt (Ausnahme: China).

"Strafrecht in Reaktion auf Systemunrecht" untersucht im Querschnitt Länder aus unterschiedlichen politisch-geographischen Regionen. Wegen der erwarteten und erwünschten hohen Varianz des Ablaufs von Reaktionen auf systemtypisches Unrecht zwischen den Ländern besteht die Herausforderung darin, über die komparative Methode einen höchstmöglichen Erklärungsgehalt bei gleichzeitiger hoher Abstraktion zu erzielen. 


\section{Vorläufige Erkenntnisse:}

Die Herausforderung, einen höchstmöglichen Erklärungsgehalt bei gleichzeitiger hoher Abstraktion zu erzielen, wird durch die Entwicklungsphasen vorläufiger Strukturmodelle dokumentiert. Nachdem die Modellbildung zunächst entlang des Ergebnisses strafrechtlicher Reaktionen erfolgte, sind diese nunmehr in einer Auswahl von Reaktionen ausdifferenziert, die zugleich Staat, Gesellschaft, Täter und Opfer adressieren.

Dieser gegenwärtigen Modellbildung können von den bislang einbezogenen Ländern die acht osteuropäischen Länder und Deutschland zugeordnet werden (umfassender Strafverzicht; bedingter Strafverzicht; eingeschränkte Strafverfolgung; umfassende Strafverfolgung). Diese Zuordnung wird durch die stabilen Prozessabläufe in der Region und die geringe interne Varianz der Reaktionen von Strafrecht auf typisches Unrecht des abgelösten Systems erleichtert. Das gilt besonders für Deutschland und die vier osteuropäischen EU-Beitrittsländer (Polen, Ungarn, Estland, Litauen), wie auch für die drei GUSLänder (Georgien, Russland, Weißrussland). Ein regionales Kolloquium 2002 belegt jedoch, dass sich diese Erkenntnis nicht für die allgemeine Entwicklung des Strafrechts in der Region generalisieren lässt.

Für die lateinamerikanische Region steht die Einordnung in ein Strukturmodell offen. Instabile Wandlungsgeschwindigkeiten des politischen Systems bei hoher interner Varianz der Reaktionen von Strafrecht auf typisches Unrecht des abgelösten Systems stellen die Zuordnung in einem Strukturmodell vor eine große Herausforderung. Dem begegnete 2002 vor Ort ein Kolloquium in São Paulo. Dabei wird vor allem deutlich, dass für die Zuordnung in ein Strukturmodell die Betrachtungsebenen weiter ausdifferenziert werden müssen. Von entscheidendem Einfluss auf die Reaktionen am Tatortstaat scheinen auch strafrechtliche Reaktionen in Drittstaaten zu sein.

\section{- $\quad$ Arbeitsbericht 2002/2003:}

Im Berichtszeitraum sind in der Reihe "Strafrecht in Reaktion auf Systemunrecht" Berichte zu zehn Ländern veröffentlicht worden. Diese Länderberichte wurden mehrsprachig von Aufsätzen und Vorträgen im In- und Ausland begleitet.

Der dritte Band von den Autoren Marcelo A. Sancinetti und Marcelo Ferrante (unter Mitarbeit von Kai Ambos und Jan-Michael Simon) erschien in der Reihe "Strafrecht in Reaktion auf Systemunrecht" im Frühjahr 2002 als Landesbericht zu Argentinien. Der fünfte Band von den Autoren Ewa Weigend und Andrzej Zoll (unter Mitarbeit von Helmut Kreicker) und Judit Udvaros (unter Mitarbeit von Julie Trappe) erschien im Sommer 2002 als Landesbericht zu Polen und Ungarn. Der sechste Band von den Autoren Kumelio Koffi A. Afanđe und Novisi G. Vukor-Quarshie (unter Mitarbeit von Helmut Kreicker) erschien im Herbst 2002 zu Mali und Ghana. Im Jahre 2003 wurde der Band 7 von den Autoren Nora Karsten, Ludmila Obidina, Vladimir Khomitch, Siegfried Lammich, Otar Gamkrelidze, Jüri Saar, Jaan Sootak und Vytautas Piesliakas zu den fünf ehemaligen Sowjetrepubliken Estland, Georgien, Litauen, Russland und Weißrussland veröffentlicht. Schließlich erschien 2002 in der Reihe "forschung aktuell - research in brief" eine englische Projektdarstellung.

- $\quad$ Tagungen im Rahmen des Projekts:

Zwischen dem 22.-24. Februar 2002 wurde in São Paulo/Brasilien ein regionales Kolloquium zum Thema "Rechtsstaat und Staatskriminalität in Lateinamerika" durchgeführt. Das Kolloquium wurde weitgehend von dem Rechtsstaatsprogramm der Konrad-Adenauer-Stiftung/Südamerika finanziell unterstützt und dem brasilianischen Institut für Kriminalwissenschaften mitorganisiert. Ziel der Veranstaltung war es, den Zwischenstand der Forschungsergebnisse zur lateinamerikanischen Region einem breiten Publikum vorzustellen und einer kritischen Überprüfung zu unterziehen. Insgesamt nahmen 30 Personen als Referenten und Moderatoren aus Argentinien, Brasilien, Chile, Guatemala, Uruguay, 
Bolivien, Peru, Frankreich, Spanien und Deutschland teil. Es wurden insgesamt 23 Referate und KoReferate gehalten.

Im Sommer 2002 fand zu Osteuropa das von der Volkswagen-Stiftung unterstützte regionale Symposium "Strafrechtsentwicklung in Osteuropa - Zwischen bewältigten und neuen Herausforderungen" statt. 60 Strafrechtswissenschaftler aus 15 osteuropäischen Ländern und Deutschland kamen zusammen, um die Grundlinien der Entwicklung des Strafrechts und Strafprozessrechts in Osteuropa in den letzten zehn Jahren zu diskutieren. Trotz unterschiedlicher Wege der Strafrechtsentwicklung fußt dieser Prozess auf denselben rechtsstaatlichen Grundsätzen. Dabei schließen aktuelle Fragen des Strafrechts oft an Problemstellungen an, die sich bereits im Umgang mit dem Unrecht des abgelösten Systems gestellt haben. Die Ergebnisse des Symposiums wurden im Januar 2004 auf einer von der Volkswagen-Stiftung und dem Zentrum für höhere Studien der Universität Leipzig veranstalteten internationalen Tagung der Volkswagen-Stiftung "Einheit in der Vielfalt? Grundlagen und Voraussetzungen eines erweiterten Europas" präsentiert (Arnold, Trappe).

Die interdisziplinäre Konferenz "Reconciliation, Restorative Justice, Remembrance", die vom 2.-4. September 2002 in Kapstadt (Südafrika) stattfand, stellte die Erfahrungen, die Deutschland mit der Aufarbeitung von Diktaturen gesammelt hat, dem südafrikanischen Aufarbeitungsprozess zum Apartheid-Unrecht gegenüber. Historiker, Politologen, Theologen und Juristen aus Deutschland, Südafrika, Namibia und Uganda diskutierten über die Schwierigkeiten und Herausforderungen, die aus der Aufarbeitung von Systemunrecht resultieren. Die Forschungsergebnisse des Projekts "Systemunrecht" des Max-Planck-Instituts für ausländisches und internationales Strafrecht ermöglichte es, osteuropäische Länder und deren Umgang mit ihrer kommunistischen Vergangenheit in die Diskussion mit einzubeziehen (Namgalies).

- Laufende Promotionen im Rahmen des Projekts:

Jan-Michael Simon Strafrecht in Postkonfliktsituationen - eine komparative Untersuchung zum Einsatz von Strafrecht in der Internationalen Gemeinschaft

Julie Trappe Strafrechtliche Reaktion auf Systemunrecht in Rumänien nach 1989 im Vergleich zu anderen osteuropäischen Staaten.

Clivia Namgalies NS-Fortsetzungspropaganda zwischen Versammlungsrecht und Internet Ein Beitrag zum strafrechtlichen Umgang der Bundesrepublik Deutschland mit NS-bezogenen Delikten

- $\quad$ Arbeitsplanung 2004/2005:

Für das Jahr 2004 ist die Veröffentlichung der Beiträge der Kolloquien zu Osteuropa und Lateinamerika geplant. Weiter sollen die Berichte zu Brasilien, Chile, China, Spanien, Südafrika, Südkorea, Tschechien und Uruguay in der Reihe "Strafrecht in Reaktion auf Systemunrecht" veröffentlicht werden. Vorangetrieben werden soll auch die Forschung zu westeuropäischen Ländern wie Portugal und Spanien.

Zum Jahresende 2004 wird in Zusammenarbeit mit der Evangelischen Akademie Berlin-Brandenburg in Berlin eine Tagung stattfinden, zu der erste, übergreifende Forschungserkenntnisse vorgestellt werden sollen.

2005 sollen zwei Forschungsberichte fertig gestellt werden, die Osteuropa sowie Lateinamerika und Afrika im Querschnitt untersuchen. Den regionalen Forschungsberichten schließt sich ein umfassender Querschnitt an. 


\section{- $\quad$ Finanzierung:}

Das Projekt wurde durch Mittel der Volkswagen Stiftung und des Stifterverbandes für die deutsche Wissenschaft gefördert und wird nunmehr fast ausschließlich aus Eigenmitteln des Max-Planck-Instituts finanziert.

- Veröffentlichungen:

Reihe "Strafrecht in Reaktion auf Systemunrecht-Vergleichende Einblicke in Transitionsprozesse", hrsg. von A. Eser und J. Arnold (edition iuscrim):

(Band 1): Internationales Kolloquium (unter Mitarbeit von NORA KARSTEN, HELMUT KREICKER, JANMiCHAEL SIMON und JULIE TRAPPE), Freiburg i.Br. 2000.

Kreicker, H., Ludwig, M., Rossig, K., Rost, A., ZimMERmanN, S. (Band 2): Deutschland. Freiburg i.Br. 2000.

SancinetTi, M., Ferrante, M. (Band 3): Argentinien (unter Mitarbeit von Kai Ambos und JaNMICHAEL SIMON). Freiburg i.Br. 2002.

KareKLÁs S., PAPACharalambous, C. (Band 4): Griechenland (unter Mitarbeit von Helmut KreICKER). Freiburg i.Br. 2001.

Udvaros, J., Weigend, E., Zoll, A. (Band 5): Polen, Ungarn (unter Mitarbeit von Helmut KREICKER und JULIE TRAPPE). Freiburg i.Br. 2002.

AfanĐe, K., VuKor-Quarshie, N. (Band 6): Mali, Ghana (unter Mitarbeit von Helmut KREICKER). Freiburg i.Br. 2002.

Karsten, N., Obidina, L., Khomitch, V., Lammich, S., GAmkrelidze, O., SaAR, J., SoOtak, J., PIESLIAKAS, V. (Band 7): Russland, Weißrussland, Georgien, Estland, Litauen. Freiburg i.Br. 2003.

- Weitere Veröffentlichungen:

JÖRG ARNOLD:

- $\quad$ Neue Fragen an den Satz "nullum crimen, nulla poena sine lege". In: Rolf Gröschner/Gerhard Haneys (Hrsg.), Die Bedeutung P.J.A. Feuerbachs (1775-1833) für die Gegenwart. IVR-Tagung Jena 15. und 16. März 2002. ARSP-Beiheft 87, 107-123 (2003).

- (mit Nora Karsten und Helmut Kreicker), The German Border Guard Cases before the European Court of Human Rights. European Journal of Crime, Criminal Law and Criminal Justice 11, Heft 1, 67-92 (2003).

- (mit AlBIN ESER), O Direito Penal como reacção às injustiças do sistema. In: Direito Penal Internacional. Para a protecção dos direitos Humanos. Simpósio da Faculdade de Direito da Universidade de Coimbra, Goethe-Institut de Lisboa. Fim de século, Lisboa 2003, 21-42.

\section{HELMUT KREICKER:}

- $\quad$ Art. 7 EMRK und die Gewalttaten an der deutsch-deutschen Grenze. Zu den Urteilen des Europäischen Gerichtshofs für Menschenrechte. Baden-Baden 2002.

\section{JAN-MICHAEL SIMON:}

- Jurisdicción Universal - La Perspectiva del Derecho Internacional Público. In: Revista Brasileira de Ciências Criminais, Instituto Brasileiro de Ciências Criminais, São Paulo, Brasil, Ano 10, No. 39 (julho-setembro 2002), 63-101=Revista Judicial, Corte Suprema de Justicia, San José, Costa Rica, Año XXVII, No. 81 (octubre-diciembre 2002), 32-71=Revista Electrónica de Estudios Internacionales, Vol. 4 (2002), www.reei.org/reei4/Simon.PDF. 
- La Comisión para el Esclarecimiento Histórico. In: Boletín Mexicano de Derecho Comparado, Año XXXVI, No. 106 (enero-abril 2003), Instituto de Investigaciones Jurídicas de la UNAM, México D.F./México, 147-203, www.juridicas.unam.mx/publica/librev/rev/boletin/cont/106/art/art6.pdf.

- $\quad$ Przemoc popierana przez państwo - Odpowiedzialność karna a pojednanie. In: Ius et Lex 1/2003, Fundacja Ius et Lex, Warszawa/Polska, 161-173.

- Responsabilidad criminal y reconciliación. El Derecho Penal frente a la violencia política masiva en Sudáfrica, Ruanda y El Salvador. In: Fundación País Libre (Hrsg.), La Corte Penal Internacional. Instrumento de Paz para Colombia, Bogotá (im Erscheinen), www.altocomisionadoparalapaz.gov.co/opinion/articulo_\%20simon.doc

- Proceso de paz en Colombia y Corte Penal Internacional. Breves apuntes sobre el Proyecto de Ley No. 85/03 S. In: Guerrero, Víctor/Mora, Roberto (Hrsg.), Justicia y reparación en el marco de procesos de paz, Bogotá (im Erscheinen).

\section{JULIE TRAPPE:}

- (mit NORA KARSTEN) Strafrechtsentwicklung in Osteuropa - Zwischen bewältigten und neuen Herausforderungen, Tagungsbericht. ZStW (115), 443-450 (2003).

\subsubsection{Nationale Strafverfolgung völkerrechtlicher Verbrechen im internationalen Vergleich}

- Mitarbeiter(innen): Helmut Kreicker (Projektleiter), Johanna Rinceanu (Projektmitarbeiterin), Länderreferentinnen und Länderreferenten der strafrechtlichen Forschungsgruppe des Max-Planck-Instituts: Ralf Bahrenberg, Anke Biehler, Karin Cornils, Christoph Grammer, Helmut Gropengießer, Till Gut, Peter Hünerfeld, Konstanze Jarvers, Adome Blaise Kouassi, Siegfried Lammich, Juliette Lelieur-Fischer, Simon Paulenz, Christiane Rabenstein, Thomas Richter, Emily Silverman, Silvia Tellenbach, Ewa Weigend, Ingeborg Zerbes, sowie externe Mitarbeiterinnen und Mitarbeiter: Alejandro Aponte (Kolumbien), Maria Thereza R. Assis Moura (Brasilien), Machtheld Boot-Matthijssen (Niederlande), Carlos Caro (Peru), Moshe Cohen (Israel), Dan Frände (Finnland), Alicia Gil Gil (Spanien), José Luis Gonzalez (Uruguay), José Luis Guzmán (Chile), Marc Henzelin (Schweiz), Damjan Korošec (Slowenien), Kremnitzer (Israel), Ezequiel Malarino (Argentinien), Juan Luis Modollel (Venezuela), Patricia Neri (Mexiko), Petar Novoselec (Kroatien), Andres Parmas (Estland), Tristan Ploom (Estland), Paul Hernández Salmaceda (Costa Rica), Elisabeth Santalla Vargas (Bolivien), Milan Skulic (Serbien), Max Wolpert (Kanada)

- $\quad$ Zeitrahmen: 2001 bis 2005/06

- Projektstatus: in Bearbeitung

- $\quad$ Projektbeschreibung:

Die Verabschiedung des Römischen Statuts für einen Internationalen Strafgerichtshof (IStGH) im Juli 1998 hat die Staaten zum einen vor die Frage gestellt, ob sie den Vertrag ratifizieren sollen oder nicht und inwieweit hierfür innerstaatliche Verfassungsänderungen erforderlich sind. Zum anderen gilt es für die Mitgliedsstaaten des Statuts, nationale Rechtsgrundlagen für die vom Römischen Statut geforderte Zusammenarbeit der Staaten mit dem Gerichtshof zu schaffen. Darüber hinaus aber stellt sich für die Staaten drittens die Frage, inwieweit sie selbst in der Lage sind, völkerrechtliche Straftaten zu verfolgen und zu bestrafen beziehungsweise hierfür Änderungen der eigenen Strafrechtsordnung erforderlich sind. 
Das Römische Statut als solches zwingt die Staaten nicht, eine nationale Strafgewalt für völkerrechtliche Verbrechen zu begründen und auszuüben. Doch liegt der Gesamtkonzeption des Statuts die Vorstellung zugrunde, dass die Strafverfolgung völkerrechtlicher Verbrechen primär Aufgabe der einzelnen Staaten ist. Diese Vorrangzuständigkeit manifestiert sich im Prinzip der Komplementarität: Nach Art. 17 IStGH-Statut ist eine Strafverfolgung durch den IStGH nur dann zulässig, wenn und insoweit eine effektive Strafverfolgung auf nationaler Ebene an rechtlichen oder faktischen Hindernissen scheitert. Folge des Unterbleibens einer nationalen Strafverfolgung ist nach dem Römischen Statut also lediglich die Ahndungskompetenz des IStGH. Es liegt aber im Interesse der einzelnen Staaten, zu einer Strafverfolgung völkerrechtlicher Verbrechen zumindest in gleichem Umfang wie der IStGH in der Lage zu sein. Damit wird nicht nur der Idee einer primären Ahndung völkerrechtlicher Verbrechen durch nationale Gerichte Rechnung getragen, sondern auch nationalen Souveränitätsinteressen.

Allerdings geht das Römische Statut in Abs. 6 seiner Präambel davon aus, dass die Staaten unabhängig vom Statut durch das Völker(gewohnheits-)recht zu einer Strafverfolgung völkerrechtlicher Verbrechen verpflichtet sind: Tatsächlich ergeben sich Verpflichtungen zu einer nationalen Strafverfolgung völkerrechtlicher Verbrechen aus anderen völkerrechtlichen Verträgen wie den Genfer Abkommen und der Völkermordkonvention, die für die große Mehrzahl der Staaten bindend sind. Zunehmend gewinnt auch die Auffassung völkergewohnheitsrechtlicher Verfolgungspflichten an Boden.

Zusammenfassend ist damit festzustellen, dass die einzelnen Staaten zum Teil verpflichtet sind zu einer nationalen Strafverfolgung völkerrechtlicher Verbrechen, im übrigen eine solche aber durch das Römische Statut generell gewünscht wird und wegen des Prinzips der Komplementarität im Interesse der einzelnen Staaten ist.

In etlichen Staaten ist deshalb eine Anpassung des nationalen Strafrechts an die materiellen Strafnormen des Römischen Statuts und des Völkergewohnheitsrechts vorgenommen worden oder jedenfalls geplant. So hat beispielsweise Deutschland im Jahr 2002 ein eigenständiges Völkerstrafgesetzbuchs (VStGB) geschaffen, mit dem Deutschland befähigt wird, in die Zuständigkeit des IStGH fallende Verbrechen stets auch selbst zu verfolgen.

Vor dem Hintergrund dieser Entwicklung ist Forschungsgegenstand des rechtsvergleichenden Projekts, wie und in welcher Weise die Strafrechtsordnungen verschiedener Staaten die Ahndung von Völkerstraftaten durch eigene nationale Gerichte vorsehen bzw. ermöglichen, welche Defizite gegenüber dem geltenden Völkerrecht (und dort normierten Verfolgungspflichten) im Hinblick auf eine solche nationale Strafgewalt bestehen und welche Reformen zur Ermöglichung einer solchen Strafverfolgung durchgeführt wurden oder geplant sind.

Über den wissenschaftlichen Erkenntnisgewinn im Rahmen der strafrechtlichen Grundlagenforschung hinaus ist es Ziel des Projekts, zum einen Anstöße und Impulse für Reformüberlegungen in einzelnen Staaten zu geben, indem verschiedene Regelungsmechanismen zur Ahndung völkerrechtlicher Verbrechen rechtsvergleichend aufgezeigt und bewertet werden. Zum anderen kann dargelegt werden, inwieweit verschiedene Staaten normativ zur eigenen Strafverfolgung völkerrechtlicher Verbrechen in der Lage sind. Diese Erkenntnis dürfte im Hinblick auf das Komplementaritätsprinzip des Römischen Statuts von erheblicher praktischer Relevanz sein. Nicht zuletzt können aus Feststellungen zu den Rechtsauffassungen in verschiedenen Staaten, etwa bezüglich des Umfangs völkerrechtlicher Verpflichtungen zur nationalen Strafverfolgung, möglicherweise auch Rückschlüsse auf den Stand des Völkergewohnheitsrechts gezogen werden.

Die Untersuchungen erfolgen in Form von Landesberichten zu einzelnen Staaten, die anhand eines einheitlichen und verbindlichen Fragenkataloges erstellt werden, um so die spätere Vergleichbarkeit sicherzustellen. Im Rahmen der Landesberichte werden im Wesentlichen folgende Fragestellungen untersucht: 
- Inwieweit sind die im Römischen Statut und im geltenden Völkergewohnheitsrecht als völkerrechtliche Verbrechen pönalisierten Verhaltensweisen (Verbrechen gegen die Menschlichkeit, Völkermord, Kriegsverbrechen) nach der Strafrechtsordnung des untersuchten Landes strafbar? Ist darüber hinaus das Verbrechen der Aggression im nationalen Recht unter Strafe gestellt?

- Werden diese Straftaten durch spezielle Straftatbestände des nationalen Strafrechts erfasst, lediglich durch die "normalen" Straftatbestände eines Strafgesetzbuchs oder aber durch Verweis auf Völkerrecht (Völkergewohnheitsrecht oder das Römische Statut)?

- Welche im Völkerrecht anerkannten Völkerstraftaten sind nicht unter Strafe gestellt?

- $\quad$ Nach welchen Anknüpfungsprinzipien des so genannten "internationalen Strafrechts" wie etwa dem Territorialitätsprinzip, dem Personalitätsprinzip oder dem Weltrechtsprinzip wird die räumliche und personale Reichweite der Strafgewalt über völkerrechtliche Verbrechen begründet?

- Inwieweit gelten bei völkerrechtlichen Verbrechen Besonderheiten im Hinblick auf allgemeine Regeln der strafrechtlichen Verantwortlichkeit (Allgemeiner Teil des Strafrechts), etwa bezüglich der Rechtfertigungsgründe der "Notwehr" oder des "Handelns auf Befehl", bezüglich eines Verbotsirrtums oder der Verantwortlichkeit von Befehlsgebern (Hintermännern)?

- $\quad$ Gibt es besondere Regelungen im Hinblick auf die Zulässigkeit einer Strafverfolgung, etwa bezüglich völkerrechtlicher und verfassungsrechtlicher Immunitäten oder Verjährung?

- $\quad$ Arbeitsbericht 2002/2003:

Im Berichtszeitraum wurden die meisten der insgesamt 35 vorgesehenen Landesberichte von den Autorinnen und Autoren verfasst und der Projektgruppe zur weiteren Bearbeitung übermittelt. Die eingegangenen Landesberichte sind allerdings erst teilweise überprüft und in Zusammenarbeit mit den Verfassern überarbeitet worden. Die Berichte aus Europa, Nordamerika, Asien, Afrika und Australien werden im Max-Planck-Institut von Helmut Kreicker und Johanna Rinceanu betreut. Zum Jahresende 2003 konnten zwei Bände der neuen Reihe "Nationale Strafverfolgung völkerrechtlicher Verbrechen" mit Landesberichten zu Deutschland, Finnland, Polen und Schweden veröffentlicht werden.

Die Koordination und Bearbeitung der Berichte zu den einbezogenen mittel- und südamerikanischen Ländern fand im Rahmen eines "Teilprojekts Lateinamerika" statt, das unter der Leitung von Herrn Prof. Dr. Kai Ambos stand. Die Autorinnen und Autoren der Berichte zu den mittel- und südamerikanischen Staaten haben sich im Februar 2003 zu einem gemeinsamen Kolloquium in Montevideo, Uruguay getroffen. Die Landesberichte zu diesen Staaten sind in spanischer Sprache in Uruguay veröffentlicht worden. Diese Publikation sowie das Kolloquium sind durch finanzielle Zuwendungen und organisatorische Hilfe von der Konrad-Adenauer-Stiftung unterstützt worden.

- $\quad$ Arbeitsplanung 2004:

Die Berichte zu Estland und den USA werden spätestens Anfang 2004 dem Verlag zur weiteren Bearbeitung übergegeben werden können. Die weiteren noch ausstehenden Landesberichte werden entweder bereits von den Projektmitarbeitern überarbeitet oder aber werden voraussichtlich im Jahr 2004 von den Autoren eingereicht werden. Bereits in der verlagsseitigen Bearbeitung befinden sich die Landesberichte zu Côte d'Ivoire, Frankreich und Spanien, deren gemeinsame Veröffentlichung in einem Band 3 der Reihe "Nationale Strafverfolgung völkerrechtlicher Verbrechen" vorgesehen ist. Ebenfalls bereits im Verlag befinden sich die Landesberichte zu Kroatien, Österreich, Serbien und Montenegro, Slowenien und der Türkei, die zusammen in einem Band 4 veröffentlicht werden sollen, sowie die Berichte zu Kanada und Israel. Die beiden letztgenannten Beiträge sollen zusammen mit den Landesberichten zu Estland und den USA in einem durchgängig englischsprachigen Band (Band 5) gleichfalls im Jahr 2004 publiziert werden. 
- Zum Projekt vorliegende Veröffentlichungen:

ESER, A., KREICKER, H. (Hrsg.), Nationale Strafverfolgung völkerrechtlicher Verbrechen. National Prosecution of International Crimes. Band 1: Deutschland. edition iuscrim, Freiburg i.Br. 2003. 552 S. [im Druck].

ESER, A., KREICKER, H. (Hrsg.), Nationale Strafverfolgung völkerrechtlicher Verbrechen. National Prosecution of International Crimes. Band 2: Finnland, Polen, Schweden. edition iuscrim, Freiburg i.Br. 2003, $304 \mathrm{~S}$.

Ambos, K., Malarino, E. (eds.), Persecución penal nacional de crímenes internationales en América Latina y España. Montevideo (Uruguay) 2003, 746 S.

Ambos, K., Malarino, E. (Coord.), Persecução Penal International na América Latina e Espanha. IBCCRIM, Sao Paulo 2003, 271 S.

- Weitere einschlägige Veröffentlichungen:

ESER, A., Völkermord und deutsche Strafgewalt. Zum Spannungsverhältnis zwischen Weltrechtsprinzip und legitimierendem Inlandsbezug. In: Strafverfahrensrecht in Theorie und Praxis. Festschrift für Lutz Meyer-Goßner zum 65. Geburtstag. Hrsg. A. Eser, J. Goydke, K.R. Matz, D. Meurer. Verlag C.H. Beck, München 2001, 3-31

ESER, A., Harmonisierte Universalität nationaler Strafgewalt: ein Desiderat internationaler Komplementarität bei Verfolgung von Völkerrechtsverbrechen. In: Strafrecht, Strafprozessrecht und Menschenrechte. Festschrift für Stefan Trechsel zum 65. Geburtstag. Hrsg. A. Donatsch, M. Forster, Ch. Schwarzenegger. Verlag Schulthess, Zürich u.a. 2002, 219-236.

ESER, A., Verso una Corte Penale Internazionale: Nascita e Fondamenti dello Statuto di Roma. L'Indice Penale, Nuova Serie V/1, 279-305 (2002).

ESER, A., Diethnis kai Pankosmia Ethniki Poiniki Dikaiodosia/Internationale und Universale Nationale Strafgerichtsbarkeit. Zur Entstehung des Rom-Statuts für einen Internationalen Strafgerichtshof und seine Auswirkungen auf das nationale Strafrecht. Ant. N. Sakkoulas Verlag, Athen-Komotini 2003, $447 \mathrm{~S}$.

ESER, A., National Jurisdiction over Extraterritorial Crimes within the Framework of International Complementarity: A Comparative Survey on Transnational Prosecution of Genocide According to the Principle of Universality. In: Man's Inhumanity to Man. Essays on International Law in Honour of Antonio Cassese. Hrsg. L.C. Vohrah et al. Kluwer Law International, The Hague u.a. 2003, 279-296. ESER, A., Auf dem Weg zu einem internationalen Strafgerichtshof: Entstehung und Grundzüge des Rom-Statuts. Zeitschrift des Bernischen Juristenvereins 139/1, 1-42 (2003).

\subsubsection{Die Rolle der Ehre im Strafrecht}

- Mitarbeiterin: Silvia Tellenbach (Projektleiterin), 12 externe Länderberichterstatter(innen)

- $\quad$ Zeitrahmen: 1998 bis Ende 2004

- $\quad$ Projektstatus: in Bearbeitung

- $\quad$ Projektbeschreibung:

Ausgangssituation

Ehre ist ähnlich wie Scham in den verschiedensten Kulturen der Welt als Begriff und Wert anerkannt. Worauf sie sich aber jeweils bezieht, ist unterschiedlich und in Raum und Zeit in besonderem Maße dem Wandel unterworfen, ja selbst innerhalb derselben Gesellschaft muss keineswegs in allen Punkten Einigkeit herrschen. Beiträge zum Thema Ehre und Ehrverletzung können aus den unterschiedlichsten Disziplinen kommen (Psychologie, Ethnologie, Soziologie, Literatur, Rechtswissenschaft mit ihren 
Unterteilungen in Zivilrecht, öffentliches Recht und Strafrecht, einschließlich ihrer jeweiligen Rechtsgeschichten). Die Frage von Ehre und Ehrverletzung im Strafrecht kann vor allem in folgenden Problemkreisen eine Rolle spielen:

- $\quad$ Ehre als zu schützender Wert (Beleidigungsdelikte)

- $\quad$ Ehre als Konfliktgrund (Geschehene oder befürchtete Ehrverletzung als Motiv für eine Straftat und ihre Auswirkung auf eine Bestrafung)

- $\quad$ Rücksicht auf Ehre im Strafverfahren

- $\quad$ Ehrenstrafen

Rechtsvergleichende Untersuchungen zu Fragen von Ehre und Strafrecht sind bisher kaum durchgeführt worden. Am ehesten finden sich noch Arbeiten zum englischen und amerikanischen Recht, allerdings meistens auf die Presse orientiert. Überdies spielen strafrechtliche Fragen meist eine untergeordnete Rolle, was auch damit zusammenhängt, dass in Großbritannien und USA der Ehrenschutz vorwiegend auf zivilrechtlichem Wege erfolgt. Strafrechtsvergleichende Arbeiten mit dem Recht der Länder, die die größten Ausländergruppen in Deutschland stellen und daher für Deutschland auch von praktischem Interesse wären, nämlich der Türkei, den Nachfolgestaaten Jugoslawiens, Italien, Spanien oder Portugal, fehlen fast völlig, von Arbeiten, die sich rechtsvergleichend mit der Rolle der Ehre im Strafrecht in fernerstehenden Kulturen, etwa Ostasien, befassen, ganz zu schweigen. Bereits die Definition des Rechtsguts Ehre bringt Probleme mit sich, allein in der deutschen Literatur lässt sich eine Vielzahl an Definitionen von Ehre feststellen.

\section{Ziel des Projekts}

Ziel des Projekts ist es, zu ermitteln, wie andere Rechtssysteme Fragen, die mit der Ehre als Wert oder Konfliktgrund zusammenhängen, bewerten und bewältigen und in welcher Weise sie das Strafrecht dabei einsetzen. Dabei werden interessante Aufschlüsse über die unterschiedliche Gewichtung von Ehre und Ehrverletzung in verschiedenen Kulturen und Gesellschaften erwartet, die nicht nur rein wissenschaftliche Erkenntnisse bedeuten, sondern in einer Zeit zunehmender Globalisierung und Migration das Verstehen zwischen diesen Kulturen und Gesellschaften fördern, insbesondere auch Quellen für Missverständnisse offen legen. Dabei werden möglicherweise auch Positionen des eigenen Rechts relativiert, andere Positionen (z.B. bei Migration) verständlicher gemacht und der angemessene Umgang mit ihnen erleichtert. Die zunehmende Zahl von Prozessen mit ausländischen Angeklagten in Deutschland, bei denen es um schwere Straftaten auf dem Hintergrund eines abweichenden Verständnisses von Ehre geht und die Gerichte immer wieder vor große Probleme stellen, zeigt auch die praktische Notwendigkeit eines solchen Projekts.

\section{Fragestellungen im Einzelnen}

In dem Projekt werden zunächst 12-14 Länderberichte von besonders interessant erscheinenden Ländern erstellt und auf deren Grundlage ein rechtsvergleichender Querschnitt erarbeitet. Bei der Erarbeitung der Projektskizze stellten sich u.a folgende Einzelfragen

- Die Wege, auf denen Ehre geschützt wird, müssen keineswegs immer strafrechtliche sein. Die Beschreibung des Gewichts des Strafrechts im Verhältnis zu etwaigen anderen Rechtsgebieten ist daher eine wichtige Grundfrage.

- $\quad$ Bei den Grundstrukturen von Ehrverletzungsdelikten sind zunächst Fragen zu möglichen Opfern und zum Inhalt von Ehrverletzungen zu behandeln (Wer kann Opfer sein? Haben alle Opfer gleichen Ehrenschutz? Lässt sich aus Lehre und Rechtsprechung des Berichtslands deutlicher kategorisieren, was als Ehrverletzung angesehen wird?) 
- Unter welchen Umständen ist ein Angriff auf die Ehre ausnahmsweise erlaubt? Wann ist der Wahrheitsbeweis zulässig? Welche Rechtfertigungsgründe insgesamt sind zu beachten? Dabei verdient besonders der Fragenkreis Aufmerksamkeit, der im deutschen Recht mit der Wahrnehmung berechtigter Interessen (Art. 193 StGB) umschrieben wird.

- Welche Umstände bei einer Bestrafung von Ehrverletzungsdelikten wirken strafmildernd oder strafschärfend? Gibt es bei Ehrverletzungsdelikten gegebenenfalls Besonderheiten bei den Strafen oder im Strafverfahren?

- Im Bereich der Ehrverletzungsdelikte kommt es bei alltäglichen Delikten in Deutschland nur noch selten zu Strafverfahren und noch seltener zu Verurteilungen; eine ähnliche Sachlage scheint sich in vielen anderen Ländern anzudeuten. Von Wichtigkeit sind dagegen bestimmte einzelne Sachgebiete, vor allem die Meinungsfreiheit im öffentlichen Raum, mit den wichtigsten Einzelfragen Pressefreiheit und Kunstfreiheit, dem Ehrenschutz von Persönlichkeiten des politischen oder sonstigen öffentlichen Lebens sowie des Staates, seiner Institutionen und Amtsträger überhaupt. Die Frage, wieweit Personengesamtheiten durch Ehrverletzungen tangiert werden können, führt zu dem Problem, wieweit Diskriminierungen aus rassischen, sozialen, nationalen, religiösen und sonstigen gruppenbezogenen Merkmalen auch als Ehrverletzungen aufgefasst und geahndet werden können.

- $\quad$ Bei der Frage der Ehrverletzung als Motiv für eine Tat und ihre Berücksichtigung im Bereich von Unrecht und Schuld ist zwar das deutsche Recht nicht sehr ergiebig, wohl aber spielen in anderen Rechtsordnungen die Vorschriften über Provokation, die den Ansatz für Strafmilderungen oder gar -freistellungen bilden können, eine erhebliche Rolle.

- $\quad$ Ein nicht zu übergehender Bereich einer möglichen Ehrverletzung ist das Strafverfahren. Welche Folgerungen sind aus der heute weltweit anerkannten Unschuldsvermutung zu ziehen? Wie darf durch Medien, aber auch durch Pressestellen von Polizei, Staatsanwaltschaft oder Gerichten über einen Tatverdächtigen berichtet werden? Wie weit darf ein Tatverdächtiger über Lebensumstände befragt werden, die nicht unbedingt zur Klärung des Tatvorwurfs gehören? Ähnliche Fragen stellen sich im Umgang mit Zeugen.

- Jede Strafe enthält ein ehrenrühriges Element, mit anprangernden Strafen sind jedoch nur Strafen gemeint, welche die Prangerwirkung gezielt als besonderes Strafelement einsetzen. Hier ist heute vor allem an Diskussionen in den USA zu denken. $\mathrm{Zu}$ erörtern ist auch, inwieweit aus Sicherheitsgründen Maßregeln zulässig sein können, die zu einer Stigmatisierung des Betroffenen führen.

- $\quad$ Ein Abschnitt "Rechtstatsächliches" soll Ausführungen zur Bedeutung der Rolle von Ehre und Strafrecht in der Praxis geben und gegebenenfalls zu kürzlich erfolgten oder geplanten Reformvorhaben enthalten.

- $\quad$ Arbeitsbericht 2002/2003:

Elf Länderberichte wurden in der Erstfassung erstellt, vier lagen bis Anfang Dezember in der Zweitfassung vor. Insgesamt besteht jedoch noch sehr großer Überarbeitungsbedarf. Im April 2003 wurde mit den Autoren ein workshop zur Diskussion der bisherigen vorläufigen Ergebnisse und Planung der weiteren Arbeit durchgeführt.

\section{- $\quad$ Arbeitsplanung 2004:}

Erwartet wird der Eingang von drei weiteren Länderberichten in der Erstfassung und die endgültige Fassung der bereits vorliegenden Länderberichte wird angestrebt. Ferner soll der Querschnitt in Angriff genommen werden. 
- Veröffentlichungen zum Projekt:

TELLENBACH, S., Ehrenmorde an Frauen in der arabischen Welt. wuquf 13, 74-89 (2003).

TellenBACH, S., Zur Ehre im türkischen Strafrecht, in: Akten des 27. Deutschen Orientalistentags Norm und Abweichung. Hrsg. S. Wild/H. Schild. Würzburg 2001, 473-479.

\subsubsection{Private Commercial Bribery Laws in Major OECD Country Groups}

- Mitarbeiter(innen): Günter Heine (Projektkoordinator, Universität Gießen/Bern), Barbara Huber (Projektkoordinatorin), Roberto Acquaroli, Stéphane Bonifassi, Nadja Capus, ByungSun Cho, Jaroslav Fenyk, Luigi Foffani, Karen Guida, Keith E. Henderson, Philipp Keller, Karl-Ludwig Kunz, Madeleine Leijonhufvud, Emil Ptywaczewski, Joan Queralt, T.O. Rose, Seiji Saito, Bob Sullivan, Peter J.P. Tak, Michael Überhofen.

- $\quad$ Zeitrahmen: 2000 bis 2002

- $\quad$ Projektstatus: im Berichtszeitraum abgeschlossen

- $\quad$ Projektbeschreibung:

Das rechtsvergleichende Projekt im Auftrag der Internationalen Handelskammer (ICC), Paris, bezweckte die Darstellung der straf-, zivil- und verwaltungsrechtlichen Grundlagen, die in den Rechtsordnungen der OECD-Mitgliedsländer Deutschland, Frankreich, England, Italien, Tschechische Republik, Schweiz, Schweden, Polen, Spanien, Niederlande, Korea, Japan, USA gegen die private Korruption und Erpressung vorhanden sind. Der Schwerpunkt der Landesberichte lag auf dem strafrechtlichen Instrumentarium. Ein Bericht über die internationalen Regelungen auf diesem Gebiet ergänzt die Landesberichte. Mit einer rechtsvergleichenden Analyse wurden die Entwicklungen evaluiert und ggf. Vorschläge für eine gemeinsame Strategie der ICC vorgelegt werden.

- $\quad$ Arbeitsbericht 2000/2003 und Ergebnisse:

Die Autoren erstellten bis Ende März 2002 die nationalen und internationalen Schlussberichte. Auf der Grundlage dieses Materials verfasste Prof. Dr. Heine die rechtsvergleichende Analyse. Der Auftraggeber hat die endgültige Diskussion der vorgelegten Analyse und Thesen von November 2001 auf April 2002 verschoben. Im April 2002 fand die abschließende Sitzung mit der ICC und dem zuständigen Gremium der OECD statt, auf der der Schlussbericht vorgestellt und diskutiert wurde. Nachdem die Veröffentlichung des gesamten Materials beschlossen worden war, wurden im Laufe des Jahres 2002 Landesberichte und rechtsvergleichende Analyse für den Druck vorbereitet. Das Buch wurde im MaxPlanck-Institut redaktionell betreut und in Kooperation mit der ICC in der Institutsreihe 'Beiträge und Materialien aus dem Max-Planck-Institut für ausländisches und internationals Strafrecht' im Mai 2003 unter dem Titel: G. Heine/B. Huber/T.O. Rose (eds.), Private Commercial Bribery. A Comparison of National and Supranational Legal Structures. edition iuscrim \& International Chamber of Commerce. Freiburg \& Paris 2003, 658 S., veröffentlicht.

Der Projektbericht von G. Heine/T.O. Rose, Private Commercial Bribery - A Comparison of National and Supranational Structures, findet sich in: forschung aktuell/research in brief, Nr. 16. edition iuscrim Freiburg 2003 und ist unter www.iuscrim.mpg.de einzusehen.

\section{- Drittmittel:}

Das Projekt wurde finanziert mit Mitteln der International Chamber of Commerce, die auch die Vorbereitung der Drucklegung finanziell unterstützt hat. 
- Zum Projekt vorliegende Veröffentlichungen:

ESER, A., ÜBERHOFEN, M., HUBER, B. (Hrsg.), Korruptionsbekämpfung durch Strafrecht. edition iuscrim, Freiburg i.Br. 1997, 795 S.

ÜBERHOFEN, M., Korruption und Bestechungsdelikte im staatlichen Bereich. edition iuscrim, Freiburg $1999,516 \mathrm{~S}$.

HUBER, B., Il sistema tedesco di lotta alla corruzione: una comparazione con quelli di altri paesi europeo. Rivista trimestrale di Diritto Penale dell'Economia, 507-525 (1999).

HubER, B. (Hrsg.), Combating Corruption in the European Union/Korruptionsbekämpfung in der Europäischen Union/La lutte contre la corruption dans l'Union européenne. Bundesanzeiger, Köln 2002, $265 \mathrm{~S}$.

HUBER, B., La lotta alla corruzione in prospettiva sopranazionale. XIV (2001) Rivista Trimestrale di Diritto Penale dell'Economica, 467-489.

Huber, B., Sanctions against Bribery Offences in Criminal Law. In: Corruption, Integrity and Law Enforcement. Eds. C. Fijnaut. L. Huberts. Kluwer, The Hague 2002, 137-150.

HUBER, B., Introduzione. In: La corruzione tra privati. Eds. R. Acquaroli, L. Foffani. Guiffrè, Milano 2003, 31-42.

HUBER, B., La lucha contra la corrupción desde una perspectiva supranacional. In: Annales de la Facultad de Derecho, La Laguna 2002, 95-115; weiterhin in: Iter Crimines, Revista de Sciencias Penales, no. 7, 2003, 159-188; sowie in: La Ley - Revista penal, vol. 11, 2003, 41-52.

\subsubsection{Freiburg Proposal on Concurrent Jurisdictions and the Prohibition of Multiple Prosecutions in the European Union}

- $\quad$ Projektkoordinatoren: Anke Biehler, Roland Kniebühler, Juliette Lelieur-Fischer, Sibyl Stein

- $\quad$ Zeitrahmen: 2002 bis 2003

- $\quad$ Projektstatus: im Berichtszeitraum abgeschlossen

- $\quad$ Projektbeschreibung:

Konkurrenzen nationaler Strafgerichtsbarkeiten und die damit verbundene Gefahr von mehrfacher Strafverfolgung ist kein völlig neues Problem, hat aber durch fortschreitende Globalisierung von Verkehr und Wirtschaft und damit verbundenem Ansteigen grenzüberschreitender Kriminalität wachsendes Gewicht erlangt. Durch die Einrichtung von internationalen Straftribunalen ist zur horizontalen nationalen Konkurrenz nun auch noch eine vertikale zwischen nationalen und internationalen Strafgewalten hinzugekommen. Deshalb will sich der nächste internationale Strafrechtskongress der Association Internationale de Droit Pénal (AIDP) im September 2004 in Beijing dieser Problematik annehmen. Zur Vorbereitung darauf wurde im Juni 2003 unter Leitung von Prof. Dr. Albin Eser in Berlin ein vorbereitendes Kolloquium zum Thema "Concurrent National and Internationale Criminal Jurisdictions and the Principal of 'ne bis in idem'" durchgeführt. Parallel zu diesem globalen Ansatz gibt es auf europäischer Ebene schon seit längerem das Bemühen um bessere Vermeidung von Mehrfachverfolgungen, wobei für diesen Kontinent das ne bis in idem-Prinzip bereits in der Europäischen Union als Menschenrecht anerkannt ist. Zudem ist aber die effiziente Durchsetzung des Verbots der Mehrfachverfolgung ein und derselben Person wegen derselben kriminellen Handlung Voraussetzung für die Schaffung eines gemeinsamen Raums der Freiheit, der Sicherheit und des Rechts, was ein Ziel der Europäischen Union ist. Trotzdem macht die Umsetzung dieses Prinzips immer wieder Probleme.

Vor diesem Hintergrund hat eine Gruppe von Experten im Europäischen Strafprozessrecht unter Schirmherrschaft des Max-Planck-Instituts für ausländisches und internationales Strafrecht und seines Direktor Emeritus Prof. Dr. Albin Eser das "Freiburg Proposal on Concurrent Jurisdictions and the 
Prohibition of Multiple Prosecutions in the European Union" entwickelt. Mitglieder der Expertengruppe waren: Anke Biehler (Deutschland), Thomas Elholm, Ph.D. (Dänemark), Christopher Gane (Vereinigtes Königreich), Roland Kniebühler (Deutschland), Otto Lagodny (Deutschland/Österreich), Juliette Lelieur-Fischer, LL.M. (Frankreich), A.H.J. Lensing (Niederlande), Tom Ongena (Belgien), Michał Płachta (Polen), Dionysios Spinellis (Griechenland), Sibyl Stein (Deutschland), Asbjörn Strandbakken (Norwegen) und Frau Helge Elisabeth Zeitler (Deutschland).

Ziel des Vorschlags ist, ein umfassendes Regelungsmodell zu geben wie Mehrfachverfolgungen und bestrafungen für dieselbe Tat in verschiedenen Jurisdiktionen zu vermeiden sind. Dies schützt einerseits den Beschuldigten und die Rechtssicherheit, erlaubt aber andererseits effektive Strafverfolgung. Ergebnis der Beratungen war der Vorschlag einer dreistufigen Lösung: Auf der ersten Stufe sollen Mehrfachverfolgungen von vornherein durch gegenseitige Information und effektive Koordination zwischen Verfolgungsbehörden vermieden werden. Wenn - trotz allem - eine Mehrfachverfolgung nicht vermieden werden konnte, ist das ne bis in idem-Prinzip auf der zweiten Stufe anwendbar. Im Mittelpunkt der Freiburger Gruppe stand dabei das Bemühen, die Anwendbarkeit einer ne bis in idemRegelung auf alle repressiven Entscheidungen auszudehnen, anstatt sie auf strafrechtliche Urteile zu beschränken. Wenn dennoch mehrere Verfolgungen stattfinden, ist das Anrechnungsprinzip auf der dritten Stufe als letzter Rettungsanker anwendbar.

Der erste Teil des Projekts bestand in der Konzeption und der Organisation von zwei Seminaren, die in Freiburg vom 22. bis zum 24. Mai und vom 10. bis zum 12. Juli stattfanden und an denen ca. 15 Experten aus dem Europäischen Ausland teilnahmen. In den Seminaren wurde ein Regelungsvorschlag für die Europäsche Union erarbeitet. Der zweite Teil des Projekts bestand in der Anfertigung einer Kommentierung dieses Regelungsentwurfs in englischer Sprache (36 Seiten).

Das Projekt wurde unter dem Titel Freiburg Proposal on Concurrent Jurisdictions and the Prohibition of Multiple Prosecutions in the European Union veröffentlicht (edition iuscrim, forschung aktuell/research in brief sowie online Publikationen des Max-Planck-Instituts). Für weitere Informationen, siehe MaxPlanckForschung, Das Wissenschaftsmagazin der Max-Planck-Gesellschaft, 3/2003, S. 71. Siehe hierzu auch: http://www.iuscrim.mpg.de/forsch/straf/projekte/nebisinidem.html

- Veröffentlichungen:

ESER, A., Harmonisierte Universalität nationaler Strafgewalt: ein Desiderat internationaler Komplementarität bei Verfolgung von Völkerrechtsverbrechen. In: Strafrecht, Strafprozessrecht und Menschenrechte. Festschrift für Stefan Trechsel zum 65. Geburtstag. Hrsg. A. Donatsch, M. Forster, Ch. Schwarzenegger. Verlag Schulthess, Zürich u.a. 2002, 219-236.

ESER, A., DE LA CUESTA, J.L., Les Compétences criminelles concurrentes nationales et internationales et le principe "ne bis in idem"(in französisch, englisch und spanisch). Revue Internationale de Droit Pénal 72, 739-777 (2002).

ESER, A., National Jurisdiction over Extraterritorial Crimes within the Framework of International Complementarity: A Comparative Survey on Transnational Prosecution of Genocide According to the Principle of Universality. In: Man's Inhumanity to Man. Essays on International Law in Honour of Antonio Cassese. Hrsg. L.C. Vohrah et al. Kluwer Law International, The Hague u.a. 2003, 279-296. ESER, A., Justizielle Rechte. In: Kommentar zur Charta der Grundrechte der Europäischen Union. Hrsg. J. Meyer. Nomos Verlagsgesellschaft, Baden-Baden 2003, 501-555.

ESER, A., Auf dem Weg zu einem internationalen Strafgerichtshof: Entstehung und Grundzüge des Rom-Statuts. Zeitschrift des Bernischen Juristenvereins 139/1, 1-42 (2003). 


\title{
2.3 Einzelvorhaben
}

\subsubsection{Schwerpunkt: Deutsches Straf- und Strafverfahrensrecht}

\author{
NS-Fortsetzungspropaganda zwischen Versammlungsrecht und Internet - \\ Ein Beitrag zum strafrechtlichen Umgang der Bundesrepublik Deutschland \\ mit NS-bezogenen Delikten
}

- $\quad$ Bearbeiterin: Clivia Namgalies

- $\quad$ Zeitrahmen: 2001 bis 2004

- $\quad$ Projektstatus: in Bearbeitung

- Projektbeschreibung: Promotionsvorhaben

Strafvorschriften, die auf die Verbreitung nationalsozialistischen Gedankenguts reagieren, wie $\S \S 86$ Abs. $1 \mathrm{Nr}$. 4, 86 a und 130 Abs. $3 \mathrm{StGB}$, haben heute eine neue Aktualität gewonnen, weil sie zunehmend im neuen Medium Internet begangen werden. So hat etwa der BGH im Dezember 2000 sein erstes Urteil in Internetstrafsachen gefällt und entschieden, dass auch das Einspeisen holocaustleugnender Äußerungen in englischer Sprache über einen australischen Server die deutsche Strafnorm des $\S 130$ Abs. 3 StGB verletzt.

Die Arbeit, die von Prof. Dr. Detlef Krauß (Humboldt-Universität zu Berlin) betreut wird, soll zunächst die Entwicklungsgeschichte von NS-Propagandaverboten nachzeichnen (Teil 1). Ausgehend von den zur Verfügung stehenden strafrechtsdogmatischen Kategorien sind die Delikte in einem zweiten Teil auf ihre Eigenart hin zu untersuchen (Teil 2). Schließlich sollen die Delikte daraufhin untersucht werden, ob sie symbolisches Strafrecht darstellen (Teil 3).

In der Entwicklungsgeschichte soll untersucht werden, wie die Gesetzgebung im Bereich von NSFortsetzungspropaganda auf neu entstehende Probleme reagiert hat. Anlass und Motive für die jeweilige Gesetzgebung sollen herausgearbeitet werden. Die Darstellung der Entwicklungsgeschichte soll dabei die nachfolgende dogmatische Analyse des zweiten Teils vorbereiten.

Im zweiten Teil sollen vor allem die durch die NS-Bezugsdelikte geschützten Rechtsgüter näher untersucht werden. Dabei sind die herkömmlich als die geschützten Rechtsgüter bezeichneten Schutzgüter wie der "öffentliche Friede" im Falle des $\S 130$ Abs. 3 StGB und die "freiheitlich-demokratische Grundordnung" und der "Gedanke der Völkerverständigung" bei den $\S \S 86$ Abs. 1 Nr. 4, 86 a StGB kritisch zu beleuchten. Da es sich dabei nicht um Individualrechtsgüter handelt, die das System des StGB ansonsten prägen, ist auf die Besonderheit dieser Rechtsgüter insgesamt näher einzugehen. Ergänzend sollen die verfassungsrechtlichen Probleme der NS-Propagandaverbote untersucht werden. Es soll gezeigt werden, dass die Besonderheiten, die die strafrechtsdogmatische Ausgestaltung dieser Delikte prägen, sich auch in ihrem Verhältnis zu verfassungsrechtlichen Vorgaben widerspiegeln. Zweifel an der Verfassungsmäßigkeit der NS-Propagandaverbote bestehen in Bezug auf zwei Fragen: Erstens ist schon fraglich, ob solche Äußerungen überhaupt vom Schutzbereich der Meinungsfreiheit des Art. 5 Abs. 1 GG erfasst werden. Fallen die entsprechenden Äußerungen in den Schutzbereich der Meinungsfreiheit, so ist zweitens problematisch, ob Einschränkungen von der Schranke der allgemeinen Gesetze in Art. 5 Abs. 2 GG gedeckt sind. Daran anschließen soll sich die Frage, ob die neue Form der Begehung - die $\S \S 86$ Abs. 1 Nr. 4, 86 a StGB und $\S 130$ StGB werden heute hauptsächlich mittels Internet begangen - Probleme verdeutlichen, die bereits in ihnen angelegt waren. Es soll der innere Zusammenhang zwischen der generellen Problematik der Delikte einerseits und der Problematik, die sich durch eine Internetbegehung andererseits ergibt, untersucht werden. Schwerpunkt dabei wird die Frage nach der Anwendbarkeit deutschen Strafrechts auf im Internet begangene NS-Be- 
zugsdelikte sein. Schwierigkeiten bereiten hier die Fälle, in denen der Täter rechtswidrige Inhalte von einem ausländischen Server aus ins Netz einspeist. Eine mögliche Strafbarkeit nach deutschem Recht setzt nach $\S 3$ i.V.m. $\S 9$ StGB voraus, dass entweder der Handlungsort oder aber der Erfolgsort im Inland liegt. Probleme ergeben sich insbesondere bei abstrakten Gefährdungsdelikten, da diese gerade keinen Erfolgsort als klaren Anknüpfungspunkt aufweisen. Als abstrakte Gefährdungsdelikte eignen sich die $\S \S 86$ Abs. 1 Nr. 4, 86a und 130 Abs. 3 StGB in besonderem Maße, die Diskussion um eine Anwendbarkeit deutschen Strafrechts darzustellen und schließlich zu hinterfragen. Schließlich soll in einem dritten Teil der Frage nachgegangen werden, inwieweit die NS-Propagandaverbote symbolisches Strafrecht darstellen.

- $\quad$ Arbeitsbericht 2002/2003:

Bisher konnte der erste Teil zur Gesetzgebungsgeschichte der NS-Propagandaverbote sowie einzelne Teile aus dem dogmatischen, zweiten Teil fertig gestellt werden. Außerdem wurde mit wesentlichen Vorarbeiten zum dritten und letzten Teil der Arbeit, zum symbolischen Strafrecht, begonnen.

- $\quad$ Arbeitsplanung 2004:

Es ist beabsichtigt, die Arbeit in der ersten Jahreshälfte 2004 fertig zu stellen.

\subsubsection{Schwerpunkt: Ausländisches Straf- und Strafverfahrensrecht}

\subsubsection{Islamisches Strafrecht in der modernen Welt}

- $\quad$ Bearbeiterin: Silvia Tellenbach

- $\quad$ Zeitrahmen: 1999 bis 2006

- $\quad$ Projektstatus: in Bearbeitung

- $\quad$ Projektbeschreibung:

Geplant ist eine Monographie von voraussichtlich ca. 300-400 Seiten, die sich mit dem islamischen Strafrecht in der heutigen Welt befasst. Hierbei sind folgende Themenschwerpunkte zu setzen

1. Islamisches Strafrecht in der Diskussion fundamentalistisch- islamischer und modernistischislamischer Kreise

2. Islamisches Strafrecht als staatliches Recht und die dabei bestehenden Probleme in der Rechtspraxis (z.B. Iran, Sudan, Pakistan)

Islamisches Strafrecht wird zum einen diskutiert in dem größeren Rahmen des Geltungsanspruchs der Šari'a, des als gottgegeben angesehenen Teils islamischen Rechts, überhaupt. In den heutigen Staaten mit mehrheitlich muslimischer Bevölkerung gilt nur noch in wenigen Bereichen islamisches Recht. Das zentrale Anliegen der fundamentalistischen Kreise ist die Wiedereinführung des islamischen Rechts, die Geltung des islamischen Rechts ist das entscheidende Kriterium, das den muslimischen Staat zum islamischen Staat macht. Hier müssen zwar auch wesentliche Züge einer breiteren Diskussion dargestellt werden, jedoch stets mit Schwerpunktsetzung auf die Darstellung der strafrechtsbezogenen Teile.

Zentrales Problem ist, dass das, was prinzipiell als unveränderliches göttliches Recht anzusehen ist, häufig den Erfordernissen der heutigen Zeit nicht mehr gerecht wird. Besonders in den Fällen, in denen islamisches Strafrecht geltendes staatliches Recht ist, zeigen sich praktische Probleme. Viele Beteiligte suchen auf ihre Art nach Wegen, Entwicklungen in religionsgesetzlich zulässiger Weise Rech- 
nung zu tragen. Nur ein Beispiel: dass etwa ein Diebstahl nur durch Geständnis oder Zeugen bewiesen werden kann, ist bei den heutigen kriminalistischen Möglichkeiten nicht mehr akzeptabel. So versuchen z.B. schiitische Juristen, das "Wissen des Richters" als Beweismittel in derartigen Fällen einzuführen und religionsrechtlich abzusichern. Aber auch Stimmen in der Diskussion, die die alten Interpretationen nicht aufgeben wollen, müssen mit neuen Argumentationen ihren Standpunkt verteidigen.

Fast alle derartigen Fragen bleiben in der Literatur in westlichen Sprachen, die bis auf wenige noch nicht erreichbare Texte ausgeweitet wurde, so gut wie unberührt. Eine Darstellung dieser Diskussionen wird ein wesentlich differenzierteres Bild vom islamischen Strafrecht liefern als es bis jetzt westlichen Lesern zugänglich ist. Was an der Arbeit weiterführend sein soll, ist fast nur aus arabischen und persischen Quellen zu erarbeiten, bei denen manchmal die Beschaffung nicht leicht sein wird. Je nach den anderen Aufgaben, die hier anfallen, und den Schwierigkeiten, die die Beschaffung unverzichtbarer Literatur aus dem Nahen Osten bietet, wird man eine zeitliche Perspektive von noch ca. 3 Jahren ansetzen müssen.

- $\quad$ Arbeitsbericht 2002/2003:

Sammlung und Auswertung von Materialien

- $\quad$ Arbeitsplanung 2004:

Sammlung und Auswertung von Materialien

\subsubsection{2 Übersetzung der türkischen Strafprozessordnung}

- $\quad$ Bearbeiterin: Silvia Tellenbach

- Zeitrahmen: 2001 bis 2003

- Projektstatus: abgeschlossen

- $\quad$ Projektbeschreibung:

Nachdem die Übersetzung des türkischen Strafgesetzbuchs auf rege Nachfrage gestoßen ist und immer wieder der Wunsch geäußert wurde, auch eine Übersetzung der türkischen Strafprozessordnung zur Hand zu haben, wurde eine Übersetzung der türkischen StPO erstellt. Ihr wird eine kurze Einführung in die türkische Strafprozessordnung beigegeben. In einem Anhang werden auch noch strafprozessrechtliche Vorschriften wichtiger Nebengesetze (z.B. Staatssicherheitsgerichtsgesetz, Gesetz gegen die organisierte Kriminalität) aufgenommen. Da in der nächsten Zeit möglicherweise tief greifende Reformen der türkischen StPO erfolgen werden, wird die vorliegende Übersetzung zunächst nicht in der Reihe Ausländischer Strafgesetzbücher veröffentlicht, sondern ins Internet eingestellt. 


\subsubsection{Strafrechtliche Reaktion auf Systemunrecht in Rumänien nach 1989 im Vergleich zu anderen osteuropäischen Staaten}

- $\quad$ Bearbeiterin: Julie Trappe

- $\quad$ Zeitrahmen: 2003 bis 2005

- $\quad$ Projektstatus: in Bearbeitung

- $\quad$ Projektbeschreibung: Promotionsvorhaben

Das aus dem Institutsprojekt "Strafrecht in Reaktion auf Systemunrecht" hervorgegangene von Privatdozent Dr. Jörg Arnold (Humboldt-Universität zu Berlin) betreute Promotionsvorhaben beschäftigt sich mit der strafrechtlichen Reaktion auf Systemunrecht in Rumänien.

Im Dezember 1989 wurde in Rumänien das diktatorische Regime Ceausescus gestürzt und durch ein demokratisches System ersetzt. Obwohl der Umbruch in Rumänien schon nahezu 15 Jahre zurückliegt, findet eine Aufarbeitung des vor 1989 begangenen staatsgestützten Unrechts nur zögerlich statt. Im Unterschied zu anderen ehemals kommunistischen Staaten, in denen die strafrechtliche Reaktion nunmehr abgeschlossen ist, beginnt dieser Prozess in Rumänien erst allmählich. Die Arbeit beschreibt diesen Prozess und stellt die einschlägigen Veränderungen des Rechtssystems dar. Es wird sowohl auf die täterbezogenen als auch auf die opferbezogenen Reaktionen eingegangen. Neben der strafrechtlichen Reaktion werden auch andere rechtliche Prozesse dargestellt. Die Rehabilitationsurteile und die gesetzlichen Regelungen zur Entschädigung werden ebenso behandelt wie die Frage der Lustration (Überprüfung von Personen bezüglich ihrer früheren Tätigkeit für die Geheimpolizei). Im Mittelpunkt der Arbeit steht jedoch die kritische Analyse der relevanten Strafprozesse. Dabei wird die rechtliche Situation dargestellt, aber auch die politischen und historischen Bezüge erläutert.

Die Arbeit versucht zu klären, welche Rolle das Strafrecht bei dem Umgang mit der Vergangenheit spielt, und wo die Grenzen der Leistungsfähigkeit des Strafrechts in diesem Bereich liegen.

Dies ist auch die Fragestellung für den rechtsvergleichenden Teil, in dem die Situation der strafrechtlichen Reaktion in anderen osteuropäischen Staaten nach 1989 dargestellt und analysiert wird.

- $\quad$ Arbeitsbericht 2002/2003:

In einem ersten Schritt ging es darum, einen Überblick zu erlangen über die rechtliche Lage und die relevanten Strafprozesse. Da es in der rumänischen Strafrechtswissenschaft - bis jetzt - nur wenig Auseinandersetzung mit diesem Thema gibt, stellten in die betreffenden Prozesse involvierte Rechtspraktiker eine wichtige Informationsquelle dar. Aufgrund der Aktualität des Themas fand auch eine Auswertung der aktuellen Presse statt. Außerdem wurden auch die einschlägigen Forschungsergebnisse auf historischem Gebiet berücksichtigt. Parallel dazu konnten die relevanten Strafprozesse je nach Stand analysiert werden.

- $\quad$ Arbeitsplanung 2004:

Der Prozess der Reaktion auf Systemunrecht in Rumänien wird weiter verfolgt, insbesondere die laufenden Strafprozesse, und sukzessive analysiert. Außerdem ist geplant, noch fehlende Dokumente zu beschaffen, so dass ein vollständiges Bild der Rolle des Strafrechts bei dem Umgang mit Systemunrecht in Rumänien nach 1989 entsteht. 


\subsubsection{Schwerpunkt: Rechtsvergleichung}

\subsubsection{Wiedergutmachungsansätze für Kriminalitätsopfer im deutschen und amerikanischen Recht}

- $\quad$ Bearbeiterin: Emily Silverman

- $\quad$ Zeitrahmen: 1997 bis 2005

- $\quad$ Projektstatus: in Bearbeitung

- $\quad$ Projektbeschreibung: Promotionsvorhaben

Die Arbeit wird die wichtigsten materiellen und strafprozessualen Entwicklungen der letzten Jahrzehnte, durch die den Interessen von Kriminalitätsopfern in den beiden zu berücksichtigenden Ländern stärker Rechnung getragen werden soll, erforschen und einer rechtsvergleichenden Analyse unterziehen. $\mathrm{Zu}$ den bedeutsamen Themenbereichen zählen insbesondere:

- die Verpflichtung von Verurteilten oder Beschuldigten zu Geldleistungen an die Opfer der Straftat als Strafe, Bewährungs- oder "Diversions"-Auflage ("Restitution");

- $\quad$ staatliche Opferentschädigung aus speziell dafür eingerichteten Opferfonds ("Compensation");

- $\quad$ Mitwirkungs- und Informationsrechte im Strafprozess und bei der Strafzumessung;

- $\quad$ sowie Zugang zum Täter-Opfer-Ausgleich ("Victim-Offender Mediation").

Aktuelle Bestrebungen nach einer Ergänzung der amerikanischen Verfassung durch ein VictimsRights-Amendment werden im Hinblick auf die rechtspolitischen Hintergründe und möglichen Erfolgschancen diskutiert.

Darüber hinaus wird auch Entwicklungen der zivilrechtlichen Schiene spezielle Aufmerksamkeit gewidmet, wo ebenfalls eine Verbesserung der rechtlichen Position von Kriminalitätsopfern angestrebt wird. Besonders erwähnenswert ist in diesem Bereich das deutsche "Opferanspruchsicherungsgesetz", für das in den USA unter dem Namen der so genannten Son-of-Sam-Gesetze ein rechtliches Pendant existiert, sowie die jüngst in verschiedenen Einzelstaaten der USA erlassenen Drug-Dealer-LiabilityActs. Nach diesen Gesetzen, die wegen ihrer Erweiterung des Kausalitätsbegriffs eine teils heftige Diskussion auslösten, können Opfer von Beschaffungskriminalität im Falle der Mittellosigkeit ihrer Täter im Durchgriff Schadensersatzansprüche direkt gegen Drogendealer geltend machen, selbst wenn diese an der Straftat nicht unmittelbar beteiligt waren, jedoch zur Tatzeit Drogen in der Umgebung des betreffenden Tatortes verkauften.

Die Arbeit wird auch zeigen, dass - zumindest in den USA - die in den letzten Jahren implementierten Änderungen oft neben einer Verbesserung der rechtlichen Position von Kriminalitätsopfern auch mit einer erkennbar repressiven Motivation verbunden sind. Nicht von ungefähr finden "Opfergesetze" häufig Unterstützung von politischen Gruppierungen ganz unterschiedlicher Couleur. 


\subsubsection{Grenzüberschreitende Auswirkungen von ne bis in idem in horizontaler und vertikaler Richtung}

- $\quad$ Bearbeiter: Roland Michael Kniebühler

- $\quad$ Zeitrahmen: 2000 bis 2003

- $\quad$ Projektstatus: in Bearbeitung

- $\quad$ Projektbeschreibung: Promotionsvorhaben

Ziel der Arbeit ist es, durch eine rechtsvergleichende Untersuchung Erkenntnisse im Hinblick darauf $\mathrm{zu}$ gewinnen, ob überhaupt und wenn ja, in welcher Form eine Verfahrensbeendigung strafklageverbrauchende Wirkung sowohl im zwischenstaatlichen (horizontalen) als auch im staatlich/überstaatlichen (vertikalen) Bereich entfaltet.

$\mathrm{Zu}$ diesem Zweck werden die rechtlichen Konzeptionen Deutschlands und Belgiens auf folgende Punkte hin untersucht:

- Welches Verständnis herrscht hinsichtlich der ne bis in idem-Wirkung von Urteilen und sonstigen Verfahrensbeendigungen im rein nationalen Bereich

- Welche Regelungen des nationalen Rechts bestehen im Hinblick auf eine zwischenstaatliche (horizontale) ne bis in idem-Wirkung von Urteilen und sonstigen Verfahrensbeendigungen

- Welche internationalen und supranationalen Bestimmungen hinsichtlich einer zwischenstaatlichen (horizontalen) ne bis in idem-Wirkung von Urteilen und sonstigen Verfahrensbeendigungen sind für diese Staaten bindend

- Welche Regelungen des nationalen Rechts bestehen im Hinblick auf eine staatlich/überstaatliche (vertikale) ne bis in idem-Wirkung von Urteilen und sonstigen Verfahrensbeendigungen

- Welche internationalen und supranationalen Bestimmungen hinsichtlich einer staatlich/überstaatlichen (vertikalen) ne bis in idem-Wirkung von Urteilen und sonstigen Verfahrensbeendigungen sind für diese Staaten bindend

Im Anschluss hieran erfolgt in einem zweiten Schritt die Untersuchung derjenigen europäischen und internationalen Regelungen, in denen ein zwischenstaatliches ne bis in idem enthalten ist, wobei die ausführliche Behandlung von Art. 54 ff. des Schengener Durchführungsübereinkommens an zentraler Stelle steht.

Schließlich werden in einem dritten Schritt die Statute der Internationalen Strafgerichtshöfe, also des ICTY, des ICTR und des ICC im Hinblick auf ihre ne bis in idem-Bestimmungen untersucht.

Neben diesen Hauptfragen soll in der Arbeit noch der Frage nachgegangen werden, ob eine ne bis in idem-Problematik auch im überstaatlich/horizontalen Bereich (also zwischen internationalen Gerichtshöfen) entstehen kann.

Zusätzlich zu den oben genannten Punkten ist ein Bereich der Arbeit Überlegungen gewidmet, die auf eine Vermeidung der ne bis in idem-Problematik zielen, etwa durch ein System von Kompetenzhierarchien.

Das Ziel der Arbeit ist es, durch die Analyse der unterschiedlichen nationalen Konzeptionen, der europäischen und internationalen Übereinkommen sowie der Statute der Internationalen Strafgerichtshöfe Grundaussagen zu finden, mit Hilfe derer allgemeingültige Rechtsansätze im Hinblick auf ein grenzüberschreitendes ne bis in idem entwickelt werden können.

- $\quad$ Arbeitsbericht 2002/2003:

Die Fertigstellung und Abgabe der Arbeit erfolgte im August 2003. 


\subsubsection{Schwerpunkt: Europäische Zusammenarbeit in Strafsachen}

\section{Beweisrechtsgrundsätze für eine grenzüberschreitende Strafverfolgung}

- $\quad$ Bearbeiterin: Sabine Gleß

- Zeitrahmen: 2000 bis 2004

- Projektstatus: in Bearbeitung

- $\quad$ Projektbeschreibung: Habilitationsvorhaben (Das Projekt wird betreut von Frau Prof. Dr. Ursula Nelles, Universität Münster, und gefördert durch ein Stipendium des Landes Nordrhein-Westfalen [Lise Meitner-Habilitationsprogramm].)

Vor dem Hintergrund der immer engeren Zusammenarbeit der Strafverfolgungsbehörden und der Gerichte der EU-Mitgliedstaaten einerseits und eigener Ermittlungstätigkeit supra-nationaler Organe der EG andererseits stellen sich in Rechtswissenschaft und -praxis folgende Fragen: Unter welchen Voraussetzungen und in welchem Umfang sind (1.) im Rahmen eines nationalen Verfahrens erhobene Beweise in den anderen Mitgliedstaaten, (2.) im Zusammenhang mit einer Maßnahme grenzüberschreitender Strafverfolgung gewonnene Ermittlungsergebnisse in den jeweiligen Mitgliedstaaten und (3.) Ergebnisse aus Untersuchungen der EG-Organe in allen Mitgliedstaaten (ohne Einschränkungen) im Strafverfahren verwertbar? Diese Fragen werden am Beispiel ausgewählter Rechtsordnungen (Deutschland, Frankreich, England) untersucht - mit dem Ziel, Grundsätze für einen "europaweit verkehrsfähigen" Beweis zu entwickeln.

Als Vorarbeit für die Formulierung solcher Grundsätze wurden in einem ersten Schritt die einschlägigen Regelungen und Prinzipien des Beweisrechts im deutschen, französischen und englischen Strafprozess dokumentiert und (rechtsvergleichend) analysiert. Der zweite Schritt lag in der Aufarbeitung der zunehmend auf Beweissammlung ausgerichteten Zusammenarbeit der zuständigen Behörden der EU-Mitgliedstaaten sowie der grenzüberschreitenden Ermittlungstätigkeit supra-nationaler Organe der EG. In einem dritten Schritt wurden einschlägige Prinzipien der EMRK herausgearbeitet, die für einen europäischen Beweistransfer von Bedeutung sein könnten.

Diese drei vorbereitenden Arbeitsschritte führten zunächst zu dem Ergebnis, dass zur Erreichung des gesteckten Zieles - nämlich Beweisrechtsgrundsätze für eine grenzüberschreitende Strafverfolgung herauszuarbeiten - eine grundlegendere Analyse der strafprozessualen Beweisführung notwendig ist. Denn in jedem nationalen Strafprozess stellt sich die gleiche erkenntnistheoretische Frage: Wie kann ein vergangener Sachverhalt aus in der Gegenwart vorliegenden Informationsträgern zuverlässig, also mit größtmöglicher Gewähr für seine Richtigkeit festgestellt werden? Diese immer gleiche Frage wird aber in jeder Rechtsordnung anders beantwortet. Das zeigt sich sowohl in der jeweiligen Ausgestaltung des Beweisrechts, wie auch an den - in diesem Punkt sehr zurückhaltend formulierten - Vorgaben der Straßburger Organe, wie auch in der noch unüberschaubaren Handhabung des Beweisrechtstransfers in der Praxis. Ein europaweit verwertbarer strafprozessualer Beweis muss aber überall die grundlegende - in allen nationalen Rechtsordnungen gleiche - Funktion des Beweises im Strafverfahren gewährleisten: nämlich als Substrat für eine zuverlässige und faire Feststellung von (vergangenen) Tatsachen zu dienen, auf deren Grundlage das erkennende Gericht eine strafrechtliche Entscheidung treffen kann.

Das Habilitationsprojekt geht deshalb mit einer grundlegenden Untersuchung des gesamten Beweisverfahrens im Strafverfahren weit über die - in der bisherigen Diskussion zum Beweistransfer üblicherweise hervorgehobene - Phase der Beweisgewinnung hinaus und berücksichtigt insbesondere, dass Beweismittel und -verfahren eben keine unabhängigen Vermittler einer empirisch objektiven Wahrheit sind, sondern (nur) unter den spezifischen Bedingungen ihrer Rechtsordnung als valide 
Grundlage für die Rekonstruktion einer historischen Wahrheit anerkannt werden. Ebenso wie ein "faires Verfahren" immer nur aus Sicht der Rechtsgemeinschaft als solches definiert werden kann, in dessen Namen die strafrechtliche Sachentscheidung ergeht. Wenn durch den Beweistransfer die spezifische Legitimation eines Beweismittels bzw. einer Beweisführung als Grundlage für eine "zuverlässige" und "faire" Sachverhaltsfeststellung in Frage gestellt wird, weil die (in einem Rechtssystem) zusammen gehörenden rechtlichen Rahmenbedingungen für die Beweisgewinnung, -verwertung und würdigung mehr oder weniger willkürlich getrennt werden, dann muss diese Legitimation wieder hergestellt werden. Dies könnte etwa durch ein "Europäisches Beweiszulassungsverfahren" geschehen.

- $\quad$ Arbeitsplanung 2004:

Im kommenden Jahr soll zunächst die Analyse der spezifischen Anforderungen der ausgewählten Rechtsordnungen an ein "zuverlässiges" und "faires" Beweisverfahren abgeschlossen werden. Auf dieser Grundlage sollen dann die zur Lösung der mit einem Beweistransfer verbundenen Probleme bereits unterbreiteten Vorschläge - im Lichte der aus der Analyse abgeleitete Anforderungen an ein "zuverlässiges" und "faires" Verfahren - einer kritischen Prüfung unterzogen werden. Schließlich sollen die Grundsätze für einen grenzüberschreitenden Beweistransfer formuliert werden, ausgehend von den rechtsvergleichend gewonnenen Ergebnissen über die Anforderungen der nationalen Rechtsordnungen an eine "zuverlässige" und "faire" Beweisführung.

- Veröffentlichungen:

GLEß, S., Die "Verkehrsfähigkeit von Beweisen" im Strafverfahren. Zeitschrift für die gesamte Strafrechtswissenschaft (ZStW) 115, 131-150 (2003).

GLEß, S., § 247 a StPO - (auch) eine Wohltat für den Angeklagten? Juristische Rundschau (JR), 97 f. (2002).

GLEß, S., The Prominent Procedural Issues: Obtaining Evidence Abroad - a European Approach, in: Albrecht/Fijnaut (eds.), The Containment of Transnational Organized Crime. Comments on the UN Convention of December 2000, Freiburg i.Br. 2002, 133-143.

GLEß, S., Zur "Beweiswürdigungs-Lösung" des BGH. Neue Juristische Wochenschrift (NJW) 2001, $306 \mathrm{f}$.

GLEß, S., Fair Trial Rights and the European Community's Fight against Fraud. European Law Journal (ELJ) 2001, 219-237 (zusammen mit Helge Elisabeth Zeitler).

GLEß, S., Zur Verwertung von Erkenntnissen aus verdeckten Ermittlungen im Ausland im inländischen Strafverfahren. Neue Zeitschrift für Strafrecht (NStZ) 2000, 57-62.

\subsubsection{Schwerpunkt: Internationales Strafrecht, Völkerstrafrecht sowie Menschenrechte}

\subsubsection{Völkerrechtliche Exemtionen von strafrechtlicher Verantwortlichkeit}

- $\quad$ Bearbeiter: Helmut Kreicker

- Zeitrahmen: 2000 bis 2005

- $\quad$ Projektbeschreibung:

Fälle aus jüngster Zeit machen deutlich, dass verschiedenartige Regelungen des Völkerrechts, eine Befreiung bestimmter Personen von strafrechtlicher Verantwortlichkeit bewirken, obwohl diese eigentlich alle von den nationalen Rechtsordnungen für eine strafrechtliche Verantwortlichkeit aufgestellten Voraussetzungen erfüllt haben. So haben sich in den im Rahmen der strafjuristischen "Aufarbeitung" der DDR-Vergangenheit stattfindenden Gerichtsverfahren gegen DDR-Funktionsträger diese 
wiederholt darauf berufen, ein bundesdeutsches Gericht dürfe über ihre Taten nicht urteilen, da sie für den Staat DDR gehandelt hätten und somit Immunität genössen. Nachdem im Februar 1999 Wachpersonal des israelischen Konsulats in Berlin mehrere auf dem Konsulatsgrundstück demonstrierende Kurden erschossen hatte, durfte die Berliner Staatsanwaltschaft keine Strafverfahren einleiten, da die Angehörigen des Konsulats sich auf ihre Immunität beriefen. Im Februar 1998 starben in Oberitalien Insassen einer Seilbahngondel, nachdem ein US-amerikanischer Pilot mit seinem Militärflugzeug das Tragseil durchschnitten hatte. Aufgrund von Regelungen des NATO-Truppenstatuts konnte die italienische Strafjustiz nicht gegen ihn vorgehen. Besondere Aufmerksamkeit in der Öffentlichkeit fand auch der "Fall Pinochet". Der chilenische Ex-Diktator war im Oktober 1998 in London festgenommen worden, da die spanische Justiz seine Auslieferung beantragt hatte, um ihn in Spanien wegen seiner Verantwortung für die Ermordung vieler Regimegegner in Chile während der Militärherrschaft vor Gericht zu bringen. Heftig umstritten war, ob Pinochet sich auf eine "diplomatische Immunität", eine Immunität als "ehemaliges Staatsoberhaupt" oder auf "Staatenimmunität" berufen und somit wegen einer Exemtion von strafrechtlicher Verantwortlichkeit nicht ausgeliefert werden könne. Das oberste britische Gericht, das House of Lords, hat dies in zwei Entscheidungen verneint. Im Februar 2002 hat der Internationale Gerichtshof in einem Rechtsstreit zwischen Belgien und der Demokratischen Republik Kongo entschieden, dass amtierende Außenminister vollständige Immunität von der Strafgerichtsbarkeit anderer Staaten genießen, die selbst bei völkerrechtlichen Verbrechen keine Ausnahme erfährt.

Ziel der Arbeit ist es, die verschiedenen völkerrechtlichen Exemtionen aus spezifisch strafrechtlicher Sicht darzustellen und zu analysieren, insbesondere ihre Reichweite zu untersuchen. Der Schwerpunkt der Arbeit wird dabei auf dem Institut der Staatenimmunität liegen, da diese völkervertraglich nicht normiert ist und im Hinblick auf das Strafrecht ihre Voraussetzungen und Grenzen vielfach unklar sind. Aber auch die detailliert normierten Exemtionen wie die diplomatische und konsularische Immunität oder die besonderen Regeln für Militärangehörige müssen in die Untersuchung einbezogen werden, da diese zum einen zum Institut der Staatenimmunität abgegrenzt werden müssen und zum anderen auch im Hinblick auf ihre Bedeutung für die Strafjustiz etliche offene Rechtsfragen existieren.

Die völkerrechtlichen Exemtionen werden, dem spezifischen Blickwinkel der Arbeit entsprechend, nur insoweit untersucht und dargestellt, als sie für das Strafrecht von Relevanz sind. Darin wird sich die Arbeit von bisher vorliegenden deutschsprachigen Untersuchungen zu völkerrechtlichen Exemtionen unterscheiden.

Angesichts der rasant fortschreitenden Entwicklung einer supranationalen Strafgerichtsbarkeit soll nicht nur untersucht werden, inwieweit die völkerrechtlichen Exemtionen einer Strafverfolgung auf nationaler Ebene entgegenstehen, sondern auch, ob sie eine Strafverfolgung durch supranationale Gerichte zu verhindern vermögen. Hierbei wird es vor allem um eine Analyse von Art. 27 des Statuts für den Internationalen Strafgerichtshof (Römisches Statut) und der entsprechenden Bestimmungen in den Statuten für die ad-hoc-Gerichtshöfe für das ehemalige Jugoslawien (Art. 7) und für Ruanda (Art. 6) gehen.

In einem weiteren Teil der Arbeit soll der Frage nach der strafrechtsdogmatischen Einordnung der untersuchten Institute nachgegangen werden. So stellt sich für das deutsche Strafrecht beispielsweise die Frage, ob es sich bei den Exemtionen um materielle Strafausschließungsgründe oder lediglich um prozessuale Strafverfolgungshindernisse handelt. Dies ist in der deutschen Strafrechtswissenschaft umstritten, aber von großer Bedeutung für die Rechtspraxis, da sich hieran Fragen wie die nach der Geltung des Zweifelsgrundsatzes oder nach der Art der vorgeschriebenen Beweiserhebung (Freibeweis oder Strengbeweis) anschließen. Umstritten ist ferner, ob der Beschuldigte auf seine Immunität verzichten kann, ob ein unter Missachtung völkerrechtlicher Exemtion ergangenes Urteil Rechtswirkung zu entfalten vermag oder - um ein weiteres Beispiel zu nennen - die Gerichte selbstständig über die Frage bestehender Exemtion entscheiden dürfen. Während sich gegen Ende des 19. Jahrhunderts respektive Anfang des 20. Jahrhunderts die deutsche Strafrechtswissenschaft mit diesen Fragen aus- 
führlich befasst hat (vgl. etwa Ernst Beling, Die strafrechtliche Bedeutung der Exterritorialität, Breslau 1896; Karl Binding, Die Privilegien der Straflosigkeit, Leipzig 1885) und zur Exemtion von Militärangehörigen mehrere Arbeiten aus den fünfziger und sechziger Jahren vorliegen, gibt es aktuelle Untersuchungen nicht.

- $\quad$ Arbeitsbericht 2002/2003:

Im Berichtszeitraum wurde der Text der Dissertation im Wesentlichen fertig gestellt.

- $\quad$ Arbeitsplanung 2004:

Im Jahr 2004 soll das Promotionsvorhaben abgeschlossen werden. Die Dissertation soll so überarbeitet werden, dass ihre Veröffentlichung erfolgen kann.

\subsubsection{Die Rolle des Anklägers eines Internationalen Strafgerichtshofs}

- $\quad$ Bearbeiterin : Wu Wei

- Zeitrahmen: Dezember 2000 bis voraussichtlich Mitte 2004

- $\quad$ Projektstatus: in Bearbeitung

- $\quad$ Projektbeschreibung: Promotionsvorhaben

Am 17. Juli 1998 wurde das Rom-Statut des Internationalen Strafgerichtshofs (IStGH) verabschiedet, das erste Statut für die Einrichtung eines ständigen internationalen Strafgerichtshofs. Für die Funktionsfähigkeit des IStGH sind die Aufgaben und Befugnisse des Anklägers von maßgeblicher Bedeutung. Ziel der Arbeit ist es, durch die Untersuchung des Anklagesystems des zukünftigen IStGH und durch die rechtsvergleichende Betrachtung nationaler Anklagesysteme einen Beitrag zur Ermittlung der Rolle des Anklägers für die internationale Sicherheit und die Möglichkeit des Aufbaus eines internationalen Anklagesystems, insbesondere eines internationalen Strafverfahrensrechts, zu leisten.

In der Einleitung (§§ 1-3) werden die Problematik und Gang der Untersuchung dargelegt. Die Rechtsstellung und die Funktion der nationalen Anklagebehörden werden im Überblick dargestellt. Der erste Teil (§§ 4-5) untersucht den Aufbau der Anklagebehörde und die Rechtsstellung des Anklägers des IStGH. Im zweiten Teil ( $\S 6-10)$ werden die Rolle des Anklägers des IStGH in verschiedenen Verfahrensabschnitten (Ermittlungs-, Zwischen-, Haupt-, Rechtsmittel- und Strafvollstreckungsverfahren) untersucht. Hierfür soll insbesondere auf die Erfahrung und Rechtsprechung der beiden ad hoc-Tribunale in Den Haag und Arusha in Bezug auf die Rolle der jeweiligen Anklage zurückgegriffen werden. Auch die einzelnen nationalen Anklagesysteme, die sich mit dem Anklagesystem des IStGH befassen, sollen berücksichtigt werden. Im dritten Teil wird über die Eingangsuntersuchung hinaus eine eigene Auffassung über die Rolle des Anklägers eines internationalen Strafgerichtshofs entwickelt.

- $\quad$ Arbeitsbericht Dezember 2000 - Oktober 2003:

Die Kapitel über die Rechtsstellung des internationalen Anklägers und die Rolle des Anklägers im Ermittlungs-, Zwischen-, Haupt- und Rechtsmittelverfahren wurden fertiggestellt.

- $\quad$ Arbeitsplanung November 2003 bis Mitte 2004:

Für diesen Zeitraum ist angestrebt, die Arbeit zu überarbeiten. Voraussichtlich wird die Arbeit Anfang 2004 abgegeben. 


\subsubsection{Sexuelle Gewalt als verbotenes Mittel der Kriegsführung}

- $\quad$ Bearbeiterin: Anke Biehler

- Zeitrahmen: 2001 bis 2004

- $\quad$ Projektbeschreibung: Promotionsvorhaben

Das im Jahr 2001 begonnene und von Herrn Prof. Dr. Wolfrum (Universität Heidelberg) betreute Dissertationsvorhaben untersucht den gezielten Einsatz von sexueller Gewalt und Vergewaltigung als Waffe in internationalen und nicht-internationalen bewaffneten Konflikten aus völkerrechtlicher Sicht. Dazu wird die Entwicklung kriegs- bzw. humanitär-völkerrechtlicher Vergewaltigungsverbote vor dem Hintergrund der jeweiligen Rechtswirklichkeit untersucht. Die Arbeit besteht aus fünf Teilen:

Im ersten Teil wird die historische Entwicklung kriegsrechtlicher Vergewaltigungsverbote von der Antike bis zu den Kriegsverbrechertribunalen von Nürnberg und Tokio untersucht. Besonderes Interesse kommt dabei der tatsächlichen historischen Durchsetzung des Vergewaltigungsverbots in bewaffneten Konflikten vor dem Hintergrund der Entwicklung des sich - zumindest theoretisch - entwickelnden kriegsvölkerrechtlichen Vergewaltigungsverbots zu. Dies beinhaltet auch den Beginn der Entwicklung des Völkerstrafrechts im Sinne erstmals zu beobachtender Bemühungen einzelne Täter wegen Verstößen gegen das Kriegsvölkerrecht (wozu auch das Verbot sexueller Gewalt gehört) zur Verantwortung zu ziehen.

Im zweiten Teil erfolgt eine Bestandsaufnahme der Entwicklung des Verbots des Einsatzes sexueller Gewalt in bewaffneten Konflikten in humanitär-völkerrechtlichen und menschenrechtlichen Kodifikationen seit etwa 1945.

Der dritte Teil beschäftigt sich mit dem systematischen Einsatz von sexueller Gewalt und Massenvergewaltigungen in bewaffneten Konflikten seit dem 2. Weltkrieg. Neben dem Auftreten dieses Phänomens wird auch die Frage nach den tatsächlichen und rechtlich möglichen Konsequenzen untersucht, wobei besonders die Fragen von Bedeutung sind, unter welchen Umständen Vergewaltigungen im Rahmen kriegerischer Auseinandersetzungen bis heute vorkamen, ob sie einem Zweck dienten, wie die jeweilige theoretische Rechtslage war und ob und wie diese praktisch durchgesetzt wurde.

Gegenstand des vierten Teils ist das Verbot von sexueller Gewalt und Vergewaltigung im Völkerstrafrecht. Dazu werden die Statute der internationalen Strafgerichtshöfe auf die Ausgestaltung der Bestrafung wegen sexueller Gewalt untersucht und die einschlägigen völkerrechtlichen Tatbestandsvoraussetzungen untersucht.

Abschließend wird im füntten und letzten Teil die Rechtsprechung des Jugoslawien- und des RuandaTribunals zum systematischen Einsatz von sexueller Gewalt und Vergewaltigungen als Waffe untersucht. Hierbei wird auf mit sexueller Gewalt im Zusammenhang stehende Probleme des Allgemeinen Teils, des Besonderen Teils und des Prozessrechts eingegangen.

\section{- Arbeitsbericht:}

Die ersten beiden Teile der Arbeit sind weitestgehend abgeschlossen. Der dritte Teil, der sich im Gegensatz zu den anderen Teilen mit Tatsachen befasst, ist ebenfalls weitgehend fertig, er erfordert jedoch ständige Aktualisierung. Die Arbeit am vierten Teil wird in allernächster Zeit abgeschlossen werden. Für 2004 ist der Abschluss der Arbeit anvisiert. 


\subsubsection{Völkerstrafrechtliche Verbrechen und ihre Erfassung durch die rumänische Strafgewalt - Ein Vergleich des rumänischen Strafgesetzbuchs mit dem Römischen Statut und dem deutschen Völkerstrafgesetzbuch}

- $\quad$ Bearbeiterin: Johanna Rinceanu

- $\quad$ Zeitrahmen: 2003 bis 2005

- $\quad$ Projektstatus: in Bearbeitung

- $\quad$ Projektbeschreibung: Promotionsvorhaben

Rumänien hat das Römische Statut am 7. Juli 1999 unterzeichnet und am 11. April 2002 ratifiziert. Damit steht Rumänien vor der Aufgabe, das Römische Statut in das rumänische Recht zu implementieren. Angesichts der immer größeren Bedeutung Rumäniens auf internationaler Ebene ist es Ziel der von Privatdozent Dr. Arnold betreuten Arbeit, zu analysieren in welcher Weise die rumänische Strafgewalt die Ahndung völkerstrafrechtlicher Verbrechen durch rumänische Gerichte vorsieht, welche Defizite die rumänische Strafgewalt gegenüber geltendem Völkerrecht im Hinblick auf eine solche nationale Strafverfolgung aufweist und welche Reformen zur Behebung dieser Defizite sowie zur Ermöglichung einer nationalen Strafverfolgung völkerrechtlicher Verbrechen durchgeführt wurden bzw. vorgesehen sind.

Ein weiterer Schwerpunkt der Arbeit stellt in diesem Zusammenhang die Analyse des bilateralen Abkommens Rumäniens mit den Vereinigten Staaten dar, die Überstellung eines US-Staatsbürgers an den Internationalen Strafgerichtshofes nur nach ausdrücklicher Zustimmung der Vereinigten Staaten vorzunehmen. Die Vereinigten Staaten haben zwar das Römische Statut ihrerseits unterzeichnet, jedoch erklärt, das Römische Statut nicht zu ratifizieren. Nachdem die Vereinigten Staaten damit eine Schwächung des Internationalen Strafgerichtshofes bereits im Sicherheitsrat der Vereinten Nationen erreicht haben, versuchen sie nun, die Immunität ihrer Staatsangehörigen vor einer Strafverfolgung durch den Internationalen Strafgerichtshofes auch in bilateralen Abkommen durchzusetzen. Rumänien hat als erstes Land ein solches bilaterales Abkommen mit den Vereinigten Staaten abgeschlossen. In diesem bilateralen Abkommen hat sich Rumänien gegenüber den Vereinigten Staaten dazu verpflichtet, die Überstellung eines US-Staatsbürgers an den Internationalen Strafgerichtshofes nur nach ausdrücklicher Zustimmung der Vereinigten Staaten vorzunehmen. Wie sich ein solches bilaterales Abkommen auf die Implementierung des Römischen Statuts in Rumänien auswirkt, soll analysiert werden. Hier soll zunächst nach der Rechtmäßigkeit eines solchen bilateralen Abkommens im Allgemeinen, und anschließend in der vorliegenden Situation gefragt werden. In diesem Zusammenhang ist auch nach der Motivation Rumäniens zu fragen, ein solches bilaterales Abkommen mit den Vereinigten Staaten zu unterzeichnen.

- $\quad$ Arbeitsplanung 2004:

Nach einem Forschungsaufenthalt in Bukarest wird mit der Ausarbeitung begonnen. 


\subsubsection{Strafrecht in Postkonfliktsituationen - eine komparative Untersuchung zum Einsatz von Strafrecht in der Internationalen Gemeinschaft}

- $\quad$ Bearbeiter: Jan-Michael Simon

- $\quad$ Zeitrahmen: 2002 bis 2005

- $\quad$ Projektstatus: neu begonnen

- $\quad$ Projektbeschreibung: Promotionsvorhaben

\section{Gegenstand und Fragestellung}

Gegenstand des Promotionsprojekts ist der Einsatz von Strafrecht in Postkonfliktsituationen. Nach einem gewalttätigen Konflikt stehen verschiedene Formen des Umgangs mit diesem Konflikt zur Verfügung. Typische politische Zielformeln für den Umgang mit der Gewalt in dem Konflikt sind dabei "Frieden" bzw. "Versöhnung". Wird die Gewalt in dem Konflikt als Straftat bezeichnet, dann tritt der Umgang mit Straftaten in den Vordergrund. So gerät in Postkonfliktsituationen der Einsatz von Strafrecht in ein Spannungsverhältnis mit Zielformeln wie "Frieden" bzw. "Versöhnung". Die Lösung dieses Spannungsverhältnisses im Tatortstaat gerät dann ihrerseits in ein Spannungsverhältnis mit der internationalen Gemeinschaft, wenn die Straftaten die internationale Gemeinschaft als Ganzes berühren.

Bislang stellen Untersuchungen zum Einsatz von Strafrecht in Reaktion auf internationale Straftaten überwiegend das Ergebnis der Lösungsfindung zum Spannungsverhältnis zwischen dem Einsatz von Strafrecht im Tatortstaat und den im materiellen internationalen Strafrecht kristallisierten Normen der internationalen Gemeinschaft in den Vordergrund. Ihr Forschungsinteresse richtet sich dabei primär auf zwei Fragen: Führt das Lösungsergebnis zum Einsatz von Strafrecht oder zur Straflosigkeit und steht diesem Ergebnis eine völkerrechtliche Staatenpflicht entgegen? Dabei geht es vorwiegend um die Staatenpflicht zum Einsatz von Strafrecht und deren Verletzung. Weder die Bewertung des Verhältnisses von Strafrecht und "Frieden" bzw. "Versöhnung" unter den für internationale Straftaten typischen Bedingungen werden berücksichtigt, noch wird der Einfluss untersucht, den weitere Umgangsformen mit Gewalt - über den Einsatz von Strafrecht hinaus - auf das Ergebnis der Lösung zum Verhältnis von Strafrecht und "Frieden" bzw. "Versöhnung" in Postkonfliktsituationen haben können.

Aus der Perspektive des Völkerrechts liegt der Wert der bisherigen Untersuchungen in der Möglichkeit, beschreiben zu können, dass die Staatsgewalt auf einem ihrer elementaren Gebiete - der Ausübung von Strafgewalt - von der Völkerrechtsordnung verpflichtet werden kann. Für das Strafrecht liegt der Wert der Untersuchungen weiter darin, die völkerrechtlichen Bedingungen für das Strafrecht und seinen Einsatz im Tatortstaat beschreiben zu können. Jedoch wird das Ergebnis dieses Untersuchungsansatzes Postkonfliktsituationen und damit der Völkerrechtsordnung als Friedensordnung sowie dem materiellen internationalen Strafrecht als Durchsetzungsinstrument eben dieser Rechtsordnung dann nicht gerecht, wenn die Verletzung einer völkerrechtlichen Staatenpflicht alleine mit Straflosigkeit erklärt wird. Die so erarbeiteten völkerrechtlichen Bedingungen für das Strafrecht und seinen Einsatz im Tatortstaat stehen damit vor allem in Postkonfliktsituationen auf einer unvollständigen und damit unsicheren - Grundlage.

Die Begrenzung der Forschungsperspektive auf Straflosigkeit wird auch den Anforderungen an die Praxis nicht gerecht. Das Ergebnis eines so begrenzten Ansatzes gibt der internationalen Gemeinschaft kein anderes Kriterium zur Erfassung der Lösungsfindung im Tatortstaat an die Hand als deren Ergebnis, die Straflosigkeit. Es liegt auf der Hand, dass dieser auf das Lösungsergebnis im Tatortstaat begrenzte Ansatz nicht die geeignete Grundlage zur Abschätzung der Chancen und Risiken für so weitreichende Entscheidungen liefert, wie den Einsatz von Strafrecht in Postkonfliktsituationen durch die internationale Gemeinschaft, oder den Einsatz in ihrem Namen. Dies gilt zentral für den VN-Sicherheitsrat und die ad hoc Errichtung internationaler Tribunale oder den Internationalen Strafgerichtshof. Dies gilt vor allem auch dezentral für die Ausübung der Strafgewalt nach dem Weltrechtsprinzip. 
Ungeachtet dieser Vorbehalte gegenüber der auf Straflosigkeit begrenzten Forschungsperspektive haben die daran anschließenden Untersuchungen eine wichtige Grundlage geliefert. Ihr wesentlicher Beitrag liegt in der Beschreibung der Möglichkeit einer Verpflichtung des Tatortstaats zum Einsatz von Strafrecht, die sich nicht alleine aus der innerstaatlichen Rechtsordnung, sondern vielmehr aus der Völkerrechtsordnung ableiten lässt. Dadurch entsteht zwischen dem Umgang mit Straftaten in Postkonfliktsituationen am Tatortstaat und dem materiellen internationalen Strafrecht als Instrument zur Durchsetzung der Ordnung der internationalen Gemeinschaft ein Spannungsverhältnis. Genau an dieser Stelle soll mit dem Dissertationsvorhaben angeschlossen werden. Es geht darum, den Lösungsweg für die Entscheidung über den Einsatz von Strafrecht in dem Spannungsverhältnis mit "Frieden" bzw. "Versöhnung" in Postkonfliktsituationen zu beschreiben und vergleichend zu untersuchen. Dadurch soll eine Grundlage erarbeitet werden, an die eine Diskussion über Mindeststandards zum Umgang mit internationalen Straftaten in Postkonfliktsituationen anschließt.

Eine aktuelle Herausforderung, die den für Wissenschaft und Praxis gleichermaßen hohen Bedarf an einer breiteren Fragestellung zum Einsatz von Strafrecht in Postkonfliktsituationen verdeutlicht, ist das Statut des Internationalen Strafgerichtshofs. Das im Juli 2002 in Kraft getretene Statut stellt in seiner Präambel das Mandatsziel des Strafgerichtshofs klar. Es geht darum, komplementär zur dezentralen Durchsetzung des materiellen internationalen Strafrechts die Straflosigkeit von Tätern schwerster, die internationale Gemeinschaft als Ganzes berührender Verbrechen zu verhindern. Wegen des übergeordneten Ziels der Völkerrechtsordnung als Friedensordnung kann jedoch nicht der Einsatz des materiellen internationalen Strafrechts unter allen Umständen und in vollem Umfang gemeint sein. Vielmehr geht es darum, dass Gewalttäter nicht um ihrer selbst willen der strafrechtlichen Verantwortlichkeit entzogen werden sollen. Diese Überlegungen sind auch für Maßnahmen der Vereinten Nationen von zentraler Bedeutung. Dies wurde zuletzt im September 2003 unter dem eigens dafür eingerichteten Tagesordnungspunkt "Justice and the rule of law: the United Nations Role" auf den Sitzungen des VN-Sicherheitsrats Nr. 4833 und 4835 auf Ministerebene diskutiert.

\section{Methode}

Gegenstand und Fragestellung des Promotionsprojekts erfordern eine Betrachtung im Querschnitt und stellen damit besondere Anforderungen an die Fallauswahl. Um für die adäquate Darstellung einen möglichst hohen Grad an Differenzierung und Vergleichbarkeit zu erzielen, werden zunächst unterschiedliche Entwicklungen auf dem lateinamerikanischen Subkontinent in Argentinien, Uruguay, Chile, El Salvador, Guatemala und Peru erfasst. So werden Entwicklungen in einer Weltregion im Querschnitt untersucht, die 1983 in Argentinien begannen und zwanzig Jahre später in Peru endeten und die wie bisher zu keiner anderen Weltregion das Interesse an Untersuchungen zum Einsatz von Strafrecht bei internationalen Straftaten gefunden hat. Um den Differenzierungsgrad der Untersuchung zu erhöhen, wird der Befund aus der Querschnittbetrachtung der lateinamerikanischen Region dem südafrikanischen Modell gegenübergestellt.

Gelingt eine differenzierte Darstellung und Untersuchung zu den Entwicklungen in Lateinamerika und Südafrika, so kann daran eine Diskussion über Mindeststandards zum Umgang mit internationalen Straftaten in Postkonfliktsituationen anschließen. Diese sollen dann in einem weiteren Schritt dem Umgang mit den gewalttätigen Konflikten in Sierra Leone und Ost-Timor gegenübergestellt und unter der Frage der Kompatibilität diskutiert werden. Diese Diskussion zum Umgang mit den gewalttätigen Konflikten in Sierra Leone und Ost-Timor, an deren Gestaltung sich die internationale Gemeinschaft direkt beteiligt, ermöglicht dann, die erarbeiteten Standards an der Praxis der internationalen Gemeinschaft selbst zu beurteilen. Die Überprüfung der Standards kann so zum Ausgangspunkt für Diskussionen über mögliche Anpassungen dieser Bedingungen genommen werden. Diese Diskussion kann auch neue Herausforderungen für den Umgang der internationalen Gemeinschaft mit bewaffneten Konflikten wie dem kolumbianischen einbeziehen, in der eine Abgrenzung von Verbrechen gegen die Menschlichkeit (Kriegsverbrechen)/Terrorismus/Organisierte Kriminalität nur noch schwer zu führen 
ist. Schließlich bietet sich in der Form eines Ausblicks die Überprüfung der Standards an den Herausforderungen gewalttätiger Konflikte in der muslimischen Welt an, wie sie sich insbesondere im Anschluss an die Geschehnisse vom 11. September 2001 in New York stellen.

- $\quad$ Arbeitsbericht 2002/2003 und vorläufige Erkenntnisse:

In den Jahren 2002 und 2003 wurden im Wesentlichen Vorleistungen erbracht, die sowohl dem Promotionsprojekt als auch dem Institutsprojekt "Strafrecht in Reaktion auf Systemunrecht" zugute kommen. Das Promotionsprojekt ist aus diesem Institutsprojekt hervorgegangen. Es schließt mit seinem Forschungsgegenstand und seiner Fragestellung an dieses Institutsprojekt an. Die ursprünglich in dem Institutsprojekt formulierte Fragestellung wurde von dem Promotionsprojekt weiterentwickelt. Dadurch wirkt es auch auf das Institutsprojekt zurück. Die Wechselwirkung zwischen Institutsprojekt und Herausbildung des Promotionsprojekts beinhaltete u.a. die Konzeption, Vorbereitung und Durchführung eines regionalen Kolloquiums zu Lateinamerika in São Paulo/Brasilien (02/02), die Aufarbeitung der Kolloquiumsberichte, die Koordination der lateinamerikanischen Landesberichte in dem Institutsprojekt. Dem Fortgang des Promotionsprojekts diente die Konzeption, Vorbereitung und Durchführung (mit Hassan Rezaei) eines regionalen Kolloquiums zum Nahen Osten in Istanbu1/Türkei (12/03). Die zentralen Thesen des Dissertationsprojekts wurden auf 14 wissenschaftlichen Veranstaltungen in Deutschland, Frankreich, Polen und Lateinamerika in 11 Referaten zur Diskussion gestellt und weiterentwickelt.

Als Zwischenergebnis aus den bisherigen Arbeiten lässt sich Folgendes festhalten: Die Entscheidung zur Lösung des Spannungsverhältnisses zwischen dem Einsatz von Strafrecht und "Frieden" bzw. "Versöhnung" erfolgt in Postkonfliktsituationen über eine Bewertung der Beziehung beider Seiten. Diese Bewertung kann positiv oder negativ ausfallen. Dabei fließen in das Ergebnis der Bewertung, über den Einsatz von Strafrecht hinaus, weitere Umgangsformen mit Gewalt ein. Dazu gehören insbesondere Maßnahmen gegenüber Gewaltopfern, einschließlich zur Täter-Opfer-Beziehung, aber auch zur individuellen Verantwortlichkeit von Gewalttätern außerhalb des strafrechtlichen Verantwortungsbereichs. Beim Umgang mit institutioneller Gewalt geht es darüber hinaus um Maßnahmen zur institutionellen Verantwortlichkeit.

- $\quad$ Arbeitsberichtsplanung 2004/2005:

Für das Jahr 2004 ist im Rahmen des Institutsprojekts die Veröffentlichung der Beiträge der Kolloquien zu Lateinamerika geplant. Geplant ist ferner die Veröffentlichung des Kolloquiums zum Nahen Osten.

Im Anschluss an die Landesberichte zu Lateinamerika des Institutsprojekts "Strafrecht in Reaktion auf Systemunrecht" (Argentinien, Brasilien, Chile und Uruguay) sollen erste Erkenntnisse zu der Region zum Jahresende 2004 auf einer Tagung des Max-Planck-Instituts mit der Evangelischen Akademie in Berlin vorgestellt werden. Im Jahr 2005 soll das Promotionsprojekt abgeschlossen werden.

- Zum Promotionsprojekt vorliegende Veröffentlichungen:

Simon, Jan-Michael, Jurisdicción Penal Universal, Revista Brasileira de Ciências Criminais, Instituto Brasileiro de Ciências Criminais, São Paulo, Brasil, Ano 10, No. 39 (julho-setembro 2002), S. 63101.

SimON, JAN-MichaEL, La Comisión para el Esclarecimiento Histórico, in: Boletín Mexicano de Derecho Comparado, Año XXXVI, No. 106 (enero-abril 2003), Instituto de Investigaciones Jurídicas de la Universidad Autónoma de México, México D.F./México, S. 147-203.

SIMON, JAN-MiCHAEL, Przemoc propierana przez państwo - Odpowiedzialność karna a pojednanie, in Ius et Lex 1/2003, Fundacja Ius et Lex, Warszawa, Polska, S. 161-173. 
SimON, JAN-MiChAEL, Responsabilidad criminal y reconciliación. El Derecho Penal frente a la violencia política masiva en Sudáfrica, Ruanda y El Salvador. In: Fundación País Libre (Hrsg.), La Corte Penal Internacional. Instrumento de paz para Colombia, Bogota (im Erscheinen).

SIMON, JAN-MiCHAEL, Proceso de paz en Colombia y Corte Penal Internacional. Breves apuntes sobre el Proyecto de Ley No. 85/03 S. In: Guerrero, Víctor/Mora, Roberto (Hrsg.), Justicia y reparación en el marco de procesos de paz, Bogota (im Erscheinen).

\subsubsection{Schwerpunkt: Recht und Medizin}

\subsubsection{Medizinrechtliche Aspekte des Klonens}

- $\quad$ Bearbeiterin: Silke Hetz

- $\quad$ Zeitrahmen: 2001 bis 2004

- $\quad$ Projektstatus: in Bearbeitung

- $\quad$ Projektbeschreibung: Promotionsvorhaben

- $\quad$ Finanzierung: Stipendium der Landesgraduiertenförderung Baden-Württemberg

Die Arbeit beschäftigt sich mit der rechtlichen Handhabung des Klonens. Der gesamten Diskussion über das Klonen liegt die zentrale Fragestellung zugrunde, ob grundsätzlich menschliche Embryonen und im Besonderen geklonte Entitäten - Schutzwürdigkeit genießen, ab wann gegebenenfalls von einer solchen auszugehen ist, und in welchem Umfang sie bestehen soll. Während aus medizinischnaturwissenschaftlicher Sicht der Zeitpunkt des Beginns menschlichen Lebens empirischen Untersuchungen zugänglich ist, bleibt bei der hier relevanten Frage nach dem Anfang der Schutzwürdigkeit menschlichen Lebens und deren Ausmaß Raum für unterschiedliche Ansichten. Denn der Fragestellung liegt die überaus komplexe Thematik zugrunde, was die rechtliche Schutzwürdigkeit menschlichen Lebens begründet, woran diese anknüpft, was sie ausmacht.

Die Arbeit untergliedert sich in zwei größere Teile. Zuerst werden die medizinischen Grundlagen der Embryonalentwicklung, die Klonverfahren sowie deren Anwendungsbereich aufgezeigt. Im juristischen Teil wird vorab die gegenwärtige Rechtslage in Hinblick auf die neuen naturwissenschaftlichen Entwicklungen dargestellt. Da durch die Problematik des Klonens im Humanbereich die Rechtsordnung Raum für unterschiedliche Interpretationen, Auslegungen und Wertungen gewährt, schließt sich daran ein kurzer Überblick über das Verhältnis von Ethik und Recht. Ferner wird gerade die öffentlichen Diskussion über das Klonen häufig von den unterschiedlichen ethischen Positionen her geführt und diese Überlegungen werden sodann oftmals ohne weitere Begründung auf die rechtliche Situation übertragen. Das Recht baut zwar auf ethischen Überlegungen - meist in Tradition einer bestimmten ethischen Richtung - auf, jedoch kann die ethische Argumentationsweise nicht mit der juristischen gleichgesetzt werden. Während durch eine rechtliche Regelung ein Mindeststandart festlegt wird, an den alle gebunden sind, mag eine bestimmte ethische Richtung zwar dem Einzelnen verbindlich erscheinen, jedoch kann ihr in einer säkularisierten pluralistischen Gesellschaft keine eigenständige Rechtsgültigkeit für die Allgemeinheit zukommen. Diesen Unterschied zwischen ethisch-philosophischer und rechtlicher Diskussion gilt es herauszuarbeiten und sich bewusst zu machen. Aus diesem Grunde werden sodann die gängigen ethischen Kriterien und Diskussionsansätze aufgegriffen und dargestellt. Die rechtlichen Ausführungen knüpfen teilweise an die ethischen Kriterien an und erörtern sie aus rechtlicher Perspektive. Hierbei richtete sich das Augenmerk hauptsächlich auf die spezifische Problematik des Klonens. Hierbei wird zwischen reproduktiven Klonen und Klonen zu therapeutischen Zwecken unterschieden. Schließlich werden Überlegungen in Hinblick auf eine Neuregelung der Thematik angestellt. 
Ein Schwerpunkt der Arbeit bildet die Darstellung, Überprüfung und Weiterentwicklung des Menschenwürdearguments, Art. 1 Abs. I GG, im Rahmen der Klondiskussion.

Es ist beabsichtigt, die Arbeit 2004 abzuschließen.

\subsubsection{Der Status des extrakorporalen Embryos in interdisziplinärer Perspektive}

- $\quad$ Projektleitung und -koordination: Giovanni Maio, Zentrum für Ethik und Recht in der Medizin, Freiburg

- Beteiligte Institutionen:

Max-Planck-Institut für ausländisches und internationales Strafrecht, Freiburg (Eser, Koch)

Institut für Psychologie, Abteilung für Rehabilitationspsychologie, Freiburg (Bengel, Barth)

Zentrum für Anthropologie und Gender Studies, Freiburg (Degele)

Lehrstuhl für Ethik in den Biowissenschaften, Tübingen (Engels)

Universitäts-Frauenklinik, Abteilung Reproduktionsmedizin, Freiburg (Keck)

Zentrum für Ethik und Recht in der Medizin (Maio)

Zentrum für molekulare Medizin und Zellforschung, Freiburg (Peters)

Institut für Systematische Theologie, Arbeitsbereich Moraltheologie, Freiburg (Schockenhoff, Bormann)

Institut für Öffentliches Recht VI, Freiburg (Wahl)

Institut für Humangenetik und Anthropologie, Freiburg (Wolff)

Max-Planck-Institut für ausländisches öffentliches Recht und Völkerrecht, Heidelberg (Wolfrum, Vöneky)

- Kooperationspartner:

Abteilung für Plastische und Handchirurgie, Freiburg (Stark)

Klinikum für Frauenheilkunde und Geburtshilfe, Lübeck (Diedrich)

Institut für Humangenetik, Schwerpunkt Frauengesundheitsforschung, Münster

(Nippert)

Institut für Biologie III, Freiburg (Sippel)

- Mitarbeiter: Hans-Georg Koch (Teilprojektleiter), Carola Müller (wissenschaftliche Mitarbeiterin)

- $\quad$ Zeitrahmen: 1.10 .2002 bis 30.9.2005

- Projektbeschreibung:

Das Projekt (das vom Bundesministerium für Bildung und Forschung gefördert wird) hat es sich zur Aufgabe gemacht, einen Beitrag zur moralischen und rechtlichen Bewertung des Embryos zu leisten.

Die Interdisziplinarität des Projekts soll der Tatsache Rechnung tragen, dass es sich bei der Frage um den Status des Embryos um eine sowohl weltanschauliche als auch philosophisch und theologisch geprägte Frage handelt, die außerdem maßgeblich von den sozio-kulturellen Gegebenheiten des jeweiligen Landes abhängt. 
Ziel des Verbundprojekts ist es, die disziplinspezifischen Vorannahmen, die der Bewertung des extrakorporalen Embryos zugrunde liegen und den unabdingbaren Dialog zwischen den Disziplinen erschweren, herauszuarbeiten und anhand dieser Vorannahmen disziplinübergreifende Kriterien zu entwickeln, die tauglich sind, in konkrete Regelungsvorschläge zum Umgang mit dem Embryo in vitro einzugehen.

Das juristische Teilprojekt besteht aus einem verfassungs- und einem völkerrechtlichen sowie einem rechtsvergleichenden Teil, welcher im Aufgabenbereich des Max-Planck-Institutes für ausländisches und internationales Strafrecht liegt.

Im Rahmen des Rechtsvergleichs (zugleich Promotionsprojekt) sollen ausgewählte europäische und nicht europäische Länder daraufhin untersucht werden, welche Positionen bezüglich des Status des Embryos in vitro sich aus ihren einschlägigen Regelungen, insbesondere zur Fortpflanzungsmedizin und zur Forschung mit Embryonen, ergeben.

Dabei soll es nicht bei einer bloße Darstellung der gesetzlichen Lage in den einzelnen Staaten bleiben, vielmehr sind insbesondere auch die Entstehungsgeschichte und die Hintergründe der verschiedenen Regelungen unter Einbeziehung der Gesamtheit des rechtlichen Regelwerkes eines Staates - vom Verfassungsrecht bis zum ungeschriebenen Gewohnheitsrecht und der Praxis der Rechtsanwendung - zu erforschen und darzustellen. Vor allem ist zu ergründen, welche rechtspolitischen Zielvorstellungen hinter einschlägigen Gesetzen stehen, aber auch hinter der möglichen Entscheidung, bestimmte Bereiche ungeregelt zu lassen. Schließlich sollen etwaige Reformbestrebungen dargestellt werden.

Neben den materiellrechtlichen Fragen hat sich der Rechtsvergleich auch auf die verfahrensrechtliche Dimension des Problemkreises zu beziehen. So ist beispielsweise zu überprüfen, welche Vor- oder Nachteile kategorische Verbote oder Verbote mit Erlaubnisvorbehalten gegenüber einer administrativen Kontrolle durch Behörden oder Kommissionen haben und welche Alternativen zu diesen Verfahrensformen gefunden wurden, insbesondere, ob das eine oder das andere Verfahren gesellschaftlich zu einer höheren Akzeptanz der rechtlichen Regelung führt.

Die Erarbeitung einer rechtsvergleichenden Analyse der Regelungen in den oben angesprochenen Ländern wird anhand schriftlicher Landesberichte erfolgen, die von sachkundigen Personen in den jeweiligen Ländern erarbeitet werden. In den Landesberichten sollen die verschiedenen Regelungen zu den verschiedenen Themenkomplexen dargestellt und in den Kontext der Gesamtrechtsordnung in dem betreffenden Land gestellt werden. Vorwiegend soll herausgearbeitet werden, welcher spezifische Schutz sich daraus für den extrakorporalen Embryo ergibt, welche Gründe zu dieser Normierung geführt haben und inwieweit möglicherweise entgegenstehende ethische Konzepte innerhalb der Gesellschaft dabei mitberücksichtigt wurden.

Die durch den Vergleich gewonnenen Erkenntnisse sollen für den nationalen Diskurs keine Lösungen vorgeben. Ziel ist es aber, Anregungen, Argumente und Denkanstöße zu erwerben und so das Niveau der Diskussion um das eigene gesetzliche Regelwerk zu verbessern und vor dem Hintergrund soziokulturell bedingter Eigenheiten einen fundierten Regelungsvorschlag erarbeiten zu können.

- $\quad$ Arbeitsbericht 2002/2003:

Erarbeitung von Desideraten an alle Disziplinen

Regelmäßige Erstellung von disziplinspezifischen Literaturberichten über neueste Publikationen zum Thema

Einführung der Mitarbeiter der fremden Disziplinen in die disziplineigenen Grundlagen und Methoden

Disziplininterne Überprüfung der projekteigenen Kriteriologie (Extrakorporalität, Entstehungsbedingungen, Intentionalität, Artspezifität) auf ihre Relevanz hinsichtlich der Status- 
begründung einerseits und ihrer sonstigen Relevanz andererseits und disziplinübergreifende Bewertung der jeweiligen Ergebnisse

Auswahl und Einladung der Landesberichterstatter

Erstellung einer Gliederung mit detaillierten Erläuterungen der einzelnen Punkte für die Landesberichterstatter

Planung und Organisation eines internationalen Symposiums zum Thema (Datum: 14.-16. Oktober 2004)

- $\quad$ Arbeitsplanung 2004:

Organisation des internationalen Symposiums

Analyse der Landesberichte und Erstellung eines rechtsvergleichenden Querschnitts

\subsubsection{Der Schutz des Menschen in der biomedizinischen Forschung. Ein Vergleich der Bioethik-Konvention mit dem deutschen und dem griechischen Recht}

- $\quad$ Bearbeiterin: Irini Kiriakaki, LL.M. (Freiburg)

- $\quad$ Zeitrahmen: 1999 bis voraussichtlich 2004

- $\quad$ Projektstatus: in Bearbeitung

- $\quad$ Projektbeschreibung: Promotionsvorhaben

- $\quad$ Projektmittel: Promotionsstipendium von der Claussen-Simon-Stiftung im Stifterverband für die deutsche Wissenschaft nach den Richtlinien der Max-Planck-Gesellschaft.

Dieses Promotionsvorhaben aus dem Bereich des Referats "Recht und Medizin" befasst sich mit der Prüfung der biomedizinischen Forschung am Menschen einschließlich an Embryonen in vitro anhand ethischer Überlegungen und rechtlicher bzw. rechtsvergleichender Gesichtspunkte auf ihre prinzipielle Zulässigkeit sowie auf ihre Voraussetzungen, Grenzen, Durchführungs- und Kontrollbedingungen.

Aktueller Anlass der Arbeit sind Forschungsprojekte mit embryonalen Stammzellen, die die Verwendung von überzähligen Embryonen in vitro oder gar die Herstellung von Embryonen in vitro auch mittels therapeutischen Klonens zur Gewinnung von embryonalen Stammzellen (ES-Zellen) notwendig machen und die anschließende Überprüfung der mit der Verwendung von ES-Zellen verbundenen Therapieansätze auf Menschen vor deren Einsatz in der klinischen Praxis fordern. Anhand dieser Ausgangskonstellation stellt sich die Frage nach der grundsätzlichen Zulässigkeit der Herstellung von Embryonen bzw. der Verwendung von Embryonen in vitro zu Forschungszwecken und des therapeutischen Klonens sowie deren Voraussetzungen. Außerdem sind die Zulässigkeitsvoraussetzungen der Erprobung neuartiger Methoden mit embryonalen Stammzellen auf Menschen festzulegen.

Aus dem Bedarf an überstaatlichen Regelungen als Folge der Internationalisierung der Forschung ist das Menschenrechtsübereinkommen zur Biomedizin (im Folgenden MRÜ-Biomedizin) des Europarates entstanden, das auf die Schaffung eines internationalen Rahmens abzielt. Da dies ein völkerrechtliches Übereinkommen ist, ist es auf die Ratifikation und die tatsächliche Umsetzung ins nationale Recht durch so viele Einzelstaaten wie möglich angewiesen. So wird die Verbindung zu den beiden Ländern hergestellt, die in diese Arbeit einbezogen werden. Für Deutschland wird die Frage nach der Unterzeichnung und Ratifizierung des Übereinkommens aufgeworfen, während bezüglich Griechenlands seine tatsächliche Umsetzung ins nationale Recht durch konkrete Maßnahmen nach der bereits erfolgten Ratifizierung zu untersuchen ist. 
Ausgangspunkt der Untersuchung sind die Vorschriften zur Forschung am Menschen (Art. 16, 17) und zur Forschung an Embryonen in vitro (Art. 18) des am 1.1.2000 in Kraft getretenen MRÜ-Biomedizin. Im Anschluss an eine inhaltliche Erläuterung der allgemeinen Grundsätze und der forschungsrelevanten Bestimmungen des Übereinkommens und einer kritischen Auseinandersetzung mit der Problematik zur Forschung an Menschen und an Embryonen in vitro aus ethischer Sicht werden Reflexionen zur deutschen Rechtslage bezüglich der grundsätzlichen Zulässigkeit der medizinischen Forschung an Embryonen und am Menschen, und ihrer Voraussetzungen hinsichtlich einer künftigen Unterschreibung und Ratifizierung des MRÜ-Biomedizin angestellt.

Diesbezüglich werden zum einen die einschlägigen Bestimmungen des Embryonenschutzgesetzes (ESchG) in Verbindung mit dem jüngsten Stammzellgesetz dargestellt. Das in den Straftatbeständen des ESchG enthaltene Verbot der Embryonenforschung soll dahingehend untersucht werden, ob im Hinblick auf eine adäquate Auslegung des Schutzzweckes, des Zeitpunkts der Befruchtung und der embryonalen Totipotenz (Entwicklungsfähigkeit) als Anknüpfungspunkte für den strafrechtlichen Schutz des Embryos in vitro und die neuesten naturwissenschaftlichen Entwicklungen (wie z.B. das therapeutische Klonen) zu novellieren sind. Für eine abschließende Betrachtung ist die systematische Herausarbeitung des dem Embryo zukommenden rechtlichen Status unter Heranziehung verfassungsrechtlicher Vorgaben erforderlich.

Hinsichtlich der Forschung am Menschen gilt das Hauptaugenmerk zunächst der strafrechtlichen Einordnung und Regelung der Durchführung von Forschungsmaßnahmen am Menschen einschließlich Einwilligungsunfähigen, erstmals geprüft anhand der spezialgesetzlichen Regelungen für bestimmte Forschungsbereiche (AMG, MPG). Außerhalb der spezialgesetzlich geregelten Anwendungsbereiche werden allgemeinstrafrechtliche, nicht auf konkrete Forschungssachverhalte zugeschnittene Grundsätze und Vorschriften auf Grundlage verfassungsrechtlicher Ausführungen zur Anwendung herangezogen, welche zwar Interpretationsspielräume zugunsten der Zulässigkeit nichttherapeutischer Forschung an Einwilligungsunfähigen lassen, andererseits aber keine hinreichende Sicherheit in Bezug auf die Voraussetzungen und die Grenzen ihrer Durchführung und die Überwachung und strafrechtliche Absicherung ihrer Einhaltung zum Schutz der Einwilligungsunfähigen gewährleisten.

In einem letzten Teil wird hinsichtlich des griechischen Rechts der rechtspolitischen Frage nachzugehen sein, inwieweit Griechenland, das durch das Gesetz N. 2619/1998 das MRÜ-Biomedizin ratifiziert hat, über genügende Bestimmungen zum Schutz des Menschen in jedem Stadium seiner Entwicklung bei der biomedizinischen Forschung verfügt, die den Schutzstandards des Übereinkommens entsprechen. In dieser Hinsicht wird - auch unter Berücksichtigung der verfassungsrechtlichen Vorgaben geprüft, ob der griechische Gesetzgeber mit dem Gesetz 3089/2002 zur "medizinischen Assistierung bei der Humanreproduktion" genügende Schutzmaßnahmen getroffen hat, um das im Übereinkommen und im Zusatzprotokoll zum Klonverbot festgehaltene Schutzniveau bezüglich der Herstellung von Embryonen (Art. 18 Abs. 1: Absolutes Verbot) bzw. Verwendung von überzähligen Embryonen in vitro zu Forschungszwecken (Art. 18 Abs. 2: Gewährleistung adäquaten Schutzes durchs nationale Recht) und des therapeutischen Klonen ins nationale Recht umzusetzen. Ausschlaggebend für die Beantwortung der Fragestellungen ist, die Form der rechtlichen Anerkennung und der Schutzwürdigkeit festzulegen, welche den Embryonen als menschlichen Wesen im Rahmen der griechischen Rechtsordnung zuerkannt wird oder zuerkannt werden muss.

Darüber hinaus werden die Regelungen zur Forschung am Menschen auf ihre Vereinbarkeit mit den Artikeln 16, 17 des MRÜ-Biomedizin untersucht.

- $\quad$ Arbeitsbericht 2002/2003:

Im Berichtszeitraum stand aufgrund der aktuellen Entwicklungen im Bereich der Stammzellforschung und der Vielzahl der neuen Publikationen zum großen Teil weiterhin die Problematik der ethischen und rechtlichen Zulässigkeit der Forschung mit Embryonen in vitro und der dazugehörigen Fragen 
(Beginn menschlichen Lebens, Beginn rechtlichen Schutzes für den Embryo, verfassungsrechtlicher Status des Embryos, verbrauchende Embryonenforschung, therapeutisches Klonen) im Vordergrund. Deren Abhandlung ist noch abzuschließen. Vorausgegangen ist die Erarbeitung und Darstellung des aktuellen Forschungsstandes bezüglich der Anwendungsbereiche für den Einsatz humaner ES-Zellen und von ethisch unbedenklicheren Alternativen (adulte Stammzellen/Transdifferenzierung somatischer Zellen). Ferner wurden die Fragen der Embryonenforschung und des therapeutischen Klonens aus der Sicht des Menschenrechtsübereinkommens zur Biomedizin (Art. 18 MRÜ-Biomedizin) und des Zusatzprotokolls zum Verbot des Klonens von Menschen, der Lage in Deutschland und der griechischen Rechtsordnung weitgehend abgehandelt.

- $\quad$ Arbeitsplan 2004:

Für das Jahr 2004 soll der Teil zur Problematik der Forschung am Menschen und vor allem an Einwilligungsunfähigen aus der Sicht des MRÜ-Biomedizin, der deutschen und der griechischen Rechtordnung unter Berücksichtigung der bevorstehenden Verabschiedung der 12. Novelle zum Arzneimittelgesetz und des von der Verfassung vorgegeben Rahmens vervollständigt werden. Außerdem soll der einführende Teil fertig gestellt und ein abschließender Teil mit rechtspolitischen Überlegungen zur Bedeutung des MRÜ-Biomedizin als einheitlichen Mindestschutzrahmen zu seiner eventuellen Unterzeichnung und Ratifizierung seitens Deutschlands und zu seiner wirksamen Umsetzung in die griechische Rechtsordnung erarbeitet werden.

\section{$2.4 \quad$ Länder- und Sachbereiche}

\subsubsection{Allgemeine Aufgaben}

Die strafrechtliche Forschungsgruppe ist in Länder- und Sachbereiche gegliedert. Zu letzteren ist neben den bereits seit längerem existierenden Referaten "Internationales Strafrecht" und "Recht und Medizin" im Jahr 1998 der Sachbereich "Europarecht" hinzugekommen, um den rechtsvergleichenden Herausforderungen auf diesem Gebiet besser gerecht werden und eine europarechtliche Forschungsplanung entwickeln und umsetzen zu können.

Neben der Mitarbeit in den vorgenannten Projekten, der Erteilung von Auskünften und der Erstattung von Gutachten (wobei in der Regel jeweils das Gutachtenreferat die Federführung hat) obliegen den Referentinnen und Referenten noch folgende allgemeine Aufgaben:

- die ständige Beobachtung der Strafrechtsentwicklung in den zu betreuenden Ländern oder Sachbereichen,

- die intensive wissenschaftliche und persönliche Betreuung der ausländischen Gäste des jeweiligen Bereichs sowie

- das Beschaffen, Bestellen und Signieren der Referatsliteratur für die Bibliothek.

Diese allgemeinen Aufgaben werden, soweit keine Besonderheiten dazu Anlass geben, in der nachfolgenden Tätigkeitsbeschreibung nicht jeweils eigens erwähnt. Um eine größere Effizienz vor allem der Servicefunktion zu gewährleisten, befinden sich die Länderreferate seit der Neuberufung von Herrn Prof. Dr. Sieber zum Leiter der strafrechtlichen Forschungsgruppe in der Umstrukturierung. Es ist insbesondere vorgesehen, größere Länderbereiche zu bilden.

Im Folgenden werden die Länderreferate aber noch so dargestellt, wie sie im Berichtszeitraum existierten. 


\subsubsection{Länderbereich Deutschland}

1. Leitung: Albin Eser (bis Mai 2003)

Mitarbeiter: Kai Ambos (bis März 2003), Jörg Arnold, Helmut Gropengießer, Peter Hünerfeld (bis März 2003), Hans-Georg Koch

2. Aktuelle Forschungsschwerpunkte:

- Allgemeiner Strafrechtlicher Strukturvergleich (Eser, Perron, Gropengießer)

- Strafrecht in Reaktion auf Systemunrecht - Vergleichende Einblicke in Transitionsprozesse (Arnold, Eser)

- Völkerstrafrecht (Eser, Gropengießer, Kreicker)

- Verfassungsbeschwerde und Strafrecht (Arnold)

3. Lehrveranstaltungen:

siehe die Angaben zu den zuvor unter 1. Genannten unten VIII.

4. Gästebetreuung:

Informationsleistungen für ausländische Gäste zum deutschen Recht.

5. Veröffentlichungen:

siehe die Angaben zu den zuvor unter 1. Genannten unten IV.

\subsubsection{Länderbereich Schweiz und Österreich}

1. Leitung: Jörg Arnold (Schweiz bis 31.12.2003), Ingeborg Zerbes

Mitarbeiter: Jonas Peter Weber (Schweiz)

2. Erfasste Länder: siehe Titel

3. Aktuelle Forschungsschwerpunkte:

a) im Rahmen von Gemeinschaftsprojekten

- Nationale Strafverfolgung völkerrechtlicher Verbrechen im internationalen Vergleich. Landesbericht Österreich.

b) im Rahmen von Einzelprojekten

- Geheime Ermittlungen (Österreich)

- Formen der Beteiligung an einer Straftat (Österreich)

- Strafprozessrecht (Kommentar, Österreich)

- Internationale Bekämpfung der Korruption

4. Abgeschlossene Projekte:

Commentary on the OECD-Convention on Combating Bribery of Foreign Public Officials in International Business Transactions. Hrsg. M. Pieth: Bearbeitung der Art. 1, 2-3 gemeinsam mit M. Pieth, 4,

- Art. 1 wurde 2002/2003 teils in Basel, teils in Wien geschrieben und wird mit der fortschreitenden Umsetzung der Konvention durch die beteiligten Länder aktualisiert. 
- Art 4 und die Mitarbeit an Art. 2 und 3 sind für den Sommer 2004 geplant.

- Fertigstellung des Kommentars: Ende 2004.

Wiener Kommentar zur Österreichischen Strafprozessordnung. Hrsg. H. Fuchs, E. Ratz. Bearbeitung der Bestimmungen zur Hausdurchsuchung, Beschlagnahme und Postbeschlagnahme gemeinsam mit A. Tipold, der Bestimmungen zur verdeckten Ermittlung, Scheingeschäft und Observation, der Bestimmungen zur Datenermittlung und Datenverarbeitung gemeinsam mit H. Fuchs und der Bestimmungen zur Rasterfahndung gemeinsam mit S. Reindl,

- Hausdurchsuchung, Beschlagnahme und Postbeschlagnahme wurden 2003 fertig gestellt und sind im Druck.

- Fertigstellung des gesamten Kommentars ist für die erste Jahreshälfte 2004 geplant.

Fallweise Mitarbeit an Gutachten des Basel Institut on Governance, z.B. zu den Korruptionsrisiken internationaler Konzerne anhand von "Case Studies", Mai 2002.

\section{Veröffentlichungen:}

ZERBES, I., Schuldausschluss bei Affekttaten. Springer, Wien 1999.

ZERBES, I., Landesbericht Österreich. In: M. Becker, J. Kinzig (Hrsg.), Rechtsmittel im Strafrecht, edition iuscrim, Freiburg i.Br. 2000, 251-316.

ZERBES, I., Landesbericht Österreich. In: P. Tak (Hrsg.), Undercover policing in the Member-States of the European Union, Intersentia Rechtswetenschappen. Antwerpen 2000, 623-680 (erschienen in niederländischer Übersetzung; englische Fassung in Arbeit).

ZERBES, I., Landesbericht Österreich. In: Justitielle Einbindung und Kontrolle von Europol. Hrsg. S. Gleß, R. Grote, G. Heine. edition iuscrim, Freiburg i.Br. 2001, 445-529.

ZERBES, I., Bekämpfungsstrategien gegen die OK in der Schweiz. Vortrag zu Studientagungen der Katholischen Akademie Trier, 15.12.2000 und 17.5.2001 (im Druck).

GLEß, S., "Aus 29 mach 1" - Die jüngsten Bemühungen um die Vereinheitlichung des Strafverfahrensrechts in der Schweiz. ZStW, 419-426 (2001).

ZERBES, I., Unfaires Verfahren. Der Falter 31, 6 (2001).

ZERBES, I., Anonyme Zeugen - Faires Verfahren in Österreich und der Schweiz? In: Information und Recht. Hrsg. M. Cottier, K. Sahlfeld, D. Rüetschi. Helbing und Luchterhand, Basel (im Druck).

ZERBES, I., Verfolgung völkerrechtlicher Verbrechen in Österreich. Landesbericht. In: Nationale Strafverfolgung völkerrechtlicher Verbrechen im internationalen Vergleich. National Prosecution of International Crimes. Band 4: Kroatien, Österreich, Serbien-Montenegro, Slowenien, Türkei. Hrsg. A. Eser, H. Kreicker. edition iuscrim, Freiburg 2004, 103 S. (im Druck).

WEBER, J.P., Verhältnismäßigkeit der Sicherungsverwahrung, Ausblick auf die künftige Anwendung von Art. 64 EStGB. Schweizerische Zeitschrift für Strafrecht, Band 120, Heft 4, 398-409 (2002).

\subsubsection{Länderbereich Frankreich}

1. Leitung: Juliette Lelieur-Fischer, LL.M.

Mitarbeiterinnen: Leveke Neumann (bis 31.8.2003), Peggy Pfützner LL.M. (seit 1.11.2003).

2. Erfasste Länder: Frankreich, Luxemburg, Monaco

3. Aktuelle Forschungsschwerpunkte:

- "Nationale Strafverfolgung völkerrechtlicher Verbrechen im internationalen Vergleich":

Anfertigung eines Landesberichts zu Frankreich (Der Bericht umfasst ca. 130 Seiten inkl. Bibliographie) und Entwurf von Projekt-Skizzen über die Rechtslage in Luxemburg und Monaco. 
Der Landesbericht zu Frankreich wird im Moment von dem Verlag bearbeitet und demnächst veröffentlicht (edition iuscrim, Beiträge und Materialen aus dem Max-Planck-Institut für ausländisches und internationales Strafrecht Freiburg).

- "Ne bis in idem - Projekt"

Mitinitiierung, am Anfang des Jahres 2003, des Projekts "Grenzüberschreitendes ne bis in idem - Ein Regelungsvorschlag für die Europäische Union".

Der erste Teil des Projekts bestand in der Konzeption und der Organisation von zwei Seminaren, die in Freiburg vom 22. bis zum 24. Mai und vom 10. bis zum 12. Juli stattfanden. Es nahmen ca. 15 Experten aus der Europäischen Union statt. In den Seminaren wurde ein Regelungsvorschlag für die Europäische Union erarbeitet.

Der zweite Teil des Projekts bestand in der Anfertigung einer Kommentierung dieses Regelungsentwurfs in englischer Sprache (36 Seiten).

Das Projekt wird unter dem Titel Freiburg Proposal on Concurrent Jurisdictions and the Prohibition of Multiple Prosecutions in the European Union veröffentlicht (edition iuscrim, Forschung aktuell + Online Publikationen des Max-Planck-Instituts). Für weitere Informationen, siehe "Keine Doppelbestrafung in Europa", MaxPlanckForschung - Das Wissenschaftsmagazin der Max-Planck-Gesellschaft, 3/2003, S. 71.

\section{Gästebetreuung:}

Im Jahre 2002 wurde ein französischer Gast betreut.

\section{Veröffentlichungen:}

LELIEUR-FISCHER, J., Französische Übersetzung des Völkerstrafgesetzbuchs, Online Publikationen des Max-Planck-Instituts: http://www.iuscrim.mpg.de/forsch/legaltext/VStGBfrz.pdf, Freiburg 2002, $65 \mathrm{~S}$.

LELIEUR-FISCHER, J., Rezension zur Monographie: Beschleunigte Strafverfahren im deutschen und im französischen Recht, von Eva Kohler (Duncker \& Humblot, Kölner Kriminalwissenschaftliche Schriften, Band 36, 2001), Revue de science criminelle et de droit pénal comparé 2002-3 (701).

LELIEUR-FISCHER, J., Rezension zur Monographie: Quelles réponses à la petite délinquance? Etude du droit répressif français sous l'éclairage comparé du droit répressif allemand, von Jocelyne LebloisHappe (Presses universitaires d'Aix-Marseilles, 2002), Revue pénitentiaire et de droit pénal 2003-4 (609-610).

LELIEUR-FISCHER, J., Bericht über das Kolloquium "Strafjustiz im Spannungsfeld von Fairness und Effizienz" (8.-11. Mai 2002, Tegernsee), Revue de science criminelle et de droit pénal comparé 2002$4(923-925)$. 


\subsubsection{Länderbereich Italien}

1. Leitung: Konstanze Jarvers

Mitarbeiter(in): Christoph Grammer (bis März 2003), Francesca Possenti (seit November 2003).

2. Erfasste Länder: Italien

3. Aktuelle Forschungsschwerpunkte:

Im Rahmen von Gemeinschaftsprojekten:

- Strafrechtlicher Strukturvergleich - Auswertung von Interviews mit Richtern, Staatsanwälten und Strafrechtsprofessoren in Italien über die Lösung bestimmter Musterfälle (Konstanze Jarvers).

- Strafrechtsentwicklung in Europa - Landesbericht Italien (Vincenzo Militello/Renzo Orlandi).

- Nationale Strafverfolgung völkerrechtlicher Verbrechen im internationalen Vergleich (Konstanze Jarvers)

- Ehre und Strafrecht (Giulio de Simone)

- Strafbarkeit und Rechtsfolgen bestimmter Delikte der Makrokriminalität in ausgewählten Ländern (Konstanze Jarvers)

\section{Gästebetreuung:}

Im Jahr 2002 haben 13 Gäste, im Jahr 200315 Gäste aus Italien das Institut während eines Forschungsaufenthalts von mindestens einem Monat besucht und wurden persönlich und wissenschaftlich betreut

\section{Veröffentlichungen (Auswahl):}

HeIn, S., Der Fall Priebke und die italienische Strafjustiz. Deutsche Richterzeitung (1996), 476-484.

HeIN, S., Landesbericht Italien. In: Korruptionsbekämpfung durch Strafrecht. Hrsg. A. Eser, M. Überhofen, B. Huber. edition iuscrim, Freiburg 1997, 213-280.

HEIN, S., Landesbericht Italien. In: Die Beweisaufnahme im Strafverfahrensrecht des Auslands. Hrsg. W. Perron. edition iuscrim, Freiburg 1995, 149-193.

JARVERS, K., Das neue italienische Anti-Dopinggesetz. Zeitschrift für die gesamte Strafrechtswissenschaft (2001), 947-954.

JARVERS, K./KINZIG, J., Organisierte Kriminalität und Zeugenschutz - eine vergleichende Betrachtung der italienischen und der deutschen Situation. Monatsschrift für Kriminologie und Strafrechtsreform (2001), 439-452.

JARVERS, K., Bericht über die Diskussion zum Thema "Konsensuale und andere entformalisierte Verfahrensarten". In: Strafjustiz im Spannungsfeld von Effizienz und Fairness. Konvergente und divergente Entwicklungen im Strafprozessrecht. Hrsg. A. Eser, C. Rabenstein, Freiburg 2004 (erscheint demnächst).

JARVERS, K., Profili generali del diritto processuale penale tedesco. Rivista italiana di diritto e procedura penale (erscheint demnächst). 


\subsubsection{Länderbereich Portugal, Spanien, Belgien und Brasilien}

1. Leitung: Peter Hünerfeld (bis März 2003)

Mitarbeiter(in): Roland Kniebühler, Teresa Manso

2. Erfasste Länder: Portugal, Spanien, Belgien, Brasilien

3. Aktuelle Forschungsschwerpunkte:

a) Im Rahmen von Gemeinschaftsprojekten:

- Allgemeiner strafrechtlicher Strukturvergleich: Erstellung des Landesberichts Portugal durch Hünerfeld

- Strafrecht in Reaktion auf Systemunrecht - vergleichende Einblicke in Transitionsprozesse: Erstellung des Landesberichts Portugal durch Hünerfeld.

- Nationale Strafverfolgung völkerrechtlicher Verbrechen im internationalen Vergleich: Erstellung des Landesberichts Belgien durch Hünerfeld unter Mithilfe von Roland Kniebühler; Erstellung des Landesberichts Spanien durch Gil Gil, überarbeitet von Teresa Manso in Zusammenarbeit mit der Autorin.

- Freiburg Proposal on Concurrent Jurisdictions and the Prohibition of Multiple Prosecutions in the European Union (Kniebühler): Projekt mit dem Ziel eines Regelungsvorschlags für die Europäische Union zum Thema "Grenzüberschreitendes ne bis in idem". Teil 1: Konzeption und Organisation von zwei Seminaren, die in Freiburg vom 22. bis zum 24. Mai und vom 10. bis zum 12. Juli stattfanden; Teil 2: Kommentierung dieses Regelungsentwurfs in englischer Sprache (36 Seiten). Das Projekt ist unter dem Titel Freiburg Proposal on Concurrent Jurisdictions and the Prohibition of Multiple Prosecutions in the European Union veröffentlicht (edition iuscrim, Forschung aktuell sowie online-Publikationen des Max-Planck-Instituts). Für weitere Informationen, siehe MaxPlanckForschung, Das Wissenschaftsmagazin der MaxPlanck-Gesellschaft, 3/2003, S. 71.

b) als Einzelprojekte

- Erschließung der Reform des spanischen StGB von 1995 (Ley orgánica 15/2003 de 25 de noviembre, por la que se modifica la Ley orgánica 10/1995, de 23 de noviembre, del Código Penal) (Manso)

- Erschließung der Reform der Verfolgung völkerrechtlicher Verbrechen in Belgien (Loi du 16 juin 1993 relative à la répression des violations graves du droit international humanitaire; Loi modifiant la loi du 16 juin 1993 relative à la répression des violations graves du droit international humanitaire et l'article 144ter du Code judiciaire vom 23.4.2003; Loi relative aux violations graves du droit international humanitaire vom 5.8.2003) (Kniebühler)

- Beobachtung und Verfolgung der Publikationen von spanischen Autoren in deutscher Sprache, sowie von deutschen Autoren zum spanischen Recht unter besonderer Berücksichtigung derjenigen Beiträge, sie sich mit der Entwicklung der spanischen Strafrechtswissenschaft beschäftigen oder für die gemeinsame Entwicklung bzw. Rechtsvergleichung bedeutsam sind sowie Bestandsaufnahme der spanischen Übersetzungen von deutschen Lehrbüchern bzw. Monographien und Aufsätze zum Allgemeinen Teil (Manso).

- Übersetzung des Aufsatzes "Es la reparación una tercera vía del Derecho penal?" von Julio B. Maier ins Deutsche (Kniebühler)

- Rezession ausländischer Monographien: Actualité du Droit International Humanitaire von Henri-D. Bosly (Kniebühler) bzw. Error iuris. El conocimiento de la antijuricidad y el art. 14 del Código penal, von David Felip i Saborit (Manso). 


\section{Gästebetreuung:}

Es wurden 33 Gäste betreut. Die durchschnittliche Aufenthaltsdauer der Gäste betrug 2,5 Monate.

\section{Veröffentlichungen (Auswahl):}

KNIEBÜHLER, R., BIEHLER, A., LeLIEUR-FISCHER, J., SteIN, S., Freiburg Proposal on Concurrent Jurisdictions and the Prohibition of Multiple Prosecutions in the European Union. edition iuscrim, Freiburg (2003), 1-36.

KnIEBÜHLeR, R., MAnso, T., The Punishment of Serious Crimes - A Comparative Analysis of Sentencing Law and Practice, Landesbericht Belgien (Kniebühler) und Spanien (Manso).

MANSO, T., Artikel: Efectos jurídico-penales del error de prohibición en los sistemas colombiano, español y alemán. In: El funcionalismo en Derecho Penal, Libro Homenaje al Profesor Günther Jakobs. Universidad Externado, Colombia 2003, 307-321.

MANSO, T., Artikel: La consumación en los delitos contra el medio ambiente: comparación de los modelos colombiano, español y alemán. In: El funcionalismo en Derecho Penal, Libro Homenaje al Profesor Günther Jakobs. Universidad Externado, Colombia, 2003, 445-461.

GIL GIL, A., Landesbericht Spanien zum Projekt "Nationale Strafverfolgung völkerrechtlicher Verbrechen im internationalen Vergleich". In: Ambos/Malarino (Hrsg.), Persecución penal nacional de crímenes internacionales en América Latina y España, (2003), 335-402.

MAnso, T., Artikel: El desconocimiento de la norma en el Código penal peruano, Revista Peruana de Ciencias Penales, Nr. 12, Sonderausgabe zum peruanischen Código Penal, Lima 2002, 60-77.

MANSO, T., Tagungsbericht: Strafverfahren und Polizei in Lateinamerika, San Pablo, 31. Juli-3. August 2001. In: Auslandsrundschau der Zeitschrift für die gesamte Strafrechtswissenschaft, ZStW 114 (2002), 176-180 (756-760).

MANSO, T., Tagungsbericht: La Policía en el Estado de Derecho Latinoamericano. In: Boletín IBCCrim, 9/106, September 2001, 6-7.

MANSO, T., Tagungsbericht: Moderne Tendenzen in Strafrechtswissenschaft und Kriminologie, Madrid 6.-10. November 2000. In: Auslandsrundschau der Zeitschrift für die gesamte Strafrechtswissenschaft, ZStW 113 (2001), 143-150, 632-638.

ESER A., HuBER, B. (Hrsg.), Strafrechtsentwicklung in Europa. Belgien (Tulkens/van de Kerchove), 1993-1996, in: Band 5, Teilband 2, 841-914; Spanien (Pérez del Valle), 1993-1996, in: Band 5, Teilband 1, 729-789. edition iuscrim, Freiburg.

HÜNERFELD, P., Alleinhandeln und Zusammenwirken aus französischer Sicht. In: Einzelverantwortung und Mitverantwortung im Strafrecht. Hrsg. A. Eser, B. Huber, C. Cornils. edition iuscrim, Freiburg (1998), 33-46.

HÜNERFELD, P., Landesbericht Belgien und Landesbericht Portugal. In: Korruptionsbekämpfung durch Strafrecht. Hrsg. A. Eser, M. Überhofen, B. Huber. edition iuscrim, Freiburg (1997), 9-19 und 359-371.

HÜNERFELD, P., La participation populaire et la justice pénale en Allemagne. In: Quelle participation des citoyens au jugement des crimes? Edition Cujas, Paris (1997).

HÜNERFELD, P., Landesbericht Portugal. In: Umweltstrafrecht in mittel- und südeuropäischen Ländern. Hrsg. G. Heine. edition iuscrim, Freiburg (1997), 359-371.

HÜNERFELD, P., La perception de la faute dans la responsabilité pénale et la responsabilité civile en droit allemand. In: Le défaut de prévoyance à l'épreuve des faits et du droit - droit belge et droit comparé -, Séminaire sous la direction de Christiane Hennau-Hublet. Revue de droit pénal et de criminologie (1994), 74, 229 ff., hier 305-312.

HÜNERFELD, P., Landesbericht Portugal und Landesbericht Brasilien. In: Schwangerschaftsabbruch im internationalen Vergleich, Teil 1. Hrsg. A. Eser, H.-G. Koch. Nomos Verlagsgesellschaft, BadenBaden 1988, 1246-1311 und Teil 2, Nomos Verlagsgesellschaft, Baden-Baden 1989, 133-169. 
HÜNERFELD, P., Die Beziehungen der deutschen zur spanischen Strafrechtswissenschaft. In: DeutschSpanisches Strafrechtskolloquium 1986. Hrsg. H.-J. Hirsch. Nomos Verlagsgesellschaft, Baden-Baden (1986), 3-18.

HÜNERFELD, P., Strafrechtsdogmatik in Deutschland und Portugal. Ein rechtsvergleichender Beitrag zur Verbrechenslehre und ihrer Entwicklung in einem europäischen Zusammenhang. Nomos Verlagsgesellschaft, Baden-Baden (1981).

\subsubsection{Länderbereich Common-Law-Länder (Schwerpunkt Großbritannien)}

1. Leitung: Christiane Rabenstein, LL.M.

Mitarbeiter(in): Ralf Bahrenberg (bis Mai 2003), Sarah Summers (ab 15. November 2003)

2. Erfasste Länder: Großbritannien, außerdem Nordirland, Republik Irland, Südafrika, Australien, Neuseeland, Kanada

3. Aktuelle Forschungsschwerpunkte:

a) im Rahmen von Gemeinschaftsprojekten

- Nationale Strafverfolgung völkerrechtlicher Verbrechen im internationalen Vergleich - Landesberichte England und Wales (Christiane Rabenstein und Ralf Bahrenberg), Australien (Anke Biehler), Kanada (Till Gut)

- Strafrecht in Reaktion auf Systemunrecht - Landesbericht Südafrika (Clivia Namgalies)

- Strafrechtlicher Strukturvergleich - Auswertung von Interviews mit Richtern, Staatsanwälten, Rechtsanwälten und Strafrechtsprofessoren in England über die Lösung bestimmter Musterfälle aus dem Bereich der vorsätzlichen Tötungsdelikte (Barbara Huber)

b) als Einzelprojekte

- "Strafjustiz im Spannungsfeld von Effizienz und Fairness, Konvergente und divergente Entwicklungen im Strafprozessrecht - Criminal Justice between Crime Control and Due Process, Convergence and Divergence in Criminal Procedure Systems", Tagung auf Schloss Ringberg, Tegernsee, 8.-11.5.2002 (Tagungsband in Vorbereitung)

- Schulvortrag "Kinder, die Kinder töten - der Fall James Bulger"

- The Punishment of Serious Crime - A Comparative Analysis of Sentencing Law and Practice Landesbericht England (Barbara Huber)

\section{Gästebetreuung:}

Forschungsaufenthalte von Wissenschaftlern aus dem Referatsbereich (u.a. Estella Baker, Leicester/England; Olympia Bekou, Nottingham/England; Fawzia Cassim, Pretoria/Südafrika; C.R. Snyman, Pretoria/Südafrika; Greg Taylor, Adelaide/Australien; Stephan Terblanche, Pretoria/Südafrika)

\section{Veröffentlichungen:}

ESER, A., RABENSTEIN, CH., Neighbours in Law, Freiburg 2001.

Rabenstein, CH., Doping - Legal Comparison and Harmonisation of Doping Rules - Landesbericht England und Wales, CD-ROM.

GÜNTHER, A., Doping - Legal Comparison and Harmonisation of Doping Rules - Landesbericht Irland, CD-ROM. 
RABEnstein, CH., Towards European Convergence in Penal Policy and Practice: Criminal Sanctions Reform Proposals in Germany and England from a Comparative Perspective, Internet-Publikation (http://www.iuscrim.mpg.de/forsch/onlinepub/rabenstein.pdf).

BOHLANDER, M., Besprechung von: Neigbours in Law. Hrsg. A. Eser, Ch. Rabenstein. Freiburg 2001. 3 International Criminal Law Review, 188-189 (2003).

\subsubsection{Länderbereich Vereinigte Staaten von Amerika}

1. Leitung: Emily Silverman, J.D., LL.M.

Mitarbeiter: Daniel Straub

2. Referatsbereich: siehe Titel

3. Aktuelle Forschungsschwerpunkte:

a) im Rahmen von Gemeinschaftsprojekten

- Nationale Strafverfolgung völkerrechtlicher Verbrechen im internationalen Vergleich

- Wiedergutmachung im Kriminalrecht - Internationale Perspektiven

b) als Einzelprojekte

- Neuere Entwicklungen im US-amerikanischen Recht

- Rechtsvergleichende Beobachtungen zur Rolle von Strafmündigkeit im amerikanischen und deutschen Jugendstrafrecht

- Wiedergutmachungsansätze für Kriminalitätsopfer im deutschen und amerikanischen Recht

\section{Gästebetreuung:}

Mehrere, im Laufe des Berichtszeitraums aus den USA gekommenen Gäste, wurden von den Mitarbeitern des Referats umfassend betreut (eine genaue Zahl kann nicht angegeben werden).

\section{Veröffentlichungen (Auswahl):}

SILVERMAn, E., Country Report USA. In: Der Einsatz akustischer und visueller Dokumentationstechniken im Strafverfahren. Hrsg. H.-J. Albrecht, M. Kilchling. edition iuscrim, Freiburg i.Br. 2002, 281305.

Silverman, E., The Role of Capacity in the Adjudication and Punishment of Youthful Offenders in Germany and the United States: A Legal Comparison. In: Konflikt der Rechtskulturen? Die USA und Deutschland im Vergleich. Hrsg. K. Krakau, F. Streng. Winter, Heidelberg. 2003, 127-142.

WALTHER, S., Wiedergutmachung im Kriminalrecht: Internationale Perspektiven. Hrsg. mit Albin Eser. edition iuscrim, Freiburg, Bd. S 57/1 (1996), 635 S.; Bd. S 57/2 (1997), 465 S.; Bd. S 57/3 (2001), $343 \mathrm{~S}$.

WALTHER, S./SILVERMAN, E., Lauschangriffe durch Informanten: Rechtsvergleichende Beobachtungen zum Schutz der Privatsphäre anlässlich der Clinton-Affäre. Zeitschrift für Rechtspolitik 32, 100106 (1999).

SILVERMAN, E., Der Zugriff auf Profite aus der Vermarktung von Straftaten . Juristenzeitung 53, $552-$ 559 (1998).

SILVERMAN, E., Landesbericht USA. In: Wiedergutmachung im Kriminalrecht: Internationale Perspektiven. Hrsg. A. Eser, S. Walther. edition iuscrim, Freiburg i.Br. 1997, Bd. 2, 1-153.

SILVERMAN, E., Hassdelikte in den USA: Abwehrmöglichkeiten im Spannungsfeld von Minderheitenschutz und Redefreiheit. Zeitschrift für die gesamte Strafrechtswissenschaft 107, 649-658 (1995). 


\subsubsection{Länderbereich Nordische Länder}

1. Leitung: Karin Cornils

Mitarbeiter(in): Tilmann Mohr, Jan Christoph Nemitz (bis 31.10.2002), Caroline Winter (bis 31.12.2001)

2. Erfasste Länder: Dänemark, Finnland, Island, Norwegen und Schweden

3. Aktuelle Forschungsschwerpunkte:

a) im Rahmen von Gemeinschaftsprojekten

- Organisierte Kriminalität - materiell-rechtliche Initiativen und besondere Ermittlungsmaßnahmen in Dänemark

- Nationale Strafverfolgung völkerrechtlicher Verbrechen im internationalen Vergleich: Finnland uns Schweden

- Jugendstrafrecht in Dänemark, Finnland und Schweden - materielles Recht, Besonderheiten des Verfahrens und Sanktionen

- Strafrechtlicher Strukturvergleich - Auswertung von Interviews mit Richtern, Staatsanwälten, Rechtsanwälten und Strafrechtsprofessoren in Schweden über die Lösung bestimmter Musterfälle

b) als Einzelprojekte

- Übersetzung der nordischen Strafgesetze. In zweisprachiger Ausgabe mit Einführung liegen vor: Cornils, K., Jareborg, N., Das schwedische Kriminalgesetzbuch - Brottsbalken, edition iuscrim, Freiburg 2000; aktualisiert auf den Stand 1.1.2004, pdf. Cornils, K., Greve, V., Das dänische Strafgesetz - Straffeloven, 2. aktualisierte Aufl., edition iuscrim, Freiburg 2001; aktualisiert auf den Stand 1.1.2003, pdf. Die Übersetzung des finnischen Strafgesetzes (gemeinsam mit Frände, Helsinki) befindet sich in der Bearbeitung.

- Die Entwicklung des Sanktionensystems in Schweden und Deutschland

- Neue Strafvollzugsgesetze in Dänemark und Norwegen

- Erweiterter Verfall im dänischen, finnischen, norwegischen und schwedischen Strafrecht

- Theoretische Grundlagen und praktische Anforderungen der Strafrechtsvergleichung

- Aufbau und Elemente der Straftat im dänischen und schwedischen Recht

\section{Gästebetreuung}

Im Zeitraum 2002/2003 haben insgesamt 35 Gäste aus den Ländern Dänemark, Finnland, Island, Norwegen und Schweden das Institut besucht. Sie wurden alle im Referat wissenschaftlich und persönlich betreut.

\section{Veröffentlichungen (Auswahl):}

CORNILS, K., HeINE, G. (Hrsg.), Umweltstrafrecht in den nordischen Ländern. Freiburg 1995; darin Landesberichte Dänemark (Jepsen), Finnland (Träskman), Island (Bragadóttir), Norwegen (Haagensen), Schweden (Cornils).

CORNILS, K., Landesbericht Schweden. In: Die Beweisaufnahme im Strafverfahrensrecht des Auslands. Hrsg. W. Perron. edition iuscrim, Freiburg 1995, 435-488.

CORNILS, K., Gemeinnützige Arbeit in den nordischen Ländern, Monatsschrift für Kriminologie und Strafrechtsreform 1995, 322-329.

CORNILS, K., Landesbericht Schweden. In: Korruptionsbekämpfung durch Strafrecht. Hrsg. A. Eser, M. Überhofen, B. Huber. edition iuscrim, Freiburg 1997, 501-535. 
ESER, A., HubER, B. (Hrsg.), Strafrechtsentwicklung in Europa. 5.1. edition iuscrim, Freiburg 1997; darin Landesberichte Finnland (Frände/Nuutila), Norwegen (Husabø/Strandbakken), Schweden (Cornils/Schütz-Gärdén).

CORNILS, K., Harmonisierungsbedarf zur grenzüberschreitenden Tatbeteiligung. In: Einzelverantwortung und Mitverantwortung im Strafrecht. Hrsg. A. Eser, B. Huber, K. Cornils. edition iuscrim, Freiburg 1998, 319-327.

CORNILS, K., Der Begehungsort von Äußerungsdelikten im Internet, Juristenzeitung 1999, 394-398.

CORNILS, K., GREVE, V., Rechtliche Initiativen gegen organisierte Kriminalität in Dänemark. Kriminalistisk Skriftserie nr. 6, Det Retsvidenskabelige Institut D, Kopenhagen 1999.

CORNILS, K., Lokalisering av brott på internet, Nordisk Tidsskrift for Kriminalvidenskab 1999, 194205.

CORNILS, K., Internetissä tehtyjen rikosten paikallistaminen, Lakimies 1999, 705-716.

SCHÜTZ-GÄRDÉN, B., Psychisch gestörte Straftäter im schwedischen und deutschen Recht - Strafrechtliche Zurechnungsunfähigkeit oder soziale Verantwortlichkeit? Diss., edition iuscrim, Freiburg 1999.

SCHÜTZ-GÄRDÉN, B., CORNILS, K., Landesbericht Schweden. In: Rechtsmittel im Strafrecht, Hrsg. M. Becker, J. Kinzig. edition iuscrim, Freiburg 2000, Bd. 1, 379-418.

CORNILS, K., JAREBORG, N., Das schwedische Kriminalgesetzbuch - Brottsbalken. Deutsche Übersetzung mit Einführung. edition iuscrim, Freiburg 2000.

CorNILS, K., GreVE, V., Das dänische Strafgesetz - Straffeloven. Deutsche Übersetzung mit Einführung. 2. aktualisierte Aufl., edition iuscrim, Freiburg 2001.

CORNILS, K., VERCH, U., Landesbericht Dänemark. In: Justitielle Einbindung und Kontrolle von Europol, Hrsg. S. Gleß, R. Grote, G. Heine. edition iuscrim, Freiburg 2001, 11-74.

CORNILS, K., GREVE, V., Landesbericht Dänemark. In: Rechtliche Initiativen gegen organisierte Kriminalität. Hrsg. W. Gropp, B. Huber. edition iuscrim, Freiburg 2001, 1-68.

CORNILS, K., Die territorialen Grenzen der Strafgerichtsbarkeit und Internet. In: Recht und Internet, Hrsg. G. Hohloch. Arbeiten zur Rechtsvergleichung Bd. 197, Baden-Baden 2001, 71-84.

CORNILS, K., Die Entwicklung des Sanktionensystems in Schweden und Deutschland. In: Flores juris et legum. Festskrift till Nils Jareborg, Hrsg. P. Asp u.a. Iustus Förlag, Uppsala 2002, 151-167.

CORNILS, K., Dopingrecht in Dänemark. In: Legal Comparison and Harmonisation of Doping Rules, eds. K. Vieweg, R. Siekmann. European Commission Project No. C 116-15, CD-ROM (www.asser.nl/sportslaw/eurodoping.htm).

CORNILS, K., Landesbericht Dänemark; NEMITZ, J.C., Landesbericht Finnland; HAVERKAMP, R., Landesbericht Schweden. In: Jugendstrafrecht in Europa. Hrsg. H.-J. Albrecht, M. Kilchling. edition iuscrim, Kriminologische Forschungsberichte, Bd. 100, Freiburg 2002, 27-49; 137-156; 337-360.

CORNILS, K., Neue Strafvollzugsgesetze in Dänemark und Norwegen, Zeitschrift für die gesamte Strafrechtswissenschaft 114, 683-695 (2002).

CORNILS, K., Landesbericht Dänemark. In: Zeugnisverweigerungsrechte bei (verdeckten) Ermittlungsmaßnahmen. Hrsg. J. Wolter/W.-R. Schenke. Bundesministerium der Justiz, Berlin 2002, 379-390.

CORNILS, K., Ein Nachruf auf die Vermögensstrafe. In: Rikosoikeudellisia Kirjoituksia VII. Pekka Koskiselle 1.1.2003 omistettu (Festschrift für Pekka Koskinen). Hrsg. R. Lahti, T. Lappi-Seppälä. Helsinki 2003, 15-29.

CORNILS, K., GREVE, V., Aufenthalts- und Zutrittsverbote als kriminalpräventive Mittel im dänischen Recht. In: Maßnahmen gegen Organisierte Kriminalität im Rechtsstaat - Möglichkeiten und Grenzen. Hrsg. B. Öztürk, W. Gropp. Seçkin Yayıncıllk. Ankara 2003, 39-54.

CORNILS, K., Grundlagen der Strafverfolgung völkerrechtlicher Verbrechen in Finnland; CORNILS, K., Grundlagen der Strafverfolgung völkerrechtlicher Verbrechen in Schweden. In: Nationale Strafverfolgung völkerrechtlicher Verbrechen. Bd. 2: Finnland, Polen, Schweden. Hrsg. A. Eser, H. Kreicker. edition iuscrim, Freiburg 2003, 21-76; 183-278.

Mohr, T., NemitZ, J.C. (Hrsg.), Strafrecht aus nordischer Perspektive - Festschrift für Karin Cornils. Shaker Verlag, Aachen 2003, 324 S. 


\subsubsection{Länderbereich Osteuropa - Schwerpunkt ehemalige sowjetische Republiken}

1. Leitung: Siegfried Lammich

2. Erfasste Länder: Ehemalige sowjetische Republiken, Tschechische Republik, Slowakische Republik, Ungarn, Rumänien, Bulgarien

3. Aktuelle Forschungsschwerpunkte:

a) im Rahmen von Gemeinschaftsprojekten

- Nationale Strafverfolgung völkerrechtlicher Verbrechen in Russland und in Belarus.

b) als Einzelprojekte

- Stand und Entwicklung des Strafrechts und der verwandten Rechtsgebiete sowie der Strafrechtspraxis in den dem Referat zugeordneten Ländern unter besonderer Berücksichtigung der diesbezüglichen Entwicklung in Russland und anderen GUS-Ländern.

- internationale Rechtshilfe in Strafsachen.

- aktuelle strafrechtliche Entwicklungen in Deutschland unter dem Gesichtspunkt der Information der interessierten Kreise in den dem Referat zugeordneten Ländern.

\section{Veröffentlichungen (Auswahl):}

LAMMICH, S., Russland: Hintergründe und Auswirkungen der Amnestie vom Mai 2000. Juristenzeitung 15/16, 2001, 813-815

LAMMICH, S., Die neuen Strafgesetzbücher der GUS-Länder - Vergleich ausgewählter Regelungen, in: M. Hoffmann, H. Küpper (Hrsg.) Kontinuität und Neubeginn. Staat und Recht in Europa zu Beginn des 21. Jahrhunderts (Festschrift für Georg Brunner aus Anlass seines 65. Geburtstages). Baden-Baden 2001, 312-323.

LAMMICH, S. (als Mitverfasser), Landesberichte Weißrußland, Litauen und Georgien. In: A. Eser, J. Arnold (Hrsg.), Strafrecht in Reaktion auf Systemunrecht, Bd. 7. edition iuscrim, Freiburg 2003.

LAMMICH, S., Die neuen russischen Geldwäschebestimmungen. Kriminalistik 6, 279-298 (2002).

LAMMICH, S. (mit H. Kury), Strafverfolgung in Georgien - das Problem Korruption. Zeitschrift für Strafvollzug und Straffälligenhilfe, 12-07 (2003).

\subsubsection{Länderbereich Osteuropa - Schwerpunkt Polen}

1. Leitung: Ewa Weigend

2. Erfasste Länder: Polen, Bundesrepublik Jugoslawien, Kroatien, Slowenien, Mazedonien, Albanien und zusätzlich Israel

3. Aktuelle Forschungsschwerpunkte:

a) im Rahmen von Gemeinschaftsprojekten

- Strafrecht in Reaktion auf Systemunrecht: Landesbericht Polen in Zusammenarbeit mit A. Zoll (Universität Krakau, zurzeit Ombudsmann der Republik Polen).

- Nationale Strafverfolgung völkerrechtlicher Verbrechen im internationalen Vergleich: Der Landesbericht Polen für das Institutsprojekt wurde im März 2003 fertig gestellt. Darüber hinaus wurden die Landesberichte der auswärtigen Mitarbeiter an diesem Projekt koordiniert und wissenschaftlich betreut. 
- "Ehre und Strafrecht": Der Landesbericht Polen für das Institutsprojekt wurde unter wissenschaftlicher Mitarbeit von Eleonora Zielińska (Universität Warschau) ebenfalls im Sommer 2003 abgeschlossen und druckreif abgegeben.

b) als Einzelprojekte

- Übersetzung der polnischen StPO ins Deutsche: Die polnische Strafprozessordnung vom 6. Juni 1997 mitsamt ihrer Novellen (bereits in den Jahren 2000 - 2002 waren es drei bedeutende Gesetzesänderungen) wurde ins Deutsche übertragen. Im Januar 2003 wurde eine umfangreiche Novelle der StPO (280 Artikel) vom Parlament verabschiedet, die sich seit Juli dieses Jahres in Kraft befindet. Auch diese Gesetzesnovelle wurde in die Übersetzung eingearbeitet.

- Eine Einführung zur unter 1. genannten Übersetzung wurde ebenfalls verfasst und in abgekürzter und leicht veränderter Form unter dem Titel "Grundzüge der neuen polnischen Strafprozessordnung von 1997" in der ZStW 115 (2003) veröffentlicht.

- Strafbarkeit juristischer Personen im polnischen und deutschen Recht: Zu diesem Zweck wurde ein Aufsatz über das neue polnische Gesetz, das die Verantwortung von Kollektivsubjekten regelt und am 28.11.2003 in Kraft getreten ist, für eine Veröffentlichung in der ZStW erarbeitet sowie einen Vortrag über die strafrechtliche Verantwortlichkeit von Unternehmen im deutschen Recht vorbereitet und auf einer Konferenz in Polen (Oktober 2003) gehalten. Dieser Beitrag wird in den Materialien der Konferenz "Strafbarkeit von Kollektivsubjekten" in Polen veröffentlicht.

- Medienfreiheit und das Strafverfahren: In Zusammenhang mit der Einladung zu einer Konferenz über das Recht auf Privatheit und Medienfreiheit in Warschau (20.10.2003) wurde die Problematik der rechtlichen Grenzen der Medienteilnahme am deutschen Strafprozess im Vergleich mit den einschlägigen Regelungen der polnischen StPO 1997 analysiert. Im Zentrum des rechtsvergleichenden Interesses stand dabei die Medienöffentlichkeit des Ermittlungsverfahrens in beiden Rechtssystemen, was auch das Thema des Konferenzbeitrags darstellte. Dieser Vortrag wurde bereits in Form eines Aufsatzes in der Nr. 1/2004 der polnischen Zeitschrift "Prokuratura i Prawo" (Staatsanwaltschaft und Recht) zur Veröffentlichung angenommen.

- Die neuesten Entwicklungstendenzen im deutschen Strafprozess vor dem Hintergrund der jüngsten Novellen der polnischen StPO 1997.

\section{Gästebetreuung:}

In den Jahren 2002-2003 haben 26 Gäste aus den Ländern des Referats das Institut während eines Forschungsaufenthaltes von mindestens einem Monat besucht und wurden wissenschaftlich und persönlich betreut.

\section{Veröffentlichungen (Auswahl):}

WeIGEND, E., Deutsche Übersetzung und Einführung des polnischen Strafgesetzbuchs vom 6. Juni 1997. Zweisprachige Ausgabe, Band 112, Reihe: Sammlung ausländischer Strafgesetzbücher in deutscher Übersetzung, edition iuscrim, Freiburg 1998, 264 S.

WEIGEND, E., Der Lügendetektorbeweis im deutschen und polnischen Strafprozeß auf der Schwelle zum XXI. Jahrhundert (polnisch). In: Festschrift für S. Waltoś. Hrsg. J. Czapska, A. Gaberle, A. Światłowski, A. Zoll, Wydawnictwo Prawnicze, Warszawa 2000, 641-654.

WEIGEND, E., ZIELIŃSKA, E., Aktuelle Entwicklungen im polnischen Recht des Schwangerschaftsabbruchs. Goltdammer's Archiv für Strafrecht 7, 320-328 (2000). 
WEIGEND, E., ZIELIŃSKA, E., Schutz der Wirtschaftinteressen der Europäischen Union und das polnische Strafrecht. Osteuropa-Recht 4, 274-288 (2001).

WEIGEND, E., Więcej wyjątków niż reguły [Mehr Ausnahmen als Regeln] (polnisch), Rzeczpospolita vom 22.3.2001, C3.

WeIGEND, E., Zoll, A., Landesbericht Polen. In: Strafrecht in Reaktion auf Systemunrecht. Vergleichende Einblicke in Transitionsprozesse, Bd. 5: Polen, Ungarn. Hrsg. A. Eser, J. Arnold (Hrsg.), edition iuscrim, Freiburg 2002, 29-150.

WEIGEND, E., Das neue polnische StGB vom 6. Juni 1997. In: Kriminalität im Grenzgebiet, Bd. 5/6 Das neue polnische Strafgesetzbuch (Kodeks karny). Springer, Berlin 2002, 1-13.

WeIGEND, E, Landesbericht Polen. In: A. Eser/H. Kreicker (Hrsg.), Nationale Strafverfolgung völkerrechtlicher Verbrechen. Bd. 2: Finnland, Polen, Schweden. edition iuscrim, Freiburg 2003, 77-181.

WEIGEND, E., Grundzüge der neuen polnischen Strafprozessordnung von 1997. ZStW 115, 153-174 (2003).

WeIGEND, E., Die Vorbereitung auf den Anwaltsberuf vor dem Hintergrund der deutschen Juristenausbildung (polnisch). Palestra, Nr. 7/8, 273-277 (2003).

WEIGEND, E., Die polnische Strafprozeßordnung - Kodeks postępowania karnego -. Zweisprachige Ausgabe. Übersetzung und Einführung von EWA WEIGEND. Freiburg i.Br. 2003, 420 S.

\subsubsection{Länderbereich Türkei, Iran, arabische Staaten}

1. Leitung: Silvia Tellenbach

2. Erfasste Länder: Türkei, Iran und die arabischen Staaten; Schwerpunktländer sind die Türkei und Iran

3. Aktuelle Forschungsschwerpunkte:

a) im Rahmen von Gemeinschaftsprojekten

- Ehre und Strafrecht (Projektleitung)

b) als Einzelprojekte:

- Islamisches Strafrecht in der modernen Welt

4. Gästebetreuung:

Im Jahr 2002 haben 6 Gäste, im Jahr 2003 haben 7 Gäste aus den Ländern des Referats das Institut während eines Forschungsaufenthalts von mindestens einem Monat besucht und wurden wissenschaftlich und persönlich betreut.

\section{Veröffentlichungen (Auswahl):}

TELLENBACH, S., Einführung in das türkische Strafrecht. edition iuscrim, Freiburg i.Br. 2003, 308 S.

TellenbACH, S., AYDIN, Ö.D., Türkei. In: Jugendstrafrecht in Europa. Hrsg. H.-J. Albrecht, M. Kilchling. edition iuscrim, Freiburg 2002, 455-474.

TELlENBACH, S., Muslime im deutschen Strafvollzug. In: Multireligiosität im vereinten Europa - Historische und juristische Aspekte. Hrsg. H. Lehmann, Wallstein Verlag, Göttingen 2003, 135-144.

TELLENBACH, S., Zur Änderung der türkischen Verfassung durch das Gesetz Nr. 4709 vom 3. Oktober 2001. VRÜ 35, 532-547(2001).

TELLENBACH, S., Ehrenmorde an Frauen in der arabischen Welt. wuquf 13, 74-89 (2003).

TELLENBACH, S., Die Vielfalt der Rechtsmeinungen gilt dem Islam als Gnade. MaxPlanckForschung 4/2001, 94-97 (engl.: MaxPlanckResearch 1/2002, In Islam, Diversity of Opinions is seen as a Divine Gift, 90-95). 


\subsubsection{Länderbereich Ostasien}

1. Leitung: Thomas Richter

Mitarbeiter: Zhao Yang, Somi Miscunescu

2. Erfasste Länder: China (Volksrepublik und Taiwan), Japan und Korea

3. Aktuelle Forschungsschwerpunkte:

a) im Rahmen von Gemeinschaftsprojekten

- Strafrecht in Reaktion auf Systemunrecht in verschiedenen Ländern. In einem Landesbericht zur Volksrepublik China wird die strafrechtliche Bewältigung der so genannten Kulturrevolution analysiert. Ein Landesbericht zu Korea geht auf den Transitionsprozess Südkoreas seit Beginn der 1980er Jahre ein.

- Nationale Verfolgung völkerrechtlicher Verbrechen im internationalen Vergleich. Landesbericht China.

b) als Einzelprojekte

- Strafrechtsstrukturen in der Volksrepublik China und Deutschland

4. Veröffentlichungen (Auswahl):

Chen, G.-Z., Albrecht, H.-J. (Hrsg.), Zhong-De qiangzhi cuoshi guoji yantaohui lunwenji (Proceedings of Sino-German Symposium on Compulsory Measures). Beijing 2003.

RICHTER, T., Umweltstrafrecht in der Volksrepublik China. Freiburg 2002.

Albrecht, H.-J., Chen, G.-Z. (Eds.), Non-Prosecution Policies. A Sino-German Comparison. Freiburg 2002.

ChEN, G.-Z., Albrecht, H.-J. (Hrsg.), Zhong-De bu-qisu zhidu bijiao yanjiu (Comparative Research on Sino-German Non-prosecution Policies). Zhongguo Jiancha Chubanshe, Beijing 2002.

RICHTER, T., Zur Diversion im chinesischen Strafverfahren - Eindrücke einer Reise, in: Monatsschrift für Kriminologie und Strafrechtsreform 1/2000, 23-29.

AlbreCht, H.-J., EsER, A., RICHTER, T. (Hrsg.): Drittes deutsch-chinesisches Kolloquium über Strafrecht und Kriminologie. Wirtschaftsstrafrecht und Wirtschaftskriminalität, Staatsanwaltschaft und Diversion, Strafvollzugsanstalten und ihre Überfüllung. Freiburg 2000.

AlBRECHT, H.-J., KURY, H. (Hrsg.), Kriminalität, Strafrechtsreform und Strafvollzug in Zeiten des sozialen Umbruchs. Beiträge zum Zweiten deutsch-chinesischen Kolloquium. Freiburg 1999.

CHO, B.-S., Vergangenheitsbewältigung in Südkorea aus strafrechtlicher Perspektive. Internationales Asienforum 3-4/1998 (Vol. 29), 239-276.

RICHTER, T., Landesbericht Volksrepublik China (21-67) sowie LENZ, K.-F., Landesbericht Japan (281-322), in: ESER, A., ÜBERHOFEN, M., HuBER, B. (Hrsg.), Korruptionsbekämpfung durch Strafrecht, Freiburg 1997.

LENZ, K.-F., HEUSER, R., Strafrechtsentwicklung in Japan und der Volksrepublik China. Freiburg i.Br. 1995. 


\subsubsection{Länderbereich Hispanoamerika}

1. Leitung: Kai Ambos (bis 31.12.2003)

Mitarbeiter: Ezequiel Malarino (bis 31.12.2003)

2. Erfasste Länder: Mittel- und Südamerika, Mexiko, sowie spanischsprachige karibische Staaten (insbesondere Kuba); Brasilien ab 1.10.2003

3. Aktuelle Forschungsschwerpunkte:

a) Im Rahmen von Gemeinschaftsprojekten

aa) Die Polizei im lateinamerikanischen Rechtsstaat

Mit der Veröffentlichung des Buches "La Policía en los Estados de Derecho Latinoamericanos" (Bogotá, 2003) wurde das Forschungsprojekt, das im Oktober 2000 auf einem internationalen Seminar in Santiago de Chile erstmals diskutiert wurde, beendet. Die Veröffentlichung enthält neben ausführlichen Landesberichten zur normativen und tatsächlichen Lage der Polizeien in Lateinamerika einen rechtsvergleichenden Querschnitt und einführende Beiträge von Gómez Colomer und Vogler. Eine genaue Beschreibung des Projekts findet sich unter: http://www.iuscrim.mpg.de/forsch/straf/projekte/ambos3.html.

bb) Nationale Strafverfolgung völkerrechtlicher Verbrechen im internationalen Vergleich

Prof. Ambos war verantwortlich für die lateinamerikanischen Berichte in o.g. Projekt (näher http://www.iuscrim.mpg.de/forsch/straf/projekte/nationalstrafverfolung2.html).

Die Arbeit wurde mit der Veröffentlichung der Bücher "Persecución penal de crímenes internacionales en América Latina y España (Montevideo 2003) und " Persecução Penal International na América Latina e Espanha " (São Paulo 2003) beendet.

\section{Gästebetreuung}

Im Berichtszeitraum kamen zahlreiche lateinamerikanische Gäste an das Institut, sei es auf eigene Kosten oder mit Stipendien (MPG, DAAD, AvH u.a.). Die genauen Zahlen liegen dem Gästereferat vor.

\section{Veröffentlichungen (Auswahl);}

Ambos, K., Gómez Colomer, J.-L., Vogler, R., con la participación de MAlarino, E. (eds.): La Policía en los Estados de Derecho Latinoamericanos. Un proyecto internacional de investigacíon. Ediciones Jurídicas Gustavo Ibáñez C., Ltd., Bogotá, D.C. 2003, 629 S.

Ambos, K., Malarino, E. (eds.), Persecución penal de crímenes internacionales en América Latina y España. Montevideo 2003.

AMBOS, K., MALARINO, E. (coord.), Persecução Penal International na América Latina e Espanha. São Paulo 2003.

AMBOS, K., Straftäter oder Polizist - einerlei? In Lateinamerika ist die Polizei weit von rechtsstaatlichen Standards entfernt. Entwicklung und Zusammenarbeit 43, 51-53 (2002); in Spanisch: Delincuente y policía: ¿la misma cosa? En América Latina, la policía está aún lejos de cumplir con los estándares del Estado de Derecho. Desarollo y Cooperación 3, 24-26 (2002). 


\subsubsection{Länderbereich Afrika (südlich der Sahara)}

1. Leitung: Adome Blaise Kouassi Mitarbeiter: Simon Paulenz

2. Erfasste Länder: Afrika (südlich der Sahara) außer Südafrika, die arabophonen und lusophonen Länder sind ausgeschlossen

3. Aktuelle Forschungsschwerpunkte:

a) Gemeinschaftsprojekte:

- Strafrecht in Reaktion auf Systemunrecht. Vergleichende Einblicke in Transitionsprozesse:

Fertigstellung des "Landesberichts Mali"

Fertigstellung des "Landesberichts Ghana"

Projektplanung des "Landesberichts Ruanda".

- Nationale Strafverfolgung völkerrechtlicher Verbrechen im internationalen Vergleich: Fertigstellung des "Landesberichts Côte d'Ivoire".

- Menschenhandel.

b) Einzelprojekt:

- Sanktionensysteme in afrikanischen Ländern südlich der Sahara im Spannungsfeld zwischen Tradition und Moderne: Projektplanung.

c) Referatsarbeit, die über die allgemeine Tätigkeit hinausging.

\section{Gästebetreuung}

Gäste aus Benin, Kamerun, Tansania, Senegal und Zimbabwe.

\section{Veröffentlichungen (Auswahl):}

AfANĐE, K.K.A., Jeune délinquant et jeune marginal au Togo. Aperçu de comparaison AllemagneFrance. edition iuscrim, Freiburg 1997, $336 \mathrm{~S}$.

AFANĐE, K.K.A., Le jeune togolais de la rue: au carrefour du droit et du non-droit. Recht in Afrika. Zeitschrift der Gesellschaft für afrikanisches Recht Nr. 1, 87 ff. (1998).

AFANĐE, K.K.A., Brouillon de culture - culture de brouillon. Papyrus Nr. 2, 20 ff. (1994).

AfANDE, K.K.A., Landesbericht Mali. In: Strafrecht in Reaktion auf Systemunrecht. Band 6: Mali, Ghana. Hrsg. A. Eser, J. Arnold. edition iuscrim, Freiburg 2002, 28 ff.

KouASSI, A.B., PAulenZ, S., Landesbericht Côte d'Ivoire. In: Nationale Strafverfolgung völkerrechtlicher Verbrechen - National Prosecution of International Crimes. Hrsg. A. Eser, H. Kreicker. edition iuscrim, Freiburg 2004 (erscheint demnächst).

KOUASSI, A.B., Straßenkinder und Jugendkriminalität. Ein kriminologischer Vergleich: Côte d'Ivoire und Deutschland, April 2004 (erscheint demnächst).

PAulenZ, S., Selbstjustiz in Benin. Zur Debatte über den Charakter außerstaatlicher Sanktionen in Afrika. Afrika spectrum Nr. 1, 99 ff. (1999).

PAUlenZ, S., Gesellschaft und Staat in Afrika (Rezension). Blätter des iz3w Nr. 259, 54 f. (2002).

PAULENZ, S., Ungerechte Gerechtigkeit. Der Internationale Strafgerichtshof als Politikum. Blätter des iz3w Nr. 271, 26 ff. (2003).

VUKOR-QUARSHIE, N.G., Ghana, in: Strafrecht in Reaktion auf Systemunrecht. Band 6: Mali, Ghana. Hrsg. A. Eser, J. Arnold. edition iuscrim, Freiburg 2002, 169 ff. 


\subsection{Sachbereiche}

\subsubsection{Sachbereich Internationales Strafrecht}

1. Leitung: Kai Ambos (bis Oktober 2003), Helmut Kreicker (seit November 2003) Mitarbeiterin: Johanna Rinceanu

2. Erfasste Sachbereiche: Völkerstrafrecht und Internationaler Strafgerichtshof, Strafanwendungsrecht, Auslieferung und Rechtshilfe

3. Aktuelle Forschungsschwerpunkte:

a) Im Rahmen von Gemeinschaftsprojekten

- Koordination und Betreuung des Projekts "Nationale Strafverfolgung völkerrechtlicher Verbrechen" (Kreicker; Rinceanu, Grafunder),

- Mitwirkung im Projekt "Strafrecht in Reaktion auf Systemunrecht" (Kreicker).

b) Als Einzelprojekte

- Promotionsvorhaben "Völkerrechtliche Exemtionen von strafrechtlicher Verantwortlichkeit" (Kreicker),

- Der Irak-Krieg und das Völkerrecht (Ambos/Arnold).

\section{Veröffentlichungen (Auswahl):}

ESER, A., Internet und internationales Strafrecht. In: Rechtsfragen des Internet und der Informationsgesellschaft. Symposion der rechtswissenschaftlichen Fakultäten der Albert-Ludwigs-Universität Freiburg und der Städtischen Universität Osaka. Hrsg. D. Leipold. Verlag C.F. Müller, Heidelberg 2002, 303-326.

ESER, A., Individual Criminal Responsibility. In: The Rome Statute of the International Criminal Court: A Commentary. Hrsg. A. Cassese, P. Gaeta, J.R.W.D. Jones. Oxford University Press, New York 2002, 767-822.

ESER, A., Mental Elements - Mistake of Fact and Mistake of Law. In: The Rome Statute of the International Criminal Court: A Commentary. Hrsg. A. Cassese, P. Gaeta, J.R.W.D. Jones. Oxford University Press, New York 2002, 889-948.

ESER, A., Harmonisierte Universalität nationaler Strafgewalt: ein Desiderat internationaler Komplementarität bei Verfolgung von Völkerrechtsverbrechen. In: Strafrecht, Strafprozessrecht und Menschenrechte. Festschrift für Stefan Trechsel zum 65. Geburtstag. Hrsg. A. Donatsch, M. Forster, Ch. Schwarzenegger. Verlag Schulthess, Zürich u.a. 2002, 219-236.

ESER, A., Verso una Corte Penale Internazionale: Nascita e Fondamenti dello Statuto di Roma. L'Indice Penale, Nuova Serie V/1, 279-305 (2002).

ESER, A., Diethnis kai Pankosmia Ethniki Poiniki Dikaiodosia/Internationale und Universale Nationale Strafgerichtsbarkeit. Zur Entstehung des Rom-Statuts für einen Internationalen Strafgerichtshof und seine Auswirkungen auf das nationale Strafrecht. Ant. N. Sakkoulas Verlag, Athen-Komotini 2003, $447 \mathrm{~S}$.

ESER, A., Auf dem Weg zu einem internationalen Strafgerichtshof: Entstehung und Grundzüge des Rom-Statuts. Zeitschrift des Bernischen Juristenvereins 139/1, 1-42 (2003).

ESER, A., KREICKER, H. (Hrsg.), Nationale Strafverfolgung völkerrechtlicher Verbrechen - National Prosecution of International Crimes. Band 2: Finnland, Polen, Schweden. edition iuscrim, Freiburg i.Br. 2003, $304 \mathrm{~S}$. 
ESER, A., KREICKER, H. (Hrsg.), Nationale Strafverfolgung völkerrechtlicher Verbrechen - National Prosecution of International Crimes. Band 1: Deutschland. edition iuscrim, Freiburg i.Br. 2003. 552 S. (im Druck).

AMBOS, K., MAlarino, E. (editores), Persecución penal nacional de crímenes internationales en América Latina y España. Montevideo (Uruguay) 2003, 746 S.

Ambos, K., Malarino, E. (coordenadores), Persecução Penal International na América Latina e Espanha. IBCCRIM, Sao Paulo 2003, 271 S.

ARnOLD, JÖRG, AMBOS, K., KAUß, U., ThUn, K., "Freiburg Lawyers' Declaration" of 10 February 2003 - On German Participation in a War Against Iraq". German Law Journal, Vol. 4 No. 3-1 (2003).

KREICKER, H., Die völkerstrafrechtliche Unverjährbarkeit und die Regelung im Völkerstrafgesetzbuch. Neue Justiz, Heft 06/2002, 281-286.

KREICKER, H., Art. 7 EMRK und die Gewalttaten an der deutsch-deutschen Grenze. Zu den Urteilen des Europäischen Gerichtshofs für Menschenrechte. Nomos Verlagsgesellschaft, Baden-Baden 2002, $127 \mathrm{~S}$.

\subsubsection{Sachbereich Europarecht}

1. Leitung: Sabine Gleß (ab 1.11.2001 beurlaubt), Anke Biehler (bis 31.12.2003)

Mitarbeiter: Michael Libota

2. Erfasste Sachbereiche: Europäisches Gemeinschaftsrecht, Polizeiliche und Justizielle Zusammenarbeit in Strafsachen (3. Säule der EU)

3. Aktuelle Forschungsschwerpunkte:

a) im Rahmen von Gemeinschaftsprojekten

- Koordination des Projekts "Justitielle Einbindung und Kontrolle von Europol", Ausarbeitung des Berichtes über "Justizielle Einbindung und Kontrolle von polizeilicher Ermittlungstätigkeiten auf der Ebene der Europäischen Union"

- Koordination des Projekts "Rechtsvergleichende Übersichten - die Schengen-Zusammenarbeit und Rechtsintegration in der Europäischen Union"

- "Report on the Cooperation in the European Union" für das Projekt "The Individual Facing International Cooperation in Criminal Matters - The Legal Position of the Individual in the Law of International Cooperation in Criminal Matters from a Comparative Perspective"

a) "Grenzüberschreitendes ne bis in idem - Ein Regelungsvorschlag für die Europäische Union" (vgl. oben 2.2.6).

b) als Einzelprojekte

- Beweisrechtsgrundsätze einer europäischen Strafverfolgung

- Terrorismusbekämpfung im Rahmen der 1. Säule der EU - Das Einfrieren von Geldern von mit dem Terrorismus in Verbindung gebrachten Organisationen

bb) "Analyse des Grünbuchs zum strafrechtlichen Schutz der finanziellen Interesse der EG und zur Einrichtung einer Europäischen Staatsanwaltschaft" im Auftrag des Haushaltskontrollausschusses des Europäischen Parlaments

cc) "Justitielle Einbindung und Kontrolle von Europol durch Eurojust". 


\section{Veröffentlichungen:}

GLEß, S., Zur Verwertung von Erkenntnissen aus verdeckten Ermittlungen im Ausland im inländischen Strafverfahren. Neue Zeitschrift für Strafrecht, 57-62 (2000).

GLEß, S., Zum Begriff des mildesten Gesetzes (§ 2 Abs. 3 StGB). Goltdammer's Archiv, 224-236 (2000).

GLEß, S., LÜKE, M., Rechtsschutz gegen grenzüberschreitende Strafverfolgung in Europa. JURA Juristische Ausbildung, 400-406 (2000).

GLEß, S., NELLES, U., Grenzenlose Strafverfolgung. Neue Kriminalpolitik 3, 22-25 (2000).

GLEß, S., "... dass überall dem Gesetz ein Genüge geschehe. Justitielle Kontrolle des strafrechtlichen Ermittlungsverfahrens". Deutsche Richterzeitung, 367-375 (2000).

Gleß, S., ZeITLER, H.E., Fair Trial Rights and the European Community's Fight against Fraud. European Law Journal 7, 219-237 (2001).

ESER, A., Una justicia penal "a la medida del ser humano" en la época de la globalización ("Menschengerechte" Strafjustiz im Zeitalter von Europäisierung und Globalisierung). Übersetzung ins Spanische von Teresa Manso Porto. In: Tendencias del Derecho Penal y la Política Criminal del Tercer Milenio (Colección Memorias), Mexiko 2002, 39-66.

ESER, A., Von der Konkurrenz zur Kongruenz nationaler Strafrechtsordnungen: Wege zur Rechtsannäherung in Europa. Poinikos Logos (zweimonatige Revue für Strafrecht und Kriminologie) 5, 21572170 (2002).

ESER, A., Aktuelle Perspektiven transnationalen Strafrechts/Current perspectives of transnational criminal law. In: Rechtsraum Europa. Perspektiven für die Harmonisierung/The European Area of Justice. Perspectives for Harmonisation. Zweisprachige Broschüre der Konferenz aus Anlass der Einweihung des Bundesministeriums der Justiz in Berlin am 30.-31.5.2002. Hrsg. Bundesministerium der Justiz. Berlin 2003, 53-94.

ESER, A., Brauchen wir ein Europäisches Strafgesetzbuch? In: Recht schafft Zukunft. Perspektiven der Rechtspolitik in einer globalisierten Welt. Dokumentation des Rechtspolitischen Kongresses 2002 in Karlsruhe. Hrsg. H. Däubler-Gmelin, I. Mohr. Verlag J.H.W. Dietz, Bonn 2003, 136-150.

ESER, A., Harmonization of Penal Sanctions in Europe: Comparative Typology of Convergences and Divergences. In: L'Harmonisation des sanctions pénales en Europe. Hrsg. M. Delmas-Marty, G. Giudicelli-Delage, E. Lambert-Abdelga-wad. Société de Législation Comparée, Paris 2003, 379-442.

\subsubsection{Sachbereich Recht und Medizin}

1. Leitung: Hans-Georg Koch

Mitarbeiter(innen): Katharina Haubold, Silke Hetz, René Kieselmann, Carola Müller

2. Erfasster Bereich: Das 1982 eingerichtete Referat widmet sich den Rechtsfragen, die durch die Medizin aufgeworfen werden, und zwar schwerpunktmäßig solchen, die strafrechtliche Bezüge aufweisen, ohne sich auf diese zu beschränken. Neben der Betreuung umfangreicher rechtsvergleichender Projekte befasst sich das Referat mit zahlreichen Fragestellungen zum deutschen Medizinrecht und wirkt interdisziplinär am Freiburger Zentrum für Ethik und Recht in der Medizin (ZERM) mit.

3. Aktuelle Forschungsschwerpunkte:

a) im Rahmen von Gemeinschaftsprojekten

- Rechtsvergleichende und kriminologische Untersuchungen zum Schwangerschaftsabbruch: Veröffentlichung je eines deutsch- und englischsprachigen Abschlussbandes

- Verbundprojekt: Der Status des extrakorporalen Embryos in interdisziplinärer Perspektive 
b) als Einzelprojekte

Neben den gesondert dargestellten Promotionsvorhaben seien folgende aktuelle Arbeitsschwerpunkte genannt:

- Allgemeines Medizinrecht: Das Referat "Recht und Medizin" betreut die im Nomos-Verlag herausgegebene Reihe "Medizin in Recht und Ethik" und pflegt eine umfangreiche Datenbank zu medizinrechtlichen Quellen (Gesetzgebung, Rechtsprechung, Literatur, derzeit ca. 18.000 Datensätze). Die Arbeiten an der Herausgabe eines Tagungsbandes über "Perspektiven des Medizinrechts" sind nahezu abgeschlossen. Eine vergleichend angelegte Magisterarbeit befasste sich mit der strafrechtlichen Verantwortung des Arztes in Deutschland und in verschiedenen afrikanischen Ländern (Gbekou).

- Themenschwerpunkt Forschung am Menschen: Anknüpfend an die Mitgliedschaft in der Ethik-Kommission der Albert-Ludwigs-Universität (Eser, Koch) beansprucht dieser Themenkomplex spezielle Aufmerksamkeit, wobei insbesondere eine rechtsvergleichend (Deutschland/Österreich/Schweiz) angelegte Dissertation überarbeitet und zur Pubikationsreife gebracht wurde (Hägele) und Fragen im Zusammenhang mit der anstehenden Reform des Arzneimittelgesetzes (12. AMG-Novelle) bearbeitet wurden. Fragen der Forschung mit Einwilligungsunfähigen, insbesondere vor dem Hintergrund des Europäischen Menschenrechtsüberreinkommens zur Biomedizin, sind Gegenstand eines rechtsvergleichenden Dissertationsvorhabens (Kiriakaki).

- Themenschwerpunkt Fortpflanzungsmedizin: Der aktuellen rechtspolitischen Bedeutung dieses Themenfeldes (einschließlich Stammzellforschung) gemäß wurde über das interdisziplinäre Projekt zum Status des In-vitro-Embryos hinaus eingehend zu Fragen grenzüberschreitender Stammzellforschung Stellung genommen, wie sie sich aus dem Stammzellgesetz vom 25.4.2002 ergeben haben. In diesem Zusammenhang war auch der Embryo-Begriff von Stammzellgesetz und Embryonenschutzgesetz zu problematisieren, und zwar insbesondere im Hinblick auf Entitäten, die zwar als entwicklungsfähig gelten können, jedoch nicht durch Befruchtung entstanden sind (zu diesem Fragenkreis vgl. auch das Dissertationsvorhaben von Hetz), sowie auf Rechtsfragen einzugehen, die das Bemühen um eine Effizienzsteigerung fortpflanzungsmedizinischer Maßnahmen betreffen..

- Themenschwerpunkt Sterbehilfe: Mit Rücksicht auf andere Vorhaben wurde das Projekt einer Fortschreibung der "Materialien zur Sterbehilfe" zurückgestellt. Eine rechtsvergleichende Übersicht nach dem Muster der zu Fragen der Fortpflanzungsmedizin erarbeiteten Tabelle liegt in einer Entwurfsfassung vor. Aus aktuellem Anlass wurde eine deutsche Übersetzung des neuen belgischen Sterbehilfe-Gesetzes erarbeitet und über die Homepage der Öffentlichkeit zugänglich gemacht. Weitere Forschungsarbeiten betreffen insbesondere den Problembereich Vorsorgevollmacht und Patientenverfügung und damit auch das Verhältnis zwischen zivilrechtlicher Präventivkontrolle und strafrechtlicher "Nachschau". Daneben sind Fragen der Behandlungsbegrenzung im klinischen Einzelfall regelmäßiger Gegenstand interdisziplinärer Ethik-Konsile des ZERM.

\section{Gästebetreuung:}

Besonders hervorzuheben ist die Betreuung von Doktoranden aus dem Ausland, die in deutscher Sprache promovieren, bis hin zur Veröffentlichungsreife ihrer Arbeiten, sowie von Magisterstudenten und Praktikanten aus dem In- und Ausland. 


\section{Veröffentlichungen (Auswahl):}

ESER, A., Auf der Suche nach dem mittleren Weg: Zwischen Fundamentalismus und Beliebigkeit. In: Unterwegs mit Visionen. Festschrift für Rita Süssmuth. Hrsg. M. Langer, A. Laschet. Verlag Herder, Freiburg i.Br. 2002, 117-139.

ESER, A., Stellungnahmen zur Stammzellforschung. In: Ethische Fragen zur Stammzellforschung: Import oder "Eigenbau". Hrsg. D. Groß, G. Keil, U.R. Rapp. Würzburger Kreis, Band 2, Würzburg 2002, 42, 44, 45, 47-49, 51, 52, 53, 54, 57, 58, 62 f., 64, 65, 69-70, 79-81, 83-84, 85, 86.

ESER, A., KOCH, H.-G., Forschung mit humanen embryonalen Stammzellen im In- und Ausland. Rechtsgutachten zu den strafrechtlichen Grundlagen und Grenzen der Gewinnung, Verwendung und des Imports sowie der Beteiligung daran durch Veranlassung, Förderung und Beratung. In: Forschung mit humanen embryonalen Stammzellen. Strafrechtliche Grundlagen und Grenzen. Hrsg. Deutsche Forschungsgemeinschaft. WILEY-VCH Verlag, Weinheim 2003, 37-207.

ESER, A., Stellungnahmen zur Stammzellforschung. In: Ethische Fragen zur Stammzellforschung: Import oder "Eigenbau". Hrsg. D. Groß, G. Keil, U.R. Rapp. Würzburger Kreis, Band 2, Würzburg 2002, 42, 44, 45, 47-49, 51, 52, 53, 54, 57, 58, 62 f., 64, 65, 69-70, 79-81, 83-84, 85, 86.

ESER, A., KOCH, H.-G., Rechtsprobleme biomedizinischer Fortschritte in vergleichender Perspektive. Zur Reformdiskussion um das deutsche Embryonenschutzgesetz. In: Strafrechtsprofessoren der Tübinger Juristenfakultät und Justizministerium Baden-Württemberg (Hrsg.), Gedächtnisschrift für Rolf Keller, Mohr Siebeck, Tübingen 2003, 15-36.

ESER, A., KOCH, H.-G., Schwangerschaftsabbruch und Recht: Vom internationalen Vergleich zur Rechtspolitik. Nomos Verlagsgesellschaft. Baden-Baden 2003, 360 S.

ESER, A., KOCH, H.-G., Schwangerschaftsabbruch im internationalen Vergleich: Rechtliche Regelungen - Soziale Rahmenbedingungen - Empirische Grunddaten, Teil 1: Europa, 1744 S., Teil 2: Außereuropa, 1353 S., Teil 3: Rechtsvergleichender Querschnitt - Rechtspolitische Schlussbetrachtungen Dokumentation zur neueren Rechtsentwicklung, XLIV, 932 S., Nomos Verlagsgesellschaft, BadenBaden, 1988, 1989 und 1999.

ESER, A., KOCH, H.-G., Forschung mit humanen embryonalen Stammzellen im In- und Ausland. Rechtsgutachten zu den strafrechtlichen Grundlagen und Grenzen der Gewinnung, Verwendung und des Imports sowie der Beteiligung daran durch Veranlassung, Förderung und Beratung. In: Deutsche Forschungsgemeinschaft (Hrsg.), Forschung mit humanen embryonalen Stammzellen, Strafrechtliche Grundlagen und Grenzen, Bonn 2003, 144 S.

Koch, H.-G., Status des Embryos in vitro, in: G. Maio/H. Just (Hrsg.), Die Forschung an embryonalen Stammzellen in ethischer und rechtlicher Perspektive. Nomos Verlagsgesellschaft, Baden Baden 2003 (Reihe Ethik und Recht in der Medizin, Band 36), 97-118.

KoCH, H.-G., Rechtlicher Status des In-vitro-Embryos: Maßnahmen zur Effizienzsteigerung bei medizinisch unterstützter Fortpflanzung aus rechtlicher und rechtsvergleichender Sicht. gpk - Gesellschaftspolitische Kommentare Jahrgang 44, Sonderausgabe 3/2003, 27-32.

\subsubsection{Gutachtenreferat}

\section{Leitung: Hans-Georg Koch}

2. Zuständigkeit:

Koordinierende Betreuung und gegebenenfalls eigenständige Beantwortung von Rechtsfragen zum Strafrecht, die von außen, insbesondere von Gerichten, Behörden und Rechtsanwälten, aber auch von Medien, an die strafrechtliche Forschungsgruppe des Instituts gerichtet werden.

Die "Richtlinien für die Bearbeitung von Anfragen auf dem Gebiet des deutschen, ausländischen und internationalen Strafrechts" vom 17.10.1996 regeln Art und Weise der Erledigung, das Verfahren sowie die Zeichnungsberechtigung. Die "Gebührenregelung für die Bearbeitung von Anfragen durch das 
Max-Planck-Institut für ausländisches und internationales Strafrecht" vom 17.10.1996 regelt die Erhebung und Berechnung der Gebühren für die Bearbeitung dieser Anfragen; sie richtet sich grundsätzlich nach dem Gesetz über die Entschädigung von Zeugen und Sachverständigen vom 1.10.1969 in seiner jeweils gültigen Fassung.

\section{Gegenstand:}

Mit Blick auf zunehmende Internationalisierung und Globalisierung nimmt das Max-Planck-Institut für ausländisches und internationales Strafrecht mit seinen vielfältigen Spezialkenntnissen gesellschaftliche Aufgaben wahr, die andernorts nicht zu leisten sind. Dies umfasst sowohl Fragen der Strafbarkeit nach ausländischem Strafrecht bei Auslandsbezügen von Tat und/oder Täter, der Zusammenarbeit von Behörden im Wege der Rechtshilfe, der Auslieferung, der ausländischen Strafverfahrensrechte, des Völkerstrafrechts und der Menschenrechte als auch sonstige Fragen des transnationalen Strafrechts. Spezialbereiche im In- und Ausland betreffen vor allem Recht und Medizin, daneben auch Umwelt-, Unternehmens- und Wirtschaftsstrafrecht. Erhebliche Bedeutung kommt der Klärung strafrechtlicher Vorfragen im Zusammenhang mit anderen Rechtsgebieten zu, etwa bei Asylverfahren, zivilrechtlichem Schadensersatz, Personenstandsfragen, oder bei unternehmerischen Investitionsentscheidungen. Gutachtliche Stellungnahmen dienen nicht nur der Klärung im konkreten Einzelfall, sondern betreffen auch rechtsvergleichende kriminalpolitische Anliegen von Gesetzgebern und Institutionen im In- und Ausland.

Das Gutachtenreferat betreut sämtliche Anfragen, berät die Fragesteller, klärt die Zuständigkeit des Instituts bzw. die Möglichkeit einer sachlichen Bearbeitung und sorgt für die Weiterleitung an den zuständigen Referenten/die zuständige Referentin oder vermittelt sonstige kompetente Auskunftspersonen. Im regelmäßigen Fall einer institutsinternen Beantwortung wird die schriftliche Stellungnahme dem Gutachtenreferenten zur Prüfung und Zeichnung vorgelegt und von diesem der weitere Fortgang veranlasst. Ein Teil der Anfragen kann erfahrungshalber vom Gutachtenreferat ohne Beiziehung von Länder- oder Sachreferenten erledigt werden.

Die Anzahl der vom Gutachtenreferat bearbeiteten Anfragen beträgt pro Jahr derzeit ca. 170. Dabei sind in den vergangenen Jahren Anfragen in Asylsachen spürbar zurückgegangen. Im Zentrum stehen aktuell Anfragen zum internationalen sowie zum europäischen Strafrecht. Über den Kreis der traditionellen Fragesteller hinaus (Gerichte, Behörden, Anwälte) gelangen in erheblichem Umfang Anfragen von anderen Teilen der Gesellschaft, wie insbesondere von politischen Gremien, universitären Einrichtungen, gemeinnützigen Institutionen oder Wirtschaftsunternehmen, an das Institut. Bei Anfragen aus dem Mediensektor (Presse, Funk, Fernsehen) nimmt das Gutachtenreferat auch Aufgaben der Öffentlichkeitsarbeit des Instituts wahr. Circa 25 Anfragen pro Jahr wurden zuständigkeitshalber an die kriminologische Forschungsgruppe weitergeleitet und sind in der Statistik des Gutachtenreferats nicht enthalten.

\section{Gutachten und Auskünfte}

Von den einzelnen Bearbeitern in den Landes- und Sachreferaten wird auf den verschiedensten Gebieten eine besondere Sachkunde erwartet, wie etwa Asylverfahren, Wirtschafts- und Umweltdelikte, Computer- und Internetkriminalität, oder Straßenverkehrsdelikte. Bei zahlreichen Anfragen geht es um Probleme des internationalen Strafrechts, die neben vertieften nationalen Untersuchungen auch völkerstrafrechtliche Stellungnahmen erfordern. Etliche Anfragen betreffen zudem eine Mehrheit von Ländern, so dass jeweils eine aufwendigere Koordination erforderlich ist.

Einen großen Umfang nehmen Anfragen zum internationalen Strafrecht ein. Weitere Themen betrafen aus dem materiellen Recht u.a. Tötungsdelikte, Straßenverkehrsdelikte, Doppelehe, Unterhaltspflichtverletzung, Sexualdelikte, Volksverhetzung sowie aus dem Verfahrensrecht die z.B. die Voraussetzungen für Zeugenvernehmungen im Ausland und nach ausländischen Strafverfahrensordnungen. 
Traditionell einen Schwerpunkt bilden Anfragen, die gleichsam im Wege eines kleinen Rechtshilfeverkehrs von Freiburg zu den skandinavischen Staaten erledigt werden (Cornils); zu den am meisten gefragten Ländern zählen weiters Frankreich (Lelieur), Italien (Jarvers), USA (Silverman) sowie arabische Staaten und die Türkei (Tellenbach). Seit langem etabliert haben sich aufgrund der besonderen Sachkunde Anfragen zu verschiedenen Aspekten des Medizinrechts (Koch).

\subsubsection{Veröffentlichungsreferat (Strafrechtliche Abteilung)}

1. Leitung: Barbara Huber

Mitarbeiterinnen: Irene Kortel, Petra Lehser, Lieselotte Lüdicke, Christa Wimmer, Käte Obermaier-Hiß

\section{Zuständigkeit}

Das Referat betreut die institutseigenen Reihen "Beiträge und Materialien aus dem Max-PlanckInstitut für ausländisches und internationales Strafrecht", "Sammlung ausländischer Strafgesetzbücher in deutscher Übersetzung", "forschung aktuell/research in brief" und die "Interdisziplinären Untersuchungen aus Strafrecht und Kriminologie", soweit strafrechtliche Arbeiten betroffen sind. Hinzu treten Beiträge zu Festkolloquien des Instituts. Dem Referat obliegt zudem die Redaktion des Auslandsteils der Zeitschrift für die gesamte Strafrechtswissenschaft, die im Verlag de Gruyter, Berlin, viermal jährlich erscheint.

\section{Gegenstand}

Die Aufgabe des Referats umfasst die redaktionelle Aufbereitung der Manuskripte für den Druck, Einleitung und Überwachung der Herstellung in der Druckerei sowie Vertrieb der Bücher im In- und Ausland. In möglichst engem Kontakt mit Herausgebern und Autoren bringen die auch fremdsprachlich ausgebildeten Mitarbeiterinnen die Skripten sprachlich und häufig auch inhaltlich zur Veröffentlichungsreife, wobei ein in jeder Hinsicht hoher Maßstab angestrebt wird. Für die in fremden Verlagen veröffentlichten Reihen "Rechtsvergleichende Untersuchungen zur gesamten Strafrechtswissenschaft", "Medizin in Recht und Ethik" (beide beim Verlag Nomos, Baden-Baden) und "Strafrecht und Kriminologie" (beim Verlag de Gruyter, Berlin) entfällt die drucktechnische und kaufmännische Seite.

Der Schwerpunkt der Arbeit im Berichtszeitraum lag erneut im Bereich der in der edition iuscrim erscheinenden Reihen: Es wurden 8 aus Institutsprojekten hervorgegangene Titel (z.T. zweibändig), 1 Monographie und 5 Dissertationen veröffentlicht. 3 neue Übersetzungen von Strafgesetzbüchern konnten erscheinen bzw. bis zur Druckreife gebracht werden. 3 vergriffene Bände wurden in beiden Berichtsjahren nachgedruckt. Der verstärkten Öffentlichkeitsarbeit dienten die 5 Hefte von forschung aktuell/research in brief, in denen Forschungsprojekte und -ergebnisse kurz skizziert werden.

Einzelheiten der Veröffentlichungen und die in Vorbereitung stehenden Publikationen können der Zusammenstellung unter III. des Berichts (Veröffentlichungen) entnommen werden. 


\subsection{6 Übersetzungsreferat (Deutsch-Englisch)}

1. Leitung: Emily Silverman, J.D., LL.M.

2. Erfasste Sachbereiche:

Übersetzung sowie sprachliche Überarbeitung und Korrektur von deutsch bzw. englisch gefassten wissenschaftlichen Beiträgen der strafrechtlichen Forschungsgruppe.

\section{Gegenstand:}

Die Beiträge von Wissenschaftlern und Wissenschaftlerinnen des Instituts sollten eine möglichst weitreichende Verbreitung finden und möglichst internationale Aufmerksamkeit erlangen. Da Englisch die lingua franca sowohl für schriftliche Publikationen als auch für Vorträge auf internationalen Veranstaltungen und Konferenzen geworden ist, besteht die Notwendigkeit von terminologisch exakten Übersetzungen in die englische Fachsprache. Voraussetzung dafür und für die Aufrechterhaltung der vom Institut gesetzten hohen sprachlichen Maßstäbe sind - neben der Beherrschung der deutschen und der englischen Sprache - profunde Kenntnisse sowohl im deutschen als auch im Common Law-Recht.

In den Jahren 2002/2003 wurde die Expertise des Übersetzungsreferats von mehreren Projekten und Referaten in Anspruch genommen.

\section{Veröffentlichungen (Auswahl):}

ESER, A., ARnold, J., Kreicker, J., Criminal Law in Reaction to State Crime: Comparative Insights into Transitional Processes. forschung aktuell/research in brief. edition iuscrim, Freiburg 2002, 1-17.

ESER, A., National Jurisdiction over Extraterritorial Crimes Within the Framework of International Complementarity: Comparative Survey on Transnational Prosecution of Genocide According to the Principle of Universality. In: Man's Inhumanity to Man: Essays in Honour of Antonio Cassese. Hrsg. L.C. Vohrah et al. Kluwer Law International, Netherlands 2003, 279-296.

Ambos, K. Superior Responsibility. In: The Rome Statute of the International Criminal Court: A Commentary. Hrsg. A. Cassese et al. Oxford University Press, Oxford, 2002, 823-872.

KARSTEN, N., Final Considerations. In: Strafrecht in Reaction auf Systemunrecht: Vergleichende Einblicke in Transitionsprozesse. Hrsg. A. Eser, J. Arnold. edition iuscrim, Freiburg 2003, 321-329.

Ambos, K., OthmAn, M., Introduction. In: New Approaches in International Criminal Justice: Kosovo, East Timor, Sierra Leone and Cambodia. Hrsg. K. Ambos, M. Othman. edition iuscrim, Freiburg 2003, 1-7. 


\section{Forschungsschwerpunkte und Forschungsplanung auf dem Gebiet der Kriminologie}

\subsection{Arbeitsschwerpunkte und Forschungsplanung}

\subsubsection{Arbeitsschwerpunkte}

Die laufenden Arbeiten der kriminologischen Forschungsgruppe lassen sich insgesamt sechs Schwerpunkten zuordnen, und zwar "Sanktions- und Vollzugsforschung", "Organisierte Kriminalität und Innere Sicherheit", "Normanwendung im Strafverfahrensrecht", "Opferforschung", dem "LEA - Laboratoire Européen Associé" sowie dem Thema "Sozialer Wandel, Veränderung von Lebenslagen, Kriminalität und Kriminalitätskontrolle". Im Berichtszeitraum 2002-2003 wurden aus diesen Schwerpunkten 12 Untersuchungen mit Forschungsberichten fertig gestellt ("Überwachung der Telekommunikation", "Evaluation des hessischen Experiments zum elektronisch kontrollierten Hausarrests", "Sanktionseinstellungen und Delinquenz Jugendlicher", "Strafzumessung im Vergleich Deutschland und Frankreich", "Gewalt- und Jugenddelinquenz im sozialökologischen Kontext", "Jugenddelinquenz im interethnischen Vergleich", "Subjektive Kriminalitätstheorien - Alltagswissen und Vorstellungen über Kriminalität in der Bevölkerung", "Sanktion und Legalbewährung im Jugendstrafverfahren", "Grenzüberschreitende polizeiliche Kooperation - Praktiken, Institutionen und Strukturen entlang der deutsch-französischen Grenze", "Die rechtliche Bewältigung von Erscheinungsformen organisierter Kriminalität", "Rechtsberatungs- und Wirtschaftsprüfungsberufe aus der Perspektive von Geldwäsche und Geldwäschekontrolle" sowie "Opfer von Sexualstraftaten"). Ferner erschienen Arbeitsberichte und Kurzberichte (Forschung aktuell) aus verschiedenen Forschungsschwerpunkten.

Im Schwerpunkt "Sanktions- und Vollzugsforschung" wurde eine Differenzierung vorgenommen, nachdem sich - den Planungen entsprechend - eine Konzentration von Projekten auf die Behandlung gefährlicher Straftäter (Sexualstraftäter) ergeben hat. Eine Gruppe von Projekten befasst sich mit der Implementation von Sanktionen, eine Reihe von Untersuchungen zielt auf Evaluation der Sanktionierung und Behandlung von Sexualstraftätern und anderen gefährlichen Straftätern. Die Studie zur Evaluation des hessischen Experiments zum elektronisch kontrollierten Hausarrest wurde mit der Vorlage des Berichts fertig gestellt ebenso wie die Forschungen zu "Opfer von Sexualstraftaten".

Im Schwerpunkt "Organisierte Kriminalität und Innere Sicherheit" wurde die Untersuchung "Die justizielle Bewältigung von Erscheinungsformen organisierter Kriminalität" mit der Vorlage des Forschungsberichts (gleichzeitig Habilitationsschrift) abgeschlossen. Ebenfalls fertig gestellt wurde die Untersuchung zu "Rechtsberatungs- und Wirtschaftsprüfungsberufe aus der Perspektive von Geldwäsche und Geldwäschekontrolle".

Im Schwerpunkt "Normanwendung im Strafverfahrensrecht" wurde die Untersuchung zur "Überwachung der Telekommunikation" mit der Vorlage und Veröffentlichung eines ersten Forschungsberichtes zunächst abgeschlossen. Vertiefende Untersuchungen schließen sich an. Ferner wurde der Forschungsbericht zum hessischen Fußfesselexperiment vorgelegt.

Innerhalb des vierten Forschungsschwerpunktes "Opferforschung" sind die Ost- und Westdeutschland in vergleichender Perspektive erfassenden Untersuchungen jetzt abgeschlossen. Der Schwerpunkt liegt hier nunmehr auf der Fortentwicklung der Fragestellungen.

Im Schwerpunkt "LEA - Laboratoire Européen Associé" sind verschiedene deutsch-französische Kooperationsprojekte, die als vergleichende Untersuchungen angelegt sind, zusammengefasst. Das Laboratoire wurde im Jahre 2002 um weitere 4 Jahre verlängert. Neben verschiedenen workshops zu den einzelnen Schwerpunkten des Laboratoire in Frankreich und in Deutschland wurde im Jahre 2002 in Zusammenarbeit mit dem CESDIP Paris ein europäisches Kolloquium zum Stand der Forschungen über den elektronisch kontrollierten Hausarrest durchgeführt, dessen Ergebnisse im Jahre 2003 veröf- 
fentlicht worden sind. Fertig gestellt und partiell bereits veröffentlicht wurden die Projektteile "Sanktionen und Strafzumessung im deutsch-französischen Vergleich", "Viktimisierungsforschung im deutsch-französischen Vergleich" sowie "Polizeiliche Kooperation in der deutsch-französischen Grenzregion". Die "Vergleichenden Untersuchungen zu Drogenproblemen und Drogenkontrolle" wurden abgeschlossen; es ist vorgesehen, die Befunde in französischer Sprache und in einem französischen Verlag im Laufe des Jahres 2004 zu veröffentlichen. In den Untersuchungen zur Mediation im Strafverfahren und zur Rolle und Funktion der Arbeit im Strafvollzug sind Datenerhebung und -auswertung abgeschlossen. Mit der Vorlage der Berichte ist in der ersten Hälfte des Jahres 2004 zu rechnen.

Im Schwerpunkt "Sozialer Wandel, Veränderung von Lebenslagen, Kriminalität und Kriminalitätskontrolle" ist die Studie "Sanktionsprofile, abweichendes Verhalten, Gewalt- und Wertorientierungen Jugendlicher" fertig gestellt und veröffentlicht worden. Ebenfalls abgeschlossen wurden die Untersuchung "Gewalt- und Jugenddelinquenz im sozialökologischen Kontext" sowie die in diesem Kontext entstandene Arbeit zu "Jugenddelinquenz im interethnischen Vergleich". Aus der "Kohortenstudie zur Entwicklung polizeilich registrierter Kriminalität und strafrechtlicher Sanktionierung" ging eine Studie zu "Sanktion und Legalbewährung im Jugendstrafverfahren" hervor, mit der eine vergleichende Analyse des Rückfalls nach Diversion (Einstellung) sowie nach formeller Sanktionierung durchgeführt wurde.

\subsubsection{Forschungsplanung}

Auch in den Jahren 2004 und 2005 wird sich die Tätigkeit der Forschungsgruppe Kriminologie auf die genannten Schwerpunkte und deren Fortentwicklung konzentrieren. Dabei wird besonderes Gewicht auf die Integration strafrechtlicher und kriminologischer Fragestellungen und Untersuchungen gelegt werden. Vor allem in der Untersuchung von Sanktionen und der Strafzumessung am Internationalen Strafgerichtshof sowie der Cyberkriminalität und ihrer Kontrolle wird ein herausragendes Entwicklungspotential für ein interdisziplinäres Forschungsprogramm des Gesamtinstituts gesehen.

Im Schwerpunkt "Sanktions- und Vollzugsforschung" werden die Forschungen zum elektronisch kontrollierten Hausarrest in Hessen fortgeführt. Damit wird die bereits abgeschlossene und auf die Experimentalphasse beschränkte Evaluationsstudie vertieft und auf die Fragestellung ausgeweitet, wie der elektronisch kontrollierte Hausarrest unter normalen (und nicht experimentellen) Bedingungen implementiert wird. Die Strafvollzugsdimension des Schwerpunkts hat sich nunmehr auf die Behandlung gefährlicher Straftäter konkretisiert. Hier werden die Untersuchungen eingeordnet, die sich aus unterschiedlichen Perspektiven mit Fragen der Behandlung und des Rückfalls gefährlicher Straftäter befassen. Hier ist zunächst die Nachuntersuchung der Legalbewährung von Sicherungsverwahrten im Vergleich zu einer Kontrollgruppe einzuordnen ebenso wie die weitgehend abgeschlossene Studie zu "Diagnose und Behandlung gefährlicher Straftäter, insbesondere Sexualstraftäter", in der der Frage nachgegangen wird, welche Ansätze zur Behandlung gefährlicher Straftäter derzeit im In- und Ausland implementiert und diskutiert werden und inwiefern diese Ansätze zur Rückfallvermeidung beitragen. Grunddaten zur Stellung von Sexualkriminalität im Lebenslängsschnitt liefern dann spezielle Auswertungen der Freiburger Kohortenstudie. Im Zentrum der Behandlungsforschung wird freilich eine Längsschnittuntersuchung zur Evaluation von Sozialtherapie bei Sexualstraftätern stehen, die auf etwa 10 Jahre angelegt ist und die sich auf die in der Zukunft im Mittelpunkt sozialtherapeutischer Bemühungen stehenden Sexualstraftäter konzentrieren wird. Eine weitere Längsschnittstudie, die dieser Untersuchung zuzuordnen ist, wird sich der Gruppe junger Sexualstraftäter und der Evaluation der Sozialtherapie im Rahmen des Jugendstrafvollzugs widmen.

Im Schwerpunkt "Organisierte Kriminalität und Innere Sicherheit" werden sich die Untersuchungen auf die Drogenmarktstudien konzentrieren, die in verschiedenen Teilprojekten durchgeführt werden. Hier geht es zum einen um die Zusammenarbeit mit der RAND Corporation USA in einer Unter- 
suchung zum Weltheroinmarkt sowie um kleinräumige Studien zu Drogenmärkten in Deutschland und in Italien. Ferner ist für das Jahr 2004 der Abschluss des in Zusammenarbeit mit der Universität Tilburg durchgeführten Projekts "Organized Crime in Europe: Manifestations and Policies in the European Union and Beyond" vorgesehen, dessen Ergebnisse anlässlich einer internationalen Konferenz in Den Haag Ende 2004 vorgestellt werden sollen.

Im Schwerpunkt "Normanwendung im Strafverfahrensrecht" werden Vertiefungsstudien zu Effizienz und Implementation das Projekt zur "Rechtswirklichkeit und Effizienz der Überwachung der Telekommunikation" fortführen. Ferner wurde die Untersuchung ausgeweitet auf die Evaluation der Wohnraumüberwachung. In der Untersuchung zu "Prosecution Policies in Cannabis Cases" ist die Datenerhebung weitgehend abgeschlossen. Die Studie ist Teil einer vergleichenden Untersuchung zur Strafverfolgungspolitik bei Cannabis, in der Auswirkungen von Entkriminalisierungsstrategien analysiert werden sollen.

Im Schwerpunkt "Opferforschung" ist das Projekt "Unerwünschte Einwanderer als Opfer und als Bedrohung an den Außengrenzen der EU" weiter konkretisiert worden. In einem komparativen Ansatz sollen in dieser Untersuchung Opfererleben und Risikowahrnehmung in der besonderen Situation der illegalen Immigration in mehreren Ländern erforscht werden. In einer weiteren Untersuchung werden Besonderheiten der Viktimisierung und der Viktimisierungsverarbeitung in und nach Bürgerkriegssituationen im ehemaligen Jugoslawien thematisiert. Beide Projekte sind im Berichtszeitraum bereits so weit vorbereitet worden, dass die Beantragung von Drittmitteln sehr aussichtsreich erscheint.

Im Schwerpunkt "LEA - Laboratoire Européen Associé" ist es mit Erfolg gelungen, das Forschungsprogramm inhaltlich umzusetzen und darüber hinaus junge Forscher aus Frankreich und aus Deutschland in das Laboratoire einzubinden. Ferner dient das Laboratoire nunmehr als Kristallisationspunkt deutsch-französischer komparativer Forschung auf den Gebieten des Strafrechts und der Kriminologie. Damit wird im Übrigen auch eine verlässliche Brücke zwischen der französischsprachigen und der englischsprachigen Forschungscommunity geschlagen.

Aus der Umsetzung des Anfangsprogramms hat sich eine Vielzahl neuer Fragestellungen ergeben, die aufgegriffen und in komparativer Art und Weise umgesetzt werden. Hierbei handelt es sich beispielsweise um Fragestellungen zur Evaluation elektronischer Kontrolle, zur Entwicklung des Strafprozesses und zur Integration ethnischer Minoritäten in die Polizei.

Im Rahmen des Schwerpunkts "Sozialer Wandel, Veränderung von Lebenslagen, Kriminalität und Kriminalitätskontrolle" wird sich eine Akzentverschiebung zunächst daraus ergeben, dass die verschiedenen Studien aus dem Projekt zur Gewalt- und Jugenddelinquenz im sozialökologischen Kontext nunmehr im Wesentlichen abgeschlossen sind. Damit verlagert sich das Forschungsinteresse jedoch nicht völlig von dem auch in den nächsten Jahren virulenten Thema der Jugendkriminalität ab. Noch weiter zunehmende Bedeutung wird jedoch auch in diesem Bereich die Bearbeitung und vertiefende Analyse von Daten aus der Freiburger Kohortenstudie erlangen. Insbesondere die neu begonnenen Projekte "Analyse von Deliktsähnlichkeiten auf der Basis von Individualdaten" sowie "Gewaltkriminalität im Lebenslauf - Eine Längsschnittstudie von jugendlichen Gewalttätern anhand der Daten der Freiburger Kohortenstudie" belegen das große Potenzial, das in diesem in Deutschland einmaligen Datensatz angelegt ist. Das Institut wird sich mit weiteren auf die Heranziehung von Kohortendaten bezogenen Projektvorschlägen auch an dem institutsübergreifenden gemeinsamen Programm 2005plus der Geisteswissenschaftlichen Sektion der MPG beteiligen. Wachsende Bedeutung wird auch dem Themenkomplex Punitivität zukommen. Die bereits in diesem Tätigkeitsbericht beschriebenen Projekte "Kriminalitätswahrnehmung und die Schwereeinschätzung von Delikten" und "Punitivität - ein konzeptioneller und empirischer Ansatz" sind als Vorstudien für größere Untersuchungen zu lesen, die zugleich als Kooperationsprojekte mit anderen Universitäten und Forschungseinrichtungen angelegt sind. 


\subsection{Schwerpunkt "Sanktions- und Vollzugsforschung"}

\subsubsection{Die Implementation von Sanktionen}

\subsubsection{Berücksichtigung von Angehörigen bei der Auswahl und Vollstreckung von Sanktionen}

- $\quad$ Bearbeiterin: Juliane Laule (Juristin)

- Zeitrahmen: 2002 bis 2004

- $\quad$ Projektstatus: in Bearbeitung

- $\quad$ Projektbeschreibung: (zugleich Promotionsvorhaben)

Schon lange ist in der kriminologischen Forschung das Problem bekannt, dass Sanktionen im Strafrecht zwar nur den Täter einer Straftat individuell betreffen sollen, seine Angehörigen durch die Strafe jedoch auch belastet werden. Die Individualisierung der Strafe wird in der Literatur teilweise sogar als Fiktion bezeichnet. Denn gerade die Tatsache, dass "Sippenhaft" vermieden und - dem modernen Gerechtigkeitsgedanken entsprechend - die Strafe individuell angewandt werden soll, beeinträchtigt den Blick auf die Wirklichkeit. Schließlich sind die Menschen keine wirtschaftlich, sozial und emotional total unabhängigen Individuen, sondern in ihr soziales Umfeld eingebunden. So wirkt eine individuelle Bestrafung immer auch auf das Umfeld des Bestraften und insbesondere auf die nahen Angehörigen.

Die Auswirkungen der Strafe auf die Angehörigen stehen im Spannungsfeld zweier Ursachen. Zum einen hat der Delinquent selbst durch seine Straftat die erste Ursache für die Inhaftierung und damit für eine Belastung seiner Angehörigen gesetzt. Zum anderen wird jedoch das Verhalten des Delinquenten durch strafgerichtliche Verurteilung sanktioniert und die Angehörigen dadurch von staatlicher Seite belastet. Soweit die Belastungen dem Staat anzurechnen sind, ist von einer (faktischen) Mitbestrafung Dritter auszugehen.

Als "Mitbetroffene Dritte" bezeichnet man die Angehörigen, die sozial, psychisch und/oder ökonomisch durch die Verurteilung in Mitleidenschaft gezogen werden. Genaue Angaben, wie viele Menschen als Angehörige von Strafgefangenen betroffen sind, gibt es nicht. Geht man davon aus, dass sich in der Bundesrepublik Deutschland am Stichtag 31.3.2000 insgesamt 41.699 Gefangene im geschlossenen Vollzug befanden und von diesen 23,04 \% verheiratet waren (Zahlen aus "Statistisches Bundesamt, Rechtspflege, Fachserie 10, Reihe 4.1, 2000, Tabelle 2"), so sind 9.606 Ehepartner als von der Inhaftierung betroffen zu bezeichnen. Rechnet man die Partner aus nicht-ehelichen Lebensgemeinschaften, angehörige Kinder und andere, in häuslicher Gemeinschaft lebende Angehörige dazu, ergibt sich, dass eine sehr große Anzahl von Menschen mitbetroffen ist. Zudem ist zu beachten, dass die Gefangenenpopulation ständig wechselt, so dass ständig neue Betroffene zu registrieren sind.

Überdies sind Angehörige jedoch nicht nur "Opfer", sondern können auch für die Erreichung des Vollzugsziels der Reintegration des Täters eine bedeutsame Rolle spielen.

Daher sind die Einführungen von neuen Sanktionen und die Ausgestaltung der Freiheitsstrafe heute deutlich geprägt von dem Versuch, die Beziehungen zwischen Verurteiltem und seinen Angehörigen nicht zu zerstören, sondern zu festigen. So sollte, als das Strafvollzugsgesetz (StVollzG) in den Jahren 1967-1976 erarbeitet wurde, durch einige Maßnahmen erreicht werden, dass die Inhaftierten zum Lebensunterhalt ihrer Angehörigen beitragen könnten (u.a. durch leistungsgerechte Entlohnung der Gefangenenarbeit). Ferner war neben der Einführung anderer angehörigenfreundlichen Neuerungen geplant, die Gefangenen in die gesetzliche Kranken- und Rentenversicherung einzubeziehen. Diese Reformbewegungen scheiterten jedoch aus finanziellen Gründen. Soweit sich unter der Geltung des StVollzG "angehörigenfreundliche" Maßnahmen durchsetzten konnten, sind sie fast ausschließlich im 
Bereich der persönlichen Kontakte angesiedelt, z.B. der Einführung von verbesserten Besuchsmöglichkeiten.

Nachdem, wie auch die oben angesprochene Diskussion um die Einführung des StVollzG verdeutlicht, in den Sechziger und Siebziger Jahren die Frage der Angehörigen von Straftätern in der Forschung durchaus ein Thema war, wurde in den letzten Jahren bzw. Jahrzehnten verstärkt der Fokus auf die Opfer der Straftaten gerichtet. Somit trat die Forschung über Täter und deren Umfeld in den Hintergrund. Erst mit der Diskussion über die "Elektronische Fußfessel" wurde die Frage der Angehörigen für die Forschung wieder wichtiger.

Jedoch nicht nur für die eventuelle Einführung der elektronischen Fußfessel ist das Thema "Angehörige von Straftätern" von Wichtigkeit. Eine Berücksichtigung der Angehörigen ist in vielen Phasen des modernen Strafrechts nicht nur möglich, sondern sogar gesetzlich vorgesehen.

Ziel dieser empirischen Untersuchung ist es, zu überprüfen, inwieweit der Faktor "Angehörige", und hier insbesondere der Faktor "Kinder", bei verschiedenen juristischen Entscheidungen, bei denen den Betroffenen Haft droht bzw. bei denen sich die Betroffenen bereits in Haft befinden, Berücksichtigung findet.

Inwieweit Angehörige von Tätern bei der Aussetzung zur Bewährung nach $\S 56$ StGB eine Rolle spielen, soll durch eine Aktenanalyse von durch Urteil abgeschlossenen Verfahren geklärt werden. Dafür sollen bei drei Staatsanwaltschaften (Freiburg, Stuttgart und Waldshut-Tiengen) jeweils 50 Akten ohne Bewährungsbeschluss mit Freiheitsstrafe bis zu zwei Jahren analysiert werden. Diese werden dann mit jeweils 50 Akten mit Bewährungsbeschluss von den gleichen Staatsanwaltschaften verglichen werden.

Ebenfalls im Rahmen einer Aktenanalyse soll untersucht werden, inwieweit der Faktor "Angehörige" und insbesondere der Faktor "Kinder" bei der Reststrafenaussetzung zur Bewährung nach $\S 57$ StGB und bei Entscheidungen in Haft nach dem StVollzG, zum Beispiel Lockerung und Urlaub, eine Rolle spielen. Es ist geplant, eine Stichprobe aus dem Entlassungsjahrgang 2001 der Justizvollzugsanstalten Schwäbisch Gmünd, Heilbronn und Bruchsal zu ziehen, bei welcher zwischen weiblichen und männlichen Gefangenen unterschieden wird. Insgesamt sollen dafür etwa 150 Gefangenenpersonalakten anhand eines standardisierten Fragebogens ausgewertet werden.

Ergänzend soll eine schriftliche Befragung bei allen Erwachsenenvollzugsanstalten in Baden-Württemberg durchgeführt werden, um zu evaluieren, wie die verschiedenen Möglichkeiten der Gefangenen, Außenkontakte nach den $\S \S 23-36$ StVollzG wahrzunehmen, von den einzelnen Anstalten ausgestaltet wurden.

Durch Befragung von Rechtspflegern in verschiedenen Vollstreckungsbehörden in Baden-Württemberg (Freiburg, Stuttgart, Waldshut-Tiengen) soll untersucht werden, ob die Frage der Angehörigen Einfluss auf die Art der Vollstreckung der Geldstrafe ( $\S 459$ ff. StPO), vor allem hinsichtlich der Bewilligung der Ratenzahlung, der Stundung und der Anordnung der Ersatzfreiheitsstrafe, hat.

- $\quad$ Arbeitsbericht 2002/2003:

Die schriftliche Befragung bei den Erwachsenenvollzugsanstalten in Baden-Württemberg hat Anfang des Jahres 2003 begonnen und ist inzwischen abgeschlossen. Erste Ergebnisse liegen vor.

Die notwendigen Genehmigungen für die Aktenanalyse wurden eingeholt. Es wurden etwa 250 der 300 Staatsanwaltsakten und alle 150 Gefangenenpersonalakten anhand eines standardisierten Fragebogens analysiert. Die EDV-mäßige Erfassung der Daten hat im Mai 2003 begonnen. 
- $\quad$ Arbeitsplanung 2004:

Die noch fehlenden Staatsanwaltsakten werden ausgewertet. Die EDV-mäßige Erfassung der Daten soll bis Februar 2004 abgeschlossen sein. Es schließt sich dann die Datenanalyse an.

Die Interviews der Rechtspfleger bezüglich der Geldstrafenpraxis sind ab Frühling/Sommer 2004 geplant.

\subsubsection{Evaluation eines Modellprojekts zum Einsatz der elektronischen Fußfessel (Hessen)}

- $\quad$ Bearbeiter: Markus Mayer (Soziologe)

- $\quad$ Zeitrahmen: 2000 bis 2004

- $\quad$ Projektstatus: in Bearbeitung

- $\quad$ Projektbeschreibung: (zugleich Promotionsvorhaben)

Im Mai 2000 hat das Hessische Justizministerium im Rahmen eines Modellversuchs die Möglichkeit geschaffen, im Land- und Amtsgerichtsbezirk Frankfurt unter bestimmten Voraussetzungen den elektronisch überwachten Hausarrest anzuordnen. Dieser Modellversuch wurde im Mai 2002 in eine ständige Einrichtung überführt und soll sukzessive auf andere Landgerichtsbezirke ausgedehnt werden. Das Max-Planck-Institut für ausländisches und internationales Strafrecht wurde mit der wissenschaftlichen Begleitung dieses Projekts betraut.

\section{Beschreibung des Modellprojekts in Frankfurt:}

Für das Modellprojekt wurde ein Stab von Bewährungshelfern zusammengestellt, der die Betreuung der betroffenen Personen während des Überwachungszeitraums übernimmt. Elektronisch überwachter Hausarrest kann in folgenden Fällen angeordnet werden:

- als Weisung im Rahmen einer Strafaussetzung zur Bewährung ( $§ 56$ ff. StGB),

- als Weisung zur Vermeidung eines anstehenden Bewährungswiderrufs ( $§ 56$ ff. StGB),

- als Weisung bei Aussetzung eines Strafrestes zur Bewährung ( $§ 57$ f. StGB),

- als Weisung innerhalb der Führungsaufsicht ( $§ 68 \mathrm{ff}$. StGB),

- als Maßnahme bei Aussetzung des Vollzuges eines Haftbefehls (§ 116 StPO),

- als Weisung im Rahmen eines Gnadenaktes entsprechend der Hessischen Gnadenordnung.

Auf Vorschlag eines oder mehrerer Prozessbeteiligten (Staatsanwaltschaft, Richter, Haftrichter, Rechtsanwalt, Angeklagter, Verurteilter, Bewährungshilfe, ...) prüfen die Mitarbeiter des Projekts, ob die betroffene Person für eine Teilnahme am Programm geeignet ist. Wenn die betroffene Person einverstanden ist und der elektronisch überwachte Hausarrest angeordnet wird, dann werden Fußfessel und Empfangsgerät in Zusammenarbeit mit der Hessischen Zentrale für Datenverarbeitung in der Wohnung des Betroffenen eingerichtet. 


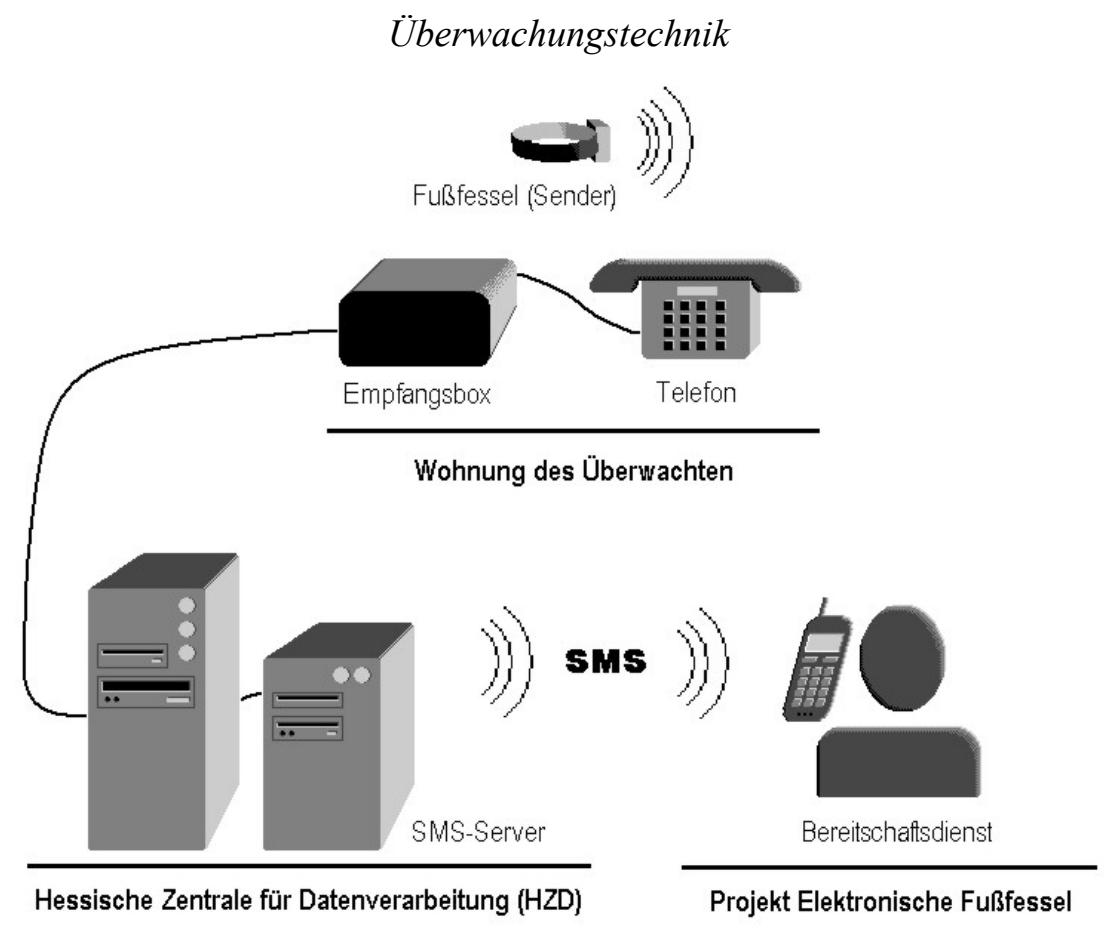

Die überwachte Person trägt am Fußgelenk einen Sender, der beständig Signale abgibt. Die Signale werden von einem Empfangsgerät registriert, das in der Wohnung der überwachten Person steht und über den Telefonanschluss mit einem Rechner der Hessischen Zentrale für Datenverarbeitung (HZD) verbunden ist.

Die Mitarbeiter des Projekts nehmen mindestens ein Mal pro Woche persönlichen Kontakt mit der überwachten Person auf. Grundsätzlich ist rund um die Uhr ein Bereitschaftsdienst der Bewährungshilfe erreichbar. Werden die vom Gericht festgelegten An- und Abwesenheitszeiten überschritten, so kann die Bewährungshilfe unmittelbar reagieren. Jede gravierende Überschreitung wird dem zuständigen Gericht gemeldet.

Stand des Modellprojekts am Ende der Pilotphase (1.5.2002):

Im bisherigen Verlauf wurden die Mitarbeiter/innen des Projekts "Elektronische Fußfessel" in insgesamt 123 Fällen (darunter in einigen Fällen mehrmals) gebeten, potentielle Probanden auf ihre Eignung zur Teilnahme am Projekt zu überprüfen.

\begin{tabular}{|l|c|c|c|c|}
\hline Anfrage im Rahmen von & $\begin{array}{c}\text { nehmen } \\
\text { teil }\end{array}$ & nehmen nicht teil & noch offen & Summe \\
\hline Strafaussetzung zur Bewährung & 26 & 39 & 8 & $\mathbf{7 3}$ \\
\hline Vermeidung des Widerrufs der Bewährung & 10 & 17 & 3 & $\mathbf{3 0}$ \\
\hline Vermeidung von Untersuchungshaft & 14 & 2 & & $\mathbf{1 6}$ \\
\hline Gnadenentscheidung & 2 & 1 & 1 & $\mathbf{4}$ \\
\hline Summe & $\mathbf{5 2}$ & $\mathbf{5 9}$ & $\mathbf{1 2}$ & $\mathbf{1 2 3}$ \\
\hline
\end{tabular}

Im Rahmen von Strafrestaussetzung bzw. Führungsaufsicht wurden dem Projekt bisher keine Fälle zur Prüfung vorgelegt. 
Fragestellungen des Forschungsprojekts:

Im Rahmen der wissenschaftlichen Begleitung sollen folgende Themenbereiche untersucht werden:

- Kriterien für die Auswahl der überwachten Personen,

- Möglichkeiten und Probleme der technischen Installation,

- Form der Begleitung und Betreuung durch die Mitarbeiter des Projekts,

- Auswirkungen der elektronischen Überwachung auf die überwachte Person und ihre Angehörigen,

- Wirkung der elektronischen Überwachung auf den Bewährungsverlauf,

- Einstellung von Experten zum elektronisch überwachten Hausarrest,

- Vergleich zwischen elektronischer Überwachung und anderen Sanktionsformen bezüglich der Wirkungen auf Betroffene,

- Analyse des Diskurses zur elektronischen Überwachung.

Die Datenerhebung findet überwiegend durch Leitfadeninterviews mit den Betroffenen und durch Expertengespräche mit den Projektmitarbeitern statt. Gleichzeitig werden die Akten aller Personen, die dem Projekt vorgestellt werden, ausgewertet.

Parallel wurde im Januar 2001 in Hessen eine schriftliche Expertenbefragung von Richtern, Staatsanwälten, Rechtsanwälten, Bewährungshelfern und Leitern von Justizvollzugsanstalten durchgeführt. Der Vergleich zwischen elektronischer Überwachung und anderen Sanktionsformen soll über Kontrollgruppen hergestellt werden.

\section{Bisherige Erfahrungen aus der Sicht der überwachten Personen:}

Im Rahmen der Begleitforschung wurde mit den elektronisch überwachten Personen zu Beginn und nach Abschluss des Überwachungszeitraumes ein Leitfadeninterview geführt. Dabei zeigten sich die überwachten Personen mit ihrer Situation und dem Projekt überwiegend zufrieden, wenngleich sie sich durchaus durch die elektronische Fußfessel belastet fühlten. Die hier dargestellten Erfahrungen beschreiben erste Eindrücke, wie sie sich auf der Basis des bislang erhobenen Datenmaterials ergaben.

\section{Einschränkungen im Alltag}

Als Einschränkung oder Kontrolle wird vor allem die ständige Erinnerung an die Überwachung empfunden, die durch das physische Empfinden des Fußbandes entsteht. Die überwachten Personen sehen sich gezwungen, ihren Tagesablauf stärker als bisher zu strukturieren, was der Mehrzahl mit fortschreitender Überwachungsdauer auch gelingt. Ebenso wird einschränkend erlebt, dass die bisherige Form der Freizeitgestaltung nicht mehr möglich ist, da die Überwachten in aller Regel die Abende und das Wochenende (von einigen Stunden "Ausgang" abgesehen) zu Hause verbringen müssen. In Familien verändert sich somit auch der Alltag der Angehörigen, da die Überwachten für manche Haushaltsarbeiten ausfallen (Einkäufe, Besorgungen). Kinder nehmen ebenfalls Veränderungen wahr, wenn ihnen auch mitunter die Wahrheit vorenthalten wird. Umgekehrt scheint die elektronische Überwachung gerade in Familien die Position der Angehörigen, insbesondere aber der Partnerinnen zu stärken, da nun deren Bedürfnis nach einer geregelten Lebenssituation von außen unterstützt wird.

\section{Stigmatisierungsängste}

Bei der großen Mehrheit der elektronisch Überwachten wissen nur nahe Verwandte und gute Freunde von der Fußfessel und der elektronischen Überwachung. Die Probanden befürchten vor allem negative Konsequenzen, sollte der Arbeitgeber von der Fußfessel erfahren. Leben die Überwachten in dörflichen oder kleinstädtischen Milieus, sorgen sie sich auch um das Gerede der Nachbarn. Manche beschreiben ein Schrumpfen des Freundeskreises, da sie einerseits nicht wie bisher gewohnt an dessen 
Aktivitäten teilnehmen können, andererseits aus Angst vor Stigmatisierung nicht jedem von der Fußfessel erzählen wollen. Weiter befürchten einige, die Fußfessel könne von Fremden entdeckt und als solche erkannt werden. Viele wünschen sich ein kleineres Gerät, das beispielsweise als Armbanduhr getarnt weniger Aufmerksamkeit auf sich ziehen würde. Insoweit decken sich freilich die Befürchtungen mit dem, was von strafgerichtlichen Verurteilungen im Allgemeinen und Verurteilungen zu Freiheitsstrafe im Besonderen an negativen Konsequenzen erwartet wird. Diesen Ängsten steht dann die Tatsache gegenüber, dass die Träger der Fußfessel bisher nur äußerst selten von Fremden als solche erkannt wurden. Jedoch bleibt hier abzuwarten, welche Erfahrungen in den Sommermonaten bei entsprechender Bekleidung gemacht werden.

\section{Technische Probleme}

Die Überwachungsgeräte funktionieren im Wesentlichen zuverlässig, wenngleich es in Einzelfällen zu Fehlermeldungen kam, deren Ursache sich nicht klären ließ. Schwierigkeiten gab es mitunter auch, wenn sich die Installation des Telefonanschlusses aufgrund noch bestehender Forderungen seitens der Telekom gegenüber der überwachten Person verzögerte. Die hiermit verbundenen Probleme erweisen sich allerdings als durchaus überwindbar.

\section{Betreuung und Förderung der Verurteilten durch die Projektmitarbeiter/innen}

Die Betreuung durch die Mitarbeiter/innen des Projekts Elektronische Fußfessel wird von den Überwachten als positiv bewertet. Hervorgehoben wird, dass die Mitarbeiter/innen neben den Kontrollaufgaben den Überwachten Unterstützung beim Umgang mit Behörden, der Suche nach einem Arbeitsplatz oder der Schuldenregulierung bieten. In verschiedenen Fällen hat sich dadurch die Zukunftsperspektive für die Betroffenen aus ihrer eigenen Sicht deutlich verbessert. Ebenso schätzen die Probanden, dass die Projektmitarbeiter/innen über die Rufbereitschaft kurzfristig und rund um die Uhr erreichbar sind.

\section{Beendete Maßnahmen:}

Der überwiegende Teil der Maßnahmen wurde unter regulären Umständen beendet. In fünf Fällen führte das Verhalten des Probanden zum Abbruch der Maßnahme. Bei sechs Fällen lagen andere Gründe für den Abbruch der Maßnahme vor. Die verschiedenen Anwendungsbereiche der elektronischen Überwachung waren hinsichtlich der Abbrüche der Maßnahme unterschiedlich erfolgreich:

\begin{tabular}{|l|r|r|r|r|}
\hline \multirow{2}{*}{ Teilnahme im Rahmen von } & \multicolumn{4}{|c|}{ Art der Beendigung der Maßnahme } \\
\cline { 2 - 5 } & Regulär & $\begin{array}{c}\text { Abbruch auf } \\
\text { Grund des } \\
\text { Probanden }\end{array}$ & $\begin{array}{c}\text { Abbruch aus } \\
\text { anderen } \\
\text { Gründen }\end{array}$ & Gesamt \\
\hline Strafaussetzung zur Bewährung & 15 & 3 & 3 & $\mathbf{2 1}$ \\
\hline $\begin{array}{l}\text { Vermeidung eines } \\
\text { Bewährungswiderrufs }\end{array}$ & 8 & & 1 & $\mathbf{9}$ \\
\hline $\begin{array}{l}\text { Vermeidung von } \\
\text { Untersuchunghaft }\end{array}$ & 9 & 2 & 2 & $\mathbf{1 3}$ \\
\hline Gnade & 2 & & & $\mathbf{2}$ \\
\hline Gesamt & $\mathbf{3 4}$ & $\mathbf{5}$ & $\mathbf{6}$ & $\mathbf{4 5}$ \\
\hline
\end{tabular}

Zieht man den Abbruch der Maßnahme als Kriterium für ihr Scheitern heran, dann schneidet innerhalb der drei Hauptanwendungsbereiche der Einsatz der elektronischen Überwachung zur Vermeidung eines Bewährungswiderrufs am besten ab. Abbrüche aufgrund des Probandenverhaltens traten dagegen beim Einsatz im Rahmen einer Strafaussetzung zur Bewährung sowie bei der Vermeidung von Untersuchungshaft auf. 


\section{Expertenbefragung zur elektronischen Überwachung:}

Teil der Evaluation des Modellprojekts ist die Befragung von Experten der Praxis, die im Januar 2001 durchgeführt wurde. Dazu wurden in Hessen alle Bewährungshelfer, Staats- und Amtsanwälte, JVALeiter sowie alle in Strafsachen tätigen Richter um Teilnahme gebeten. Von den 1037 angeschriebenen Befragten wurden 539 verwertbare Fragebogen $(51,9 \%)$ zurückgesandt.

\section{Generelle Einschätzung der elektronischen Überwachung}

Auf die Frage: "Käme Ihrer Ansicht nach eine generelle Anwendung der elektronischen Überwachung in Deutschland in Betracht?" antworteten:

\begin{tabular}{|l|c|c|c|c|c|}
\hline & Richter & $\begin{array}{c}\text { Staats-/ Amts- } \\
\text { anwälte } \\
(\mathrm{N}=184)\end{array}$ & $\begin{array}{c}\text { Bewährungs- } \\
\text { helfer } \\
(\mathrm{N}=108)\end{array}$ & $\begin{array}{c}\text { Leiter JVA } \\
(\mathrm{N}=16)\end{array}$ & $\begin{array}{c}\text { alle } \\
\text { Befragten } \\
(\mathbf{N}=\mathbf{5 3 2})\end{array}$ \\
\cline { 2 - 3 }$(\mathrm{N}=222)$ & $11,3 \%$ & $7,6 \%$ & $4,6 \%$ & $25,0 \%$ & $\mathbf{9 , 0} \%$ \\
\hline ja, wünschenswert & $47,3 \%$ & $45,1 \%$ & $27,8 \%$ & $18,8 \%$ & $\mathbf{4 1 , 5 \%}$ \\
\hline ja, denkbar & $5,0 \%$ & $3,8 \%$ & $4,6 \%$ & $18,8 \%$ & $\mathbf{5 , 0} \%$ \\
\hline weiß nicht & $20,7 \%$ & $19,6 \%$ & $31,5 \%$ & $37,5 \%$ & $\mathbf{2 2 , 9 \%}$ \\
\hline nein, eher nicht & $15,8 \%$ & $23,9 \%$ & $31,5 \%$ & & $\mathbf{2 1 , 4 \%}$ \\
\hline nein, überhaupt nicht & $\mathbf{1 0 0 , 0} \%$ & $\mathbf{1 0 0 , 0} \%$ & $\mathbf{1 0 0 , 0} \%$ & $\mathbf{1 0 0 , 0} \%$ & $\mathbf{1 0 0 , 0} \%$ \\
\hline Gesamt & \multicolumn{4}{|l}{} \\
\hline
\end{tabular}

Etwa die Hälfte der Befragten hält die Anwendung der elektronischen Überwachung in Deutschland für wünschenswert oder denkbar, wobei sich zwischen den Berufsgruppen deutliche Unterschiede ausmachen lassen: Besonders aufgeschlossen zeigen sich die Richter, gefolgt von Staats- und Amtsanwälten. Die Bewährungshelfer stehen der elektronischen Überwachung dagegen mehrheitlich reserviert bis ablehnend gegenüber.

\section{Einschätzung des Frankfurter Modellprojekts}

Auf die Frage: "Was halten Sie von dem seit dem 2. Mai 2000 laufenden Versuchsprojekt zur elektronischen Überwachung in Frankfurt?" antworteten:

\begin{tabular}{|l|c|c|c|c|c|c|}
\hline & $\begin{array}{c}\text { Richter } \\
(\mathrm{N}= \\
222)\end{array}$ & $\begin{array}{c}\text { Staats-/ } \\
\text { Amtsanwälte } \\
(\mathrm{N}=181)\end{array}$ & $\begin{array}{c}\text { Bewährungs- } \\
\text { helfer } \\
(\mathrm{N}=107)\end{array}$ & $\begin{array}{c}\text { Leiter } \\
\text { JVA } \\
(\mathrm{N}=16)\end{array}$ & $\begin{array}{c}\text { alle Befrag- } \\
\text { ten } \\
(\mathbf{N}=\mathbf{5 2 8})\end{array}$ & $\begin{array}{c}\text { LG-Bezirk } \\
\text { Frankfurt } \\
(\mathrm{N}=125)\end{array}$ \\
\hline $\begin{array}{l}\text { Ich begrüße das Pro- } \\
\text { jekt }\end{array}$ & $22,5 \%$ & $20,4 \%$ & $10,3 \%$ & $25,0 \%$ & $\mathbf{1 9 , 3} \%$ & $19,2 \%$ \\
\hline $\begin{array}{l}\text { Ich begrüße das Pro- } \\
\text { jekt überwiegend }\end{array}$ & $22,5 \%$ & $26,0 \%$ & $16,8 \%$ & $37,5 \%$ & $\mathbf{2 2 , 9} \%$ & $25,6 \%$ \\
\hline Ich weiß es nicht & $14,4 \%$ & $11,0 \%$ & $9,3 \%$ & & $\mathbf{1 1 , 9 \%}$ & $8,0 \%$ \\
\hline Ich bin eher skeptisch & $31,5 \%$ & $29,8 \%$ & $35,5 \%$ & $18,8 \%$ & $\mathbf{3 1 , 3 \%}$ & $33,6 \%$ \\
\hline Ich bin dagegen & $9,0 \%$ & $12,7 \%$ & $28,0 \%$ & $18,8 \%$ & $\mathbf{1 4 , 6} \%$ & $13,6 \%$ \\
\hline Gesamt & $\mathbf{1 0 0 , 0} \%$ & $\mathbf{1 0 0 , 0} \%$ & $\mathbf{1 0 0 , 0} \%$ & $\mathbf{1 0 0 , 0} \%$ & $\mathbf{1 0 0 , 0} \%$ & $\mathbf{1 0 0 , 0} \%$ \\
\hline
\end{tabular}

In der Einschätzung des Frankfurter Modellprojekts zeigen sich ebenfalls Unterschiede zwischen verschiedenen Befragtengruppen. Insgesamt begrüßen 42,2 \% aller Befragten das Projekt; dem steht eine ähnlich große Gruppe $(45,9 \%)$ mit skeptischen bis ablehnenden Einstellungen gegenüber. Dabei überwiegen bei Richtern, Staatsanwälten und Anstaltsleitern die positiven Einschätzungen, während bei der Gruppe der Bewährungshelfer eine ablehnende Haltung überwiegt. Dagegen unterscheidet sich 
Beurteilung der im Landgerichtsbezirk Frankfurt Tätigen kaum gegenüber der Gesamtheit der Befragten.

Bisherige Bewertung aus Sicht der Begleitforschung:

Soweit sich anhand der bisher ausgewerteten Daten ein erstes Fazit ziehen lässt, kann der bisherige Projektverlauf durchaus positiv beurteilt werden. In vielen Fällen stabilisierte sich die soziale Situation der Überwachten zumindest während der Überwachungszeit. Misserfolge und Abbrüche sind in einem Modellprojekt selbstverständlich zu erwarten und im Übrigen auch notwendig, um die Grenzen der Maßnahme zu bestimmen. Die weiteren Forschungsschritte werden dazu dienen, Fragestellungen aufzuarbeiten, die erst mit größeren Fallzahlen und mit einem ausgedehnteren Zeitrahmen angegangen werden können. Hierzu gehören die präzise Bestimmung der Auswirkungen der elektronischen Überwachung auf Teilnehmer und Familien- bzw. Haushaltsangehörige, Fragen des so genannten "net widening" und der Veränderungen in den Einstellungen der Justiz.

Fasst man die vorläufigen Evaluationsbefunde zusammen, so kann folgendes hervorgehoben werden:

1. Die Überwachung mittels elektronischer Fußfessel ist grundsätzlich durchführbar. Dies gilt in technischer Hinsicht wie aus der Perspektive der Strafjustiz.

2. Erwartungsgemäß wird die elektronische Fußfessel von einer Mehrheit von Richtern, Staatsund Amtsanwälten sowie Strafvollzugsleitern begrüßt, während in der Berufsgruppe der aus der Sozialarbeit kommenden Bewährungshelfer bzw. Sozialen Dienste der Justiz eine eher skeptische Haltung überwiegt.

3. Offensichtlich ist ein durchaus bedeutsames Anwendungspotential für die elektronische Fußfessel vorhanden, das im Frankfurter Modellprojekt allerdings bisher nicht ausgeschöpft wird.

4. Die Verteilungen zeigen an, dass neben der Strafaussetzung zur Bewährung durch das erkennende Gericht auch die Vermeidung des Bewährungswiderrufs sowie die Vermeidung der Untersuchungshaft relevante Anwendungsbereiche darstellen.

5. Das Anwendungspotential wäre noch höher anzunehmen, wenn eine Strafvollzugslösung systematisch einbezogen würde. Darauf weisen die Erfahrungen in Holland, der Schweiz oder England hin.

6. Die Wahrnehmung der Überwachung durch die Probanden zeigt, dass die elektronische Fußfessel als fühlbare Einschränkung empfunden wird. Insoweit erfüllt die elektronische Überwachung aus dieser Perspektive die Voraussetzungen für eine intermediäre Sanktion, die zwischen vollstreckter Freiheitsstrafe einerseits und Geldstrafe oder bloßer Bewährungsstrafe andererseits angesiedelt werden kann.

7. Aus der Befragung der Probanden wird deutlich, dass auch ein Resozialisierungspotential der elektronischen Fußfessel vorhanden ist. Hervorgehoben wird eine soziale Stabilisierung durch die elektronische Überwachung bzw. den damit verbundenen strukturierten Tagesablauf und durch die Unterstützung der Projektmitarbeiter/innen. 


\subsubsection{Die Implementation der Fußfessel in Hessen}

- Eine Evaluation des Einführungsprozesses anhand empirischer Analyse der Rechtswirklichkeit und Effizienz des elektronisch überwachten Hausarrests

- $\quad$ Bearbeiterin: Daniela Jessen (Juristin)

- $\quad$ Zeitrahmen: 2003 bis 2005

- $\quad$ Projektstatus: in Bearbeitung

- $\quad$ Projektbeschreibung: (zugleich Promotionsvorhaben)

Nachdem der elektronisch überwachte Hausarrest in Deutschland erstmals im Rahmen eines Modellprojekts beim Land- und Amtsgericht Frankfurt am Main zum Einsatz kam, wird die Maßnahme nun nach Abschluss der zweijährigen Erprobungsphase landesweit eingeführt. Dieser Implementationsprozess wird - wie auch bereits das Pilotprojekt - durch das Max-Planck-Institut für ausländisches und internationales Strafrecht in Freiburg wissenschaftlich begleitet und evaluiert.

\section{Evaluationsgegenstand: Projekt Elektronischen Fußfessel in Hessen}

Die Elektronische Überwachung wird bis zum Jahre 2005 in allen Amts- und Landgerichtsbezirken Hessens etabliert sein. Die Einführung der Maßnahme dient dem Zweck der Haftvermeidung und einer hierdurch bedingten Entlastung des Strafvollzugs sowie der Kostenreduzierung. Durch eine verhaltenstherapeutisch unterlegte Stabilisierung der Selbstkontrolle des Verurteilten wird eine verbesserte Grundlage der Legalbewährung angestrebt; eine ansonsten negative Sozialprognose soll verbessert und somit eine bislang notwendige Inhaftierung vermieden werden. Soweit die konkrete Anwendung der elektronischen Überwachung im Rahmen einer Weisung erfolgt, zielt die Maßnahme inhaltlich auf eine verbesserte Resozialisierung der Programmteilnehmer ab. Das Programm richtet sich an Straftäter mit erheblichen Rückfallrisiken und dem Bedarf an einer Regulierung der Lebensführung zur Vermeidung zukünftiger Straffälligkeit. Der pädagogischen Arbeit liegt die Annahme zugrunde, dass die Festlegung eines verbindlichen Wochenplans - der An- und Abwesenheitszeiten der betreffenden Person in der Wohnung regelt und zu sinnvollen Tätigkeiten obligatorisch verpflichtet - zu einer besseren Strukturierung des Zeitbudgets führt und der Proband hierdurch eine regelmäßige und sinnvolle Lebensführung trainieren kann. Die durch Absprachen abgesicherte Selbstbindung des Betroffenen soll in Verbindung mit der durch die Zeitbudgetierung erfolgenden faktischen Beschränkung von Gelegenheiten straffällig zu werden zu einer Reduktion des Rückfallrisikos beitragen. Die elektronische Kontrolle könnte somit eine neue Kombination von intensiver Betreuung, enger Überwachung und Selbstkontrolle bieten, durch welche die Strafaussetzung zur Bewährung bereichert und Widerrufe vermieden werden könnten.

Die Fußfessel kommt in Hessen im Rahmen der bestehenden Gesetzeslage in folgenden Fällen zur Anwendung:

- Weisung bei Strafaussetzung zur Bewährung gem. $\S \S 56 \mathrm{c}, 56 \mathrm{StGB}$,

- Weisung bei Strafrestaussetzung zur Bewährung gem. $\S \S 57,56 \mathrm{c}$ StGB analog,

- Weisung innerhalb der Führungsaufsicht gem. $\S 68$ ff. StGB,

- Maßnahme bei Aussetzung des Vollzuges eines Haftbefehls gem. § $116 \mathrm{StGB}$,

- Weisung iRe Gnadenerweises gem. § 19 Hessische Gnadenordnung.

\section{Projektverlauf:}

In jedem Landgerichtsbezirk koordiniert ein verantwortlicher Projektbeauftragter den Projektbetrieb. Auf Anfrage eines Richters oder Staatsanwalts überprüfen die für den entsprechenden Gerichtsbezirk 
bestellten Projektmitarbeiter noch im Vorfeld einer Hauptverhandlung die sachlichen und personellen Voraussetzungen einer möglichen Projektteilnahme des Beschuldigten. Innerhalb von 7 Werktagen wird ein diesbezüglicher Sozialbericht mit entsprechender Empfehlung erstellt und dem Gericht vorgelegt. Die Entscheidung über eine Teilnahme am Projekt ergeht durch Beschluss des Richters oder der Gnadenbehörde. Mit Rechtskraft der Entscheidung wird dem Teilnehmer die Fußfessel angelegt und die erforderliche Technik in dessen Wohnung installiert. Ab diesem Zeitpunkt kann die An- und Abwesenheit des Probanden in dessen Wohnung registriert und somit die Einhaltung des im gerichtlichen Beschluss fixierten Wochenprogramms kontrolliert werden. Während der gesamten Maßnahme wird der Proband durch einen ihm zugewiesenen Bewährungshelfer betreut. Die Dauer der elektronischen Überwachung richtet sich nach dem vom Gericht festgesetzten Zeitraum.

Teilnahmevoraussetzungen:

Zur Sicherstellung des Projektbetriebs wurden folgende Kriterien als Voraussetzung für eine Teilnahme definiert:

1. Fester Wohnsitz im entsprechenden Gerichtsbezirk,

2. Telefonanschluss,

3. Einverständniserklärung des Überwachten und der Mitbewohner,

4. Geistige und körperliche Gesundheit; Fähigkeit, einem angemessenen Arbeits-, Ausbildungsoder Beschäftigungsverhältnis nachzugehen,

5. Sinnvolle Tagesbeschäftigung (Erwerbstätigkeit, gemeinnützige Arbeit, Ausbildung etc.) von mind. 25 Stunden pro Woche,

6. Kein aktueller Drogenkonsum,

7. Keine aktuelle Straffälligkeit,

8. Keine Ausweisung nach den Vorschriften des Ausländergesetzes.

\section{Technik}

Die überwachten Personen tragen während der Überwachungszeit einen Sender am Fußgelenk. Ein in der Wohnung des Überwachten installiertes Empfangsgerät registriert die vom Sender ständig ausgehenden Signale, welche über die Telefonleitung an einen Rechner der Hessischen Zentrale für Datenverarbeitung (HZD) weitergeleitet werden. Manipulationen an den technischen Geräten sowie Verstöße der überwachten Person gegen den Zeitplan werden automatisch aufgezeichnet und durch die Mitarbeiter der HZD an den Bereitschaftsdienst des Fußfesselprojekts per SMS weitergeleitet. Der zuständige Bewährungshelfer kann dann die erforderlichen Maßnahmen ergreifen.

\section{Begleitforschung}

\section{Wissenschaftliches Erkenntnisinteresse}

Die Evaluationsstudie zielt auf eine empirische Analyse der Rechtswirklichkeit und Effizienz des Fußfesselprojekts in Hessen.

In Abgrenzung zur bisherigen wissenschaftlichen Begleitforschung des Max-Planck-Instituts im Rahmen des Modellprojekts, die den Einsatz der elektronischen Fußfessel unter den experimentellen Bedingungen des Pilotprojektes beleuchtete, steht im Mittelpunkt der vorliegenden Untersuchung die Implementierung und Ausgestaltung der neuen Maßnahme unter den regulären Bedingungen der Strafvollstreckung in Hessen.

Zentrales Forschungsanliegen ist es, den möglichen Stellenwert des elektronisch überwachten Hausarrests als Sanktionsalternative zur Vermeidung von Inhaftierung innerhalb des Sanktions- und Voll- 
zugsgefüges zu bestimmen und den augenblicklichen Stand der Reformbemühungen übergreifend zu bilanzieren. Im Rahmen rechtssoziologischer Effektivitätsforschung sollen Ausführung, Angemessenheit, Leistungsfähigkeit, Ablauf, Ergebnis und Nutzen des Projekts rational bewertet werden. Durch systematische Auswertung der Erfahrungen wird überprüft, ob das Programm der Zielsetzung entsprechend vollzogen, im Rahmen der geltenden Gesetzeslage richtig angewandt und die erstrebte Wirkung erzielt wird.

Die Bewertung der Wirksamkeit des Programms und dessen Auswirkungen erfolgt unter spezieller Analyse der Implementationsstrukturen, da anzunehmen ist, dass den Besonderheiten der staatlichen Intervention, der damit befassten Implementationsträger und der Interaktion zwischen ihnen und den Programmadressaten signifikante Bedeutung für den Programmerfolg zu kommt. Insofern ist das Erkenntnisinteresse in diesem Zusammenhang nicht darauf begrenzt, allein den Erfolg oder Misserfolg der Maßnahme zu erfassen, sondern erstreckt sich darüber hinaus auf ein möglichst differenziertes Verständnis der internen Dynamik sowie der Eigenart und Ursachen spezifischer Implementationsprozesse. Die vorliegende Studie erfolgt somit auf Grundlage deskriptiver Erfassung und umfassender Erklärung der komplexen Umsetzung des Projekts im Interesse einer möglichst differenzierten Nachzeichnung des gesamten Prozesses der Institutionalisierung.

Vor dem Hintergrund der bereits im Rahmen der Modellphase gewonnenen Erkenntnisse konkretisiert sich das generelle Forschungsanliegen in folgenden Schwerpunkten:

- Wie ist die Maßnahme der elektronischen Überwachung konzipiert?

- Welche Ausgestaltung findet das Programm der elektronischen Überwachung in der praktischen Umsetzung?

- Welche Auswirkungen hat das Projekt der elektronischen Überwachung?

\section{Evaluationsmethodik}

Die Dokumentation und Analyse des Implementationsprozesses erfolgt unter systematischer Anwendung sowohl quantitativer wie auch qualitativer sozialwissenschaftlicher Erhebungsmethoden.

Der Analyse der Programmentwicklung und Implementationspraxis liegen in erster Linie Intensivinterviews mit Implementationsakteuren, Implementationsträgern und Implementationsadressaten zugrunde.

Befragungen der jeweils betreuenden Bewährungshelfer sowohl zu Projektbeginn wie auch nach Beendigung einer Maßnahme sollen Aufschluss über den Betreuungsverlauf und über die Probleme, Grenzen und Möglichkeiten der pädagogischen Arbeit geben.

Im Rahmen der parallel verlaufenden Befragung der Projektteilnehmer und deren Mitbewohner soll die praktische Umsetzung der elektronischen Überwachung und deren Auswirkungen auf die Betroffenen untersucht werden. Hierbei ist insbesondere auch die Analyse der betreffenden Probandenakten von Bedeutung.

Expertengespräche mit Mitarbeitern des Hessischen Justizministeriums werden Einblicke in die Programmentwicklung und Einführungsstrategien geben.

Eine Befragung der hessischen Bewährungshilfe über deren Einstellung und Beurteilung bzgl. der Maßnahme soll weiteren Aufschluss über den Prozess der landesweiten Implementation gewähren.

Die Wirkungskontrolle hinsichtlich der Maßnahme umfasst schließlich mehrere Teilstudien, in deren Rahmen die Bedeutung der elektronischen Fußfessel im Hinblick auf die Resozialisierung der Probanden aufgezeigt werden soll. Neben einer Untersuchung zum späteren Legalverhalten der Programmteilnehmer werden ferner im Rahmen einer Kontrollgruppenstudie unter dem Blickwinkel der jeweiligen Rückfälligkeit die Daten inhaftierter Personengruppen und normaler Bewährungsunterstellter mit 
denen der Projektteilnehmer vergleichen. Ergänzend hierzu soll eine weitere Effizienzforschung durch vergleichende Evaluation einer Kontrollgruppe aus der normalen Bewährungshilfe erfolgen, in deren Rahmen der Betreuungsverlauf differenziert nachgezeichnet werden wird. In diesem Zusammenhang ist insbesondere die Funktion, die der elektronischen Kontrolle für den Betreuungsverlauf zu kommt, von Interesse.

Durch die Befragung beteiligter Richter sollen Erfahrungen und Akzeptanz bezüglich der neuen Maßnahme untersucht und insbesondere deren Einfluss und Auswirkung auf die Zusammenarbeit zwischen Richtern und Bewährungshelfern erfasst werden.

Hieran schließt sich eine Strafzumessungsuntersuchung bei hessischen Richtern an, in deren Rahmen Auswirkung und Stellung der Maßnahme bzgl. des Sanktionsgefüges unter besonderer Beachtung einer möglichen strafverschärfenden Wirkung der Fußfessel untersucht werden soll.

- $\quad$ Arbeitsplanung 2004:

Die Gespräche mit den Projektbeteiligten (Bewährungshelfer, Richter, Probanden und Angehörige) werden über den gesamten Zeitraum der Datenerhebungsphase (2003-2005) entsprechend dem Projektverlauf kontinuierlich geführt. Auch die Aktenauswertung erfolgt fortlaufend.

Die Strafzumessungsuntersuchung wird im Jahre 2004 durchgeführt werden.

Im Anschluss daran wird die Befragung der Bewährungshilfe erfolgen.

\subsubsection{Untersuchungshaftvermeidung bei Jugendlichen und Heranwachsenden in Baden-Württemberg aus Sicht der Praxis}

- $\quad$ Bearbeiterin: Imke Hotter (Juristin)

- $\quad$ Zeitrahmen: 2001 bis 2004

- $\quad$ Projektstatus: in Bearbeitung

- $\quad$ Projektbeschreibung: Promotionsvorhaben

Ziel der Arbeit ist eine Evaluation der Alternativen zur Untersuchungshaft für jugendliche und heranwachsende Straftäter durch die im Bereich des Jugendstrafrechts tätigen Praktiker. Obwohl durch das 1. JGG-ÄndG von 1990 die Voraussetzungen für die Verhängung von Untersuchungshaft gegen Jugendliche verschärft wurden, befanden sich bundesweit am 31.12.2001 immer noch 923 Jugendliche und 2.097 Heranwachsende in Untersuchungshaft. Davon waren insgesamt 128 Jugendliche und 222 Heranwachsende in Baden-Württemberg inhaftiert. Seit Bestehen der Einrichtung der Untersuchungshaft werden deren schlechten Vollzugsbedingungen kritisiert, die sich nachteilig auf die Entwicklung der Untersuchungshäftlinge auswirken können: Bereits durch den Freiheitsentzug sind die Jugendlichen zumeist erheblichen psychischen Belastungen ausgesetzt; hinzu kommen Raumnot, eine unzureichende Betreuung, Sprachschwierigkeiten und ein erhebliches Gewaltpotential in den Anstalten.

Bereits seit mehreren Jahrzehnten bestehen in der Bundesrepublik Deutschland Bestrebungen, Untersuchungshaft bei jugendlichen und heranwachsenden Rechtsbrechern durch die Unterbringung in Einrichtungen der Jugendhilfe zu ersetzen. Gemäß § 72 IV JGG kann unter denselben Voraussetzungen, unter denen ein Haftbefehl erlassen werden kann, auch die einstweilige Unterbringung in einem Heim der Jugendhilfe angeordnet werden.

Baden-Württemberg hat sich bei der Einführung derartiger Einrichtungen als eines der ersten Bundesländer engagiert. So gehörte das Heinrich-Wetzlar-Haus im Landesjugendheim Schloss Stutensee zu den ersten spezialisierten Einrichtungen, die in Deutschland ausschließlich zur Vermeidung von Un- 
tersuchungshaft bei Jugendlichen eingerichtet wurden. Diese Einrichtung ist eine der wenigen in Deutschland, die die Jugendlichen für eine bestimmte Zeit geschlossen unterbringt. In Stuttgart befindet sich ein durch die Sozialberatung Stuttgart e.V. geführtes offenes Haus, in dem u.a. Haftvermeidung für Heranwachsende praktiziert wird. Weitere Einrichtungen der Jugendhilfe nehmen zumindest eine kleine Anzahl Jugendlicher nach $§ 72$ IV JGG auf. Daneben wurden zwischenzeitlich neue Wege der Haftvermeidung beschritten, indem nach Hamburger Vorbild Heranwachsende, für die die $\S \S 71$, 72 und 72a JGG gemäß § 109 JGG nicht gelten, zum Zwecke der Haftverschonung, d.h. nachdem sie sich bereits in Untersuchungshaft befunden hatten, in Jugendarrestanstalten untergebracht wurden. Rechtsgrundlage der Unterbringung war in diesen Fällen $\S 116$ StPO. Diese Form der Haftvermeidung wird jedoch nur noch vereinzelt praktiziert.

Der erste Teil der Untersuchung beschäftigt sich mit der Situation der Untersuchungshaft für Jugendliche. Nach einer Erarbeitung der normativ-theoretischen Grundlagen sowie den Hauptkritikpunkten der Untersuchungshaft schließt sich ein praktischer Teil an, in welchem am Beispiel der Haftabteilung der Justizvollzugsanstalt Freiburg sowohl die Haftsituation hinsichtlich der Belegung und der sozialen Faktoren der Inhaftierten als auch der Haftalltag hinsichtlich der pädagogischen Angebote im Vollzug empirisch untersucht wird. Durch die JVA wurden zu diesem Zweck anonymisierte Daten zur Belegungssituation sowie zu biographischen Faktoren der Jugendlichen zur Verfügung gestellt, welche aufbereitet und durch Interviews mit Mitarbeitern aus unterschiedlichen Bereichen des Justizvollzuges ergänzt werden.

Der zweite Teil der Arbeit beschäftigt sich mit den Alternativen zur Haft durch Einrichtungen der Jugendhilfe. Auch hier wurden die theoretischen Grundlagen sowie der bisherige Stand der empirischen Forschung erarbeitet. Sodann sollen in erster Linie die folgenden Fragen erörtert werden:

1. Welche unterschiedlichen Konzeptionen zur Haftvermeidung gibt es in Baden-Württemberg und wie werden diese von den im Bereich des Jugendstrafrechts tätigen Praktikern angenommen?

2. Welche Jugendlichen kommen zur Haftvermeidung in Betracht? Neben den zumeist vorhandenen Vorgaben der Jugendhilfeeinrichtungen (z.B. kein Drogenkonsum der Jugendlichen, ausreichende Deutschkenntnisse etc.) stellt sich die Frage, ob z.B. Richter bestimmte Faktoren wie das begangene Delikt oder biographische Faktoren des Jugendlichen als bestimmend zur Anordnung einer alternativen Unterbringung statt der Haft ansehen.

3. Welche Erfolge oder Defizite gibt es im Bereich der Zusammenarbeit von Justiz und Jugendhilfe?

Zur Klärung dieser Fragestellungen wurden zunächst unterschiedliche Einrichtungen in BadenWürttemberg hinsichtlich ihrer Konzeption, Organisation und Insassenstruktur der Jahre 2000/2001 untersucht. Da zahlreiche Jugendhilfeeinrichtungen lediglich zeitweilig Plätze zur Haftvermeidung anbieten, war diesbezüglich eine Gesamterhebung nicht möglich; vielmehr galt es, möglichst viele unterschiedliche Konzeptionen exemplarisch gegenüberzustellen. Diese Untersuchungen basieren methodisch auf durch die Einrichtungen zur Verfügung gestelltes Material sowie problemorientierten Interviews mit den vor Ort tätigen Mitarbeitern.

Darauf aufbauend werden Jugendrichter, Jugendstaatsanwälte, Jugendgerichtshelfer und Strafverteidiger in ganz Baden-Württemberg zu ihren Erfahrungen und ihren Eindrücken von derartigen Einrichtungen befragt.

Eine Untersuchung in Baden-Württemberg bietet sich an, da sich hier sowohl geschlossene als auch teilgeschlossene und offene Einrichtungen finden. Die unterschiedliche Akzeptanz dieser Konzepte durch die justizielle Praxis zeigt sich an den stark voneinander abweichenden Einweisungszahlen in die verschiedenen Häuser.

Durch die Analyse der Ergebnisse der Befragung sollen mögliche Problemlagen im Bereich der Untersuchungshaftvermeidung aufgezeigt werden und Perspektiven für die zukünftige Gestaltung der Haft- 
vermeidung entwickelt werden. Die tatsächlichen Gegebenheiten betreffend die Einrichtungen zur Untersuchungshaftvermeidung sollen der Wahrnehmung durch die Praktiker gegenübergestellt werden. Entscheidendes Kriterium für die Häufigkeit des Erlasses eines Unterbringungs- statt eines Haftbefehls ist nicht nur die bereits häufig diskutierte (und nicht selten kritisch bewertete) Zusammenarbeit der unterschiedlichen Berufsgruppen, sondern auch die grundsätzliche Haltung der Praktiker zu Einrichtungen zur Untersuchungshaftvermeidung. Hier stellt sich die Frage, welche Faktoren gerade auch der Einrichtungen in ihrer Organisation von den Praktikern für gut befunden oder in Frage gestellt werden, sodass eine insgesamt befürwortende oder ablehnende Haltung entwickelt wird.

Im Rahmen der Befragung der Jugendrichter und Jugendstaatsanwälte war eine Gesamterhebung geplant, weswegen als Erhebungsinstrument für diese Befragung lediglich ein schriftlich durch die Praktiker auszufüllender standardisierter Fragebogen in Betracht kam. Nach der Datenerhebung bei den Richtern und Staatsanwälten in der ersten Jahreshälfte wurden anhand einer ersten Auswertung der Ergebnisse Interviewleitfäden entwickelt, anhand derer in der zweiten Jahreshälfte ergänzende qualitative Interviews sowohl mit Richtern und Staatsanwälten als auch mit Jugendgerichtshelfern und Strafverteidigern geführt werden.

- $\quad$ Arbeitsbericht 2002/2003:

Nach einer ersten Auswertung relevanter Literatur wurden im Frühjahr 2002 die Einrichtungen zur Haftvermeidung untersucht. Aus den gewonnenen Erkenntnissen wurden Fragebögen für die schriftliche Befragung der Jugendrichter und Jugendstaatsanwälte erarbeitet, welche Anfang Dezember 2002 versandt wurden. Parallel wurde mit der Niederschrift der Arbeit begonnen. Die Datenerhebung aus der schriftlichen Befragung sowie die Eingabe der Daten wurden im März 2003 abgeschlossen. Nach einer ersten Auswertung wurde ein Interviewleitfaden entwickelt, anhand dessen bis Ende 2003 ergänzende qualitative Interviews sowohl mit den Richtern und Staatsanwälten als auch mit Jugendgerichtshelfern und Strafverteidigern geführt werden.

- $\quad$ Arbeitsplanung 2004:

Nach einer weiteren Analyse der erlangten Daten ist im Frühjahr 2004 die Fertigstellung der Arbeit vorgesehen.

\subsection{2 "Gefährliche Straftäter": Rückfall und Behandlung}

\subsubsection{Sexuelle Gewalt im Lebenslängsschnitt}

In der Freiburger Kohortenstudie werden schwerpunktmäßig die sexuellen Gewaltdelikte (Vergewaltigung und Nötigung) analysiert. Im Zentrum stand dabei die Frage, in wie weit sexuelle Gewalttäter der Gruppe der chronisch Delinquenten zuzuordnen sind? Aus einem breiten Spektrum von Auswertungsergebnissen sind hier zwei hervorzuheben: Die Alters(un)abhängigkeit polizeilicher Registrierungen sexueller Gewaltdelikte und die Häufigkeit allgemeiner Delinquenz bei Sexualtätern. Im Gegensatz zur üblichen age-crime-Kurve mit ihrem nach einem Maximum in den Jugendjahren abfallenden Verlauf zeigen die Registrierungsraten wegen sexueller Gewalt nach einem Anstieg während der Adoleszenz einen bis zum letzten ausgewerteten Alter (27 Jahre) konstanten Verlauf (s. Abbildung). Diese Konstanz legt eine Interpretation im Sinne chronischer Delinquenz nahe. Allerdings ist hier abgesehen von der Schwierigkeit von einem aggregierten Datenniveau auf individuelle Verläufe zu schließen - zu beachten, dass diese niedrige jährliche Rate von ca. 23 Registrierten / 100.000 sich zum überwiegenden Teil aus Erstregistrierungen ergibt. Über die Altersspanne von 14 bis 27 Jahren haben die Erstregistrierungen einen Anteil von fast $77 \%$ an den Registrierungen wegen sexueller Gewalt. Über 'alle Delikte' liegt dieser Anteil bei $28 \%$. 
Abbildung: Jährliche polizeiliche Prävalenzraten der männlichen Deutschen bei sexuellen Gewaltdelikten (mit logistischer Anpassung)

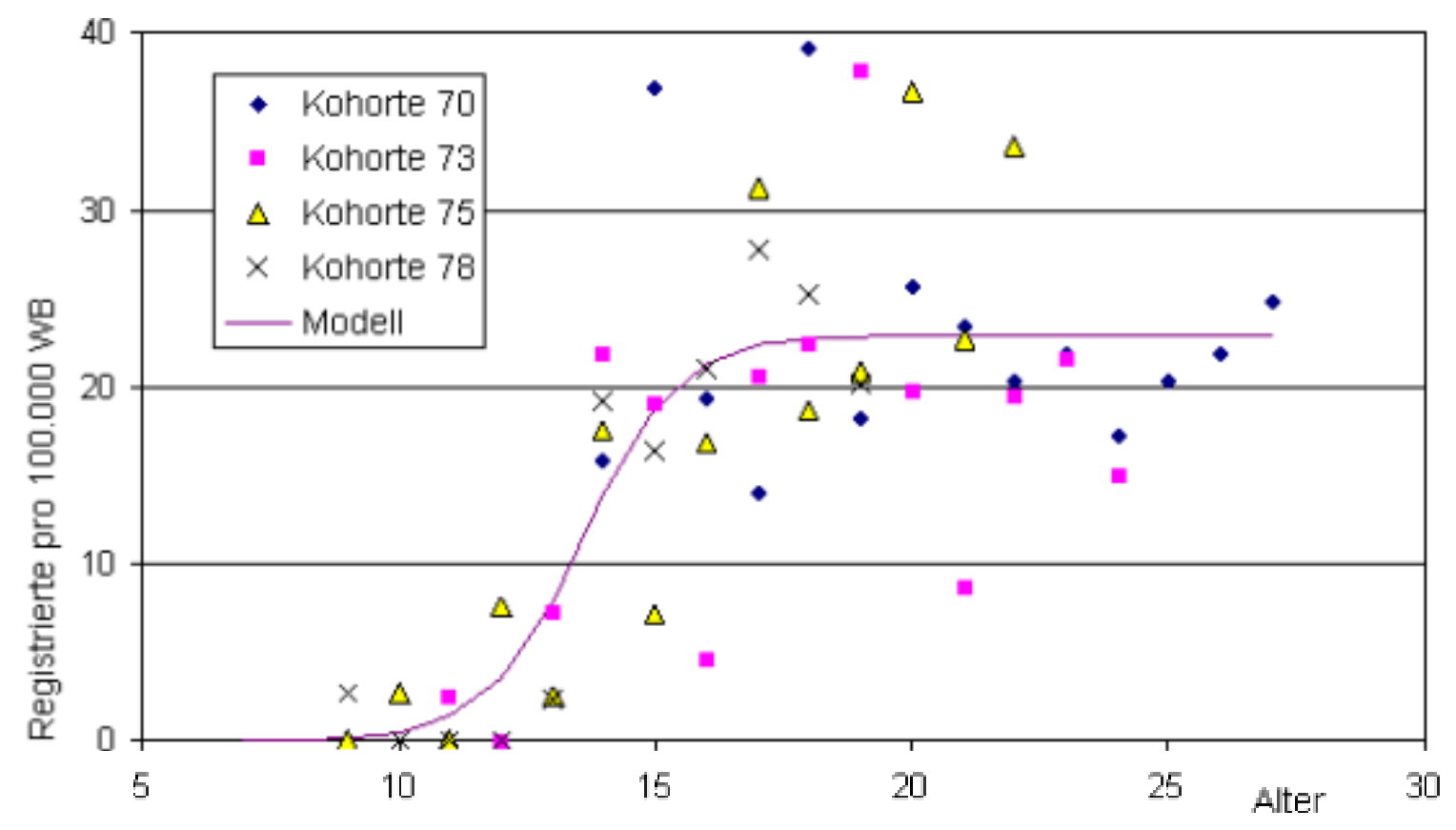

Weiter war festzustellen, dass die Registrierungshäufigkeit bezüglich beliebiger Delikte bei Personen, die u.a. bis zu einem Alter von 27 Jahren auch wegen sexueller Gewalt registriert sind, wesentlich höher ist als die derjenigen, bei denen kein Eintrag wegen sexueller Gewalt vorlag. So sind z.B. innerhalb eines vierjährigen Zeitraums (18-21 Jahre) über $40 \%$ der sexuellen Gewalttäter mehr als viermal registriert ( $25 \%$ einmal). Dies ist mit der Registrierungshäufigkeit von Jugendlichen zu vergleichen für die keine Registrierung wegen sexueller Gewalt vorlag (mehr als 4 mal $14 \%$, einmal $61 \%$ ). Auch dies weist darauf hin, dass es sich bei den wegen sexueller Gewalt registrierten zu einem großen Teil um chronisch Delinquente handelt. Allerdings sollten auch hier nicht die $25 \%$ übersehen werden, bei denen eine delinquente Handlung vereinzelt auftritt.

\subsubsection{Legalbewährung von Sicherungsverwahrten und gefährlichen Straftätern - eine Nachuntersuchung}

- $\quad$ Bearbeiter: Jörg Kinzig (Jurist)

- $\quad$ Zeitrahmen: 1999 bis 2004

- $\quad$ Projektstatus: in Bearbeitung

- $\quad$ Projektbeschreibung:

Am Max-Planck-Institut wurde in den Jahren von 1992 bis 1996 eine umfangreiche Studie zur Sicherungsverwahrung durchgeführt und im Jahr 1996 unter dem Titel "Die Sicherungsverwahrung auf dem Prüfstand" in der edition iuscrim veröffentlicht. 
Im Mittelpunkt dieser Arbeit steht eine empirische Untersuchung über die Anwendungspraxis der Sicherungsverwahrung und die zu ihr verurteilten Straftäter.

Die Studie gründete auf folgendem Datenfundament: Vom Bundeszentralregister (BZR) wurden für die Bundesländer Baden-Württemberg, Bayern und Nordrhein-Westfalen alle Aktenzeichen mit Anordnungen von Sicherungsverwahrung in den Jahren von 1981 bis 1990 gezogen. Insoweit handelte es sich um eine Vollerhebung. Zu diesen Fällen wurden alle diejenigen Anordnungen vor dem Jahr 1981 hinzugenommen, aufgrund derer in diesen drei Bundesländern Mitte des Jahres 1993 Sicherungsverwahrte noch oder schon wieder im Vollzug dieser Maßregel einsaßen. Insgesamt wurden auf diese Weise die Anlasstaten, Verfahren, Sanktionen, Gutachten und Legalbiographien von 318 zu Sicherungsverwahrung verurteilten Personen erfasst.

Da eine Fragestellung der damaligen Untersuchung darin bestand, den möglicherweise über das im Gesetz verankerte Merkmal des Hangs zu weiteren Straftaten hinaus bestehenden Kriterien nachzuspüren, nach denen die Anordnung dieser schärfsten Maßregel des deutschen Strafrechts erfolgt, war die Bildung einer Kontrollgruppe notwendig. In diese wurden alle Straftäter aufgenommen, die in den drei genannten Bundesländern in den Jahren 1988-1990 wegen Sexual-, Raub- oder Erpressungsdelikten verurteilt worden waren und die außerdem die formellen Voraussetzungen für die Anordnung von Sicherungsverwahrung nach $\S 66$ Abs. 1 a.F. StGB erfüllt hatten. Bei ihnen aber durfte die Maßregel, aus welchem Grund auch immer, nicht angeordnet worden sein. So ergab sich eine Kontrollgruppe, die aus weiteren 183 Personen bestand.

Die Legalbewährungsergebnisse der entlassenen Sicherungsverwahrten erwiesen sich zum Zeitpunkt der Hauptuntersuchung als überraschend günstig. Jedoch war der Legalbewährungszeitraum bei einigen Probanden wegen der vorangehenden langen Haft- bzw. Sicherungsverwahrungszeiten noch zu kurz, um valide Aussagen treffen zu können.

Mittlerweile sind seit dem ersten Untersuchungszeitpunkt mehr als zehn Jahre vergangen, so dass jetzt fundiertere Berechnungen über die Legalbewährung dieser insgesamt 501 Probanden möglich sind. Die oben genannte Anschlussuntersuchung soll im Sinne einer Längsschnittstudie die weitere (strafrechtliche) Entwicklung dieser Personen (ehemals Sicherungsverwahrter sowie Probanden der Kontrollgruppe) beleuchten. Behandelt werden sollen Fragen der Legalbewährung wie der justitiellen Karriere, wobei der Vergleich zwischen Sicherungsverwahrungs- und Kontrollgruppe besonders ertragreich zu werden verspricht. Geplant sind auch Quervergleiche dieser beiden Gruppen besonders hoch belasteter Straftäter zu ausgewählten Straftätern (vor allem Sexual- und Gewalttäter) aus der Freiburger Kohortenuntersuchung.

Eine besondere Aktualität erhält die Studie durch eine ganze Reihe von Gesetzen, die zwischenzeitlich auf diesem Gebiet in Kraft getreten sind.

Zunächst hat das "Gesetz zur Bekämpfung von Sexualdelikten und anderen gefährlichen Straftaten" vom 26.1.1998 Änderungen sowohl bei den Anordnungsmodalitäten der Sicherungsverwahrung wie bei den Kriterien gebracht, nach denen die Entlassung aus der Sicherungsverwahrung zu verfügen ist. Im Frühjahr 2001 hat Baden-Württemberg als erstes Bundesland (und ihm folgend Bayern sowie Sachsen-Anhalt) mit dem Gesetz über die Unterbringung besonders rückfallgefährdeter Straftäter (LTDr 12/6037) einen landesrechtlichen Weg eingeschlagen, um im Wege des Polizeirechts mittels einer so genannten nachträglichen Sicherungsverwahrung eine Unterbringung von Strafgefangenen über das Ende ihrer Freiheitsstrafe hinaus zu ermöglichen, wenn von ihnen eine erhebliche gegenwärtige Gefahr für bestimmte höchstpersönliche Rechtsgüter ausgeht. Schließlich hat der Bund mit dem Gesetz zur Einführung der vorbehaltenen Sicherungsverwahrung (vom 21.8.2002, BGBl 2002, 3344) eine weitere Variante dieser Maßregel verabschiedet. Gesetzentwürfe, die den Anwendungsbereich der Sicherungsverwahrung noch weiter ausdehnen wollen, liegen bereits vor. 
Damit stellt die strafrechtliche Behandlung vor allem schwerer Sexualstraftäter nach wie vor einen Brennpunkt der kriminalpolitischen Diskussion dar. Obwohl sich die kriminologischen Bemühungen um diese Tätergruppe verstärkt haben, fehlt es unverändert an aussagekräftigen Untersuchungen über die als besonders gefährlich angesehenen Straftäter, die ja vor allem mit der Maßregel der Sicherungsverwahrung erfasst werden sollen.

- $\quad$ Arbeitsbericht 2002/2003:

Nach weitgehendem Abschluss des Habilitationsprojektes des Verfassers über "Die rechtliche Bewältigung von Erscheinungsformen organisierter Kriminalität" (s. dort) konnten die Arbeiten an dieser Studie im Herbst 2003 wieder verstärkt aufgenommen werden. Derzeit laufen die Erfassung und Aufbereitung der Bundeszentralregisterdaten.

Diese sind allerdings deswegen mit gewissen Schwierigkeiten verbunden, weil ein Teil der Bundeszentralregisterdaten ersichtlich unvollständig ist. Probleme bereitet es vor allem, dass nur zum Teil das Datum der Entscheidungen der Strafvollstreckungskammern erfasst ist, in denen Strafen, vor allem aber Maßregeln zur Bewährung ausgesetzt werden. In diesem Fall kann allenfalls über die zumeist vermerkte Dauer der Führungsaufsicht auf den Zeitpunkt der Entlassung aus der Strafe bzw. der Maßregel geschlossen werden. Da jedoch für die genaue Berechnung der Rückfallzeiträume diese Daten vorliegen müssen, wird in einem vorrangigen Schritt darüber zu befinden sein, für welche Probanden unter Umständen Vollstreckungshefte anzufordern sind.

Derzeit ist in Überlegung, die mit der Erfassung der Bundeszentralregisterdaten verbundenen methodischen Schwierigkeiten in einem Aufsatz zu dokumentieren.

- $\quad$ Arbeitsplanung 2004:

Die angeforderten Daten aus den BZR-Auszügen sind zunächst einzugeben und mit den Ausgangsdaten zu verknüpfen. Danach sollen zunächst Fragen der Legalbewährung von Sicherungsverwahrungs- wie Kontrollgruppe im Vergleich, sodann solche der kriminellen Karriere bearbeitet werden.

- Zum Projekt vorliegende Veröffentlichungen (Auszug):

KINZIG, J., Die Sicherungsverwahrung auf dem Prüfstand, Freiburg i.Br. 1996 (Ausgangsstudie).

BECKER, M. \& KinZIG, J., Therapie bei Sexualstraftätern und die Kosten: Von den Vorstellungen des Gesetzgebers und den Realitäten im Strafvollzug. Zeitschrift für Strafvollzug und Straffälligenhilfe 47, 259-264 (1998).

KINZIG, J., Die Sicherungsverwahrung: ein geeignetes Instrument zum Schutz vor gefährlichen Straftätern? In: Kriminalität, Prävention und Kontrolle. Hrsg. D. Rössner, J.-M. Jehle. Heidelberg 1999, 281-294.

KINZIG, J., Schrankenlose Sicherheit? - Das Bundesverfassungsgericht vor der Entscheidung über die Geltung des Rückwirkungsverbots im Maßregelrecht, Strafverteidiger 20, 330-335 (2000).

KINZIG, J., Sicherungsverwahrung: Perspektive für nichtsozialisierungsfähige Jugendliche? In: Kinder- und Jugendkriminalität. Über den Umgang mit einem gesellschaftspolitischen Sprengsatz (Perspektiven und Konzepte). Hrsg. G. Gehl. Weimar 2000, 123-141.

KINZIG, J., Sicherungsverwahrung. In: Reform des strafrechtlichen Sanktionensystems. Hrsg. Strafrechtsausschuß des Deutschen Anwaltvereins. Bonn 2000, 106-107.

KINZIG, J., Als Bundesrecht gescheitert - als Landesrecht zulässig? Das neue baden-württembergische Gesetz über die Unterbringung besonders rückfallgefährdeter Straftäter, Neue Juristische Wochenschrift 54, 1455-1459 (2001).

KINZIG, J., Neues von der Sicherungsverwahrung - ein Überblick über den Stand der Gesetzgebung -. Strafverteidiger 22, 500-504 (2002). 
KINZIG, J., Das Gesetz zur Einführung der vorbehaltenen Sicherungsverwahrung. Neue Juristische Wochenschrift 55, 3204-3208 (2002).

KINZIG, J., Verhältnismäßigkeit fraglich: Problematische Sanktion im Strafrecht. Frankfurter Rundschau vom 21.7.2003, 8.

\subsubsection{Opfer von Sexualstraftaten}

- $\quad$ Bearbeiter: Joachim Obergfell-Fuchs (Psychologe)

- $\quad$ Zeitrahmen: 1999 bis 2003

- $\quad$ Projektstatus: abgeschlossen

- Projektbeschreibung:

(vgl. dazu bereits die Tätigkeitsberichte 1998/1999, S. 135; 2000/2001, S. 164)

In den vergangenen Jahren ist, nicht zuletzt auf der Grundlage besonders schwerer Fälle sexueller Straftaten gegen Kinder, eine intensive Diskussion zum Thema Sexualstraftaten geführt worden. Dabei stand jedoch in erster Linie der Umgang mit den Tätern im Vordergrund. So wurde auf der einen Seite durch die Verabschiedung neuer Gesetze, so z.B. dem "Gesetz zur Bekämpfung schwerer und Sexualstraftaten" von 1998 oder der baden-württembergischen Fassung des Straftäterunterbringungsgesetzes aus dem Jahr 2001, versucht, durch verstärkte Repression die Bürger vor Sexualstraftaten, insbesondere durch Rückfalltäter, zu schützen. Auf der anderen Seite wurde vermehrt die Forderung nach effektiven therapeutischen Intervention für die Täter gestellt, wenngleich hier in Deutschland bislang nur zögerliche Fortschritte erzielt wurden.

Zwar wurde bereits durch das 1976 eingeführte Opferentschädigungsgesetz sowie das 1987 in Kraft getretene Opferschutzgesetz sowohl die finanzielle Unterstützung für Verbrechensopfer sowie deren Stellung im Strafverfahren verbessert und auch im Zusammenhang mit den genannten repressiven Maßnahmen gegenüber Tätern werden immer wieder Belange des Opferschutzes in den Mittelpunkt gerückt, eine evaluierte flächendeckende psychische Betreuung der Opfer ist jedoch in Deutschland bislang nicht verwirklicht. So bieten der Weisse Ring als bundesweite Opferhilfsorganisation mit zahlreichen Regionalbüros sowie viele lokale Beratungs- und Kriseninterventionsstellen oftmals intensive Hilfe für Opfer von Sexualdelikten an, inwieweit diese jedoch von den Betroffenen selbst als hilfreich erlebt werden, ist weitgehend unklar.

Ziel des Forschungsprojektes ist es, in erster Linie die Wirksamkeit von Opferhilfe bei Opfern schwerer Sexualstraftaten zu untersuchen. Dabei wird, ausgehend von verschiedenen situationsbezogenen Opfertypen, zunächst das Verhalten der Opfer und der Täter vor und nach der Tat betrachtet. Eine wichtige Frage hierbei ist, wie es zur Viktimisierungssituation kam und welche Reaktionen danach erfolgten. Darauf aufbauend wird untersucht, welche Rolle die verschiedenen Hilfsangebote (z.B. Beratungsstellen, Psychotherapie, Selbsthilfegruppen) für die Bewältigung der erlittenen Straftat spielen. Das heißt, gibt es Formen der Hilfe welche eine Bewältigung erleichtern und welche Strukturen sind hierbei relevant. Es wird angenommen, dass Opferhilfen, die eine umfassende, tiefergehende und die Lebensumstände berücksichtigende Intervention beinhalten (z.B. Psychotherapie) eher zur Bewältigung post-traumatischer Stressstörungen beitragen als nur beratende oder allgemein unterstützende Angebote (z.B. Beratungsstellen, Selbsthilfegruppen). Weiterhin wird angenommen, dass Opfergruppen, die umfassende und tiefergehende Hilfe erhalten rascher und nachhaltiger sich von posttraumatischen Stresssymptomen erholen als die anderen Gruppen.

Darüber hinaus spielt die Reaktion des sozialen Umfeldes eine wichtige Rolle in der Bewältigung des Viktimisierungserlebnisses. Es wird davon ausgegangen, dass verständnisvolle und unterstützende Reaktionen durch relevante Angehörige des sozialen Nahraums (z.B. Partner, Freunde, Verwandte oder 
Arbeitskollegen) einen positiven Einfluss auf die Erholung von post-traumatischen Belastungsstörungen haben. Dabei stellt sich die Frage, inwieweit sich differentielle Unterschiede, z.B. aufgrund der Beziehungsnähe zum Opfer, feststellen lassen.

Diese Informationen sollen durch die Befragung von weiblichen Opfern schwerer Sexualstraftaten (Vergewaltigung, versuchte Vergewaltigung, sexuelle Nötigung) erhoben werden, als Datenquelle dient hierbei in erster Linie die Opferdatenbank des Weissen Rings. Daneben sollen weitere Informationen über den Zugang zur lokalen Opferhilfseinrichtung Frauenhorizonte in Freiburg gewonnen werden.

\section{- $\quad$ Arbeitsbericht 2002/2003:}

Nach den Vorarbeiten und einer umfangreichen Pretestphase im Jahr 2001 wurden in der ersten Jahreshälfte 2002 die empirischen Erhebungen anhand der beiden Stichproben "Weisser Ring" und "Frauenhorizonte" durchgeführt. Während durch den Weissen Ring eine Bruttostichprobe von 800 Personen vorgegeben wurde, stellte Frauenhorizonte den gesamten Adressenbestand der vergangenen 10 Jahre zur Verfügung $(n=396)$. Es zeigte sich jedoch rasch, dass in beiden Stichproben eine Vielzahl der Adressen veraltet war und entsprechend zahlreiche Fragebögen nicht zustellbar waren. Dies führte in der Gruppe "Weisser Ring" zu Nachziehungen und erneuter Versendung der als unzustellbar zurückkommenden Fragebögen. Nach Abschluss der Datenerhebungsphase lagen in der Stichprobe "Weisser Ring" 250 und in der Stichprobe "Frauenhorizonte" nur 50 auswertbare Fragebögen vor, die Rücklaufquoten bezogen auf die bereinigte Bruttostichprobe (Weisser Ring 800; Frauenhorizonte 236) betragen somit $31 \%$ bzw. $21 \%$. Da die Anlage der Untersuchung nicht auf Repräsentativität ausgerichtet war, sind die geringen Rücklaufquoten weniger problematisch, allenfalls die für Unterauswertungen rasch zu gering werdende Fallzahl ist kritisch.

In der zweiten Jahreshälfte 2002 konnten die umfangreichen Dateneingabearbeiten abgeschlossen und mit der Auswertung begonnen werden. Im Folgenden werden einige zentrale Forschungsergebnisse berichtet. Es ergab sich eine Reihe von Unterschieden zwischen den beiden Stichproben: Während z.B. in der bundesweiten Stichprobe des Weissen Rings eine breite Verteilung über alle Bildungsabschlüsse vorhanden war, waren die Frauen der auf die Region Freiburg konzentrierten Stichprobe Frauenhorizonte überwiegend hoch gebildet. Dies entspricht zwar der Bevölkerungszusammensetzung Freiburgs, zeigt aber, dass die beiden Stichproben nicht unbedingt miteinander vergleichbar sind. Dies konnte auch durch weitere Analysen bestätigt werden, was darauf hindeutet, dass die Kontaktaufnahme zu einer Beratungsstelle durchaus auch von demographischen Faktoren und Einstellungen zur bzw. Erwartungen an die beratende Stelle abhängt.

Was die Opfercharakteristika anbelangt, so überwogen in beiden Stichproben Vergewaltigungsdelikte, geben in der Gruppe Weisser Ring 59 \% der Frauen an, sie seine Opfer einer vollendeten Vergewaltigung geworden, $19 \%$ berichteten von einer versuchten Vergewaltigung und $23 \%$ von einer sexuellen Nötigung. In der Gruppe Frauenhorizonte wurde aufgrund der kleinen Fallzahlen nur zwischen vollendeter Vergewaltigung (64 \%) und anderen Sexualdelikten (versuchte Vergewaltigung, sexuelle Nötigung) (36\%) unterschieden. Während es somit hinsichtlich der Viktimisierungsschwere kaum Unterschiede zwischen den beiden Gruppen gibt, lassen sich um so größere Differenzen in Bezug auf die Anzeigequote feststellen: Während in der Gruppe Weisser Ring immerhin $96 \%$ der Frauen die Tat bei der Polizei anzeigen, sind es in der Gruppe Frauenhorizonte nur $50 \%$. Dieser Unterschied dürfte durch die oftmals enge Kooperation zwischen Weissem Ring und der Polizei bedingt sein. Andererseits sind diese Zahlen auch Beleg dafür, dass beide Stichproben keinen Gradmesser für Sexualdeliktsopfer im Allgemeinen darstellen, hier wird in aller Regel von einer Anzeigequote von nur etwa $10 \%$ ausgegangen.

Von den anzeigenden Opfern berichteten $48 \%$ aus der Gruppe Weisser Ring, dass bereits eine Gerichtsverhandlung gegen den Täter stattgefunden habe, in der Frauenhorizonte-Gruppe waren es 61 \%. 
Als Strafmaß überwog bei beiden Gruppen die unbedingte Freiheitsstrafe (Weisser Ring $58 \%$; Frauenhorizonte 50 \%). Dennoch war, abhängig von der Härte des gefällten Urteils, jeweils die Mehrheit der Frauen der Ansicht, dass das Strafmaß zu milde ausgefallen sei. Obwohl beide Opfergruppen die Verhandlung insgesamt als fair erlebten und die Prozessbeteiligten positiv bewerteten, war doch eine erhebliche psychische Belastung durch die Verhandlung festzustellen. Auf einer Skala von 1 (keine Belastung) bis 10 (extreme Belastung) lag das Mittel in der Gruppe Weisser Ring bei 9,09 und in der Gruppe Frauenhorizonte bei 8,54. Damit wurde - zumindest in der Gruppe Weisser Ring - die Verhandlung als belastender eingestuft als die Befragungen bei der Polizei (Weisser Ring 8,02; Frauenhorizonte 8,68$)$.

Hinsichtlich der durch den Weissen Ring erhaltenen Unterstützung konnte festgestellt werden, dass der relativ größte Anteil der Opfer (46\%) eine umfassende Unterstützung bestehend aus finanziellen Zuwendungen, Beratungsangeboten, Hilfen bei Behörden und weiteren Empfehlungen (z.B. Therapeuten) erhielt, etwa ein Viertel der Frauen erhielt dieses Angebot allerdings ohne finanzielle Zuwendungen. Die restlichen Frauen erhielten ein geringeres Angebot, etwa 9\% bekamen nur finanzielle Mittel. Da die Beratungsstelle Frauenhorizonte im Gegensatz zum Weissen Ring keine finanziellen Hilfen leisten kann, waren hier andere Schwerpunkte zu erwarten: Es zeigte sich jedoch, dass auch hier die Beratung der Opfer (82\%) im Vordergrund stand, ebenso wurden häufig Empfehlungen von Anwälten oder Therapeuten gegeben. Anders jedoch als beim Weissen Ring gab ein Viertel der Opfer an, eine durch Frauenhorizonte selbst durchgeführte gruppentherapeutische Behandlung erhalten zu haben. Dies zeigt, dass die beiden, in ihrer Struktur sehr unterschiedlichen Opfereinrichtungen sich in erster Linie in spezifischen Anteilen unterscheiden - auf der Seite Weisser Ring das finanzielle Hilfsangebot, auf Seiten Frauenhorizonte die selbst durchgeführte Therapie -, die "Angebotspalette" jedoch in vergleichbarer Form abgefragt wird.

Aus der Stichprobe Weisser Ring gaben $56 \%$ der Frauen an, dass sie eine Psychotherapie in Anspruch genommen hätten, hierbei dominieren eindeutig die ambulanten Therapieformen (70\%; $12 \%$ ambulant in Einrichtungen; 18 \% stationär). Während es hinsichtlich der Opferschwere und eines möglichen Stadt-Land-Gefälles keine bedeutenden Unterschiede gab, fiel auf, dass Opfer aus unteren sozioökonomischen Schichten deutlich seltener Psychotherapie erhielten, bei Frauen aus mittleren Bildungsund höheren Einkommensschichten war sie dagegen vergleichsweise häufig. Dies bestätigt Befunde aus der allgemeinen Psychotherapieforschung, wonach sozial schlechter Gestellte - nicht selten aufgrund von Vorurteilen gegenüber psychotherapeutischen Behandlungen - oftmals nicht den Weg in eine angemessene Therapie finden. Als Therapieformen wurde von den Frauen in erster Linie die Gesprächspsychotherapie genannt, dabei ist es allerdings für Laien in aller Regel schwer zu beurteilen, ob es sich tatsächlich um die gleichnamige Therapieform handelt oder aber um die - fast allen Therapien gemeinsame - Form des Dialogs. Darüber hinaus wurden fast durchweg verschiedene Kombinationen der Intervention genannt, dies entspricht auch dem mittlerweile gängigen Trend einer eklektischen Mischung von Therapieschulen.

In der Gruppe Frauenhorizonte war die Zahl der Frauen, die über das eigene Angebot von Frauenhorizonte hinaus Psychotherapie in Anspruch nahmen mit $69 \%$ größer als in der Gruppe Weisser Ring, auch hier standen mit $68 \%$ ambulante Therapieformen im Mittelpunkt. Dabei war die Zahl der verschiedenen Therapieschulen noch größer, erneut dominierten jedoch eklektische Ansätze.

Der Besuch anderer Beratungsstellen war in beiden Gruppen eher selten, während $28 \%$ der Frauen aus der Weisser Ring Gruppe weitere Beratungsstellen aufsuchten, waren es in der Gruppe Frauenhorizonte $29 \%$. Selbsthilfegruppen wurden ebenfalls eher selten aufgesucht, wenngleich der Anteil in der Gruppe Frauenhorizonte (16\%) in etwa doppelt so groß war wie in der Gruppe Weisser Ring (7\%).

Ein besonderes Schwergewicht der Auswertung wurde auf die Frage der Bewertung der unterschiedlichen Formen erhaltener Unterstützung gelegt. Hierzu wurde in das Instrument eine Fülle von Variab- 
len aufgenommen. Als besonders aussagekräftig erwies sich dabei die anhand einer 10-stufigen Skala gegebene Bewertung wie hilfreich die erhaltene Unterstützung für die Bewältigung des Ereignisses gewesen sei (1 gar nicht hilfreich ... 10 extrem hilfreich). Abbildung 1 zeigt die Ergebnisse für beide Gruppen im Überblick.

\section{Abbildung 1: $\quad$ Bewertung der Hilfseinrichtungen im Hinblick auf die Bewältigung der Viktimisierung}

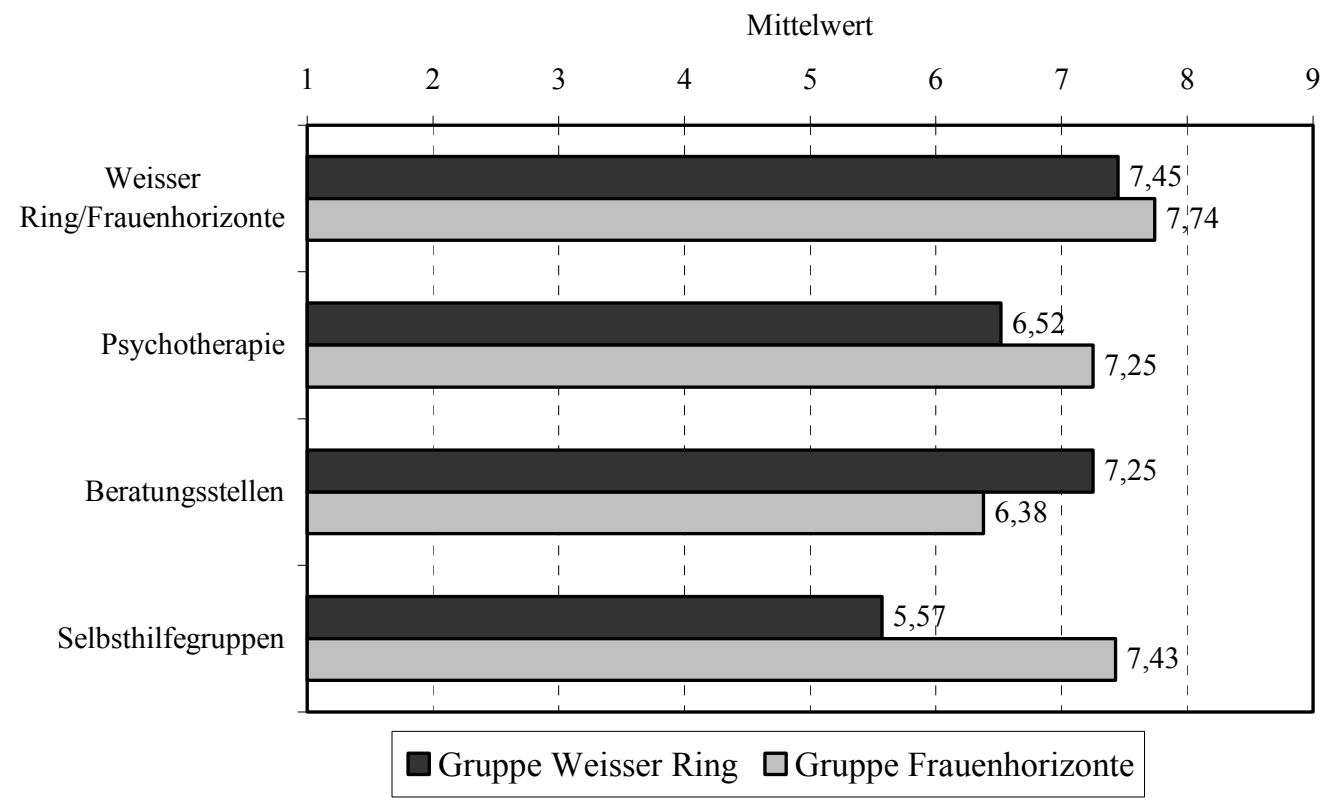

Die Abbildung zeigt, dass Weisser Ring und Frauenhorizonte von den jeweiligen Gruppen relativ gleich bewertet werden, in beiden Fällen geben die Frauen an, von dieser Unterstützung am meisten profitiert zu haben. Während jedoch in der Gruppe Weisser Ring die Tätigkeit anderer Beratungsstellen hilfreicher bewertet wird als Psychotherapie und Selbsthilfegruppen, ist dies bei der Frauenhorizonte-Gruppe umgekehrt. Dies könnte darauf hindeuten, das Sexualdeliktsopfer die Kontakt zum Weissen Ring suchen stärker an Beratung und Unterstützung orientiert sind, wohingegen der Kontakt zu Frauenhorizonte eher von Frauen gesucht wird, die Psychotherapie oder auch das Klima von Selbsthilfegruppen bevorzugen. Hier könnten die oben genannten Bildungsunterschiede eine gewisse Rolle spielen. Nicht auszuschließen ist allerdings, dass durch den spezifischen Kontakt derartige Präferenzen erst geschaffen werden.

Ein weiteres auffallendes Ergebnis kann man feststellen, wenn man innerhalb der Gruppe Weisser Ring der Frage nachgeht, welche erhaltenen Formen der Unterstützung mit einer besonders positiven Bewertung verbunden sind. Hier zeigt Abbildung 2, dass die erhaltenen Hilfen dann als besonders positiv bewertet werden, wenn sie möglichst umfassend sind. So zeigt ein Vergleich der ersten und letzten abgebildeten Kategorie, dass z.B. der Wegfall finanzieller Hilfe zu einer deutlichen Verschlechterung der Bewertung führt, was dafür spricht, dass auch Geldleistungen zur subjektiven Bewältigung des Viktimisierungsgeschehens beitragen können. 
Abbildung 2: $\quad$ Art der erhaltenen Unterstützung durch den Weissen Ring und deren Bewertung im Hinblick auf die Bewältigung der Viktimisierung

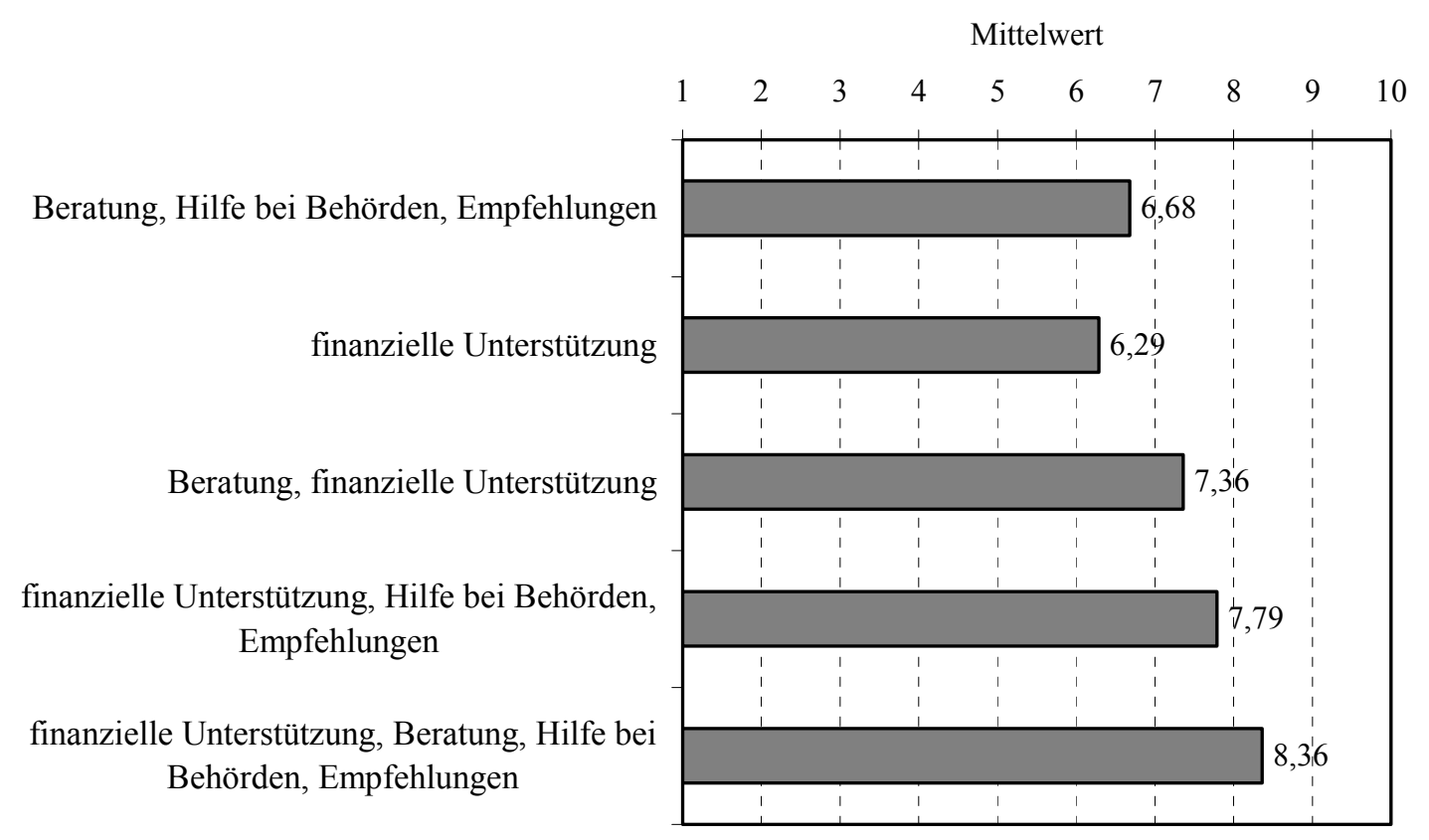

Hinsichtlich eines möglichen Einflusses des sozialen Nahraums auf die Bewältigung der Opferwerdung konnte zunächst gezeigt werden, dass nur wenige Frauen ihre Viktimisierung verheimlichen konnten oder wollten (Weisser Ring $1 \%$; Frauenhorizonte $4 \%$ ). Am häufigsten gelangte das Ereignis Freunden und Bekannten zur Kenntnis (Weisser Ring $91 \%$; Frauenhorizonte $84 \%$ ), gefolgt von Verwandten (jeweils $83 \%$ ) und dem Lebenspartner (61\%; $68 \%$ ). Deutlich seltener erfuhren Arbeitskollegen $(55 \% ; 36 \%)$ oder auch Nachbarn $(23 \% ; 11 \%)$ von der Viktimisierung.

Geht man der Frage nach, wie hilfreich die Unterstützung des sozialen Nahraums für die Bewältigung des erlebten Geschehens war, so findet man deutliche Unterschiede. Anhand einer vierstufigen Skala (1 "sehr hilfreich" ... 4 "überhaupt nicht hilfreich") war diese Information für den Partner, Freunde und Bekannte, Arbeitskollegen sowie Verwandte erhoben worden. Wie Abbildung 3 zeigt, wird in der Gruppe Weisser Ring die Unterstützung des Partners als besonders hilfreich empfunden, gefolgt von Freunden und Bekannten. In der Gruppe Frauenhorizonte stehen dagegen Freunde und Bekannte im Vordergrund, der Partner rangiert hier erst auf dem zweiten Platz. Zudem fällt auf, dass in dieser Gruppe die Unterschiede zwischen Freunden und Bekannten sowie dem Partner auf der einen Seite und Arbeitskollegen und Verwandten auf der anderen Seite deutlich größer sind als in der Gruppe Weisser Ring. Hier ist nicht auszuschließen, dass es sich um ein Charakteristikum der Stichprobe handelt, bereits oben wurde ein differentieller Zugang zu den Hilfsangeboten diskutiert. 
Abbildung 3: $\quad$ Bewertung des sozialen Nahraums im Hinblick auf die Bewältigung der Viktimisierung

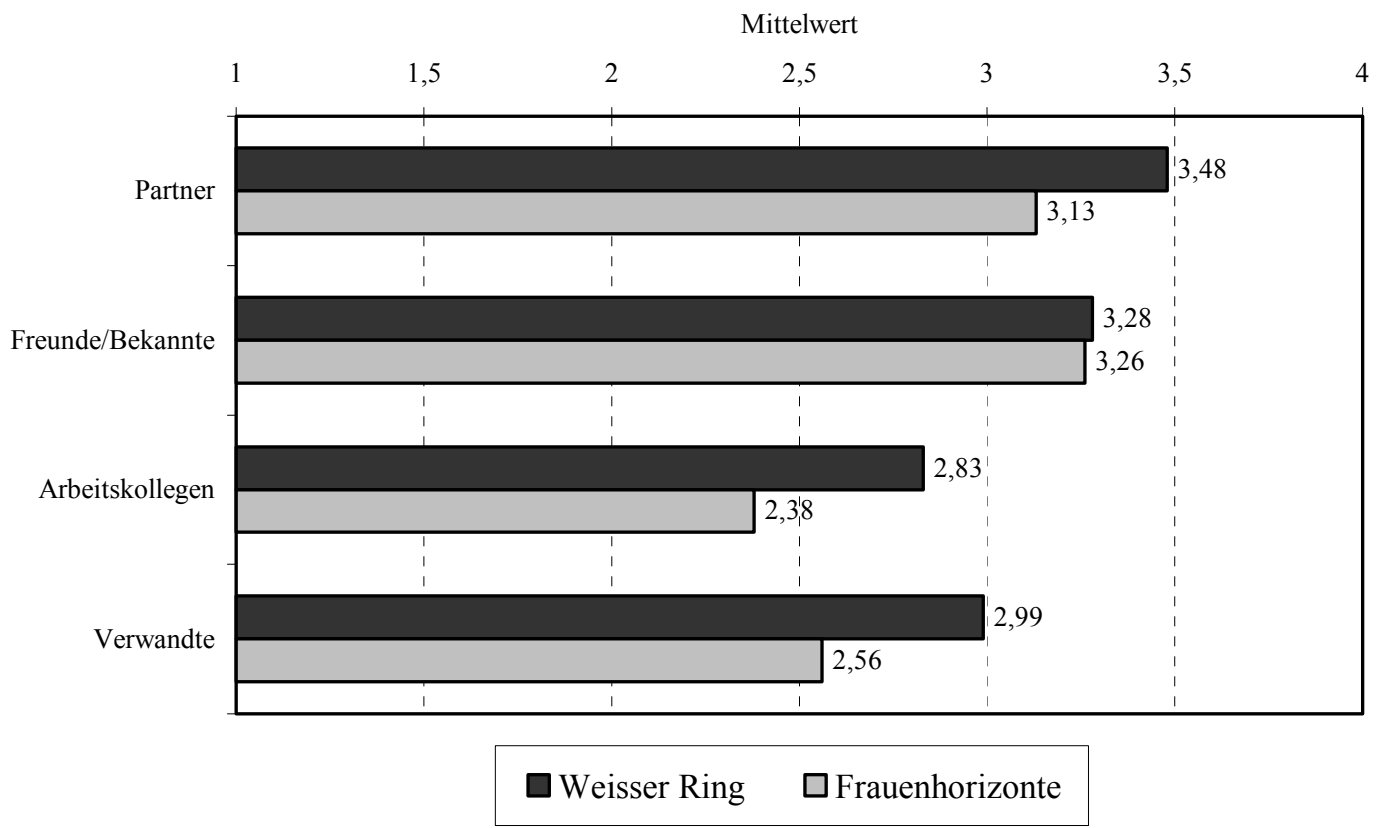

Anhand multivariater Analysen wurde schließlich geprüft, welches Gewicht den verschiedenen Faktoren - Hilfseinrichtungen, soziales Umfeld, sozioökonomischer Status und Viktimisierungsschwere für die Bewältigung der erlebten Sexualstraftat zukommt. Als Methode wurde dabei die Kategoriale Regressionsanalyse gewählt, welche den Vorteil bietet, dass auch nominal skalierte Prädiktoren aufgenommen sowie nicht-lineare Variablenzusammenhänge modelliert werden können. Als Kriteriumsvariablen dienten auf der einen Seite subjektive Angaben zur Verbesserung der aufgrund der Viktimisierung aufgetreten Symptomatik. Diese wurden faktorenanalytisch zu folgenden Symptombereichen zusammengefasst: "psychosomatische Störungen und Flashbacks", "Angst und Wut", "schwere psychosomatische Krankheitsbilder", "Autoaggressionen" und "Substanzmissbrauch". Auf der anderen Seite wurden die drei Skalen der Posttraumatische Belastungsstörungen erfassenden Impact of Event Scale (IES-R) von Maercker und Schützwohl (1998) "Intrusion", "Vermeidung" und "Übererregung" als Kriteriumsvariablen eingeführt. Da angesichts der kleinen Fallzahl die statistischen Modelle der Gruppe Frauenhorizonte nur wenig zufrieden stellend waren, sollen nur einige, statistisch signifikante Ergebnisse der Gruppe Weisser Ring dargestellt werden.

Im Hinblick auf "psychosomatische Störungen und Flashbacks" $(\mathrm{R}=.32)$ zeigt sich, dass eine positiv bewertete Unterstützung durch den Weissen Ring (beta $=.11$ ) sowie durch Psychotherapie (.16) mit einer Verbesserung der Symptomatik einherging. Dagegen ist die - ebenfalls positiv bewertete - Hilfe durch Arbeitskollegen (-.17) und Familienmitglieder (-.21) eher kontraproduktiv im Hinblick auf dieses Störungsbild. Bezüglich der Symptomatik "Angst und Wut" $(\mathrm{R}=.30)$ wirkt sich die Unterstützung durch Freunde und Bekannte (.14) sowie ein hoher sozioökonomischer Status (.13) positiv aus, negativ dagegen die Hilfe durch Arbeitskollegen (-.14). Was die Verbesserung "schwerer psychosomatischer Störungsbilder" $(\mathrm{R}=.40)$ anbelangt, erweisen sich Psychotherapie (.20), die Unterstützung durch Verwandte (.13) und ein hoher sozioökonomischer Status (.20) als wirksame Faktoren, es ergeben sich aber wenig hilfreiche Einflüsse durch die Unterstützung des Weissen Rings (-.17), Beratung im allgemeinen (-.13) und die Hilfe durch Freunde (-.11). Auch bezüglich "Autoaggressionen" $(\mathrm{R}=.34)$ zeigen sich differentielle Wirkfaktoren: Während die Unterstützung durch Kollegen (.13) einen positiven 
Einfluss auf die Verbesserung der Symptomatik hat, erweisen sich dagegen Psychotherapie (-.19), Beratung (-.13) und auch ein hoher sozioökonomischer Status (-.11) als ungünstige Faktoren. Was den "Substanzmissbrauch" ( $\mathrm{R}=.26$ ) betrifft, so ist die Zahl der signifikanten Einflussfaktoren gering, während Selbsthilfegruppen (.11) einen symptommindernden Einfluss zeigen, haben Beratungsstellen eher einen negativen Effekt (-.14).

Diese Ergebnisse zeigen, dass es weder hinsichtlich der angebotenen Hilfseinrichtungen noch im Hinblick auf die Unterstützung durch das soziale Netzwerk einen ausnahmslos wirksamen Faktor gibt. Vielmehr ist es, um ein Angebot optimal nutzen zu können, notwendig, eine genaue Analyse der vorliegenden Symptomatik vorzunehmen um dann - soweit möglich - die entsprechenden Interventionen darauf abzustimmen oder aber mit den möglichen negativen Konsequenzen, z.B. durch Bemühungen aus dem sozialen Umfeld, umzugehen.

Auch hinsichtlich der aktuelle vorhandenen Posttraumatischen Belastungsstörungen - erfasst anhand des IES-R - lassen sich differentielle Einflüsse feststellen: So verstärken die Interventionen durch den Weissen Ring (beta $=.12$ ) eher die "Intrusion" (z.B. immer wiederkehrende Gedanken an die Viktimisierung; $\mathrm{R}=.33)$, wogegen sie durch die Hilfe der Arbeitskollegen (-.13) oder auch durch einen hohen sozioökonomischen Status (-.17) gemildert wird. Schwerere Viktimisierungen, d.h. vollzogene Vergewaltigungen, haben ebenfalls einen symptomverstärkenden Einfluss (.15). Auf die "Vermeidung" (Vermeidung von Gedanken und Gefühlen; $\mathrm{R}=.41$ ) haben eine Fülle von Variablen Einfluss, so ist zunächst eine verstärkende Wirkung der Viktimisierungsschwere zu sehen (.15), ebenso aber auch durch die Unterstützung durch den Weissen Ring (.15), andere Beratungsstellen (.14) sowie durch Selbsthilfegruppen (.15). Gemildert wird die Vermeidung durch eine positiv bewertete Psychotherapie (-.16), sowie Unterstützung durch die Familie (-.19). Was die Übererregung betrifft $(\mathrm{R}=.34)$ so zeigt sich hier nur, dafür jedoch deutlich, ein mildernder Einfluss durch einen hohen sozioökonomischen Status (-.26). Was den Gesamtscore der Impact-of-Event Skala betrifft, d.h. das Vorliegen einer Posttraumatischen Belastungsstörung, so wird diese eher ungünstig beeinflusst durch die Unterstützung des Weissen Rings (.14) und die Schwere der Opferwerdung (.15). Positiv wirken sich dagegen Psychotherapie (-.12), die Unterstützung durch Kollegen (-.13) sowie ein hoher sozioökonomischer Status (-.20) aus. Damit sind die Ergebnisse hier eindeutiger als in Bezug auf die Symptomveränderungen. Es lassen sich klarer Wirkfaktoren herausarbeiten die einen positiven Einfluss auf Posttraumatische Belastungsstörungen haben bzw. solche, die trotz positiver Bewertung durch das Opfer, eher einen negativen Effekt zeigen. Insgesamt bestätigt sich hier die eingangs aufgestellte Hypothese, dass umfassende, tiefergehende und die Lebensumstände berücksichtigende Interventionen (Psychotherapie) zu einer geringeren Ausprägung post-traumatischer Belastungsstörungen beitragen als beratende Angebote (Weisser Ring).

Diese Ergebnisse sind nur ein kleiner Ausschnitt aus der Fülle der Gesamtresultate, deren Analyse in der zweiten Jahreshälfte 2003 abgeschlossen werden konnte und die mittlerweile in einem Gesamtmanuskript vorliegen, das 2004 in der Reihe des Weissen Ring erscheinen wird.

- $\quad$ Drittmittel: Das Projekt wurde mit Mitteln des Weissen Rings gefördert. 


\subsubsection{Sexualstraftäter in sozialtherapeutischen Anstalten des Freistaates Sachsen}

- $\quad$ Bearbeiter: Rüdiger Ortmann (Psychologe)

- $\quad$ Zeitrahmen: 2003 bis 2012

- $\quad$ Projektstatus: in Bearbeitung

- $\quad$ Projektbeschreibung:

Nach dem Gesetz zur Bekämpfung von Sexualdelikten und anderen gefährlichen Straftaten vom 26. Januar 1998 sollen ab Januar 2003 alle Sexualstraftäter mit mehr als zwei Jahren Freiheitsstrafe sozialtherapeutische Behandlung erhalten, sofern deren Behandlung "angezeigt" ist. Die neue Gesetzeslage schafft auch eine Herausforderung für die kriminologische Forschung, von der die Sozialtherapie auf diesem schwierigen und erst in Anfängen erforschten Gebiet wissenschaftlich begründete Orientierung erwarten kann. Auf diesem Hintergrund wurde in Kontakten mit dem Sächsischen Justizministerium und dem Lehrstuhl für Strafrecht, Kriminologie, Jugendstrafrecht und Strafvollzugsrecht der Technischen Universität Dresden ein Projekt des Max-Planck-Instituts und der TU Dresden ins Auge gefasst, das aus drei Modulen mit jeweils eigenen Zuständigkeiten besteht: Die Sozialtherapie in kriminalpolitischer Perspektive (Albrecht [MPI] \& Hefendehl [TU Dresden]), Sozialtherapie im Strafvollzug bei jugendlichen Gewalt- und Sexualstraftätern (ab Herbst 2003: Joachim Obergfell-Fuchs [MPI]) und die Studie zu Sexualstraftätern in sozialtherapeutischen Anstalten (Rüdiger Ortmann [MPI]).

- $\quad$ Arbeitsbericht 2002/2003:

Es wurde ein Positionspapier zu den Auswirkungen der neuen Gesetzeslage auf den Forschungsbedarf und mögliche Schwerpunkte zukünftiger Forschung zur Sozialtherapie geschrieben und dem Sächsischen Justizministerium Mitte 2001 vorgelegt. Das JM hat sodann im Sommer 2002 seine grundsätzliche Bereitschaft erklärt, ein entsprechendes Forschungsvorhaben zur Sozialtherapie zu unterstützen und mit einem substantiellen finanziellen Betrag zu fördern. In Besprechungen mit Vertretern des Freistaates Sachsen, an denen maßgeblich auch Therapeuten und Therapeutinnen der sächsischen Justizvollzugsanstalten Waldheim, Bautzen und Zeithain teilgenommen haben, wurden die Forschungschwerpunkte weiter präzisiert. Dabei wurde übereinstimmend festgestellt, dass es bei der Behandlung von Sexualstraftätern vor allem ein erhebliches Defizit im Theoretischen gibt, und dass das Projekt deshalb eine im Kern theoretische Ausrichtung braucht.

Auf dieser Grundlage wurde ein genauerer Forschungsplan für eine Studie zu erwachsenen Sexualstraftätern erarbeitet und dem JM im Dezember 2002 vorgelegt. Der Forschungsplan ist Teil des Forschungsvertrags mit dem JM, der nach dem erfolgreichen Abschluss der Gespräche und Verhandlungen im August 2003 unterzeichnet werden konnte.

Der Vertrag sieht, beginnend ab 1.1.2004, eine neunjährige Projektdauer vor und einen finanziellen Zuschuss des JM von 75.000 € im ersten und jeweils 70.000 € in den acht folgenden Jahren.

Zur Zeit werden die Datenschutzfragen des Projektes mit dem Sächsischen Datenschutzbeauftragten besprochen und MitarbeiterInnen für die externen Projektstellen (Psychologen) gesucht. Eine volle BAT-Stelle ist für die JVA Waldheim vorgesehen und eine halbe für die JVA Bautzen.

Nach dem Forschungsplan werden mit der Studie vorrangig drei Ziele verfolgt:

- Wissenschaftliches Hauptziel der Studie ist die Darstellung und Analyse der Rückfallkriminalität von Sexualstraftätern sowie der sie bedingenden (Stichwort "kriminogene Faktoren") oder auf sie Einfluss nehmenden (therapeutische Maßnahmen, Klima in der Anstalt) Faktoren bei erwachsenen Häftlingen, die nach der neuen Gesetzeslage in eine sozialtherapeutische Abteilung Sachsens (JVA Waldheim oder Bautzen) verlegt wurden. Zweitens gilt es, unter den neuen Rahmenbedin- 
gungen sozialtherapeutischer Anstalten zu einer fundierten Einschätzung ihrer Arbeitsmöglichkeiten zu gelangen sowie Vorschläge für Verbesserungen des sozialtherapeutischen Konzeptes zu ermöglichen. Ein drittes Ziel der Studie ist, einen Beitrag zur Verbesserung von Prognosen der Rückfallkriminalität von Sexualstraftätern zu leisten. Alle drei Ziele werden, wenn überhaupt, nur durch eine vorrangig der Theorie verpflichtete Studie erreichbar sein, und die Bearbeitung dieser drei Hauptziele der Studie steht in einem ganz engen Zusammenhang.

Eine wichtige Frage zur Theorie ist z.B., ob und inwieweit für Sexualstraftaten deliktspezifische Erklärungen erforderlich sind, welche theoretischen Begründungen und empirischen Belege hier vorhanden sind und welchen Stellenwert z.B. die viel beachtete allgemeine Kriminalitätstheorie von Hirschi \& Gottfredson, die ja gleichermaßen für alle Delikte gelten soll, in der Erklärung hat. Da ein großer Teil des Rückfalls von Sexualstraftätern nicht einschlägig, also keine neue Sexualstraftat, ist (Rückfall nach 5 Jahren bei Sexualstraftätern: alle Delikte 69.2 \%; nur Sexualdelikte $23.1 \%$ (Ortmann 2002: S. 506, S. 508)), haben Sexualstraftaten und andere Straftaten offenbar auch eine gemeinsame, deliktunspezifische Wurzel. Deshalb muss auch nach allgemeinen, deliktunspezifischen Erklärungen eines Sexualdeliktes gesucht werden. Auch darf man die Argumente nicht völlig ignorieren, die Hirschi \& Gottfredson für ihre Theorie vorbringen. Mit gleicher Begründung - theoretisch und empirisch - sollten sich Prognosen des Rückfalls, die Einschätzung ihrer Qualität und Bemühungen um eine Verbesserung der Prognosen auch nicht auf Sexualstraftaten beschränken. Auch der allgemeine Rückfall muss hier einbezogen werden, der im übrigen ja auch durchaus eine gefährliche Straftat sein kann. Jedenfalls scheinen Prognosen des Rückfalls von Sexualstraftätern zur Zeit kaum viel mehr als Korrelationen von etwa .30 zu erreichen. Dies ist natürlich ein sehr unbefriedigender Zustand.

Vorgesehen ist, außer Sexualstraftätern auch eine Stichprobe von Gewaltstraftätern zu berücksichtigen, um so einen Zugang zur Trennung der Sexual- und Gewaltkomponente in Fällen sexueller Gewalt zu haben. Auch dieser Punkt folgt der aus dem Forschungsstand ableitbaren Logik, dass man Sexualstraftaten am besten wird voraussagen können, wenn man sich nicht auf die Untersuchung von Sexualstraftätern und Sexualstraftaten beschränkt.

- Der Forschungsplan gliedert den Untersuchungsablauf in vier Studien. Studie 1, sie ist auf mehrere Jahre angelegt, gilt der Auswahl und Erfassung von für Erklärung und Prognose des Rückfallverhaltens von Sexualstraftätern relevanten Merkmalen (Stichwort: "kriminogene Merkmale") sowie der Prüfung und evtl. Verbesserung ihrer diagnostischen Erfassung nach den Kriterien der Testkonstruktion. Studie 2 untersucht die Phase der Inhaftierung und der Betreuung und Behandlung der Häftlinge, Studie 3 (Option) die Situation der ehemaligen Häftlinge nach der Entlassung aus der Haft und Studie 4 den Rückfall nach Bundeszentralregister.

\section{- $\quad$ Arbeitsplanung 2004:}

Zunächst müssen die Datenschutzfragen abschließend geklärt werden. Ferner sind die externen Projektstellen zu besetzen und die Projektmitarbeiter einzuarbeiten. Der Schwerpunkt der Arbeiten wird, sowie die beiden ersten Punkte zufrieden stellend abgeschlossen sind, bei der Aufnahme der konkreten, im Forschungsplan spezifizierten, Forschungsarbeiten liegen.

- $\quad$ Finanzierung: Sächsisches Justizministerium.

- $\quad$ Ausgewählte Literatur:

ORTMANN, R., Sozialtherapie im Strafvollzug. Eine experimentelle Längsschnittstudie zu den Wirkungen von Strafvollzugsmaßnahmen auf Legal- und Sozialbewährung. edition iuscrim, Freiburg i.Br. 2002, $681 \mathrm{~S}$. 


\subsubsection{Jugendliche Sexualstraftäter in sozialtherapeutischen Abteilungen des Freistaates Sachsen}

- $\quad$ Bearbeiter: Joachim Obergfell-Fuchs (Psychologe)

- $\quad$ Zeitrahmen: 2003 bis 2006

- $\quad$ Projektstatus: in Bearbeitung

- $\quad$ Projektbeschreibung:

Im Zuge der öffentlichen und politischen Diskussion um den Umgang mit Sexualstraftätern und des Schutzes der Allgemeinheit sind in den vergangenen Jahren nicht nur erwachsene Sexualstraftäter in das Blickfeld gelangt, auch jugendlichen und heranwachsenden Tätern wurde ein zunehmendes Interesse zuteil, oftmals unter dem Aspekt, dass der erwachsene Täter bereits als Jugendlicher durch einschlägige Sexualstraftaten auffällig wurde. Auch von den strafrechtlichen Veränderungen im Zusammenhang mit dem 1998 in Kraft getretenen "Gesetz zur Bekämpfung von Sexualdelikten und anderen gefährlichen Straftaten" sind jugendliche Sexualstraftäter betroffen. So wurde auch hier die Erprobungsformel für die Aussetzung des Restes der Freiheitsstrafe gestrichen und dagegen das Sicherheitsinteresse der Allgemeinheit hervorgehoben.

Eine Besonderheit bei der Betrachtung jugendlicher Sexualstraftäter ist die Erwartung, dass aufgrund der noch stark vorhandenen Entwicklungsfähigkeit Jugendlicher durch gezielte Interventionen einer Verfestigung des abweichenden Verhaltens entgegengewirkt und somit eine mögliche einschlägige kriminelle Karriere verhindert werden kann. Allerdings ist die Forschungssituation hinsichtlich des Problems des einschlägigen Rückfalls bei jugendlichen Sexualstraftätern äußerst heterogen. So reichen, je nach berücksichtigtem Zeitraum, die Rückfallquoten von nur etwa $4 \%$ bis hin zu $79 \%$. Zwischenzeitlich hat sich allerdings auch in der diesbezüglichen Forschung die Meinung durchgesetzt, dass chronische Sexualstraftaten bei Jugendlichen eher die Ausnahme als die Regel sind. Dennoch besteht für jugendliche Sexualstraftäter eine höhere Wahrscheinlichkeit als für die Allgemeinpopulation erneut ein Sexualdelikt zu begehen, unabhängig von der Art des begangenen Deliktes. Allerdings besteht hier ein Mangel an kontrollierten Langzeitstudien und die erhebliche Diskrepanz zwischen den Rückfallraten ist nicht zuletzt eine Folge unterschiedlicher Vorgehensweisen, z.B. Verlaufsstudien vs. (subjektive) retrospektive Erfassungen, aber auch der sehr heterogenen Rückfallzeiträume. Darüber hinaus spielen jugendspezifische Probleme eine nicht unbedeutende Rolle, so z.B. der Zugang zu den oftmals sensibleren Jugenddaten, die geringe Anzeigequote der häufig selbst jugendlichen Opfer aber auch das sich erst entwickelnde interpersonelle Sexualverhalten, das es schwierig macht, einen Fall eindeutig als Sexualstraftat einzuschätzen.

Auffallend bei jugendlichen Sexualstraftätern ist deren erhebliche Heterogenität, was in den vergangenen Jahren zu intensiven Forschungsbemühungen hinsichtlich einer Typologie führte. Neben einer Typisierung nach Art des jeweiligen begangenen Delikts als erster Unterscheidungsebene unterhalb welcher sich dann weitere Kriterien, z.B. soziale Kompetenz u.ä., wieder finden, findet zunehmend eine Typisierung anhand von Persönlichkeitsmerkmalen statt, welche eine bessere klinisch-psychologische Handhabbarkeit aufweist und damit auch größere Relevanz für die Behandlung jugendlicher Sexualstraftäter hat.

Gerade hinsichtlich der Therapie jugendlicher Sexualstraftäter ist, anders als beim erwachsenen Sexualstraftäter, eine Fokussierung auf das spezifische Delikt und dessen Entstehung erheblich zu kurz gegriffen, vielmehr müssen die zahlreichen, sich noch in der Entwicklung befindlichen Bereiche berücksichtigt werden. Dies betrifft die Sexualentwicklung ebenso wie die Entwicklung der persönlichen Identität oder die Entwicklung sozialer Rollen und Beziehungen. 
Allerdings liegen, im Unterschied zur Behandlung erwachsener Sexualstraftäter, bei Jugendlichen kaum kontrollierte Wirksamkeitsstudien vor. Zwar deutet sich - ähnlich wie in der Psychotherapieforschung allgemein - eine Überlegenheit kognitiv-verhaltenstherapeutischer Interventionen, insbesondere in Verbindung mit erzieherischen und unterstützenden Maßnahmen unter Einbeziehung des Familiensystems, an, die Datenlage ist jedoch bislang zu gering um von gesicherten Befunden sprechen zu können.

Den meisten der bislang durchgeführten Untersuchungen zur Wirkung von Behandlung bei jugendlichen Sexualstraftätern ist gemeinsam, dass sie das Kriterium der (einschlägigen) Legalbewährung in den Mittelpunkt stellen. Dieses Kriteriums des Auftretens einer erneuten Sexualstraftat - teils auch in Abgrenzung zu anderen nicht sexuellen Straftaten - ist sicherlich eine der zentralen Fragen der Behandlungsforschung, inwieweit jedoch psychologische Variablen durch die Behandlung dauerhaft verändert werden können, ist bislang in Bezug auf jugendliche Sexualstraftäter kaum untersucht worden. Dabei ist davon auszugehen, dass diese psychologischen Parameter, v.a. kognitiv-behaviorale Variablen, eine erhebliche Rolle für die Legalbewährung spielen. Darüber hinaus sind Aspekte der sozialen Integration nach Haftentlassung bedeutsam, hier besteht ebenfalls hinsichtlich der Gruppe jugendlicher Sexualstraftäter noch erheblicher Forschungsbedarf. Zudem liegen die meisten bisherigen Forschungsergebnisse aus Nordamerika vor, eine Übertragbarkeit z.B. auf Deutschland ist - auch angesichts der kulturellen Gebundenheit sexuellen Verhaltens - nicht zwingend gegeben.

Die geplante Untersuchung richtet sich zunächst auf Insassen der Justizvollzugsanstalt Zeithain in Sachsen, die hier als Jugendliche oder Heranwachsende nach Jugendstrafrecht wegen Sexualstraftaten untergebracht sind. Ziel der Untersuchung ist es, Ergebnisse dahingehend zu erlangen, wie die Sozialtherapie ausgestaltet werden soll, um so Bedingungen zu schaffen, die es ermöglichen einen Rückfall der jugendlichen Sexualstraftäter zu vermeiden und so einer einschlägigen kriminellen Karriere vorzubeugen. Dabei sollen - unter jugendspezifischen Gesichtspunkten - Kriterien einer Legalprognose entwickelt werden und diese möglichst anhand des registrierten Rückfalls auf der Grundlage des Bundeszentralregisters geprüft werden. Dabei soll der follow-up Zeitraum mindestens 3 Jahre betragen, darüber hinaus wäre jedoch ein längerfristiger follow-up Zeitrahmen wünschenswert.

Ein besonderer Schwerpunkt soll auf die Veränderung kognitiv-behavioraler Variablen wie auch sozialer Faktoren nach der Haftentlassung gerichtet werden. So sollen zu Beginn und zum Ende der Behandlung Ausgangswerte erhoben werden, die Erfassung der entsprechenden Parameter geschieht mittels standardisierter Befragungen. Auch anhand strukturierter persönlicher Interviews soll ein Verlauf des Rückfallrisikos erfolgen, dies geschieht unter Einsatz vorliegender Instrumente (z.B. SVR-20; PCL-R-SV). Nachbefragungen sind jährlich vorgesehen, ähnlich wie bei der o.g. Legalbewährung über einen Zeitraum von mindestens 3 Jahren, hier wird ebenfalls ein längerer follow-up Zeitraum angestrebt. Ein nicht zu vernachlässigendes Problem stellt allerdings die mögliche "experimental mortality" dar, d.h. eine fehlende Erreichbarkeit der Probanden nach Ende ihrer Haftzeit. Hier soll durch gezielte kontinuierliche Maßnahmen die Motivation der Beteiligten erhöht werden, auch für Nachbefragungen zur Verfügung zu stehen.

Da die Zahl der in der Sozialtherapie untergebrachten jugendlichen Sexualstraftäter sehr klein ist, soll die Untersuchung, soweit möglich, auf andere Bundesländer mit derselben Methodik ausgedehnt werden. Ziel ist dabei kein spezifischer Bundesländervergleich sondern vielmehr eine Herausarbeitung wirksamer Faktoren der Sozialtherapie. Diese geringen Fallzahlen stellen auch für die Bildung einer geeigneten Kontrollgruppe ein erhebliches Problem dar. So dürfte eine randomisierte Zuweisung der Jugendlichen zur Treatment- und Kontrollgruppe nicht möglich sein, eher kann davon ausgegangen werden, dass die Kontrollgruppe sich u.a. über Therapieverweigerer und Therapieabbrecher zusammensetzt, was zwar die Validität der gefundenen Ergebnisse einschränkt, jedoch angesichts der mangelnden Forschungsbefunde in Deutschland zu diesem Bereich keinen generellen Hinderungsgrund für die Durchführung der Untersuchung darstellt sondern eher intensive statistische Kontrollen verlangt. 
Was das Behandlungsmodell anbelangt, so liegt für die Anstalt Zeithain ein elaboriertes Konzept vor, das einen Behandlungszeitraum von bis zu 2 Jahren umfasst. Bausteine dieses Konzepts sind die Soziotherapie zur Förderung von Kommunikation, Regelbewusstsein sowie selbständiger Strukturierung des Lebensumfeldes, Psychotherapie als kognitiv-verhaltenstherapeutische Einzel- und Gruppentherapie sowie Kunsttherapie, Sozialpädagogik zur Förderung sozialer Kompetenzen, Bildung und Ausbildung als protektive Faktoren für die berufliche Eingliederung nach Entlassung, Ergotherapie zur Förderung von Basiskompetenzen und Freizeitarbeit zur Ausbildung eines strukturierten Freizeitverhaltens. Der modulare Aufbau des Programms sowie die vorgesehene intensive Diagnostik erleichtern die Begleitforschung und erlauben es, diesen Ansatz von denen anderer noch einzubeziehender Anstalten abzugrenzen um so letztendlich differenzierte Aussagen hinsichtlich der Wirksamkeit einzelner Programmteile machen zu können.

- $\quad$ Arbeitsbericht 2002/2003:

Während die Planungen für das Gesamtprojekt (vgl. zu erwachsenen Sexualstraftätern Projektbericht Ortmann) in Kooperation mit der Universität Dresden bereits 2002 ihren Anfang fanden, wurde erst Ende des Jahres 2003 mit der Konzeption der vorliegenden Studie zu jugendlichen Sexualstraftätern begonnen. Insbesondere wurden auf der Grundlage vorhandener Forschungsliteratur mögliche Fragestellungen entwickelt und auch eine Parallelisierung der Struktur zum Projekt zu erwachsenen Sexualstraftätern vorgenommen.

- $\quad$ Arbeitsplanung 2004:

$\mathrm{Zu}$ Beginn des Jahres 2004 sollen zunächst die Fragestellungen erweitert und präzisiert werden, ebenso wird eine umfassende Hypothesenentwicklung erfolgen. Ein weiterer Arbeitsschwerpunkt bildet die Zusammenstellung eines geeigneten Untersuchungsinventars, dieses wird neben den oben genannten bereits vorliegenden Skalen (z.B. SVR-20; PCL-SV) auch einen strukturierten Interviewleitfaden zur Erfassung der durch die Operationalisierung der Hypothesen gewonnen Forschungsvariablen sowie einige standardisierte Fragebogenverfahren beinhalten. Noch in der ersten Jahreshälfte 2004 soll dann kontinuierlich mit der Untersuchung der in Zeithain (und ggf. anderen Anstalten) einsitzenden jugendlichen und heranwachsenden Sexualstraftäter begonnen werden.

- $\quad$ Finanzierung:

Das Gesamtprojekt wird durch Mittel des Freistaates Sachsen gefördert.

\subsubsection{Die Entwicklung eines empirisch begründeten, differentialdiagnostischen Modells zur Typisierung von Sexualstraftätern nach therapie- und prognoserelevanten psychomet- rischen Daten}

- $\quad$ Bearbeiterin: Gunda Wößner (Psychologin)

- $\quad$ Zeitrahmen: 2001 bis 2004

- $\quad$ Projektstatus: in Bearbeitung

- $\quad$ Projektbeschreibung: (zugleich Promotionsvorhaben)

Vor dem Hintergrund des am 28.1.1998 in Kraft getretenen Gesetzes zur Bekämpfung von Sexualdelikten und anderen gefährlichen Straftaten, das jedem behandelbaren Sexualstraftäter ab dem Jahre 2003 therapeutische Maßnahmen zusichert, kommt der Diskussion um effektive Interventionen und die adäquate Zuordnung zu solchen sowohl in der Politik, in Fachkreisen als auch in der Öffentlichkeit 
ein hoher Stellenwert zu. Dabei wird vor allem in Fachkreisen eine differenziertere Diskussion und Herangehensweise gefordert. Ausgangspunkt ist die Überlegung, dass eine erfolgreiche Therapie generell auf eine Therapiezuordnung zurückzuführen ist, die auf differentialdiagnostischen Aussagen basiert. Beruhend auf interindividuellen Unterschieden und Eigenschaftswerten werden klassischerweise Behandlungsstrategien für eine psychotherapeutische Intervention abgeleitet bzw. Patienten/Klienten einer adäquaten Therapie zugeordnet. Da es gegenwärtig keine konformen Kriterien für eine Zuordnung von Sexualstraftätern zu einer bestimmten Intervention gibt, sollen im vorliegenden Projekt als Ausgangspunkt für eine gezielte Therapie Indikationsgrundlagen zur Intervention entsprechender Typen von Tätern ermittelt werden. Ziel des Projektes ist es, als Grundlage für eine effiziente Behandlung ein empirisch begründetes Indikationsmodell bereit zu stellen.

\section{Fragestellung}

Mit dem vorliegenden Projekt soll somit die Fragestellung untersucht werden, inwieweit es möglich ist ein differentialdiagnostisches Modell zu entwickeln, mit dem Sexualstraftäter nach therapeutisch relevanten Variablen voneinander differenziert und somit eventuell klassifiziert werden können. Idealerweise ließe sich ein basales Modell erstellen, aus dem weiterführende Hypothesen abgeleitet werden können a) zur Behandelbarkeit des Täters und b) zu adäquaten, spezifischeren Interventionsansätzen für Tätergruppen.

Die Fragestellung ist somit zugleich hypothesenprüfend als auch hypothesengenerierend: Hypothesenprüfend, weil einerseits die Hypothese überprüft wird, ob sich empirisch Subtypen von Sexualstraftätern feststellen lassen (hier vor allem nicht nur nach deliktsorientierten Kriterien, sondern gerade auch nach klinisch bzw. diagnostisch relevanten Kriterien); hypothesengenerierend, weil andererseits diese etwaig feststellbaren Typen dazu anregen sollen, Ideen zu typenspezifischen Interventionsansätzen zu generieren.

\section{Untersuchungsdesign}

Die Untersuchung besteht aus zwei empirischen Teilen

A) einer Expertenbefragung und

B) einer Untersuchung von Sexualdelinquenten durch (i) ein halb-strukturiertes persönliches Interview und (ii) eine Aktenanalyse.

\section{Bisherige Ergebnisse}

Die Durchführung der Expertenbefragung wurde im Oktober 2001 abgeschlossen und danach ausgewertet. Mit der Expertenbefragung wurden folgende Ziele verfolgt:

- Bestandsaufnahme des gegenwärtigen Standes der Sexualstraftäterbehandlung in Deutschland

- Spezifizierung der Variablen für eine Typologie zur Klassifikation von Sexualstraftätern.

Experten waren Psychologen, Psychiater und Wissenschaftler die entweder in der Therapie, Begutachtung oder Forschung von Sexualstraftätern tätig sind.

Der professionelle und institutionelle Hintergrund der Experten sah dabei wie folgt aus.

Mit 41 Psychologen war diese Berufsgruppe am stärksten vertreten. Dies entspricht $71 \%$. Die 14 Psychiater unter den Experten machen $24 \%$ der Experten aus.

Die meisten der insgesamt 57 eingegangen Expertenbögen waren sozialtherapeutischen Einrichtungen zuzuordnen ( $\mathrm{n}=18,32 \%$ ). Jeweils $25 \%$ der Bögen kamen aus dem Regelvollzug ohne sozialtherapeutischen Hintergrund oder aus Forschungseinrichtungen. Neun Bögen (das entsprach 16\%) kamen aus dem MRV. 
In der schriftlichen Expertenbefragung wurden Daten zu folgenden Fragen erhoben:

- Basisdaten der Experten

- Wie sieht das therapeutische und diagnostische Vorgehen in der Praxis der Experten aus?

- Können Experten aufgrund beruflicher Erfahrung Typen feststellen?

- Wenn ja, anhand welcher Merkmale sind diese Typen unterscheidbar?

- Sind Typen von Tätern erkennbar, die gut bzw. weniger gut auf Behandlung ansprechen?

- Wenn ja, anhand welcher Merkmale können die Experten diese Typen unterscheiden?

- Gibt es besonders effiziente spezifische therapeutische Stile (nicht Schulen!) für bestimmte Täter?

Die ausführlichen Ergebnisse der Expertenbefragung liegen in Form eines Arbeitsberichtes vor. Ein wichtiges Ergebnis dieser Expertenbefragung lag in der Identifikation von Variablen, anhand derer Experten unterschiedliche Tätertypen unterscheiden. Hieraus wurde ein Modell entwickelt mit den als für die Forschungsfrage relevant erachteten Konstrukten (siehe Abbildung 1). In einem nächsten Schritt wurden aufgrund dieser Konstrukte Variablen abgeleitet, die dann operationalisiert und in den Erhebungsinstrumenten integriert wurden (Erfassungsbogen für die Aktenanalyse und das Interview mit dazugehörigem Leitfaden).

Abbildung 1: $\quad$ Darstellung der vorläufigen Typisierungsmerkmale für ein Modell zur Typisierung von Sexualstraftätern

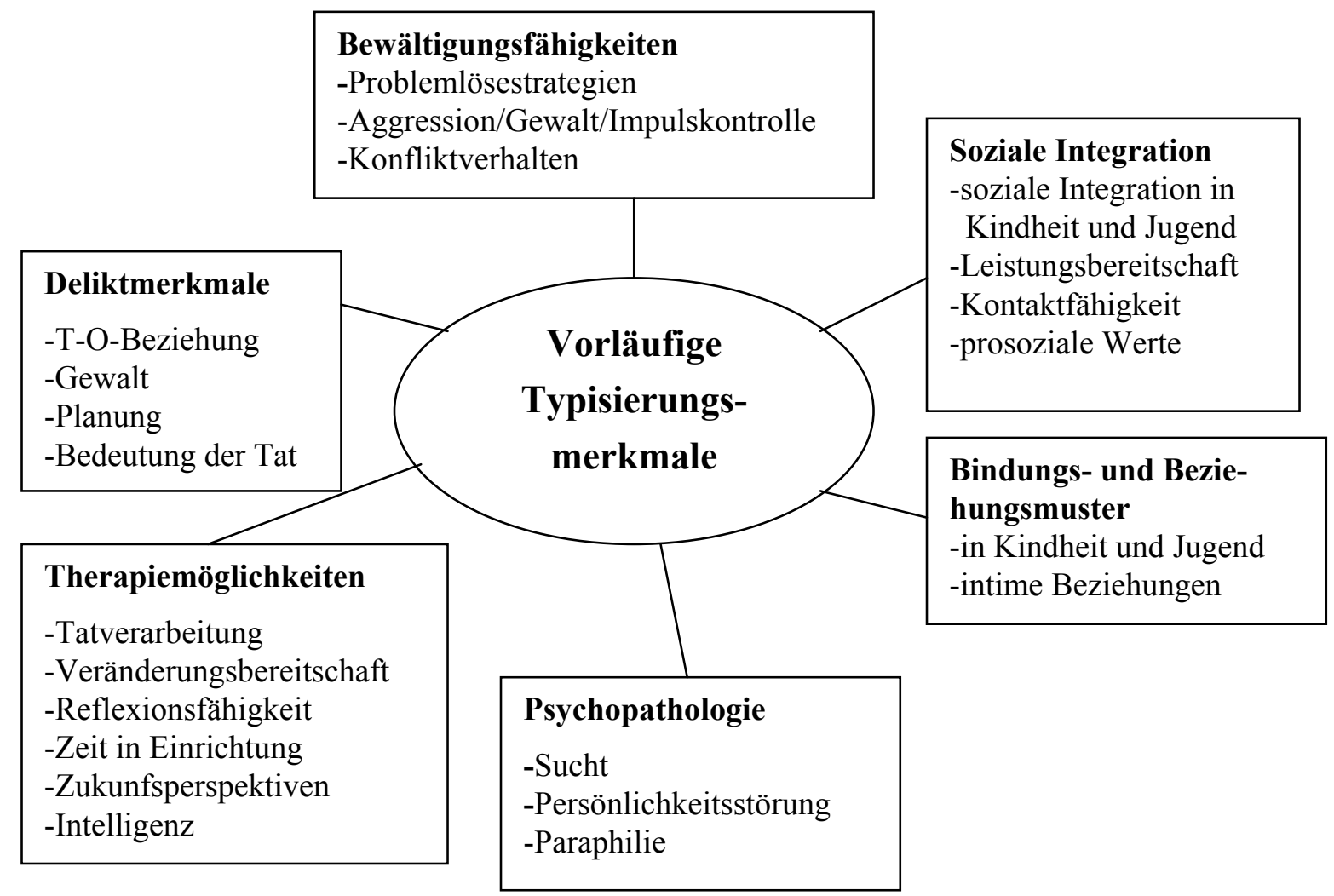


Datenquellen für den Typisierungsversuch sind somit:

1. Die persönlichen Interviews mit den Sexualstraftätern (hier vor allem zur Erfassung der Bindungs- und Beziehungserfahrungen und -gestaltung, zur sozialen Integration, zur Tatverarbeitung und Veränderungsbereitschaft, aber auch ansatzweise zu Konfliktbewältigungsstrategien).

2. Angaben aus den Akten (vor allem zu Deliktsmerkmalen, Psychopathologie, Ergänzung, Bestätigung oder Korrektur - der o.g. Variablengruppen).

3. PSSI und Einstellungsbogen zu Vergewaltigungs- bzw. Missbrauchsmythen (PSSI zur Feststellung, ob Tendenzen zur einer Persönlichkeitsstörung vorliegen).

Diese Daten werden nicht unabhängig voneinander betrachtet, sondern werden in Beziehung zueinander analysiert. So werden zum Beispiel zur Feststellung einer Persönlichkeitsstörung nicht nur die eigenen Verdachtsdiagnosen berücksichtigt, sondern auch Angaben zu psychiatrischen Diagnosen aus internen Stellungnahmen der Einrichtung, in der der Proband untergebracht ist, und solche aus externen Gutachten.

Seit Sommer 2002 läuft die Datenerhebung der Sexualstraftäteruntersuchung.

Probanden sind Straftäter, die wegen eines Sexualdeliktes oder Deliktes mit sexuellem Hintergrund verurteilt sind. Hierfür wurden in ausgewählten Unterbringungen der Bundesländer Baden-Württemberg, Berlin und Sachsen alle Sexualstraftäter der jeweiligen Einrichtung anonym kontaktiert und um freiwillige Teilnahme an der Untersuchung gebeten. Die Probanden sind entweder im Regel- oder Maßregelvollzug untergebracht. Nach dem JGG verurteilte Sexualtäter werden nicht berücksichtigt. Als Untergruppe der im Regelvollzug untergebrachten Täter wurden auch Probanden aus den Sozialtherapeutischen Anstalten der drei Bundesländer exploriert.

Tabellen 1a und 1b geben einen Überblick über die Basisdaten der bisher interviewten Probanden.

Tabellen 1a-b: Bisher explorierte Probanden - vorl. Basisdaten (Stand: 23.10.2003)

Tabelle la: $\quad$ Anzahl bisheriger Probanden nach Bundesländern und Unterbringung

\begin{tabular}{|l|c|c|c|c|}
\hline Unterbringung* & $\begin{array}{l}\text { Baden- } \\
\text { Württemb. }\end{array}$ & Berlin & Sachsen & Gesamt \\
\hline JVA & 37 & 0 & 12 & 49 \\
\hline SoThA & 11 & 17 & 11 & 39 \\
\hline MRV & 41 & 26 & 11 & 78 \\
\hline N Total & $\mathbf{8 9}$ & $\mathbf{4 3}$ & $\mathbf{3 4}$ & $\mathbf{1 6 6}$ \\
\hline
\end{tabular}


Tabelle 1b: $\quad$ Verteilung der Delikte (Mehrfachnennungen möglich)

\begin{tabular}{|c|c|c|c|c|c|}
\hline Unterbringung* & Land & Missbrauch & $\begin{array}{l}\text { Vergewalti- } \\
\text { gung/Nöti- } \\
\text { gung }\end{array}$ & Exhibition & Mord** \\
\hline \multirow[t]{3}{*}{ JVA } & Ba-Wü & 27 & 19 & 0 & 1 \\
\hline & Berlin & 0 & 0 & 0 & 0 \\
\hline & Sachsen & 7 & 6 & 1 & 0 \\
\hline \multirow[t]{3}{*}{ SoThA } & Ba-Wü & 5 & 6 & 0 & 1 \\
\hline & Berlin & 10 & 10 & 0 & 1 \\
\hline & Sachsen & 8 & 3 & 0 & 0 \\
\hline \multirow[t]{3}{*}{ MRV } & Ba-Wü & 13 & 23 & 3 & 1 \\
\hline & Berlin & 7 & 13 & 0 & 5 \\
\hline & Sachsen & 6 & 4 & 1 & 0 \\
\hline \multicolumn{2}{|l|}{ Gesamt } & 83 & 84 & 5 & 9 \\
\hline
\end{tabular}

* JVA = Regelvollzug, SoThA = Sozialtherapeutische Anstalt, MRV = Maßregelvollzug

** Mord, Totschlag, oder Körperverletzung mit Todesfolge

\section{Weiteres Vorgehen}

Die Datenerhebung für das Bundesland Baden-Württemberg ist bereits abgeschlossen. Anfang 2004 soll die Datenerhebung auch in Berlin und Sachsen vollständig erfolgt sein. Mit der Dateneingabe wurde bereits begonnen, so dass diese ebenfalls Anfang 2004 abgeschlossen sein sollte. Danach wird mit der Datenanalyse begonnen.

Nach Abschluss dieses Projekts ist, nach einem angemessenen Beobachtungszeitraum, die Durchführung einer Rückfallstudie geplant. Durch die Kooperation mit dem Kriminologischen Dienst BadenWürttemberg (Kooperationspartnerin Frau Dolde) stehen die Daten der zurzeit durchgeführten Stichtagserhebung zur Behandlung von sämtlichen Sexualstraftätern im Justizvollzugs Baden-Württemberg dem Institut ebenfalls für eine spätere Rückfallstudie zur Verfügung.

- Zum Projekt vorliegende neuere Veröffentlichungen:

Kury, H., Obergfell-Fuchs, J., KloppenburG, V., \& Woessner, G., New approaches of preventing sexual crimes in Germany. In: Crime Prevention - New Approaches. Hrsg. H. Kury \& J. Obergfell-Fuchs. Weißer Ring, Mainz 2003, 277-320.

WÖßNER, G., Behandlung, Behandelbarkeit und Typisierung von Sexualstraftätern: Ergebnisse einer bundesweiten Expertenbefragung. Arbeitsberichte aus dem Max-Planck-Institut 2/2002, edition iuscrim, Freiburg i. Br. 2002, 56 S. 
WÖßNER, G., Statement on the conduct of investigations into past cases of abuse (in children's homes) - Memorandum 73. In: The conduct of investigations into past cases of abuse in children's homes, Volume II: Memoranda. Hrsg. House of Commons, Home Affairs Committee. The Stationary Office, London, 2002 EV 129-130.

WÖßNER, G., State of the Art of Sex Offender Treatment in Germany: Results of an Expert Survey. Forensische Psychiatrie und Psychotherapie (Supplement) 9, 151 (2002).

\subsection{Schwerpunkt "Organisierte Kriminalität und Innere Sicherheit"}

\subsubsection{Rechtsberatungs- und Wirtschaftsprüfungsberufe aus der Perspektive von Geldwäsche und Geldwäschekontrolle}

- $\quad$ Bearbeiter: Michael Kilchling (Jurist), Tim Lukas (Soziologe)

- $\quad$ Zeitrahmen: 1999 bis 2003

- $\quad$ Projektstatus: abgeschlossen

- $\quad$ Projektbeschreibung:

(vgl. dazu bereits dieTätigkeitsberichte 1998/1999, S. 98; 2000/2001, S. 121)

Bei dem vorliegenden Projekt handelt es sich um eine Auftragsforschung, die auf eine Ausschreibung des BMJ aus dem Jahr 1998 zurückgeht. Hintergrund war die Erforschung der bislang ungeklärten Frage nach dem quantitativen Umfang des Phänomens Geldwäsche im Bereich der Rechtsberatungsund Wirtschaftsprüfungsberufe und der Gefährdung dieser Berufsgruppen durch Geldwäsche im Zusammenhang mit den damals noch umstrittenen Plänen der EU, die Geldwäschekontrolle auszuweiten und die genannten Berufsgruppen in den Kreis der meldepflichtigen Personen einzubeziehen.

Das Forschungsprojekt umfasste zwei Module: zum einen die Durchführung einer schriftlichen Befragung bei den genannten Berufsgruppen, zum anderen die Ermittlung relevanter Ermittlungsverfahren sowie der inhaltlichen Analyse der zugehörigen Verfahrensakten. Der Projektabschluss war zunächst für das Jahr 2002 vorgesehen. Auf einer Sitzung des wissenschaftlichen Beirats am 23.4.2002 in Berlin wurden die bis dahin vorliegenden Ergebnisse vorgestellt und diskutiert. Dabei wurde von allen Seiten eine Fortsetzung des Forschungsprojektes als sinnvoll erachtet. Die Gründe hierfür lagen zum einen in der schwierigen Erreichbarkeit einschlägiger Akten, zum anderen in der zwischenzeitlich signifikant veränderten politischen Situation. Nach den Anschlägen des 11. September war die zuvor auch im Europäischen Parlament stark umstrittene EU-Richtlinie 2001/97/EG im Dezember 2001 verabschiedet worden, ohne dass es noch die Chance gegeben hätte, den vorgebrachten Bedenken zumindest durch Änderungen Rechnung zu tragen. Das Antwortverhalten der von uns im Jahr 2000 Befragten hatte allerdings noch die Einschätzung widergespiegelt, dass die Richtlinie nicht oder nicht in der von der EU-Kommission eingebrachten Form erlassen würde. Die kritische Haltung vor allem der Anwaltschaft wurde durch ein zweite, rechtspolitisch ebenfalls sehr einschneidende Entwicklung verstärkt. Ebenfalls im Jahr 2001 hatte der BGH bekanntlich entschieden, dass auch Strafverteidiger grundsätzlich der Geldwäschestrafbarkeit unterliegen.

Diese besondere rechtspolitische Entwicklung ermöglichte die aus wissenschaftlicher Sicht sehr reizvolle Situation, durch eine zweite Befragung mögliche Einstellungsänderungen zwischen der Prä- und der Postimplementationsperspektive zu erforschen. Darüber hinaus bot sich die Chance, auch für die Aktenanalyse eine zweite Erhebungswelle durchzuführen. 
- $\quad$ Arbeitsbericht bis 2003

Zusätzlich zu den insgesamt 4.065 Befragten aus dem Jahr 2000 wurden im Jahr 2003 auf der Grundlage einer zweiten Zufallsstichprobe weitere 4.060 Berufsgruppenvertreter postalisch befragt. Nach einem Rücklauf von 18,9 Prozent $(\mathrm{N}=767)$ in der 2000er Untersuchung, konnte in der 2003er Erhebung sogar eine erhöhte Rücklaufquote von 20,2 Prozent $(\mathrm{N}=821)$ erreicht werden.

Hinsichtlich der Aktenanalyse konnten zusätzlich zu den Akten aus 59 Verfahren, die bis Anfang April 2002 erreicht und ausgewertet wurden, bis August 2003 weitere 36 Akten erfolgreich nachgeordert werden. Auf diese Weise konnten die Akten aus insgesamt 95 personenbezogenen Ermittlungsverfahren in die Analyse einbezogen werden.

Der Forschungsbericht wird nach Ablauf des vertraglichen Erstverwertungszeitraumes für die auftraggebenden Ministerien publiziert werden.

- $\quad$ Kurzzusammenfassung der wesentlichen Ergebnisse

Aus den Ergebnissen der Befragungen lässt sich insgesamt auf ein recht gut ausgeprägtes, zumindest abstraktes Problembewusstsein für mögliche Gefährdungen des eigenen Berufsstandes durch Geldwäsche schließen. So sind in der Informantenperspektive innerhalb beider Untersuchungen einem Viertel der Antwortenden Fälle eines Geldwäscheverdachts gegen Angehörige der relevanten Berufsgruppen bekannt. Ebenso wie in der Erhebung des Jahres 2000 geben auch in 2003 die meisten Befragten, die von derartigen Verdachtsfällen wussten, an, von durchschnittlich drei solchen Fällen Kenntnis erlangt zu haben. Hinsichtlich der Frage nach der Verbreitung derartiger Fälle schätzen in beiden Erhebungen mehr als drei Viertel der Antwortenden diese allerdings als "eher selten" oder "sehr selten" ein.

In der Selbstberichtungsperspektive ist zwischen beiden Befragungen eine Zunahme von Fällen zu verzeichnen, in denen Berufgruppenvertreter den Eindruck gewannen, dass Geldwäsche in der eigenen Berufsausübung eine Rolle gespielt haben könnte. Hinsichtlich der Häufigkeit solcher Fälle geben Rechtsanwälte, Notare und Steuerberater durchschnittlich zwei Fälle, Wirtschaftsprüfer im Jahr 2000 einen und im Jahr 2003 ebenfalls zwei Fälle an. Sinkende Prozentwerte hingegen erfährt im Jahr 2003 die Bejahung der Frage, ob aufgrund des Eindrucks einer beabsichtigten Geldwäsche schon einmal die Annahme eines Mandats verweigert wurde.

Ein gesteigertes Geldwäscherisiko wird unter der Viktimisierungsperspektive von Rechtsanwälten und Notaren vor allem bei (Bar-)Zahlungen von Honoraren in Straf- und Steuerrechts-, Gesellschafts- und Unternehmens- sowie Wirtschaftsrechtsangelegenheiten hervorgehoben. Darüber hinaus wird insbesondere die treuhänderische Verwaltung von Fremdgeldern über Anderkonten als überaus anfällig für den Missbrauch durch Geldwäsche beschrieben. Wirtschaftsprüfer heben ein Geldwäscherisiko insbesondere bei Treuhandtätigkeiten, Immobilientransaktionen und Unternehmensbeteiligungen hervor. Steuerberater verweisen zumeist auf Branchen mit hohem Barmittelumlauf (z.B. Gaststätten) sowie auf Treuhandaufträge und die Verwaltung fremden Geldes.

Einleitend in die Geldwäscheperspektive wurde danach gefragt, welches unterstellte Wissen für Zwecke der Geldwäsche missbraucht werden könnte. Im Ergebnis sind es vor allem die Kenntnisse von Recht und Gesetz, die aus der Sicht der Antwortenden die relevanten Berufsgruppen für potentielle Geldwäscher attraktiv erscheinen lassen. Signifikant dominieren darunter die Rechtsanwälte und Notare. Wirtschaftsprüfer hingegen überwiegen in der Frage nach Kenntnissen der wirtschaftlichen $\mathrm{Zu}$ sammenhänge und wirtschaftsrechtlichen Verhältnisse. Gefragt nach weiteren Qualitäten die für Geldwäscheaktivitäten interessant sein könnten, hebt eine deutliche Mehrheit der Antwortenden die Seriosität des eigenen Berufsstandes hervor. Von untergeordneter Bedeutung erscheinen dagegen das Renommee und der individuelle Ruf des jeweiligen Berufsgruppenvertreters. Darüber hinaus findet sich in allen drei Berufsgruppen das Mandatsgeheimnis als das herausragende Argument in der Begründung möglichen Missbrauchs durch Geldwäscheaktivitäten. Hinsichtlich spezieller Geldwäsche- 
techniken, zu deren Durchführung die Berufsgruppen besonders attraktiv erscheinen könnten, werden sowohl im Jahr 2000 als auch in 2003 aus allen Berufsgruppen vornehmlich die Einrichtung von Treuhandkonten und die Weiterleitung von Fremdgeldern thematisiert. Als typisierter "Kundenkreis" erscheint allen Berufsgruppen die Klientel aus dem Bereich der Organisierten Kriminalität als besonders risikobehaftet.

Als relevante Informationen für die Strafverfolgungsbehörden, die im Rahmen der beruflichen Tätigkeit anfallen, werden unter der Kontrollperspektive aus den Berufsgruppen die Herkunft der zu "waschenden" Gelder und das Wissen um personelle und geschäftliche Verflechtungen genannt. Rechtsanwälte führen überdies alle mandatsinternen Kenntnisse und persönliche und wirtschaftliche Verhältnisse der Mandanten an. Zugleich aber wird dezidiert auf die Verschwiegenheitspflicht verwiesen, die keinerlei Hinweise an die Strafverfolgungsbehörden zulasse. Wirtschaftsprüfer nennen das gesamte Prüfwissen und Kenntnisse von Einkaufs- und Verkaufspreisen, sprechen sich aber ebenfalls für die Schweigepflicht aus. Dies trifft in gleicher Weise für Steuerberater zu, die daneben die Kenntnis von Buchführungsunterlagen nennen.

Bezogen auf die Implementationsperspektive war die EU-Richtlinie zum Zeitpunkt der 2000er Befragung in den Berufszweigen gleichermaßen zu einem Viertel bekannt, wobei Rechtsanwälte früher von der Novellierung Kenntnis genommen hatten als Wirtschaftsprüfer und Steuerberater. Das novellierte Geldwäschegesetz hingegen ist im Jahr 2003 drei Vierteln der Antwortenden bekannt, darunter am geläufigsten den Wirtschaftsprüfern und Steuerberatern. Wurden indes noch im Jahr 2000 mehrheitlich gravierende Probleme für die eigene Berufsausübung antizipiert, so zeigen sich gegenwärtig deutlich weniger Berufsgruppenvertreter kritisch gegenüber dem Gesetz. Problematisiert aber wird vor allem der Gewissenskonflikt zwischen dem Mandatsgeheimnis auf der einen und der drohenden Strafbarkeit auf der anderen Seite. Die in der Richtlinie bzw. dem Gesetz vorgesehene Verpflichtung zur Identifizierung, Aufzeichnung und Aufbewahrung wird von einem Teil der Antwortenden nicht als Änderung der bisherigen Praxis gesehen, andere werden sich diesen Pflichten unterwerfen. Wurde bereits im Rahmen der 2000er Befragung die Einführung einer Meldepflicht bei Verdacht der Geldwäsche vehement abgelehnt, so schätzen zum Zeitpunkt ihrer Implementation durch das novellierte Gesetz nahezu drei Viertel der Antwortenden die Anzeigepflicht als problematisch ein. Eine deutliche Mehrheit in allen Berufsgruppen und beiden Befragungen sieht vor allem den Schutz der Vertraulichkeit gefährdet. Gleichwohl hält sowohl im Jahr 2000 als auch in 2003 über die Hälfte der Antwortenden die in nationales Recht überführte EU-Richtlinie für grundsätzlich sinnvoll. Ob das novellierte Geldwäschebekämpfungsgesetz jedoch ein geeignetes Mittel ist, um die Gefährdung des eigenen Berufsstandes durch Geldwäscheaktivitäten zu verringern und die Organisierte Kriminalität und den internationalen Terrorismus zu bekämpfen, wird aus allen Berufszweigen mehrheitlich bezweifelt.

Bei der Aktenanalye konnte die Zahl der erreichten Verahrensakten, wie berichtet, deutlich erhöht werden. Von den urspünglich 163 von den Landeskriminalämtern als einschlägig gemeldeten Ermittlungsverfahren konnten letztendlich die Akten zu 95 Verfahren ausgewertet werden. Bedingt durch unterschiedliche Meldekriterien und -praktiken waren der Rücklauf und die Trefferquote in den einzelnen Bundsländern allerdings sehr unterschiedlich. Viele der registrierten Verfahren waren nicht einschlägig: entweder wiesen die Ermittlungen keinerlei erkennbare Bezüge zu den untersuchten Berufsgruppen auf oder es ergaben sich keine Anhaltpunkte auf Tatelemente, die rechtlich unter den Geldwäschetatbestand subsumiert werden könnten.

\begin{tabular}{|l|l|l|}
\hline Tätigkeit der Verdächtigen & Anzahl & Prozent \\
\hline Rechtsanwalt & 68 & 72,3 \\
\hline Fachanwalt & 0 & 0,0 \\
\hline
\end{tabular}




\begin{tabular}{|l|l|l|}
\hline Wirtschaftsprüfer & 0 & 0,0 \\
\hline Notar & 11 & 11,7 \\
\hline Steuerberater & 8 & 8,5 \\
\hline Rechtsanwaltsgehilfe & 1 & 1,1 \\
\hline Sonstiges & 6 & 6,4 \\
\hline & 94 & 100 \\
\hline
\end{tabular}

Erwartungsgemäß kann aus den Ergebnissen der Aktenanalyse geschlossen werden, dass das abstrakte Gefährdungsszenario, das (auch) aus der Einschätzung der befragten Berufsgruppenvertreter spricht, die Strafverfolgungswirklichkeit nicht ansatzweise widerspiegelt. Die Analyse der hier ausgewerteten Ermittlungsverfahren hat nämlich ergeben, dass fast drei Viertel der Verfahren nach Abschluss der Ermittlungen von der Staatsanwaltschaft gemäß $§ 170$ Abs. 2 eingestellt wurden $(n=70)$. Dabei war schon der aus den Aufzeichnungen zu entnehmende Tatverdacht, was die mögliche Relevanz auf den Vorwurf strafrechtlich relevanter Geldwäsche betrifft, wenig substantiiert. Verdachtauslösende Faktoren waren zumeist Tätigkeiten im Zusammenhang mit der Eröffnung von oder einzelnen Transaktionen über Anderkonten. Zu einer Anklage kam es denn auch nur in 6 Fällen. Und in keinem einzigen dieser Fälle erfolgte - jedenfalls bis zum Ende des Erhebungszeitraumes - eine rechtskräftige Verurteilung wegen Geldwäsche.

Überraschend war hingegen, dass sich die Ermittlungen in ebenfalls fast drei Viertel aller Fälle gegen Rechtsanwälte richteten. Entgegen der Gefährdungseinschätzung des Gesetzgebers scheint das Fachwissen insbesondere von Wirtschaftsprüfern und Steuerberatern bislang nicht in dem zu erwartenden Umfang zu Geldwäschezwecken missbraucht zu werden. Zumindest scheinen konkrete Verdachtsfälle in diesen Tätigkeitsbereichen in dem untersuchten Zeitraum (1994 bis 2002) nicht Gegenstand konkreter Ermittlungsverfahren gewesen zu sein.

\section{- $\quad$ Finanzierung:}

Gefördert durch die Bundesministerien der Justiz und des Inneren (je zur Hälfte). 


\subsubsection{Strafverfolgung von Menschenhandel}

- $\quad$ Bearbeiterin: Annette Herz (Juristin)

- $\quad$ Zeitrahmen: 2002 bis 2004

- $\quad$ Projektstatus: in Bearbeitung

- $\quad$ Projektbeschreibung: (zugleich Promotionsvorhaben)

Vor dem Hintergrund rückläufiger und regional unterschiedlicher Verfahrenszahlen wegen Menschenhandels erwog das Bundesministerium des Innern (BMI), in einer wissenschaftlichen Studie feststellen zu lassen, wo hierfür die Gründe liegen und insbesondere, in welchem Umfang und warum Polizei und Justiz auf andere, möglicherweise einfacher zu handhabende Straftatbestände (Einschleusen von Ausländern, illegaler Aufenthalt usw.) ausweichen. Das auf ein Jahr befristete Forschungsvorhaben wurde nach Ausschreibung durch das BMI als Kooperationsprojekt an das Max-PlanckInstitut für ausländisches und internationales Strafrecht in Freiburg (MPI) und die Kriminologische Zentralstelle in Wiesbaden (KrimZ) im März 2003 vergeben. Aufgabe des MPI ist es, schriftliche Befragungen mit Mitgliedern aus Strafverfolgungsbehörden und der Justiz in ausgewählten Bundesländern durchzuführen. Darauf aufbauend sind vertiefende Einzelinterviews vorgesehen. Die KrimZ wertet in der thematisch gut zu ihrem Forschungsprojekt zur Schleuserkriminalität passenden Untersuchung Ermittlungsakten zum Menschenhandel aus. Über die Aktenauswertung hinaus analysiert die KrimZ die in den Jahren 1996-2000 erfolgten 915 Verurteilungen wegen $\S \S 180$ b, 181 StGB, deren Daten vom Bundeszentralregister zur Verfügung gestellt wurden.

\section{Methodik:}

Zur Methodik des Forschungsprojektes lassen sich folgende Aspekte zusammenfassen:

Rückläufige Verfahrenszahlen im Bereich der Straftat Menschenhandel (§§180b, 181 StGB) können bedingt sein durch'

- Eigenheiten der polizeilichen Erfassung, hier vor allem durch ein Ausweichen auf andere Straftatbestände

- Eigenheiten von Kontrolldelikten, hier vor allem durch Determinanten der Anzeigeerstattung und der Verdachtsschöpfung

- Besonderheiten des spezifischen Straftatbestands "Menschenhandel", hier vor allem Beweisschwierigkeiten.

Zur Überprüfung bietet sich deshalb ein Mehrebenenansatz an, mit dem die genannten Bereiche von Variablen in verschiedenen Bundesländern und damit in einem Bundesländervergleich untersucht werden. Dabei werden solche Bundesländer einbezogen, in denen einerseits entsprechende Schwankungen in den jährlichen Ermittlungszahlen beobachtet werden können und wo zum anderen entsprechende Milieus für kontinuierliche Ermittlungen im Bereich von Menschenhandel, Prostitution und damit zusammenhängenden Straftaten (insbes. organisierter Kriminalität) sorgen, nämlich die Bundesländer Berlin, Hamburg, Nordrhein-Westfalen, Hessen, Baden-Württemberg, Niedersachsen, Sachsen, Bayern, Mecklenburg-Vorpommern und Brandenburg sowie der Flughafen Frankfurt/Main (stellvertretend für den Bereich des Bundesgrenzschutzes).

\section{- $\quad$ Arbeitsbericht 2003:}

Zunächst erfolgte eine Analyse von Gerichtsakten zu Menschenhandelsverfahren, deren Auswahl sich an der zu untersuchenden Fragestellung orientierte. Von Interesse waren daher in erster Linie solche Verfahren, in deren Verlauf der Tatvorwurf Menschenhandel zu Gunsten anderer Delikte fallengelas- 
sen wurde. Ein weiteres Auswahlkriterium war der Ermittlungsverlauf und ob das Verfahren eingestellt oder angeklagt wurde bzw. ob es zu einer Verurteilung wegen Menschenhandels kam. Die Aktenauswertung soll zum einen den zeitlichen und organisatorischen Verlauf der Verfahren untersuchen. Ferner sind die Art der Verfahrensauslösung (unabhängige polizeiliche Erkenntnisgewinnung oder Initiativermittlungen) und der Einsatz besonderer Ermittlungsmaßnahmen von Interesse. Anhand einer Tatphänomenologie wurden Eigenheiten im Vorgehen des/ $\mathrm{r}$ zu untersuchenden Täters/Tätergruppe insbesondere im Hinblick auf die Verbringung der Opfer nach Deutschland, die Unterbringung und Überwachung der Opfer in Deutschland und organisierte Kriminalitätsstrukturen erfasst. Im Hinblick auf das zu untersuchende Dunkelfeld wurde die Bedeutung und Struktur des Rotlichtmilieus für die Abwicklung des Menschenhandels erhoben. Eine eigene Opferphänomenologie hielt nähere Informationen vor allem in Bezug auf den sozialen Hintergrund der Opfer und die Umstände der Kontaktaufnahme zwischen Tätern und Opfern sowie Einzelheiten zu Zwangs- und Gewaltsituationen fest. Anhand einer Täter-Opfer-Phänomenologie sollten vor allem die Phase der Prostitutionsausübung unter den Gesichtspunkten Unterbringung der Opfer, Ort der Prostitutionsausübung und Kontrolle der Opfer untersucht werden.

In einem zweiten Schritt erfolgte eine umfangreiche schriftliche Befragung von unmittelbar an der Strafverfolgung beteiligten Personen aus den Bundesländern Bayern, Baden-Württemberg, Hessen, NRW, Hamburg, Berlin, Sachsen, Mecklenburg-Vorpommern, Niedersachsen und Brandenburg. Die Datenerhebung war hier darauf ausgerichtet, Einstellungen und Perzeptionen sowie (behörden-)internes Wissen der Befragten zu ermitteln. Es handelte sich hierbei um Polizisten aus dem Bundeskriminalamt, den Landeskriminalämtern, OK-Dezernaten sowie örtlichen "Rotlicht"-Dezernaten, Staatsanwälten und Richtern. Die schriftliche Befragung griff zum einen die der Aktenuntersuchung zugrunde liegenden Fragestellungen auf und entwickelte diese weiter. Zum anderen diente sie zusammen mit den Ergebnissen der Aktenauswertung der Vorbereitung auf Einzelinterviews, indem praxisrelevante Problemschwerpunkte herausgefiltert wurden. Besondere Schwerpunkte sind auch hier die Phase der Verfahrensauslösung, der Gang der Ermittlungen sowie die Häufigkeit und die Gründe für ein Ausweichen auf alternative Tatbestände.

\section{- $\quad$ Arbeitsplanung 2004:}

In einem dritten Schritt sollen anhand von Interviews Schlüsselpersonen im Rahmen von Menschenhandelsverfahren befragt werden. Geplant sind offene, leitfadengestützte Interviews mit dem Ziel, aus der schriftlichen Befragung gewonnene Erkenntnisse zu vergleichen und zu ergänzen sowie klärungsbedürftige Problemschwerpunkte zu thematisieren. Da es hier um vertiefende Informationen zu besonderen Auffälligkeiten im Hinblick auf die der Untersuchung zugrunde liegenden Fragestellungen geht, ist die Konzentration auf eine bestimmte Auswahl an Bundesländern (voraussichtlich Berlin, Hamburg, Nordrhein-Westfalen, Hessen und Sachsen) angebracht; die Auswahl soll auf der Grundlage der in den ersten beiden Forschungsabschnitten gewonnenen Erkenntnisse getroffen werden. Neben Vertretern der Strafverfolgungsbehörden und Richtern handelt es sich um Mitarbeiter von Hilfsorganisationen bzw. Fachberatungsstellen, Ordnungsämtern, Anwälten und, soweit möglich, Opfer und Täter. Um weitere Informationen über das Umfeld und Ausmaß von Menschenhandel in Deutschland speziell im Hinblick auf das zu vermutende Dunkelfeld zu erfahren, sind darüber hinaus Interviews mit Mitgliedern aus der Prostitutionsszene geplant.

\section{- $\quad$ Finanzierung:}

Gefördert durch das Bundesministerium für Familie, Senioren, Frauen und Jugend (BMFSFJ) und das Bundesministerium des Innern (BMI). 


\title{
3.3.3 Die rechtliche Bewältigung von Erscheinungsformen organisierter Kriminalität
}

\author{
- $\quad$ Bearbeiter: Jörg Kinzig (Jurist) \\ - $\quad$ Zeitrahmen: 1997 bis 2004 \\ - $\quad$ Projektstatus: abgeschlossen \\ - $\quad$ Projektbeschreibung: (zugleich Habilitationsvorhaben))
}

Die organisierte Kriminalität steht bereits seit einiger Zeit im Mittelpunkt kriminalpolitischer Überlegungen und Aktivitäten. Während es inzwischen weitgehend anerkannt zu sein scheint, dass es unter den vielfältigen Erscheinungsformen delinquenten Verhaltens einen Bereich organisierter Kriminalität gibt, enden mit dieser Feststellung aber auch schon die Gemeinsamkeiten in der Einschätzung der Größe der von ihr ausgehenden Gefahr, ihres Inhalts und der notwendigen gesetzgeberischen Aktivitäten. Die unterschiedliche Wahrnehmung dieses Phänomens ist darauf zurückzuführen, dass ein hinreichend klar konturierter Begriff und eine Vorstellung davon, was organisierte Kriminalität ausmacht und worin ihre besondere Gefährlichkeit begründet liegt, sowie differenzierte empirische Erkenntnisse hierüber nach wie vor nicht vorhanden sind.

Ziel der Arbeit ist zu erforschen, wie die Strafjustiz das Phänomen organisierte Kriminalität aufgreift und bewältigt. Die Untersuchung begegnet dabei der Schwierigkeit, dass es kaum Grundlagen gibt, auf denen eine empirische Studie auf diesem Gebiet in Deutschland aufbauen könnte. Im Mittelpunkt des Projektes stehen drei Aspekte:

- Zunächst erfolgt eine theoretische Bestandsaufnahme der Entwicklung, des Inhalts und der Bedeutung des Begriffes OK sowie der Veränderungen des Strafrechtssystems, die durch neue legislative Maßnahmen zur OK-Bekämpfung entstanden sind. Diese betreffen im Wesentlichen einen prozessualen und einen materiell-rechtlichen Kern.

- So wurde unter Berufung auf die Notwendigkeit zur OK-Bekämpfung eine Reihe strafprozessualer Instrumente neu geschaffen oder geregelt, über deren Einsatz und Effizienz noch keine Erkenntnisse vorliegen. Die konkrete Anwendung der besonderen Ermittlungsmaßnahmen bei der Aufklärung von OK, insbesondere deren Bedeutung zur Ermittlung und Aburteilung der Straftaten, stellt daher einen weiteren Forschungsschwerpunkt dar. Damit verbunden ist die Frage, inwieweit sich dadurch die so genannte Verpolizeilichung des Strafverfahrens dokumentiert.

- OK-Verfahren sind durch eine besondere Komplexität aufgrund einer Vielzahl von Beschuldigten sowie vom System zu verarbeitenden Straftaten geprägt. Dies stellt hohe Anforderungen an einen Strafprozess, der sich traditionell mit einer Straftat eines Straftäters befasst. Die Ebene der Mehrtäterschaft bei OK und ihre Behandlung durch die Justiz bilden daher den dritten Schwerpunkt. Materiell-rechtlich stehen hier die Teilnahmeformen von der bloßen Mittäterschaft über die Bande bis zur kriminellen Vereinigung im Vordergrund der Betrachtungen.

\section{- $\quad$ Arbeitsbericht 2002/2003:}

In den Berichtsjahren wurde das Vorhaben mit der Einreichung der Habilitationsschrift "Die rechtliche Bewältigung von Erscheinungsformen organisierter Kriminalität" bei der Rechtswissenschaftlichen Fakultät der Universität Freiburg und der Verleihung der "venia legendi" für die Fächer Strafrecht, Strafprozessrecht, Kriminologie, Jugendstrafrecht und Strafvollzug vorläufig abgeschlossen. Die Arbeit wird voraussichtlich im Frühjahr 2004 in der Reihe "Strafrecht und Kriminologie" erscheinen. Druckbeihilfen wurden bei der DFG und der VG Wort beantragt.

Darstellung der Datenquellen für das Forschungsprojekt OK 
Zusammenfassend lassen sich die für die Untersuchung ausgewerteten Datenquellen wie folgt darstellen:

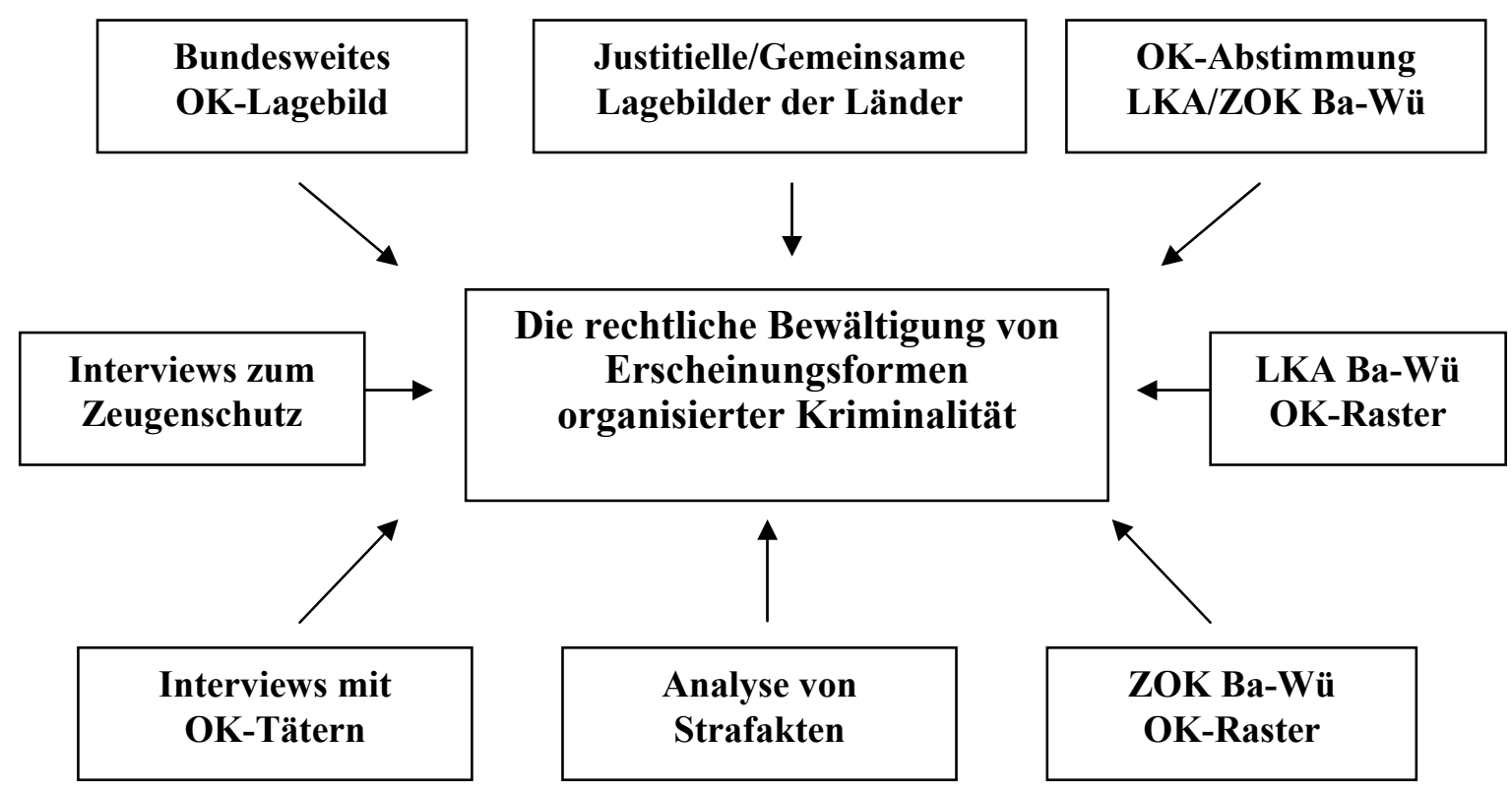

Am Anfang der Untersuchung stand eine Analyse des bundesweiten OK-Lagebildes des BKA (1).

Daneben wurden auch die in einzelnen Bundesländern erstellten justitiellen bzw. gemeinsamen Lagebilder OK ausgewertet, die über die Innen- bzw. Justizministerien beschafft wurden (2). Hier ließen sich bei einem Vergleich der Lagebilder untereinander regionale Besonderheiten bei den OKErmittlungen aufzeigen. Eine gesonderte Betrachtung der Situation in Baden-Württemberg führte zu dem Ergebnis, dass die dort vorliegenden Daten als repräsentativ für die Bundesrepublik Deutschland angesehen werden können. Eine weitere Quelle (3) bildete die Teilnahme an den Sitzungen von LKA und ZOK Baden-Württemberg, bei denen über die Aufnahme der Komplexe in das Lagebild entschieden wird. Zudem wurden die vom Landeskriminalamt Baden-Württemberg überlassenen Raster von 154 OK-Komplexen, die aus den Jahren 1994 bis 1998 stammen, ausgewertet (4). Des weiteren wurde die Datensammlung der ZOK mit den darin enthaltenen justitiellen Angaben genutzt (5). Kernstück der Untersuchung ist eine Analyse von Strafakten aus Baden-Württemberg (6). Zur Ergänzung haben wir zehn Personen interviewt, die in Verfahren verurteilt wurden, die von der Polizei als Formen organisierter Kriminalität angesehen wurden (7). Eine weitere Quelle (8) bildeten Interviews zum Zeugenschutz.

Gang der Darstellung: Die Arbeit gliedert sich in einen kürzeren primär rechtstheoretisch ausgerichteten Abschnitt A (Kapitel 1-8) sowie einen längeren, die empirischen Befunde ausbreitenden Teil B (Kapitel 9-22).

Zunächst wird die historische Entwicklung organisierter Kriminalität in Deutschland dargestellt. Die Versuche, eine OK-Definition zu entwickeln, wie die Kritik an ihr werden aufgezeigt. Des Weiteren werden die Gefahren beschrieben, die der OK gemeinhin beigemessen werden (Kapitel 1-4). Die folgenden Kapitel 5-8 widmen sich vor allem den rechtlichen Neuerungen, die in den vergangenen zehn Jahren zur Bekämpfung der OK implementiert worden sind. Sie betreffen nicht nur das Strafprozessrecht, sondern auch das Polizeirecht. Dazu gehören zudem verschiedene Dimensionen des Themas OK und Zeugenschutz. Gegenüber diesen eher prozessualen Ansätzen beziehen sich die Konzepte des 
materiellen Rechts zur OK-Bekämpfung vor allem auf die Ausweitung der banden- und gewerbsmäßigen Delikte sowie Maßnahmen zur Abschöpfung krimineller Gewinne. Der erste Teil der Arbeit endet mit einer Analyse, welche Bedeutung der Begriff organisierte Kriminalität bisher in der Rechtsprechung erfahren hat.

Nach der Vorstellung der rechtlichen Grundlagen beginnt der empirische Teil der Untersuchung mit einem Überblick über die in Deutschland zum Thema organisierte Kriminalität vorliegenden, rechtstatsächlichen Forschungsarbeiten. Die ergänzende Auswertung polizeilicher wie justitiell allgemeinstatistischer Daten kann mangels eines OK-Tatbestandes kurz gehalten werden. Mehr Informationen enthalten die so genannten Lagebilder Organisierte Kriminalität. Nach einer Analyse des Lagebildes Organisierte Kriminalität des Bundeskriminalamtes werden die in den letzten Jahren zunehmend angefertigten Gemeinsamen Lagebilder der Länderpolizeien bzw. der Justiz erörtert, bevor sich der Blick speziell auf die Situation in Baden-Württemberg und die dort vorhandenen Lagebilder richtet (Kapitel 9-11).

Nach einer Diskussion der Ziele, Hypothesen und der Datenquellen der Untersuchung beginnen die eigenen empirischen Arbeiten mit den Ergebnissen einer teilnehmenden Beobachtung anlässlich von Besprechungen zwischen Polizei und Justiz in Baden-Württemberg, in denen über die Aufnahme von Fällen als OK in das Lagebild entschieden wurde. Vor dem eigentlichen Beginn der Aktenanalyse wird die Auswahl der zu untersuchenden Strafverfahren dargelegt (Kapitel 12-14).

Die Aktenanalyse (Kapitel 15-19) beleuchtet in einem Längsschnitt nach einer einleitenden Übersicht über die untersuchten Sachverhalte den gesamten Ablauf der Ermittlungen in 52 ausgewählten OKKomplexen von ihrer Einleitung und der Abschlussverfügung der Staatsanwaltschaft über die Ausgestaltung der Hauptverhandlung bis zum rechtskräftigen Urteil. Neben den besonderen Ermittlungsmaßnahmen auf einer prozessualen Ebene stehen die Formen arbeitsteiligen kriminellen Verhaltens auf einer materiell-rechtlichen Ebene im Mittelpunkt der Auswertung. Am Ende der Darstellung der Ergebnisse der Aktenanalyse wird aufgezeigt, welche Faktoren gegeben sein müssen, damit am ehesten von einer funktionierenden organisierten Kriminalität gesprochen werden kann.

Von vornherein erschien es wünschenswert, die Ergebnisse der Aktenanalyse durch die Führung von Interviews mit Akteuren aus dem Gebiet organisierter Kriminalität anzureichern und zu validieren. Daher wurden zehn Personen interviewt, die in Verfahren verurteilt wurden, die von der Polizei als OK-Formen angesehen wurden. Diese Straftäter wurden nach ihrer Einschätzung von OK und den dabei geführten Ermittlungen befragt. Da fünf der interviewten Straftäter in den Strafverfahren als so genannte Kronzeugen aufgetreten waren, wurden diesen ergänzend Fragen zum System des Zeugenschutzes gestellt (Kapitel 20-21).

Nach der Beschreibung der in den Interviews gewonnenen Erkenntnisse wird abschließend (Kapitel 22) der Frage nachgegangen, ob sich aus der empirischen Untersuchung die Tragfähigkeit der bisherigen OK-Definition ergibt bzw. weitergehend, ob sich eine Form kriminellen Verhaltens feststellen lässt, die sinnvoller weise mit dem Begriff OK belegt werden kann. Auch wird erörtert, ob sich organisierte Kriminalität nicht eher als eine Bezeichnung für einen neuen Verfahrenstyp darstellt, der sich unter diesem Begriff etabliert hat und der in vielfältigen Beziehungen quer zu dem herkömmlichen Strafverfahren liegt, auf das die Strafprozessordnung bisher im wesentlichen zugeschnitten ist.

- $\quad$ Arbeitsplanung 2004:

Die Publikation der Habilitationsschrift ist für die erste Jahreshälfte vorgesehen. Weitere Veröffentlichungen zu den Ergebnissen des Projekts sind in Vorbereitung. 
- Zum Projekt vorliegende neuere Veröffentlichungen:

KINZIG, J.: Die strafrechtliche Verfolgung organisierter Kriminalität - Eindrücke aus einem empirischen Forschungsvorhaben. In: Kriminologie zwischen Grundlagenwissenschaften und Praxis. Hrsg. V. Dittmann \& J.-M. Jehle. Forum Verlag Godesberg 2003, 345-361.

KINZIG, J.: Organisierte Kriminalität in Deutschland: Begriff - Rechtliche Maßnahmen - empirische Erkenntnisse. Angewandte Sozialforschung 23. Heft 1/2, 27-40 (2003) sowie Erwiderung zu einer Anmerkung von Friedrich Schneider, 44.

\subsubsection{Organisierte Kriminalität im internationalen Kontext}

- $\quad$ Bearbeiterin: Anna Luczak (Juristin)

- $\quad$ Zeitrahmen: 2001 bis 2004

- $\quad$ Projektstatus: in Bearbeitung

- $\quad$ Projektbeschreibung: (zugleich Promotionsvorhaben)

\section{Ziel der Studie}

Auf internationaler wie auf europäischer Ebene besteht ein breiter Konsens, dass gegen die so genannte organisierte Kriminalität in besonderer Art und Weise vorgegangen werden muss. In diesem $\mathrm{Zu}$ sammenhang ist ein vorrangiges Ziel der an diesbezüglichen Entscheidungen und der Entwicklung von Strategien beteiligten Akteure die supranationale Koordination und darüber hinausgehend die Vereinheitlichung entsprechender Maßnahmen.

Angesichts dessen stellt sich die Frage, ob überhaupt und inwieweit derartige Schritte notwendig und gerechtfertigt sind. Voraussetzung für die kriminalpolitische Notwendigkeit von Koordination und Vereinheitlichung auf internationaler Ebene ist, dass eben dort auch ein bestimmtes Phänomen "organisierte Kriminalität" existiert, das im Verhältnis zu traditionellen Formen der Kriminalität eine besondere Bedrohung darstellt. Um herauszufinden, ob diese Voraussetzung tatsächlich erfüllt ist, wird in dieser Studie das Verständnis von organisierter Kriminalität, wie es in verschiedenen Ländern vorherrscht, analysiert und verglichen.

Einen elementaren Bestandteil dieses Verständnisses bilden dabei die mit dem Phänomen in Zusammenhang gebrachten rechtlichen und tatsächlichen Umgestaltungen des jeweiligen Strafrechts- und Strafprozessrechtssystems. Neben ihrer Bedeutung für die Begriffsprägung sind die einzelstaatlichen Maßnahmen auch für die Klärung der Frage von Belang, inwieweit sich aus den jeweiligen nationalen Lösungsansätzen generelle Vorgaben für das internationale Vorgehen ableiten lassen.

\section{Inhalt der Studie}

Zur Beantwortung der Frage, ob ein Vorgehen gegen organisierte Kriminalität auf internationaler Ebene kriminalpolitisch notwendig und gerechtfertigt ist, soll in einem ersten Schritt geklärt werden, ob eben dort eine besondere Bedrohungslage aufgrund dieser Erscheinungsform von Kriminalität überhaupt nachzuweisen ist.

In den politischen Konzepten oder Dokumenten zu internationalen Maßnahmen wird die Existenz einer derartigen Gefahr stillschweigend vorausgesetzt, ohne dass sie konkret belegt würde. Auch von Seiten der Wissenschaft ist ein eindeutig fassbares Phänomen "organisierte Kriminalität" bisher weder empirisch nachgewiesen noch theoretisch - sei es über eine Definition oder über ein Konzept - unstreitig erfasst. Die Polizeien wiederum legen ihrer Tätigkeit zumeist sehr breite Begriffskonzeptionen 
zugrunde, aus denen nur unter großen Schwierigkeiten eindeutige Schlussfolgerungen in Hinblick auf die reale Bedrohungssituation zu ziehen sind.

Zusammenfassend lässt sich sagen, dass der in den internationalen Konzepten verwandte Begriff "organisierte Kriminalität" inhaltlich unbestimmt und zudem ungeklärt ist, ob und in welchem Ausmaß faktisch eine besondere Form von Kriminalität zu beobachten ist, die nicht nur die Existenz des Begriffs, sondern auch die dagegen unternommenen rechtlichen und politischen Schritte rechtfertigen würde.

Um diese Lücke zu schließen, wird in der vorliegenden Arbeit zunächst versucht, zu eruieren, was in einzelnen Ländern unter organisierter Kriminalität verstanden wird. Denn aus dem Verständnis von organisierter Kriminalität in verschiedenen Ländern lassen sich in zweierlei Hinsicht Rückschlüsse ziehen. Zum einen zeigt ein Vergleich des jeweiligen auf nationaler Ebene vorherrschenden Verständnisses, ob es überhaupt ein international identisches Phänomen dieses Namens oder jedenfalls einen kleinsten gemeinsamen Nenner von unter diesem Begriff kursierenden Erscheinungen gibt. Zum anderen kann der Inhalt dessen, was unter dem Begriff verstanden wird, an sich Hinweise darauf geben, inwiefern "organisierter" im Verhältnis zu "sonstiger" Kriminalität ein besonderes Bedrohungspotential zukommt.

Für eine länderübergreifende Untersuchung des Verständnisses bietet sich die Sekundäranalyse als Methode an, bei der bereits vorhandenes Material unabhängig von dem ursprünglichen Zweck und Bezugsrahmen ausgewertet wird. Es gibt verschiedene Quellen, aus denen sich das jeweilige Verständnis von organisierter Kriminalität herleiten lässt, die sich sowohl in ihrer Herkunft aus den Bereichen Polizei, Politik oder Wissenschaft als auch in ihren jeweiligen Ansätzen unterscheiden. Die Bandbreite der Zielrichtungen, die die jeweiligen Texte verfolgen, die Jahresberichte des Innenministeriums oder wissenschaftliche Zeitschriftenbeiträge sein können, bewegt sich dabei zwischen dem Darstellen von Erfolgen der Strafverfolgungsbehörden und der grundsätzlichen Infragestellung des Bestehens einer besonderen Gefahr.

Aus der Analyse aller den Diskurs zu organisierter Kriminalität prägenden Texte soll sich schließlich ein Konzept ergeben, durch das der fehlenden Eindeutigkeit der Begrifflichkeit abgeholfen werden soll. Darüber hinaus soll das Konzept eine Einschätzung in Bezug auf die Art und damit das Bedrohungspotential der Kriminalität ermöglichen.

In einem zweiten Schritt sollen die nationalen Rechtsordnungen daraufhin untersucht werden, wie das jeweils festgestellte Konzept organisierter Kriminalität dort seinen Niederschlag findet. Insbesondere anhand eines Vergleichs der Strafbarkeit assoziierten Vorgehens oder des Umgangs mit bestimmten Ermittlungs- und Verfahrensproblemen, die auf der Art der Kriminalität beruhen, soll festgestellt werden, inwieweit der Diskurs zur organisierten Kriminalität durch strafrechtssystematischen Veränderungswillen geprägt wurde.

Schließlich sollen die so gefundenen Ergebnisse durch die qualitative Befragung von Expertinnen und Experten in den jeweiligen Einzelstaaten eine Vertiefung erhalten, die sowohl die festgestellten Vorstellungen von organisierter Kriminalität in den einzelnen Ländern validieren als auch darüber Auskunft geben sollen, ob die verschiedenen normativen und tatsächlichen Veränderungen des Rechtssystem gut geheißen oder für ergänzungsbedürftig gehalten werden. Ferner sollen die Expertinnen und Experten dazu Stellung nehmen, welche internationalen Maßnahmen sie für sinnvoll halten.

Insgesamt soll aus den im Rahmen der Sekundäranalyse wie der qualitativen Befragung ermittelten Erkenntnissen zunächst für die einzelnen untersuchten Länder eine Konzeption von organisierter Kriminalität entwickelt und eruiert werden, in welchem Zusammenhang davon gesprochen wird. Darauf aufbauend soll aufgrund einer Zusammenstellung der einzelnen Konzepte eine Antwort auf die Frage gefunden werden, ob ein international koordiniertes Vorgehen notwendig und gerechtfertigt wäre. 
Die Auswahl der in die Untersuchung einbezogenen Länder richtete sich danach, ob in den entsprechenden Ländern Quellen für die Sekundäranalyse vorhanden sind. Um Vergleichbarkeit zu gewährleisten, bot sich die Einengung der in Frage kommenden Staaten auf den europäischen Raum, genauer die EU-Mitgliedstaaten, an, da es hier zum einen die am weitesten reichenden Konzeptionen zur Vereinheitlichung und zum anderen in Gestalt der jährlichen Berichte an Europol zumindest eine empirische Erhebung gibt, die in allen Ländern an denselben Parametern ausgerichtet ist.

Innerhalb der europäischen Staaten ist die Entwicklung der Auseinandersetzung mit organisierter Kriminalität unterschiedlich weit fortgeschritten. Zu den Ländern, in denen neben den jährlichen Berichten an den Europarat und die Europäische Union auch eigenständige Datenerhebungen durchgeführt werden sowie umfangreiche Literatur zum Thema vorliegt, zählen neben Deutschland insbesondere die Niederlande und England.

Die bereits beendete Untersuchung des die organisierte Kriminalität betreffenden Diskurses in England hat ergeben, dass der Begriff seit den 70er Jahren Erwähnung findet, seine Deutung in diesem Zeitraum mannigfachen Veränderungen unterlag und die Begründung, dass das Vorgehen gegen organisierte Kriminalität dies unabdingbar erfordere, eine grundsätzliche Umstrukturierung der Polizeiarbeit begleitete. Kernpunkte der inhaltlichen Konzeption sind in England die Netzwerkstruktur, die Ausrichtung auf die illegalen Märkte und die besonderen Taktiken der organisierten kriminellen Gruppierungen. Wichtigstes Stichwort in Zusammenhang mit den eingeführten Maßnahmen ist das so genannte pro-active polizeiliche Vorgehen, wonach unabhängig von der Kenntniserlangung von einer konkreten Straftat aufgrund eines eher abstrakten Verdachts gegen bestimmte Personengruppen Ermittlungen eingeleitet werden. Von vordringlicher Bedeutung ist ferner der zunehmende Einsatz verdeckter Methoden der Ausforschung.

\section{Abstract}

Die Sekundäranalyse verschiedener Quellen in Hinblick auf die Frage, was auf nationaler Ebene in Deutschland, England und den Niederlanden unter organisierter Kriminalität verstanden wird und welche Maßnahmen damit in Zusammenhang gebracht werden, wird zeigen, ob auf internationaler Ebene ein derartiges spezifisches Phänomen festzustellen ist. Daraus wird sich ergeben, ob und in welcher Form ein zwischenstaatlich koordiniertes Vorgehen gerechtfertigt ist.

\section{- $\quad$ Arbeitsbericht 2003:}

Im Jahr 2002 wurde die Literaturrecherche beendet und die Gliederung der Arbeit, dabei insbesondere die Fragestellung in Hinblick auf die Länderberichte ausgearbeitet. Ferner wurde mit dem Landesbericht England die dortige, die organisierte Kriminalität betreffende Situation abschließend behandelt. Im Jahr 2003 wurde der Landesbericht Niederlande durchgeführt und abgeschlossen. Im Zuge dessen wurden bereits erste vergleichende Ansätze verfolgt.

- $\quad$ Arbeitsplanung 2004:

Bis Januar 2004 soll weiter der Deutschland betreffende Länderbericht erstellt und mit dem auf England bezogenen Bericht in einem Ergebnisteil zusammengestellt werden, der die Gemeinsamkeiten und Unterschiede der jeweiligen nationalen Diskurse zu organisierter Kriminalität aufzeigen soll. Zur Überprüfung dieses Ergebnisteils sollen die ExpertInneninterviews durchgeführt werden. Diese sollen außerdem zu den Schlussfolgerungen dazu überleiten, ob und inwieweit auf internationaler Ebene Maßnahmen ergriffen werden sollten. 
- $\quad$ Ausgewählte Literatur:

AlBRECHT, H.-J.:. Organisierte Kriminalität - Theoretische Erklärungen und empirische Befunde. In: Organisierte Kriminalität und Verfassungsstaat. Hrsg. H.-J. Albrecht. Heidelberg 1998, 1-40.

BESOZZI, C.: Organisierte Kriminalität und empirische Forschung. Chur/Zürich 1997, 117 S.

GROPP, W. \& HUBER, B. (Hrsg.): Rechtliche Initiativen gegen organisierte Kriminalität. edition iuscrim, Freiburg i. Br. 2001, $991 \mathrm{~S}$.

KERNER, H.-J.: Organisierte Kriminalität: Realitäten und Konstruktionen. Neue Kriminalpolitik, 40-46 (1995).

KINZIG, J. \& LUCZAK, A. (im Erscheinen): Organized Crime in the European Union and in particular in Germany. In: Instituto Nacional des Ciencias Penales (INACIPE), Combate al la delincuencia organizada (erscheint in spanischer Sprache).

KINZIG, J. \& LUCZAK, A. (im Erscheinen): Organized Crime Today. Germany. In: Organized Crime in Europe: Manifestations and Policies in the European Union and Beyond. Hrsg. C. Fijnaut, L. Paoli.

LUCZAK, A.: Keine Monopole im illegalen Markt. Die Fehldeutung des Drogenhandels. Forum Recht 2, 44-47 (2003).

LUCZAK, A.: Mafiakraken. Die Konstruktion "organisierte Kriminalität". Forum Recht 2, 44-46 (2002).

MACK, J.: The Crime Industry. Westmead, Farnboruogh, Hants., England 1975, 209 S.

Militello, V., ARNOlD, J. \& PAOli, L. (Hrsg.): Organisierte Kriminalität als transnationales Phänomen. edition iuscrim, Freiburg i. Br. 2000, 445 S.

PÜTTER, N. (1998): Der OK-Komplex. Münster 1998, 450 S.

\subsubsection{The Double Construction of Crime. Patterns of Definition and of Organization of Crime in Two European Cities (Milan and Frankfurt)}

- $\quad$ Bearbeiterin: Letizia Paoli (Soziologin)

- $\quad$ Zeitrahmen: 1998 bis 2004

- $\quad$ Projektstatus: in Bearbeitung

- $\quad$ Projektbeschreibung:

(vgl. dazu bereits die Tätigkeitsberichte 1998/1999, S. 103; 2000/2001, S. 126)

As explained in previous Tätigkeitsberichte, the present study aims to analyse the patterns of definition and social organisation of crime during the post-war period in two European cities: Milan and Frankfurt. The underlying conviction is that crime does not exist in se, but must, in a social constructivist perspective, be conceived as the result of a double process of social construction. First of all, crime is the result of an on-going process of social interaction through which specific sets of actions are perceived as dangerous or deviant, and are codified as criminal. Secondly, crime is the product of individuals' actions, individuals who violate public laws, taking precautions to avoid prosecution and occasionally establishing relationships with each other.

To examine this double process of social construction, it was decided to focus on the topic of organised crime. I) On the one hand, organised crime has, in fact, clearly been 'constructed' as a social problem over the past ten years. II) On the other hand, the patterns of interaction between offenders emerge most vividly in those spheres of activity that are usually referred to with the term 'organised crime': that is, illegal markets. In order to circumscribe the fieldwork, the primary data collection was restricted to Frankfurt's and Milan's illegal drug markets. This decision was also prompted by the fact that in 1999 Paoli won a tender to study the drug markets of the two cities on behalf of the European 
Monitoring Centre for Drugs and Drug Addiction (see the project 'Drug Markets in Frankfurt and Milan').

I) Understanding how organised crime came to be constructed as a social problem in the two countries under consideration is the first of the two major aims of the present study. In fact, its first part intends to reconstruct how the public sphere, as well as the legislative and law enforcement bodies of the two countries, and, specifically, those of the two cities under examination, have framed the problem of organised crime.

II) The second part of the present research is devoted to the analysis of the organisation of crime in Frankfurt and Milan. In particular, its goals are the following:

1. To reconstruct the development of illegal markets in the two cities since the end of the Second World War, as recorded by law enforcement bodies, the media, and the public

2. To focus on the development and the organisation of the urban illegal markets, and specifically the illegal drug market, exploring as far as possible their links to national and foreign suppliers

3. To examine the organisation and action of drug-supplying enterprises

4. To look for the presence of organised clusters of illegal actors - such as mafia families terrorist groups or other crime - assessing their position and role in the criminal economy, and examining their internal organisation and culture

5. To investigate the role of non-conventional criminal actors in illegal markets (i.e. actors who are not involved full-time in illegal activities and do not regard themselves as criminal)

6. To analyse the relationships - or to highlight the lack of relationships - among the abovementioned actors. In particular, special attention will be given to the relationships (or absence of) among subjects involved in illegal activities with a different ethnic or regional origin (for example, Turkish vis-à-vis Italian drug traffickers), as well as a contrasting socio-economic background or criminal expertise (i.e. white-collar criminals vis-à-vis members of traditional organised crime groups).

The organisation of the two cities' illegal markets will ultimately be confronted with the different conceptions of organised crime developed in the two contexts.

- $\quad$ Progress Report 1998-2003:

To investigate how organised crime came to be perceived as an important social problem, a media analysis in both cities was conducted in 1998-2000. This investigation focused in particular on Frankfurt's and Milan's two main newspapers, which are also two of the most widely sold in Germany and Italy: the Frankfurter Allgemeine Zeitung (FAZ) and Il Corriere della Sera. In 1993, both newspapers started to be available on CD-Rom. A systematic analysis of the articles on organised crime, published from 1993 to 1999, was conducted. To fully appreciate the emergence of organised crime as a problem, the CD-Rom investigation was complemented in Frankfurt by an archival research. Due to friendlier conditions and lower prices, the archival research was started at the Frankfurter Rundschau, Frankfurt's second-largest newspaper. An analogous investigation was pursued in 2000 in the Milanese archive of Corriere della Sera. Additionally, the articles on organised crime and illegal markets, which were published in the two countries' most important weeklies, were selected and are now being analysed: Der Spiegel and L'Espresso.

In addition to the analysis of the media discourse, interviews with experts - prosecutors, judges, police officials, journalists and politicians of the two cities - were conducted. Fifteen in-depth interviews were carried out both in Frankfurt and Milan. These interviews fulfil the aims of both the first and second parts of the project. In fact, they are utilised not only to reconstruct the emergence of organised crime as a social problem, but also to analyse the development and organisation of Frankfurt's and Milan's illegal markets and, specifically, the illegal drug market. 
Interviews were finally conducted with the participants of the two cities' illegal markets. With the help of Nimet Güller and Salvatore Palidda, Paoli interviewed seventy drug users and suppliers in Frankfurt and fifty-five in Milan. To ensure the comparability of the results, the in-depth interviews were conducted on the basis of an open-ended questionnaire, which was translated both in English and Italian. Twelve interviews with drug dealers were carried out in one high-security prison of the State of Hesse: Butzbach. Additional interviews with convicted drug offenders will be carried out in 2004, in the Hessian prison of Schwalmstadt and the Milanese prison of San Vittore.

Interviews are complemented by the analysis of the academic, government and grey literature, statistics, police reports, and criminal cases. In both cities, statistics and police reports were collected and studied. At each of the two sites, moreover, fifty criminal cases were collected and analysed. The analysis of the criminal cases will be furthered in 2004 .

On the basis of the data collected so far, several articles on both the debate and the empirical manifestations of organised crime in Italy and Germany were published by Paoli between 1999 and 2003.

- Work Plan 2004:

In 2004 primary and secondary data will be collected to conclude and update the analysis of the Frankfurt and Milan drug markets (i.e. the second part of the prject). The data collection for the first part of the study is already completed and its findings have served as the basis for the introductory and comparative chapters of the book 'Organised Crime in Europe: Conception, Patterns and Policies in the European Union and Beyond', which is edited by Paoli together with Cyrille Fijnaut (see the description of the related project in this Tätigkeitsbericht). The findings concerning the illegal drug markets in Frankfurt and Milan will be published in a separate report (see the project 'Drug Markets in Frankfurt and Milan').

As the principal investigator of the current project has been largely working on other projects with tighter deadlines, the present project will not end with an hoc final report. A comparison of the different conceptions of organised crime in Germany and Italy, on the one hand, and the organisation of the two cities' illegal markets, on the other hand will take place exclusively in Paoli's Habilitationsschrift and in several shorter publications.

- $\quad$ Funding:

Funded by the European Union, Marie Curie Programme (1998-2001).

- Selected Publications:

PAOLI, L. (2002): Mafia Brotherhoods: Organized Crime, Italian Style, Oxford University Press, New York 2003, 289 S.

PAOLI, L. (2002): Il crimine organizzato. In: Rapporto sulla criminalità in Italia. Hrsg. Marzio Barbagli. Il Mulino, Bologna 2003, 275-300.

PAOLI, L. (2002): Il mercato delle droghe In: Rapporto sulla criminalità in Italia. Hrsg. Marzio Barbagli. Il Mulino, Bologna 2003, 81-108.

PAOLI, L. (2002): The Invisible Hand of the Market: The Illegal Drugs Trade in Germany, Italy, and Russia. In: Criminal Finances and Organising Crime in Europe. Hrsg. Petrus C. van Duyne, Klaus van Lampe and James L. Newell. Wolf, Nijmegen 2003, 19-40.

PAOLI, L. (2002): The Italian Mafia. In: D. Levinson (Ed.): Encyclopedia of Crime and Punishment. Sage, London.

PAOLI, L. (2002): The Paradoxes of Organised Crime. Crime, Law and Social Change 1, 1-47.

PAOLI, L. (2001): Mafia e Paradigm Shifts: atteggiamento, impresa, industria della protezione o fratellanze multifunzionali e segrete? Polis 4.

PAOLI, L. (2001): Il crimine all'italiana. In: S. Graubard \& T. Padoa-Schioppa (Eds.): Garzanti Il caso italiano 2. Dove sta andando il nostro paese?, Milano 
PAOLI, L. (2001): Mafia: modello universale di crimine organizzato? Rassegna italiana di sociologia XLII, 579-608.

PAOLI, L. (2001): Da Caino a Caino. Narcomafie IX (10), 35-38

PAOLI, L. 2001): Organised Crime in Italy and Germany: A Sociological and Criminological Perspective. In: V. Militello \& B. Huber (Eds.): Towards a European Criminal Law Against Organised Crime. Proposals and Summaries of the Joint European Project to Counter Organised Crime. edition iuscrim, Freiburg i. Br., 161-166.

PAOLI, L. (2001): La mafia è sconfitta? Il Mulino L, 477-485.

PAOLI, L. (2001): Crime, Italian Style. Daedalus Summer, 157-185.

Paoli, L. (2001): Criminal Fraternities or Criminal Enterprises? In: P. Williams \& D. Vlassis (Eds.): Combating Transnational Crime. Concepts, Activities and Responses. Frank Cass, London, 88-108.

PAOLI, L. (2000): Fratelli di Mafia: Cosa Nostra e 'Ndrangheta. Il Mulino, Bologna.

Militello, V., ARNOLD, J., \& PAOLI, L. (Eds.) (2000): Organisierte Kriminalität als transnationales Phänomen: Erscheinungsformen, Prävention und Repression in Italien, Deutschland und Spanien. edition iuscrim, Freiburg i. Br.

Militello, V., PAOLI, L. \& ARNOLD, J. (Eds.) (2000): Il crimine organizzato come fenomeno transnazionale: manifestazioni empiriche, prevenzione e repressione in Italia, Germania e Spagna. edition iuscrim, Freiburg i. Br.

PAOLI, L. (2000): Organisierte Kriminalität: Erscheinungsformen, Prävention und Repression in Italien, Deutschland und Spanien. In: Max-Planck-Gesellschaft (Ed.): Jahrbuch 2000. Vandenhoeck \& Ruprecht, Göttingen, 857-863.

PAOLI, L. (2000): La criminalità organizzata, Appendice 2000, Enciclopedia Italiana, Roma, Treccani, 997-1004.

PAOLI, L. (2000): Il crimine organizzato in Italia e in Germania. In: V. Militello, L. Paoli \& J. Arnold (Eds.): Il crimine organizzato come fenomeno transnazionale: manifestazioni empiriche, prevenzione e repressione in Italia, Germania e Spagna. edition iuscrim, Freiburg i. Br., 85-122.

PAOLI, L. (2000): Das Organisierte Verbrechen in Italien und Deutschland. In: V. Militello, J. Arnold \& L. Paoli (Eds.): Organisierte Kriminalität als transnationale Phänomen: Erscheinungsformen, Prävention und Repression in Italien, Deutschland und Spanien. edition iuscrim, Freiburg i. Br., 55-62.

PAOLI, L. (1999): Organized Crime in Germany. In: The Mafia. 150 years of facts, stories and faces, CD-Rom. Cliomedia Officina, Torino 1999.

PAOLI, L. (1999): Organised Crime: Criminal Organisations or the Organisation of Crime? In: H.-J. Albrecht (Ed.): Forschungen zu Kriminalität und Kriminalitätskontrolle am Max-Planck-Institut für ausländisches und internationales Strafrecht. edition iuscrim, Freiburg i. Br., 135-173.

PAOLI, L. (1999): Die italienische Mafia: Paradigma oder Spezialfall der organisierten Kriminalität? Monatsschrift für Kriminologie und Strafrechtsreform 6, 425-440.

Selected Lectures:

"The Mafia in Italy and the United States". Law School, New York University: 21.03.2002

"Mafia and Organized Crime". "G. Beto Lecture",.Criminal Justice Center, Sam Houston State University, Huntsville: 27.03.2002.

"The Fight Against the Mafia in Italy: Lessons for the United States". Criminal Justice Center, Sam Houston State University, Huntsville: 28.03.2002

"The Price of Freedom: Illegal Drug Markets and Drug Policies in Post-Soviet Russia". Criminal Justice Center, Sam Houston State University, Huntsville: 01.04.2002.

"»The Invisible Hand of the Market«: Illegal Drug Trade in Germany, Italy, and Russia". Criminal Justice Center, Sam Houston State University, Huntsville: 02.04.2002.

"Mafia = or Organised Crime?". 1st European Conference on Drug Trafficking and Law Enforcement, London, 11.10.2001.

"Mafia, organisierte Kriminalität und illegale Märkte". Schulvortrag anlässlich der Hauptversammlung der Max-Planck-Gesellschaft 2001 in Berlin, Max-Reinhardt-Oberschule, 21.6.2001. 
"Die Mafia in Italien: Ihre Geschäfte und ihre Gewinne". Studientagung für Polizeibeamte, Richter, Staatsanwälte und Interessierte: "Geldwäsche, Gewinnabschöpfung und Zeugenschutz: Wege zur Bekämpfung der Organisierten Kriminalität? - Ein europäischer Vergleich", Katholische Akademie Trier, 3.-4.3.2000 - 13.12.2000 - 16.-17.5.2001.

"Mafia: Modello universale di crimine organizzato?". Convegno sul tema: "I sistemi informativi per la prevenzione della criminalità e la giustizia", Facoltà di Scienze Statistiche, Bologna: 27.10.2000.

"Crime and Illegality: Is Italy a Special Case?". Daedalus Conference on Italy, European University Institute, Firenze, 15.7.2000.

"Die italienische Mafia". Sonderprogramm der baden-württembergische Polizeifachhochschule, Villingen-Schwenningen, 16.5.2000.

"Die italienische Mafia: Paradigma oder Spezialfall der organisierten Kriminalität?". Seminare am hessischen Landeskriminalamt, Wiesbaden, 21.1.2000.

\subsubsection{Organized Crime in Europe: Manifestations and Policies in the European Union and Beyond}

- $\quad$ Bearbeiter(innen): Letizia Paoli (Projektkoordinatorin, Soziologin), Cyrille Fijnaut (Projektkoordinator, Jurist, Tilburg and Leuven Universities) and other external researchers

- Zeitrahmen: 2001 bis 2004

- $\quad$ Projektstatus: in Bearbeitung

- $\quad$ Projektbeschreibung:

(vgl. dazu auch den Tätigkeitsbericht 2000/2001, S. 124)

Long regarded as an issue concerning only a limited number of nations, during the last fifteen years organised crime has been recognised as a truly international problem. Today, at the dawn of the twenty-first century, it attracts the attention of international organisations as well as of state institutions and the general public of many countries, parties that did not previously consider themselves affected by the problem. Since the late 1980s, in fact, the expression 'organised crime' has been used as a catchphrase to express the growing anxieties of national and supranational public institutions and private citizens in view of the expansion of domestic and world illegal markets, the increasing mobility of criminal actors across national borders, and their perceived growing capability to pollute the licit economy and undermine political institutions.

In the past decade, numerous initiatives have been launched to tackle the problem of organised crime at both the national and international level, culminating in the adoption of a 'United Nations Convention on Transnational Organised Crime' in December 2000. Despite these international coordination efforts, very little comparative research has as yet been conducted on the perception and empirical patterns of organised crime in Europe, or on the concrete implementation and the effectiveness of the organised crime control policies of the single European States. The present project, which is jointly coordinated by Letizia Paoli and Cyrille Fijnaut, aims to fill such a gap.

The Project Aims and Structure: Relying on the expertise and contacts of the two projects coordinators, a team of leading international scholars was set up to analyse the current and historical manifestations of organised crime in several European countries and their organised crime control policies.

To make our endeavour more interesting, we decided not to focus merely on the Member States of the European Union, but instead adopted a wider, geographical definition of Europe, which by and large takes the membership criteria of the Council of Europe into account. Thus, in addition to the current and future EU Member States, the project includes a few other European countries, that have either no 
interest or no means to enter the European Union, but host organised crime activities and actors representing a potential or actual threat to the European Union. In particular, experts from the fourteen following countries were recruited:

\begin{tabular}{|l|l|}
\hline \multicolumn{1}{|c|}{$\quad$\begin{tabular}{l|} 
Current and Future \\
EU-Member States:
\end{tabular}} & \multicolumn{1}{|c|}{ Non EU-Member States: } \\
\hline Denmark & Albania \\
France & Russia \\
Germany & Switzerland \\
Ireland & Turkey \\
Italy & \\
The Netherlands & \\
Spain & \\
United Kingdom & \\
Czech Republic & \\
Poland & \\
\hline
\end{tabular}

Depending on their interests and specialisation, the country experts were requested to write a report on either the historical and current patterns of organised crime or the control policies. The project, as well as the resulting book publication, is divided in three major parts:

\section{Part I: The History of Organised Crime \\ Part II: Organised Crime Today \\ Part III: Organised Crime Control Policies}

Only a few of the above-mentioned countries are included in Part I: Italy, The Netherlands, Germany, France, Russia and Turkey. This selection is based on several factors, ranging from the roots of the organised crime phenomenon itself, to the extent of historical research on crime and deviance and, last but not least, the availability of experts.

All fourteen countries are, instead, involved in the following two parts of the project that respectively concern the current organised crime patterns and the organised crime control policies. Depending on the country, one or two national experts were selected to participate in the second and third part of the project.

Each of the national experts involved in Part II was commissioned a report on the perceptions and the empirical manifestations of organised crime in his/her country of origin and/or specialisation. As far as possible, the two project coordinators selected scholars who were currently carrying out empirical research on these issues. Besides summarising the findings of their own research projects, the experts participating in Part II were invited to rely on a plurality of sources: police statistics and reports, judicial proceedings, reports written by other government and private bodies and media articles in addition to the scientific and grey literature.

The research hypothesis underlying the whole project is that organised crime is defined and understood in various ways in different countries and this plurality of definitions constitutes a relevant hindrance to smooth international cooperation. Hence, each national expert involved in Part II was asked to open his/her report with a section on the perception of organised crime in his/her country. 
A second section of each country report is devoted to the most relevant patterns of organised crime in that specific context. To ensure comparability, however, each national expert was also asked to focus on some illicit activities considered typical of organised crime (such as drug trafficking, the smuggling and exploitation of prostitutes and racketeering) and to describe how and by whom these activities are carried out. In the third section of their reports, the experts are called to assess the infiltration of organised crime into the legitimate economy and its capability to corrupt government officials and to pollute the political life of each selected country.

Likewise, all the contributions of Part III follow a common outline. A first section analyses the legal provisions that aim to prevent and/or repress organised crime. The second section focuses on institutional reforms affecting the government agencies responsible for the prevention and control of organised crime. In the third section, the authors were asked to assess the effectiveness of the policies being implemented, the threat they may represent to individuals' rights and the support they receive from the civil society.

Written by the two project coordinators, the final chapter of each part is devoted to cross-country comparisons. Fijnaut and Paoli will also write the opening chapters of each part. At the beginning of Part I, Paoli will critically summarise the debate on organised crime from the 1920 s to the present. At the onset of the following part, Fijnaut will describe organised crime in Europe, as it emerges from the reports published by supranational organisations, ranging from Europol to the Council of Europe. Finally, in Part III, Fijnaut will also be in charge of reviewing the policy initiatives adopted by the European Union and Council of Europe to prevent and repress organised crime.

- $\quad$ Progress Report 2001-2003:

To ensure comparability, at the very beginning of the project Paoli and Fijnaut developed a detailed outline, specifying the issues to be dealt with and the methods to be employed in each of the project parts. The outline was discussed at an informal meeting with several project participants, which took place at the margins of the conference on the UN Convention on Transnational Organised Crime, hosted by the Max Planck Institute in Freiburg in December 2001. In early 2002, the revised outline was sent out to all project participants. These, then, had time up to November 2002 to write the first draft of their reports, which were then circulated among all the project participants. With the financial support of the Fritz-Thyssen-Stiftung, an international conference was organised from February 27 to March 1, 2003 at the Max Planck Institute in Freiburg to discuss the draft country reports and single out both the peculiarities of each country and transnational characteristics and trends.

After the conference, each country report was commented by the two project coordinators and the comments were sent to the authors. These then had time to revise and finalise their reports, most of which were submitted during the summer of 2003.

The reports are currently being revised and edited by the two project coordinators and by a native English-speaking copyeditor. Fijnaut and Paoli are currently drafting the introductory and comparative chapters.

- Work Plan 2004:

Fijnaut and Paoli will further the revision of the country reports and complete the introductory and comparative chapters of the book

The book will be published in the first half of 2004 by Kluwer and will be entitled: 'Organised Crime in Europe: Conception, Patterns and Polices in the European Union and Beyond'

- $\quad$ Funding:

The project has been partially funded by the Fritz-Thyssen-Stiftung. 
- $\quad$ Links:

Fritz-Thyssen-Stiftung

Tilburg and Leuven Universities

\subsubsection{Drug Markets in Frankfurt and Milan}

- Bearbeiter(innen): Letizia Paoli (Projektkoordinatorin, Soziologin), Nimet Güller (Juristin), Salvatore Palidda (Soziologe, externer italienischer Mitarbeiter)

- $\quad$ Zeitrahmen: 1999 bis 2005

- $\quad$ Projektstatus: in Bearbeitung

- $\quad$ Projektbeschreibung:

(vgl. dazu bereits die Tätigkeitsberichte 1998/1999, S. 109; 2000/2001, S. 133)

By analysing the illegal drug markets of two major European cities, the project aims to fill a serious gap in the European drug research. In fact, as a recent review of the European Monitoring Centre on Drugs and Drug Addiction (EMCDDA) proves, drug market research is still rather underdeveloped in Europe. Though a few studies on single drug (usually heroin) markets were carried out, the focus has usually been on consumption patterns, whereas the interplay of demand and supply has hardly been studied yet. This interplay is, instead, the main research object of the present project. Moreover, the latter does not concern a single illegal substance, but analyses and compares the Frankfurt and Milan drug markets as a whole.

The research project is co-ordinated by Letizia Paoli, who also leads the fieldwork at both sites. During the first phase of the research, she was assisted, in Frankfurt, by Nimet Güller (MPI, Freiburg and Universität Bielefeld), in Milan by Salvatore Palidda (Politecnico di Milano).

The first phase of the project, which began in September 1999 and lasted twelve months, was financed by the EMCDDA. It was originally planned to extend the project to three additional cities during a year-long second phase: Amsterdam, Copenhagen, and Paris. Due to the unavailability of funds, however, this extended second phase was cancelled by the EMCDDA. The research work will, thus, be completed in Frankfurt and Milan at the expenses of the Max Planck Institute. As Paoli has been in charge of other projects with more pressing deadlines, the fieldwork will resume in the course of 2004, after the other research projects are closed. The main aim of this second phase of fieldwork will be to understand how the drug markets in Frankfurt and Milan have changed since 2000.

- $\quad$ Report of Activities 1999-2001:

Ever since the project began, Paoli's team has employed a multifaceted methodology which emphasises qualitative research instruments and whose rationale is to collect information from as many different perspectives as possible. In particular, both primary and secondary sources have been used, as shown in Figure 1. ${ }^{1}$

1 In order to represent the sources graphically, we have relied on the distribution categories elaborated from the empirical observations of heroin markets made by several American and European researchers. These categories, however, have not been considered as a blueprint. In each city and for each substance, Paoli's team aims to assess to what extent local markets resemble or differ from this ideal-typical distribution system. 
Figure 1. THE DRUG DISTRIBUTION SYSTEM (Heroin): Sources and Research Methods

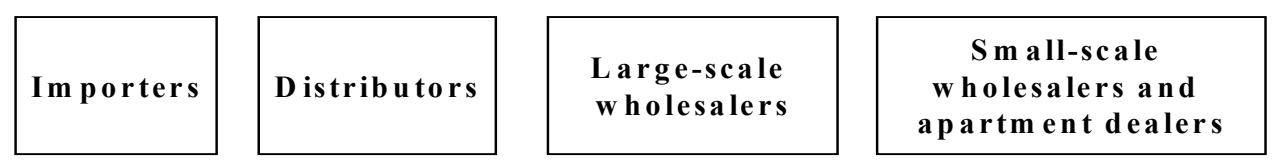

\begin{tabular}{|c|}
\hline Street and \\
appointment dealers, \\
user-sellers
\end{tabular}

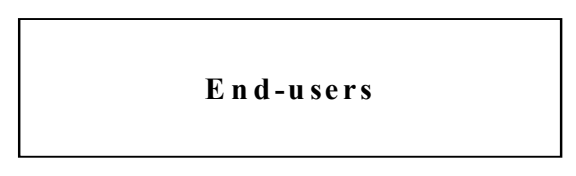

- Judicial and police documents

- Interviews with dealers in prison or through their lawyers

- Interviews with drug police, prosecutors, judges, and lawyers

- Data and reports from

drug treatment centres

- Interviews with drug treatm ent providers

- Interviews with 'light' and 'heavy' drug users and users/dealers reached with various methodologies

- Participant observation

- Interviews with minority dealers conducted by native speakers 
As far as primary sources are concerned, the research teams in Frankfurt and Milan have collected first-hand information from the four main actors of today's illegal markets: consumers, suppliers, law enforcement personnel, as well as public and private drug treatment providers. In particular, during 1999, 2000 and 2001 the two research teams carried out more than thirty interviews with law enforcement officials, public drug treatment providers, and the representatives of drug-related NGOs in each of the two cities. Additionally, seventy drug users and suppliers were interviewed in Frankfurt and fifty-five in Milan. In order to obtain standardised and comparable results, a questionnaire was developed. At both sites, more than half of the interviews with drug users and dealers were carried out by the core members of the two research teams, the rest by ad-hoc recruited interviewers.

Among secondary sources, four main ones can be listed:

- $\quad$ existing studies, including grey literature;

- the periodical and ad hoc information released by local and national law enforcement agencies, drug treatment services, and other public bodies;

- judicial files, and

- $\quad$ media articles and reports.

Besides collecting all the existing publication and grey literature on drug markets at the local, regional and national level, Paoli and her team collected more than fifty criminal cases in each of the two cities. These cases are to be added to a considerable sample of criminal cases that were examined by Paoli and her team members in both Milan an*d Frankfurt in previous research projects. The case sample will be updated with a limited number of new cases in 2004.

Additionally, the articles published by Milan's and Frankfurt's main dailies (respectively, Il Corriere della Sera and the Frankfurter Rundschau) on the local drug markets from the early 1970s onwards were collected and analysed.

- $\quad$ Preliminary Findings:

The preliminary findings that were gathered so far show surprising similarities between the Frankfurt and Milan drug markets. In both cities, drug markets seem to have evolved in parallel ways, by and large following analogous time sequences. The similarities are most evident on the demand side. In both cities, the substances preferred by the users, the latter's social characteristics and the meanings they attach to drug use seem to have evolved along roughly parallel paths over the last thirty years.

In the late 1960s and early 1970s, at both sites cannabis and LSD consumption spread among the youths who participated in the 1968 collective movement and who were most closely influenced by the 'flower power' American subculture. Around the mid-1970s opiates and then heroin made their appearance on both markets and heroin use spread among those who were disappointed by the failure of the youth protest movements and, increasingly among marginalised, lower-class youths.

While LSD largely disappeared from both cities in the late 1970s, during the following decade two large, parallel drug markets developed: one for heroin and one for cannabis. In both cities, these markets have always (with an initial exception in Frankfurt) been physically separate, as they have been located in different, though changing, parts of the two metropolises. During the 1990s, however, the polarisation of the illegal drug market was shaken by the diffusion of several new illegal drugs. Some of them, such as ecstasy, were indeed entirely new. Others, such as cocaine, amphetamines, and LSD, were largely rediscovered and/or became attractive to a wider pool of consumers. In both contexts, the turn of the century recorded a strong diffusion of cocaine, which has become a 'passe-partout' drug and is increasingly used by a wide-ranging spectrum of people. Since the early 1990s, even crack cocaine has registered a veritable boom on the Frankfurt open drug scene. Long a peculiarity of Frankfurt, crack cocaine has also become available in Milan in the late 1990s. 
The wider drug supply has been paralleled in both contexts by the growing diversification of drug consumers. Today the latter can no longer be described with reference to a single cluster of demographic, social, and cultural characteristics, nor can their drug use be explained by referring to one or few economic or social variables.

In both cities, there is a strong core of heavy drug addicts, for whom drug use and the search for drugs represent two of the most important daily activities. In Frankfurt as well as in Milan, the latter are estimated between 4.000 and 7.000. At both sites, a growing portion of these marginalised, dependent drug users are foreign migrants.

Neither in Frankfurt nor in Milan, however, are illegal drugs exclusively used by the former category of people, the so-called 'junkies'. Though they are the most visible component of the drug using population, the latter by no means exhaust the demand for illegal drugs in either city. Indeed, 'traditional' heavy drug addicts represent only a minority. At least some illegal drugs - above all, hashish, but also increasingly cocaine, ecstasy and other synthetic drugs - are regularly or occasionally consumed by dozens of thousands of teen-agers and young (and not so young) adults, who belong to all social strata and cultural backgrounds.

In Milan, about 30 percent of high-school students admit to having smoked cannabis at least once in their life and 8 percent say that they have used cocaine or acid. Roughly seven percent have allegedly used ecstasy and more than 50 percent have friends who use it. Analogous percentages of cannabis and cocaine users can also be estimated among Milanese in their twenties and thirties. At least 1214.000 residents of Frankfurt are assumed to smoke cannabis regularly, 6.000 of whom are young adults. About 24 percent of the German young adults (age 18-24) admit to having used cannabis at least once in their life, whereas 13.2 percent report use in the last 12 months. Slightly more than five percent have tried ecstasy pills at least once and 3.2 percent admit use in the last 12 months.

The drug use of this new generation of consumers can certainly not be explained with reference to their supposed marginalisation. Rather, it is fostered by the mass youth culture, which - through songs, movies and entertainment stars - spreads the same myths, values, and expectations among young people at all corners of the world. This international cultural movement has also spread the positive, mythical image of psychoactive drugs and, above all, stimulants. Over the past ten years, both metropolises have registered a normalisation of drug use. Despite their illegal status, the use of some drugs above all, hashish, but in some contexts also cocaine and ecstasy- has by and large become 'normal' and it is widely practised and accepted. It is no longer the expression of a rebellious counterculture, but it has instead entered the mass youth culture. Though it may have dangerous consequences for some, the use of some illegal substances seems to have become a sort of generalised rite de passage from childhood into adulthood.

On the supply side too, there are striking similarities. In both cities, drug entrepreneurs of all kinds are subject to the constraints deriving from the illegal status of the products they sell. These constraints have so far prevented the rise of large, hierarchically organised firms to mediate economic transactions in the illegal marketplace. The factors promoting the development of bureaucracies in the legal section of the economy - namely, the advantages deriving from economies of scale and specialisation of roles - are outbalanced in the illegal arena by the very consequences of product illegality. Due to these constraints, within the drug economy there is no immanent tendency towards the consolidation of large-scale, modern bureaucracies.

In Frankfurt as well as in Milan, the great majority of drug deals, even those involving large quantities of drugs, seem to be carried out by numerous, relatively small, and often ephemeral enterprises. Some of them are family businesses: that is, they are run by the members of a blood family, who resort on an ad hoc basis to non-kin people in order to carry out the most dangerous tasks. Some are veritable nonkin groups, which are formed around a (charismatic) leader and then manage to acquire a certain de- 
gree of stability and develop a rudimentary division of labour. Others are 'crews': loose associations of people, which form, split, and come together again as opportunity arises.

Even Southern Italian mafia families, whose members were deeply involved in large drug deals in Milan during the 1980s and early 1990s, do not seem to operate like monolithic productive and commercial units. On the contrary, their members frequently set up crews with a few other mafia affiliates or even with external people to make drug deals. These crews are far from being stable working units that could be compared to the branch office of a legal firm. Their composition frequently changes depending on the moment when deals take place or on the availability of single members. After one or a few drug transactions some teams are disbanded, while others continue to operate for a longer time, eventually changing their composition to some extent.

Especially at the intermediate and lower levels, many dealers work alone, either to finance their own drug consumption habits or, more rarely, to earn fast money. Most of these drug entrepreneurs have no contact whatsoever with the underworld, but instead are often inconspicuous persons, who can hardly be distinguished from 'normal' people.

In both cities, the street drug market is largely dominated by foreign dealers, as both police statistics and interviews with key witnesses, drug users and dealers point out. Within a few years a veritable substitution process has taken place: the lowest and most dangerous positions, which used to be occupied by the most marginalised Italian/German drug users, are now taken over by foreigners, especially those who have immigrated recently, are applicants for political asylum or do not have a residence permit. Like other forms of crime in the past, the involvement in today's largest illegal market is used by immigrants as a 'queer ladder of social mobility'. To a greater extent than in the past, moreover, migrants today have a harder time accessing the legal economy and, due to the restrictive policies adopted by most Western European states, are more likely to find survival means only in the informal and illegal economies. Many of them, finally, are also drug users, who have begun to deal drugs in order to finance their consumption patterns.

Especially during the 1980s, several mafia and underworld drug dealing enterprises operating in Milan tried to exercise monopoly claims over the areas in which they were settled, obliging the local intermediate and street dealers to buy drugs from them. Nonetheless, neither in Milan nor in Frankfurt has a person or group ever succeeded in controlling the city market for any illegal substance. The drug markets of both cities have always been open markets, in which anybody can try to earn his/her fortune, selling, importing, or producing drugs.

In both cities, illegal drugs arrive on the market through a plurality of different channels and the drug distribution chain is frequently much shorter than the six-level hierarchical model developed by Preble and Casey in the late 1960s for the New York heroin market. At both sites, empirical evidence additionally shows that the relationships between drug dealing enterprises are closer to competition than to collusion. Although some suppliers may occasionally enjoy a considerable monopolistic power over a local (usually small) market, in Frankfurt, as in Milan, most drug enterprises seem to be price-takers rather than price-givers. That is, none of them are able to influence the commodity's price appreciably by varying the quantity of the output sold.

It is not by chance that the wholesale and retail prices of all the main substances - with the exception of cannabis- have steadily decreased in both contexts. This decline has been accompanied by a comparable fall of purity levels. Only cannabis prices are reported stable in Frankfurt and increasing in Milan. Apparently following international trends, the prices for all the main illegal substances are strikingly similar in both cities, though slightly higher in Milan than in Frankfurt. 
- Work Plan 2004:

During 2004 additional information will be gathered from the sources above described in order to update the first report, to answer questions left open by the original fieldwork and to check hypotheses developed during the first year. In Frankfurt, it is necessary to carry out some additional interviews with foreign street dealers and with socially integrated users of cannabis, ecstasy, and cocaine. Eventually, external interviewers will have to be recruited. Paoli also intends to interview offenders convicted for drug offences in the Hessian prison of Schwalmstadt.

Interviews with people convicted for drug offences also need to be carried out in the Milanese prison of San Vittore. In Milan, interviews also need to be made with some experienced users and dealers of heavy drugs and cannabis, who can provide information about the evolution of the city's open drug scene.

A final report will then be written, which will be published as a book.

- $\quad$ Funding:

European Monitoring Centre for Drugs and Drug Addiction (first phase of the project)

- $\quad$ Selected Publications:

Paoli, L. (2000): Pilot Project to Describe and Analyse Local Drug Markets - First Phase Final Report: Illegal Drug Markets in Frankfurt and Milan. EMCDDA, Lisbon, $155 \mathrm{~S}$.

PAOLI, L. (2001): 'Milano-Francoforte: I Supermercati della Droga'. Narcomafie IX (4), 41-44.

PAOLI, L. (2001): 'Il confronto tra Milano e Francoforte'. In: Ufficio Tossicodipendenze del Comune di Milano (ed.), Tossicodipendenze a Milano 2000. Comune di Milano, Milano.

AlBrecht, H.-J./PAOLI, L., (2001): Ministry of Justice and ES\&E, The Netherlands (eds.), 'Cannabis Policies in Frankfurt. In: Drug Policies in European Countries and Cities - Reference Book. The Hague: Ministry of Justice 2001, 63-77.

PAOLI, L. (2002): 'Flexible Hierarchies and Dynamic Disorder: The Drug Distribution System in Frankfurt and Milan'. Drugs: Education, Prevention and Policy.

PAOLI, L. (2002): 'Drug Trafficking'. In: D. Levinson (ed.), Encyclopedia of Crime and Punishment. Sage, London.

- $\quad$ Selected Lectures:

PAOLI, L., 'Drogenmärkte in Europa am Beispiel Frankfurt und Mailand', Freiburg i. Br.: 36. Sudwestdeutsches Kriminologisches Kolloquium, 1.7.2000.

PAOLI, L., 'Illegal Drug Markets in Frankfurt and Milan - Preliminary Findings of an Ongoing Project', Lisbon: European Monitoring Centre on Drugs and Drug Addiction, 23.10.2000.

PAOLI, L.,'Pilot Project to Describe and Analyse Local Drug Markets - First Phase Final Report: Illegal Drug Markets in Frankfurt and Milan', Lisbon: European Monitoring Centre on Drugs and Drug Addiction, 28.11.2000.

PaOLI, L., 'The "Invisible Hand of the Market": Illegal Drug Trade in Germany, Italy, and Russia', Venice: 12th Annual Conference of the European Society of Social Drug Research, 5.10.2001.

PAOLI, L., 'Mafia = or | Organised Crime?' London: 1st European Conference on Drug Trafficking and Law Enforcement, 11.10.2001.

- $\quad$ Links:

http://www.emcdda.org 


\subsubsection{Modelling the World Heroin Market: Assessing the Consequences of Changes in Afghanistan Production}

- Bearbeiter(innen): Letizia Paoli (Projektkoordinatorin, Soziologin), Peter Reuter (economist, University of Maryland and RAND); Victoria Greenfield (economist, RAND)

- $\quad$ Zeitrahmen: 2002 bis 2004

- $\quad$ Projektstatus: in Bearbeitung

- $\quad$ Projektbeschreibung:

(vgl. dazu auch den Tätigkeitsbericht 2000/2001, S. 138)

The Max Planck Institute (MPI) and the Drug Policy Research Center at the RAND Corporation in the United States have launched an international collaborative effort to develop the first comprehensive model of the global heroin market. This worldwide model, which will have both a flow and behavioural component, does not merely represent an advance in the drug-related academic research; it will be also an invaluable instrument for policy-makers and law enforcement agencies to assess the consequences of possible changes in opium production in Afghanistan and elsewhere and to identify major policy opportunities and problems.

Production in Afghanistan, which was the source of as much as two thirds to three quarters of the global supply of illicit opiates in the second half of the 1990s, has fluctuated dramatically since then. The year 2001 recorded a drastic drop in opium production in Afghanistan. This cutback was largely determined by the Taliban's edict against opium production, which was enacted in the summer of 2000 and effectively enforced for over a year in most of the country. The ban slashed the 2001 harvest to a mere 185 tons, the lowest level in living memory and less than $10 \%$ of the level of the previous year.

However, in the turmoil that followed the American-led bombing campaign and fall of the Taliban regime, many impoverished farmers returned to sowing poppy, which is more profitable than any legal crop. The Afghan Interim Administration banned opium poppy cultivation and drug trafficking on January 17, 2002. This prohibition went beyond the Taliban's decree, to include processing and trafficking, which the Taliban had tolerated and, to some extent, profited from. With the financial and logistical support of the British government, in April 2002 the cabinet of Hamid Karzai also launched an eradication program of the poppy crop and as of end of May 2002, was able to eradicate over 16,000 hectares, offering Afghan farmers a \$ 1,750 pro hectare compensation (Ryder 2002).

Despite these efforts, the UN estimates that Afghanistan's total opium production in 2002 was in range of the levels attained in the late-1990s, roughly 3,400 tons (UNOCD 2003a: 16). In 2003 potential opium production further increased by $6 \%$ (up to 3,600 tons), in addition to its cultivation spreading to previously unaffected or marginally affected areas (UNODC 2003d).

In contrast, opium production has substantially decreased in Southeast Asia over the past five years, particularly in Myanmar (former Burma), the main production country of the Golden Triangle. Between 1998 and 2002, in fact, opium poppy cultivation declined by $40 \%$ in this area (UNODC 2003a: 13). The results of the latest UN poppy surveys additionally show a continuing decline in Myanmar (over $20 \%$ ) and Laos (about 15\%) in 2003 (UNODC 2003b and 2003c). As the United Nations Office on Drugs and Crime (2003a: 7) notes, "if the current rate of reduction in Southeast Asia is sustained, the Golden Triangle could well become a minor source of illicit opium in the next few years. This would close a century long chapter in the history of drug control". It may be too soon to celebrate the disappearance of opium poppy cultivation in Southeast Asia, however, there are no doubts that opium production is increasingly becoming concentrated in one single country, namely Afghanistan. Leaving aside the 2001 cutback, in fact, opium poppy cultivation increased by $16 \%$ in Afghanistan between 1998 and 2002. This shift in the areas cultivated is multiplied by the higher productivity of Afgha- 
nistan's irrigated fields that typically produce four times more opium per hectare than the rain-fed fields of the mountainous Shan States in Myanmar. As a result, Afghanistan accounted for $76 \%$ of the world illicit opium production in 2002, while Myanmar's share had declined to $18 \%$ (UNODC 2003a: $15)$.

Given this shift from Southeast to Southwest Asia, any significant reduction of Afghanistan's opium production could have a tremendous impact on the world heroin market, as shown even by the events following the Taliban's ban. Although stocks delayed and reduced the impact of the 2001 sharp reduction in Afghanistan's of opium production, some data suggest that heroin purity levels in Europe declined that year with the trend continuing in the first two quarters of 2002. Similarly, opium seizures decreased consistently throughout the countries bordering Afghanistan, which can be read as an indication of the diminished availability of opium. According to the UN, there are indications that in the countries of Central Asia the growth of drug abuse declined markedly as a consequence of the reduced supply (UNODC 2003a: 8). Given the very low precision of estimates in that region, however, we do not yet give much weight to this claim.

Despite the weakness of the new Afghan administration, both this and the international donor community remain strongly committed to curbing opium production and trafficking. Indeed, the latter is likely to make the flow of international aid at least partially dependent on the concrete achievement of such an objective. Whereas a significant and lasting reduction in Afghanistan's opium production ultimately depends on the political stabilization of the country, the next five years or so may thus offer an unprecedented chance to both international agencies and the Western countries most affected by the heroin consumption problem to intervene effectively in the main country of the drugs origin.

A new Afghan cutback or, alternatively, a further reduction of Southeast Asian opium production could have profound and varied effects in many parts of Asia, Europe or Australia, where consumption and/or trafficking of heroin and opium are major problems. A major supply shock would also provide a unique opportunity to test the long-standing claim of drug warriors that large cutbacks in source country production could lead to a substantial reduction in drug problems, the contrary being that eradication policy can only change the location of supply rather than quantity.

Currently there exists no basis for systematic analysis of the consequences of a possible Afghan cutback beyond broad speculations. Preliminary analysis suggests that the consumption effects will be greatest in Iran, Pakistan and other nations near Afghanistan, moderate in Western Europe and small in the United States. A continued decrease of opium poppy cultivation in Myanmar would, instead, have major consequences throughout Southeast Asia (particularly in China) and Australia, with limited effects in Europe and the United States. However both scenarios depend on how rapidly production can expand in other nations and on the speed with which new trafficking connections among producer and consumer nations can be developed.

The Max Planck Institute and RAND have thus launched an international collaborative effort to develop the capacity to identify and assess the consequences of Afghan cutback or other shocks in the heroin supply system. By developing the first comprehensive model of the worldwide heroin market, the two organizations also aim to help policy-makers single out the major policy problems and opportunities stemming from dramatic changes in the global heroin industry. Policy interventions arising from the analysis may be as broad as the need to expand treatment capacity for heroin addicts in China or as narrow as focusing on Western European traffickers with Central Asian connections. The project should also generate a base for longer-term policy actions.

- $\quad$ Progress Report 2002-2003:

The project began on April 1, 2002 thanks to the funds provided to the Max Planck Institute (MPI) by the Dutch Ministry of Justice. The MPI has since then obtained additional funds from the European Commission and the British Foreign and Commonwealth Office. The activities of the American colla- 
borating institution, the RAND Drug Policy Research Center, are largely funded by the Smith Richardson Foundation.

Five activities have taken most of the first twenty months: (1) Creation of a data base. (2) Recruiting collaborating researchers in six Asian nations, Turkey and Colombia and developing research protocols and procedures. (3) Convening of a first working conference in Freiburg for advisory committee members and collaborators, a second working conference in Istanbul for a second group of collaborators and a third meeting in Beijing to instruct the Chinese collaborators (4) Launch and monitoring of the extensive data collection in the eight selected countries (5) Targeted data collection in Europe.

(1) To establish a baseline for modelling, we have assembled the available information on quantities in an Excel data base. For each nation that is significant in the heroin trade, we have estimates of how much is produced or imported (from specific sources), consumed and exported (to specific countries). For most countries our consumption estimates are the first ones available, though they are for the moment pro forma.

This exercise has enabled us to identify the principal problems in obtaining consistency in production and consumption. The data base has already provided additional evidence that the bulk of opiate consumption occurs in Asia. We are focusing particular attention on collecting data on annual consumption per addict by country, a critical variable that has received little attention in the past.

(2) We have recruited collaborators in the six originally selected Asian nations (India, Iran, Pakistan, Tajikistan and Thailand) as well as in Turkey and Colombia. Each collaborator is experienced in data collection related to drug policy and drug markets; they represent a variety of disciplines and institutional settings. Draft protocols were then prepared, which have been negotiated with each individual collaborator to take account of the differing circumstances of their nation. The first three sub-contracts were signed in autumn 2002 (India, Tajikistan, Thailand), a fourth was signed in early 2003 (Pakis$\tan )$.

There were some problems in negotiating collaborations in China and Iran, as the two scholars who had originally agreed to work with us and participated in the Freiburg conference, did not deliver their promises. In Iran we found a new research partner in the spring of 2003; in China we were only able to find interested and competent collaborators in the autumn of the same year.

Following the suggestion of the advisory board, during the course of 2003 the data collection was extended to include Turkey, a key transshipment country for Afghan heroin on its way to Europe, and to Colombia, which became the main source of heroin for the United States in the late 1990s.

(3) In September 2002 a first working conference was held at the Max Planck Institute in Freiburg. An advisory board including representatives from the European Commission and the governments of Germany, the Netherlands, the United Kingdom and the U.S. met for a day of presentations and discussions; the collaborators of the six nations originally selected for the project were able to participate in those sessions. A second day was devoted then to discussion of the goals and procedures with the collaborators.

In June 2003, a second working conference was held in Istanbul, Turkey to instruct the new Iranian and Turkish collaborators as well as the new head of the Tajik research team. A third meeting was convened mid-October 2003 in Beijing to instruct the new Chinese collaborators.

(4) The data collection is being carried out in all of the eight selected countries: namely, China, Colombia, India, Iran, Pakistan, Tajikistan, Thailand and Turkey. The collaborators are being monitored by the principal project investigators, above all through the MPI.

The collaborators from India, Iran, Pakistan, Tajikistan and Thailand have already delivered their draft final reports and, at the request of the principal investigators, are currently gathering additional information on some specific issues and/or revising their reports. The final reports from China, Colombia and Turkey are expected in early 2004. 
(5) A limited primary data collection is also being carried out in several European countries, in most cases by the principal investigators themselves. The aim is to collect selected data (most crucially, information on heroin prices, purity levels and the number of regular consumers) on the European heroin markets. In order to do this, trips and phone calls were made and emails were sent to government drug control and treatment bodies, law enforcement agencies and academics in Germany, Italy, The Netherlands, Spain, Sweden and The United Kingdom. A French researcher was entrusted with the data collection in France on the basis of a research protocol delivered by the principal investigators.

The activities carried out so far cover the first phase and, partially, the second phase of the project. The first phase was completed between April to September 2002. The second phase, which was originally supposed to end in September 2003, has been extended for six months up to the end of March 2004.

\section{- Work Plan 2004:}

The first part of 2004 will be spent primarily in data collection in Asia and in Europe. We will continue actively monitoring the activities of our collaborators, mostly through email. In the next few months, moreover, each collaborator will be visited by one of the principal investigators in order to provide some technical assistance and to assess data quality. Due to the SARS outbreak, the war on Iraq and the war on drugs launched by the Thai government in early 2003, most of the trips planned for the spring and summer of 2003 were delayed and are now scheduled for the first few months of 2004. The data collection in Europe will also be furthered.

Furthermore, we will develop the behavioural economic model, incorporating information that has been collected on the agronomy of opium growing and the technology of processing. This will be followed by a third working conference at the beginning of the third phase to review the findings.

During the third phase, which will last six months up to September 2004, the project results will be disseminated rapidly to interested governments. These will include a number of policy documents (how the Afghan cutback or other changes are affecting various nations and the opportunities presented) as well as technical reports (the model, price changes in various regions, etc.). Besides information about the model, these documents and reports will provide qualitative analyses of the opium and heroin drug trafficking on the basis of the first-hand data collected by the network of Asian collaborators. The model itself will be made available to interested governments. Results will also be reported in a variety of publication formats, aimed at both lay and technical audiences.

In its final phase (for which funding is not sought at this time), the project should lead to the development of an infrastructure for continued monitoring and assessment of the effects of the eventual Afghan cutback or other shocks in the heroin supply system. Additional data over the period will allow further testing of the forecasting capacities of the model and identification of continued policy opportunities. This infrastructure should be funded by national and international agencies.

\section{- References:}

RYDER, M., "Drugs as a Cross-Cutting Issue in Afghan Reconstruction: Turning the Rhetoric into Reality". Chair's Conclusions from a Seminar at Winston House, UK, February, 27-28 2002.

United Nations Office for Drug Control and Crime Prevention (2002) Update March 2002. Online: Available at $<$ http://www.undcp.org/newsletters.html $>$.

United Nations Office on Drugs and Crime (2003a). Global Illicit Drug Trends. Online: Available at $<$ http://www.unodc.org/unodc/index.html $>$.

United Nations Office on Drugs and Crime (2003b). Laos Opium Survey 2003. June. Online: Available at $<$ http://www.unodc.org/unode/index.html $>$.

United Nations Office on Drugs and Crime (2003c). Myanmar Opium Survey 2003. June. Online: Available at $<$ http://www.unodc.org/unodc/index.html $>$. 
United Nations Office on Drugs and Crime (2003d). Afghanistan Opium Survey 2003. October. Online: Available at $<$ http://www.unodc.org/unodc/index.html $>$.

- $\quad$ Selected Lectures:

"Modeling the World Heroin Market: Project Rationale and Conference Goals". First Working Conference: "Modeling the World Heroin Market: Assessing the Consequences of Changes in Afghanistan Production", Freiburg: 13.09.2002.

"Moving into Terra Incognita: Knowledge Gaps and Makeshift Research Methods". First Working Conference: "Modeling the World Heroin Market: Assessing the Consequences of Changes in Afghanistan Production". Freiburg: 13.09.2002.

"Modeling the World Heroin Market: Project Rationale and Conference Goals". Second Working Conference: "Modeling the World Heroin Market: Assessing the Consequences of Changes in Afghanistan Production", Istanbul: 24.06.2003.

"What We Do Not Know and How We Might Learn It". Second Working Conference: "Modeling the World Heroin Market: Assessing the Consequences of Changes in Afghanistan Production", Istanbul: 24.06.2003.

\subsection{Schwerpunkt "Normanwendung im Strafverfahrensrecht"}

\subsubsection{Rechtswirklichkeit und Effizienz der Überwachung der Telekommunikation nach den $\S \S 100 a, 100 b$ StPO und anderer verdeckter Ermittlungsmaßnahmen}

- $\quad$ Bearbeiter(innen): Hans-Jörg Albrecht (Jurist), Claudia Dorsch (Juristin), Christiane Krüpe (Juristin) und weitere Mitarbeiter(innen)

- $\quad$ Laufzeit: 1999 bis 2003

- $\quad$ Projektstatus: abgeschlossen

- $\quad$ Projektbeschreibung:

(vgl. dazu bereits die Tätigkeitsberichte 1998/1999, S. 125; 2000/2001, S. 150)

\section{Ausgangspunkt und Untersuchungsinhalt}

Fragen des Grundrechts- und insoweit vor allem des Persönlichkeitsschutzes, aber auch des Schutzes des Fernmeldegeheimnisses sowie die Forderungen nach einer Minimierung der Überwachungszahlen stehen in einem Dauerkonflikt zur angenommenen Notwendigkeit einer effizienten Strafverfolgung insbesondere im Bereich der Organisierten Kriminalität. Eine sachgerechte Abwägung zwischen dem sich aus der Überwachung der Telekommunikation (TKÜ) ergebenden Nutzen für die Strafverfolgung einerseits und den mit der Überwachung zwangsläufig verbundenen Eingriffen in die grundrechtlich geschützten Positionen der betroffenen Personen andererseits ist ohne verlässliche empirische Erkenntnisse nicht möglich.

Die im Auftrag des Bundesministeriums der Justiz durchgeführte Untersuchung "Rechtswirklichkeit und Effizienz der Überwachung der Telekommunikation nach den $\S \S 100 \mathrm{a}, 100 \mathrm{~b}$ StPO und anderer verdeckter Ermittlungsmaßnahmen" beinhaltet daher deskriptive, theoretische und evaluative Bestandteile. Im deskriptiven Teil der Studie waren es vor allem die Bereiche des Rechtstatsächlichen, die einer Überprüfung unterzogen wurden. Ein Schwerpunkt lag hierbei auf der Ermittlung des "Umfangs" der Telekommunikationsüberwachung, gemessen an Anordnungshäufigkeit, Befristung der TKÜMaßnahme und tatsächlicher Überwachungsdauer und den betroffenen Personen. Daneben wurde die Rolle von Polizei, Staatsanwaltschaft und Ermittlungsrichter hinsichtlich ihres Einflusses auf die Ent- 
scheidung, eine TKÜ durchzuführen, betrachtet. Weitere Fragestellungen betrafen die Situation, in der die Schaltung einer TKÜ in Erwägung gezogen und durchgeführt wurde, sowie die Zusammenarbeit von Polizei, Staatsanwaltschaft und Ermittlungsrichter bei der Initiierung, Antragstellung und Anordnung. Daneben wurden hier Probleme, die aus der Entwicklung des Telekommunikationsmarktes, aber auch aus Veränderungen der Täterstrukturen und der Anpassung von Täterverhalten resultieren, betrachtet.

Die Untersuchung bezweckt neben der Beschreibung des tatsächlichen Rechtszustands auch die Evaluation der Effizienz. In diesem Zusammenhang erfolgte zunächst eine Auseinandersetzung mit den Erfolgen einer TKÜ im Ermittlungsverfahren. Daneben wurden Verbindungen zwischen den Erkenntnissen, die aus einer TKÜ gewonnen werden konnten, und der "Ersetzung" dieser Erkenntnisse durch Erfolge anderer (Folge-) Ermittlungsmaßnahmen und Beweismittel, der Verwertung der Erkenntnisse in Anklage und Hauptverhandlung sowie dem Verfahrensausgang hergestellt.

- $\quad$ Arbeitsbericht 2000/2001:

Ab Oktober 1999 wurde zum einen die empirische Strafverfahrensforschung ab 1990 auch zu "neuen Ermittlungsmaßnahmen" erfasst und aufbereitet. Zum anderen wurden die aktuellen Statistiken zu Eingriffen in die Telekommunikation analysiert. Deren Auswertung lässt dabei verschiedene Aussagen zu, die auch zur Gestaltung des Untersuchungsdesigns genutzt wurden. Hierbei wurde ein Mehrmethoden- bzw. Mehrebenenansatz zugrunde gelegt, der sich neben der Analyse der bislang vorhandenen Statistiken zur TKÜ auf eine Aktenanalyse, eine schriftliche Befragung von Praktikern und mündliche Experteninterviews stützt. Der Untersuchungsaufbau sah daher wie folgt aus:

1. Analyse von 813 Strafverfahrensakten (bundesweit), in welchen Maßnahmen nach den $\S \S 100 \mathrm{a}$, 100b StPO zum Einsatz gekommen waren, mit Hilfe eines standardisierten Fragebogens

2. Schriftliche Befragung von über 6000 Praktikern (Polizeibeamte, Staatsanwälte, Richter und Verteidiger)

3. Mündliche Experteninterviews ( $\mathrm{n}=51)$

4. Analyse einer Kontrollgruppe, bestehend aus Verfahren ohne TKÜ-Anordnung

Für die Analyse der Verfahrensakten mit TKÜ-Bezug wurde sodann ein Fragebogen entwickelt, der, einer linearen Struktur folgend, auf das Ermittlungsverfahren als Grundinformation abstellte. In einer Testphase anhand der ersten eingegangenen Akten wurde das Erhebungsinstrument überprüft und entsprechend modifiziert. Daneben wurde eine "Kommentierung" zum Fragebogen erarbeitet, die Anmerkungen, Erläuterungen und Besonderheiten der abgefragten Variablen festschrieb, und somit einen möglichst großen Gleichklang bei der Aktenauswertung unter den auswertenden Mitarbeitern gewährleistete.

- $\quad$ Arbeitsbericht 2002:

Im Jahr 2002 wurden nach und nach alle Akten angefordert und ausgewertet. Hierbei wurde die lineare Struktur des Fragebogens dergestalt verändert, dass die einzelnen Module "Verfahren", "TKÜMaßnahme" und "Beschuldigte" so verknüpft wurden, dass die tatsächliche komplexe Struktur dieser Module auf den Fragebogen übertragen werden konnte. Diese Struktur wurde als relationale Datenbank realisiert und eine Access-Datenmaske geschaffen.

Parallel wurde die schriftliche Befragung vorbereitet. Hierzu wurde zunächst ein entsprechendes Erhebungsinstrument entwickelt, mit welchem es möglich war, die subjektiven Einschätzungen der zu befragenden Praktiker zur TKÜ abzufragen. Sodann wurde eine Stichprobe gezogen und die Fragebögen versandt ( $\mathrm{n}=6256)$. Mit einem Wert von etwa $46 \%$ gestaltete sich der Rücklauf erfreulich.

Des Weiteren wurden, basierend auf ersten Erkenntnissen aus Aktenanalyse und schriftlicher Befragung, Interviewleitfäden für die Gespräche mit "TKÜ-Experten" entwickelt. 
- $\quad$ Arbeitsbericht 2003:

Im Januar 2003 wurde damit begonnen, ausgewählte Experten der TKÜ mündlich zu interviewen. Hierbei wurden sowohl Polizeibeamte, Staatsanwälte, Richter und Strafverteidiger befragt. Die Interviewphase endete im Frühjahr 2003. Parallel hierzu wurden Aktenanalyse und schriftliche Befragung ausgewertet und der Abschlussbericht für das Bundesministerium der Justiz verfasst. Dieser wurde dem Ministerium im Mai 2003 übergeben und im August 2003 in der Reihe Kriminologische Forschungsberichte veröffentlicht. Im Folgenden sollen kurz die wesentlichen Ergebnisse der Untersuchung dargestellt werden.

\section{Entwicklung der TKÜ in Deutschland und im internationalen Vergleich}

Die Anzahl an Überwachungsmaßnahmen nach $\S \S 100 \mathrm{a}, 100 \mathrm{~b}$ StPO und die Anzahl an Verfahren mit TKÜ hat in den letzten Jahren in Deutschland stetig zugenommen (vgl. Abbildung 1).

Abbildung 1: Entwicklung der Zahl der TKÜ-Anordnungen 1990 - $2002^{2}$

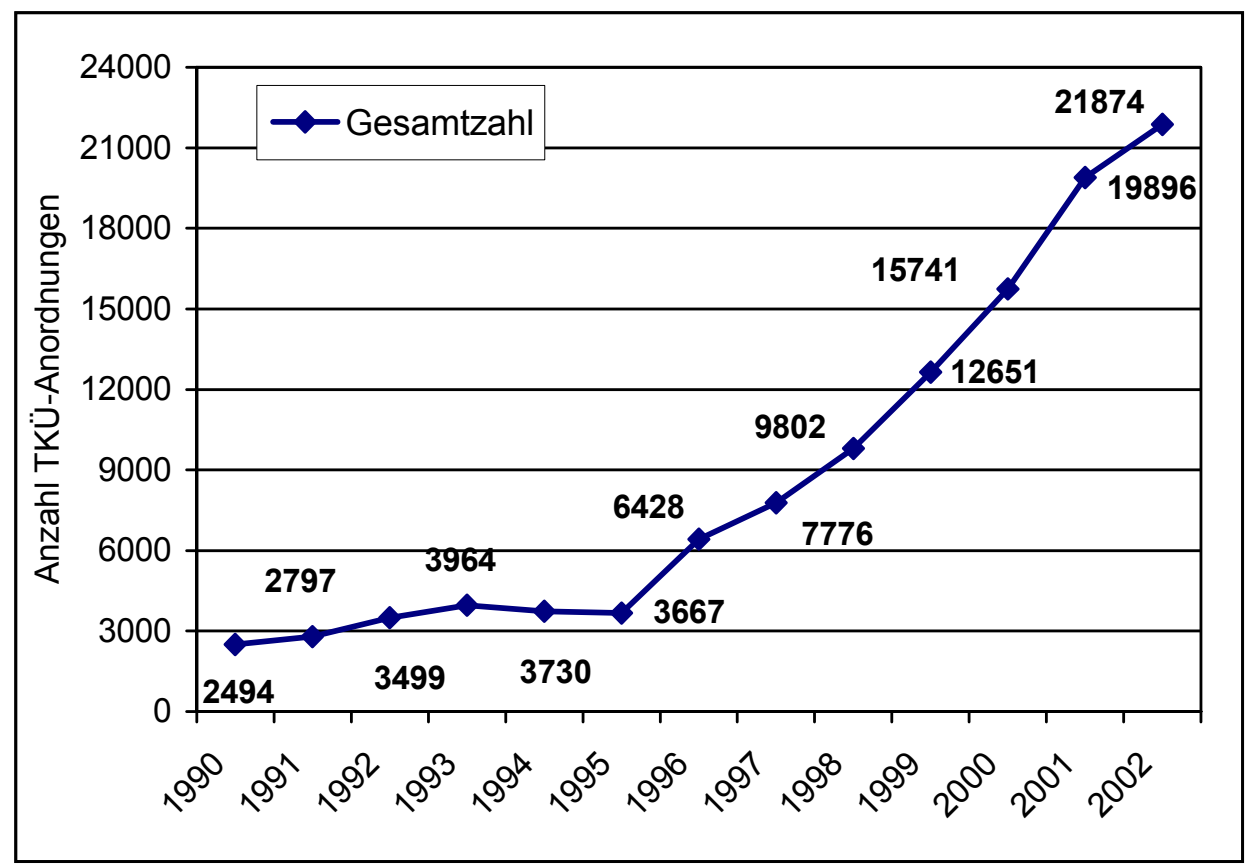

Quellen: BT-Sten.Ber. 12/30, S. 2354; Pütter, Bürgerrechte \& Polizei 1995, 78 f.; BT-Drs. 12/5269; BT-Drs. 12/7116 und 12/8306; Bundesregierung zit. nach DuD 1996, 109, 227; BT-Drs. 13/618; BT-Drs. 13/3618; BTDrs. 13/7341; BT-Drs. 13/11354; BT-Drs. 14/1522, 14/4863; BT-Drs. 14/7521; RegTP, 2. Tätigkeitsbericht 2000/2001, S. 148.

Der Anstieg der Überwachungszahlen kann jedoch als Trend in den 90er Jahren international festgestellt werden. Deutschland ist dabei im Vergleich der relativen Häufigkeit der Anordnung der Überwachung der Telekommunikation pro 100.000 der Wohnbevölkerung unter den kontinentaleuropäischen Ländern im Mittelfeld zu verorten (vgl. Abbildung 2). Insgesamt ist jedoch ein großer Unterschied in der Anordnungshäufigkeit zwischen kontinentaleuropäischen Ländern einerseits und angloamerikanischen Ländern andererseits zu beobachten.

2 Für das Jahr 1990 beziehen sich die Zahlen bis 2.10.1990 auf die alten Bundesländer ohne Berlin (West), ab 3.10.1990 auch auf Berlin (West), siehe Stenografische Berichte 12/30, S. 2354. Anordnungen in den neuen Bundesländern wurden selbständig erst seit 1992 erfasst, 1991 allerdings durch die Oberpostdirektionen der alten Länder miterfasst, siehe Bericht des Strafrechtsausschusses auf der Herbstkonferenz der Justizministerinnen und -minister am 6.11.1997, S. 4. 
Abbildung 2: Anordnungen von Überwachungen der Telekommunikation im Vergleich (pro 100.000 der Wohnbevölkerung)

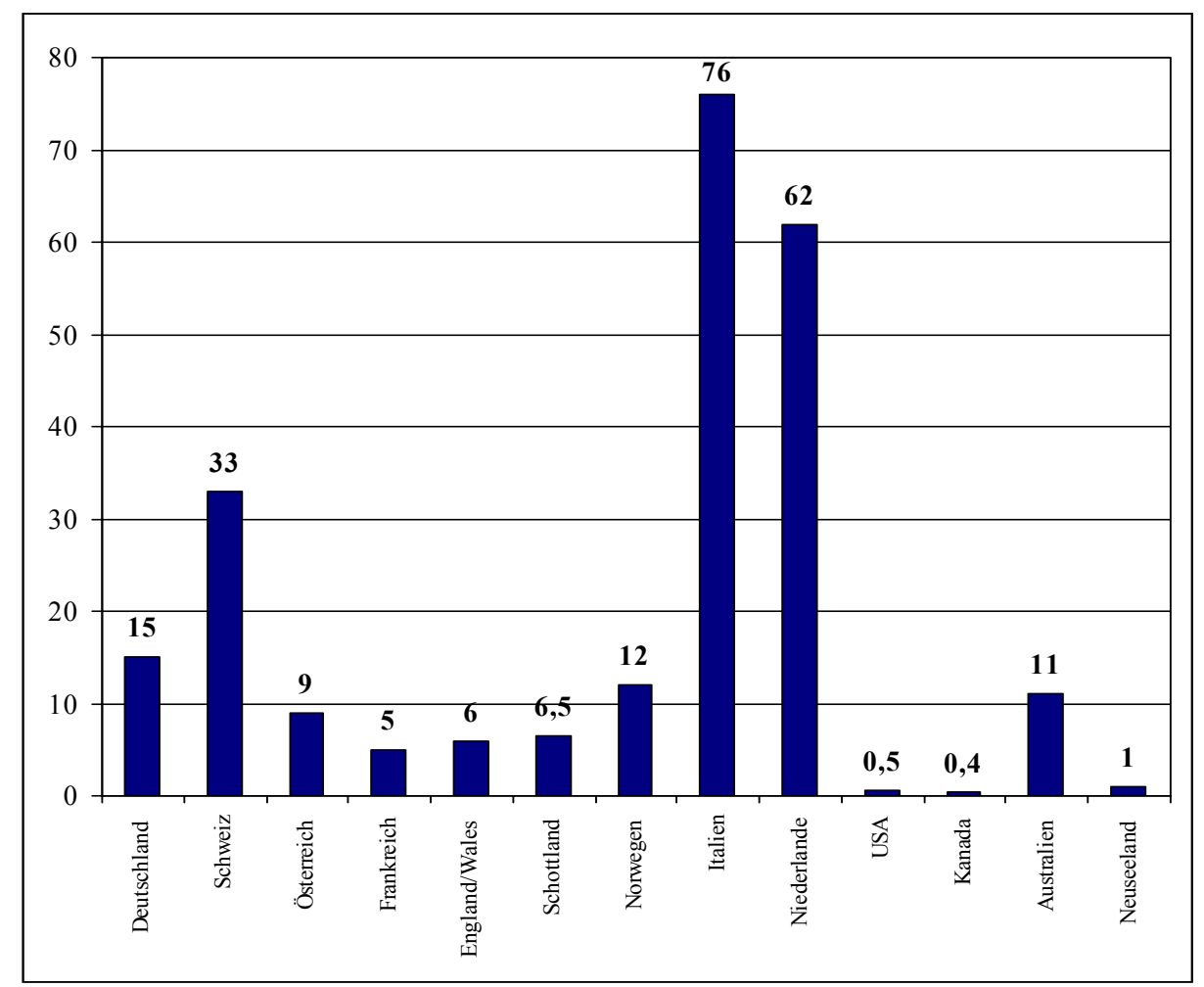

Als Erklärungsansätze für die Zunahme der Überwachungstätigkeit werden verschiedene Gesichtspunkte angeführt. Betrachtet man die Zahlen zur Kriminalitätsentwicklung ${ }^{3}$ und zu den Veränderungen des Telekommunikationsmarktes, ergibt sich, dass der Anstieg der TKÜ-Anordnungen nicht mit dem Ansteigen der BtM-Kriminalität erklärt werden kann. Ein Zusammenhang zwischen der Entwicklung des Mobilfunkmarktes und den entsprechenden Kommunikationsformen einerseits und der Zunahme der Überwachungsintensität andererseits ist jedoch festzustellen. Bezieht man beispielsweise die Überwachungen von Mobiltelefonen auf die Anzahl angemeldeter Mobiltelefone, dann lässt sich im Zeitraum 1997 bis 2001 ein Rückgang der Überwachungsdichte von 0,5 pro 1000 auf 0,3 pro 1000 Mobiltelefone beobachten. Für den Zeitraum 1997 bis 2001 lässt sich feststellen, dass die Zahl der Mobilfunkteilnehmer deutlich stärker zunahm als die der entsprechenden TKÜ-Anordnungen.

\section{Rechtstatsächliche Erkenntnisse der Untersuchung}

Die Anordnungsdauer der TKÜ orientierte sich überwiegend am gesetzlichen Maximum. Gut drei Viertel der staatsanwaltschaftlichen Anträge legten diese Frist zugrunde, in $97 \%$ der Anordnungen wurde dem Antrag im richterlichen Beschluss (auch hinsichtlich der beantragten Überwachungsdauer) entsprochen.

Die tatsächliche Ausführungsdauer überschritt nur in einem Viertel der Fälle die Zweimonatsgrenze. Der Median der Dauer der TKÜ liegt bei etwa 30 Tagen; das heißt, dass die Hälfte der Überwachungen der Telekommunikation unter einem Monat andauerten. Der Mittelwert liegt bei etwa 40 Tagen. Insgesamt ergibt sich aus diesen Verteilungen, dass die gesetzlich zulässige und gerichtlich ermöglichte Dauer der Überwachung bei weitem nicht ausgeschöpft wird. Die Praxis korrigiert somit selbst den in den Anordnungen erzeugten Überschuss an Überwachungs- und Eingriffspotential. 
Der Umfang der TKÜ ist - soweit aus den Akten erkennbar - immens. Sie bereitet aufgrund der Datenfülle großen Personal- und Kostenaufwand für die Ermittlungsbehörden, die Justiz und die Verteidigung. Für 146 Verfahren wurde die Gesamtzahl der Gespräche aller überwachten Anschlüsse ermittelt. In 23 Verfahren wurde kein einziges Gespräch aufgezeichnet, in 21 Verfahren wurden bis zu $100 \mathrm{Ge}-$ spräche überwacht. Bis zu 1000 Gespräche wurden in 60 Verfahren abgehört, in 31 Verfahren zwischen 1000 und 5000 Gespräche. Für die übrigen 11 Fälle sind aus den Akten mehr als 5000 abgehörte Gespräche ermittelt worden, hierbei in einem Fall knapp 20.000, in einem anderen 30.500.

Schwierigkeiten mit den Telekommunikationsunternehmen sind sowohl aus den Akten wie auch den Ergebnissen der schriftlichen Befragung und Expertengesprächen erkennbar. Sie beziehen sich auf die Kostentragungspflicht sowie in Einzelfällen auf eine durch die Unternehmen angenommene Rechtswidrigkeit der Beschlüsse.

Bei selteneren Sprachen konnten allgemein Probleme beim Übersetzen festgestellt werden. Zum Teil ist es offensichtlich für einige Sprachen nicht möglich, geeignete Dolmetscher oder überhaupt eine Person zu finden, die zur Übersetzung in der Lage ist. Auch bei häufiger auftretenden Sprachen sind allerdings bei bestimmten Dialekten vereinzelt Engpässe festzustellen.

Unter dem Gesichtspunkt der Transparenz, Kontrolle und Nachvollziehbarkeit bei TKÜ-Maßnahmen lassen sich vor allem drei Problemkreise anführen: zum einen die Ausgestaltung der Begründungen von TKÜ-Anordnungen, zum anderen die Frage der betroffenen Personen und schließlich die Benachrichtigungspflicht und ihre Umsetzung.

Für die Begründungen ist anzuführen, dass sich diese Problematik nahezu zur Gänze mit der Frage des Richtervorbehaltes, seines Zweckes und dem Ermittlungsrichtermodell heutiger Prägung verbindet. Zwar stellt auch diese Untersuchung nicht mit abschließender Klarheit fest, dass die Richter ihrer auferlegten Kontrollpflicht nicht nachkommen, sie kann aber vor allem auch nicht das Gegenteil berichten und den Ermittlungsrichtern einen einwandfreien Umgang mit den Anforderungen der $\S \S 100 \mathrm{a}$, 100b StPO bescheinigen. Deutlich sei darauf hingewiesen, dass der Inhalt einer Begründung keine Aussage über die Vornahme und die Tiefe einer tatsächlichen Kontrolle treffen kann. Jedoch entfalten diese Erkenntnisse eine gewisse Indizwirkung, wenn man zudem noch die Äußerungen der befragten Ermittlungsrichter zugrunde legt, die nahezu einstimmig auf ihre Arbeitsbelastung verweisen und eine Prioritätensetzung zugunsten "schwerwiegenderer Eingriffe" erläutern. Regelmäßig werden polizeiliche Anregungen auf eine TKÜ durch die Staatsanwaltschaft und in der Folge durch den Ermittlungsrichter übernommen. Die Begründungstätigkeit erfolgt ausweislich der Akten und nach Selbsteinschätzung befragter Kriminalbeamter nahezu ausschließlich durch die Polizei. Häufig verbleibt sodann von einem umfassenden polizeilichen Ermittlungsvermerk und einem bereits wesentlich knapperen staatsanwaltschaftlichen Antrag ein weiter verkürzter Beschluss.

$22,5 \%$ der Beschlüsse wurden durch die Auswerter als formelhaft gewertet, 23,5\% als substantiell begründet. ${ }^{4}$ In diesem Zusammenhang und im Rahmen der Erfassung als substantiell lässt sich damit auch festhalten, dass eine tiefergehende Auseinandersetzung mit dem Merkmal der Subsidiarität überwiegend in den Beschlüssen nicht dokumentiert wurde. ${ }^{5}$ Bei etwa $21 \%$ der Beschlüsse lag eine Ausfertigung durch den Richter vor, die dem Antrag der Staatsanwaltschaft entsprach. Etwa $15 \%$ der Richter gaben in ihren Beschlüssen allein die Gesetzesformel zur Begründung wieder, in etwa $9 \%$ der Beschlüsse wurde auf die Ausführungen der Polizei / Staatsanwaltschaft oder auf vorherige Beschlüsse verwiesen. In den übrigen Fällen wurden Vordrucke verwandt, konnte die Begründung aufgrund des Fehlens des Beschlusses nicht bewertet werden oder lagen Kombinationen vor.

$4 \mathrm{Zu}$ beachten ist, dass trotz vorgegebener Kriterien für formelhafte und substantielle Begründungen eine subjektive Bewertung durch die Auswerter erfolgte.

5 Erneut ergeht jedoch der Hinweis, dass die Nichtdokumentation nicht auf eine fehlende Kontrolle der Voraussetzung schließen lässt. Jedoch wäre es mit Blick auf die Nachvollziehbarkeit des Geschehens durchaus wünschenswert, einen Niederschlag der Überprüfungstätigkeit vorzufinden. 
TKÜ-Anordnungen ergingen nach Anregung und Antragstellung sehr schnell. So lag in etwa $63 \%$ der TKÜ-Anordnungen zwischen Anregung und Antrag maximal ein Tag. In der Regel (70 \% der Fälle) erfolgte ein richterlicher Beschluss spätestens einen Tag nach Antragstellung. ${ }^{6}$

Hinsichtlich der durch eine TKÜ betroffenen Personen konnte folgendes festgestellt werden. Etwa $60 \%$ der überwachten Anschlüsse gingen auf Dritte, also Nichtbeschuldigte in den jeweiligen Verfahren, als Anschlussinhaber zurück. Für $38 \%$ der Anschlüsse wurden Beschuldigte als Inhaber und Nutzer des Anschlusses festgestellt. In knapp $2 \%$ der Fälle handelte es sich um Anschlüsse, deren Inhaber nicht ermittelt wurden, und um Fälle eines Beschuldigtenanschlusses, der allein von Dritten genutzt wurde. In zwei Dritteln der Fälle waren Beschuldigte ausschließliche oder zumindest Mitnutzer der überwachten Anschlüsse.

Sowohl die Fragen der Kontrollpflicht wie auch der Drittbetroffenen finden in der Problematik der Benachrichtigung ihren Niederschlag. Nach $\S 101$ StPO sind die Beteiligten von der getroffenen Maßnahme des $\S 100 \mathrm{a}$ StPO zu unterrichten. Auch wenn die Stimmen aus der Praxis und weitere Auffassungen in der Rechtspolitik unter diesem Begriff nur den Beschuldigten, gegebenenfalls den Anschlussinhaber und weitere Nutzer sowie Kontaktpersonen verstehen wollen, ist in der Kommentarliteratur. ${ }^{7}$ Beteiligter jeder, mit dem der Beschuldigte einen überwachten Telekommunikationskontakt hatte. Eine Benachrichtigung aller Gesprächsteilnehmer erfolgte ausweislich der Akten ersichtlich nicht, dies vor allem aufgrund von nachvollziehbaren praktischen Schwierigkeiten, die ihre Ursache erneut in der veränderten und massenhaften Kommunikation der Jetztzeit haben mögen. Aber auch die (relativ unproblematische) Unterrichtung des Beschuldigten und / oder des Anschlussinhabers unterblieb weit häufiger, als es die in $\S 101$ I S.1 StPO vorgesehenen Ausnahmen zulassen. So erfolgte für etwa $15 \%$ aller Anschlüsse eine Benachrichtigung, in knapp $12 \%$ der Fälle lag eine anderweitige Kenntniserlangung im weiteren Verlauf des Ermittlungsverfahrens, insbesondere durch Akteneinsichtnahme, vor. In 6,4 \% der Fälle wurde in den Akten ausdrücklich niedergelegt, dass eine Benachrichtigung nicht erfolgen solle. Für zwei Drittel der Anschlüsse ließ sich den Akten keinerlei Hinweis auf eine Benachrichtigung entnehmen (vgl. Abbildung 3).

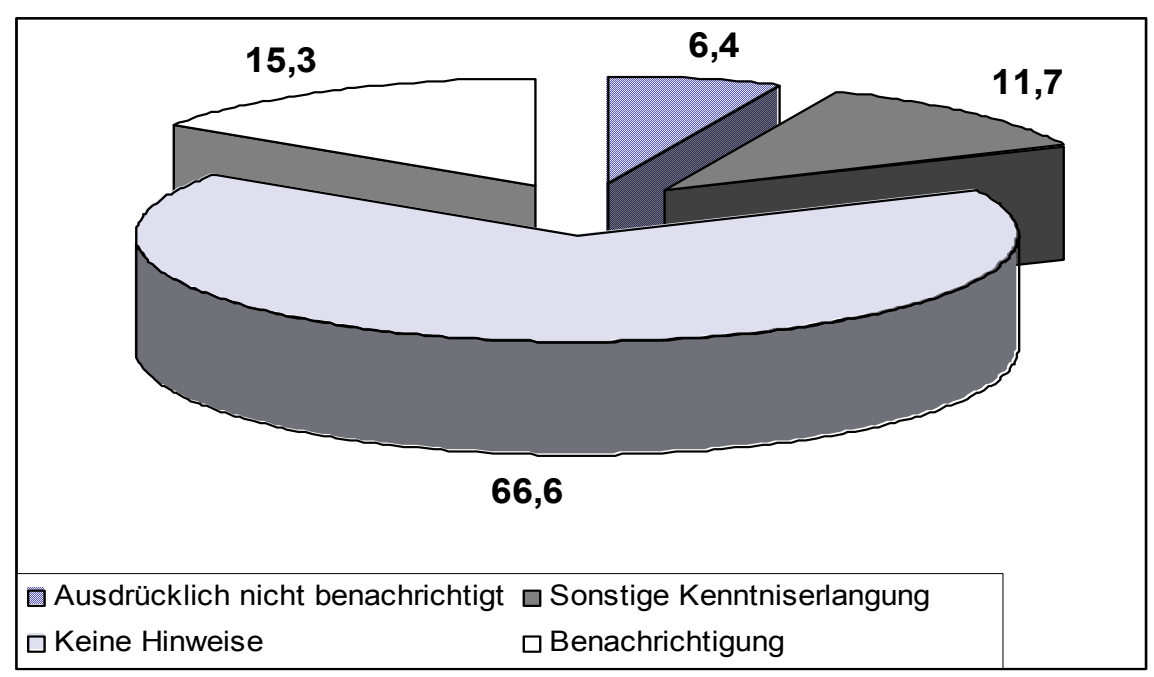

6 Es handelt sich dabei um Anregungen und Anträge, die nicht in Fällen der staatsanwaltschaftlichen Eilmaßnahmen erfolgten.

7 Siehe nur Kleinknecht, Theodor/Meyer-Gossner, Lutz, Strafprozessordnung, München 2001, § 101 Rn. 2. 


\section{Evaluation und Effizienz}

In etwa $60 \%$ der untersuchten Verfahren waren Ermittlungserfolge der TKÜ zu verzeichnen. Unterteilt wurden diese Erfolge in unmittelbare, mittelbare und sonstige Erkenntnisse. Den deutlich größten Anteil an Ermittlungserfolgen nahmen mit etwa $62 \%$ die mittelbaren Erkenntnisse, wie beispielsweise Hinweise auf neue Straftaten Dritter oder des Beschuldigten, mittelbare Ermittlungsansätze wegen Katalogstraftaten o.ä., ein. Die unmittelbaren Erkenntnisse, unter die beispielsweise Entlastungen, Selbstbelastungen, Aussagen Dritter wegen Katalogstraftaten oder auch Aufenthaltsortsermittlungen subsumiert wurden, machten insgesamt etwa $28 \%$ der Ermittlungserkenntnisse aus. Sonstige Erkenntnisse stellten einen Anteil von etwa $10 \%$.

In etwa drei Viertel der Verfahren, die nicht völlig eingestellt wurden, war den Akten mindestens ein Erfolg aus der TKÜ zu entnehmen. In knapp 60 \% der Verfahren, in welchen gegen alle Beschuldigten eine Einstellungsverfügung erging, war den Akten kein TKÜ-Erfolg zu entnehmen.

In Anklage und Urteil spielt die TKÜ jedoch eine relativ geringe Rolle. So taucht die TKÜ als Beweismittel bei etwa $16 \%$ der Beschuldigten in der Anklage auf, in die Hauptverhandlung eingeführt wird sie bei etwa $20 \%$ der Angeklagten. Hauptgrund hierfür ist die Tatsache, dass die TKÜ relativ ungern im weiteren Verlauf des Verfahrens verwendet wird. Dies hängt mit dem erheblichen Aufwand zusammen, der mit ihrer Einführung verbunden ist. Aus ökonomischen, verfahrensstrategischen und Beschleunigungsgesichtspunkten wird daher häufig versucht, auf eine Verwertung der TKÜ als Beweismittel dann zu verzichten, wenn ausreichend andere Sachbeweise zur Verfügung stehen.

Die durchgeführten Befragungen haben dementsprechend durchgehend - wenn auch unter Nennung unterschiedlicher Gründe hierfür - einen Einfluss der TKÜ auf Geständnis- und Absprachebereitschaft der Beschuldigten bejaht.

\section{Schlussfolgerungen}

Im Rahmen der Untersuchung ist erkennbar geworden, dass die TKÜ sich einer zum Zeitpunkt ihrer Implementierung völlig veränderten Kommunikationsgrundlage gegenüber sieht. Insbesondere in den 90er Jahren hat eine Veränderung des Kommunikationsverhaltens und -aufkommens stattgefunden, die mit der Annahme der Überwachung eines Beschuldigten bezogen auf einen (Festnetz-)Anschluss nicht vereinbar ist. TKÜ ist - in den Worten eines Praktikers - ein Massengeschäft geworden. Um in dieser Massierung des Überwachungsaufkommens rechtsstaatliche und dabei praktikable Voraussetzungen zu wahren, bedarf es einer praxisbezogenen Regelung.

Bei der Beurteilung der Effizienz von TKÜ-Maßnahmen muss zwischen deren Erkenntnis- und Beweiswert unterschieden werden. Die durchgeführte Untersuchung hat gezeigt, dass die TKÜ selbst als Beweismittel relativ selten verwendet wird. Dies bedeutet jedoch nicht, dass sie über das Ermittlungsverfahren hinaus nicht fortwirkt. In Gestalt von anderen Sachbeweisen und bzw. oder Geständnissen bleibt die TKÜ häufig auch über das Ermittlungsverfahren hinaus "in unsichtbarer Form" relevant.

Die Ermittlungsverfahren haben in Fällen der Transaktionskriminalität eine andere, nämlich proaktive Ausrichtung in Ermittlungstätigkeit und Zielsetzung der Maßnahmen erfahren. ${ }^{8}$ Dieser Änderung stehen repressiv gestaltete StPO-Vorschriften gegenüber. Hier können im Einzelfall Friktionen entstehen. Da die veränderte Ausrichtung des Ermittlungsverfahrens für den Bereich marktförmiger Kriminalität in Teilen auch nachvollziehbar erscheint, wird eine entsprechende offene und deutliche Anpassung der Gesetzeslage an die geänderte Praxis zu erwägen sein.

8 Unter Proaktion wird hier diejenige Ermittlungstätigkeit verstanden, die sich nicht allein in der Aufklärung vergangener Taten erschöpft, sondern in Form von Vor- und Strukturermittlungen unter Einbeziehung von Erkenntnissen aus anderen Verfahren und im Rahmen von Initiativermittlungen im Bereich vor allem der opferlosen Kriminalität bei fehlenden Anzeigenerstattern erfolgt. 
Als großes Manko der TKÜ erscheint die Umsetzung des Richtervorbehaltes im Zusammenhang mit der damit verbundenen Begründungsanforderung. Man wird den Vorwurf erheben müssen, dass es derzeit an Transparenz, Nachvollziehbarkeit und Kontrolle mangelt. Es handelt sich um ein strukturelles Problem, das in Zusammenhang mit der Aufgabenverteilung und Arbeitsbelastung im Ermittlungsverfahren zu bewerten ist. Daneben bestehen die Schwierigkeiten, die bei der Abgabe einer komplexen Prognose (im Rahmen der Subsidiaritätsbeurteilung) zu erwarten sind und dadurch eher verstärkt werden, dass mit dem Ermittlungsrichter eine Person, die nicht im entsprechenden Ausmaß in den Ermittlungen steht, diese Vorhersage treffen soll. Ebenso wie die Kontrolle auf der Makroebene letztlich durch eine Stärkung der Verantwortlichkeiten erreicht werden muss, bedarf es auf der Mikroebene einer Optimierung der Aus- und Fortbildung derjenigen, die eine TKÜ einsetzen.

Was die Frage der Benachrichtigungspflicht angeht, so zeigt sich in erheblichem Umfang, dass die Begriffe des "Betroffenen" (§ 100b I S.2 StPO) und des "Beteiligten" (§ 101 I S.1 StPO) als Definitions- und Abgrenzungskriterium nicht taugen. In diesem Zusammenhang ist zu überprüfen, wer unter welchen (auch formalen) Voraussetzungen überwacht werden darf bzw. von einer Überwachung als Inhaber oder Mitnutzer in Mitleidenschaft gezogen werden kann, ohne dass er Nachrichtenmittler des Beschuldigten ist. Daneben bedarf es auch einer Auseinandersetzung mit dem Zielobjekt der Maßnahme und der Frage, ob die TKÜ sich auf einen durch die Telefonnummer spezifizierten Anschluss, ein Gerät oder allein den Beschuldigten bezieht. Einer Klärung zuzuführen ist die Frage, wer von einer durchgeführten TKÜ zu unterrichten ist. Hierbei handelt es sich sicher um die Person des (abgehörten) Beschuldigten. Gegebenenfalls ist zu erwägen, ob von seiner ausdrücklichen Benachrichtigung abgesehen werden kann, wenn er auf anderem und sicher festgestelltem Wege Kenntnis von der TKÜ erlangt hat. Sofern die TKÜ auch weitere Dritte als Gesprächsteilnehmer in die Abhörtätigkeit einbezogen hat, stellt sich die Frage, inwieweit diesen die Überwachung zur Kenntnis gebracht werden muss. In diesem Zusammenhang wäre ein trennscharfes Kriterium wünschenswert, jedoch sicherlich schwer umzusetzen. Hierbei sind zudem faktische Begrenzungen bei der Benachrichtigung der Beteiligten anzuerkennen. Eine zwar in rechtsstaatlicher Weise normierte, aber tatsächlich nicht durchführbare Regelung erscheint als Provokation des Regelungsbruchs.

\section{- Veröffentlichungen zum Projekt:}

AlBRECHT, H.-J., DORSCH, C., KRÜPE, CH., Rechtswirklichkeit und Effizienz der Überwachung der Telekommunikation nach $\S \S 100 \mathrm{a}, 100 \mathrm{~b}$ StPO und anderer verdeckter Ermittlungsmaßnahmen. edition iuscrim, Kriminologische Forschungsberichte aus dem MPI, Bd. 115, Freiburg i.Br.

AlBRECHT, H.-J., DORSCH, C., KRÜPE, CH., Rechtswirklichkeit und Effizienz der Überwachung der Telekommunikation nach $\S \S 100 \mathrm{a}, 100 \mathrm{~b}$ StPO und anderer verdeckter Ermittlungsmaßnahmen. forschung aktuell / research in brief Nr. 17, Freiburg i.Br. 2003.

- Drittmittel: Gefördert vom Bundesministerium der Justiz. 


\subsubsection{Rechtswirklichkeit der Überwachung der Telekommunikation nach $\S 100 a, 100 b$ StPO}

- $\quad$ Bearbeiterin: Christiane Krüpe (Juristin)

- $\quad$ Laufzeit: 2002 bis 2004

- $\quad$ Projektstatus: in Bearbeitung

- $\quad$ Projektbeschreibung: (zugleich Promotionsvorhaben)

In vielen Bereichen des Strafverfahrensrechts wird beklagt, dass die theoretischen Vorstellungen des Gesetzgebers und darauf basierend die praktische Umsetzung einer Regelung nur bedingt übereinstimmen. Die vorliegende Arbeit beschäftigt sich mit der Frage nach der Rechtswirklichkeit der Überwachung der Telekommunikation nach $\S \S 100 \mathrm{a}, 100 \mathrm{~b}$ StPO. Ziel soll es sein, die gesetzliche Regelung der Telekommunikationsüberwachung (TKÜ) einer Überprüfung mit Blick auf die tatsächliche Umsetzung durch die Strafverfolgungspraxis zu unterziehen. Hinsichtlich der TKÜ findet seit langem eine rege Reformdiskussion statt, die sich allerdings mangels empirisch gesicherter Daten bisher auf weitgehend ungesichertem Grund bewegt.

Die Studie steht in Zusammenhang mit der Untersuchung des Max-Planck-Institutes zu "Rechtswirklichkeit und Effizienz der Überwachung der Telekommunikation nach $\S \S 100 \mathrm{a}, 100 \mathrm{~b}$ StPO und anderer verdeckter Ermittlungsmaßnahmen" und der Arbeit von Frau Claudia Dorsch zu Effizienzfragen der TKÜ. Das Gutachten wurden dem Bundesministerium der Justiz im Mai 2003 vorgelegt und ist im September des Jahres erschienen.

Die Fragestellungen der Hauptstudie werden in dieser Arbeit erweitert und vertieft. Hierbei wird das Augenmerk vor allem auf der Überwachungsintensität und der Schnelligkeit der Entscheidung zur Anordnung einer TKÜ liegen. Weiterhin werden deliktsspezifische Auswertungen erfolgen.

Der Untersuchung wird das Datenmaterial aus der Aktenanalyse und der schriftlichen Befragung zugrunde gelegt, die im Rahmen der Hauptuntersuchung durchgeführt werden. Daneben werden die Erkenntnisse aus den Experteninterviews zu einer Überprüfung der so gewonnenen Ergebnisse herangezogen. Diesbezüglich sei für den methodischen Aufbau dieses Projektes auf den Beitrag zur Gesamtuntersuchung im vorliegenden Forschungsbericht verwiesen.

- $\quad$ Arbeitsbericht bis 2003:

Im Jahr 2003 wurde zunächst das Gutachten zur Überwachung der Telekommunikation für das Bundesministerium der Justiz erstellt und im Mai dem Ministerium übergeben. Anschließend wurde die Drucklegung zur Veröffentlichung vorbereitet.

Im August und September wurden die Abschlussdatenfiles für die Dissertation erstellt und die letzten Fragebögen der Schriftlichen Befragung EDV-mäßig aufbereitet. Parallel wurde mit der Datenkorrektur begonnen. Des Weiteren wurde die Durchführung der Kontrollgruppe vorbereitet.

- $\quad$ Arbeitsplanung 2004:

Zusammenstellen der Ergebnisse.

- Veröffentlichungen zum Projekt:

Albrecht, H.-J., DORSCH, C., KRÜPE, CH., Rechtswirklichkeit und Effizienz der Überwachung der Telekommunikation nach $\S \S 100 \mathrm{a}, 100 \mathrm{~b}$ StPO und anderer verdeckter Ermittlungsmaßnahmen. edition iuscrim, Kriminologische Forschungsberichte aus dem MPI, Bd. 115, Freiburg i.Br. 
AlBRECHT, H.-J., DORSCH, C., KRÜPE, CH., Rechtswirklichkeit und Effizienz der Überwachung der Telekommunikation nach $\S \S 100 \mathrm{a}, 100 \mathrm{~b}$ StPO und anderer verdeckter Ermittlungsmaßnahmen. forschung aktuell / research in brief Nr. 17, Freiburg i.Br. 2003.

\subsubsection{Effizienz der Überwachung der Telekommunikation nach den $§ \S 100 a, 100 b$ StPO}

- $\quad$ Bearbeiterin: Claudia Dorsch (Juristin)

- $\quad$ Laufzeit: 2002 bis 2004

- $\quad$ Projektstatus: in Bearbeitung

- $\quad$ Projektbeschreibung: (zugleich Promotionsvorhaben)

Die Zahl der Strafverfahren, in denen mindestens eine Anordnung zur Überwachung der Telekommunikation (TKÜ) nach den $\S \S 100 \mathrm{a}, 100 \mathrm{~b}$ StPO erging, ist in den vergangenen Jahren stetig angestiegen. Zugenommen hat damit auch die Anzahl der mit Maßnahmen der Überwachung der Telekommunikation automatisch verbundenen Eingriffe in Freiheitsrechte der Bürger.

Auf den ersten Blick scheinen die auf jeweiliger Seite vorhandenen Interessen unvereinbar. Ein Ausgleich zwischen Strafverfolgungsbehörden und "abgehörten Bürgern" mag jedoch dann gelingen, wenn sich die Überwachung der Telekommunikation als effektives Instrument zur Verbrechensbekämpfung bewährt hat und/oder bewähren wird.

$\mathrm{Ob}$ und in welcher Form die TKÜ als polizeiliches Aufklärungs- und verfahrenrechtliches Beweismittel wirksam ist und/oder sein könnte, soll mit vorliegender Arbeit erstmals empirisch untersucht werden.

Die Studie ist eingebettet in das vom Bundesministerium der Justiz dem MPI in Auftrag gegebene Forschungsvorhaben "Rechtswirklichkeit und Effizienz der Überwachung der Telekommunikation nach den $\S \S 100 \mathrm{a}, 100 \mathrm{~b}$ StPO und anderer verdeckter Ermittlungsmaßnahmen" und steht im Zusammenhang mit der Arbeit von Frau Christiane Krüpe zur Rechtwirklichkeit der TKÜ.

Im Mittelpunkt der Untersuchung werden zunächst der Begriff der Effizienz und seine Übertragbarkeit auf das Strafverfahrensrecht im Allgemeinen und die Ermittlungstätigkeit im Besonderen stehen. Im Folgenden wird anhand der gefundenen theoretischen Maßstäbe das Handeln der Strafverfolgungsbehörden auf Grundlage des im Rahmen oben genannten Forschungsvorhabens erhobenen Datenmaterials aus Aktenanalyse, schriftlicher Befragung und mündlichen Interviews auf seine Effektivität hin überprüft. Zentrale Bedeutung wird dabei dem Verhältnis von Beweis- zu Erkenntniswert der TKÜ zukommen, sowie der Frage einer möglichen Effizienzsteigerung.

- $\quad$ Arbeitsbericht bis 2003:

Im Jahr 2003 wurde zunächst das Gutachten zur Überwachung der Telekommunikation für das Bundesministerium der Justiz erstellt und im Mai dem Ministerium übergeben. Anschließend wurde die Drucklegung zur Veröffentlichung vorbereitet.

Im August und September wurden die Abschlussdatenfiles für die Dissertation erstellt und die letzten Fragebögen der Schriftlichen Befragung EDV-mäßig aufbereitet. Parallel wurde mit der Datenkorrektur begonnen. Des Weiteren wurde die Ermittlung der Kontrollgruppe vorbereitet.

- $\quad$ Arbeitsplanung 2004:

Analyse der Kontrollgruppe und Zusammenstellen der Ergebnisse. 
- Veröffentlichungen zum Projekt:

AlBRECHT, H.-J., DORSCH, C., KRÜPE, CH., Rechtswirklichkeit und Effizienz der Überwachung der Telekommunikation nach $\S \S 100 \mathrm{a}, 100 \mathrm{~b}$ StPO und anderer verdeckter Ermittlungsmaßnahmen. edition iuscrim, Kriminologische Forschungsberichte aus dem MPI, Bd. 115, Freiburg i.Br.

AlBRECHT, H.-J., DORSCH, C., KRÜPE, CH., Rechtswirklichkeit und Effizienz der Überwachung der Telekommunikation nach $\S \S 100 \mathrm{a}, 100 \mathrm{~b}$ StPO und anderer verdeckter Ermittlungsmaßnahmen. forschung aktuell / research in brief Ne. 17, Freiburg i.Br. 2003.

\subsubsection{Rechtswirklichkeit und Effizienz der akustischen Wohnraumüberwachung ("großer Lauschangriff") nach § 100c I Nr. 3 StPO}

- $\quad$ Bearbeiter: Hans-Jörg Albrecht (Jurist); Hannes Meyer-Wieck (Jurist)

- $\quad$ Laufzeit: 2002 bis 2004

- $\quad$ Projektstatus: in Bearbeitung

- $\quad$ Projektbeschreibung: (zugleich Promotionsvorhaben von Hannes Meyer-Wieck)

Die Einführung der akustischen Wohnraumüberwachung zu Strafverfolgungszwecken durch das Gesetz zur Änderung des Grundgesetzes vom 26. März 1998 und das Gesetz zur Änderung der Strafprozessordnung vom 4. Mai 1998 (v.a. § 100c I Nr. 3 StPO mit Folgeregelungen) - bekannt unter dem Stichwort "großer Lauschangriff" - gehört zu den umstrittensten kriminalpolitischen Themen der letzten Jahre. Durch die Grundgesetzänderung erlangt das Thema auch in verfassungstheoretischer Hinsicht besondere Relevanz.

$\mathrm{Zu}$ verweisen ist hier auch auf ein derzeit laufendes Verfahren vor dem Bundesverfassungsgericht.

Trotz der äußerst kontroversen Diskussion um dieses Ermittlungsinstrument ist jedoch allseits der Mangel an für eine fundierte Beurteilung erforderlichen empirischen Daten zu konstatieren. - Dabei ist gleichzeitig zu beachten, dass es sich hier um einen äußerst sensiblen Bereich staatlicher Eingriffsbefugnis handelt.

Die bisher vorliegenden Untersuchungen behandeln das Problem auf rechtspolitischer, dogmatischer und theoretischer Ebene, wobei ebenfalls auf die bisher fehlende Datenbasis hingewiesen wird. Aufgrund der nunmehr in Art. 13 GG normierten Berichtspflichten liegen seitens der Bundesregierung Berichte mit Zahlen für die in den Jahren 1998-2001 durchgeführten Maßnahmen vor; zum 31. Januar 2002 wurde ein "detaillierter Erfahrungsbericht" vorgelegt. Während erstere wegen ihrer wenig aussagekräftigen tabellarischen Darstellung mehrfach kritisiert wurden, wird in letzterem auf weiteren Forschungsbedarf hingewiesen.

Das seit dem Jahr 1999/2000 am MPI laufende Forschungsprojekt über "Rechtswirklichkeit und Effizienz der Überwachung der Telekommunikation nach $\S \S 100 \mathrm{a}, 100 \mathrm{~b}$ StPO" wurde daher auf "andere verdeckte Ermittlungsmaßnahmen" erweitert. Eine rechtstatsächliche Evaluation auch der akustischen Wohnraumüberwachung steht somit zusätzlich an erster Stelle. Damit soll zum einen für diesen Bereich eine möglichst präzise beschreibende Aufbereitung von Daten erfolgen, mit denen Entwicklungen und Strukturen der akustischen Wohnraumüberwachung in ihren ersten Einsatzjahren nachgewiesen werden können. Zum zweiten geht es um die Erklärung der Anordnung von Wohnraumüberwachungsmaßnahmen, also um theoretisch geleitete Korrelationsanalysen, in denen Bedingungen, Ursachen und Konsequenzen der Wohnraumüberwachungsanordnungen aufgedeckt werden sollen. Schließlich geht es um die Evaluation der Überwachungsmaßnahmen, womit der Nutzen der Wohnraumüberwachung (in Form von Ermittlungs-, Aufklärungs- und Verurteilungsresultaten) in ein kausal 
interpretierbares Verhältnis zu ihrer Verwendung, und zwar ihrer Verwendung insgesamt, zu spezifischen Eingriffsfolgen sowie auch zu ihren Kosten gebracht wird.

- $\quad$ Arbeitsbericht 2002:

Nach einer Auswertung des (theoretischen) Forschungsstandes und der Entwicklung der evaluierungsbedürftigen maßnahmenspezifischen Fragestellungen sowie einer gründlichen Einarbeitung in den anhand der Datenerhebung zur Telefonüberwachung gewonnenen Erfahrungsstand wurde ein Erhebungsinstrument für die Aktenanalyse entwickelt. Die Aktenanalyse ist im letzten Quartal 2002 angelaufen.

- Arbeitsbericht/Arbeitsplanung 2003/2004:

Die Aktenanalyse wird derzeit sukzessive in allen Bundesländern durchgeführt. Das hierdurch gewonnene Erfahrungswissen soll in ab dem Ende des Jahres 2003/Beginn des Jahres 2004 durchzuführenden Experteninterviews vertieft werden. Entsprechende Vorbereitungen hierzu werden in Koordination mit dem Fortgang der Aktenanalyse getroffen.

- $\quad$ Drittmittel: gefördert mit Mitteln des Bundesministeriums der Justiz.

\subsubsection{Möglichkeiten und Praxis elektronischer Überwachungsmaßnahmen in Europa}

- $\quad$ Bearbeiterin: Elisabeth Braun (Juristin)

- $\quad$ Laufzeit: 2000 bis 2004

- $\quad$ Projektstatus: in Bearbeitung

- $\quad$ Projektbeschreibung: (zugleich Promotionsvorhaben)

Elektronische Überwachungsmaßnahmen werden als besonders effektive Maßnahmen bei Ermittlungen im Rahmen von Verfahren gegen die Organisierte Kriminalität (OK) angesehen. In den 90er Jahren wurde die Zunahme von OK-Straftaten als eine wesentliche Begründung für die Notwendigkeit der Einführung neuer strafprozessualer Ermittlungsmethoden herangezogen - so zum Beispiel bei der Einführung des 'großen Lauschangriffes'. Auch die Ausweitung bereits vorhandener Maßnahmen, wie zum Beispiel die Erweiterung des Straftatenkatalogs der Telefonüberwachung auf Straftaten, die typischerweise unter die OK subsumiert werden, wurde damit gerechtfertigt. Deutschland ist diesbezüglich jedoch kein Einzelfall. In fast allen EU Mitgliedsstaaten wurden in den letzten Jahren zum Teil substantielle Gesetzesänderungen in Bezug auf besondere Ermittlungsmaßnahmen vorgenommen meist ebenfalls mit dem kriminalpolitischen Hinweis auf die Zunahme von OK-Straftaten.

Da die meisten Straftaten, die unter den Begriff der OK subsumiert werden, transnationale Dimensionen aufweisen, spielen für eine effiziente grenzüberschreitende Strafverfolgung gerade auch die elektronischen Ermittlungsmaßnahmen eine immer bedeutendere Rolle. Die justitielle Zusammenarbeit der verschiedenen europäischen Länder bei der Beschaffung von Beweismitteln wird mit einer zunehmenden Anzahl grenzüberschreitender Verfahren immer wichtiger.

Ziel der Untersuchung ist eine rechtsvergleichende Analyse und Evaluation der in den Mitgliedsstaaten der Europäischen Union implementierten elektronischen Ermittlungsmethoden - und hierbei vor allem der Wohnraum- und Telekommunikationsüberwachung. Dabei soll ermittelt werden, wie sich die einzelnen Maßnahmen in ihren Voraussetzungen und Anwendungsbereichen unterscheiden, und aufgrund welcher Begründung sie jeweils eingeführt wurden. Besonderes Augenmerk wird auf die Fragestellung gelegt, inwieweit die einzelnen Maßnahmen in den jeweiligen Ländern rechtsstaatlich 
gesichert sind und welchen Kontrollmechanismen sie unterliegen. Interessant ist dabei auch die Frage, ob überprüfbare Zahlen zur Anwendungshäufigkeit der Maßnahmen sowie zu deren Erfolg existieren. Die Untersuchung wird sich voraussichtlich auf Deutschland, die Niederlande, Großbritannien, Frankreich, Belgien, Dänemark, Italien und Österreich erstrecken.

Im Hinblick auf die transnationale Strafverfolgung, insbesondere bei Anwendung elektronischer Überwachungsmaßnahmen, werden zudem Fragen der europäischen Rechtshilfe näher beleuchtet. Schließlich soll auch die Frage nach Sinn und Zweck einer integrierten europäischen Strafverfolgung und deren Realisierbarkeit untersucht werden.

Den methodischen Hintergrund bildet die Aufbereitung und Analyse der Gesetzgebung sowie der polizeilichen und justiziellen Praxis. Darüber hinaus sollen vorhandenes Datenmaterial und empirische Untersuchungen zur TÜ und zur akustischen Wohnraumüberwachung untersucht und ausgewertet werden. Dadurch wird eine vergleichende Bewertung der deutschen Theorie und Praxis vor dem Hintergrund europäischer Systeme und Erfahrungen ermöglicht. Zudem sollen schriftliche und mündliche Expertenbefragungen zu den in den jeweiligen Ländern implementierten Regelungen sowie deren praktischer Umsetzung in den einzelnen Ländern durchgeführt werden. Im Hinblick auf die Frage nach der europäischen Rechtshilfe in transnationalen Verfahren wird eine Aufbereitung und Analyse der Gesetzgebung des Europarates und der Europäischen Union sowie der Rechtsprechung des Europäischen Gerichtshofes für Menschenrechte erfolgen. Neuere Entwicklungen, insbesondere die des Übereinkommens vom 29. Mai 2000 über die Rechtshilfe in Strafsachen zwischen den Mitgliedsstaaten der Europäischen Union und die Einrichtung von Eurojust, sollen unter dem Gesichtspunkt der besonderen Relevanz für das vorliegende Untersuchungsthema erörtert werden.

- $\quad$ Arbeitsbericht bis 2003:

Das im Jahr 2000 begonnene Projekt hat mit der Aufbereitung und Analyse der Gesetzgebung Deutschlands, Belgiens, der Niederlande, Österreichs und Großbritanniens, sowie der Erhebung und Aufarbeitung der jeweiligen Daten und Untersuchungen begonnen. Auch für den europäischen Rahmenteil der Arbeit wurde bereits eine grundlegende Struktur herausgearbeitet und erste Experteninterviews auf europäischer Ebene durchgeführt. Danach wurde die Arbeit an dem Projekt wegen des Referendariats unterbrochen.

- $\quad$ Arbeitsplanung 2004:

Im Jahr 2004 sollen die verbleibenden Länder untersucht werden. Parallel dazu sollen die Daten der bereits in der Untersuchung befindlichen Länder weiter analysiert und aktualisiert werden, so dass daran anschließend ein europaweiter Vergleich ausgearbeitet werden kann. Besonderes Augenmerk wird dabei auf die Frage der Effizienz, Rechtsstaatlichkeit und Kontrolle der implementierten elektronischen Ermittlungsmaßnahmen in den einzelnen Mitgliedsstaaten gelegt. Zudem werden die eingeführten Maßnahmen unter dem Blickwinkel einer europaweiten Strafverfolgung beleuchtet. Anschließend soll aus jedem untersuchten Land jeweils eine strategisch-politische Person (beispielsweise aus dem Innen- bzw. Justizministerium) und eine Person aus dem operationellen Bereich (zum Beispiel aus einer höheren Polizeibehörde) interviewt werden.

\subsubsection{Cannabis Non-Prosecution Policies in Germany}

- $\quad$ Bearbeiter(in): Letizia Paoli (Soziologin), Carsten Schäfer (Jurist)

- Zeitrahmen: 2002 bis 2004

- $\quad$ Projektstatus: in Bearbeitung 
- $\quad$ Projektbeschreibung:

The Max Planck Institute has been commissioned by the Drug Policy Research Center at the RAND Corporation in the United States to conduct a study of cannabis non-prosecution policies in Germany. The study is part of two larger projects:

The first one is a research project on the effects of cannabis depenalisation in the United States and in several other Western countries. The overall aim of the project is to learn more about the likely effects of widespread decriminalisation by examining changes in cannabis use associated with changes in cannabis laws in the United States, Australia, Germany, the Netherlands and the United Kingdom. The overall project is coordinated by Rosalie Pacula (RAND and National Bureau of Economic Research), Jamie Chriqui (The MayaTech Corporation), Robert MacCoun (University of California at Berkeley and RAND) and Peter Reuter (University of Maryland and RAND). Letizia Paoli and Carsten Schäfer are in charge of the study in Germany.

The study on cannabis non-prosecution policies is also part of a wider project on 'Drug Consumption and Criminal Prosecution Praxis in Germany,' that is carried out by Paoli and Schäfer on behalf of the German Federal Ministry of Health and Public Security (see 'Drogenkonsum und Strafverfolgungspraxis'). Whereas this larger project analyses prosecution and non-prosecution policies of all consumption-related drug offences, the present study exclusively focuses on cannabis. It has three major aims:

- To understand under which conditions and for which drug amounts criminal cases against cannabis users are dismissed by the prosecutor's offices and courts in different German states (Länder)

- To assess state differences in the implementation of the Federal Constitutional Court's decision of March 9, 1994 (the so-called 'cannabis decision')

- To evaluate the eventual impact of the different non-prosecution policies pursued by German states on cannabis consumption rates and patterns.

\section{The Problem: Legislative Background and Judicial Praxis}

The German drug legislation currently contains several provisions according to which criminal cases against drug users can be dismissed. According to the section 29, fifth paragraph, of the Act on Narcotics (Betäubungsmittelgesetz, shortly referred to as BtMG), certain drug offences may be exempted from punishment by a criminal court, if small amounts of drugs are involved and if these are exclusively intended for personal consumption. The offences concern, among others, cultivation, production, import, export, transfer, possession, purchase and acquiring of illegal drugs.

The non-prosecution of such cases is also foreseen by section 31a of the Act on Narcotics, which was added by the German Parliament in 1992. If there is no public interest in prosecution and the offender's guilt can be considered minor, the first paragraph of section 31a BtMG allows the prosecutor's office to dismiss the cases meeting the above conditions without consulting the court. According to the second paragraph of the same section, the court can also dismiss the above cases at a later stage in agreement with the prosecutor's office and the defendant. Section 31a BtMG can be considered as a special case of section 153 and the following sections (sections 153a and 154 are particularly relevant here) of the Code of Criminal Procedure (Strafprozeßordnung), which generally regulate the dismissal of criminal cases.

A conditional dismissal is allowed by section 37 of the Act on Narcotics. This allows the prosecutor's office to temporarily dismiss a case in agreement with the competent criminal court, if the defendant is a drug addict, the expected conviction would be shorter than two years and the defendant agrees to initiate a drug detoxification therapy (according to the principle of Therapie statt Strafe, i.e. therapy instead of conviction). The case can be reopened, however, if the offender abandons the detoxification 
program or commits new crimes. Further dismissal opportunities are finally foreseen by the Juvenile Court Act (Jugendgerichtsgesetz) for minors (and in some cases defendants younger than 21-yearsold).

Section 31a of the Act on Narcotics is most commonly resorted to in order to dismiss criminal cases concerning the possession of small quantities of cannabis for personal use. For its application (and for the application of section 29, fifth paragraph), the crucial concept is that of small amounts (geringe Menge), which is left undefined by the law. According to the jurisprudence of some high courts (Oberlandesgerichte), small amounts of drugs encompass quantities corresponding to three consumption units of a non-addicted drug user. Up to six grams of hashish (the cannabis resin, which is most commonly consumed in Germany) are usually considered small amounts by the more conservative higher courts. In March 1994 the Federal Constitutional Court ruled that criminal cases involving the possession, purchase or import of small amounts of cannabis for occasional personal use must be dismissed because both the guilt (Schuld) of the offender and the injustice (Unrechtsgehalt) of the offence have to be considered small and in Germany criminal law can be resorted to only as ultima ratio.

Except for this case, the Federal Constitutional Court further argued that criminal drug laws outlawing the purchase and possession of controlled substances for personal consumption do not infringe the German Constitution, but that dramatic differences in non-prosecution policies cannot be accepted because they would amount to a serious violation of the right of equal and non-discriminatory treatment. The court further stated that under certain conditions the criminal prosecution of the possession of small quantities of illegal drugs - specifically cannabis - could amount to excessive state intervention and thus seriously infringe upon the principle of proportionality. The highest German judicial body thus concluded that the infringements of the basic rights of equal treatment and proportionality could be avoided by properly applying criminal drug laws and implementing consistent non-prosecution policies throughout Germany in cases involving the possession of small drug quantities for personal use.

Despite this ruling, German states are far from having developed and implemented a uniform policy of non-prosecution. In the German federal system, the implementation of the law is entrusted to the single states. Except by enacting or amending laws - and the German Constitutional Court has been criticised for not formally requesting a legislative amendment in its 1994 landmark decision - federal bodies can in no way interfere with the implementation of criminal law at the state level. It must be considered, furthermore, that the public prosecutor has a monopoly in prosecuting criminal cases and selecting the cases which have to be brought to the criminal court. And although the German criminal system subscribes to the principle of legality, in terms of statutory powers and practical outcomes, public prosecutors enjoy a relatively high degree of discretion in the decision whether to prosecute a criminal case or to dismiss it.

The implementation of the Constitutional Court's verdict should have thus been based on consensual policy decisions in the single states, which were supposed to enact uniform guidelines for their prosecutor's offices. Such a consensus, however, has not been reached and considerable regional differences continue, therefore, to exist. Several northern and middle states (among others Hamburg, LowerSaxony, North Rhine-Westphalia and Schleswig-Holstein) have adopted guidelines or recommendations requiring or allowing the non-prosecution in cases involving ten to fifteen grams of cannabis and, in Schleswig-Holstein, up to thirty grams of cannabis. In contrast, the southern states and several eastern ones (such as Baden-Württemberg, Bavaria, Saxony-Anhalt and Thuringia) have issued more restrictive guidelines, ruling that prosecutor's offices and courts can only dismiss cases involving less than six grams of cannabis. The more liberal states also allow dismissals for repeat offenders, whereas conservative states usually rule out this possibility or allow dismissals only in exceptional circumstances. Some states (such as Mecklenburg-West Pomerania and Saxony) have issued no such guidelines so far. 
- $\quad$ Progress Report 2002/2003 and Work Plan 2004:

To reach the above-mentioned aims of the study, several research methods are being employed. A preliminary step was constituted by the retrieval and analysis of the guidelines and recommendations issued by the German Länder for the application of section 31a of the Act on Narcotics. Statistical data concerning the dismissal of cannabis criminal cases on the basis of section 31a BtMG and all other relevant provisions were also be collected and analysed on a state by state basis, as far as they are available.

The core of the project is represented by the primary data collection and analysis of about 1,200 cannabis-related criminal cases initiated in 2001. The cases are drawn from six Länder with varying drug control policies and, within them, from following twenty-four jurisdictions:

\begin{tabular}{|c|c|}
\hline States ('Bundesländer') & Jurisdictions ('Landesgerichtsbezirk') \\
\hline Bavaria & $\begin{array}{l}\text { Bamberg } \\
\text { Landshut } \\
\text { Prosecution I in the court district Munich } \\
\text { Nuremberg-Fürth } \\
\text { Traunstein }\end{array}$ \\
\hline Berlin & Prosecution I in the court district Berlin \\
\hline Hesse & $\begin{array}{l}\text { Kassel } \\
\text { Frankfurt a. M. } \\
\text { Fulda } \\
\text { Hanau }\end{array}$ \\
\hline North Rhine-Westphalia & $\begin{array}{l}\text { Aachen } \\
\text { Cologne } \\
\text { Münster } \\
\text { Paderborn }\end{array}$ \\
\hline Saxony & $\begin{array}{l}\text { Bautzen } \\
\text { Chemnitz } \\
\text { Dresden } \\
\text { Görlitz } \\
\text { Leipzig } \\
\text { Zwickau }\end{array}$ \\
\hline Schleswig -Holstein & $\begin{array}{l}\text { Flensburg } \\
\text { Itzehoe } \\
\text { Kiel } \\
\text { Lübeck }\end{array}$ \\
\hline
\end{tabular}

The data collection is ongoing and is carried out simultaneously for this study and the Federal Ministry of Health-funded project on 'Drug Consumption and Criminal Prosecution Praxis'. About 700 criminal cases have so far been retrieved. The data collection is expected to be completed within the first three months of 2004. The analysis of the collected data will then immediately follow suit.

The analysis of criminal cases shall produce new findings and statistical data on the frequency and modalities of the dismissal of cannabis cases according to section 31a BtMG and other related sections 
and acts. The project shall also indicate to what extent the intentions of the legislator have been fulfilled, and if the demands imposed by Constitutional Court on public prosecutors have actually been met.

In addition to the case analysis, expert interviews are being carried out in eleven of the selected jurisdictions. In each of these eleven jurisdictions, we plan to interview three police officers, two prosecutors, two judges, one attorney as well as the heads of the Foreigners and Driving Licence Authorities (respectively, Ausländerämter and Fahrerlaubnisbehörde). For each of these interviews a specific protocol has been developed. As of December 2003, interviews in three Länder were already carried out: namely, Bavaria, Berlin and North Rhine-Westphalia. Interviews in the three remaining states are planned for the beginning of 2004.

The interviews investigate not only the criminal prosecution and non-prosecution practices of law enforcement agencies and courts but also the imposition of administrative measures by the Foreigners and Driving Licence Authorities (such as the withdrawal of the driving licences or a residence permit), which often turn out to be an alternative penalty for the defendants. Right now, the latter is politically and judicially a veritable 'hot' topic. On several occasions in 2002, the German Constitutional Court criticised the practice of some driving licence authorities that suspended the licenses of drug offenders caught in possession of small quantities of 'soft drugs' (especially cannabis). The licences were withdrawn despite the lack of proof that the offenders were unable to drive a vehicle due to the drug influence.

Finally, Paoli and Schäfer intend to look for correlations between the different cannabis nonprosecution policies pursued by the German federal states and the local prevalence rates and patterns of cannabis use. This goal will be primarily achieved by comparing the results of expert interviews and the criminal case analysis with the state-level cannabis prevalence rates recorded by national population surveys on drug use. A request to access state-level drug prevalence rates was granted to the German Federal Ministry of Health after it obtained the necessary authorisation from the single Länder.

The final report will be submitted by Paoli and Schäfer to the RAND Drug Police Research Center within the first half of 2004.

- Drittmittel: Robert Wood Johnson Foundation. 


\title{
3.4.3 Implementations- und Evaluationsprojekt zu Täter-Opfer-Ausgleich und Wiedergut- machung im allgemeinen Strafrecht im deutsch-österreichischen Vergleich
}

\author{
- Bearbeiter(in): Michael Kilchling (Jurist); Marianne Löschnig-Gspandl (Juristin, externe \\ österreichische Forschungspartnerin) \\ - $\quad$ Zeitrahmen: 1997 bis 2004 \\ - $\quad$ Projektstatus: in Bearbeitung \\ - $\quad$ Projektbeschreibung: \\ (vgl. dazu bereits die Tätigkeitsberichte 1996/1997, S. 78; 1998/1999, S. 116; 2000/01, \\ S. 144)
}

Die rechtsvergleichende Implementations- und Evaluationsstudie zum Täter-Opfer-Ausgleich im allgemeinen Strafrecht in Österreich (ATA-E) und Deutschland (TOA - eigentlich TOA-E) wird seit 1997 in enger Kooperation mit dem Institut für Strafrecht, Strafprozeßrecht und Kriminologie der Universität Graz durchgeführt. Ziel der Untersuchung ist die ausführliche Analyse der justiziellen Anwendungspraxis in einem Setting, das sowohl durch unterschiedliche rechtliche Rahmenbedingungen als auch durch eine gerade im Erwachsenenbereich zu verzeichnende unterschiedliche Anwendungshäufigkeit gekennzeichnet ist. Auf der Grundlage verschiedener quantitativer und qualitativer Forschungsschritte werden nicht nur die rechtlichen und praktischen Gründe für das unterschiedliche Anwendungsverhalten der Justiz erforscht. Darüber hinaus geht es auch um die Untersuchung der Frage, ob diese Unterschiede lediglich ein rein quantitatives Phänomen darstellen oder ob sich die Ausgleichsfälle auch qualitativ unterscheiden. In diesem Zusammenhang soll insbesondere der Frage nachgegangen werden, ob sich die evident häufigere Anwendung in Österreich möglicherweise in einer erkennbaren Ausdehnung auf schwerere Fallkategorien niederschlägt oder ob der österr. ATA-E nicht eher ein Fallspektrum erfaßt, das in Deutschland im Wege weniger eingriffsintensiver Diversionsalternativen erledigt wird und somit erst gar nicht in den Täter-Opfer-Ausgleich gelangt.

Konzeption und Methodik der Studie wurden im vorigen Tätigkeitsbericht ausführlicher beschrieben. Aufgrund der zwischenzeitlich eingetretenen Änderung des rechtlichen Rahmens für den ATA in Österreich, in deren Zuge die Rechtsgrundlage aus dem materiellen Strafrecht in das mit 1. Januar 2000 in Kraft getretene neue Diversionsrecht überführt wurde (vgl. $\S \S 90 \mathrm{a} f f$. öStPO), wurde entschieden, die vorliegende Studie um einen zusätzlichen, in der ursprünglichen Forschungsplanung nicht vorgesehenen Teil zu erweitern. Andernfalls wäre die Analyse der noch auf der Grundlage des $\S 42$ öStGB entschiedenen Fälle zum Zeitpunkt der Publikation für Österreich nurmehr von historischem Interesse gewesen. Daher soll in der Steiermark eine weitere Welle erhoben werden (abhängig von der noch ausstehenden Genehmigung sollen dies Fälle aus dem Jahr 2002 oder 2003 sein). Diese neuerliche Erhebung wird für die österreichischen Fälle interessante Vergleichsanalysen über etwaige Veränderungen in der dortigen Zuweisungs- und Erledigungspraxis ermöglichen und dem Projekt damit eine zusätzliche Dimension geben.

\section{- $\quad$ Arbeitsbericht bis 2003}

Im Berichtszeitraum wurden die gesammelten Daten aus der Aktenerhebung aufbereitet und im Wesentlichen ausgewertet. Erste Zwischenergebnisse auf der Basis der ersten Welle in BadenWürttemberg sowie der Gesamtstichprobe aus der Steiermark ergaben bereits, dass sich die Fälle über eine unterschiedliche Anwendungshäufigkeit hinaus auch in der jeweiligen Anwendungspraxis deutlich unterscheiden. Diese betreffen u.a. die Fallstruktur, die Ausgleichspraxis selbst sowie das justizielle Zuweisungs- und Endentscheidungsverhalten. Einige dieser Befunde sind auszugsweise bereits veröffentlicht worden (vgl. Kilchling 2000a). 
- $\quad$ Arbeitsplan 2004

Nach erfolgter Genehmigung sollen die Akten aus der zweiten Welle österreichischer Fälle ausgewertet werden. Die nachfolgenden Vergleichsanalysen werden auch Bestandteil des ebenfalls noch zu erstellenden Abschlussberichtes sein.

- $\quad$ Neuere Veröffentlichungen

LÖSCHNIG-GSPANDL, M., KILCHLING, M. (1999): Täter-Opfer-Ausgleich und Wiedergutmachung im allgemeinen Strafrecht von Deutschland und Österreich - Konzeptualisierung einer vergleichenden Implementations- und Evaluationsforschung. In: H.-J. Albrecht (Hrsg.): Forschungen zu Kriminalität und Kriminalitätskontrolle am Max-Planck-Institut. Kriminologische Forschungsberichte aus dem MaxPlanck-Institut für ausländisches und internationales Strafrecht. Freiburg i. Br. 1999, 243-290.

LÖSCHNIG-GSPANDL, M. (1999): Der außergerichtliche Tatausgleich im allgemeinen Strafrecht: Voraussetzungen und Anwendungsmöglichkeiten. In: R. Miklau u. H.V. Schroll (Hrsg.): Diversion, Ein anderer Umgang mit Straftaten, Analysen zur Strafprozeßnovelle 1999. Wien 1999, 85-97.

KILChling, M., LÖSCHNIG-GSPANDL, M. (2000): Legal and Practical Perspectives on Victim/ Offender Mediation in Austria and Germany. International Review of Victimology 7 (2000), 305-332. LÖSCHNIG-GSPANDL, M. (2000): TOA-E versus ATA-E - Ausgewählte Fragen zu den normativen Grundlagen. In: J.M. Jehle (Hrsg.): Täterbehandlung und neue Sanktionsformen. Kriminalpolitische Konzepte in Europa. Neue Kriminologische Schriftenreihe Bd. 106, Mönchengladbach 2000, 277-294. KILChLING, M. (2000a): TOA-E versus ATA-E - empirische Befunde zur Praxis des Täter-Opfer-Ausgleichs. In: J.M. Jehle (Hrsg.): Täterbehandlung und neue Sanktionsformen. Kriminalpolitische Konzepte in Europa. Neue Kriminologische Schriftenreihe Bd. 106, Mönchengladbach 2000, 295-321.

KILCHLING, M. (2000b): «TOA $\neq$ TOA = TOA?» - Anmerkungen zur derzeitigen rechtlichen Ausgestaltung des Täter-Opfer-Ausgleichs im deutschen Erwachsenenstrafrecht. TOA-Infodienst Nr. 12 (November 2000), 26-30.

LÖSCHNIG-GSPANDL, M. (2001): Diversion in Austria - Legal Aspects. European Journal of Crime, Criminal Law and Criminal Justice 9 (2001), 281-290.

GRAFL, C. (2001): Diversion in Austria - Empirical Data. European Journal of Crime, Criminal Law and Criminal Justice 9 (2001), 291-298.

\subsubsection{Drogenkonsum und Strafverfolgungspraxis}

- $\quad$ Bearbeiter(in): Letizia Paoli (Sozialwissenschaftlerin), Carsten Schäfer (Jurist)

- $\quad$ Zeitrahmen: November 2002 bis Oktober 2004

- $\quad$ Projektstatus: in Bearbeitung

- $\quad$ Projektbeschreibung: (zugleich Promotionsvorhaben von Carsten Schäfer)

Ziel des Forschungsprojektes "Drogenkonsum und Strafverfolgungspraxis" ist eine empirische Untersuchung der (repressiven) Behandlung "konsumbezogener" Drogendelikte durch die Strafverfolgungsbehörden und der sich daran anschließenden (präventiven) Maßnahmen durch die Ordnungsbehörden. Das Projekt wird im Auftrag des Bundesministeriums für Gesundheit und Soziale Sicherung durchgeführt.

\section{Problemstellung}

Mit der 1992 in Kraft getretenen Vorschrift des § 31a des Betäubungsmittelgesetztes (BtMG) hat der Gesetzgeber die Möglichkeiten des Absehens von der Strafverfolgung durch die Staatsanwaltschaften ohne gerichtliche Zustimmung bei Drogendelikten neben den allgemeinen Einstellungsvorschriften 
der Strafprozessordnung bzw. des Jugendgerichtsgesetzes wesentlich erweitert. Das Ziel des Gesetzgebers war vorrangig, eine Entlastung der Strafverfolgungsorgane zu erreichen, gleichzeitig sollte aber auch die kriminalpolitische Funktion der Vorschrift als prozessuales Mittel der Entpönalisierung bezweckt werden. Zudem ist damit die Erwartung verknüpft, dass gemäß dem Grundsatz "Hilfe vor Strafe" und unter Verzicht auf strafrechtliche Sanktionen, möglichst viele Konsumenten für Maßnahmen der Drogenberatung und gegebenenfalls Drogentherapie zu gewinnen wären.

Bereits 1994 war die Vorschrift des § 31a BtMG Gegenstand einer verfassungsgerichtlichen Entscheidung. Dabei wurde die Verfassungsmäßigkeit der betäubungsmittelrechtlichen Strafvorschriften (§ 29 BtMG) in Bezug auf die Strafbarkeit von Cannabis-Delikten bestätigt, gleichzeitig aber festgestellt, dass nach dem Übermaßverbot unter bestimmten Voraussetzungen von der Verfolgung der in $\S 31 \mathrm{a}$ BtMG bezeichneten Straftaten abgesehen werden muss. Außerdem wurde eine im Wesentlichen einheitliche Einstellungspraxis der Staatsanwaltschaften im Hinblick auf den verfassungsrechtlichen Gleichheitssatz und dem Verfassungsgebot der "Einheitlichkeit der Lebensverhältnisse" im gesamten Bundesgebiet angemahnt.

Die Frage einer möglichst einheitlichen Einstellungspraxis der Staatsanwaltschaften und somit die Frage nach einer im Wesentlichen gleichmäßigen Rechtsanwendung bei eigenkonsumbezogenen Drogenverfahren steht im Zentrum dieser Forschungsstudie. Dies erscheint vor allem deshalb zweifelhaft, weil es auch acht Jahre nach der Entscheidung des Bundesverfassungsgerichts noch nicht zu einer formellen Einigung der Bundesländer über eine einheitliche Handhabung der staatsanwaltlichen Einstellungspraxis im Bereich von § 31a BtMG gekommen ist und daher jedes Land die Anwendung mit eigenen Empfehlungen bzw. Richtlinien an die Staatsanwaltschaften regelt, die weiterhin in entscheidenden Punkten - wie etwa bei der Bestimmung des Kriteriums "geringe Menge", der Frage des "öffentlichen Interesses" bei Drogenbesitz im Strafvollzug oder der Behandlung von Wiederholungstätern - zum Teil deutliche Diskrepanzen aufweisen.

An dieser Problemstellung setzt die Forschungsstudie an. Es sollen Erkenntnisse und statistische Daten gewonnen werden etwa über die Häufigkeit und Umstände von Verfahrenseinstellungen nach $\S 31 \mathrm{a}$ BtMG und anderen Vorschriften, aber auch über die Verwirklichung der vom Gesetzgeber verfolgten Anliegen und die Umsetzung der in der Entscheidung des Bundesverfassungsgerichtes enthaltenen Vorgaben.

Schon eine Vorgängerstudie der Kriminologischen Zentralstelle in Wiesbaden ("Aulinger-Studie") hat sich mit der Problematik der Rechtsgleichheit bei der Strafverfolgung von Drogenkonsumenten befasst und hierzu staatsanwaltschaftliche Ermittlungsakten aus dem Jahr 1995 - also ein Jahr nach der Entscheidung des Bundesverfassungsgerichts - ausgewertet. Für einen möglichst direkten Vergleich der Ergebnisse wird auf dieselben Bundesländer und - mit der Ausnahme von München, Fulda und Kassel (statt Darmstadt) - auch auf alle 22 in der "Aulinger-Studie" untersuchten Landgerichtsbezirke zurückgegriffen. Eine wesentliche Vertiefung wird aber dadurch erreicht, dass nunmehr nicht nur eingestellte Verfahren ausgewertet werden, sondern auch solche Verfahren, die zu einer Anklage führten. Hierdurch erhöht sich zwar die Stichprobe im Vergleich zur "Aulinger-Studie", es können nun aber auch aus dem Anklageverhalten der Staatsanwaltschaften Rückschlüsse auf die Anwendungspraxis des $\S 31$ a BtMG gezogen werden.

Weiterhin soll anhand von qualifizierten Experteninterviews der Frage nachgegangen werden, wie sich verwaltungsrechtliche Maßnahmen der Ordnungs- und Ausländerbehörden nach erfolgter Verfahrenseinstellung im Hinblick auf eine mögliche "Ersatzstrafe" auswirken. So hat das Bundesverfassungsgericht im Jahr 2002 in mehreren Entscheidungen die Praxis einiger Fahrerlaubnisbehörden für verfassungswidrig erklärt, obligatorisch die Entziehung der Fahrerlaubnis wegen verweigerter Beibringung eines behördlich angeforderten Drogenscreenings nach festgestelltem Besitz einer geringen Menge "weicher" Drogen anzuordnen, ohne im einzelnen die Ungeeignetheit zum Führen eines Kraftfahrzeuges explizit festzustellen. Darüber hinaus soll auch in diesem Zusammenhang das Prob- 
lem der Rechtsanwendungsgleichheit untersucht und auf ihre verfassungsrechtliche Relevanz überprüft werden.

Abschließend sei an dieser Stelle noch auf den konkreten Forschungsrahmen und -kontext dieser Studie hingewiesen. Das Forschungsprojekt "Drogenkonsum und Strafverfolgungspraxis" wird den ebenfalls im Jahr 2002 am Institut von Letizia Paoli begonnenen Deutschland-Teil einer weit umfangreicheren internationalen Untersuchung des amerikanischen Drug Policy Research Center der RAND Corporation in Santa Barbara und Washington, DC eigenständig ergänzen. Diese beschäftigt sich mit der Frage nach den möglichen Auswirkungen verschiedener Modelle zum strafrechtlichen Umgang mit Cannabiskonsumenten etwa in den USA, Europa und Australien auf den jeweiligen Drogenkonsum (siehe 3.5.2 "Cannabis Non-Prosecution Policies in Germany").

Infolge der vereinbarten Kooperation mit dem Bundesministerium für Gesundheit und Soziale Sicherung (BMGS) wurde der Umfang des Deutschland-Teils dieser Studie jedoch erheblich modifiziert und erweitert. So wird die Untersuchung der Einstellungspraxis nach § 31a BtMG auf sämtliche illegale Betäubungsmittel erweitert, sowie auf sechs Bundesländer (anstatt ursprünglich drei oder vier) und damit auf insgesamt 24 Landgerichtsbezirke (anstatt ursprünglich drei bis vier) ausgedehnt. Dadurch erhöht sich die Stichprobe von zu analysierenden Ermittlungsverfahren auf 1.800 (anstatt ursprünglich 600).

\section{Ziele des Forschungsprojektes}

Mit der Studie sollen folgende Ziele verfolgt und Vorgaben überprüft werden:

- die empirische Analyse der Einstellungsvorschriften und -praxis bei Drogenkonsumdelikten in allen respektive in nur sechs Bundesländern;

- die Evaluation der gegenwärtigen Rechtspraxis bei der Anwendung von § 31a BtMG im Kontext anderer Einstellungsvorschriften;

- der Aspekt einer wesentlich gleichmäßigen oder ungleichmäßigen Rechtsanwendung von $\S 31$ a BtMG in den sechs untersuchten Bundesländern;

- Art und Umfang einer Entlastung der Strafverfolgungsbehörden bei der Verfolgung drogenkonsumbezogener Kleinkriminalität unter Rückgriff auf § 31a BtMG;

- die Anwendbarkeit und Handhabung der entsprechenden Einstellungsvorschriften für die Verwirklichung des Grundsatzes "Hilfe vor Strafe";

- die Bedeutung von administrativen Maßnahmen (Fahrerlaubnisentzug, Urinkontrollen, ausländer- und polizeirechtliche Maßnahmen) bei Drogenkonsumdelikten in den untersuchten Bundesländern;

- die mögliche Relevanz der unterschiedlichen Einstellungsvorschriften und -praxen für das konkrete Drogenkonsumverhalten.

\section{Forschungsansatz}

Die empirische Untersuchung wird in sechs Bundesländern und in insgesamt 24 Landgerichtsbezirken durchgeführt: 


\begin{tabular}{|c|c|}
\hline Bundesland & Landesgerichtsbezirk \\
\hline Bayern & $\begin{array}{l}\text { Bamberg } \\
\text { Landshut } \\
\text { München I } \\
\text { Nürnberg-Fürth } \\
\text { Traunstein }\end{array}$ \\
\hline Berlin & Berlin \\
\hline Hessen & $\begin{array}{l}\text { Kassel (statt ursprünglich Darmstadt) } \\
\text { Frankfurt } \\
\text { Fulda } \\
\text { Hanau }\end{array}$ \\
\hline Nordrhein-Westfalen & $\begin{array}{l}\text { Aachen } \\
\text { Köln } \\
\text { Münster } \\
\text { Paderborn }\end{array}$ \\
\hline Sachsen & $\begin{array}{l}\text { Bautzen } \\
\text { Chemnitz } \\
\text { Dresden } \\
\text { Görlitz } \\
\text { Leipzig } \\
\text { Zwickau }\end{array}$ \\
\hline Schleswig-Holstein & $\begin{array}{l}\text { Flensburg } \\
\text { Itzehoe } \\
\text { Kiel } \\
\text { Lübeck }\end{array}$ \\
\hline
\end{tabular}

Um die Forschungsziele zu erreichen, sind folgende Methoden vorgesehen:

- Eine vergleichende Analyse der länderspezifischen Richtlinien zum Vollzug von §31a BtMG und zur Implementation der "Cannabis-Entscheidung" des Bundesverfassungsgerichtes.

- Die Auswertung vorhandener statistischer Daten insbesondere zur Einstellung der Verfahren nach $\S 31 \mathrm{a}$ BtMG und zu anderen Einstellungsvorschriften ( $\S 153$ Abs. 1, 153a Abs. 1 StPO; $\S 29$ Abs. 5 BtMG i.V.m. § 153b Abs. 1 StPO; $\S \S 45,47$ Abs. 1 JGG sowie $\S \S 37$ Abs. 1 bzw. 38 Abs. 2 i.V.m. 37 Abs. 1 BtMG).

- Die Aktenanalyse von 1.800 drogenbezogenen Ermittlungsverfahren, die von den Staatsanwaltschaften der 24 Landgerichtsbezirke wegen Verstoßes gegen § 29 BtMG eingeleitet wurden. Um eine möglichst hohe Repräsentativität pro Gerichtsbezirk zu gewährleisten, werden 300 Ermittlungsverfahren pro Bundesland aus dem Jahr 2001 analysiert. Die Grundlage der Aktenauswertung ist ein spezifischer Erhebungsbogen zu den relevanten Themenbereichen.

Um die konkreten Unterschiede in der Einstellungs- respektive Strafverfolgungspraxis der einzelnen Länder spezifischer herausarbeiten zu können, werden nicht nur eingestellte drogenbezogene Ermittlungsverfahren analysiert, sondern alle eingeleiteten Verfahren, die einen Verstoß nach § 29 BtMG zum Gegenstand haben, also unabhängig davon, ob eine Einstellung oder Anklage erfolgte. Grundsätzlich zielt die Untersuchung auf "Konsumentendelikte", dabei 
handelt es sich überwiegend um Fälle des Besitzes, Erwerbes, der Ein- und Ausfuhr von Rauschgift ohne Handel zu treiben sowie ähnlicher Delikte. Da die betreffenden Akten nicht im Voraus von anderen nach $\S 29$ BtMG eingeleiteten Ermittlungsverfahren, etwa Drogenhandel oder -schmuggel, unterschieden werden können, wird man eine wesentlich größere Stichprobe von etwa 2.700 Akten ziehen müssen (nach dem Rauschgiftjahresbericht des Bundeskriminalamtes betreffen etwa zwei Drittel aller Ermittlungsverfahren sog. Konsumentendelikte).

- Die qualitative Expertenbefragung von je drei Polizisten, zwei Staatsanwälten, Richtern und einem Strafverteidiger sowie dem jeweils zuständigen Behördenleiter der Ordnungs- und Ausländerämter in elf ausgewählten Landgerichtsbezirken.

- Ein abschließender Quervergleich zwischen den statistischen Angaben, den Ergebnissen der Experteninterviews und der Aktenanalyse einerseits und andererseits zwischen den unterschiedlichen Prävalenzraten des Drogen- und speziell des Cannabiskonsums in den einzelnen Bundesländern (soweit entsprechende Daten vorhanden sind auch in den ausgewählten Großstädten und Landgerichtsbezirken).

- $\quad$ Arbeitsbericht 2002/2003:

Phase 1 (November 2002 bis April 2003):

- Vorarbeiten (Datenzugang und Datenschutz, Genehmigungen für die Akteneinsicht)

- Analyse der länderspezifischen Richtlinien zum Vollzug von § 31a BtMG

- Auswertung bereits vorhandener statistischer Daten und Materialien

- Vorbereitung des Erhebungsbogens für die Aktenauswertung

Phase 2 (Mai bis Dezember 2003):

- Beginn der Aktenerhebung und -auswertung: Bisher wurden ca. 1.200 Verfahrensakten aus Berlin, Bayern, Nordrhein-Westfalen und Sachsen ausgewertet.

- Qualitative Expertenbefragung in den Landgerichtsbezirken Berlin, Bamberg, München I, Köln und Paderborn.

- Erstellung des Zwischenberichts für das BMGS.

- $\quad$ Arbeitsplanung 2003/2004:

Phase 3 (Januar bis Mai 2004):

- Fortsetzung der Aktenanalyse in Hessen und Schleswig-Holstein.

- Qualitative Expertenbefragung in den Landgerichtsbezirken Dresden, Görlitz, Frankfurt, Fulda, Itzehoe und Kiel.

- Auswertung der gesammelten Daten und Informationen zur cannabisbezogenen Einstellungsrespektive Strafverfolgungspraxis.

- Erstellung des Berichtes zur cannabisbezogenen Einstellungs- respektive Strafverfolgungspraxis

Phase 4 (Juni bis Oktober 2004):

- Auswertung der gesammelten Daten und Informationen zur Einstellungs- respektive Strafverfolgungspraxis bei Konsumdelikten harter Drogen.

- Abschließender Quervergleich zwischen den statistischen Angaben, den Ergebnissen der Experteninterviews und der Aktenanalyse einerseits und zwischen den unterschiedlichen Prävalenzraten des Drogen- und speziell des Cannabiskonsums in den einzelnen Bundesländern andererseits Erstellung des Abschlussberichtes.

\section{- $\quad$ Finanzierung:}

Das Forschungsprojekt wird vom Bundesministerium für Gesundheit und soziale Sicherung bezuschusst. 


\subsection{Schwerpunkt "Opferforschung"}

\subsubsection{Viktimisierung und Viktimisierungsverarbeitung in den Bürgerkriegsregionen des ehemaligen Jugoslawien}

- $\quad$ Bearbeiter: Uwe Ewald (Jurist), Ernesto Kiza (Politologe)

- $\quad$ Zeitrahmen: 2001 bis 2005

- $\quad$ Projektstatus: in Vorbereitung

- $\quad$ Projektbeschreibung:

(vgl. dazu bereits den Tätigkeitsbericht 2000/2001, S. 167)

Das Forschungsprojekt "Viktimisierung und Viktimisierungsverarbeitung in den Bürgerkriegsregionen des ehemaligen Jugoslawien" wird die wird die Situation in den Bürgerkriegsregionen des ehemaligen Jugoslawien in mikro- und makro-viktimologischer Perspektive untersuchen und dabei die konventionelle individualistisch orientierte Viktimisierungsforschung mit Fragestellungen weiterentwickeln, die sich aus dem Kontext von Krieg und Bürgerkrieg ergeben.

Zur Vorbereitung der Studie wurde vom 2. bis 4. November 2001 ein internationaler Workshop unter dem Thema "War - Victimization - Security: The Case of the Former Yugoslavia" durchgeführt.

Der Workshop wurde gemeinsam mit der Friedrich-Ebert-Stiftung und finanziell unterstützt vom Stabilitätspakt organisiert. Mit Beiträgen aus Slowenien, Kroatien, Bosnien-Herzegowina, SerbienMontenegro und Mazedonien sowie Deutschland und der Schweiz wurde das Ziel verfolgt, konzeptionelle und methodologische Voraussetzungen einer komplexen Studie zur Opferwerdung in ehemaligen Kriegsgebieten und anderen von struktureller Gewalt (wie z.B. ethnische Auseinandersetzungen, Terror, Vertreibungen) betroffenen Gebieten zu diskutieren. Dabei soll gerade der Vergleich der verschiedenen Teile des ehemaligen Jugoslawiens differenzierte Befunde möglich machen. Gleichzeitig wurden die für eine solche Studie notwendigen organisatorischen Rahmenbedingungen sowie die Beteiligung von Forschungspartnern aus dem ehemaligen Jugoslawien diskutiert. Die auf dem Workshop gehaltenen Beiträge sind im European Journal of Crime, Criminal Law and Criminal Justice (2/2002) erschienen.

Auf der Grundlage der Ergebnisse des Workshops wird das Forschungsdesign für die geplante Studie gemeinsam mit den bereits feststehenden Partnern des Projektes (aus Serbien, Slowenien, Kroatien, Montenegro, Bosnien-Herzegowina, Mazedonien) 2003 erarbeitet werden. In diesem Zusammenhang ist eine Folgekonferenz in Zagreb geplant, die ein erweitertes Forschungsspektrum (hinsichtlich der Opferproblematiken in den aktuellen Konflikten z.B. Irak, Israel, Kongo) abdeckt, und auf der die Erkenntnisse und Problematiken aus den bisher erarbeiteten Konzepten diskutiert werden, um mögliche Erklärungsmechanismen im globalen Kontext diskutieren zu können (Programm und Information folgen). Gleichzeitig soll die eigentliche Feldphase der Forschungsarbeiten weiter vorbereitet werden.

- $\quad$ Arbeitsjahr 2003: Schaffung eines theoretischen Rahmens

Das Arbeitsjahr 2003 kennzeichnet sich vor allem durch die Weiterentwicklung eines theoretischen Zugangs zur Forschungsmaterie. Im Diskurs mit den Kooperationspartnern wird ein umfassendes Forschungsprogramm entwickelt, welches nicht nur die theoretischen Probleme umfasst, sondern auch auf forschungsethische Aspekte im Bereich dieser sozio-psychologischen und politisch brisanten Thematik eingeht und letztendlich aus diesen Teilaspekten eine Methode entwickelt, um fundiertes empirisches Material zu sammeln. 
Ziel ist die erstmalige systematische Erfassung von Kriegs-Viktimisierung, zunächst beschränkt auf die Länder der ehemaligen Sozialistischen Föderativen Republik Jugoslawien (SFRJ). Mithilfe einer breit angelegten quantitativen Untersuchung werden die Kernhypothesen einer makro-viktimologischen Theoriekonstruktion erstmals im "Feld" erprobt werden, um zu einem strukturell angelegten funktionalen Modell von Kriegs-Viktimisierung zu gelangen.

Erste bekannte Forschungen in diesem Bereich gehen in der Erfassung von Formen, Ursachen, Perzeption und Folgen zumeist qualitativ vor und beschränken sich auf die Erfassung von Opferwerdungsphänomenen im Tiefeninterview mit betroffenen (z.B. Nikolic-Ristanovic 2000).

Andere Untersuchungen arbeiten hingegen indirekt mit dem Problem der Kriegs-Viktimisierung, indem sie z.B. die Opferzufriedenheit von Zeugen in Prozessen des ICTY (International Criminal Tribunal for the former Yugoslavia) zu messen versuchen (so z.B. Stover 2003), oder aber andere Teilaspekte von Kriegs-Viktimisierung erfassen. Beeindruckende Ergebnisse liefern beispielsweise Forscher aus Bosnien und Herzegowina $(\mathrm{BiH})$ in internationaler Zusammenarbeit, die über die letzten Jahre hinweg mit interdisziplinären Ansätzen eine systematische Erfassung der psychosozialen Konsequenzen des Krieges in BiH und anderen Teilen der ehemaligen SFRJ vornehmen (Durakovic-Belko, Powell 2000).

Aber auch umfassende Forschungen zu den Themenkomplexen Gesundheit und Krieg (WHO 2002) oder das "People on War Project" des International Comitee of the Red Cross (ICRC 1999), mit der bisher umfangreichsten Forschungsprogrammatik zum Themenkomplex "Kriegsopfer" - mit einem Sample von 12.860 von Kriegen betroffenen Menschen aus 12 verschiedenen Ländern -, liefern äußerst wertvolle Hinweise für die Entwicklung einer kohärenten Forschungsprogrammatik zur Erfassung von Kriegs-Viktimisierung.

Auch das Gesamtausmaß der Kriegs-Viktimisierung wird durch bereits bestehende Forschungen dokumentiert. So konzentrieren sich Forschungseinrichtungen wie der Arbeitskreis Krieg und Frieden (AKUF) oder das Peace Research Institute in Oslo (PRIO) auf die quantitative Erfassung von Kriegen und daraus resultierenden Todesopfern im globalen Kontext. Die hier erfassten Ergebnisse zeichnen ein verheerendes Bild des globalen menschlichen Leides durch Kriege (Abb. 1). Dabei ist zu betonen, dass die hier abgebildeten Dimensionen nur auf Zivilpersonen bezogen sind. Entgegen den internationalen Bemühungen, Zivilisten in Kriegen zu schützen, ist festzustellen, dass diese in den 1990er Jahren ca. $90 \%$ aller Kriegstoten ausmachten, während das Verhältnis im Zweiten Weltkrieg 50 \% und im Ersten Weltkrieg "nur" $5 \%$ betrug. 
Abbildung 1: Zivile Todesopfer durch Kriege von 1945 bis 2000

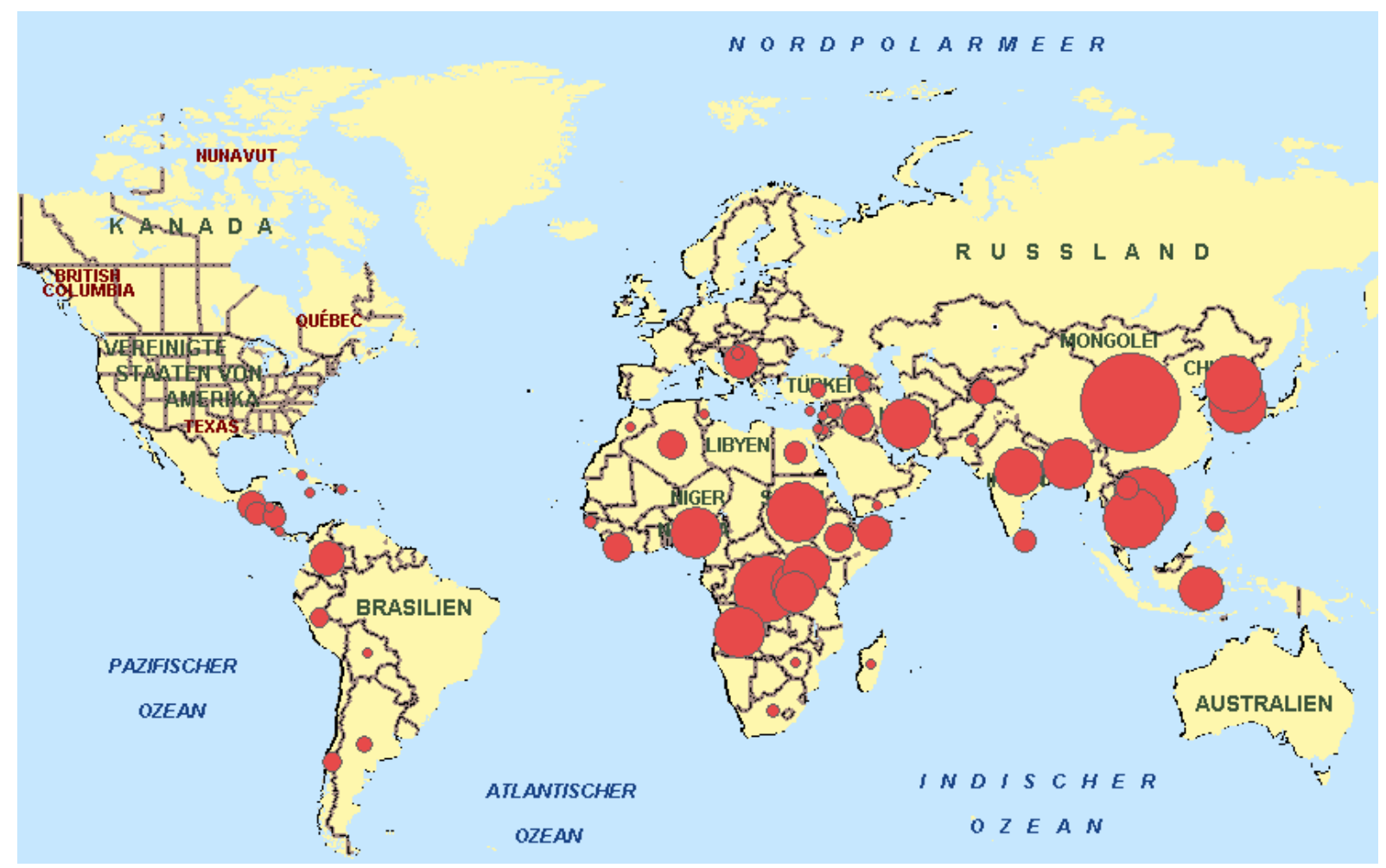

Sources: Leitenberg 2001; Melcic/ Vetter 1999; International Red Cross 2001; PRIO 2003.

Gleichzeitig zu den Leidenserfahrungen der von Krieg betroffenen Bevölkerungen (oben abgebildet durch Todesraten unter Zivilisten, die andere Leidensformen wie Verletzung, Vertreibung, Verlust etc. nicht einbeziehen), geht Krieg immer mit der Destabilisierung gesellschaftlicher und politischer Strukturen einher, welche selbst auch immer eine Erosion von Sicherheit impliziert. Der Begriff Erosion lässt sich hierbei nur im globalen Kontext verstehen, da die von Kriegen ausgehenden "Schockwellen" in einer globalisierten Welt überall zu spüren sind und zur Destabilsierung und sukzessiven Erosion der ohnehin fragilen globalen Sicherheitsmechanismen führen. In den durch Krieg - aber auch durch low-intensity conflicts - heimgesuchten Regionen kann hingegen nicht von einer Erosion der Sicherheitsstrukturen gesprochen werden, vielmehr handelt es sich in diesem Kontext meist um den völligen Wegfall solcher Strukturen, der in den sog. "neuen Kriegen" durch einen arbiträren Ordnungsbegriff der vorherrschenden Kriegspartei substituiert wird. Somit wird auch der lokal begrenzte "interne Konflikt" oder "innerstaatliche Krieg" zu einem Problem globalen Ausmaßes in einer vernetzten Welt und gleichzeitig zu einem kollektiv-traumatischen Ereignis auf regionaler Ebene.

Reaktionen auf solche Bedrohungsszenarien scheinen sich zumeist auf militärischer Ebene abzuspielen ("humanitäre Interventionen", "Präventivkriege" etc.), die, frei nach der Clausewitzschen Definition des Krieges, auf ein Scheitern der Politik im Bereich der Konflikteindämmung und Konfliktbearbeitung schließen lassen. Auch Versuche das Führen von Kriegen unter Strafe zu stellen sind eher zwiespältig ausgefallen, oder aber weitestgehend Erfolglos (z.B. das generelle Kriegsverbot der UNCharta).

Die internationalen Tribunale (Ruanda: ICTR; Jugoslawien: ICTY) konnten sicherlich einen entscheidenden Schritt zur Abschaffung der "impunity" (Nichtbestrafung) im internationalen Kontext beitragen, haben aber andererseits auch zu großer Enttäuschung bei den betroffenen Bevölkerungen, Politikern, Juristen und in der International Community an sich geführt, da durch die unsystematische und häufig engstirnige Arbeitsweise Zieldimensionen wie Opferzufriedenheit, Wiedergutmachung und 
ähnlich wichtige Faktoren, die gemeinhin - also nicht in einem streng juristischen Sinne - mit Gerechtigkeit verbunden werden, nicht berücksichtigt wurden. Im Zusammenhang mit der Etablierung des Internationalen Strafgerichtshofes (ICC) gilt es nunmehr eine systematische Arbeitsweise zur Erfassung von Kriegsverbrechen, die zwangsläufig mit einer kumulierten Form von Viktimisierung einhergehen, zu erarbeiten, um mit den globalen Herausforderungen einer modernen internationalen Strafgerichtsbarkeit umgehen zu können, ohne dabei die Opfer ganz aus den Augen zu verlieren. Die Herausforderungen die mit einem makroviktimologischen Projekt einhergehen sind demnach mannigfaltig.

Einen Orientierungsversuch zum Verständnis dieser Prozesse stellt die Herangehensweise über die Erforschung von Kriegs-Viktimisierung dar. Erst wenn die Grundlagen dieser Prozesse, die alle anderen Prozesse bedingen, transparenter werden, können adäquate und systematische Versuche die o.g. Probleme einzudämmen und zu bearbeiten erfolgreich sein. $\mathrm{Zu}$ diesem Zwecke wendet sich das geplante Forschungsvorhaben eben dieser grundlegenden Erforschung von Bedürfnis-, Funktionsstrukturen und -Mechanismen von Kriegs-Viktimisierung zu. Und dies zunächst in einem regional begrenzten Kontext mit dem Fokus auf die Balkan-Kriege von 1991 bis 2001.

Mit Hilfe von Datenbanken zur Viktimisierungsstruktur wurde der Versuch unternommen, bisherige Darstellungen der Jugoslawien-Kriege, die unabhängig von einander bestimmte Einzelaspekte der Krieg betrachteten, zusammenzuführen und somit ein "theoretical Sampling" zu ermöglichen auf dessen Grundlagen spätere empirische Untersuchungen innerhalb der betroffenen Gebiete durchgeführt werden sollen. Unter Berücksichtigung von Flüchtlingszahlen und militärstrategischen Untersuchungen ergibt sich beispielsweise für Bosnien und Herzegowina folgendes Bild von Regionen mit besonders starker Viktimisierung der Zivilbevölkerung (Abb. 2).

Abbildung 2: Orte von Kriegshandlungen, deren Dauer und die damit verbundene Anzahl von Kriegsflüchtlingen und "Internally Displaced Persons"

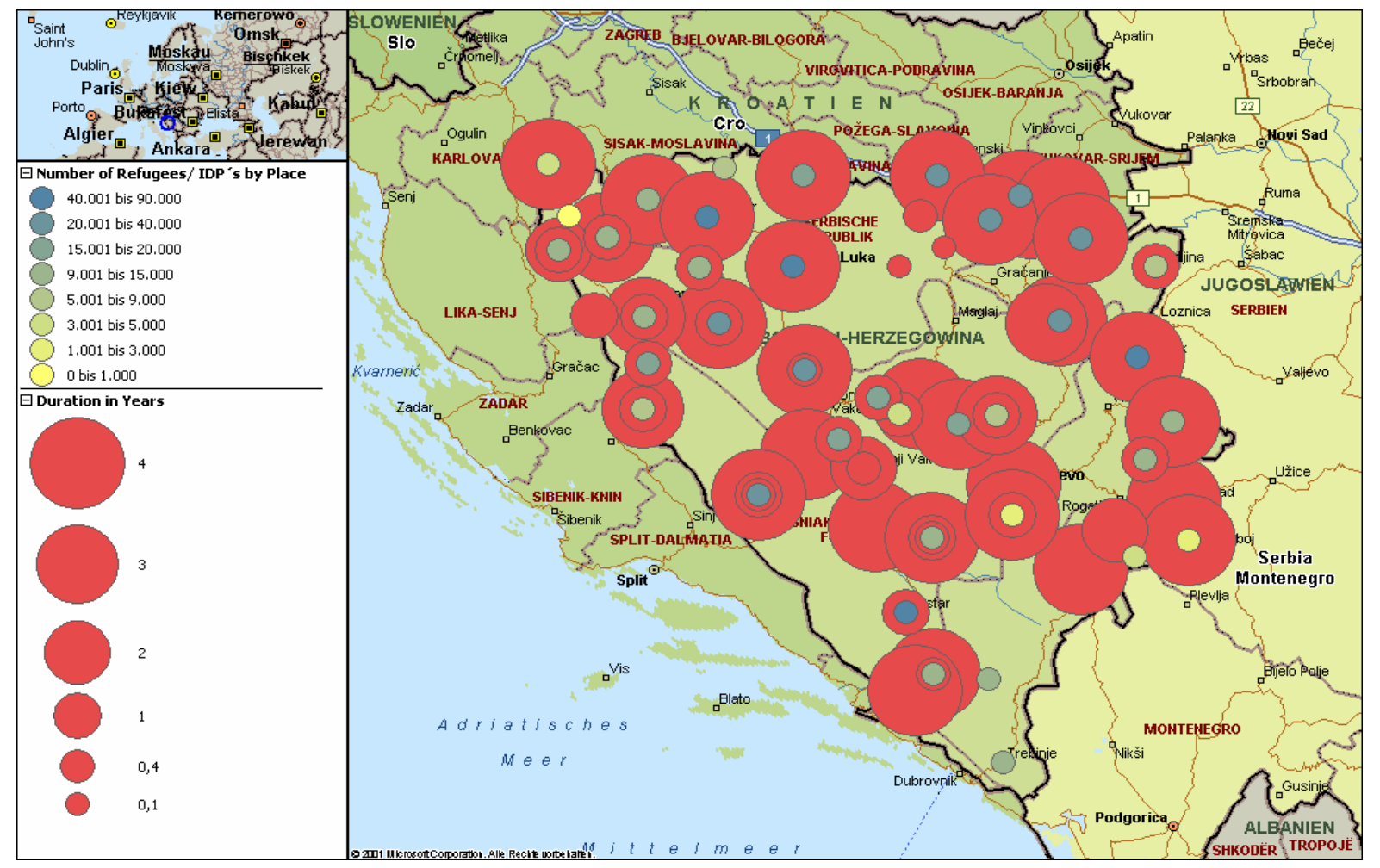

Quelle: Eigene Ausarbeitungen 
Hinsichtlich der Untersuchung von Viktimisierung bietet eine solche Vorgehensweise die Möglichkeit, zielgerichtete Forschung in solchen Gebieten vorzunehmen, die besonders stark durch Kriegshandlungen betroffen waren. Vor allem in Bezug auf die Perzeption von Viktimisierung und die daraus resultierenden Bedarfsstrukturen, ist davon auszugehen, dass Personen, die sich zu Kriegszeiten in diesen Gebieten befanden, Aussagen über ihre Leidenserfahrungen in Bezug auf direkte Anwendung von Gewalt geben können. Gleichzeitig können auf diese Weise ermittelte Ergebnisse innerhalb des Landes im komparativen Zugang mit den Ergebnissen, die in von Kriegshandlungen weniger betroffenen Gebieten ermittelt wurden, Auskunft über die Unterschiede in der Perzeption und der Bedarfsstrukturen geben. Darüber hinaus sind wertvolle Hinweise über Gemeinsamkeiten von KriegsViktimisierung zu erwarten, die nicht mit direkter Gewalteinwirkung einhergehen, sondern vielmehr das Phänomen der strukturellen Viktimisierung durch Krieg (als ubiquitäres strukturelles Phänomen) wiedergeben.

\section{- $\quad$ Arbeitsplanung 2004:}

Die bis zum Ende des Jahres 2003 weiterentwickelten theoretischen Grundlagen der Untersuchung sollen im Frühjahr 2004 auf einer Folgeworkshop mit allen bisherigen Teilnehmern des Forschungsprojektes abgestimmt werden, um eine kohärente Forschungsstrategie, basierend auf einer gemeinsamen theoretischen Grundlage, für die Feldforschung zu entwickeln. Die interdisziplinäre und internationale Arbeitsatmosphäre dient der Sicherstellung eines umfassenden Zugangs zur Materie.

Aufgrund des großen internationalen Interesses wird die Konferenz auch Teilnehmern aus Israel, Palästina, Nord-Irland, Großbritannien, Russland und Estland offen stehen. Es ist zu erwarten, dass die Vertreter wissenschaftlicher Einrichtungen aus den genannten Ländern an einer Forschungskooperation im Sinne der Durchführung eines standardisierten Forschungsprogramms den ursprünglich geplanten Rahmen der Studie deutlich erweitern werden. Auf diese Weise sollte eine umfassende komparative Erfassung des Forschungsproblems Kriegs-Viktimisierung möglich sein.

Gleichzeitig wird während des Workshops ein verbindlicher Zeitplan für den Ablauf der Untersuchung verabschiedet, um eine zügige Ergebnissammlung zu ermöglichen.

Die im Rahmen diese Workshops erarbeiteten Pläne - Zeitpläne, Theoriekonzeptionen, Methoden sollen sodann noch im laufenden Jahr weiter ausgearbeitet werden, um spätestens im Frühjahr 2005 mit der eigentlichen Datenerhebung beginnen zu können.

- $\quad$ Finanzierung:

Die Einwerbung von Drittmitteln, zur Finanzierung der geplanten Untersuchung, befindet sich zurzeit in Arbeit.

- $\quad$ Ausgewählte Literatur:

DuRAKoviC-B. \& Powell, St.: Sarajevo 2000: The Psychosocial Consequences of War. Results of empirical Research From the Territory of Former Yugoslavia, Sarajevo 2000.

EWALD, U.: Victimization in the Context of War - 'History' and Perspectives of a Research Project. European Journal of Crime, Criminal Law and Criminal Justice, 2-3, 90-97 (2002).

ICRC: The People on War Report, URL:

http://www.icrc.org/Web/eng/siteeng0.nsf/htmlall/onwar_reports/\$file/globalreport.pdf (1999)

IGNJATOVIC, D.: Some Problems in Investigation of War Victimization in the Territory of the former Socialist Federal Republic of Yugoslavia. European Journal of Crime, Criminal Law and Criminal Justice, 2-3, 98-108 (2002).

JAUKOVIC, J.: The Forms of Victimization in the Territory of former Yugoslavia, in: European Journal of Crime, Criminal Law and Criminal Justice 2-3, S. 109-116 (2002a). 
JAUKOVIC, J.: The Manners of Overcoming Stress Generated by War Conflict Trauma, in: European Journal of Crime, Criminal Law and Criminal Justice 2-3, 177-181 (2002).

NiKOliC-RistanoviC, V.: Zrtve ratova u bivsoj Jugoslaviji: obim, Struktura I obrasci viktimizacije. Temida 2, 11-20 (2000).

NiKOLIC-RistanOVIC, V. (Hrsg.): Women, Violence and War. Wartime Victimization of Refugees in the Balkans. Budapest 2000.

Nikolic-Ristanovic, V.: War and Post-War Victimization of Women. European Journal of Crime, Criminal Law and Criminal Justice 2-3, 138-145 (2002a).

International Peace Research Institute Oslo, PRIO: Armed Conflict 1946-2002, URL: http://www.prio.no/cwp/ArmedConflict/ (2003).

LEITENBerg, M.: Deaths in Wars and between 1945 and 2000, Conference Paper, Uppsala, URL:

http://www.pcr.uu.se/conferenses/Euroconference/Leitenberg_paper.pdf (2001).

RomBouTs, H.: Importance and Difficulties in Victim Based Research in Post-Conflict Societies. European Journal of Crime, Criminal Law and Criminal Justice 2-3, 216-232 (2002).

StOVER, E.: The Witnesses. War Crimes and the Promise of Justice in The Hague. Berkley 2003.

TURKOVIC, K.: Overview of the Victimological Data Related to War in Croatia. European Journal of Crime, Criminal Law and Criminal Justice 2-3, 2002-215 (2002).

\subsubsection{Methoden und Diskurse empirischer Beschreibung von Massen-Viktimisierungen. Eine Untersuchung am Beispiel der Opferwerdung im ehemaligen Jugoslawien und an EU-Außengrenzen}

- $\quad$ Bearbeiter: Ernesto Kiza (Politologe)

- $\quad$ Zeitrahmen: 2003 bis 2005

- $\quad$ Projektstatus: in Bearbeitung

- $\quad$ Projektbeschreibung: (zugleich Promotionsvorhaben)

\section{Problem und Ziele}

Gegenstand des Promotionsvorhabens sind nicht-sozialwissenschaftliche Diskurse zu Massen-Viktimisierungen, die zum einen am Beispiel der Opferwerdung unerwünschter/irregulärer Einwanderer bzw. Flüchtlinge beim Versuch illegalen Grenzübertritts an EU-Außengrenzen sowie zum anderen in Konfliktzonen z.B. des früheren Jugoslawiens untersucht werden.

Beide Formen von Massen-Viktimisierungen sind eng miteinander verbunden und erscheinen in der Perspektive der Betroffenen (die zunächst in der Konfliktregion und dann erneut auf der Flucht bzw. Wanderung viktimisiert werden) als multiple Opferwerdung.

Unter dem Blickwinkel europäischer Sicherheitspolitik sind diese Aspekte der Migrationskontrolle sowie der Herstellung von Stabilität zu herausragenden Themen geworden. Häufig wird in der öffentlichen und politischen Debatte auf empirische Daten zur Darstellung der Realität derartiger Viktimisierungen Bezug genommen, die u.a. aus Quellen des investigativen Journalismus, aus Expertenberichten oder von NGOs stammen, deren Zustandekommen jedoch methodisch oft nicht nachvollzogen werden kann. Gleichwohl werden 'gestützt' auf diese Informations- und Datenlage Meinungsbilder erzeugt und politische Entscheidungen begründet. Zweifel und Kritik an der methodischen Zuverlässigkeit (ohne dass diese sozialwissenschaftliche Begrifflichkeit Verwendung finden muss) sind dabei selbst Gegenstand heftigster politischer Auseinandersetzungen, wie die in Deutschland geführte Debatte um den "Fall" Racak oder die auf Anfragen der PDS-Fraktion im Deutschen Bundestag zurückgehende Debatte um Todesopfer unter unerwünschten Einwanderern an der deutsch-polnischen Grenze zeigen. 
Das wissenschaftliche Anliegen des geplanten Promotionsvorhabens:

a) besteht neben einer methodenkritischen Datenanalyse in einer externen Validierung vorhandener nicht-wissenschaftlicher Datenquellen zu den genannten Massen-Viktimisierungen mit Hilfe amtlicher Quellen (z.B. Daten der Ämter für Statistik) oder anhand wissenschaftlicher Daten (z.B. Opferstudien). Das geplante Promotionsvorhaben verfolgt dabei folgende Fragen:

- Unter welchen Bedingungen können Informationen und Daten aus nicht-wissenschaftlichen Diskursen als zuverlässig gelten?

- Kann mit Hilfe empirischer Methoden die Validität vorhandener Daten überprüft und gegebenenfalls erhöht werden?

- Welche Möglichkeiten der Datensammlung bieten die neuen Medien (in erster Linie das Internet)?

b) wird die im Rahmen des geplanten Promotionsvorhabens beabsichtigte Untersuchung analysieren, in welcher Weise die o.g. Daten im Kontext öffentlicher politischer Diskurse und Entscheidungsbegründungen verwendet werden. Häufig dienen solche Daten als Grundlage für weitreichende Entscheidungen (z.B. Vorgehensweise und Engagement bei sog. humanitären Interventionen oder in der Konfliktnachbearbeitung z.B. in Bosnien Herzegowina oder im Kosovo, aber auch in vermeintlich stabilen Regionen wie Kroatien). Auf der Folie konstruktivistischer Ansätze soll das Spannungsverhältnis von "Wahrheit" - "Konsens" - "Macht" am Beispiel des gewählten Gegenstandes der Massen-Viktimisierung und ihrer diskursiven Reflexion untersucht werden. Hierin zeigt sich eine wesentliche Problematik des (öffentlichen und politischen) Umgangs mit nicht gesicherten bzw. nicht-wissenschaftlich erhobenen Daten. Hypothetisch kann nicht ausgeschlossen werden, dass aufgrund der (u.U. gewollten, interessengeleiteten) Verwendung unzuverlässigen Datenmaterials politische Diskussionen in Gang gesetzt werden, mit denen Reaktionen von Seiten staatlicher, supra-staatlicher und nicht-staatlicher Akteure begründet werden, welche jedoch an den Bedürfnissen der zum Opfer/Flüchtling gewordenen Zivilpersonen aus Kriegs- und Konfliktregionen vorbeigehen, bzw. diese nur partiell berücksichtigen.

\section{Methoden}

\subsection{Verbesserung der Reliabilität und Validität von Datenmaterialien}

In einem standardisierten Verfahren werden von anderer Stelle bereits erhobene Daten systematisch in eine standardisierte Datenbank eingepflegt und durch Kreuzvergleiche der unterschiedlichen Quellen auf Validität und Reliabilität überprüft. Gleichzeitig findet eine Aufbereitung der Daten für eine statistische Bearbeitung selbiger statt.

\subsection{Visualisierung}

Zum besseren Verständnis werden die in der Datenbank angelegten Daten gleichzeitig in einem Mapping-Verfahren visualisert. Mithilfe eines Geographischen Informationssystems (GIS) können "Brennpunkte" der Migrationsproblematik und Orte von Viktimisierung illegaler Migranten kartographisch dargestellt werden und ermöglichen somit eine präzise räumliche Verortung. Darüber hinaus lässt diese Methode im Zusammenhang mit migrationstheoretischen Modellen und Theorieansätzen ein besseres Verständnis der räumlichen Migrationsstruktur (Ursprungs-Zielländer) zu. 


\subsection{Diskursanalyse}

Nach Abschluss der Datensammlung werden die Ergebnisse als Grundlage für die Aufbereitung des Migrationsdiskurses in Deutschland dienen. Ausgehend von politischen Debatten zur Migrationskontrolle wird zunächst ein Abgleich der im Diskurs verwendeten Zahlen und Daten mit den in dieser Untersuchung erhobenen Materialien erfolgen, um sodann diskursanalytisch die Konstruktion des Themas "Migrationskontrolle" nachzuzeichnen und in kritischer Weise die Argumentationsgrundlagen zu rekapitulieren.

\section{Kooperation}

In Zusammenarbeit mit UNITED for Intercultural Action und 47 weiteren Nicht-Regierungs-Organisationen (siehe Tab. 1) entsteht kontinuierlich eine Liste von Todesfällen, die im Zusammenhang mit dem Versuch der Überwindung der Europäischen Außengrenze als irregulärer Migrant steht. Diese Liste dient als "Ausgangssituation" für die Darstellung der erfassten Todesfälle und damit die Quantifizierung von Viktimisierungen irregulärer Migranten. 
Tabelle 1: $\quad$ In die Datensammlung involvierte Akteure (Stand: 2003)

\begin{tabular}{|c|c|}
\hline Antirassismus Büro Bremen & Germany \\
\hline Flüchtlingsrat - Niedersachsen & Germany \\
\hline Ulla Jelpke - Bundestagsabgeondnete & Germany \\
\hline Antirassistische Gruppe für Freies Fluten & Germany \\
\hline Flüchtlingsrat - Brandenburg & Germany \\
\hline Campaign Against Racism and Fascism & Great-Britain \\
\hline Institute of Race Relations & Great-Britain \\
\hline National Coalition of Anti-Deportation Campaigns & Great-Britain \\
\hline Statewatch & Great-Britain \\
\hline National Coalition of Anti-Deportation Campaigns & Great-Britain \\
\hline National Coalition of Anti-Deportation Campaigns & Great-Britain \\
\hline Greek Refugee Council & Greece \\
\hline $\begin{array}{l}\text { Netuork for Social Support to Immigrants + } \\
\text { Refugees }\end{array}$ & Greece \\
\hline Voluntany Work of Athens & Greece \\
\hline Greek Helsinki Monitor/ Minority Rights Group & Greece \\
\hline Hungarian Red Cross Refugee Senvice & Hungary \\
\hline $\begin{array}{l}\text { Italian Refugees Council - Consiglio Ital. per i } \\
\text { Rifugiati }\end{array}$ & Italy \\
\hline Associazione Rieti Immigrant-Provincia & Italy \\
\hline Associazione Nazionale Oltre le Frontiere & Italy \\
\hline Associazione Ya Basta! & Italy \\
\hline Associazione Nazionale Oltre le Frontiere & Italy \\
\hline Autonoom Centrum & Netherlands \\
\hline Particip ating Refugees in Multicultural Europe & Netherlands \\
\hline Norsk Organisasjon For Asylsskere & Nonuay \\
\hline Nonuegian Refugee Council - Flyktningerădet & Nomuay \\
\hline SOS Racismo- Portugal & Portugal \\
\hline $\begin{array}{l}\text { Portuguese Ref. Council - Conselho Port } \\
\text { Refugiados }\end{array}$ & Portugal \\
\hline Sin Fronteras Magazine - Comrade & Spain \\
\hline Asociación Pro Derechos Humanos de Andaluáa & Spain \\
\hline Swedish Refugee Council - Svenła Flyktingrădet & Sweden \\
\hline Flyktinggruppernas och Asylkommittée rnas Riksrăd & Sweden \\
\hline Fortress Europe? - Circular Letter & Sweden \\
\hline Solidarité sans F rontières & Suvitzerland \\
\hline $\begin{array}{l}\text { Suviss Refugee Council - Schweizer. } \\
\text { Flüchtlingshilfe }\end{array}$ & Suvitzerland \\
\hline Gruppe Augenauf! - Zürich & Switzerland \\
\hline
\end{tabular}

Hierbei handelt es sich lediglich um registrierte Todesfälle die durch öffentliche Quellen (Medien, Nicht-Staatliche-Organisationen, Anfragen im Bundestag, Anfragen bei Behörden) dokumentiert sind. Es ist von einer weitaus höheren Dunkelziffer auszugehen. Eine Projektion möglicher Todeszahlen 
wird auf Grundlage der Opferdatenbank im Kontext mit offiziellen Angaben zum Migrationsvolumen irregulärer Migranten (z.B. Jahresberichte des Bundesgrenzschutzes) und mit Untersuchungen zum "Migration-Stock" der Ursprungsländer vorgenommen werden.

Weiterhin wird versucht, zunächst mit deutschen Behörden, eine Datengewinnung zur Problematik der Todesfälle durch irreguläre Migration zu etablieren. Hierbei stellt sich allerdings das Problem "politischer Unerwünschtheit" der Problematik. Eine Kooperation ist daher bis zum jetzigen Zeitpunkt noch nicht etabliert.

\section{Einige Ergebnisse}

\section{$4.1 \quad$ Visualisierung}

Die kartographische Darstellung von Ursprungs- und Todesländern der registrierten Todesopfer irregulärer Migration verdeutlicht die Brennpunkte der Migrationsproblematik:

- Abbildung 1 verdeutlicht, dass es sich um ein Problem globalen Ausmaßes mit deutlicher Tendenz der Abwanderung aus unterentwickelten Staaten ("Push-Faktor") handelt, diese jedoch nicht exklusiv betrifft.

- Abbildung 2 zeigt die Haupttodesländer irregulärer Migration und verdeutlicht gleichzeitig, dass nach Außen wirken europäischer Migrationskontrolle. Es ist zu beobachten, dass auch außerhalb des EU-Raumes (Drittlandabkommen, andere Abschiebungsverfahren) Todesopfer registriert werden.

Abbildung 1: $\quad$ Ursprungsländer der registrierten Todesopfer (1993-2001)

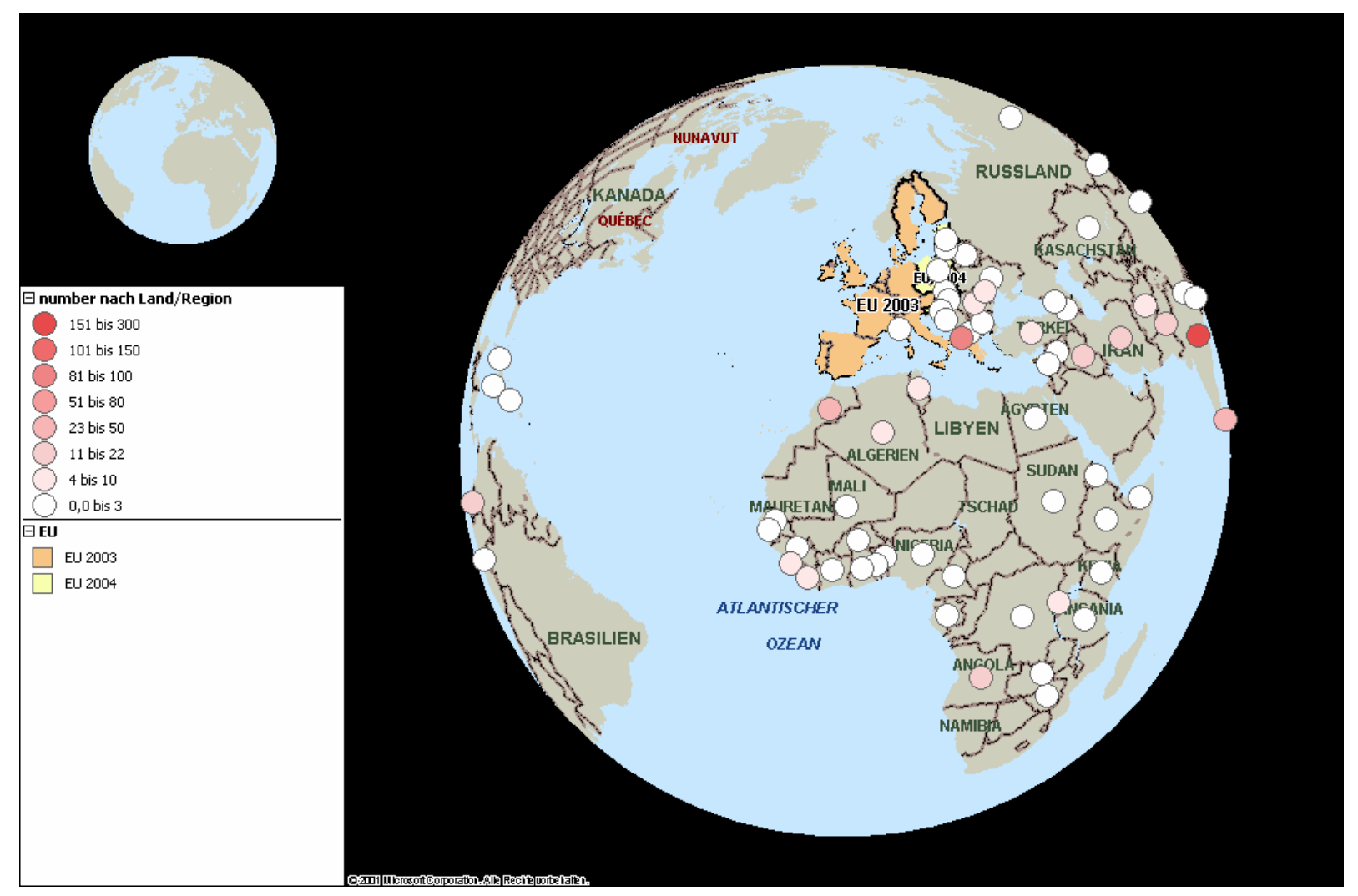


Abbildung 2: Materialisierung von Opferwerdung: Registrierte Todesopfer an der Europäischen Außengrenze "Fortress Europe" nach Staaten (1993-2001)

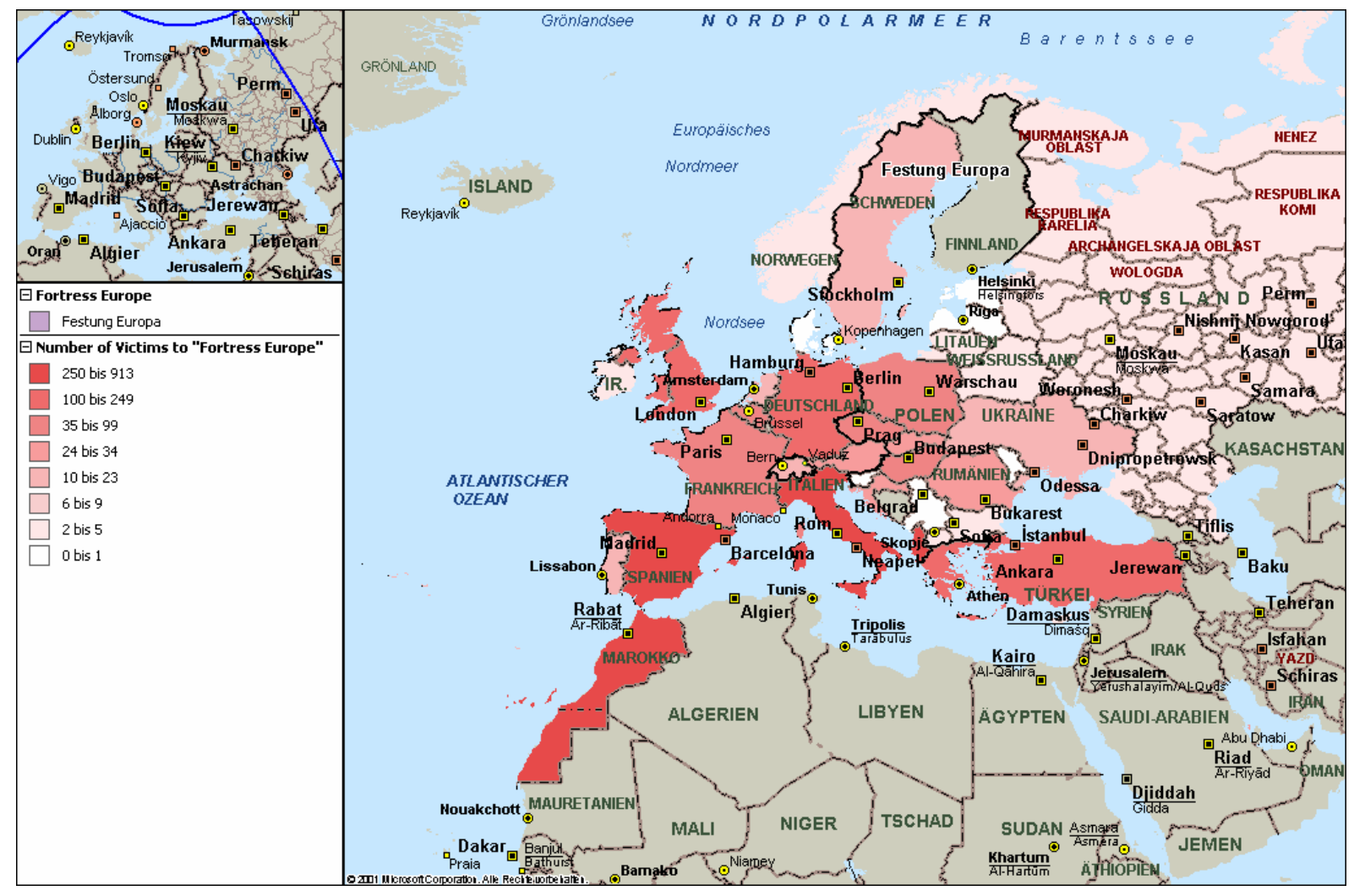

\subsection{Einige statistische Befunde in Zahlen und Grafiken}

Insgesamt wurden von 1993 bis 2001 an der Außengrenze der Europäischen Union 2406 Todesfälle durch Nicht-Regierungs-Organisationen und die Medien registriert. Mit einem prozentuellen Anteil von 68,5 ist Ertrinken die häufigste Todesursache (Tabelle 2). 
Tabelle 2: Aufschlüsselung der Anzahl der Todesopfer nach Todesursachen in absoluten und prozentualen Werten (1993-2001)

\begin{tabular}{|l|c|c|}
\hline Todesursache & $\begin{array}{c}\text { Zahl Todesopfer } \\
\text { gesamt }\end{array}$ & Prozent \\
\hline Hungertod & 5 & $0,21 \%$ \\
\hline Flucht vor Behörden & 15 & $0,62 \%$ \\
\hline Verwehrung medizinischer Versorgung & 18 & $0,75 \%$ \\
\hline Vergiftung & 20 & $0,83 \%$ \\
\hline Minenfeld & 26 & $1,08 \%$ \\
\hline Brandanschlag & 27 & $1,12 \%$ \\
\hline Erfrieren & 36 & $1,50 \%$ \\
\hline Mord & 38 & $1,58 \%$ \\
\hline Ersticken & 125 & $5,20 \%$ \\
\hline Selbstmord & 135 & $5,61 \%$ \\
\hline Unbekannt & 153 & $6,36 \%$ \\
\hline Autounfall & 160 & $6,65 \%$ \\
\hline Ertrinken & 1.648 & $68,5 \%$ \\
\hline Summe & $\mathbf{2 . 4 0 6}$ & $\mathbf{1 0 0 , 0} \%$ \\
\hline
\end{tabular}

Von den insgesamt 2406 registrierten Todesfällen sind 466 auf direkte Einwirkung staatlicher Organe zurückzuführen (Abbildung 3). Dies entspricht 19,4\% aller registrierten Fälle (Abbildung 4). Ganze 293 Fälle sind auf Interaktion mit Polizei- oder Grenzschutzbeamten zurückzuführen. Dabei fließen auch Fluchtversuche mit tödlichem Ausgang in die Statistik ein. 
Abbildung 3: $\quad$ Aufschlüsselung der Todesursachen durch staatliche Institutionen (1993-2001)

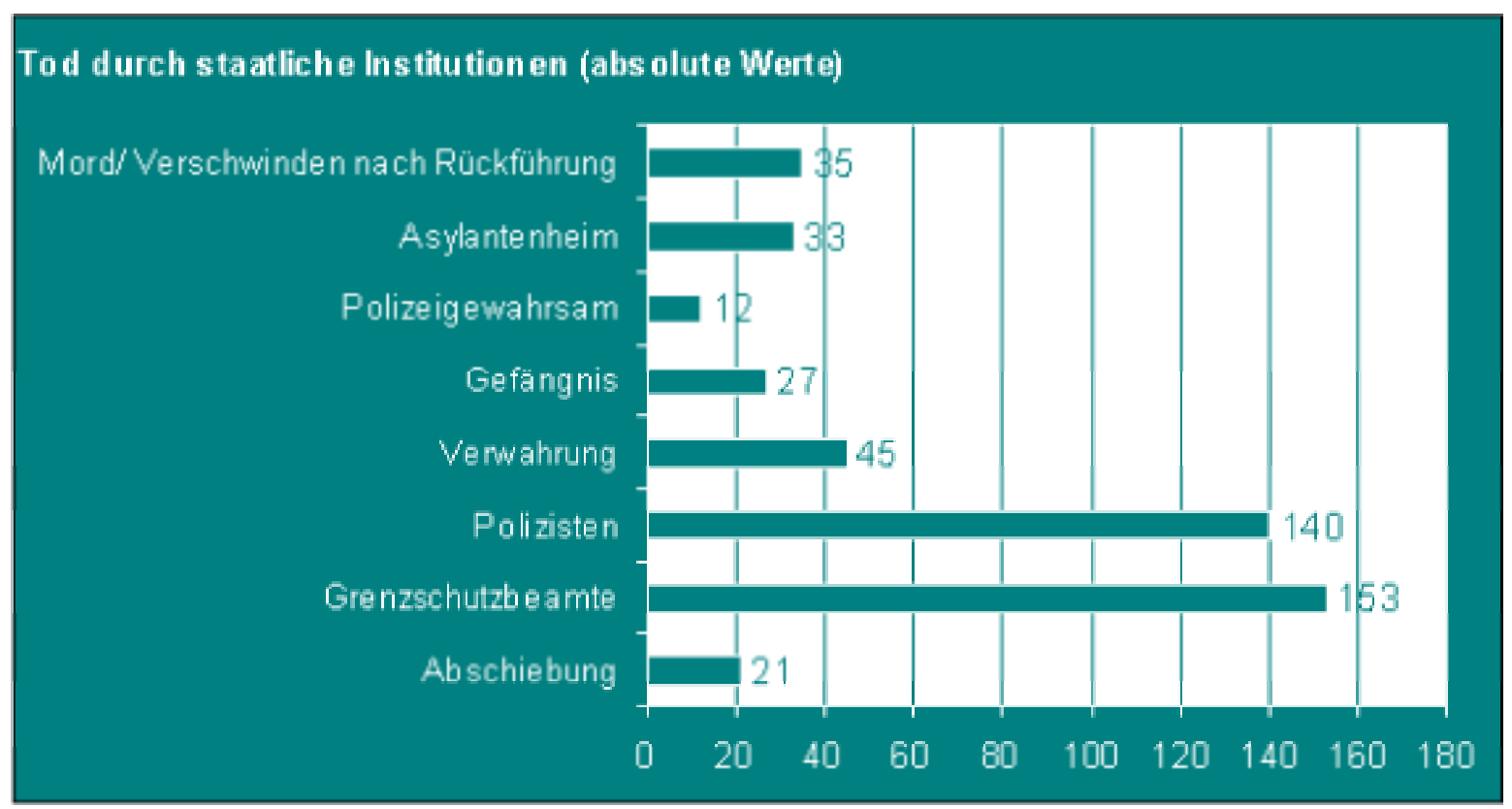

Abbildung 4: $\quad$ Prozentueller Anteil durch staatliche Institutionen verursachter Tode (1993-2001)

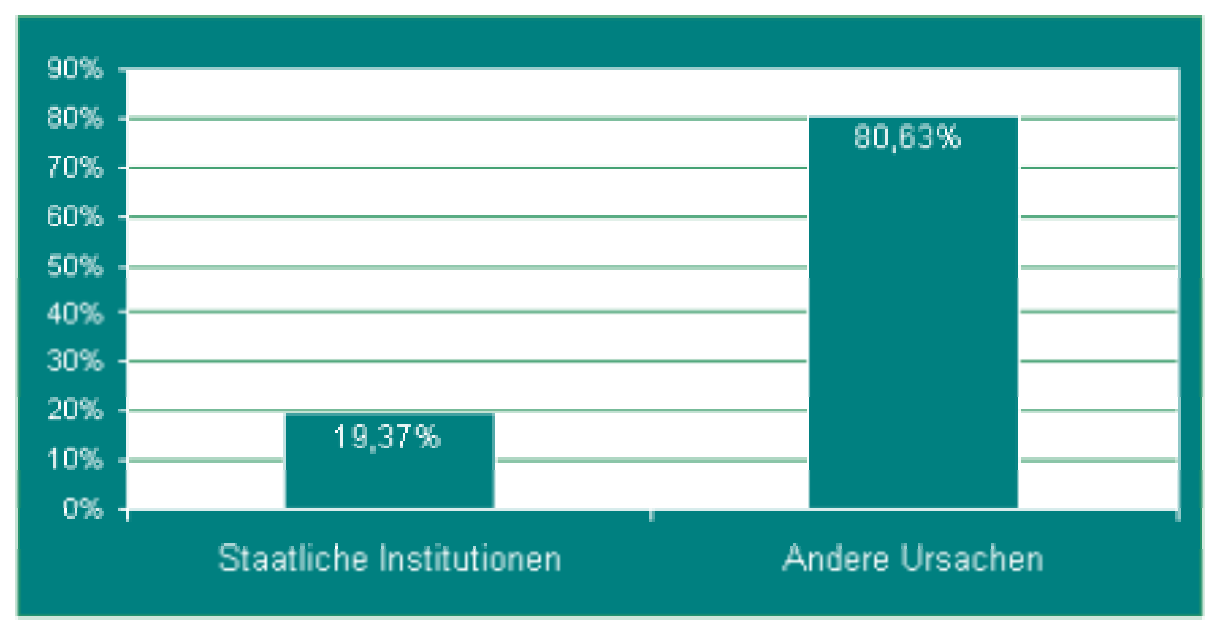

Bei der Betrachtung der Selbstmorde, die unabhängig von den oben genannten Todeszahlen durch staatliche Institutionen zu sehen sind, fällt auf, dass etwa $44 \%$ aller durchgeführten Selbstmorde nicht benannt werden können (Abbildung 5). Dies kann bedeuten, dass die Datenerhebung in diesem Falle nicht gut recherchiert wurde oder aber, dass staatliche Institutionen nicht bereit sind darüber genaue Auskunft zu erteilen. 
Abbildung 5: $\quad$ Art und Anzahl der begangenen Selbstmorde (1993-2001)

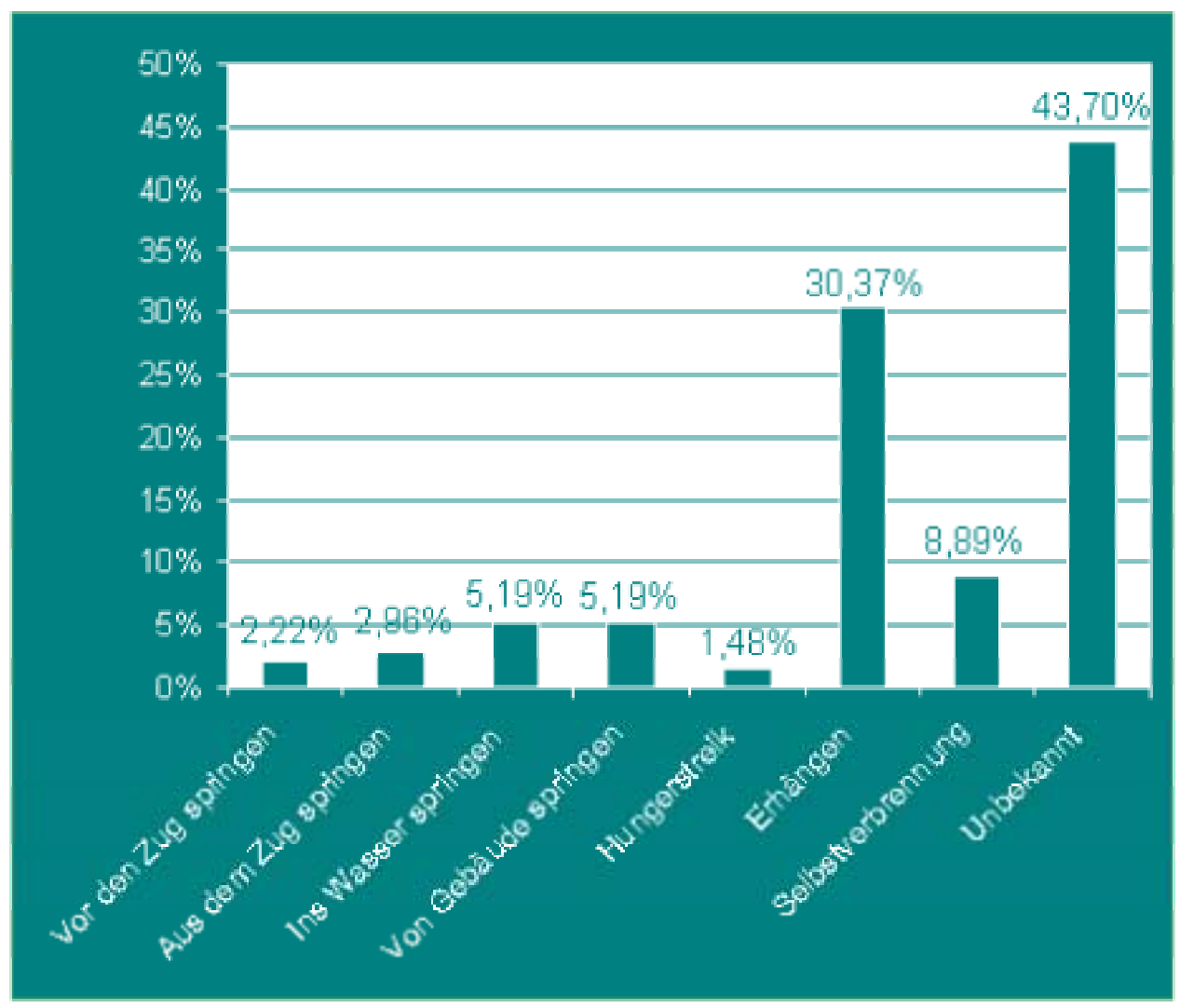

\section{- $\quad$ Arbeitsplanung 2004:}

Die Arbeiten an der Datenbank werden noch in diesem Jahr abgeschlossen. Erste Projektionsverfahren für die mögliche Bemessung von Dunkelziffern werden ebenfalls in diesem Jahr erprobt und diskutiert. Darüber hinaus wird ein "Inventory of Suffering" erstellt um Form, Ursprung und Art der Viktimisierungen durch irreguläre Migration und Migrations-Kontroll-Regime strukturell zu erfassen. In Verbindung mit den theoretischen Arbeiten zur Kriegs-Viktimisierung

(siehe: http://www.iuscrim.mpg.de/forsch/krim/ewald2.html)

wird dann ein Analysemodus für die Diskursanalyse ausgearbeitet, der Ursprungs-, Migrations- und Kontrollfaktoren in einem räumlich- zeitlichen Umfeld konzentriert und die Zielsetzung einer Analyse der Konstruktion des Diskurses operabel macht. 


\subsubsection{Viktimisierung und Verbrechensangst in den alten und neuen Bundesländern Deutschlands - Vergleich Jena - Freiburg I und II}

- $\quad$ Bearbeiter: Helmut Kury (Psychologe)

- $\quad$ Zeitrahmen: 1997 bis 2004

- $\quad$ Projektstatus: in Bearbeitung:

- $\quad$ Projektbeschreibung:

(vgl. dazu bereits die Tätigkeitsberichte 1996/1997, S. 67; 1998/1999, S. 130; 2000/2001, S. 161)

Zur Fragestellung möglicher Opferwerdungen im kommunalen Nahraum wurde zur Jahreswende 1991/92 in Zusammenarbeit zwischen dem MPI für ausländisches und internationales Strafrecht in Freiburg und der Friedrich-Schiller-Universität Jena eine Befragung repräsentativ ausgewählter Bürger aus den ostdeutschen Kommunen Jena und Kahla/Thüringen sowie aus den westdeutschen Städten Freiburg, Emmendingen und Löffingen durchgeführt. Erhoben wurden neben Viktimisierungen auch subjektive Parameter wie z.B. die Zufriedenheit mit den Ordnungs- und Strafverfolgungsbehörden, die Einschätzung der Kriminalitätsentwicklung und deren Ursachen sowie die Verbrechensfurcht und die Einstellungen zu Sanktionen. Ein besonderer Schwerpunkt der Untersuchung war der Vergleich der ost- und westdeutschen Populationen hinsichtlich der speziellen Erfahrung der Umbruchsituation und den damit verbundenen gesellschaftlichen Veränderungen. Das Untersuchungsdesign sollte zudem einen Vergleich der Kriminalitätsbelastungen und der Einstellungen der Bürger in Gemeinden unterschiedlicher Größe ermöglichen. Dabei standen Parameter wie z.B. unterschiedliche Gelegenheitsund Freizeitstrukturen sowie eine verschieden starke informelle Sozialkontrolle im Mittelpunkt.

Zur Frage, inwieweit sich im Laufe des Anpassungsprozesses in den neuen Ländern auch Einstellungsänderungen der Bürger ergeben haben und ob eine Angleichung der Kriminalitätsbelastung erfolgt ist, wurde zum Jahreswechsel 1995/96 eine weitere Vergleichsstudie zwischen Freiburg und Jena mit einem weitgehend identischen Untersuchungsinstrument durchgeführt.

\section{- $\quad$ Arbeitsbericht 2002/2003:}

Die Auswertungen der Studie von 1995/96 (Freiburg-Jena II) wurden weitergeführt und sind inzwischen weitgehend beendet. Zur Datenreduktion wurden Faktorenanalysen durchgeführt. Der Längsschnittvergleich zwischen den beiden Studien ist in den zentralen Bereichen weitgehend abgeschlossen. Insbesondere wurde die Literatur zu Methodenfragen weiter ausgewertet. Die Ergebnisse zum Einfluss unterschiedlicher Erhebungsmethoden auf die Resultate liegen weitgehend vor und wurden für eine Veröffentlichung vorbereitet.

- $\quad$ Arbeitsplanung 2004:

Neben methodischen Fragestellungen wird ein Schwerpunkt der Tätigkeit auf der Analyse der Veränderungen der Variablenausprägungen zwischen 1991/92 und 1995/96 liegen. Die Vergleiche zwischen den beiden Studien wurden inzwischen, was die Rechenarbeiten betrifft, weitgehend abgeschlossen, die Interpretation der Resultate und Zusammenfassung in mehreren Veröffentlichungen ist im Gange. Die restliche Datenauswertung zum Methodenteil der Studie soll sich auf die Fragen konzentrieren, welchen Einfluss einerseits verschiedene Erhebungsmodalitäten (schriftliche Befragung im Vergleich zu mündlichen Interviews) und andererseits eine unterschiedliche Gestaltung des Fragebogens, etwa was die Formulierung der Fragen betrifft, auf die gewonnenen Ergebnisse haben. Die Diskussion solcher Methodeneinflüsse auf Umfrageergebnisse ist in der deutschen Kriminologie weitgehend noch am Anfang, Untersuchungen hierzu können zu einer Verfeinerung der Erhebungsmethodik bei zukünf- 
tigen Umfragen, etwa im Rahmen der Viktimologie beitragen. Solche Untersuchungen werden auch in der internationalen Literatur zunehmend gefordert. Das Design war in allen Untersuchungsschritten experimentell, d.h. es erfolgte eine Zufallszuteilung der einzelnen Erhebungsmethoden auf die Befragtengruppen, was die Herausarbeitung kausaler Zusammenhänge erlaubt. Neben der Datenerhebungsart wurde insbesondere der Einfluss der Fragebogengestaltung auf die Resultate geprüft. Hierbei wurde der Schwerpunkt auf folgende Bereiche gelegt: - Fragebogeninstruktion, - Erfassung der Verbrechensangst, - Erfassung der Schwere der Viktimisierung, - Sanktionseinstellung, - demographische Variablen (wie Einkommen), - Stellung der einzelnen Fragen im Gesamtkontext, - Veränderung in den Antwortkategorien bei einzelnen Items. Der Einfluss der Position dieser inhaltlichen Bereiche im Fragebogen auf deren Ausprägung aber auch auf die Ausprägung der anderen Bereiche kann aufgrund des Forschungsdesigns jeweils geprüft werden. Vor diesem Hintergrund können Aussagen gemacht werden zum Einfluss der Fragebogengestaltung auf die Erfassung solch sensibler Bereiche wie Verbrechensfurcht oder Sanktionseinstellungen und die Validität der gewonnen Ergebnisse. Vor dem Hintergrund der breiten politischen Diskussion von Ergebnissen zu Verbrechensfurcht oder Sanktionseinstellungen kommt deren möglichst exakten Erfassung eine nicht unerhebliche Bedeutung zu. Die Berechnung der Ergebnisse ist weit fortgeschritten, ebenso die Literaturanalyse. 2004 wird das Projekt durch mehrere Veröffentlichungen zu methodischen in inhaltlichen Bereichen der zwei Opferstudien abgeschlossen. Die Veröffentlichungen sind Ende 2003 weitgehend vorbereitet.

- $\quad$ Ausgewählte Literatur:

KURY, H., OBergfell-FuchS, J. \& WÜRger, M.: Strafeinstellungen. Ein Vergleich zwischen Ostund Westdeutschland. edition iuscrim, Freiburg i.Br. 2002, $174 \mathrm{~S}$.

KURY, H., OBERGFELl-FuChS, J. \& WÜRGER, M.: Gemeinde und Kriminalität. Eine Untersuchung in Ost- und Westdeutschland. edition iuscrim, Freiburg i.Br. 2000, $770 \mathrm{~S}$

KURY, H. \& OBERGFELL-FUCHS: Kriminalität Jugendlicher in Ost und West. Auswirkungen gesellschaftlicher Umwälzungen auf psychisches Erleben und Einstellungen. In: Jugend und Gewalt. Devianz und Kriminalität in Ost und West. Hrsg. S. Lamnek. Leske + Budrich, Opladen 1995, 291-314.

KURY, H. \& WÜRGER, M.: Opfererfahrungen und Kriminalitätsfurcht - Ein Beitrag zur Viktimisierungsperspektive. In: Kriminologische Forschung in den 90er Jahren - Criminological Research in the 1990's. Hrsg. G. Kaiser \& H. Kury. edition iuscrim, Freiburg i.Br. 1993, 411-462.

KURY, H. (Hrsg.): International Comparison of Crime and Victimization: The ICVS. de Sitter Publications, Willowdale, Can 2001.

\subsection{Schwerpunkt "LEA - Laboratoire Européen Associé"}

\subsubsection{Die Entwicklung der Staatsgrenzen in den Ländern Ex-Jugoslawiens und in Albanien}

- $\quad$ Bearbeiterin: Azilis Maguer (Politologin)

- Zeitrahmen: 2003 bis 2004

- $\quad$ Projektstatus: in Bearbeitung

- Projektbeschreibung:

Dieses Projekt beruht auf einem Auftrag des französischen Verteidigungsministeriums und untersucht das Verfahren und die Durchsetzung von Maßnahmen zum Aufbau von kohärenten und effizienten Grenzkontrollen und Grenzregimen in gezielt ausgesuchten Ländern des westlichen Balkans (Albanien, Bosnien-Herzegowina, Kroatien, Mazedonien sowie Serbien und Montenegro). Es geht hier um eine Untersuchung zum staatlichen Aufbauprozess unter besonderen Umständen (Nach-Kriegs- 
Situation, Nachbarländer einer sich erweiternden Europäischen Union und generelles Einbeziehen von mehreren internationalen Organisationen in den Prozess). Diese Untersuchung geht von zwei Hauptansätzen aus: Erstens befindet sich diese Balkanregion in einer Nach-Kriegsphase, in der die Grenzen erst einmal an Konsistenz und Stabilität gewinnen müssen, um den neu gegründeten Staaten Entstehungs- und Fortbestehungskapazität zu verleihen. Die Situation stellt sich also ganz anders dar als in der Europäischen Union, in der es gerade um die allmähliche Abschaffung von Grenzkontrollen bzw. von Grenztrennpunkten geht. Zweitens liegt diese Balkanregion zwar außerhalb der EU, ist aber Ziel von umfangreichen Unterstützungsprogrammen aus Europäischen Behörden, insbesondere im Bereich des Wiederaufbaus von zivilen Sicherheitskräften (Polizei, Zoll) und von stabilen Grenzregimen. Es sind auch andere europäische und außereuropäische internationale Organisationen an diesem Wiederaufbau beteiligt. In diesem Kontext bildet sich in dieser Region mit noch umstrittenen Grenzlinien ein Knoten, der aus multiplen Interaktionen, Spannungsfeldern und verschiedenen Akteuren (Internationale Organisationen und staatliche Akteure, sowohl aus der EU als auch aus den einzelnen Balkanstaaten) besteht. Diese Akteure sollen zur Förderung eines stabilen Grenzsystems in allen Ländern beitragen, entwickeln aber unterschiedliche Strategien zur Durchführung bzw. zur Aufnahme der vorgeschlagenen Aufbauprozesse.

Daher konzentriert sich die Studie auf zwei Kernaspekte:

Zum einen wird die Analyse auf die unterschiedlichen Strategien der Akteure fokussiert. Es wird versucht, mittels der Methodologischen Perspektive der Internationalen Beziehungen herauszufinden, zu welchen bestimmten Zwecken und mit welchen Mitteln sich manche Akteure (OSZE, EU, NATO...) in dieser Region am Wiederaufbau beteiligen. Weiter wird untersucht, in welchem Grad und mit welchen Ergebnissen diese internationalen Akteure miteinander kooperieren und ihre Programme koordinieren. Daraus soll unter anderem eine Gesamtdarstellung der Positionen und Strategien der wichtigsten internationalen politischen Akteure gegenüber diesen Balkanländern und deren Entwicklung in staatliche Einheiten erstellt werden.

Zum anderen soll untersucht werden, unter welchen praktischen, politischen und sozialen Umständen die verschiedenen Aufbauprogramme umgesetzt werden. Hierfür werden Methoden der soziopolitologischen Analyse angewendet, um die Frage der Durchführungsmöglichkeit und der Anpassung der Programme auf die soziale Lage der Länder zu untersuchen. Dabei wird vor allem auf die Faktoren geachtet, die auf die Implementierung der verschiedenen Programme (die Umorganisation der Grenzkontrollen, aber auch die Ausbildung der Sicherheitskräfte, die rechtliche Basis derer Arbeit, sowie die allgemeinen Grenzbeziehungen zwischen Sicherheitskräften und zwischen Grenzbevölkerungen) besonderen Einfluss nehmen. Es wird nicht nur auf die verfügbaren Ressourcen und die Bedürfnisse in den verschiedenen Grenzsystemen geachtet, sondern auch auf die Spannungsverhältnisse und deren Ursachen zwischen den jeweiligen staatlichen Grenznachbarn. Außerdem wird auch die "Qualität" der jeweiligen Grenzlinie untersucht, d.h. ob diese über einen international und national anerkannten und unumstrittenen Status verfügt. Denn es gehört wahrscheinlich zu den größten Herausforderungen für diese Region und für die beteiligten Akteure, aus den nach den Balkankriegen der 90er Jahren entworfenen staatlichen Grenzlinien feste Trennungslinien zu machen. Die Frage nach der Qualität der Grenzen wird insbesondere für Montenegro gestellt, aber auch für den Kosovo sowie für Mazedonien. Durch Spannungsverhältnisse bedingt bestehen Schwierigkeiten, Grenzkontrollen zu organisieren, eine grenzüberschreitende Zusammenarbeit aufzubauen, die Verhältnisse im Grenzgebiete zu normalisieren und grenzüberschreitende Kriminalitätsphänomene zu bekämpfen.

Die Analyse wird vor allem qualitativ ablaufen. Interviews mit Beamten aus den jeweiligen internationalen Organisationen und nationalen Sicherheitsorganisationen in Westeuropa und in der Balkanregion werden durchgeführt und bewertet, sowie Arbeitsdokumente zu Aufbau- und Unterstützungsprogrammen gesammelt und analysiert (als Beispiel seien hier die nach der Ohrid-Konferenz in Mazedonien am 22.05.2003 zur Grenzverwaltung und Sicherheit verabschiedeten Maßnahmen und Projekte 
genannt). Die Expertenbefragungen zielen darauf ab, die verschiedenen Positionen der Akteure zu schildern und die Artikulationen oder Anpassungsprobleme aus diesen Stellungsnahmen zu erläutern.

- $\quad$ Arbeitsplanung 2004:

2004 soll die Studie fortgesetzt und abgeschlossen werden. Erste Interviews wurden bei EU-Behörden und bei der NATO durchgeführt, weitere werden insbesondere bei der OSZE in Wien folgen. Die ersten Kontakte für einen Zugang zur Balkanregion wurden geknüpft, und es ist geplant, einen 4- bis 5wöchigen Aufenthalt in den Studienländern zur Erhebung von Material (vor allem Interviews) durchzuführen. Diese Studie wird zu einem schriftlichen Bericht für das franz. Verteidigungsministerium sowie zu einer mündlichen Vorstellung der Hauptergebnisse führen.

\subsubsection{Grenzüberschreitende polizeiliche Kooperation - Praktiken, Institutionen und Strukturen entlang der deutsch-französischen Grenze}

- $\quad$ Bearbeiterin: Azilis Maguer (Politologin)

- $\quad$ Zeitrahmen: 1998 bis 2002

- $\quad$ Projektstatus: abgeschlossen

- $\quad$ Projektbeschreibung: (zugleich Promotionsprojekt)

(vgl. dazu bereits die Tätigkeitsberichte 1998/1999, S. 138; 2000/2001, S. 172)

Das Forschungsprojekt untersucht die Anlässe, Modalitäten, Effekte und (Erfolgs-)Bilanzen der polizeilichen Zusammenarbeit von deutschen und französischen Sicherheitsbehörden entlang der gemeinsamen Grenze. Untersucht wird im einzelnen, welche "kriminogenen Anlässe" zur grenzüberschreitenden Kooperation gegeben sind, unter welchen organisatorischen und rechtlichen Voraussetzungen die verschiedenen Polizei- und Zollbehörden an der Grenze operieren, welche Problematiken dabei zu bewältigen sind und in welcher Weise bzw. inwieweit sich die beteiligten Organisationen über Eigenheiten der nationalen Rechts- und Organisationskulturen hinweg miteinander arrangieren (können). Angestrebt wird einerseits die Produktion empirisch gesicherten Wissens über konkrete Formen, Probleme und Ergebnisse der grenzüberschreitenden polizeilichen Kooperationspraxis, andererseits sollen sich aus der Untersuchung qualifizierte Aussagen über deren kriminologische Relevanz sowie Bedeutung im Kontext einer sich abzeichnenden "transnationalen Kultur innerer Sicherheit" ableiten lassen. Die Untersuchung berührt neben organisationssoziologischen und rechtlichen Problemperspektiven vor allen Dingen auch übergreifende Fragestellungen der effizienten Produktion von Sicherheit in modernen, sich rasch wandelnden demokratischen Gesellschaften. So haben sich mit der zunehmenden Verdichtung ökonomischer Austauschprozesse über nationale Grenzen hinweg und den politisch begleitenden Abbau von Zirkulationshürden für Kapital, Waren und Menschen in der Europäischen Union und darüber hinaus, aus der Perspektive der Sicherheitsbehörden auch neue Erfordernisse für Eingriffsmechanismen ergeben. Im Politikfeld "Innere Sicherheit" standen dabei von Anfang an Fragen und Probleme der Polizei- und Justizkooperation über nationale Souveränitäts- und Territorialgrenzen hinweg im Vordergrund. Ein besonders prägnantes Beispiel für diese Entwicklung ist die deutsch-französische Grenzregion. Erst 1997 wurde hier ein weiterer Ausbau der regionalen Polizeiund Justizkooperation zwischen Frankreich und Deutschland vertraglich vereinbart. In diesem $\mathrm{Zu}$ sammenhang ist auch die Einrichtung eines deutsch-französischen Polizeizentrums in Offenburg beschlossen worden, in dem erstmals deutsche wie französische Beamte unterschiedlicher Polizei- und Zollbehörden unter einem Dach gemeinsam regionale grenzüberschreitende Kriminalität bekämpfen und Hindernisse der konkreten Zusammenarbeit unbürokratisch überwinden sollen. 
Das Forschungsprojekt ist Teil der Laboratoire Européen Associé-Rahmenvereinbarung zwischen der Max-Planck-Gesellschaft und dem französischen Centre National de la Recherche Scientifique (CNRS). Die Untersuchung wird in Abstimmung und enger Zusammenarbeit mit dem Centre de Recherches Sociologiques sur le Droit et les Institutions Pénales (CESDIP, Paris) und dem Institut Fédératif de Recherches sur les Economies et les Sociétés Industrielles (IFRESI) in Lille durchgeführt.

Die gemeinsamen Arbeiten an der Projektfragestellung wurden im Mai 1998 aufgenommen, als in einem ersten Arbeitstreffen mit den französischen Forschungspartnern in Lille die Problemstellung und das Untersuchungsdesign der Studie herausgearbeitet wurden. Im Verlauf wurde das Untersuchungskonzept präzisiert und empirisch operationalisiert sowie die Kontakte im Forschungsfeld aufgebaut.

- $\quad$ Arbeitsbericht bis 2002:

In der ersten Phase der Empirie wurden Expertengespräche mit Vertretern der Gendarmerie auf lokaler und zentraler Ebene, der Police Nationale, der Douanes, der Landespolizei Baden-Württemberg, des Bundesgrenzschutzes und des Zolls auf lokaler Ebene geführt. Einbezogen wurden auch einzelne Staatsanwaltschaften im deutsch-französischen Grenzraum, die intensiv mit Rechtshilfeersuchen beschäftigt sind. Im Mittelpunkt der zweiten empirischen Phase standen verschiedene mehrtägige Feldbeobachtungen im kürzlich eröffneten "Gemeinsamen Zentrum für deutsch-französische Polizei- und Zollkooperation" in Offenburg. Die während des Aufenthalts generierten Feldnotizen waren Grundlage für eine weitere Interviewrunde mit einer Reihe von dort tätigen deutschen und französischen Beamten.

Im Oktober wurde in Verbindung mit dem Forschungsprojekt und in Zusammenarbeit mit GERN am Institut ein eintägiger, mit internationalen Experten und Praktikern besetzter Workshop (Interlabo) zur Thematik regional grenzüberschreitender polizeilicher Zusammenarbeit veranstaltet.

Im Frühjahr 2001 wurde eine Reihe von Interviews mit Staatsanwälten und Oberstaatsanwälten in Elsass und Lothringen sowie in Baden-Württemberg geführt. Als Abschluss für die empirische Phase wurde auch eine Beobachtungsphase in lokalen Polizeidienststellen realisiert. Die Entwicklung der Arbeit im Gemeinsamen Kooperationszentrum wurde weiterhin begleitet und es wurden entsprechend zusätzliche Interviews durchgeführt. Im Vordergrund standen seit dem Frühjahr die Auswertungen und die Analyse des Datenmaterials. Im Verlauf parallel dazu wurde mit der Abfassung der Doktorarbeit begonnen, die voraussichtlich im Frühjahr 2002 abgeschlossen werden kann. Darüber hinaus wurde an einem Forschungsbericht gearbeitet, der sich insbesondere mit den engeren kriminologischen Aspekten des Forschungsthemas befassen wird.

Vorläufige Ergebnisse des Forschungsprojekts wurden bereits bei einer Tagung des CESDIP (Paris) im Oktober 1999, während des Süddeutschen Kriminologischen Kolloquiums im Juli 2000 sowie im Rahmen eines Interlabos der GERN zum Thema "Grenzüberschreitende Polizeikooperation" im Oktober 2000 in Freiburg, sowie auf einem internationalen Polizeiseminar des CESDIP im März 2001 in Paris vorgestellt und mit anderen Forschern diskutiert. U.a. wurde aus der Projektarbeit heraus ein Entwurf für ein umfassendes Modell der Strukturentwicklung und des Entwicklungsstandes der polizeilich-justiziellen Kooperationsnetzwerke an der Grenze präsentiert.

Wesentliche Ergebnisse der Studie:

Der Schwerpunkt der Studie lag bei der starken Umstrukturierung der Kooperationskapazitäten (Stellen, Personal, finanzielle Mittel), die im Rahmen des Inkrafttretens des SDÜ und des deutschfranzösischen Mondorfer Vertrags in die Wege geleitet wurde. Diese Umstrukturierung wurde unter zwei unterschiedlichen Perspektiven betrachtet. In einer ersten Phase wurde der von SDÜ herbeigerufene Umbau der unterschiedlichen schon bestehenden Kooperationsstellen an der Grenze analysiert. Die Berücksichtigung von allen an der staatlichen Organisation der formellen sozialen Kontrolle betei- 
ligten Behörden in Deutschland und Frankreich hat ermöglicht, die durch das SDÜ verursachte synergetische Umorganisation innerhalb jeder einzelnen Sicherheitskraft an der Grenze festzustellen und zu bewerten. Die Einführung von neuen Interventionsformen (grenzüberschreitende Observation und Nacheile, Anerkennung und Institutionalisierung des direkten polizeilichen Informationsaustausches etc.), die mögliche Inanspruchnahme dieser Instrumenten von allen deutschen und französischen bzw. EU-Sicherheitsbehörden, wie auch die Eröffnung der grenzüberschreitenden Zusammenarbeit für alle Sicherheitsbehörden - teilweiser Abbau der für besondere Sicherheitsdienste reservierten Kompetenzbereiche im Feld der internationalen (kriminal-)polizeilichen Kooperation - haben dazu beigetragen, dem Kooperationsfeld an der Grenze ein völlig neues Arbeitssystem zu verleihen. Vor dem SDÜ war die Zusammenarbeit eher durch bilaterale deutsch-französische Netzwerke, bestehend aus homologen institutionellen Arbeitspartnern, geprägt (Police aux Frontières mit Bundesgrenzschutz, Douane mit Zoll, Police Judiciaire mit Landeskriminalämtern und Gendarmerie mit landespolizeilichen benachbarten Dienstellen). Im Rahmen vom SDÜ sind diese Netzwerke durch die Umwandlung der grenzüberschreitenden Zusammenarbeit als allgemeines und gemeinsames Arbeitsinstrument teilweise in Frage gestellt. Da jede Behörde auf diese Instrumente der grenzüberschreitenden Kooperation zurückgreifen kann, und da sie sich außerhalb der traditionellen Kooperationspartner die Sicherheitsstelle aussuchen, die für den zu behandelnden Fall am besten geeignet zu sein scheint, befinden sich die verschiedenen nationalen Sicherheitskräften in einer starken Konkurrenzsituation.

Unter diesen Bedingungen wurde 1997 der Mondorfer Vertrag über die deutsch-französische Kooperation von Zoll und Polizeibehörden in der Grenzregion unterzeichnet, der darauf zielte, eine chaotische Umsetzung der Schengener Regelungen zwischen den beteiligten lokalen und zentralen Behörden zu verhindern. In diesem Vertrag wurde das Gemeinsame Zentrum für Polizei- und Zollkooperation kreiert. Diese binationale Grenzstelle enthält Vertreter aus allen deutschen und französischen Sicherheitsdiensten und sorgt für eine möglichst reibungslose Zusammenarbeit in Bereichen der regionalen kleinen und mittleren Kriminalität. Ihre Vermittlungsfunktion für Rechtshilfe und grenzüberschreitende Interventionen wirkt auch als Filterfunktion zwischen beantragenden und ersuchten justiziellen bzw. polizeilichen Dienststellen. Da dieses Zentrum als zentrale Vermittlungsstelle für beinahe alle regionalen Kooperationseinsätze gelten will, wurden die vorher angesprochenen Konkurrenzsituationen innerhalb dieses Zentrums konzentriert und versetzt. Es wurde in der Studie festgestellt, dass die Art und Schwere der dadurch bekämpften Kriminalität keine große Rolle in der Besatzung von Schlüsselstellen im Gemeinsamen Zentrum, aber auch in den anderen regionalen Kooperationsdienststellen spielt.

Dies bedeutet nicht, dass die Bekämpfung der für diese Stellen relevanten Kriminalität kein Thema für Diskussion innerhalb des Kooperationsfeldes ist. Die zweite Perspektive der Untersuchung zielt deshalb darauf, die Arbeitsweise innerhalb dieses neuen "offenen" Kooperationsfeldes und deren Konsequenzen für die jeglichen nationalen Sicherheitssystemen zu identifizieren. Die Intensivierung des grenzüberschreitenden Austausches hat unter anderen zu einer Erweiterung der potentiellen polizeilichen Kooperationsbereiche über die Behandlung von konkreten Kriminalitätsphänomenen hinaus zu präventionsorientierten gemeinsamen grenzüberschreitenden Überlegungen zu Sicherheit und Ordnung geführt. Die tägliche Praxis der grenzüberschreitenden Zusammenarbeit wirkt sich weiterhin auf die nationalen Sicherheitssysteme aus, indem sich in der Grenzregion intensive gegenseitige Einflüsse und durch die neuen rechtlichen Arbeitsmöglichkeiten hervorgerufene Veränderungen in den Arbeitsmethoden der polizeilichen Organisationen ergeben. Die Einführung von neuen Arbeitsmethoden, neuer Arbeitstechniken, sowie die Gewinnung von neuen Kompetenzen und arbeitstechnischen Kenntnissen lassen allmählich die Behörden an der Grenze als Veränderungsquelle für die gesamte Organisation gelten. Weiterhin entwickelt sich die deutsch-französische Grenzregion zu einem an sich relevanten Sicherheitssystem mit eigenen Arbeitsmechanismen und eigenen Arbeitsmitteln, die sich zu einem einzigartigen und sich vom gesamten nationalen Verwaltungsgebiet unterscheidenden Territorium entfaltet. Dieses Phänomen der allmählichen Abtrennung der Grenzzone vom restlichen nationalen Gebiet als eigener Sicherheitsverwaltungsblock kann auch in weiteren Grenzgebieten Europas festge- 
stellt werden (deutsch-schweizerische bzw. deutsch-dänische Grenze, spanisch-französische bzw. französisch-belgische Grenze ...). Diese unauffällige Veränderung in der staatlichen Sicherheits- und Kontrollorganisation ist hauptsächlich aus technischen Gründen von polizeilichen Organisationen durchgeführt worden, sie trägt aber zu durchaus wichtigen Konsequenzen für die politischen Staatssysteme in Europa bei.

Die Doktorarbeit wurde am 19. Dezember 2002 in Paris an der Universität Paris X-Nanterre verteidigt und mit der Auszeichnung "Très honorable, avec les félicitations du jury" bewertet.

Die Jury bestand aus:

Vorsitz: Prof. Dr. Jean-Marie Demaldent, Professor für Politikwissenschaft an der Universität Paris-X Nanterre.

Doktorvater: Dr. Philippe Robert, Forschungsdirektor an dem Centre National de la recherche Scientifique.

Erster Gutachter: Prof. Dr. Lode van Outrive, Professor für Kriminologie an der Katholischen Universität Leuven.

Zweiter Gutachter: Prof. Dr. Malcolm Anderson, Professor für Soziologie an der Universität Edinburgh.

Prof. Dr. Hans-Jörg Albrecht, Professor für Kriminologie und Strafrecht an der Universität Freiburg im Breisgau und Direktor am Max-Planck-Institut für ausländisches und internationales Strafrecht, Freiburg im Breisgau.

- $\quad$ Ausgewählte Literatur:

MAGUER, A.: La coopération policière transfrontalière, moteur de transformations dans l'appareil de sécurité français, Cultures et Conflits, 33-56 (2003).

Maguer, A.: Die Einstellung von ausländischen Polizistinnen und Polizisten in Deutschland: Ergebnisse einer Untersuchung. Monatschrift für Kriminologie und Strafrechtsreform 4, 309-316 (2002).

MAGUER, A. \& MÜLLER, S.: Landesbericht Frankreich. In: Jugendstrafrecht in Europa. Hrsg. H.-J. Albrecht \& M. Kilchling. edition iuscrim, Freiburg i. Br. 2002, 157-189.

MAgueR, A.: Polizeiliche Zusammenarbeit in Europa: Teilprojekt B: Grenzüberschreitende Zusammenarbeit von Sicherheits- und Justizbehörden an der deutsch-französischen Grenze. In: Jahrbuch der Max-Planck Gesellschaft. Hrsg. Generalverwaltung der Max-Planck Gesellschaft, Vandenhoeck \& Rupprecht, München 2001, 808-811.

Nogala, D., MAGUER, A.: La coopération policière à une frontière hybride. Une vision de l'espace commun de la sécurité au delà des frontières. In: Normes, déviances, contrôle social - Nouveaux enjeux, nouvelles approches. Hrsg. Cesdip. Paris 2000 (CD-ROM). 


\subsubsection{Arbeit und Strafvollzug: eine rechtsvergleichende Studie der Aufgaben und Ausgestaltung der Gefangenenarbeit in Frankreich, Deutschland und England}

- $\quad$ Bearbeiterin: Evelyn Shea (Juristin)

- $\quad$ Zeitrahmen: 2000 bis 2004

- $\quad$ Projektstatus: in Bearbeitung

- $\quad$ Projektbeschreibung : (zugleich Promotionsprojekt)

(vgl. dazu auch den Tätigkeitsbericht 2000/2001, S. 177)

Die Gefangenenarbeit - seit Jahrhunderten ein Pfeiler des Strafvollzugs - ist in den letzten Jahren in vielen europäischen Ländern unter Kritik geraten: in ihrer jetzigen Form sei sie kaum geeignet, ihrer Resozialisierungsaufgabe gerecht zu werden. In erster Linie wird der Mangel an Arbeitsplätzen, die niedrige Entlohnung, der ungenügende Rechtsschutz und die oft unqualifizierte, monotone Art der Beschäftigung bemängelt. Sind diese Vorwürfe gerechtfertigt? Anders ausgedrückt: entsprechen Gesetzgebungen und Praxis im europäischen Raum den Aufgaben und Erfordernissen einer zeitgemäßen Arbeitstätigkeit im Vollzug? Im Rahmen der Vollzugsforschung des Laboratoire Européen Associé möchte das vorliegende Projekt diesen Fragen in drei europäischen Ländern (Frankreich, Deutschland und England) nachgehen.

Als Erstes werden dazu, nach einer kurzen historischen Einleitung, die rechtlichen Grundlagen der Gefangenenarbeit in den drei Ländern dargelegt und verglichen, insbesondere:

1. Die rechtlichen Zielsetzungen und die zu Grunde liegenden Prinzipien

2. Die Organisationsformen der Arbeit

3. Die Rechtsstellung des arbeitenden Strafgefangenen

4. Die Finanzierung der Gefangenenarbeit

Als Zweites werden statistische Daten zur Gefangenenarbeit erhoben : Zahl der Arbeitsplätze, Arbeitslosenquote, Entlohnung, Art der angebotenen Beschäftigungen, etc.

Diese Informationen sollten bereits eine erste Antwort auf die Frage erlauben, in welchem Maß die rechtlichen und organisatorischen Strukturen in den jeweiligen Ländern die verschiedenen Aufgaben, insbesondere den Resozialisierungsauftrag, der Gefangenenarbeit fördern oder hindern.

Im Strafvollzug ist oft von der Kluft zwischen Theorie und Praxis die Rede. Um ein möglichst wirklichkeitsgetreues Bild der Gefangenenarbeit zu geben und zu prüfen, in welchem Maß die Arbeit im Gefängnis konkret zur Resozialisierung und Wiedereingliederung der Gefangenen beitragen kann, ist deshalb eine ergänzende empirische Untersuchung vorgesehen. Diese Untersuchung beschränkt sich, den Möglichkeiten eines Promotionsprojekts entsprechend, pro Land auf drei Vollzugsanstalten für männliche Strafgefangene, die zu Freiheitsstrafen von mindestens drei Jahren verurteilt wurden.

Ein Fragebogen (in dreisprachiger Ausführung), der an $20 \%$ der arbeitenden Strafgefangenen verteilt wird, soll Arbeit und Wiedereingliederung vom Standpunkt der Gefangenen beleuchten. Vorgesehen sind zudem detaillierte Interviews in mit fünf arbeitenden und fünf arbeitslosen Gefangenen pro Vollzugsanstalt, Gespräche mit dem Leiter der Arbeitsverwaltung, Werkbeamten, Auftraggebern, Sozialarbeitern etc. Diese Informationen werden durch interne Dokumente und durch persönliche Beobachtungen in den Werkstätten und Arbeitsplätzen vervollständigt. Dabei interessiert uns nicht nur die Gefängnisarbeit im engeren Sinn, d.h. die Arbeit intra muros, sondern auch Arbeitsleistungen im Rahmen einer Vollzugslockerung (Außenbeschäftigung, Freigang), da man gerade da den effektiven Beitrag der Arbeit als Vorbereitung auf ein straffreies Leben am ehesten überprüfen kann. Wir erhoffen uns auch Aufschluss über den Stellenwert der Arbeit als Kriterium für die Gewährung einer Vollzugserleichterung oder Strafverkürzung. 
Die empirische Komponente des Projekts gestattet einen Einblick in die konkreten Schwierigkeiten, mit denen das vollzugliche Arbeitswesen konfrontiert ist, erlaubt es aber auch, Lösungsmodelle und innovative Projekten in die Antwort auf unsere Kernfrage einzubeziehen, ob das vollzugliche Arbeitswesen in seiner jetzigen Form seinem Resozialisierungsauftrag gerecht werden kann. Der Vergleich zwischen Frankreich, Deutschland und England ist dabei besonders fruchtbar, da die drei Länder trotz einer ähnlichen Entwicklung der Strafarbeit bis zum zweiten Weltkrieg heute unterschiedliche Schwerpunkte setzen und die Reformen von verschiedenen Gesichtspunkten aus angehen.

- $\quad$ Arbeitsbericht 2002:

Die ersten sechs Monate waren der Einführung in die Gefängnisliteratur der drei Länder gewidmet. Zwischen Mai und September wurde die Terrainuntersuchung vorbereitet (Methodologie, Zeitplan, Fragebogen und Interviewfragen in dreisprachiger Ausgabe) und die Formalitäten eingeleitet, um Zugang zu den Vollzugsanstalten zu erhalten. Die folgenden Genehmigungen wurden erteilt:

1. In Frankreich:
a) Maison centrale d'Ensisheim (Cat.A)
b) Centre de détention de Montmédy (Cat.B)
c) Maison centrale de Poissy (Cat.A)

2. In Deutschland:
a) JVA Straubing, Bayern (Cat.A)
b) JVA Kaisheim, Bayern (Cat.B)
c) JVA Schwalmstadt, Hessen (Cat.A/B)

3. In England:
a) HMP Frankland (Cat.A)
b) HMP Swaleside (Cat.B)
c) HMP Featherstone (Cat.C)

Die Untersuchung fand zwischen Dezember 2001 bis Mai 2002 statt, eine Woche pro Gefängnis, und wurde im Allgemeinen sehr positiv aufgenommen. Wir hätten so viel Interesse an dem Thema von Seiten der Verwaltung, der Beamten und der Gefangenen kaum erwartet! Dies war ein großes Plus, den der Erfolg unserer Arbeit hing zu einem nicht unbedeutenden Teil vom Wohlwollen der Direktion und ganz besonders von der Kooperationsbereitschaft des Werkdienstleiters ab, der trotz dringenderen Aufgaben einen guten Teil der Woche unserem Projekt widmen musste.

\section{- $\quad$ Arbeitsbericht 2003:}

Nach Abschluss der Terrainarbeit in den 9 Justizvollzugsanstalten wurden die Interviews und informellen Gespräche übertragen, die 524 Fragebogen ${ }^{9}$ ausgewertet und mit der Redaktion der Dissertation begonnen.

\section{Erste Ergebnisse:}

Die Vorwürfe, die an das vollzugliche Arbeitswesen gerichtet werden, sind in allen drei Ländern weitgehend gerechtfertigt.

1. Die Beschäftigungsquote ${ }^{10}$ liegt in den untersuchten Gefängnissen zwischen $46 \%$ und $87.8 \%$, mit einer mittleren Rate von 61.4 \%. Dies ist zwar um einiges höher als der Landesdurchschnitt

9 Wir möchten es an dieser Stelle nicht versäumen, Herrn Dr. J. Obergfell-Fuchs and Frau Laura Pielmayer unseren Dank für die wertvolle Hilfe bei der Auswertung auszusprechen.

10 Die Beschäftigungsquote umfasst hier nur Arbeit im eigentlichen Sinn sowie Berufausbildungs- und Weiterbildungsmaßnahmen. Schulische oder therapeutische Maßnahmen sind aus Vergleichsgründen nicht inbegriffen. 
insgesamt für alle Kategorien von Vollzugsanstalten (etwas unter $50 \%$ in Frankreich und England, leicht darüber in Deutschland), Arbeitslosenquoten von $20 \%$ oder gar $30 \%$ sind jedoch in Langzeitgefängnissen nicht hinnehmbar, weder für die arbeitslosen Gefangenen noch für die Sicherheit und Ordnung innerhalb der Anstalt.

2. Die Qualität der Arbeitsplätze ist sehr unterschiedlich. Die drei deutschen Vollzugsanstalten zeichnen sich durch eine große Vielfalt von Tätigkeiten in den Eigenbetrieben aus, in denen jede Werkstatt eine Anzahl qualifizierter Arbeitsplätze sowie Aus- und Weiterbildungsmöglichkeiten anbietet. Leider trifft dieser positive Befund nicht auf die Fremdbetriebe zu. In England haben wirtschaftliche Erwägungen zu einer Reduktion der Produktionspalette der Eigenbetriebe auf einen oder zwei Sektoren geführt, in denen der Arbeitsprozess fließbandmäßig organisiert ist. Jede Werkstatt ist gehalten, Fortbildungsmöglichkeiten anzubieten. Da die Auftragslage in den Eigenbetrieben je länger desto weniger ausreicht, um die wachsende Zahl von Gefangenen zu beschäftigen, sucht auch der englische Prison Service zusehends Kontakte zu Privatfirmen, auch wenn diese bloß einfachste Sortier- und Montagearbeiten anbieten. In Frankreich hat dieser Schritt zur Privatwirtschaft schon lange stattgefunden: die Eigenbetriebe stellen nur noch $11.2 \%$ der Arbeitsplätze in den Werkstätten.

3. Die Entlohnung liegt in allen drei Ländern deutlich unter dem Mindestlohn für Arbeiter. Im Vergleich stehen die französischen Gefangenen etwas besser da als ihre deutschen und englischen Kollegen, insbesondere in Anbetracht der relativ kurzen Arbeitswoche in Frankreich (30 Stunden) im Vergleich zu Deutschland (38.5 Stunden). England hat die kürzesten Arbeitszeiten (durchschnittlich ca. 24 Stunden), dafür auch ein Tarifniveau, das eher einem Taschengeld entspricht.

\begin{tabular}{|c|c|c|c|}
\hline \multicolumn{4}{|c|}{ Durchschnittlicher Wochenlohn } \\
\hline & Frankreich & Deutschland & England \\
\hline Werkstätte & $€ 115 .-$ & $€ 60 .-$ & $€ 20-30$ \\
\hline Hausarbeit & $€$ 40.- & $€ 40 .-$ & $€ 11.20$ \\
\hline
\end{tabular}

4. Die rechtliche Stellung der Gefangenenarbeiter ist mit derjenigen in der freien Wirtschaft nicht zu vergleichen, in erster Linie weil im Gefängnis der Abschluss von Arbeitsverträgen mit Gefangenen nicht zulässig ist. Die Rechte und das soziale Sicherheitsnetz, die normalerweise mit einem solchen Vertrag verknüpft sind, kommen deshalb nur zur Anwendung, wenn sie ausdrücklich vom Gesetzgeber oder vom common law vorgesehen sind. Deutschland und Frankreich haben die üblichen Sozialversicherungen und Sicherheitsnormen weitgehend auf die Gefangenarbeit ausgedehnt, nicht jedoch das Arbeitsrecht: Die Gefangenen haben keinerlei Möglichkeit, auf das Arbeitsverhältnis Einfluss zu nehmen, weder auf individueller noch auf kollektiver Basis. Am meisten kritisiert wird der mangelnde Kündigungsschutz. Will ein Gefangener selber ein Arbeitsverhältnis beenden, kann er das zwar, muss aber damit rechnen, dass er ans Ende der Warteliste gesetzt wird, falls überhaupt. Die Rechtsbehelfe, die den freien Arbeitern zur Verfügung stehen, sind entweder inexistent oder ihr Zugang ist erschwert. Frankreich ist das einzige Land in Europa, das wenigstens die Arbeitspflicht im Gefängnis abgeschafft und damit formelle die Trennung von Strafe und Arbeit vollzogen hat.

In England kann man sich fragen, ob der Begriff "Rechtsstellung" überhaupt zutrifft. Gefangenenarbeit gibt keinerlei Anspruch auf Sozialversicherungen und schon gar nicht auf Schutzmaßnahmen aus dem Arbeitsrecht. Selbst im Falle eines Arbeitsunfalls trägt der Gefangene die Beweislast, dass die Gefängnisverwaltung ihrer Sorgepflicht nicht nachgekommen ist. In Fairness 
muss man allerdings hinzufügen, dass die einzelnen Gefängnisse oft vorbildliche Regelungen ausarbeiten, diese aber vom guten Willen und der Initiative der lokalen Gefängnisdirektion und Arbeitsverwaltung abhängen und keinerlei Rechtsanspruch daraus erwachsen kann.

- $\quad$ Arbeitsplan 2004:

Abschluss der Redaktion bis Frühjahr 2004.

- $\quad$ Ausgewählte Literatur:

HAMmerschick, W., PILGRAM, A. (HrsG.): Arbeitsmarkt, Strafvollzug und Gefangenenarbeit. Jahrbuch für Rechts- und Kriminalsoziologie. Nomos, Baden-Baden 1997.

LORIDANT, P.: Rapport d'information fait au nom de la commission des finances, du contrôle budgétaire et des comptes économiques de la Nation sur la mission de contrôle sur le compte de commerce 904-11 de la Régie Industrielle des Etablissements Pénitentiaires (RIEP). Sénat, No 330 (2002).

MARChetTI, A.M.: Pauvretés en prison. Erès, Ramonville 1997.

SIMON, F.: Prisoners' Work and Vocational Training. Routledge, London 1999.

TALANDIER, J.: Rapport présenté au nom du Conseil Économique et Social, Travail et prison. Journal Officiel, Paris 1987.

VAN ZYL SMIT, D., DÜNKEL, F. (Hrsg.): Prison Labour: Salvation or Slavery? Onati International Series in Law and Society. Dartmouth Publishing, Aldershot 1999.

3.6.4 Strafrechts-Mediation: das Paradox eines außergerichtlichen Verfahrens im strafrechtlichen Rahmen. Eine rechtssoziologische Untersuchung am Beispiel des deutschen Täter-Opfer-Ausgleichs und der französischen médiation pénale

- $\quad$ Bearbeiterin: Stefanie Tränkle (Soziologin und Romanistin)

- $\quad$ Zeitrahmen: Juni 2001 bis Mai 2004

- $\quad$ Projektstatus: in Bearbeitung

- $\quad$ Projektbeschreibung: (zugleich Promotionsprojekt)

\section{Einleitung}

In den letzten Jahrzehnten lässt sich eine Ausdifferenzierung des Strafrechts und eine damit einhergehenden Tendenz zur Informalisierung und Auslagerung von Verfahren feststellen (LudwigMayerhofer 1998: 25). Der Trend zur Informalisierung fällt zusammen mit der "restorative justice", einer internationalen Reformbewegung, die für wiedergutmachende Formen der strafrechtlichen Sozialkontrolle eintritt. Mediationsverfahren, die im Rahmen des Strafrechts angesiedelt sind, sind eine Ausprägung dieser Tendenz zu informeller und restitutiver Justiz. Frankreich und Deutschland gehören zu den Ländern, welche die Strafrechts-Mediation etwa zeitgleich Anfang der 1990er Jahre förmlich in ihr jeweiliges Strafverfahren integriert haben; dem deutschen "Täter-Opfer-Ausgleich" (TOA) entspricht die "médiation pénale".

Die Durchführungspraxis der Strafrechts-Mediation in Deutschland und Frankreich unterscheidet sich zwar in Äußerlichkeiten (z.B. wird das Verfahren in Frankreich überwiegend im Erwachsenen-Bereich angewendet, in Deutschland überwiegend im Jugend-Bereich), im Grunde aber stehen beide Länder mit der Institutionalisierung des neuen Verfahrens vor einem gemeinsamen Problem: der Bearbeitung eines aus der Justiz ausgekoppelten, aber dennoch von ihr abhängigen Verfahrens. Die Verfahrenslogik von Mediation erfolgt nach anderen professionellen Gesichtspunkten als ein traditionelles Strafverfahren, dazu gehört u.a. die Informalität, also das Fehlen starrer Prozessregeln, die es dem Mediator 
erlauben, nach sozialpädagogischen Gesichtspunkten auf die Medianten einzugehen. Für die Strafrechts-Mediation bedeutet das, dass einander widersprechende Verfahrensweisen vereinbart werden müssen: die Informalität der Mediation muss anschlussfähig gemacht werden an die Formalität eines Strafverfahrens. Die Verwendung des Begriffs "Strafrechts-Mediation" in dieser Untersuchung als Oberbegriff für TOA und "médiation pénale" geschieht übrigens nicht ohne Absicht, sondern das Oxymoron ("Strafrecht + Mediation") drückt das aus, was Wyvekens (1997: 76) als "logique hétérogène" bezeichnet hat: das Aufeinandertreffen von zwei Verfahrensweisen, die eine formell-bürokratisch, die andere informell-pädagogisch.

Die Auslagerung des Verfahrens, das informelle Elemente ins Strafrecht einbringt, bringt für die Justiz das Problem der Wahrung der Kontrolle mit sich. Je informeller ein Verfahren ist, desto mehr fremde Verfahrenselemente schleichen sich ein, desto weniger ist es zu kontrollieren. Einerseits ist Kontrolle nötig, um eine Einschränkung von Verfahrensrechten (z.B. Unschuldsvermutung) zu verhindern. Die Justiz verfügt auch über die nötigen Mittel, um Macht bzw. Kontrolle auszuüben, beispielsweise kann sie die Mediationseinrichtungen durch selektive Fallzuweisung und Finanzierung in Abhängigkeit halten. Andererseits bringt Kontrolle das Problem mit sich, dass sich die mediative Verfahrenslogik nicht oder nur schwer entfalten kann. Mediation kann nur funktionieren, wenn sie ihre spezifischen Funktionsmechanismen anwenden kann - oder sie verkümmert zum bürokratischen Anhängsel.

So stellt sich die Frage, wieviel Formalität und Machtkontrolle - oder mit den Worten Spittlers (1980): wieviel "Schatten des Leviathan" - sein muss, um rechtsstaatliche Verfahrensgarantien gewährleisten zu können, und wieviel die Mediation verträgt, ohne ihren spezifischen Charakter zu verlieren. Wie kann ein informelles, nach sozialpädagogischen Gesichtspunkten operierendes Verfahren unter den Bedingungen eines förmlichen Strafverfahrens durchgeführt werden? Der Diskussionsstand in der rechtssoziologischen und rechtsphilosophischen Literatur beider Länder über die Möglichkeiten und Probleme der Integration des Verfahrens in die vorhandene Institutionenordnung wird referiert (vgl. Coppens 1991; de Munck 1995; Faget 1997, von Trotha 1982). Die von Jung $(1998,1999)$ aufgeworfene Frage nach einem Integrations-, Koexistenz- oder Konkurrenzmodell wird diskutiert.

\section{Theoretischer Teil}

Der theoretische Teil der Arbeit gliedert sich in ein deskriptives und ein rechtssoziologische Kapitel. Das deskriptive Kapitel behandelt die Institutionalisierungsgeschichte, rechtliche und professionelle Rahmenbedingungen sowie die Durchführungspraxis des Täter-Opfer-Ausgleichs und der "médiation pénale" und mündet in eine Beschreibung der Gemeinsamkeiten und Unterschiede.

Als gemeinsame Elemente von Täter-Opfer-Ausgleich und "médiation pénale" werden fünf Verfahrensprinzipien herausgearbeitet: Konfliktbearbeitung, Prozessorientierung, Informalität, Parteiautonomie und Neutralität. Aus rechtssoziologischer Perspektive werden diese Verfahrensprinzipien beschrieben und Hypothesen darüber entwickelt, inwiefern diese Verfahrenslogik sich unter den Bedingungen eines Strafverfahrens entfalten kann. Die Hypothesen kreisen um folgende Problematiken:

- Mediative Rahmung als Konfliktbearbeitung versus justitielle Rahmung als Strafverfahren

- Prozessorientierung der Mediation versus Ergebnisorientierung des Strafverfahrens

- Verfahrensprinzip der Informalität versus justitieller Kontrollzwang

- Das Prinzip der Parteiautonomie: Mitwirkungschance oder Mitwirkungszwang? Thesen zur Strafrechts-Mediation als Entlastungs- bzw. Belastungssituation

- Neutralität versus Gesprächsführungsanspruch: ein paradoxes Rollenprofil

Die Verfahrensprinzipien werden daraufhin untersucht, für wie wahrscheinlich ihre Realisierung in der Praxis gehalten werden kann. Die aus rechtssoziologischer Sicht erfolgenden Überlegungen führen zu einem skeptischen Urteil über ihre praktische Umsetzbarkeit. Zusammenfassen lässt sich dies zur These, dass die mediative Verfahrenslogik unter den Bedingungen eines Strafverfahrens schwerlich reali- 
siert werden kann. Es wird davon ausgegangen, dass die französische und die deutsche StrafrechtsMediation dieses Problem teilen.

\section{Konzeption des empirischen Teils}

Ausgehend von diesen theoretischen Überlegungen wird gefragt, was empirisch passiert, wenn ein informelles, nach sozialpädagogischen Gesichtspunkten operierendes Verfahren unter den Bedingungen eines förmlichen Strafverfahrens durchgeführt wird. Es wird der Frage nachgegangen, ob die mediative Verfahrenslogik entfaltet werden kann oder den Verfahrenszwängen des formellen Strafverfahrens erliegt und wovon das empirisch abhängt. Das Erkenntnisinteresse der Arbeit liegt in der Angabe von Möglichkeiten und Grenzen der Mediierbarkeit von Strafrechts-Fällen am Beispiel von zwei Ländern, Deutschland und Frankreichs. Es soll abgeschätzt werden, ob Mediation ein Potential für das Strafrecht hat bzw. was das Verfahren überhaupt leisten kann.

Die empirische Konzeption unterscheidet zwei Ebenen: erstens die Analyse des Mediationsgeschehens anhand ausgewählter deutscher und französischer Einrichtungen mittels einer Interaktions- und Kontextanalyse (a), zweitens eine Zusammenführung der gewonnenen Ergebnisse (b).

\section{a. Erste empirische Ebene: Interaktions- und Kontextanalyse}

Die methodische Konzeption wird auf die Fragestellung zugeschnitten, ob die mediative Verfahrenslogik entfaltet werden kann. Um diese Fragestellung beantworten zu können, muss untersucht werden, was während einer Strafrechts-Mediation passiert, d.h. wie der Kommunikations-prozess verläuft. Methodisch werden damit Interaktionsanalysen nahe gelegt, die mittels tontechnischer Dokumentation von Mediationsgesprächen durchgeführt werden. Die rechtssoziologische Fragestellung wird dazu in eine interaktionsanalystische übersetzt:

a) Wie handelt der Mediator empirisch? Wie rahmt er die Situation?

b) Wie gehen die Medianten mit der angebotenen Rahmung um? Wie reagieren sie auf die Situation?

In der vorliegenden Arbeit wird die Auffassung vertreten, dass zur Rekonstruktion von Sinnadäquanzen aus Gesprächsdaten Einbettungsbezüge wichtig sind. Hintergrundinformationen stellen ein Kontrollmoment gegenüber intuitiver Interpretation, mit dem man sich vor subjektiven Fehlinterpretationen schützen kann. Beispielsweise kann das Sprechhandeln eines Mediators in einem Mediationsgespräch erst dann als situationsadäquat oder dysfunktional beurteilt werden, wenn bekannt ist, welches Interesse er an der Fallbearbeitung hat. Verfahrensziele, institutionelle Einbindung und damit verbundene finanzielle und statusgebundene Abhängigkeiten sowie das professionelle Selbstverständnis sind daher nötige Hintergrundinformationen für eine Kontextanalyse. Daher wurden ergänzend zu den Gesprächsdaten folgende weitere Daten erhoben: Experten-Interviews mit den Mediatoren und Feldnotizen vom Geschehen im Mediationsbüro. Diese Informationen werden abgerundet durch die Fallakten, Informationsbroschüren, Tätigkeitsberichte und Statistiken.

Es werden also an ausgewählten Einrichtungen in Deutschland und Frankreich verschiedene Datenarten erhoben: "inszenierte" Daten (Interviews), "authentische" Daten (Mediationsmitschnitte), "beobachtete" Daten (Feldnotizen) und "objektive" Daten (Akten, Statistiken, Tätigkeitsberichte). Die Verschiedenartigkeit der Daten erfordert eine Methode, welche diese Datenarten integrieren kann. Als übergeordneter methodischer Bezugsrahmen wird daher die Grounded Theory gewählt, genauer die strukturell-interaktionale Perspektive von Anselm Strauss und Juliet Corbin (Strauss/Corbin 1996).

Da mit den Analysetechniken der Grounded Theory die für (Mediations-)Gespräche konstitutive Sequentialität des Gesprochenen nicht erfasst werden kann, wurde für den aus Gesprächsmitschnitten bestehenden Teil-Korpus eine eigene Auswertungsstrategie entwickelt, bei der die Grounded Theory um die Interpretationstechnik der Gesprächsanalyse nach Deppermann (2001) ergänzt wird. 
Die Auswertung erfolgt EDV-gestützt mit der eigens für Grounded Theory-basierte Untersuchungen entwickelte Software Atlas/ti.

\section{b. Zweite empirische Ebene: Vergleich auf Länderebene}

Ein Ländervergleich ist zur Beantwortung der oben aufgeworfenen Fragestellung eigentlich nicht erforderlich, der empirischen Umsetzung würde auch nur ein Land genüge tun. Es handelt sich daher auf der ersten empirischen Ebene nicht um eine komparative Arbeit, die den Ländervergleich als Methode einsetzt. Es geht nicht darum, in welchem Land Strafrechts-Mediation "besser" (schneller, erfolgreicher, mit höheren Fallzahlen o.ä.) realisiert wird. Sondern die beiden Länder werden als empirische Beispiele für das gleiche Problem verstanden: die Bearbeitung eines aus der Justiz ausgekoppelten oder dennoch von ihr abhängigen Verfahrens. Die zweite Ebene der methodischen Konzeption richtet sich auf die Frage, wie das Problem diesseits und jenseits des Rheins bewältigt wird, ob die im einen Land festgestellten Probleme auch im anderen auftreten oder ob länderspezifische Unterschiede zutage kommen, die darauf schließen lassen, dass die juristischen und institutionellen Rahmenbedingungen eines Landes die Entfaltung der mediativen Verfahrenslogik eher erlauben als diejenigen des Nachbarlandes. Daher werden die auf der ersten empirischen Ebene gewonnenen Ergebnisse, die für jedes Land separat ausgewertet werden, auf einer zweiten Ebene zusammengeführt und verglichen.

Da in Frankreich Strafrechts-Mediation überwiegend im Erwachsenen-Bereich durchgeführt wird - bei Jugendlichen wird eher das Sanktionsmittel des "rappel à la loi" oder eine reine WiedergutmachungsMaßnahme ("réparation pénale") angewendet - beschränkt sich diese Untersuchung aus Gründen der Vergleichbarkeit auf Strafrechts-Mediation im Erwachsenen-Bereich.

Das Forschungprojekt ist als Dissertationsvorhaben in das "Laboratoire Européen Associé" (LEA) integriert. LEA ist eine von der Max-Planck-Gesellschaft und dem Centre National de la Recherche Scientifique (CNRS) gegründetes deutsch-französisches Forschungsprogramm, das Fragen der Kriminalität und Sicherheits- bzw. Präventionspolitik behandelt.

- $\quad$ Arbeitsbericht bis 2003:

Von Juni bis Dezember 2001 wurden die Fragestellung und der heuristische Rahmen der Arbeit entwickelt. Dazu wurde eine Recherche der französischen und deutschen Literatur auf dem Gebiet der Rechtssoziologie, -philosophie und -theorie, der Interaktionsforschung sowie in der empirischen Kriminologie (Forschungsstand zur Strafrechts-Mediation) durchgeführt. Zeitgleich wurden Fragen des Feldzugangs geklärt und Einrichtungen im süddeutschen und nordfranzösischen Raum ausgewählt. Als Schlüsselkriterium für die Durchführbarkeit der Untersuchung hat sich der persönliche Zugang und die Vertrauensgewinnung der Mediatoren erwiesen.

Das Jahr 2002 war der Feldphase gewidmet. Nichtteilnehmende, offene Feldbeobachtung wurde in vier Mediations-Einrichtungen durchgeführt. Das Ergebnis ist ein für die Verhältnisse der qualitativen Sozialforschung umfangreicher deutsch- und französischsprachiger Korpus an Mediationsgesprächen und Experteninterviews, der durch die für die Kontextanalyse benötigten Daten ergänzt wird. Die Erhebungsphase wurde im Januar 2003 abgeschlossen. 


\begin{tabular}{|c|c|c|c|c|}
\hline & & $\begin{array}{l}\text { Mediations- } \\
\text { fälle }\end{array}$ & $\begin{array}{l}\text { Mediations- } \\
\text { fälle beste- } \\
\text { hend aus x } \\
\text { Gesprächen }\end{array}$ & $\begin{array}{l}\text { Interviews mit } \\
\text { Mediatoren } \\
\text { /innen }\end{array}$ \\
\hline \multirow{2}{*}{$\begin{array}{l}\text { deutscher } \\
\text { Korpus }\end{array}$} & $\begin{array}{l}\text { justiznahe TOA- } \\
\text { Einrichtung (Gerichts- } \\
\text { hilfe) }\end{array}$ & 1 & 2 & 3 \\
\hline & $\begin{array}{l}\text { justizferne TOA- } \\
\text { Einrichtung }\end{array}$ & 11 & 21 & 1 \\
\hline \multirow{2}{*}{$\begin{array}{l}\text { französischer } \\
\text { Korpus }\end{array}$} & $\begin{array}{l}\text { justiznahe Institution } \\
\text { (Maison de justice) }\end{array}$ & 5 & 7 & 1 \\
\hline & $\begin{array}{l}\text { justizferne Institution } \\
\text { (association) }\end{array}$ & 6 & 13 & 5 \\
\hline \multicolumn{2}{|c|}{ Fallmaterial insgesamt } & 23 & 43 & 10 \\
\hline
\end{tabular}

Aus den 43 Gesprächen, die zu 23 Mediationfällen gehören, wurde eine Selektion für die Auswertung getroffen. Die Transkriptionen sind weitgehend abgeschlossen, so dass der Korpus nahezu vollständig zur Auswertung bereit steht.

Die in der deutschen, justizfernen TOA-Einrichtung erhobenen Fälle wurden bislang schwerpunktmäßig ausgewertet, davon wurden vier Fälle in die Detailanalyse einbezogen. $\mathrm{Zu}$ allen vier Fällen wurden Kodierungen (offen und axial) vorgenommen und bereits teilweise für die Endfassung der Dissertation verschriftet. Anhand der Interviews mit französischen Mediatoren wurde eine Analyse des professionellen Selbstverständnisses und der Probleme in der Durchführungspraxis verschriftlicht.

Im Sommer/Herbst 2003 wurde der theoretische Teil der Arbeit (Deskription des Untersuchungsgegenstandes und heuristischer Rahmen) konzipiert und verschriftet.

- $\quad$ Arbeitsplanung 2004:

Nach redaktionellen Tätigkeiten am theoretischen Teil wird die Auswertung wieder aufgenommen. Es ist geplant, die Arbeit bis zum Frühsommer 2004 abzuschließen.

- Literatur:

COPPENS, PH.: Médiation et philosophie du droit. Archives de politique criminelle, 13, 13-23 (1991).

DE MuNCK, J.: Le pluralisme des modèles de justice. In: La justice des mineurs. Évolution d'un modèle. Hrsg. A.Garapon, D. Salas. L.G.D.J., Paris 1995, 91-138.

DEPPERMANN, A.: Gespräche analysieren. Leske + Budrich (Qualitative Sozialforschung, Band 3), Opladen 2001.

FAGET, J.: La médiation. Essai de politique pénale. Erès, Ramonville Saint-Agne 1997.

JUNG, H.: Mediation: Paradigmawechsel in der Konfliktregelung? In: Festschrift für Hans Joachim Schneider zum 70. Geburtstag am 14. November 1998. Kriminologie an der Schwelle zum 21. Jahrhundert.. Hrsg. H.-D. Schwind; E. Kube; H.-H. Kühne. de Gruyter, Berlin/New York 1998, 913-926. JUNG, H.: Mediation - ein Ansatz zu einer "Entrechtlichung sozialer Beziehungen"? In: Rechtsbegründung - Rechtsbegründungen. Günter Ellscheid zum 65. Geburtstag. Hrsg. H. Jung., U. Neumann. Nomos, Baden-Baden 1999, 68-75. 
LuDWIG-MAYERHOFER, W.: Das Strafrecht und seine administrative Rationalisierung. Kritik der informalen Justiz. Campus, Frankfurt/New York 1998.

SPITTLER, G.: Streitregelung im Schatten des Leviathan. Zeitschrift für Rechtssoziologie, 1, 1, 4-32 (1980).

StRaUSS, A., CORBIN, J.: Grounded Theory: Grundlagen Qualitativer Sozialforschung. Weinheim 1996.

VON TROTHA, T.: Recht und Kriminalität. Auf der Suche nach Bausteinen für eine rechtssoziologische Theorie des abweichenden Verhaltens und der sozialen Kontrolle. J.C.B. Mohr (Paul Siebeck), Tübingen 1982.

WYVEKENS, A.: Les maisons de justice: sous la médiation, quelle troisième voie? In: La médiation pénale. Entre répression et réparation . Hrsg. R. Cario. Paris, Montréal 1997, 61-82.

\subsubsection{Rechtliche und tatsächliche Kriterien der Strafzumessung im deutsch-französischen Vergleich}

- $\quad$ Bearbeiterin: Susanne Müller (Juristin, Richterin)

- $\quad$ Laufzeit der Untersuchung: 1999 bis 2002

- $\quad$ Projektstatus: abgeschlossen

- $\quad$ Projektbeschreibung:

(vgl. dazu bereits die Tätigkeitsberichte 1998/1999, S. 98, 2000/01, S. 121)

Mit dem vorliegenden Projekt wurden die Unterschiede zwischen dem Recht und der Praxis der Strafzumessung in Deutschland und Frankreich erstmals umfassend untersucht. Während die Strafzumessung in Deutschland schon seit längerem einem Prozess der zunehmenden Verrechtlichung unterliegt dementsprechend groß ist inzwischen die Bedeutung der richterlichen Strafzumessung als Thema der Strafrechtsdogmatik und der kriminologischen Forschung - wird in Frankreich traditionell der Ansatz der "individualisation de la peine" verfolgt. Dabei wird nahezu ausschließlich die Frage diskutiert, wie eine möglichst große Flexibilität des Gesetzes erreicht werden kann, um dem Gericht ein weitmöglichstes Reagieren auf den Einzelfall zu gestatten. Dieser Tradition folgend, besteht in Frankreich eine Begründungspflicht für die richterliche Strafzumessungsentscheidung nicht. Vielmehr gilt in ständiger Rechtsprechung der Cour de cassation, dass die Strafzumessung innerhalb der Grenzen des Gesetzes auf einer eigenständigen Befugnis des Richters beruht, über die er keinerlei Rechenschaft schuldet.

Vor diesem Hintergrund erschien ein Vergleich der die Strafzumessung leitenden Vorstellungen und der Praxis der Strafzumessung in Frankreich und Deutschland besonders interessant, geht es doch auch um einen hierin zum Ausdruck kommenden Unterschied der Rechtskulturen, der gerade angesichts der Bedeutung der beiden zu untersuchenden Staaten für die Europäischen Einheit als beispielhaft für die Schwierigkeiten einer europäischen Rechtsharmonisierung gelten darf.

Im Rahmen dieses Forschungsprojektes wurde zunächst ein vorwiegend rechtsdogmatisch ausgerichteter Vergleich des französischen Sanktionensystems mit dem einem völlig anderen Verständnis von Strafzumessung folgenden deutschen System erarbeitet. Parallel zu dieser theoretischen Arbeit wurde eine empirische Strafzumessungsstudie durchgeführt, in deren Rahmen ein in deutscher und französischer Sprache verfasster, inhaltlich aber identischer Fragebogen an Richter im badisch-elsässischen Grenzgebiet verteilt wurde. In dem Fragebogen wurden Strafvorschläge für fiktive Fälle aus dem Bereich der kleinen und mittleren Kriminalität erbeten sowie Fragen zu verschiedenen Themenbereichen gestellt, die für die Praxis der Strafzumessung von Bedeutung sein können. 
- $\quad$ Arbeitsbericht bis 2002

Die Arbeit wurde im Sommer 2002 abgeschlossen. Der theoretische Teil wurde im Wintersemester 2002/2003 als Dissertation von der Rechtswissenschaftlichen Fakultät der Albert-LudwigsUniverstität in Freiburg angenommen und im Sommer 2003 unter dem Titel "Sanktionen und Strafauswahl in Frankreich" als Band 9 der Reihe 'Interdisziplinäre Untersuchungen aus Strafrecht und Kriminologie' veröffentlicht. Die Publikation des empirischen Teils wird als zweite Monographie zu dem Projekt pünktlich zur Sitzung von Fachbeirat und Kuratorium im März 2004 erschienen sein (Band 112 der Reihe 'Kriminologischen Forschungsberichte aus dem Max-Planck-Institut').

- $\quad$ Kurzzusammenfassung der wesentlichen Ergebnisse

Die durchgeführte Analyse der französischen Rechtslage erlaubt die Schlussfolgerung, dass die rechtsdogmatische und rechtspolitische Diskussion der richterlichen Strafzumessungsfreiheit in unserem Nachbarland aus historischen Gründen von der Gleichsetzung zwischen Strafmilderung und richterlicher Ermessensfreiheit einerseits, Beschränkung des richterlichen Auswahlermessens und höherer Repressivität des Strafsystems andererseits geprägt ist. Diese Polarisierung wird erst in jüngster Zeit von Teilen der Strafrechtsliteratur in Frage gestellt und aus rechtsstaatlichen Gründen eine Beschränkung des Ermessensspielraums bzw. zumindest eine Begründungspflicht gefordert.

Die Auswertung der Fragebögen warf erhebliche methodische Probleme auf, die im Rahmen des vorliegenden Pilotprojektes nur teilweise gelöst werden konnten. Insbesondere wurde der Vergleich der für die fiktiven Fälle vorgeschlagenen Strafen durch die uneindeutige Schwereeinstufung der französischen Alternativsanktionen und die Unterschiedlichkeit der Strafarten in den beiden untersuchten Ländern erschwert. Die Auswertung ergab, dass die Richterinnen und Richter in den beiden Stichprobengruppen überwiegend ähnliche Strafzwecke und Strafzumessungskriterien für wichtig bzw. unwichtig hielten, ein Ergebnis, das angesichts der grundlegenden Unterschieden der im jeweiligen Land bestehenden Rechtslage im Hinblick auf die Strafzumessung so nicht zu erwarten war. Bei den vorgeschlagenen Strafen für die fiktiven Fälle spiegelten sich auf den ersten Blick die bereits aus den amtlichen Statistiken bekannten erheblichen Unterschiede bezüglich der Art der Sanktionen wieder: In Frankreich herrscht die Verhängung von Freiheitsstrafen mit und ohne Bewährung vor, während in Deutschland weit überwiegend Geldstrafen verhängt werden. Die Resultate weisen aber auch darauf hin, dass innerhalb des jeweils national üblichen Sanktionsspektrums von den Richtern auf die gleichen Strafzumessungsstimuli überwiegend gleich reagiert wird. Ausnahmen bestehen überwiegend im Hinblick auf die Opferentschädigung, die in Frankreich eine größere Rolle zu spielen scheint als in Deutschland, sowie auf das Geständnis des Angeklagten, dem von den deutschen Teilnehmern eine wesentlich größere Bedeutung zugemessen wurde als von den französischen.

- $\quad$ Ausgewählte Literatur:

MÜLLER, S. (2003): Sanktionen und Strafauswahl in Frankreich. Eine historische, rechtspolitische und dogmatische Analyse der Ermessensfreiheit des französischen Strafgerichts. edition iuscrim, Reihe "Interdisziplinäre Untersuchungen aus Strafrecht und Kriminologie", Bd. 9, Freiburg i. Br.

OTTENHOF, R. (2001) (Hrsg.): L'individualisation de la peine - de Saleilles à aujourd'hui. Ramonville St.Agne.

LEBLOIS-HAPPE, J. (1998): Quelles réponses à la petite délinquance? Diss. Strasbourg (Buchveröffentlichung in Vorbereitung).

PRADEL, J. (1996) (Hrsg.): Prison: Sortir avant terme. Paris.

Aubusson De CAVARLy, B. U. HuRE, M.-S. (1995): Arrestations, classements, déferrements, jugements - suivi d'une cohorte d'affaires pénales de la police à la justice, Paris.

ZIESCHANG, F. (1992): Das Sanktionensystem in der Reform des französischen Strafrechts im Vergleich mit dem deutschen Strafrecht. Berlin. 
Aubusson De CAVArly, B. U. Bernard, M., et al. (1986): Les filières pénales, étude quantitative des cheminements judiciaires, Paris.

Aubusson De CAVARLY, B. U. Godefroy, TH. (1981): Condamnations et condamnés: Qui condamne-t-on? A quoi? Pourquoi? Paris.

- $\quad$ Ausgewählte Vorträge:

"Le choix de la sanction pénale en matière correctionnelle : étude comparative France-Allemagne". (Vortragsveranstaltung der Association Française de Criminologie und des Laboratoire "cultures et sociétés en Europe", NRS, Groupe de Recherches sociologie criminelle en Europe, Universität Marc Bloch, Département de Formation continue), Straßburg, 5.3.2003.

"Le choix de la santion pénale par le juge, essai en droit comparé franco-allemand", Vortrag im Rahmen des Forschungsseminars "Mesures pénales, privation de liberté", organisiert von P. V. Tournier (Centre de recherches sociologiques sur le droit et les Institutions pénales, CESDIP, CNRS) und A. Chauvenet (Centre d'études des mouvements sociaux, EHESS/MSH), Paris, 30.11.2001.

"Le choix de la sanction - principes et pratiques de la détermination de la peine en Allemagne". Fortbildungsveranstaltung der École Nationale de la Magistrature, Bordeaux und Paris, organisiert von B. Aubusson de Cavarlay, CESDIP, Paris, 22.5.2000 und 5.3.2001.

\subsubsection{Abschiebungshaft in Deutschland und in Frankreich}

- $\quad$ Bearbeiter: Nimet Güller (Juristin), René Lévy (Soziologe, CESDIP)

- $\quad$ Laufzeit der Untersuchung: 1999 bis 2005

- $\quad$ Projektstatus: in Bearbeitung

- $\quad$ Projektbeschreibung:

(vgl. dazu bereits die Tätigkeitsberichte 1998/1999, S. 140, 2000/01, S. 174)

In den letzten Jahren hat die Zahl der sich in Abschiebungshaft befindenden Personen in Europa stark zugenommen, insbesondere nach der weitgehenden Reduzierung legaler (Arbeits-)Immigration, der Zunahme illegaler und prekärer Formen der Immigration sowie der Entwicklung dessen, was auch als "Festung Europa" bezeichnet wird. Da sich aber die politische oder wirtschaftliche Situation in den Emigrationsländern nicht geändert hat, sondern sich im Gegenteil noch weiter verschlechtert, nimmt die illegale Einwanderung samt damit zusammenhängender Probleme der Schleusung, des Menschenhandels und der Viktimisierung sowie Kriminalisierung von Migranten (im Verlaufe der Migration und vor allem auch im Zusammenhang mit der Grenzüberschreitung) zu. Die Antwort auf diese Entwicklungen wird derzeit in Gestalt weiterer Intensivierung der Außen- und Binnenkontrollen gegeben. Hierzu gehören der Einsatz präziserer Identifikationstechnologien ebenso wie die Verstärkung der technischen und personellen Ausstattung der Grenzkontrolle. Der 11. September 2001 hat dazu beigetragen, die Kontrolle von Immigranten unter verschiedenen Gesichtspunkten zu intensivieren. In dem neuen deutschen Gesetzesentwurf zur Steuerung und Begrenzung der Zuwanderung und zu Regelung des Aufenthalts und der Integration von Unionsbürgern und Ausländern (Zuwanderungsgesetz) sind unter anderem auch repressive Maßnahmen enthalten; die Beendigung des Aufenthalts wird besonders geregelt, insbesondere die Durchsetzung der Ausreisepflicht. Auch wird im Gegensatz zu der jetzigen Gesetzeslage unterschieden zwischen der Abschiebung und der Zurückschiebung, wobei letztere den Immigranten noch weniger gegen Eingriffe in seine Rechte schützt. In den vorgesehenen Änderungen des deutschen Ausländergesetzes und in dem neu geschaffenen Zuwanderungsgesetz werden die Maßnahmen gegen illegalen Aufenthalt, illegalen Grenzübertritt sowie illegale Beförderungsunternehmen intensiviert. In diesem Zusammenhang kann auch beobachtet werden, dass internationale Überein- 
kommen zur Wahrung von bestimmten Grundrechten (wie die Europäische Menschenrechtskonvention, die Genfer Flüchtlingskonvention, das Dubliner Übereinkommen, die UN Kinderrechtskonvention) auf nationaler Ebene zunehmend restriktiv ausgelegt werden.

In Deutschland gibt es Bemühungen zur Änderung der Ausländer- und Asylgesetzgebung und eine Entschließung zur "Verbesserung der Bekämpfung der Schleuserkriminalität" (BT-Drucks 471/00), welche Maßnahmen zur Bekämpfung der Schleuserkriminalität vorsieht und die Notwendigkeit einheitlicher ausländer- und asylrechtlicher Standards in der Europäischen Union betont, wie sie auch von der Europäischen Kommission immer wieder verlangt wird (z.B. Mitteilung Kom 2000, 755 vom November 2000, über die gemeinsame Asylpolitik in der EU). Freilich haben die Länder der Europäischen Union zum Teil sehr unterschiedliche Ausländer- und Asylgesetze, die sie je nach dem wiederum für die illegale Einreise oder den illegalen Aufenthalt attraktiver oder unattraktiver machen. Um zu verhindern, dass bestimmte Mitgliedsstaaten aufgrund unterschiedlicher Immigrationsbestimmungen eine größere Attraktivität auf Drittstaatsangehörige ausüben, soll nach einem Übereinkommen der EUStaaten auf Grundlage des Art. K EUV auch eine EU-weite Rahmenregelung geschaffen werden, nach der sich die einzelnen Mitgliedsstaaten bei der Zulassung von Drittstaatsangehörigen in die Länder der Europäischen Union richten sollen, um einen Beitrag zur Integration sich legal aufhaltender Drittstaatsangehöriger zu schaffen, wird in diesem Übereinkommen auch die Rechtsstellung der sich dauerhaft aufhaltenden Drittstaatsangehörigen und ihr Recht auf Familienzusammenführung in den Entwurf eingebunden. Bisher existieren auf diesem Sektor nur unverbindliche Richtlinien des Rates. Durch ein Übereinkommen kann dagegen eine rechtsverbindliche Regelung geschaffen werden, die durch die jeweiligen nationalen Ratifizierungsverfahren sowie die Anhörung des Europäischen Parlamentes auch die erforderliche demokratische Transparenz aufweist.

Eine verbindliche europaweite Regelung, wie sie von den Tampere-Resultaten gefordert wurde, gibt es aber noch nicht, so dass die Länder weiterhin selbständig repressive Maßnahmen beschließen und dabei insbesondere versuchen, die EU-Außengrenzen stärker zu kontrollieren. Jedoch hat diese Strategie die Zunahme der illegalen Migration in den europäischen Ländern nicht beenden können. Auch stieg die Zahl der sich in Abschiebungshaft befindenden Personen in Deutschland und in Frankreich in den neunziger Jahren sehr stark an, wie die Grafiken zeigen. Mit einem weiteren Anstieg wird zu rechnen sein. Insoweit kommt der Problematik der illegalen Einreise und der Abschiebungshaft erhebliche Bedeutung zu, die es rechtfertigt, die hiermit zusammenhängenden Fragestellungen in einem größeren immigrationspolitischen und juristisch-soziologischen Zusammenhang sowie in vergleichender Perspektive zu untersuchen. 


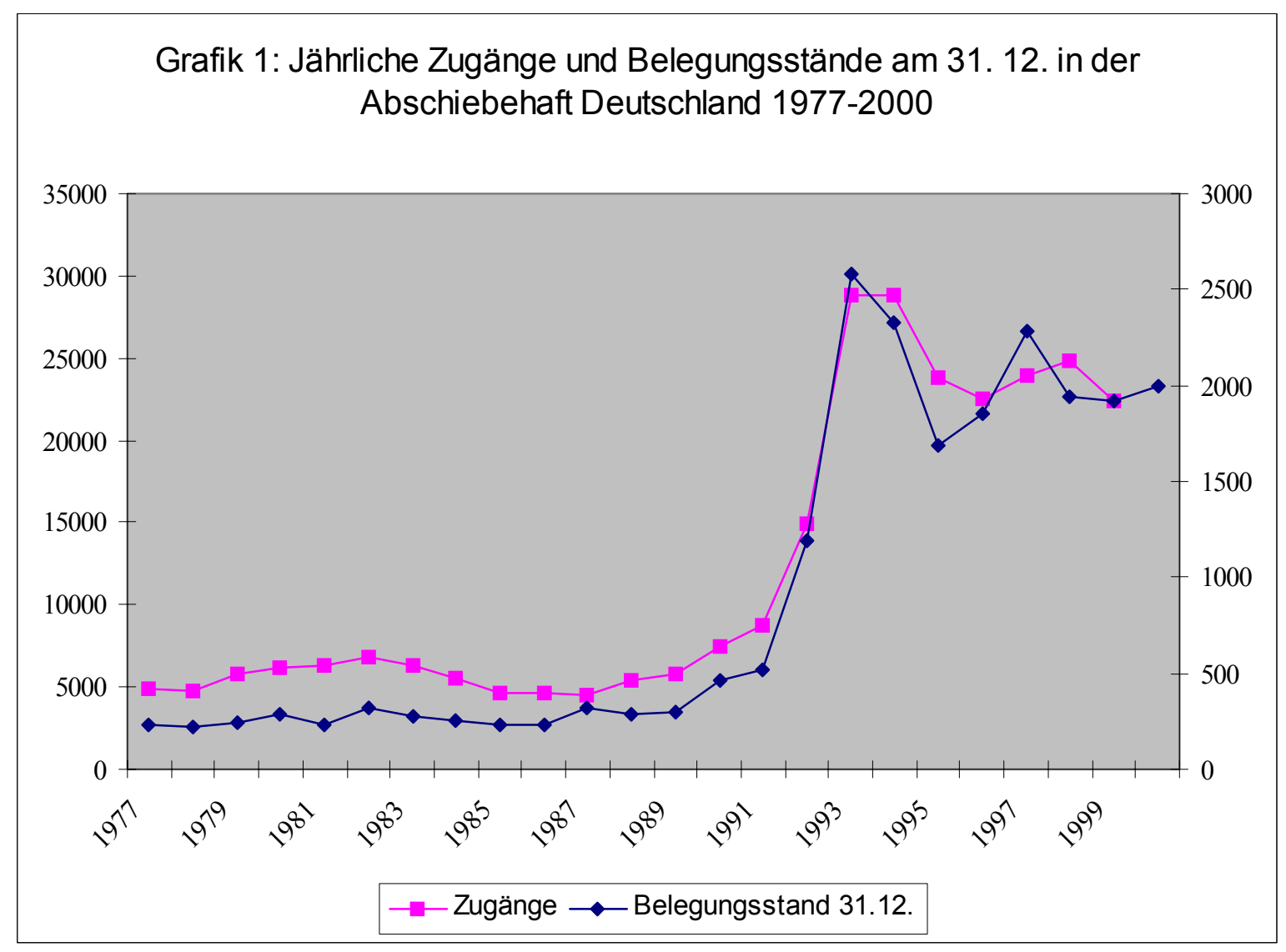

Zur Vorbereitung der Untersuchung fand nach vorherigen Kontakten und Diskussionen über das Thema im Mai 1999 ein erstes Treffen in Paris mit den französischen Forschungspartnern des CESDIP statt. Es wurden insbesondere lohnende Untersuchungsperspektiven und einzelne Fragestellungen erörtert, die zunächst in einem internationalen Workshop in Februar 2000 in Paris diskutiert werden sollten. Dieser fand vom 10. bis zum 12. Februar 2000 in Paris im Maison de Droit de l'Homme statt und hat Wissenschaftler und Praktiker aus Deutschland, Frankreich und aus anderen europäischen Ländern zusammengeführt, die sowohl über die Gesetzeslage als auch über die Praxis der Abschiebungshaft referiert sowie Probleme und Grundfragen der Abschiebungshaft insbesondere auch im Hinblick auf die nationale und supranationale Gesetzgebung diskutiert haben.

- $\quad$ Arbeitsbericht 2002-2003

Die Ergebnisse des Workshops und dessen Aufarbeitung waren Grundlage für die Entwicklung der Konzeption für eine empirische Untersuchung. Da sich die Abschiebehaft in den verschiedenen Ländern sehr unterschiedlich gestaltet, wurde beschlossen, diese empirische Untersuchung zunächst nur in Frankreich und in Deutschland durchzuführen. Daher wurde in beiden Ländern Literatur zur Abschiebehaft und zum Forschungsstand gesammelt. Zur Durchsicht der Forschung in Frankreich war ein Aufenthalt in Paris bei dem französischen Partner CESDIP erforderlich (Juli/August 2002). Bei diesem Aufenthalt wurden auch Gespräche mit französischen NGOs, mit ehemaligen Abschiebehäftlingen und mit Rechtsanwälten geführt. In den nächsten Monaten wurden wesentliche Vorarbeiten für die empirische Untersuchung geleistet. Neben der Aufarbeitung der Literatur und des Forschungsstandes in Deutschland, Frankreich und auf europarechtlicher Ebene wurden Feldbeobachtungen von Flücht- 
lingslagern und möglichen Interviewpartnern durchgeführt. Insbesondere wurde zu verschieden Organisationen Kontakt aufgenommen, die mit Flüchtlingen und Abschiebehäftlingen arbeiten. Auch wurden diesbezügliche alle politischen Entwicklungen verfolgt wie z.B die Diskussion zum Zuwanderungsgesetzes in Deutschland oder die Diskussion und das Inkrafttreten des "Loi Sarkozy" ( Loi relative à la maîtrise de l'immigration, au séjour des étrangers en France et à la nationalité). Zudem wurde $\mathrm{zu}$ diesem Thema an diversen Tagungen teilgenommen und mehrere Vorträge gehalten.

Des Weiteren wurden im Juni 2003 bei einem Treffen aller am LEA teilnehmenden Institutionen erste Ergebnisse der bis dahin erfolgten rechtsvergleichenden Untersuchungen und eine Konzeption für die empirische Untersuchung vorgestellt. Seitdem wurde mit NGOs im Dreiländereck Kontakt aufgenommen, die Arbeit von verschiedenen Organisationen die mit Flüchtlingen arbeiten analysiert sowie Vorgespräche für spätere Interviews geführt.

Seitdem konnte das Gesamtkonzept für die empirische Untersuchung erstellt werden. Dabei geht es neben Fragen der Immigrationskontrolle, der Migrationsmotive und Schleusungsvorgängen auch um die Frage nach der Abwägung zwischen dem Nutzen der Abschiebehaft und den eventuellen Eingriffen in die fundamentalen Rechte der Flüchtlinge. Dazu wird untersucht, wodurch die Abschiebehaft ausgelöst, in welchen Verfahren die Abschiebehaft angeordnet, wie die Abschiebehaft vollzogen wird und was sich tatsächlich an die Abschiebehaft anschließt. Die Durchführung der empirischen Untersuchung wird auf Fragebögen, Interviews sowie Aktenuntersuchungen beruhen.

- $\quad$ Arbeitsplanung 2004-2005

Die erste Hälfte des Jahres 2004 dient der Datenerhebung. Zunächst sollen die Erhebungsinstrumente für die schriftliche Befragung fertig gestellt werden. Dann sollen in den nächsten Monaten Fragebögen an die Experten gesendet und die Akten angefordert werden. Parallel bis zum Rücklauf der Fragebögen soll die Verschriftlichung des theoretischen Teils der Arbeit erfolgen. Danach beginnt die Interviewphase.

In der zweiten Hälfte des Jahres sind die Transkription, die Datenaufbereitung und die Datenauswertung geplant. Anfang 2005 sollen alle Ergebnisse dieser empirischen Untersuchung schriftlich dargestellt, die Situation in beiden Ländern verglichen und das Projekt Abschiebehaft in Frankreich und Deutschland beendet werden.

Nach Beendigung dieser Arbeiten soll innerhalb des LEA das Projekt auf die Länder Holland, Spanien, Italien, England sowie die Schweiz ausgeweitet werden. 


\subsection{Schwerpunkt "Sozialer Wandel, Veränderung von Lebenslagen, Kriminalität und Kriminalitätskontrolle"}

\subsubsection{Freiburger Kohortenstudie}

\subsubsection{Kohortenstudie zur Entwicklung polizeilich registrierter Kriminalität und strafrechtlicher Sanktionierung}

- $\quad$ Bearbeiter(in): Volker Grundies (Physiker), Sven Höfer (Jurist), Carina Tetal (Soziologin/Mathematikerin)

- Zeitrahmen: seit 1985

- $\quad$ Projektstatus: Langzeitstudie

- $\quad$ Projektbeschreibung:

(vgl. bereits die Darstellungen in den Tätigkeitsberichten 1994, S. 31; 1995, S. 20; 1996, S. 34; 1996/1997, S. 90; 1998/1999, S. 154; 2000/2001, S. 198)

Die Kohortenstudie verfolgt das Ziel, Analysen zu Umfang, Struktur und Entwicklung formeller Sozialkontrolle bereitzustellen. Vor diesem Hintergrund wird derzeit folgenden zentralen Fragestellungen nachgegangen:

- Welche altersabhängigen Verläufe offiziell registrierter Kriminalität lassen sich, auch im Hinblick auf Deliktsperseveranz und -spezialisierung, feststellen?

- Inwieweit ist das Auftreten und die Entwicklung offiziell registrierter Kriminalität einem sozialen Wandel unterworfen?

- Welche Zusammenhänge bestehen zwischen justiziellen Reaktionen und erneuter polizeilicher Registrierung im Verlauf der Delinquenzentwicklung?

- Welche Zusammenhänge bestehen zwischen der offiziellen Registrierung in einem frühen Lebensabschnitt und der strafrechtlichen Auffälligkeit in späteren Lebensphasen?

Die Analyse von Entwicklungen, Prozessen oder allgemein Veränderungen stellt durch die notwendige Einbeziehung der zeitlichen Dimension besondere Anforderungen sowohl an das Datenmaterial als auch an die Untersuchungsmethoden. Man benötigt Längsschnittstudien, bei der Individuen nicht nur bzgl. verschiedener Merkmale, sondern zusätzlich auch über die Zeit hinweg beobachtet werden. Eine Möglichkeit Personen im Längsschnitt zu untersuchen sind Kohortenstudien. Eine Kohorte ist eine Gruppe von Personen, die annähernd zum gleichen Zeitpunkt einem Ereignis im Lebenslauf ausgesetzt war. Häufig werden hier Geburtskohorten, d.h. Personen eines Jahrganges, gewählt.

In der Freiburger Kohortenstudie werden Personen aus Baden-Württemberg der Jahrgänge 1970, 1973, 1975, 1978, 1985 und 1988 hinsichtlich ihrer Registrierungen in zwei amtlichen Datenbeständen untersucht: zum einen Informationen zur polizeilichen Registrierung aus der Personenauskunftsdatei Baden-Württembergs (PAD), zum andern - auf justizieller Ebene - entsprechende Einträge im Bundeszentralregister (BZR).

Das Design der Studie gewährleistet durch wiederholte Datenziehung, dass die personenbezogene Zuordnung der Daten sowohl im Längsschnitt als auch zwischen den Datenquellen möglich ist. Die Erhebungsintervalle und -modalitäten sind so gewählt, dass Ausfälle durch routinemäßige Löschungen ab der ersten Datenziehung ausgeschlossen sind.

Die im Rahmen der Studie durchzuführenden Arbeiten können drei Schwerpunkten zugeordnet werden. 


\section{Aufbereitung der Daten}

Der Datenbestand der Freiburger Kohortenstudie wird jedes Jahr um die neu angefallenen Daten ergänzt. Dies hat insbesondere zwei Vorteile: zum einen wird der bei den einzelnen Kohorten erfasste Altersbereich immer größer. So ist bei der 'ältesten' Kohorte nunmehr ein Altersbereich von 7-32 Jahren der Analyse zugänglich, womit Entwicklungen bis in den Altersbereich der Erwachsenen hineinverfolgt werden können. Zum anderen können die Entwicklungen über die Periode - auch dank der hinzugenommenen weiteren Kohorten (1985 und 1988) - zeitnah verfolgt werden (z.Zt. bis 2001). Auf der anderen Seite ist die ständige Erfassung neuer Daten, trotz möglichst weitgehender Automatisierung dieses Prozesses, von beträchtlichem Aufwand. Wesentlich sind in diesem Zusammenhang insbesondere zwei Punkte:

Zum einen die Integration der jährlich vom Bundeszentralregister und der Polizei neu übermittelten Daten in die Datenbestände. Von Bedeutung ist dabei die eindeutige personenbezogene Zuordnung nicht nur zwischen den polizeilichen und justiziellen Datenbeständen, sondern auch in der temporären Abfolge insbesondere bei Personen, deren frühere Registrierungen in den offiziellen Datensammlungen gelöscht wurden, so dass erneute Registrierungen als Erstregistrierungen fehlgedeutet werden könnten.

Zum anderen zählt zu diesem Schwerpunkt auch die Aufbereitung der in den Datensätzen enthaltenen Informationen in einer Form, die sie für weitere statistische Analysen zugänglich werden lässt. Dies betrifft vor allem Informationen in sog. Freitextfeldern, die einen einfachen Zugriff nicht gestatten. So z.B. die freitextliche Angabe des Geburtsorts, dessen Umkodierung in länderspezifische Kennungen die Identifikation der Aussiedler ermöglichte.

Die Aufbereitungsprozedur für die BZR-Daten, deren Bearbeitung seit 1998 ausgesetzt war, wurde gänzlich umstrukturiert. Dies lag nahe, da immer deutlicher wurde wie stark das bisherige Verfahren, das nur BZR-Daten von Personen berücksichtigte, die gleichfalls in Baden-Württemberg polizeilich erfasst worden waren, die Verfügbarkeit und den Nutzen dieser Daten einschränkt. Unter diesem Selektionskriterium war es beispielsweise nicht möglich, die justiziellen Erledigungen in BadenWürttemberg vollständig zu erfassen. Folglich wurden die BZR-Daten in einem ersten Schritt völlig unabhängig von den polizeilichen Registrierungen aufbereitet, obgleich dadurch nochmals alle seit 1989 gelieferten Daten bearbeitet werden mussten. Erst nach diesem Schritt, durch den die justiziellen Registrierungen unabhängig von den polizeilichen Registrierungen für Baden-Württemberg (und prinzipiell auch bundesweit) verfügbar sind, werden sie mit letzteren verknüpft. Im Rahmen dieser Arbeiten konnten ferner die Neu- und Umstrukturierung des StGBs durch das 6. Strafrechtsänderungsgesetz in einer Form berücksichtigt werden, die die Zuordnungen zu den einzelnen Deliktskategorien möglichst einheitlich und konsistent hielt.

Realisiert wurde dieses Vorhaben mit Hilfe einer Oracle Datenbank, wodurch in Zukunft einfacher unter verschiedensten Auswahlkriterien auf die Daten zugegriffen werden kann. Die polizeilichen Registrierungen, deren Bearbeitung noch mit den alten Prozeduren erfolgte, sollen ebenfalls in dieses Datenbanksystem eingegliedert werden, zumal wir erwarten durch die in einem solchen Datenbanksystem möglichen Operationen eine vollständigere Verknüpfung der beiden Datensätze (auch auf Tatebene) zu erreichen.

Nach den Arbeiten in den letzten beiden Jahren sind die beiden Datensätze (PAD \& BZR) auf dem Stand der letzten Datenlieferung vom Frühjahr 2003. Der nachfolgenden Tabelle kann die Anzahl der polizeilichen und justiziellen Registrierungen bzw. der registrierten Personen - differenziert nach den einzelnen Kohorten - entnommen werden. Für die justiziellen Registrierungen galt als Selektionskriterium, dass mindestens eine der justiziellen Erledigungen einer Person in Baden-Württemberg erfolgte. 
Tabelle: $\quad$ Anzahl der polizeilichen und justiziellen Registrierungen bzw. registrierten Personen differenziert nach den einzelnen Kohorten (Baden-Württemberg)

\begin{tabular}{|l|l|r|r|r|r|}
\hline Kohorte & \multirow{2}{*}{ Maximales } & \multicolumn{1}{|c|}{ PAD } & & \multicolumn{1}{c|}{ BZR } & \\
\cline { 3 - 6 } & Alter & Registrierungen & $\begin{array}{r}\text { Registrierte } \\
\text { Personen }\end{array}$ & Registrierungen & $\begin{array}{r}\text { Registrierte } \\
\text { Personen }\end{array}$ \\
\hline 1970 & 32 & 195.580 & 56.585 & 123.300 & 45.376 \\
\hline 1973 & 29 & 162.265 & 45.750 & 92.371 & 34.667 \\
\hline 1975 & 27 & 143.701 & 42.173 & 80.457 & 31.766 \\
\hline 1978 & 25 & 117.830 & 35.411 & 64.340 & 28.252 \\
\hline 1985 & 17 & 44.900 & 17.257 & 24.103 & 16.672 \\
1988 & 14 & 15.342 & 8.087 & & \\
\hline
\end{tabular}

Wenngleich mit dieser Tabelle vor allem intendiert ist, den Umfang der inzwischen vorhandenen Datensammlung aufzuzeigen, so sei doch auf eine Auffälligkeit der Kohorte 1985 verwiesen: Bei dieser ist erstmals die Anzahl der justiziell registrierten Personen nahezu gleich groß wie die der polizeilich registrierten Personen. Eine detaillierte Analyse der Daten wird wohl Hinweise auf die Ursachen dieser Veränderung liefern.

\section{Bereitstellung von Basisdaten}

In der Freiburger Kohortenstudie werden, wenn auch durch die Zahl der Kohorten beschränkt, Daten erfasst, die über Entwicklung und Verteilung der Registrierungshäufigkeiten und damit über die Kriminalitätsbelastung im Hellfeld Auskunft geben. Diese Daten sind mit denen der Polizeilichen Kriminalstatistik bzw. der Strafverfolgungsstatistik vergleichbar, gehen aber durch einen höheren Differenzierungsgrad und der durch die Verknüpfung auf der Ebene der Personen gegebenen Spezifikationsmöglichkeiten (z.B. über das Alter kumulierte Raten) deutlich über diese hinaus. Sie sollen deshalb deskriptiv aufbereitet als Basisdaten der kriminologischen Forschung zugänglich gemacht werden.

Anfang 2002 wurde ein erster kommentierter Band der Basisdaten zur Prävalenz und Inzidenz polizeilicher Registrierung herausgegeben. Er beinhaltet jährliche Inzidenz- und Prävalenzraten, die Auskunft über den Umfang und die Entwicklung polizeilicher Registrierung in den 80er und 90er Jahren geben. Neben der Differenzierung der Registrierungsraten nach Geschlecht, Nationalität und Deliktstyp werden als zusätzliche Informationen die mittleren Zahlen von 'Taten pro Täter' und 'Tatgenossen pro Tat' angegeben. Darüber hinaus werden für verschiedene Altersspannen kumulierte Raten berechnet, die den genauen Anteil der in einer Altersspanne betroffenen Bevölkerung angeben. Sie können, da jede Person nur einmal gezählt werden soll, nicht aus den aggregierten jährlichen Raten der öffentlich zugänglichen Statistiken berechnet werden und sind nur durch Kohortenstudien bestimmbar.

Ein weiterer Band, der den Umfang und die Entwicklung der Kriminalität, die durch den obigen Band auf polizeilicher Ebene erfasst wurde, auf der justiziellen Ebene komplettiert und bezüglich der justiziellen Reaktionsformen weiter differenziert, ist geplant. Mit den Arbeiten daran kann aber erst jetzt, nach Abschluss der oben beschriebenen Neuaufbereitung der BZR-Daten, begonnen werden. Die bis dahin vorliegenden justiziellen Daten erfassten diesen Bereich auf Grund der Zusatzbedingung einer polizeilichen Registrierung nur selektiv. Voraussichtlich wird ein solcher Band im Sommer 2004 mit aktuellen Daten erstellt sein. 
Weitgehend unbeeinflusst von dem erwähnten Selektionskriterium konnte aber aus den schon länger vorliegenden justiziellen Daten die Veränderung und Abhängigkeit der Einstellungsraten nach dem JGG $(\S \S 45,47)$ für die Periode von 1985 bis 1996 bestimmt werden. Gerade in der ersten Hälfte dieser Periode stiegen die Einstellungsraten deutlich an. Unklar ist dabei, ob diese höheren Einstellungsraten auf geänderte Einstellungskriterien seitens der Justiz oder auf eine Zunahme der Bagatellkriminalität zurückzuführen sind. Wie die Abbildung zeigt, waren von dieser Entwicklung alle untersuchten Deliktskategorien fast gleich stark betroffen. Diese über alle Deliktskategorien hinweg gleichmäßige Entwicklung mag auf eine generell höhere Einstellungsbereitschaft der Justiz verweisen. Allerdings war im Fall des einfachen Diebstahls festzustellen, dass parallel zur Entwicklung der Einstellungsraten der Anteil des Ladendiebstahls am einfachen Diebstahl gleichermaßen zugenommen hat. Mithin ein Hinweis, dass vielleicht doch eine zunehmende Bagatellkriminalität die Entwicklung der Einstellungsraten bestimmt. In dem z.Z. in Druck begriffenen Band wird des weiteren ausführlich der Einfluss verschiedener Größen wie des Delikts, seiner Begehungsart, der Legalbiographie etc. auf die Einstellungsentscheidung untersucht.

Im Ergebnis zeigt sich, dass die Einstellungsentscheidungen nach $\S \S 45,47$ JGG in erster Linie durch Charakteristika der Tat (Deliktstyp, Umfang und Begehungsform) und der Legalbiographie wie auch, wenngleich nicht so stark, durch das Alter des Täters beeinflusst werden. Der gleichwohl signifikante Einfluss anderer Tätervariablen, wie Geschlecht und Nationalität, ist dagegen von geringer Bedeutung. Des Weiteren konnten innerhalb Baden-Württembergs deutliche regionale Unterschiede bezüglich der Einstellungsraten auf der Ebene der Landgerichtsbezirke nachgewiesen werden, die in ihrer Stärke in etwa dem Einfluss der Legalbiographie auf die Einstellungsentscheidung entsprechen.

\section{Schaubild: Entwicklung der Einstellungsraten ( $\$ \S 45,47$ JGG) über die Periode (1985 - 1996) differenziert nach Delikten, 16jährige deutsche Männer 1. Registrierung}

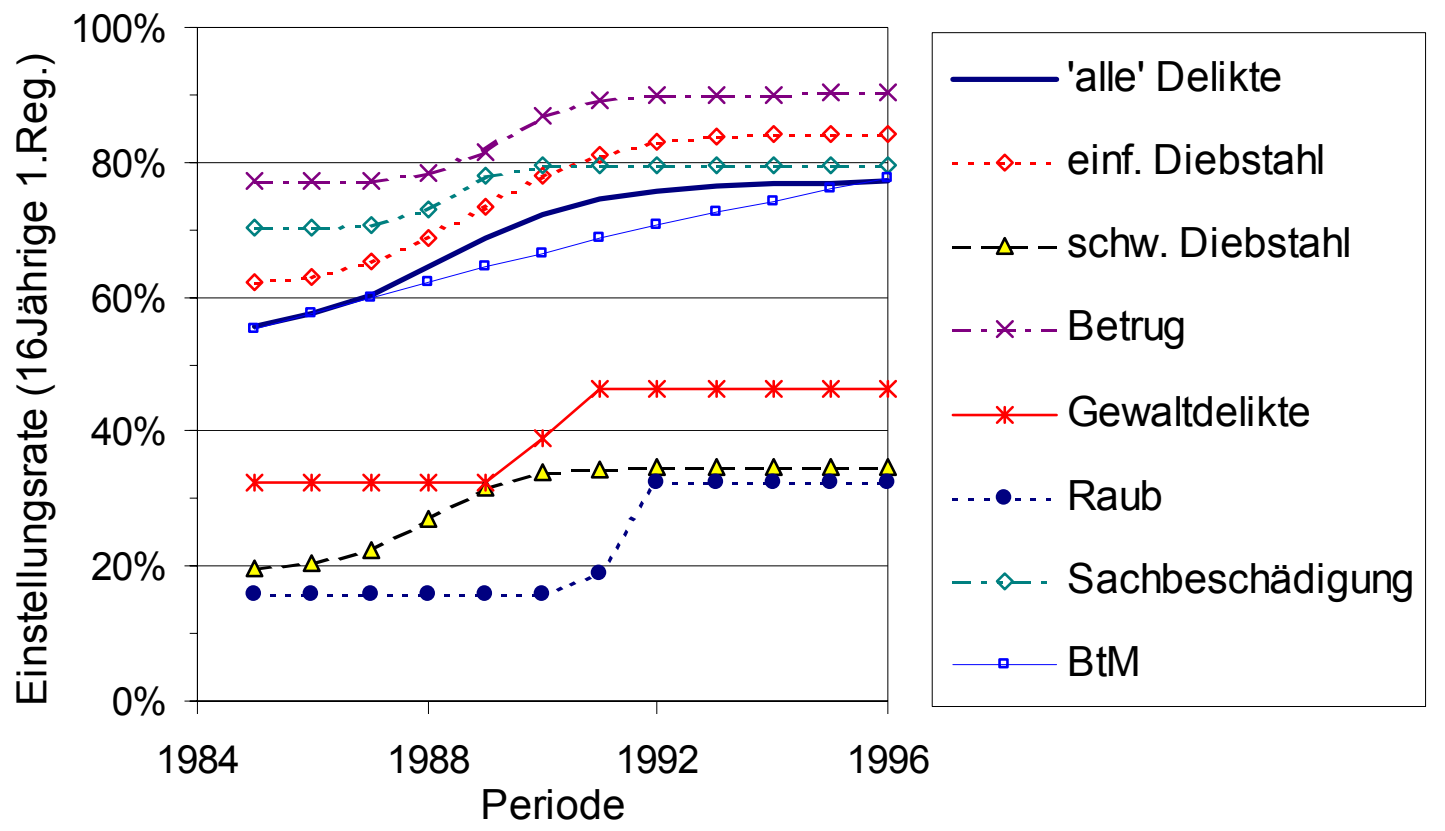

In diesen Zusammenhang ist auch die Untersuchung von Herrn Bareinske zu der Legalbewährung nach formellen bzw. informellen Sanktionierungen von Jugendlichen zu stellen. 


\section{Vertiefende Analysen}

Was die vertiefenden Analysen betrifft, sei zunächst auf die unten aufgeführten, abgeschlossenen und laufenden Promotionen im Rahmen der Studie hingewiesen, die an anderer Stelle des Berichts ausführlicher beschrieben sind. Des Weiteren sind innerhalb des Schwerpunkts Sexualstraftaten aus der Freiburger Kohortenstudie Auswertungen zu offiziellen Registrierungen sexueller Gewalt erstellt worden.

Im Sommer 2002 startete die Kooperation mit Frau Titterington (Sam Houston State University) mit einem Vergleich zwischen Houston (Texas) und Baden-Württemberg betreffend unterschiedlicher Verbreitung und Charakteristika der Kapitaldelikte Mord und Totschlag auf der Ebene polizeilicher Registrierungen. Diese gemeinsamen Arbeiten werden in Richtung des unten aufgeführten Proposals fortgeführt. Hier seien auszugsweise einige Ergebnisse dargestellt:

Die folgende Abbildung zeigt Besonderheiten der Altersabhängigkeit von Tötungsdelikten im Vergleich mit 'allgemeiner' Delinquenz. Neben dem drastischen Unterschied in der Häufigkeit des Auftretens (linke Skala Tötungsdelikte, rechte Skala 'alle Delikte'), die bei Tötungsdelikten ca. ein tausendstel der allgemeinen Delinquenzrate beträgt, ist der Verlauf bei den Tötungsdelikten um ca. 3 Jahre hin zu den Älteren verschoben. Abgesehen von dieser Verschiebung ist die Form des Verlaufs bei den Männern sehr ähnlich, insbesondere den Rückgang der Raten mit dem Alter betreffend. Der Anstieg ist im Fall der Tötungsdelikte etwas steiler als bei der 'allgemeinen' Delinquenz. Bei den Frauen fällt dagegen bei den Tötungsdelikten der mit dem Alter konstante Verlauf der Raten auf. Ein Unterschied, der vermutlich auf eine unterschiedliche Motivation für die Tatbegehung hinweist, die bei den Frauen eher in Konflikten im Nahbereich zu suchen sein dürfte.

Schaubild: Jährliche Prävalenzraten pro 100.000, Deutsche (Baden-Württemberg) für die Periode 1984-2000, polizeiliche Registrierungen

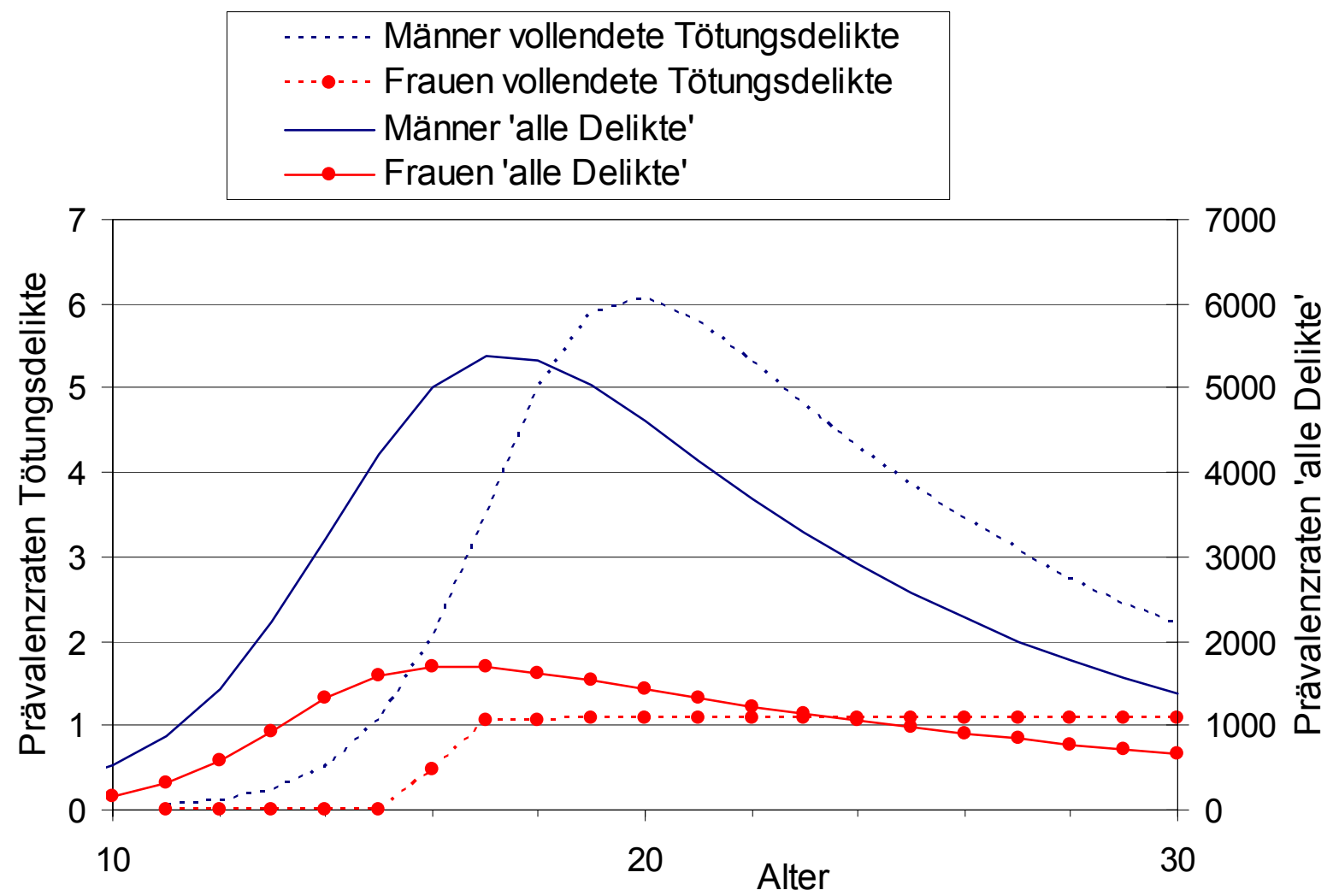


Ende 2003 wurde dieser die Gewaltdelikte umfassende Themenkreis durch eine Dissertation erweitert und ergänzt. In ihr sollen die Veränderungen im Bereich der Jugendgewalt sowohl in ihrem Auftreten (Verbreitung und spezielle Tatcharakteristika betreffend) wie auch bezüglich sich ggf. ändernder justizieller Reaktionen aufgezeigt werden.

- Promotionsvorhaben im Rahmen der Studie:

Abgeschlossen:

2001 Herr Höfer: "Sanktionsentwicklungen bei mehrfach registrierten Personen"; 2003 Herr Bareinske: "Sanktion und Legalbewährung im Jugendstrafverfahren in Baden-Württemberg"

\section{Laufend:}

2003 Frau Tetal: "Analyse von Deliktsähnlichkeiten auf der Basis von Individualdaten"

2003 Frau Zimmerling: "Gewaltkriminalität im Lebenslauf".

- $\quad$ Beteiligung an internationalen Kooperationen:

Im Rahmen eines Forschungsaufenthalts von Frau Victoria Titterington im Sommer 2002 (Sam Houston State University) wurde eine Kooperation zum Thema "Legal \& Cultural Characteristics of German \& U.S. Homicide in Families" begonnen. Bei diesem Projektvorhaben wird davon ausgegangen, dass die Art der justiziellen Reaktion auf tödliche (innerfamiliäre) Gewalt ein Indikator der gesellschaftlichen Einstellung gegenüber solcher Gewalt ist. Schwerpunktmäßig sollen dabei einerseits die Entwicklungen in den letzten 15 Jahren, insbesondere bei innerfamiliärer Gewalt, aufgezeigt werden und andererseits ein interkultureller Vergleich an Hand der Daten der Freiburger Kohortenstudie und amerikanischen Daten durchgeführt werden.

- Ausgewählte Publikationen:

HÖFER, S.: Sanktionskarrieren - Eine Analyse der Sanktionshärteentwicklung bei mehrfach registrierten Personen anhand von Daten der Freiburger Kohortenstudie. edition iuscrim, Freiburg i. Br. 2003, $198 \mathrm{~S}$.

Grundies, V., HöFER, S. \& TetAl, C.: Basisdaten der Freiburger Kohortenstudie: Prävalenz und Inzidenz polizeilicher Registrierung. Arbeitsberichte aus dem Max-Planck-Institut 2002/1, edition iuscrim, Freiburg i. Br. 2002, $202 \mathrm{~S}$.

GRUNDIES, V.: Kriminalitätsbelastung junger Aussiedler. Ein Längsschnittvergleich mit in Deutschland geborenen jungen Menschen anhand polizeilicher Registrierungen. Monatsschrift für Kriminologie und Strafrechtsreform 5, 290-305 (2000).

GRUNDIES, V.: Polizeiliche Registrierungen von 7-23jährigen - Befunde der Freiburger Kohortenuntersuchung. In: Forschungen zu Kriminalität und Kriminalitätskontrolle am Max-Planck-Institut für ausländisches und internationales Strafrecht in Freiburg. Hrsg. H.-J. Albrecht. edition iuscrim, Freiburg i. Br. 1999, 371-402.

GRUNDIES, V.: The Freiburg Cohort Study. In: Research on Crime and Criminal Justice at the Max Planck Institute.Hrsg. H.-J. Albrecht \& H. Kury. edition iuscrim, Freiburg i. Br. 1998, 29-32. 


\subsubsection{Sanktion und Legalbewährung im Jugendstrafverfahren in Baden-Württemberg - Eine Analyse der Legalbewährung von jugendlichen Straftätern nach einer formellen bzw. informellen Erledigung des Verfahrens anhand der Freiburger Kohortenstudie}

- $\quad$ Bearbeiter: Christian Bareinske (Jurist)

- $\quad$ Zeitrahmen: 2001 bis 2003

- $\quad$ Projektstatus: abgeschlossen

- $\quad$ Projektbeschreibung: (zugleich Promotionsvorhaben)

Obwohl das JGG im Rahmen der Reform im Jahre 1990 durch das 1. JGGÄndG modifiziert wurde, ging die Debatte um die Reform des Jugendstrafrechts weiter und bildet in jüngster Zeit vor dem Hintergrund der Entwicklungen der Kinder- und Jugendkriminalität wieder zunehmend einen Schwerpunkt des rechtspolitischen Interesses (vgl. dazu insbesondere "Ist das deutsche Jugendstrafrecht noch zeitgemäß?" - Gutachten für den 64. Deutschen Juristentag erstattet von Herrn Prof. Dr. H.-J. Albrecht).

Im Rahmen des jugendstrafrechtlichen Sanktionensystems wurde durch die Modifikation von Normen des JGG im Zuge der Reform des Jahres 1990 die Möglichkeit erweitert, Konzepte der Diversion anzuwenden. Dabei sind Ansätze, für junge Menschen mögliche schädliche Nebenwirkungen von förmlichen Strafverfahren und förmlicher Verurteilung, insbesondere stigmatisierende und entsozialisierende Effekte, auf ein Mindestmaß zu begrenzen, nicht erst im Gefolge der Diversionsdiskussion zum Tragen gekommen; vielmehr entsprechen die mit Diversion in spezialpräventiver Hinsicht verbundenen Erwartungen inhaltlich auch den Zielvorstellungen der Gesetzgeber der Jugendgerichtsgesetze von 1923, 1943 und 1953 (vgl. Wolfgang Heinz (1992): Diversion im Jugendstrafverfahren der Bundesrepublik Deutschland. Bonn, S. 15 mit weiteren Nachweisen).

Ausgangspunkt für den steigenden Einsatz von Diversionskonzepten ist eine zunehmende Skepsis bezüglich der Wirkungen strafrechtlicher Sanktionen und insbesondere die kriminologische Erkenntnis, dass eingriffsintensiven und vor allem den stationären Sanktionen des Strafrechts in spezialpräventiver Hinsicht keine positiven, sondern eher schädliche Wirkungen zuzuschreiben sind. Des Weiteren lag die kriminologische Einsicht zugrunde, dass Kriminalität im Jugendalter meist nicht Indiz für ein erzieherisches Defizit ist, sondern überwiegend als entwicklungsbedingte Auffälligkeit mit dem Eintritt in das Erwachsenenalter abklingt und sich nicht wiederholt.

Mit dem Projekt wurde die praktische Anwendung sowie die Verteilung und Entwicklung der jugendstrafrechtlichen Sanktionen durch die Gerichte in Baden-Württemberg seit Ende der 80er Jahre vor dem Hintergrund der normativen Erwartungen der Gesetzesänderung, sowie die Wirkung der staatlichen Reaktion auf das weitere Verhalten der auffälligen Jugendlichen in ihrem Lebenslauf empirisch untersucht und der Rückfallsverlauf nach einer formellen bzw. informellen Reaktion detailliert analysiert.

Die Analyse erfolgte unter Nutzung der Daten der Kohortenstudie zur Entwicklung polizeilich registrierter Kriminalität und strafrechtlicher Sanktionierung des Max-Planck-Institutes für ausländisches und internationales Strafrecht in Freiburg. Untersucht wurden die fünf Kohorten der Geburtsjahrgänge 1970, 1973, 1975, 1978 und 1985. Mittels der dort gewonnenen Längsschnittdaten ist es möglich, im Lebenslauf der Jugendlichen sowohl vorangegangene Auffälligkeiten anhand polizeilicher Registrierungen des Verfahrensausgangs zu dokumentieren als auch anhand der Daten aus dem Bundeszentralregister die Art der staatlichen Reaktion und das sich daran anschließende Verhalten im weiteren Verlauf des Lebens der auffällig gewordenen Person zu untersuchen. 
Untersuchte Fragestellungen:

Insbesondere werden durch das Promotionsprojekt folgende Fragestellungen evaluiert:

- Bestehen signifikante Unterschiede im Hinblick auf die Legalbewährungsrate nach einer informellen bzw. formellen Sanktion?

- Existieren Unterschiede zwischen den einzelnen Untersuchungsperioden (Kohorten)?

- Gibt es deliktsspezifische, geschlechtsspezifische, nationalitätsspezifische oder regionale Unterschiede?

- Besteht ein signifikanter Zusammenhang zwischen dem Zeitintervall der Legalbewährung und der vorangegangenen Sanktionsform?

- Verstoßen die untersuchten Jugendlichen im Falle einer erneuten Registrierung wieder gegen dasselbe Delikt und gibt es insoweit Unterschiede zwischen den formell und informell sanktionierten Jugendlichen?

- Besteht ein Zusammenhang hinsichtlich der Länge des Intervalls zwischen der Eingangsstraftat und der justiziellen Reaktion und der Legalbewährung, insbesondere, verbessert ein kürzeres Reaktionsintervall die Legalbewährung?

\section{Wesentliche Ergebnisse:}

Insgesamt überwiegt bei den untersuchten 14-15-Jährigen der Anteil der informellen Sanktionen mit 73 \% über alle Kohorten deutlich den Anteil der formellen Sanktionen (27\%). Dabei erfolgt im Zeitverlauf eine zunehmende Veränderung der Sanktionspraxis hin zu den informellen Sanktionen. Entsprechend nimmt der Anteil der informellen Sanktionen ausgehend von dem Wert 57 \% bei der Kohorte $70(1984 / 85)$ über die Kohorten bis auf den Wert $82 \%$ bei der Kohorte 78 (1992/93) zu und bleibt danach im Wesentlichen gleich.

Abbildung 1: Anteil der formellen versus informellen Sanktionierungen der vorliegend untersuchten Jugendlichen hinsichtlich der ersten Registrierung - unterschieden nach Kohorte

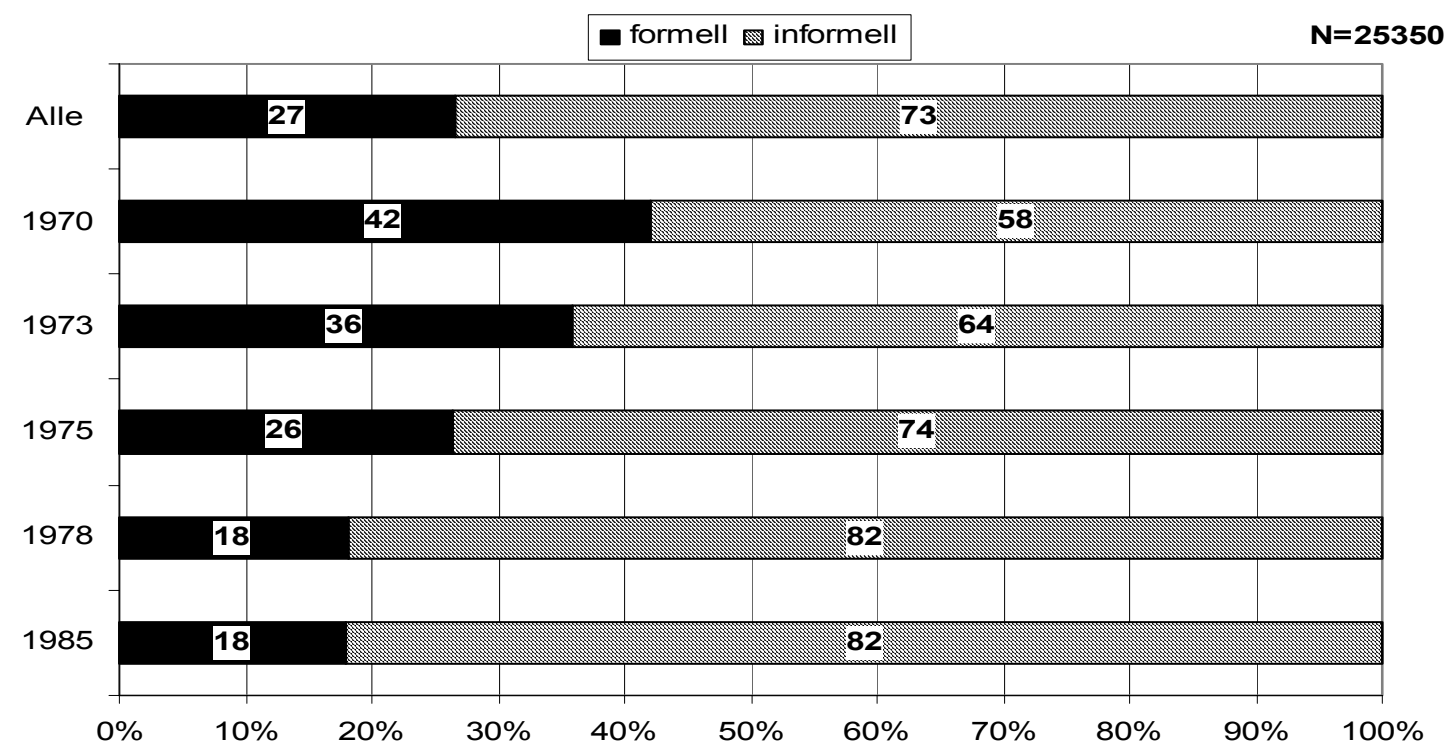


Von den formellen Registrierungen sind insgesamt - ohne eine Unterscheidung nach Kohorten vorzunehmen - etwa 43 \% Zuchtmittel. Bei einem knappen Drittel der Fälle ergingen Erziehungsmaßregeln. In $23 \%$ der Fälle wurde eine Kombination von Erziehungsmaßregeln und Zuchtmitteln als geeignet angesehen, bei den verbleibenden Fällen wurde eine unbedingte Jugendstrafe bzw. eine Jugendstrafe mit Bewährung oder ein Schuldspruch ausgesprochen.

Durchschnittlich über alle Kohorten ergingen Entscheidungen nach $\S 47$ JGG in $23 \%$ und Entscheidungen nach $\S 45$ JGG in $77 \%$ der insgesamt registrierten Fälle. Obwohl der Anteil der Maßnahmen nach $\S 47$ JGG über die Kohorte 73 zunächst leicht zunimmt, zeigt sich im Vergleich der Kohorten 70 und 78 jedoch ein deutlicher Rückgang dieser Maßnahmen um etwa $20 \%$. Dementsprechend steigt der relative Anteil der staatsanwaltschaftlichen Sanktionen bezogen auf die Gesamtzahl der Registrierungen auf $85 \%$ bei der Kohorte 78 an und bleibt danach in etwa konstant.

Von den 25.315 untersuchten Personen sind innerhalb des Untersuchungszeitraumes von 2 Jahren $18.235(72 \%)$ nicht erneut registriert worden; 7.080 Personen (28\%) weisen mindestens eine erneute Registrierung auf. Dieses prozentuale Verhältnis zwischen erneut bzw. nicht erneut registrierten Jugendlichen ändert sich im Vergleich der untersuchten Perioden nicht wesentlich (um maximal $3 \%$ ), obwohl die Sanktionspräferenz nicht unerhebliche Abweichungen (Veränderungen um 24 \%) im Vergleich der Perioden aufweist.

Abbildung 2: Legalbewährungsrate der vorliegend untersuchten Jugendlichen - insgesamt und unterschieden nach Kohorte

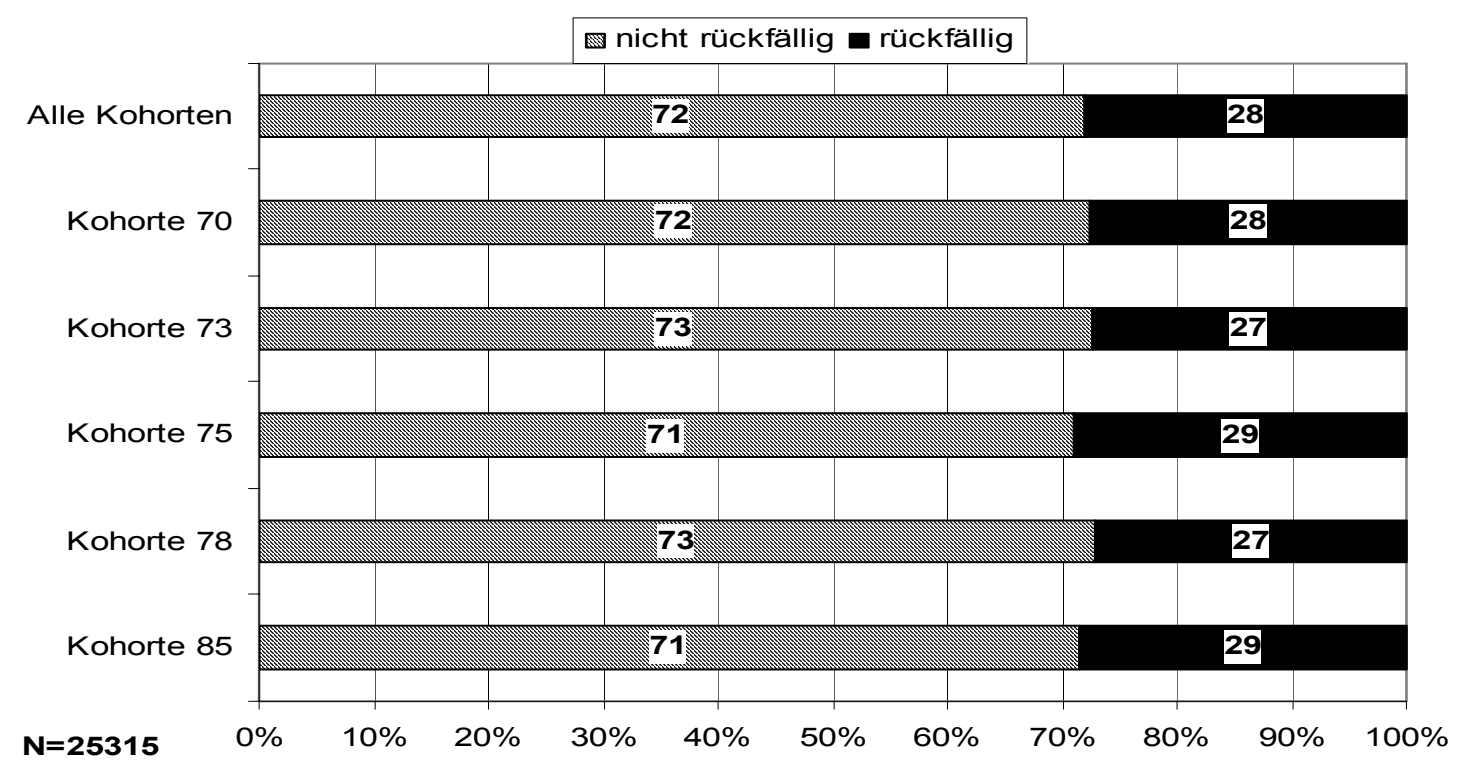

Der Vergleich der Legalbewährungsrate in Abhängigkeit von der Sanktion zeigte, dass der Anteil der nicht erneut registrierten Jugendlichen, bei welchen eine informelle Sanktion vorausgegangen ist, über alle Perioden mit durchschnittlich etwa $75 \%$ über dem Anteil der nicht erneut registrierten Jugendlichen liegt, welche formell sanktioniert wurden (durchschnittlich etwa $63 \%$ ). Die aufgezeigten Unterschiede in der Legalbewährungsrate in Abhängigkeit von der Sanktion waren über alle Kohorten signifikant. Der Zusammenhang ist jedoch eher schwach ausgeprägt $(\mathrm{V}=0,12)$.

Bei den formellen Maßnahmen ist die unbedingte Jugendstrafe mit der schlechtesten Legalbewährungsrate verbunden (30\%). Durchschnittlich - ohne eine Unterscheidung nach Kohorten zu treffen erzielten die Sanktionen der Jugendstrafe mit Bewährung und des Schuldspruchs eine deutlich niedrigere Legalbewährungsrate (48 \% und $45 \%$ ) als die Zuchtmittel, Erziehungsmaßregeln bzw. die Kom- 
binationen dieser Maßnahmen (63\%, $65 \%$ und $63 \%$ ). Der Anteil der nicht erneut registrierten Jugendlichen, die mit einem Zuchtmittel sanktioniert wurden, geht im Vergleich der Kohorten 70/73 und der Kohorten 75/78/85 um etwa 8 \% zurück. Eine ähnliche Veränderung zeigt sich auch bei den Erziehungsmaßregeln.

Bei den informellen Sanktionen war im Hinblick auf die staatsanwaltschaftlichen Maßnahmen nach $\S 45$ JGG durchweg über alle Perioden eine höhere Legalbewährung (durchschnittlich etwa $3 \%$ ) als bei den gerichtlichen Einstellungen zu beobachten ( $\$ 47 \mathrm{JGG})$, wobei allerdings auch Unterschiede in der Deliktsstruktur bestanden. Dieser Unterschied ist zwar signifikant; für das Zusammenhangsmaß V errechnet sich aber mit 0,03 ein so geringer Wert, dass ein Zusammenhang zwischen der Legalbewährungsrate und der Art der informellen Einstellung als vernachlässigbar gering angesehen werden kann. Für die Legalbewährung ist es damit unerheblich, ob die Einstellung durch das Gericht oder die Staatsanwaltschaft erfolgt. Im Vergleich der einzelnen Perioden sind die relativen Anteile der nicht erneut registrierten Jugendlichen im Zeitverlauf leicht rückläufig. Bei den Maßnahmen nach § 45 JGG geht die Legalbewährungsrate mit Schwankungen um etwa $4 \%$ zurück, bei den Maßnahmen nach $\S 47$ JGG erfolgt ein Rückgang um etwa $5 \%$.

\subsubsection{Analyse von Deliktsähnlichkeiten auf der Basis von Individualdaten}

- $\quad$ Bearbeiterin: Carina Tetal (Soziologin/Mathematikerin)

- Zeitrahmen: 2003 bis 2005

- $\quad$ Projektstatus: neu begonnen

- $\quad$ Projektbeschreibung: (zugleich Promotionsvorhaben)

Ähnlichkeiten von Delikten können über den Ansatz einer wie auch immer gewählten Deliktsschwere, über die Sanktionierung der Delikte oder über verschiedene Dimensionen wie Gewaltanwendungen, Schadenshöhe oder ähnliche definiert werden. In diesem Projekt soll jedoch keine dieser Kategorisierungen verwendet werden. Stattdessen soll die Ähnlichkeit von Delikten empirisch bestimmt werden und zwar mittels des gemeinsamen Auftretens von Delikten innerhalb der kriminellen Karriere von Personen. Die Delikte werden also über den Angelpunkt Individuum miteinander verknüpft, dem damit ein bestimmtes psychosoziales Motiv für sein abweichendes Verhalten unterstellt wird. Es wird dabei implizit angenommen, dass sich die individuelle Konstellation über die Zeit in Bezug auf das Delinquenzverhalten nicht ändert. Das schränkt die Ursachen der Kriminalität tendenziell auf länger andauernde Phänomene ein. Bei der Untersuchung ist es allerdings auch möglich, die Ähnlichkeit innerhalb von festgelegten Zeitspannen zu untersuchen.

Die Ähnlichkeit wird empirisch dadurch bestimmt, dass angenommen wird, dass Delikte, die von ein und derselben Person begangen wurden, Ähnlichkeiten aufweisen. Als Ähnlichkeitsmaß wird das tatsächliche Vorkommen von Deliktspaaren bei Personen in Relation zu dem, unter der Annahme einer zufälligen Verteilung, erwarteten Vorkommen benutzt. Von Interesse sind also die bei Personen vorkommenden Deliktskombinationen.

Der Analyse werden die Daten der Freiburger Kohortenstudie zugrunde gelegt. Es handelt sich dabei um Längsschnittdaten der Geburtsjahrgänge 1970, 1973, 1975, 1978, 1985 und 1988 der Personenauskunftsdatei (PAD) des Landeskriminalamts Baden-Württemberg und des Bundeszentralregisters (BZR). Damit werden sowohl die polizeilichen als auch die justiziellen Registrierungen einer Person erfasst. Anhand dieser Daten ist es möglich, einer Person alle registrierten Delikte zuzuordnen.

Während bei den PAD-Daten jede Registrierung genau ein Delikt beinhaltet, umfassen die BZRRegistrierungen häufig mehrere Delikte. Dies hat zur Konsequenz, dass bei BZR-Registrierungen das 
zeitliche Problem der Ähnlichkeitsbestimmung - und damit die oben erwähnte Annahme länger andauernder stabiler individueller Eigenschaften - entfällt.

Für die Auswertungen sind nur die Personen interessant, die mindestens zwei Delikte begangen haben. Voraussetzung, um die Ähnlichkeit von verschiedenen Delikten nachzuweisen, ist darüber hinaus, dass mindestens zwei Delikte aus unterschiedlichen Kategorien vorhanden sind. Da gleiche Delikte bei Personen überdurchschnittlich häufig auftreten, sind alle Delikte ähnlich mit sich selbst. Dies kann als Hinweis verstanden werden, dass die hier gewählte Definition von Ähnlichkeit für die Analyse geeignet ist.

Die Ähnlichkeit von Delikten soll mit Hilfe der Methode der multidimensionalen Skalierung dargestellt werden. Diese Methode erlaubt es, aus ordinalen Annahmen über die Daten, zu metrischen (u.a. euklidischen) Distanzen der zu beurteilenden Objekte, hier Delikte, zu gelangen. Zudem können mit dieser Methode die Ähnlichkeiten grafisch dargestellt werden.

- $\quad$ Arbeitsplanung 2004:

Die im Jahr 2003 insbesondere im Hinblick auf die Verwendbarkeit der Methodik durchgeführten Analysen sollen im kommenden Jahr weitergeführt werden. Es ist vorgesehen, die Deliktsähnlichkeiten bei verschiedenen Altersstufen zu untersuchen. Außerdem sollen die Deliktsähnlichkeiten bei chronisch Delinquenten im Vergleich zu Personen, die nur als Jugendliche (Alter zwischen 14 und 17 Jahren) auffällig sind, bestimmt werden. Dabei soll auch die Dauer zwischen den Registrierungen berücksichtigt werden.

\subsubsection{Gewaltkriminalität im Lebenslauf - Eine Längsschnittanalyse von jugendlichen Gewalttätern anhand der Daten der Freiburger Kohortenstudie}

- $\quad$ Bearbeiterin: Diana Zimmerling (Juristin)

- $\quad$ Zeitrahmen: 2004 bis 2005

- $\quad$ Projektstatus: neu begonnen

- $\quad$ Projektbeschreibung: (zugleich Promotionsvorhaben)

Seit Beginn der neunziger Jahre ist im Bereich der Kinder- und Jugendkriminalität ein beträchtlicher Anstieg der polizeilich registrierten Straftaten zu verzeichnen. Wie sich anhand der Polizeilichen Kriminalstatistik (PKS) zeigt, liegt der Schwerpunkt des Anstiegs der Registrierungen im Bereich der Gewaltkriminalität, wobei es hierbei erstmalig auch zu einem vermehrten Auftreten von Gewaltdelikten bei Mädchen und Frauen kommt.

Des Weiteren hat das Thema "Jugendgewalt" auch durch die Darstellung von spektakulären Einzelfällen in den Medien in der öffentlichen Diskussion eine Renaissance erfahren. Im Mittelpunkt steht hierbei die Frage, worauf diese Zunahme von Gewaltdelikten bei Kindern und Jugendlichen zurückzuführen ist und ob dies einhergeht mit einer gleichzeitig sinkenden Hemmschwelle und ansteigender Gewaltintensität. Themenbereiche wie Gewalt in Schulen, Gewalt gegen Obdachlose oder Ausländer, sowie die gesteigerte Präsenz von Jugendbanden, sind dabei viel erörterte Gesichtspunkte.

Im Rahmen der empirischen Untersuchung von Jugendgewalt besteht zunächst das Bedürfnis abzugrenzen, welche strafbaren Handlungen und Delikte unter diese Kategorie fallen, da der Begriff der "Gewalt" seit Jahrzehnten in der Strafrechtswissenschaft und in der Rechtsprechung umstritten ist und das StGB keine Legaldefinition beinhaltet. Vielmehr verwendet das Gesetz den Begriff der "Gewalt" an verschiedenen Stellen, wobei sich der Bedeutungsinhalt unterscheidet. Vereinzelt werden der Gewaltkriminalität auch Straftaten zugerechnet, die sich gegen Sachen oder nur mittelbar gegen Personen 
richten, z.B. Hausfriedensbruch. Um jedoch einer uferlosen Ausweitung entgegen zu wirken, erscheint eine engere Definition vorzugswürdig. Die Kategorie "Gewaltkriminalität" beschränkt sich folglich auf eine vorsätzliche Straftat, bei der körperliche Gewalt gegen Personen eine Tatbestandsvoraussetzung ist. Demnach sind unter dem Begriff der Gewaltkriminalität folgende Delikte zu fassen:

- $\quad$ Tötungs - und Körperverletzungsdelikte ( $\S 211$ ff, $\S \S 223$ ff StGB)

- $\quad$ Raub (§§ 249 ff StGB)

- $\quad$ Erpressung ( $\S 253 \mathrm{ff} \mathrm{StGB})$

- $\quad$ Sexualdelikte ( $\S 177 \mathrm{ff}$ StGB)

- $\quad$ Straftaten gegen die persönliche Freiheit ( $\$ 234 \mathrm{ff} \mathrm{StGB)}$

Über der Frage der angemessenen Reaktion auf die steigende Anzahl von Gewaltdelikten durch Jugendliche kam es in den neunziger Jahren zu einer kontroversen Debatte. Jüngst hat sich auch der Deutsche Juristentag mit dieser Frage auseinandergesetzt. Im Mittelpunkt stand dabei die Diskussion um eine Modifikation des Sanktionssystems des JGG (vgl. dazu insbesondere "Ist das deutsche Jugendstrafrecht noch zeitgemäß?" - Gutachten für den 64. Deutschen Juristentag erstattet von Prof. Dr. H.-J. Albrecht).

Durch die vorliegende Untersuchung soll für eine mögliche Modifikation des jugendstrafrechtlichen Reaktionssystems eine empirische Grundlage geschaffen werden, indem das Phänomen der Gewaltkriminalität bei Jugendlichen (vgl. § 1 JGG, Personen, die zur Tatzeit 14, aber noch nicht 18 Jahre alt sind) und Heranwachsenden (Personen, die zur Tatzeit 18, aber noch nicht 21 Jahre alt sind) in BadenWürttemberg deskriptiv dargestellt und inferenzstatistisch analysiert wird.

Mit dem Projekt wird für den Zeitraum von 1984 bis 2002 untersucht, wie sich der Anstieg der Gewaltkriminalität bei den Jugendlichen und Heranwachsenden in Baden-Württemberg im Einzelnen darstellt. In den Medien ist immer mehr die Rede davon, dass die Täter von Gewaltdelikten immer jünger würden und es bereits bei den 14jährigen zu gewalttätigen Übergriffen käme, welche teilweise sogar mit Waffen ausgeführt würden. Zudem seien die tätlichen Übergriffe wesentlich brutaler als früher da es so etwas wie einen "Ehrenkodex" nicht mehr gebe, so dass sogar noch auf am Boden liegende Opfer eingetreten würde.

Insbesondere wird deshalb der Frage nachgegangen, ob sich die Altersstruktur bei Gewaltkriminalität verändert hat und ob sich eine Zunahme hinsichtlich der Häufigkeit in gleicher Weise bei leichten wie bei schweren Gewaltdelikten zeigt. Gleichfalls soll untersucht werden, ob sich andere Tatumstände wie z.B. die Begehung der Tat in Gruppen in diesem Zeitraum vermehrt hat. In diesem Zusammenhang soll unter anderem auch die Gewaltanwendung von Mädchen untersucht werden, bei denen wenn auch von einer wesentlich niedrigeren Grundrate ausgehend in den letzten Jahren fast noch stärkere Steigerungen der Gewaltanwendung als bei den männlichen Jugendlichen festzustellen waren.

Gleichfalls werden diese Entwicklungen differenziert nach ethnischen Gruppen zu prüfen sein.

Geht man davon aus, dass die registrierte Zunahme von Gewaltdelikten zumindest teilweise auf eine veränderte Anzeigenbereitschaft zurückgeführt werden kann, so sind insbesondere bzgl. städtischer und ländlicher Regionen Unterschiede zu erwarten. Dabei wird vermutet, dass in ländlichen Regionen aufgrund der höheren informellen Sozialkontrolle eher von der Anzeigenerstattung abgesehen wird, während in städtischen Gebieten die größere Anonymität zu einer höheren Anzeigebereitschaft führen könnte. Aus diesem Grund wird angenommen, dass die Steigerungsraten regional unterschiedlich ausfallen, was geprüft werden soll.

Grundsätzlich - unabhängig von der Steigerung der Gewaltdelinquenz in den letzten Jahren- soll untersucht werden, ob Täter, die bereits als Jugendliche oder Heranwachsende Gewaltdelikte begehen häufiger eine kriminelle Karriere vor sich haben als andere Jugendliche die " nur" wegen Eigentumsdelikten oder Sachbeschädigung auffallen. Oder ob es sich auch bei Gewaltdelikten meist lediglich um 
ein jugendtypisches Phänomen handelt, das auf Übermut, Impulsivität und jugendlichem Kräftemessen beruht, und sich im Laufe der Zeit von alleine "auswächst". In den Fällen bei denen eine Karriere festgestellt werden kann, soll untersucht werden, ob die andauernde Delinquenz sich auch oder insb. in wiederholter Gewaltanwendung ausdrückt. Zudem wird die Dauer einer solchen Karriere zu untersuchen sein.

Zugrunde gelegt werden die Daten der Kohortenstudie zur Entwicklung polizeilich registrierter Kriminalität und strafrechtlicher Sanktionierung des Max-Planck-Institutes für ausländisches und internationales Strafrecht in Freiburg. Mittels der dort gewonnenen Längsschnittdaten ist es möglich sowohl die Entwicklung über die letzten Jahre zu erfassen, als auch individuelle Karrieremuster zu untersuchen.

- $\quad$ Arbeitsplanung 2004:

Im ersten Halbjahr des Jahres 2004 sollen die theoretischen Grundlagen und die bisher in diesem Zusammenhang durchgeführten Forschungsprojekte aufgearbeitet werden, sowie die Daten für die Berechnungen vorbereitet und erste Analysen zu Fragen der Verteilung und Entwicklung von Gewaltdelikten durchgeführt und mittels deskriptiver Statistik dargestellt werden.

\subsubsection{Subjektive Kriminalitätstheorien - Alltagswissen und Vorstellungen über Kriminalität in der Bevölkerung}

- $\quad$ Bearbeiter: Harald Kania (Psychologe)

- $\quad$ Zeitrahmen: 2000 bis 2004

- $\quad$ Projektstatus: abgeschlossen

- $\quad$ Projektbeschreibung: (zugleich Promotionsvorhaben)

Mit diesem Projekt soll versucht werden, ein "Lagebild" der subjektiven Vorstellungen über Kriminalität in der deutschen Bevölkerung zu erstellen. Dabei werden qualitative Erhebungs- und Auswertungsmethoden verwendet, die einen unmittelbareren und flexibleren Zugang zum Forschungsgegenstand ermöglichen als standardisierte Verfahren. Im Rahmen des Projekts wurde mit 18 Befragten aus dem Großraum Freiburg ein weitgehend offenes Gespräch (episodisches Interview) über Kriminalität im weiteren Sinne geführt. Die inhaltsanalytische Auswertung des transkribierten Datenmaterials ergibt einerseits einen Überblick über die in der Bevölkerung vorherrschenden subjektiven Kriminalitätsvorstellungen und könnte andererseits helfen, Instrumente für zukünftige standardisierte (quantitativ-repräsentative) Erhebungen zu optimieren.

\section{Fragestellung und Zielsetzung}

Was wissen und denken "normale" Menschen über Kriminalität? Wofür steht "Kriminalität" in ihren Vorstellungen, was daran ist faszinierend und welche Aspekte des Themenbereichs machen ihnen Angst - und warum ist das so? Welche eigenen Erfahrungen wurden, als Täter wie als Opfer, gemacht und auf welche Weise stehen diese Kriminalitätserlebnisse in Verbindung mit allgemeinem Wissen und Vorstellungen über Kriminalität. Weiterhin: Welche (auch politischen) Konsequenzen ziehen die Menschen aus ihrem Wissen und ihren Vorstellungen - implizit und explizit? Eine konkrete Beispielfrage: Welchen Zusammenhang gibt es zwischen eigenen Erfahrungen mit Kriminalität und der jeweiligen Strafhaltung (liberal vs. punitiv)?

Das Ziel dieses Projekts ist es, den genannten und weiteren Fragen in umfassender und differenzierter Form nachzugehen und deren Zusammenhänge zu erfassen. Dabei geht es um eine Erforschung der in der Bevölkerung vorherrschenden Vorstellungen von Kriminalität, die über die Abfrage isolierter und 
zuweilen simplifizierender Einzelaspekte hinausgehen möchte. In dieser Erhebung sollen die Befragten weitgehend frei und uneingeengt über alle Aspekte des Phänomens "Kriminalität" sprechen, die ihnen, nicht dem Forscher, wichtig erscheinen. Idealerweise erhalten wir dadurch am Ende einerseits eine Zustandsbeschreibung der Vorstellungswelt(en) in Bezug auf Kriminalität in der deutschen Bevölkerung, eine erste "(Alltags-)Psychologie der Kriminalität". Darüber hinaus könnten die derart erhaltenen Befunde aber auch helfen, die bestehenden standardisierten Befragungsinstrumente zu erweitern und damit möglicherweise deren Erklärungskraft zu verbessern.

\section{Hintergrund des Projekts}

Die bisherige Forschung hat mittlerweile eine Vielzahl empirischer Arbeiten zu subjektiven Aspekten der Wahrnehmung von Kriminalität hervorgebracht, beispielsweise zur Kriminalitätsfurcht und zur Schwere von Delikten (vgl. dazu auch den Projektbericht 3.7.3) sowie einige Arbeiten zur Strafmentalität bzw. Punitivität in der Bevölkerung (vgl. dazu auch den Projektbericht 3.7.4). Die bevorzugte Erhebungsmethode ist dabei klassischerweise der Einsatz von Fragebögen. Die dort verwendeten Operationalisierungen können allerdings - aus prinzipiellen Gründen - nicht die ganze Bandbreite des subjektiven Erlebens berücksichtigen und "kratzen" vielfach nur an der Oberfläche des Forschungsgegenstands. Unter anderem deshalb ist auch häufig das Erklärungspotenzial bzw. die erreichte Varianzaufklärung vergleichbarer standardisierter Untersuchungen eher gering.

Im Rahmen eines fortlaufenden Kooperationsprojekts mit dem Institut für Kriminologie, Universität Köln, ist mittelfristig auch eine möglichst europaweite standardisierte und möglichst repräsentative Erhebung der verschiedenen kriminalitätsrelevanten Themenbereiche geplant, die helfen soll, die Divergenzen und Konvergenzen zwischen den verschiedenen Ländern, Kulturen und Ethnien aufzuzeigen. Denn gerade im Hinblick auf eine zunehmende Globalisierung, in Europa insbesondere die Erweiterung der Europäischen Union, stellt sich verstärkt auch die Frage nach der Homogenität der Einstellungen und Wahrnehmungen in den verschiedenen (Teilnehmer-) Ländern. (Erste international vergleichende Erhebungen wurden bereits zu den Themenbereichen "Schwereeinschätzung von Delikten" und "Akzeptanz von Schlichtungsverfahren" durchgeführt und veröffentlicht, vgl. dazu im Weiteren den Projektbericht 3.7.3 "Kriminalitätswahrnehmung und die Schwereeinschätzung von Delikten").

Aus den oben genannten Gründen erscheint allerdings eine multinationale repräsentative Fragebogenerhebung zum aktuellen Zeitpunkt noch verfrüht und nur begrenzt Erfolg versprechend. Unter diesen Voraussetzungen wurde deshalb der Entschluss gefasst, zuerst ein solides erlebensbasiertes Fundament der relevanten Untersuchungskonzepte zu erarbeiten. Für diese Aufgabe wurde die hier beschriebene Untersuchung der subjektiven Kriminalitätstheorien konzipiert, die sich dem Thema mit einer erlebensnahen, qualitativ orientierten Methodik nähert.

Mithilfe einer solchen Untersuchung kann (1) eine erste Bestandsaufnahme des Spektrums an Vorstellungen, Meinungen und Stereotypen über Kriminalität in der Gesellschaft erhoben werden. Darüber hinaus wird versucht, (2) die Vereinbarkeit solcher individueller Einschätzungen mit gesamtgesellschaftlichen Wertungen (repräsentiert durch formelle Sozialkontrolle, Kriminalpolitik usw.) zu prüfen. Schließlich soll die Studie (3) auch der inhaltlichen Weiterentwicklung und Validierung bestehender quantitativer Erfassungsinstrumente, beispielsweise zu Fragen der Kriminalitätsfurcht, der Punitivität und der Deliktsschwere, dienen.

\section{Literaturüberblick relevanter Forschungsbereiche}

Den Ausgangspunkt und auch die Basis der Arbeit bildet die ausführliche und regelmäßige Sichtung der psychologischen, soziologischen und kriminologischen Literatur - einerseits zur genaueren Herausarbeitung der inhaltlichen Aspekte der Fragestellung sowie zur Bestimmung der angemessenen 
Erhebungs- und Auswertungsmethodik, andererseits aber auch, um die eigenen empirischen Befunde abschließend im Licht des bisherigen Forschungsstandes betrachten zu können.

Zu diesen Zwecken wurde im Allgemeinen die Forschungsliteratur zu Ansätzen bzw. Forschungsperspektiven mit Bezug zu "Alltagsvorstellungen und subjektiven Theorien" ausgewertet. Im Speziellen wurden weiterhin insbesondere Veröffentlichungen zu "(Alltags-)Vorstellungen von Kriminalität" berücksichtigt und ggf. verarbeitet, wobei die relevanten Befunde zu den nachfolgenden thematischen Schwerpunkten (z.T. natürlich mit thematischen Überschneidungen) gebündelt wurden (jeweils mit einer kurzen inhaltlichen Beschreibung; für eine ausführlichere Beschreibung wird auf die Publikation der Dissertation verwiesen):

- Subjektive Kriminalität: In diesem Abschnitt werden v.a. diejenigen Arbeiten berücksichtigt, die die individuelle Bedeutung von Kriminalität für die Lebensgestaltung der Menschen, beispielsweise Wünsche und Ängste im Zusammenhang mit (tatsächlicher und fiktionaler) Kriminalität thematisieren.

- "Objektive Kriminalität": Dieser Teil fasst insbesondere Arbeiten zusammen, die Kriminalität vorrangig im Spiegel von (offiziellen) Statistiken und (quantitativen) Bevölkerungsbefragungen (v.a. Dunkelfelduntersuchungen) fokussieren.

- Massenmedien und Kriminalität: In diesem Abschnitt stehen die Auswirkungen massenmedialer Kriminalitätsdarstellungen auf das Denken und Handeln der Menschen im Vordergrund.

- Verbrechenssfurcht: Hier stehen maßgeblich die Ängste und Beunruhigungen der Menschen im Zusammenhang mit (erlebter oder berichteter) Kriminalität im Vordergrund sowie die verschiedenen damit einhergehenden (vermeintlichen) Paradoxien.

- Strafeinstellungen und -bedürfnisse ("Punitivität"): Den Schwerpunkt dieses Teils bilden sämtliche Vorstellungen, Annahmen und ggf. Theorien, die Laien und verschiedene Expertengruppen über Strafen und Strafbedürfnisse entwickeln.

- Einschätzung der Deliktsschwere: In diesem Teil werden die zahlreichen (und teilweise widersprüchlichen) und sich mittlerweile über vier Jahrzehnte erstreckenden Versuche zusammengefasst, das "subjektive Ausmaß des Übels" zu gewichten - nicht zuletzt, um damit evtl. zu einem die reinen Häufigkeitsstatistiken ergänzenden Maß der Kriminalität zu gelangen (vgl. dazu auch Projektbericht 3.7.3)

- Normen, Werte und Moral: Diese Konzepte bilden die Grundlage für jede Beschäftigung mit subjektiven Kriminalitätsaspekten - beispielsweise (und insbesondere) lassen sich Strafeinstellungen ohne Berücksichtigung der zugrunde liegenden Wertesysteme überhaupt nicht sinnvoll betrachten. Aufgrund der enormen Fülle der Arbeiten und Ansätze bleibt dieser Überblick allerdings vergleichsweise kursorisch.

In einem weiteren Schritt wurde versucht, die zuvor einzeln bzw. getrennt berichteten Befunde (soweit das möglich ist) auf einen gemeinsamen Nenner zu bringen. Am Ende steht schließlich die Ableitung der Forschungsfragen für die eigene empirische Erhebung, anhand derer der Interview-Leitfaden erstellt wird.

\section{Anlage der Untersuchung und Methodik}

Anhand der o.g. Themen der einschlägigen Forschungsliteratur wurde ein Leitfaden entwickelt, der in mehreren Probeinterviews (fünf Gespräche, die nur zu diesem Zweck geführt wurden und die nicht in die inhaltliche Auswertung eingingen) in Bezug auf Inhalte, Reihenfolge, Formulierungen usw. optimiert wurde. Der in den inhaltlich ausgewerteten Interviews eingesetzte Leitfaden umfasste schließlich die folgenden Themenbereiche, jeweils mit einigen möglichen Beispielen bzw. Fragen (NB: aufgrund 
der sehr offenen Gesprächstechnik, wurde die Reihenfolge der Themen sowie deren Anteil am jeweiligen Gesamtgespräch an die aktuellen Bedingungen angepasst):

\section{Tabelle 1: Thematischer Überblick zu den Interviews}

\begin{tabular}{|c|c|c|}
\hline Themenbereich & $\underline{\text { Unterthemen }}$ & Beispiel/Frage \\
\hline 1. Eigene Erfahrungen & - aktiv/passiv & $\begin{array}{l}\text { - Schildern Sie Ihre Erlebnisse ... als Täter, als Opfer, als } \\
\text { Zuschauer, vom Hörensagen ... }\end{array}$ \\
\hline 2. Definition "Kriminalität" & $\begin{array}{ll}- & \text { abstrakt/konkret } \\
- & \text { Relativität von Nor- } \\
& \text { men } \\
- & \text { Biologie und Krimi- } \\
& \text { nalität (Gewalt) }\end{array}$ & $\begin{array}{l}\text { - Was bedeutet für Sie Kriminalität? (bzw. Was ist "Kri- } \\
\text { minalität"? Ggf. frei assoziieren lassen) } \\
\text { - Woher haben Sie Ihre Vorstellungen und ihr Wissen über } \\
\text { Kriminalität? } \\
\text { - Wie könnte es in } 30 \text { bis } 40 \text { Jahren aussehen? } \\
\text { - } \quad \text { "Berufskriminalität"/"Berufskrimineller" }\end{array}$ \\
\hline 3. Deliktsschwere & $\begin{array}{ll}- & \text { Vergleichbarkeit } \\
\text { - } & \text { Faktoren/ } \\
& \text { Determinanten }\end{array}$ & $\begin{array}{ll}\text { - } & \text { Schwereeinschätzung verschiedener Delikte? (evtl. } \\
& \text { Reihenfolge) } \\
\text { - } & \text { White-Collar- vs. Blue-Collar-Crime } \\
\text { - } & \text { Unterschiede aktiv/passiv (bzw. als Täter/Opfer) }\end{array}$ \\
\hline 4. Kriminalitätsfurcht & $\begin{array}{ll}- & \text { Risikoeinschätzung } \\
- & \text { Attraktivität/Reiz von } \\
& \text { Kriminalität }\end{array}$ & $\begin{array}{ll}- & \text { Haben Sie persönlich Angst vor Kriminalität (bzw. } \\
& \text { Verbrechen)? } \\
-\quad \text { Assoziationen zu "Krimi" (Filme, Romane) } \\
-\quad \text { Kennen Sie den Begriff "Kriminalitätsfurcht"? (Was } \\
\text { bedeutet das/könnte das bedeuten?) } \\
\text { - Vergleich der eigenen Definition mit der "Standardfrage" }\end{array}$ \\
\hline 5. Einstellungen zur Strafe & $\begin{array}{ll}- & \text { Definition } \\
- & \text { Strafzwecke } \\
- & \text { Assoziationen }\end{array}$ & $\begin{array}{ll}\text { - } & \text { Was fällt Ihnen zu "Strafe(n)" ein? } \\
\text { - } & \text { Welchen Sinn/Zweck hat den Strafen? (Wer hat was vom } \\
& \text { Strafen? Warum wird überhaupt bestraft?) } \\
\text { - } & \text { Was wäre, wenn es keine Strafgesetze gäbe? } \\
\text { - } & \text { ad "Verbrechen", "Schuld", "Strafe", "Sühne" } \\
\text { - } & \text { Gewichtung verschiedener Grundrechte (Sicherheit vs. } \\
& \text { Freiheit) } \\
\text { - } & \text { Todesstrafe vs. lebenslange Freiheitsstrafe (o. Bew.)? }\end{array}$ \\
\hline 6. Medien und Kriminalität & $\begin{array}{ll}- & \text { allgemeine Haltung } \\
- & \text { Funktion der Medien } \\
- & \text { Medienwirkung }\end{array}$ & $\begin{array}{ll}- & \text { Realismus, Repräsentativität von Medien (eigene Bsp.)? } \\
- & \text { Wirkungen (persönlich/auf andere/die Bevölkerung allg.) } \\
- & \text { moralische Botschaft (Normverdeutlichung)? }\end{array}$ \\
\hline 7. Moral, Normen, Werte & $\begin{array}{l}- \text { Definitionen } \\
- \text { Quellen/Ursprünge } \\
- \text { Einflüsse } \\
- \text { Erziehung }\end{array}$ & $\begin{array}{ll} & \text { Was ist Moral? } \\
\text { - } & \text { "gut"/"böse" (vs. "kriminell"/"nicht kriminell") } \\
\text { - } & \text { Woher haben Sie Ihre Moral/Ihre Werte? } \\
\text { - } & \text { Einschätzung der eigenen Moral (i. Vgl. z. Bevölkerung) } \\
\text { - } & \text { Gibt es allgemeingültige Normen? (die 10 Gebote, "Was } \\
& \text { du nicht willst ...", Kategorischer Imperativ) }\end{array}$ \\
\hline 8. Sonstiges & $\begin{array}{ll}- & \text { private Sicherheits- } \\
& \text { dienste } \\
- & \text { Videoüberwachung } \\
- & \text { (kommunale) } \\
& \text { Kriminalprävention }\end{array}$ & $\begin{array}{l}\text { - Was würden Sie ändern, wenn Sie Justiz- (Innen-, Fami- } \\
\text { lien-) Minister/in wären? } \\
\text { - Möchten Sie noch etwas sagen? Ist ein für Sie wichtiger } \\
\text { Punkt noch nicht (ausreichend) zur Sprache gekommen? }\end{array}$ \\
\hline
\end{tabular}

Als Erhebungsmethode kam das sog. episodische Interview zum Einsatz. Diese Technik wurde von Uwe Flick als Erweiterung bzw. Ergänzung entwickelt, einerseits zum v.a. bei biographieorientierten Fragestellungen eingesetzten narrativen Interview (vgl. bspw. Schütze, 1983), andererseits in Abgrenzung zum problemzentrierten Interview (z.B. Witzel, 1985). Für die vorliegende Aufgabenstellung ist 
das episodische Interview am besten geeignet, da dabei sowohl die erfahrungsnah-konkreten narrativepisodischen als auch die abstrahierend-verallgemeinernden semantischen Wissensbestandteile abgerufen werden können. Die folgende Abbildung 1 illustriert im Überblick den Zusammenhang der beiden Wissensdomänen und die Rolle des episodischen Interviews bei deren Abfrage.

\section{Abbildung 1: $\quad$ Schematische Darstellung des "Episodischen Interviews"}

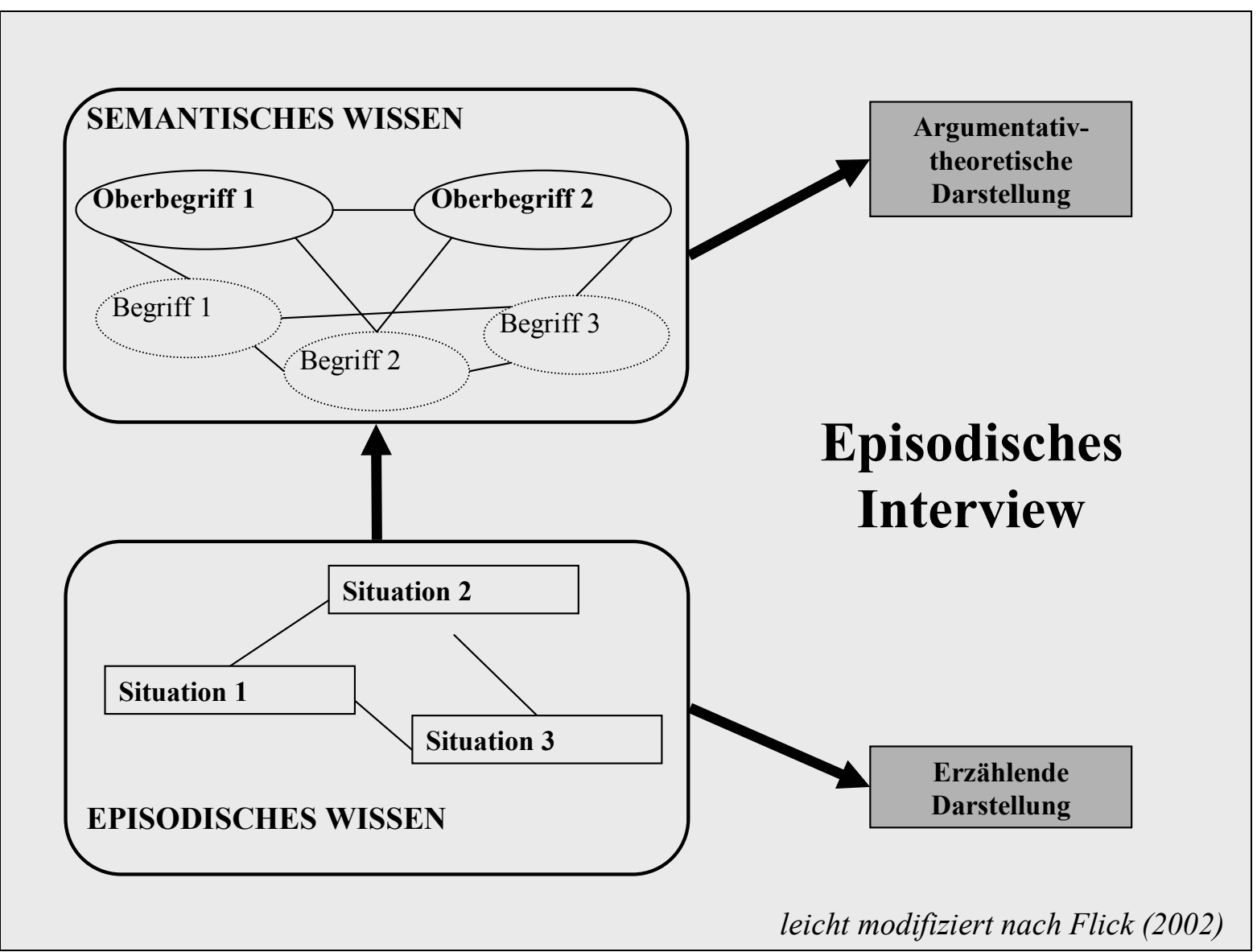

Eine nach Geschlecht, Alter und "sozioökonomischer Status" quotierte Stichprobe der Bevölkerung $(\mathrm{N}=18)$ wurde mithilfe von episodischen Interviews zum gesamten Themenbereich "Kriminalität" befragt, um ein möglichst breites Meinungsspektrum gewährleisten zu können und auch um möglichen zufälligen Selektionseffekten entgegenzuwirken. Dabei wurde zuerst eine Auswahl von Personen befragt, die sich aufgrund von Zeitungsinseraten und öffentlichen Aushängen gemeldet hatten. Diese Basisauswahl wurde in einem zweiten Schritt ergänzt durch gezielt angesprochene Personen aus denjenigen Bevölkerungsgruppen, die zuvor nicht ausreichend berücksichtigt werden konnten (v.a. ältere Menschen beiden Geschlechts und Frauen mit geringer Schulbildung). Tabelle 1 gibt einen Überblick über die Stichprobenverteilung: 
Tabelle 2: $\quad$ Quotenverteilung der episodischen Interviews $(N=18)$

\begin{tabular}{|l|l|c|c|c|}
\hline & & \multicolumn{2}{|c|}{ Schulbildung } & \\
\hline & & (o.) HS/MR & (F)HSR/(F)HSA & Gesamt \\
\hline Frauen & bis 50 Jahre & 1 & 1 & $\mathbf{2}$ \\
\hline & über 50 Jahre & 4 & 3 & $\mathbf{7}$ \\
\hline Männer & Gesamt & $\mathbf{5}$ & $\mathbf{4}$ & $\mathbf{9}$ \\
\hline & bis 50 Jahre & 2 & 2 & $\mathbf{4}$ \\
\hline & über 50 Jahre & 2 & 3 & $\mathbf{5}$ \\
\hline & Gesamt & $\mathbf{4}$ & $\mathbf{5}$ & $\mathbf{9}$ \\
\hline
\end{tabular}

Anmerkungen: (o.) HS/MR = (ohne) Hauptschulabschluss/Mittlere Reife; (F)HSR/(F)HSA = (Fach-)Hochschulreife/(Fach-) Hochschulabschluss

Die Gespräche wurden je nach Wunsch des Interviewpartners vor Ort $(n=4)$ oder im Max-PlanckInstitut $(\mathrm{n}=14)$ durchgeführt und dauerten zwischen 75 und 150 Minuten. Jedes Gespräch wurde mithilfe portabler MD-Recorder mit externen Stereomikrofonen digital aufgezeichnet. Nach den Erfahrungen in den Probeinterviews wurden in allen Gesprächen je nach Präferenzen bzw. Erfahrungen des Gesprächpartners bestimmte thematische Schwerpunkte gesetzt, sodass ein fragebogenartiger "Parforce-Ritt" durch alle Themen der Kriminologie vermieden wurde (was auch die Vorteile der offenen, qualitativ-spontanen Herangehensweise deutlich geschmälert hätte).

Nach der eigentlichen Durchführung der Interviews wurden die angefertigten Tonbandaufzeichnungen der Gespräche wörtlich transkribiert (bzw. ggf. ins Hochdeutsche überführt). Die solchermaßen vorliegenden, Transkripte wurden anschließend weitgehend offen kodiert (unter Verwendung des Auswertungsprogramms Atlas.ti). Die angewendete Auswertungsmethode orientierte sich am thematischen Kodieren (vgl. Strauss, 1991 sowie insb. Flick, 2002). Bei dieser mehrstufigen und (durch mehrere, miteinander verschachtelte induktive und deduktive Schritte) "spiralförmigen" Auswertungsstrategie werden zunächst die einbezogenen Fälle in einer Reihe von Einzelfallanalysen interpretiert. Auf Basis der anhand der einzelnen Gespräche entwickelten Kategoriensysteme wurden anschließend personübergreifende thematische Strukturen herausgearbeitet. Im abschließenden Schritt wurde dann ein erster Versuch unternommen, anhand der verschiedenen thematischen Strukturen eine übergreifende Theorie mittlerer Reichweite (eine erste "Alltagspsychologie der Kriminalität") zu entwickeln bzw. zu rekonstruieren.

Durch diese inhaltsanalytische Auswertung und Verdichtung der Gespräche konnten (1) einige wesentlichen Faktoren subjektiver Kriminalitätstheorien ermittelt werden, um dadurch (2) verschiedene kriminologische Konzepte (s.o.) zu konkretisieren bzw. "mit Leben zu füllen". Dies ermöglicht wiederum, (3) Annahmen über die Zusammenhänge zwischen den genannten Konzepten zu formulieren, die ggf. in nachfolgenden, auf diesen Ergebnissen aufbauenden (Fragebogen-)Untersuchungen überprüfbar sind.

\section{Zusammenfassung der Ergebnisse}

Gemäß der oben dargestellten Auswertungslogik steht am Anfang eine fallbezogene Ergebnisdarstellung - nicht zuletzt auch, weil bei dem hier verwendeten klassisch-ideographischen (individualisierenden) Ansatz die Person zuerst einmal als Ganzes behandelt wird bzw. als die "natürliche Einheit" der Analyse angesehen wird. Für eine detaillierte Darstellung der einzelnen Fallanalysen muss aus Platzgründen allerdings auf die nachfolgende Publikation verwiesen werden. In diesem engen Rahmen werden deshalb nachfolgend nur einige wenige, ausgewählte themenbezogene Ergebnisse skizzenhaft 
dargestellt, die die Befunde über die einzelnen Befragten hinweg zusammenfassen (nomothetischer bzw. generalisierender Ansatz). Aber auch hier muss für alle Details auf den später erscheinenden Band verwiesen werden.

\section{Was ist Kriminalität: Definitionen und Bedeutungen}

Die meisten Befragten nahmen anfangs eine legalistische bzw. positivistische Position ein, definierten Kriminalität mithin als "das, was gegen das Gesetz verstößt" usw. Im Anschluss daran kam es auf Nachfrage bzw. bei weiterem Nachdenken entweder zu einer z.T. elaborierteren Verfestigung dieser Position (v.a. unter Rückbezug auf "feststehende" moralische Grundsätze) oder zum Rückzug bzw. teilweise sogar zu recht heftigen Abwehrreaktionen, bspw. "Das muss doch ausreichen" bzw. "So etwas muss ich doch jetzt nicht wissen". Die bei einigen Befragten nach einiger Zeit eintretende Einsicht in die weitgehende Relativität von Normen ("zu anderen Zeiten bzw. in anderen Ländern sind bzw. waren ja auch schon andere Dinge strafbar - oder eben straffrei ...") geriet oft zu einer schweren Geburt, fast so, als verursache diese Erkenntnis den Befragten großes Unbehagen - was vermutlich dem damit verbundenen Aufgeben-Müssen von vormals sicher geglaubten Annahmen geschuldet ist.

Eher überraschend war die durchweg große (positive) Bedeutung, die traditionellen Strukturen und Werten (z. B. Mehrgenerationenfamilie, enge Nachbarschaftsverhältnisse und Systeme quasi "dörflicher" informeller Sozialkontrolle) im Rahmen der Kriminalitätsprävention zugeordnet wurde. Hier war, durchaus auch bei den jüngeren Befragten, eine deutliche Sehnsucht nach einer (imaginären) "guten alten Zeit" zu spüren.

\section{Einschätzung der Deliktsschwere: Äpfel und Birnen?}

Durch die Bank herrschte zu Anfang eine "Illusion der Vergleichbarkeit" aller Delikte, nicht zuletzt auch unter Bezug auf das (mehr oder weniger) eindimensionale strafrechtliche Sanktionensystem. Später anerkannten jedoch viele Befragte durchaus die Problematik, die verschiedenartigen Deliktsgruppen anhand eines einheitlichen Bewertungssystems zu beurteilen, wobei diese Erkenntnis insbesondere im Zusammenhang mit "Blue-Collar" vs. "White-Collar-Crime" bzw. bei Beispielen von opferlosen Umweltdelikten und Makrokriminalität aufkam. Insgesamt legen die Gespräche sogar den Schluss nahe, dass eine eindimensionale Einschätzung bzw. Einordnung der Deliktsschwere häufig am Wesen der Sache vorbei geht.

\section{Verbrechenssfurcht: Berechtigte Furcht und symbolische Ängste}

In diesem Zusammenhang fand sich nur sehr selten unbegründete Angst vor Viktimisierungen. Vielmehr erscheint die teilweise geäußerte Furcht vor Kriminalität bei genauerem Hinsehen bzw. bei Kenntnis der Persönlichkeit des Befragten und seiner jeweiligen Lebensumstände in den meisten Fällen als nachvollziehbare Vorsicht - und dies durchaus nicht nur (allerdings doch gehäuft) bei älteren Menschen, insbesondere bei Frauen. Überraschend war die große Akzeptanz der sog. "Standardfrage" (d.h. das subjektive Sicherheitsgefühl nachts alleine auf der Straße in der jew. Wohngegend). Nicht überraschend war dagegen, dass die Befragten sich über den enormen Einfluss der Massenmedien, insbesondere bestimmter Boulevardformate, deutlich im Klaren waren. Nachgefragt, ergab sich dann allerdings doch der eher kuriose Befund, dass die Medien zwar einen starken Einfluss auf andere haben, sie das eigene Befinden jedoch nur randständig berührten ("Illusion eigener Immunität").

\section{Einstellungen zu Strafe: Warum wird überhaupt bestraft?}

Die Befragten sahen den Sinn und Zweck von Strafe nahezu ausschließlich in der Sicherung Krimineller bzw. in der Abschreckung potenzieller Täter, mithin also in den negativen Aspekten der (speziellen und generellen) Präventionstheorie. Dagegen wurde die Besserung straffällig gewordener Bürger durch individuelle oder soziale Maßnahmen kaum spontan genannt, auf Hinweis jedoch als durchaus 
wichtig anerkannt. Deutlich schlechter erging es hingegen der positiven Generalprävention i.S.v. Normverdeutlichung, die spontan gar nicht genannt wurde und - erstaunlicherweise - oft selbst nach einigen Hinweisen bzw. nach längeren Erläuterungen nicht oder nur rudimentär verstanden wurde. Hier scheint es fast, als schieße die Strafzwecktheorie voll am Verständnis der Befragten vorbei - zumindest im gesamtgesellschaftlichen Zusammenhang: "übersetzt" man die Problematik bzw. die Prinzipien nämlich in einen Kleingruppenkontext, etwa die Kindererziehung in der Familie, verstanden viele Befragte dann doch den Sinn und Wert der Verdeutlichung bzw. des Transfers von Normen durch Strafen.

Im Zusammenhang mit der Todesstrafe nannten die Befragten (die sich im Übrigen in der Mehrheit dagegen aussprachen) fast ausschließlich rein praktische Gegenargumente (bspw. die Gefahr, Unschuldige hinzurichten oder das Problem, die "richtigen" Kriterien zu finden, ab wann die Todesstrafe zulässig sei). Nur sehr selten wurden dagegen prinzipielle Einwände geäußert. Ein wenig überraschend war es somit, dass einige anfängliche "Gegner" durchaus ins Grübeln kamen, wenn man ihnen Szenarien präsentierte, die mit (vermeintlich) hundertprozentiger Entscheidungssicherheit einhergehen (z.B. durch einen "eindeutigen DNA-Beweis").

\section{Diskussion und Ausblick: Was bieten die Daten - was bieten sie nicht?}

Insbesondere anhand der Einzelfallbeschreibungen ergeben sich teilweise tiefgehende Einblicke in die Gedanken und Emotionen von (südbadischen) "Normal-"Bürgern, an einigen Stellen auch Offenlegungen von unbewussten Vorurteilen bzw. nicht weiter hinterfragten Konzepten (was nicht zuletzt auch die jeweils Befragten überraschte). Mithin ergeben sich Möglichkeiten zur Rekonstruktion der Vorstellungswelten der Befragten im Bezug auf Kriminalität und abweichendes Verhalten (subjektive Theorien) - einschließlich Vorstellungen darüber, wie es besser sein könnte (manchmal sogar in Verbindung mit konkreten Ideen für Veränderungsmöglichkeiten).

Auf der thematischen Auswertungsebene bieten die Daten Möglichkeiten, Gemeinsamkeiten und Unterschiede verschiedener "Typen" subjektiver Theorien aufzuzeigen [NB: gemäß einem qualitativen Typenbegriff, vgl. bspw. Kelle \& Kluge, 1999, d.h. aus den Einzelfällen werden Idealtypen entwickelt - keine quantitativen (Durchschnitts-)Typen bzw. Cluster], um am Ende zu einer ersten Verallgemeinerung im Sinne einer "Alltagspsychologie der Kriminalität" zu gelangen.

Dagegen bieten die Daten (methodenbedingt) keine Angaben zu Verteilungen von Merkmalen, Meinungen und Typen in irgendeiner Gesamtpopulation. Weiterhin lässt sich, naturgemäß bei qualitativer Forschung, auch keine "Repräsentativität" der Befunde postulieren - zumindest nicht im klassisch statistischen Sinne. Allerdings kann, bei sorgfältiger und überlegter Durchführung, durchaus von einer anderen, eher qualitativen Repräsentativität gesprochen werden, dahingehend nämlich, dass die Befunde die ausgewählten Personen bzw. Einzelfälle korrekt und umfassend beschreiben, sie mithin gut repräsentieren.

Abschließend sei noch ein kurzer Ausblick auf mögliche Ergänzungen bzw. Anschlussuntersuchungen erlaubt. Vor dem Hintergrund der stark verschiedenen Erlebniswelten einiger Personen- bzw. Berufsgruppen, versprechen weitere Einzelinterviews mit spezifischen Bevölkerungsgruppen eine lohnende Erweiterung des Meinungsspektrums (so z.B. mit Insassen und Angestellten im Strafvollzug, Beteiligten am Strafverfolgungsprozess, Erziehern, Lehrern, Schülern).

Weiterhin erscheint auch die Absicherung und Validierung der Befunde (sog. "methodologische Triangulation", vgl. Denzin, 1989) durch eine zusätzliche qualitative Gruppenerhebung sinnvoll. Darüber hinaus ermöglichen solche Diskussionen mit homogen zusammengesetzten Gruppen von ca. 6 bis 8 Teilnehmern (sog. "Focus Groups") aufgrund der gänzlich anderen Gesprächssituation bzw. -dynamik auch die Erfassung "sozial unerwünschter" Meinungen und Einstellungen (sog. "Gruppenmeinungen"). Als thematischer Ausgangspunkt für solche Gruppendiskussionen wird in neuerer Zeit regelmä- 
Big die Präsentation der Ergebnisse einer vorangegangenen Einzelinterview-Studie zum gleichen Thema eingesetzt.

\section{- $\quad$ Arbeitsbericht 2002/2003:}

Nach der Durchführung der Interviews (Frühjahr bis Herbst 2002) wurden sukzessive die Transkripte erstellt. Die inhaltsanalytische Kodierung und Auswertung der Gespräche wurde gegen Ende des Jahres 2002 begonnen. Parallel dazu wurde eine Rohfassung des Forschungsstandes bzw. des Theorieteils der Arbeit erstellt. Im September 2002 wurde das inhaltliche und methodische Konzept der Arbeit zusammen mit ersten Ergebnissen im Rahmen des 43. Kongresses der Deutschen Gesellschaft für Psychologie in Berlin erstmalig einer breiteren Fachöffentlichkeit vorgestellt. Im Jahr 2003 wurden die Auswertungen weitergeführt bzw. vertieft und schließlich die Endfassung des Manuskripts erstellt.

- $\quad$ Arbeitsplanungen 2004:

Die im Rahmen dieses Projekts angefertigte Dissertation im Fach Psychologie soll im Sommersemester 2004 bei der Wirtschafts- und Verhaltenswissenschaftlichen Fakultät der Albert-Ludwigs Universität Freiburg i.Br. eingereicht werden. Darüber hinaus sollen die methodischen und inhaltlichen Erkenntnisse dieser Studie auch im Rahmen weiterer Projekte berücksichtigt werden (vgl. die Projektberichte 3.7.3 "Kriminalitätswahrnehmung und die Schwereeinschätzung von Delikten" und 3.7.4 "'Punitivität' - Versuch einer konzeptionellen und empirischen Begriffsbestimmung").

- $\quad$ Projektbezogene Veröffentlichungen:

Albrecht, H.-J., Serassis, T. \& Kania, H. (Eds.): Images of Crime II. Freiburg i. Br. 2004 (in press).

HeRZ, A. \& KANIA, H.: Everyday Perceptions of Crime. In: European Journal of Crime, Criminal Law and Criminal Justice 10, 276-285 (2002).

KANIA, H.: Kriminalitätsdarstellung in den Massenmedien. In: Bundesministerium der Justiz (Hrsg.): Kriminalität in den Medien. Mönchengladbach 2000, 78-97.

KANIA, H.: Kriminalitätsberichte im Fernsehen und die Konstruktion subjektiver Kriminalitätswirklichkeit. In: Landeskommission Berlin gegen Gewalt (Hrsg.), Berliner Forum Gewaltprävention Nr. 12, Themenschwerpunkt: Kriminalitätsopfer. Berlin 2003, 60-71.

KANIA, H.: La rappresentazione del crimine in TV e la costruzione della realtà soggettiva. In: G. Forti \& M. Bertolino (Eds.): La televisione del crimine. Milano 2004 (in press).

KANIA, H. \& HÖFER, S.: "Crime Time" zur Prime Time. Ein Kommentar zu vier Sendungen über Kriminalität in der ZDF-Reihe "Abenteuer Wissen". In: Journascience.org - JSO: Informationsportal zum Thema Kriminalität [Online Dokument]. Verfügbar über:

http://www.journascience.org/de/mediensammlung/content/crime_time.pdf (2003, November).

WALTER, M., ALBRECHT, H.-J. \& KANIA, H.: Alltagsvorstellungen von Kriminalität - Individuelle und gesellschaftliche Bedeutung für die Lebensgestaltung (research in brief - forschung aktuell, Band 11). Freiburg i. Br. 2002.

WALTER, M., KANIA, H. \& AlBRECHT, H.-J. (Hrsg.): Alltagsvorstellungen von Kriminalität. Die individuelle und gesellschaftliche Bedeutung von Kriminalitätsbildern für die Lebensgestaltung. Münster 2004 (im Druck).

- $\quad \operatorname{Im}$ Text erwähnte Forschungsliteratur:

DENZIN, N. K.: The Research Act (3rd Ed.). Englewood Cliffs, NJ 1989.

FLICK, U.: Qualitative Sozialforschung - eine Einführung (6. Aufl.). Reinbek bei Hamburg 2002.

Kelle, U. \& Kluge, S.: Vom Einzelfall zum Typus. Fallvergleich und Fallkontrastierung in der qualitativen Sozialforschung. Opladen 1999. 
SCHÜTZE, F.: Biographieforschung und narratives Interview. In: Neue Praxis 3, 283-293 (1983).

STRAUSS, A. L.: Grundlagen qualitativer Sozialforschung - Datenanalyse und Theoriebildung in der empirischen soziologischen Forschung. München 1991.

Witzel, A.: Das problemzentrierte Interview. In: G. Jüttemann (Hrsg.): Qualitative Forschung in der Psychologie. Grundfragen, Verfahrensweisen, Anwendungsfelder, Weinheim 1985, 227-256.

\subsubsection{Kriminalitätswahrnehmung und die Schwereeinschätzung von Delikten}

- $\quad$ Bearbeiter: Hans-Jörg Albrecht (Jurist/Direktor MPI), Michael Walter (Jurist/Direktor Universität Köln), Thomas Brand (Psychologe/Direktor Universität Köln), Harald Kania (Psychologe/MPI)

- $\quad$ Zeitrahmen: ab 2000

- $\quad$ Projektstatus: fortlaufend

- $\quad$ Projektbeschreibung:

Kooperationsprojekt mit dem Institut für Kriminologie der Universität zu Köln

Den Kernbereich der Zusammenarbeit des Max-Planck-Instituts und des Instituts für Kriminologie der Universität Köln (Leitung: Michael Walter) bildet ein gemeinsames Projekt zur Wahrnehmung von Kriminalität - und dabei insbesondere der Schwere von Delikten - in verschiedenen v.a. europäischen Ländern. Die Kooperation kann auf einige Vorarbeiten an beiden Instituten zurückgreifen (so etwa Villmow, 1977; Walter, 1995, 1998; Walter, Pitsela \& Brand, 2000; Walter et al., 1999). Im Rahmen dieses und weiterer geplanter Folgeprojekte finden regelmäßige Treffen und Workshops von Mitarbeitern beider Institute statt. Darüber hinaus wurde im Frühjahr 2002 ein interdisziplinäres Symposion zu "Alltagsvorstellungen von Kriminalität" an der Universität Köln veranstaltet (vgl. dazu Herz, 2002; Herz \& Kania, 2002; Walter, Albrecht \& Kania, 2002; Walter, Kania \& Albrecht, 2004; Wilms, 2002a, 2002b).

\section{Fragestellung und Forschungsrelevanz}

Allgemein gesprochen zielt die längerfristig angelegte Zusammenarbeit der beiden Institute darauf ab, die Funktionsmechanismen der Kriminalitätswahrnehmung in der Bevölkerung besser zu verstehen bzw. diese zu erklären. Im Rahmen dieses weit gespannten Themenbereichs beschäftigt sich die laufende Forschungsarbeit derzeit insbesondere mit der Wahrnehmung der Schwere krimineller Handlungen, festgelegt durch das Ausmaß, in dem eine Handlung vom jeweiligen Befragten als gravierend bzw. schwerwiegend eingeschätzt wird (Kania et al., 2003). Wichtig ist, dass diese Schwereeinschätzung prinzipiell unabhängig von der strafrechtlichen Bewertung eines Deliktes ist. Die Frage nach der Schwereeinschätzung hat forschungspraktische Relevanz, u.a. für die folgenden Bereiche:

- Die ansonsten rein quantitativen kriminalstatistischen Aussagen zur Kriminalitätsbelastung in einer Gesellschaft können mit den subjektiv von der Bevölkerung empfundenen "Gewichten" versehen werden. Dadurch wird es möglich, Ausmaß und Veränderung der Kriminalität in Form eines subjektiv gewichteten Kriminalitätskennwertes darzustellen.

- Das Anzeigeverhalten der Bevölkerung kann unter Berücksichtigung der Schwereeinschätzung besser verstanden werden. Es ist beispielsweise wahrscheinlich, dass "schwere" Delikte eher angezeigt werden als "leichte". In einer längsschnittlichen Betrachtung lassen sich zudem die damit einhergehenden Hell-Dunkelfeld-Verschiebungen analysieren. Dabei müssen aber immer auch andere Faktoren der Anzeigebereitschaft beachtet werden (Erfolgsaussichten, versicherungsrechtliche Bestimmungen u.Ä.). 
- Daneben könnte die Schwereeinschätzung auch einen weiteren Baustein zur Erforschung der Generalprävention liefern: Es ist denkbar, dass die abschreckende bzw. normverdeutlichende Wirkung von Strafen wesentlich von der eingeschätzten Schwere der Delikte abhängt.

- Auch kriminalpolitische Gewichtungen können mithilfe von Schweredaten hinsichtlich ihrer Akzeptanz bei der Bevölkerung geprüft werden. Bei einem Auseinandergehen von öffentlicher Wahrnehmung und strafrechtlicher Ahndung von Straftaten könnten gezielte Aufklärungsmaßnahmen das gesellschaftliche Verständnis für die Entscheidungen der Gerichte evtl. erhöhen. Aber auch der umgekehrte Fall ist denkbar (wenngleich nicht unbedingt wünschenswert) - die Rechtssprechung berücksichtigt die Schwereeinschätzung der Bevölkerung bei ihren Urteilen.

- Und nicht zuletzt können auch Resozialisierungsmaßnahmen kompatibel zu den Bevölkerungsvorstellungen gestaltet werden, wenn die Wahrnehmung der Schwere verschiedener Straftaten in der Bevölkerung berücksichtigt wird. Dabei ist z.B. an den Einsatz von Haft vermeidenden Strafformen zu denken, die sich bei als besonders schwer eingeschätzten Delikten häufig nur gegen massive Widerstände durchsetzen werden lassen.

Darüber hinaus werden im Rahmen der Forschungskooperation aber auch die noch allgemeineren Aspekte der Kriminalitätswahrnehmung und der Vorstellungen von Kriminalität ("Subjektive Kriminalität", vgl. Walter, 1995, 1998) in der Bevölkerung erforscht. Dieser weitgehend neue und empirisch kaum bearbeitete Forschungsbereich wurde zum einen im Rahmen eines von den Kooperationspartnern gemeinsam veranstalteten interdisziplinären Symposions ausgeleuchtet (s. 4.). Zum anderen untersucht ein mit dem Kooperationsprojekt verbundenes Promotionsprojekt am MPI einige grundlegende Aspekte subjektiver Kriminalitätsrepräsentation mithilfe qualitativer Methodik (vgl. Projektbeschreibung 3.7.2).

\section{Forschungshintergrund}

Die Bestimmung der Schwereeinschätzung hat in der kriminologischen Forschung bereits Tradition. Der ursprüngliche Anlass der ersten Arbeiten war, einen gewichteten Kriminalitätsindex zu entwickeln, gewissermaßen als ein, im Vergleich zu den gängigen Statistiken, mehr qualitatives "ergänzendes Maß der Kriminalstatistik" (Sellin \& Wolfgang, 1964). Weitere Anwendungsmöglichkeiten von Schweremaßen, wie etwa die zuvor genannten, wurden erst später expliziert. Vergröbernd gesprochen kann die bisherige Forschung zur Schwerewahrnehmung in zwei Phasen unterteilt werden: (1) Eine Pionierphase, in der von einem weitgehenden intra- und interkulturellen Konsens über die Schwere verschiedener Delikte bzw. zumindest hinsichtlich deren Rangfolge ausgegangen wurde. Als Grundlage dieses Konsenses wurden allgemeingültige und weit verbreitete "gemeinsame Kulturvorstellungen" angenommen (so etwa Schindhelm, 1972). (2) Mittlerweile werden jedoch zunehmend Zweifel an der allgemeinen Gültigkeit eines solchen Konsenses geäußert, belegt durch empirisch feststellbare Divergenzen in den Schwereeinschätzungen, und zwar sowohl zwischen verschiedenen Kulturkreisen als auch innerhalb einer Kultur. Die Befunde dieser Elaborationsphase lassen sich vor allem durch die Anwendung differenzierterer Methoden erklären, wobei u.a. Kontrastgruppenbefragungen, detaillierte Beschreibungen der einzuschätzenden Delikte und exaktere Auswertungsmethoden zu nennen sind.

\section{Internationaler Vergleich der Schwereeinschätzungen}

Der vorgenannte Forschungsstand bildete den Ausgangspunkt für eine aktuell im Rahmen des Kooperationsprojekts durchgeführte Untersuchung, in der zwei bislang - vor allem in ihrer Kombination kaum beachtete Aspekte berücksichtigt werden: (1) Der in bisherigen Untersuchungen meist bilaterale interkulturelle Vergleich wurde zu einem umfassenden multilateralen europäischen Vergleich erweitert. (2) Die einzuschätzenden kriminellen Delikte decken ein breites Spektrum kriminellen Verhaltens ab. Für diese Untersuchung konnte auf Vorarbeiten sowohl am MPI (etwa Villmow, 1977) als auch am Kölner Institut für Kriminologie (Walter et al., 1999) zurückgegriffen werden. Vor diesem Hinter- 
grund entwickelten die Kölner Mitarbeiter einen Fragebogen zur Schwereeinschätzung, der von jeweils zwei studentischen Stichproben (Studienanfänger und fortgeschrittene Studenten der Rechtswissenschaft) bisher in neun europäischen Ländern sowie Argentinien ausgefüllt wurde (weitere Erhebungen laufen bereits bzw. sind geplant). Die Daten beinhalten neben soziodemographischen Variablen und studienbezogenen Informationen auch die Schwereeinschätzungen für 22 prototypisch formulierte Delikte, die ein weites Spektrum möglicher Taten abdecken (vgl. für die einzelnen Deliktsbeschreibungen: Walter et al., 1999, Anhang). Die Übersetzung des Fragebogens und die Datenerhebung wurden durch Forschungspartner in den jeweiligen Ländern besorgt. Inzwischen wurde bereits ein Vergleich der Antwortstrukturen der griechischen und der deutschen Stichprobe veröffentlicht (Walter, Pitsela \& Brand, 2000). Dabei fanden sich einerseits Unterschiede im Antwortverhalten zwischen den beiden Ländern, andererseits aber auch Unterschiede innerhalb eines Landes bezogen auf die Variablen Geschlecht und Alter. Die dort aufgezeigten Unterschiede in der Einschätzung der verschiedenen Delikte, insbesondere bei den gewalthaften Handlungen, legen einen umfassenden internationalen Vergleich aller Länder nahe (vgl. für einen ersten Überblick Kania et al., 2003). Geplante weitergehende Analysen der Daten unter Einbezug aller beteiligten Länder werden eine noch differenziertere Analyse der verschiedenen Einflußfaktoren erlauben.

\section{Interdisziplinäres Symposion "Alltagsvorstellungen von Kriminalität - Individuelle und gesellschaft- liche Bedeutung für die Lebensgestaltung"}

Parallel zu der beschriebenen aktuellen empirischen Forschung beschäftigen sich die Projektmitarbeiter beider Institute aber auch mit den o.g. grundlegenden Fragen zur subjektiven Kriminalität. Zu diesen Bemühungen zählt, neben dem erwähnten Promotionsprojekt, insbesondere auch die Durchführung eines interdisziplinären Symposions, das in der Zeit vom 21. bis 23. Februar 2002 zum Thema "Alltagsvorstellungen von Kriminalität - Individuelle und gesellschaftliche Bedeutung für die Lebensgestaltung" an der Universität Köln stattfand. Im Rahmen dieses Symposions wurde zuerst einmal der Kenntnisstand in den verschiedenen mit Kriminalitätsvorstellungen beschäftigten Bereichen bilanziert. Darauf aufbauend wurden anschließend die relevanten Aspekte zukünftiger Forschung herausgearbeitet und hinsichtlich der Möglichkeit interdisziplinärer Zusammenarbeit diskutiert. Zu den Teilnehmern gehörten neben Forschern aus den Bereichen Kriminologie (mit den Teildisziplinen Rechtswissenschaft, Psychologie und Soziologie), Sozialpädagogik, Geschichts-, Literatur- und Medienwissenschaft auch Praktiker aus verschiedenen relevanten gesellschaftlichen Bereichen, z.B. Kriminalpolitiker, Ermittlungs- und Strafvollzugsbeamte, Gerichtsreporter und andere Medienberufe (vgl. für einen ersten Überblick Herz, 2002; Herz \& Kania, 2002; Wilms, 2002a, 2002b).

Das Symposion hat dazu beigetragen, das Verständnis von Kriminalität in einem zentralen Punkt zu erweitern: Kriminalität wird herkömmlich aus einem juristischen Grundverständnis heraus fast ausschließlich als eine Gefährdung des "gedeihlichen Zusammenlebens" betrachtet, der das Strafrechtssystem sowie Maßnahmen der Polizei, der Jugendhilfe und anderer Einrichtungen mit unterschiedlichem Erfolg entgegentreten. $\mathrm{Zu}$ wenig - und vor allem wenig systematisch und ohne die nötigen interdisziplinären Querverbindungen - wird seitens der Kriminologie berücksichtigt, dass Kriminalität neben dieser objektiven Bedrohung zugleich ein lebens-gestaltendes Thema darstellt, um das unsere Vorstellungen kreisen, auch wenn wir weder Opfer werden noch in der Versuchung stehen, selbst Straftaten zu begehen. Vergleichbar dem Thema "Sex" nimmt auch das Thema "Crime" -Straftaten, deren Täter, Opfer und Umstände - uns "gefangen" und fesselt unsere Aufmerksamkeit. Infolgedessen ist Kriminalität in mannigfacher Weise in unsere gesamte Kultur "verwoben", vom Kriminalroman über Berichterstattungen in den Massenmedien bis hin zu den grundlegenden gesellschaftlichen Auseinandersetzungen über Vergeltung und Strafe. Mit dem Symposion wurde ein erster Versuch unternommen, die "subjektive Kriminalität" in ihrer Gesamtheit zu erfassen und dazu die durchaus vorhandenen Überlegungen und Befunde zusammenzuführen und gemeinsam in den Blick zu nehmen. Indem die Vielfältigkeit der vorhandenen Ansätze und die Bedeutung von Kriminalitätsvorstellungen in individueller und gesellschaftlicher Hinsicht begreifbar gemacht und als zusammengehörig wahrgenom- 
men werden, sollen die Voraussetzungen für eine Entfaltung und systematische Erschließung dieses umfänglichen Forschungsbereichs geschaffen werden.

\section{Ausblick auf mögliche Anschlussforschungen}

Der oben beschriebene Vergleich der Schwerewahrnehmung stellt den ersten Versuch eines europaweiten Vergleichs der Kriminalitätswahrnehmung dar, wenngleich hier nur bestimmte Aspekte betrachtet werden. Je nach Lage der Ergebnisse dieser ersten Untersuchung könnten sich im Anschluss daran weitergehende Studien auch zu anderen Facetten subjektiver Kriminalität (etwa Kriminalitätsfurcht vs. Attraktivität, Punitivität, Vulnerabilität) als sinnvoll darstellen, beispielsweise eine sowohl theoretisch als auch erhebungsmethodisch weiterentwickelte Fragebogenstudie. Für den inhaltlichen und theoretischen Unterbau einer solchen Untersuchung könnten u.a. die Ergebnisse der mit diesem Projekt assoziierten Dissertation zu den Alltagsvorstellungen über Kriminalität in der Bevölkerung herangezogen werden (vgl. 3.7.2). In methodischer Hinsicht ist dabei etwa an die Erhebung von für die gesamte Bevölkerung der jeweiligen Länder repräsentativen Stichproben zu denken. Die große Bedeutung von weiteren Forschungen in diesem Bereich ergibt sich nicht zuletzt durch die zunehmende Globalisierung, in Europa insbesondere die Erweiterung der EU. Denn im Hinblick auf eine immer näher zusammenrückende Staatengemeinschaft stellt sich verstärkt auch die Frage nach der Homogenität der Einstellungen und Wahrnehmungen über die Ländergrenzen hinweg.

\section{- $\quad$ Arbeitsbericht 2002/2003:}

Der Schwerpunkt der Tätigkeit lag seit Projektstart auf der theoretisch-konzeptionellen Seite. Insbesondere wurde die internationale Literatur gesichtet und der Aufbau einer Literaturdatenbank begonnen. Verschiedene Aspekte der Kooperationsarbeit wurden in gemeinsamen Vorträgen und Workshops zu Theorien und Methoden erörtert. In der ersten Jahreshälfte 2002 lag der Fokus der Arbeit auf der Vorbereitung, Durchführung und Nachbereitung des Kölner Symposions. Dazu gehörte auch die Veröffentlichung von Tagungsberichten in verschiedenen deutsch- und englischsprachigen Zeitschriften (Herz, 2002; Herz \& Kania, 2002; Wilms, 2002a, 2002b) sowie die Publikation aller Beiträge in einem Tagungsband (Walter, Kania \& Albrecht, 2004). Daneben stellte die weitere Auswertung und Publikation der vorliegenden internationalen Daten zur Schwereeinschätzung einen weiteren wichtigen Teil der Arbeiten im Jahr 2003 dar (vgl. Kania et al., 2003).

- $\quad$ Arbeitsplanung 2004:

Im Jahr 2004 sollen einerseits die internationalen Vergleichsdaten zur Schwereeinschätzung vertiefend ausgewertet und möglichst international publiziert werden. Darüber hinaus werden sukzessive weitere Erhebungsländer in die Stichprobe einbezogen. Schließlich sollen weiterhin, u.a. auf der Basis der Ergebnisse der qualitativen Studie zu "Subjektiven Kriminalitätsvorstellungen" (vgl. 3.7.2), die Planungen für eine neue internationale Erhebung mit optimierter Methodik sowie erweiterten Inhalten vorangetrieben werden.

- $\quad$ Projektbezogene Veröffentlichungen und weitere ausgewählte Literatur:

HERZ, A.: Tagungsbericht: Alltagsvorstellungen von Kriminalität - Ein interdisziplinäres Symposium vom 21. bis 23. Februar 2002 an der Universität zu Köln. In: Monatsschrift für Kriminologie und Strafrechtsreform 85, 377-385 (2002).

HERZ, A. \& KANIA, H.: Everyday Perceptions of Crime. In: European Journal of Crime, Criminal Law and Criminal Justice 10, 276-285 (2002).

KANiA, H., BRAND, T., ZimmermanN, S. \& WALter, M.: Die Einschätzung von Gewaltdelikten im europäischen Vergleich. Eine Fragebogenuntersuchung an Studierenden in zehn Ländern. In: Monatsschrift für Kriminologie und Strafrechtsreform 86, 247-264 (2003). 
WALTER, M., AlBRECHT, H.-J. \& KANIA, H.: Alltagsvorstellungen von Kriminalität - Individuelle und gesellschaftliche Bedeutung für die Lebensgestaltung (research in brief - forschung aktuell, Band 11). Freiburg i. Br. 2002.

WALteR, M. KANiA, H. \& AlBRECHT, H.-J. (Hrsg.): Alltagsvorstellungen von Kriminalität. Die individuelle und gesellschaftliche Bedeutung von Kriminalitätsbildern für die Lebensgestaltung. Münster 2004 (im Druck).

WILMS, Y.: Alltagsvorstellungen von Kriminalität. Bericht über ein Symposium. In: Bewährungshilfe 49, 395-407 (2002a).

WILMS, Y.: Symposium über Alltagsvorstellungen von Kriminalität - Ein Überblick. In: Zeitschrift für Strafvollzug und Straffälligenhilfe 51, 297-303 (2002b).

- Weitere ausgewählte Literatur:

SCHINDHELM, M.: Der Sellin-Wolfgang-Index - ein ergänzendes Maß der Strafrechtspflegestatistik. Stuttgart 1972.

Sellin, T. \& Wolfgang, M.: The Measurement of Delinquency. New York 1964.

VILLMOW, B.: Schwereeinschätzung von Delikten. Berlin 1977.

WALTER, M.: Von einem realen zu einem imaginären Kriminalitätsverständnis? Über den Wandel kriminologischer Blickrichtung und dessen kriminalpolitische Folgen. In: Zeitschrift für Strafvollzug und Straffälligenhilfe 44, 67-73 (1995).

WALter, M.: Über subjektive Kriminalität - Am Beispiel des Kriminalitätsanstiegs. In: H.-D. Schwind, E. Kube \& H.-H. Kühne (Hrsg.): Kriminologie an der Schwelle zum 21. Jahrhundert (Festschrift für Hans Joachim Schneider zum 70. Geburtstag). Berlin 1998, 119-135.

Walter, M., Brand, T., Geiter, H., Kania, H., Kremer, O. \& KreutZ, A.: Täter-Opfer-Ausgleich aus der Sicht von Rechtsanwälten. Einschätzungen, Ansichten und persönliche Erfahrungen (hrsg. vom BMJ). Mönchengladbach 1999.

WAlter, M., Pitsela, A. \& BRAND, T.: Unterschiede in der Beurteilung von Gewaltdelikten - junge Deutsche und Griechen im Vergleich. In: Monatsschrift für Kriminologie und Strafrechtsreform 83, 375-386 (2000).

\subsection{4 "Punitivität" - ein konzeptioneller und empirischer Ansatz}

- $\quad$ Bearbeiter: Harald Kania, Helmut Kury, Joachim Obergfell-Fuchs (Psychologen)

- $\quad$ Zeitrahmen: ab 2002

- $\quad$ Projektstatus: fortlaufend

- Projektbeschreibung:

Dieses neue Projekt schließt an einige Vorarbeiten der Projektmitarbeiter an, insbesondere an das inzwischen abgeschlossene Projekt "Strafeinstellungen der Bevölkerung" (Kury, 1998-2001). Vor dem Hintergrund der immer wieder geäußerten Annahme einer zunehmenden Verstärkung von Strafbedürfnissen in den letzten Jahren, sowohl in Deutschland als auch in den meisten anderen westlichen Industrieländern, insbesondere in den USA, erscheint es geboten, im Rahmen eines wissenschaftlichen Projektes einerseits die in der Diskussion verwendeten Begriffe einer genaueren Prüfung zu unterziehen und andererseits die vorliegenden empirischen Befunde in diesem Licht zu bewerten. Dieser zweigeteilten Aufgabe soll sich das nachfolgend umrissene Projekt widmen. 


\section{Einleitung und Überblick}

Gemäß dem derzeitigen Stand der Dinge soll das Projekt auf drei Säulen aufbauen - einer inhaltlichkonzeptionellen, einer empirischen und einer methodenkritischen.

- In inhaltlicher Hinsicht soll versucht werde, den Gehalt des Konzepts zu bestimmen, mithin die Frage zu beantworten: "Was ist überhaupt 'Punitivität'?" In diesem Zusammenhang soll auch versucht werden, die bisher - in Medien und Wissenschaft - teilweise synonym gebrauchten Begriffe ("Punitivität", "Strafmentalität", "Strafeinstellungen", "Strafbedürfnisse", neuerdings sogar "Straflust", vgl. etwa Hassemer, 2000) auf ihren Gebrauchswert hin zu prüfen und dadurch (hoffentlich) eine größere begriffliche Einheitlichkeit bzw. Klarheit zu erreichen.

- Darüber hinaus soll auch der empirische Forschungsstand - aktuell und auch historisch - aufgearbeitet werden, indem gefragt wird: "Was wissen wir aktuell über Punitivität? Bei dieser Sichtung der (nationalen/internationalen) Forschungsarbeiten wird insbesondere auf die Erhebungsmethoden eingegangen und geprüft, welche Forscher mit welchen Methoden welche Ergebnisse erhalten haben - und wie diese interpretiert wurden (bzw. werden könnten)?

- Daran soll ein umfangreicher methodenkritischer Teil angeschlossen werden, in dem nach der Gültigkeit und Aussagekraft der präsentierten Befunde gefragt wird sowie die Stärken und Schwächen der verschiedenen Erhebungsmethoden kritisch unter die Lupe genommen werden.

Auf der Basis dieser drei Säulen ist zuletzt ein abschließender Ausblick geplant, in dem gefragt wird, wie sich die zukünftige Forschung im Bereich "Punitivität" verbessern lässt bzw. welche neuen Ansätze denkbar und sinnvoll sind?

\section{Konzeptionelles: Was ist Punitivität?}

Im konzeptionellen Teil soll die grundlegende Frage angesprochen werden, was Punitivität eigentlich ist, wie man den Begriff in geeigneter Weise definieren kann (oder sollte) bzw. wie er in der vorliegenden Forschung üblicherweise definiert (oder operationalisiert) wird. Bei dieser Gelegenheit soll auch auf die (unserer Meinung nach) unterschiedlichen Ebenen und den Hintergrund des Konzepts eingegangen werden:

(a) Punitivität kann zunächst einmal als die individuelle Strafmentalität bzw. das individuelle Strafbedürfnis einzelner Personen angesehen werden (z.B. Oswald, Hupfeld, Klug \& Gabriel, 2002). Auf dieser individuellen Ebene geht es vor allem um die persönlichen Annahmen, Werte, Konzepte und auch Emotionen, über die einzelne Personen bspw. in Befragungen u.Ä. berichten können. (Mikroperspektive der Punitivität)

(b) Weiterhin kann Punitivität aber auch als eine überindividuelle Größe betrachtet werden, die sich z.B. im gesamtgesellschaftlichen Diskurs (v.a. in den Medien) zeigt. (Makroperspektive der Punitivität)

(c) Darüber hinaus gibt es aber auch (mindestens) noch eine dritte Ebene der Punitivität zu berücksichtigen, nämlich die Strafmentalitäten innerhalb des Justizapparates und deren Einfluss auf verhängte Sanktionen (vgl. etwa Kuhn, Villettaz, Jayet \& Willi, 2002). (Justizielle Punitivität)

Insbesondere die Rolle der (Kriminal-)Politik soll in ihren Verknüpfungen mit den bzw. hinsichtlich ihres Einflusses auf die o.g. Punitivitätsebenen genauer analysiert werden. Gegebenenfalls soll versucht werden, die Zusammenhänge und Interaktionen der verschiedenen Instanzen und Elemente in einen ersten, sicherlich noch entwurfsartigem Gesamtkontext einzuordnen. Abbildung 1 zeigt einen solchen Versuch, die (mögliche) Reichweite des Konzeptes "Punitivität" und dessen Bedeutung für andere zentrale kriminologische Konzepte (bspw. "Verbrechensfurcht") bzw. der Einfluss von Puniti- 
vität auf die aktuelle (Kriminal-)Politik (bspw. beim Thema "Innere Sicherheit") am Beispiel der individuellen Punitivität zu veranschaulichen. Gemäß dieser Sichtweise sind die zahlreichen persönlichen und gesellschaftlichen Einflussfaktoren bzw. Determinanten - wie bei einer Zwiebel - in mehreren Lagen (und dadurch auch mit jeweils unterschiedlichem "Abstand) um den Kern, in diesem Fall die persönlichen Punitivität, geschichtet.

\section{Abbildung 1: $\quad$ Das "Zwiebelmodell" der Punitivität}

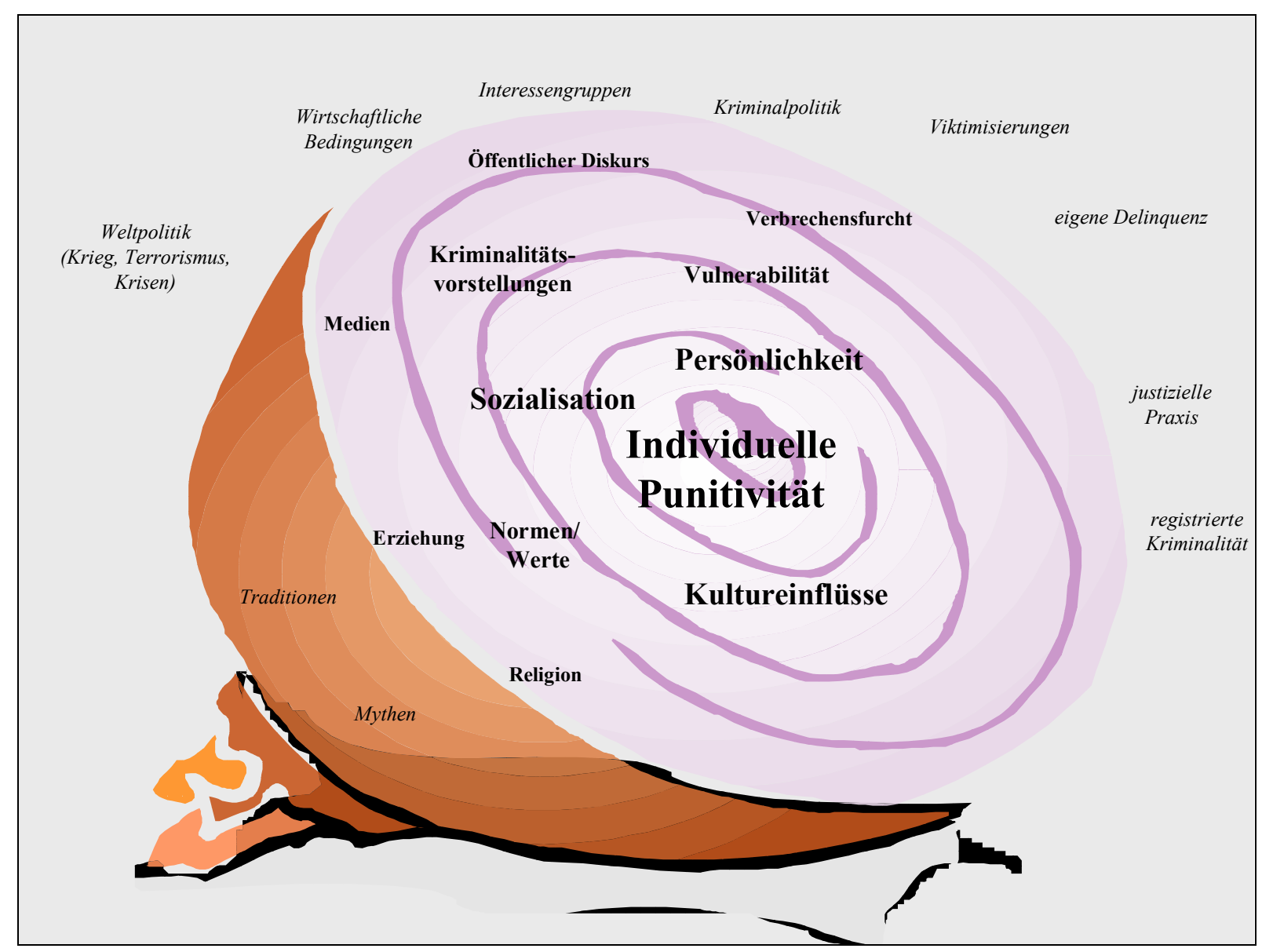

Im Weiteren soll, wiederum v.a. mit Bezug auf die erstgenannte Ebene, die individuelle Punitivität, insbesondere auch die Rolle des persönlichen Werte- und Normengefüges berücksichtigt werden (zusätzlich zu dem ebenfalls sehr gewichtigen Einfluss unterschiedlicher Eingangsinformationen, v.a. durch die Medien, s.u.). Die folgende Abbildung 2 gibt einen Überblick über die vermuteten Zusammenhänge in diesem Bereich: Eingehende Informationen zu aktuellen kriminalitätsbezogenen Themen (v.a. über Medienberichte) werden vor dem Hintergrund jeweils individueller Annahmen und Wissensbestände (individuelle Vorstellungen) verarbeitet und dann (häufig) mehr oder weniger öffentlich ausgetauscht und diskutiert ("öffentliche" Meinungsbildung), bspw. im Freundes- oder Kollegenkreis. Diese Informationsverarbeitung äußert sich dann anschließend ggf. auf der Verhaltens- und Einschätzungsebene, bspw. in gesteigerter Kriminalitätsfurcht, geändertem Wahlverhalten oder eben härteren Strafforderungen. 
Abbildung 2: $\quad$ Die Bedeutung individueller Vorstellungen

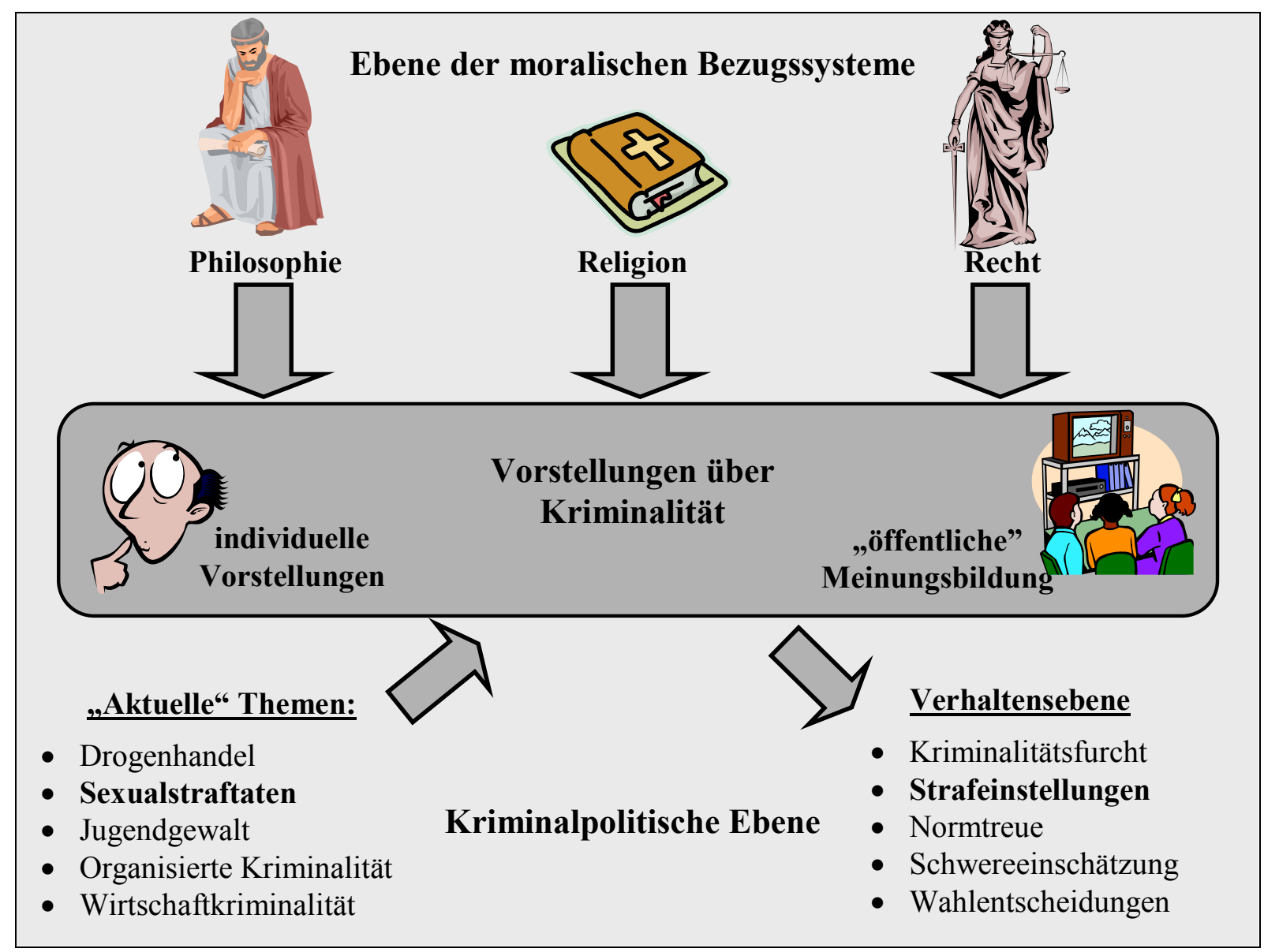

\section{Methodisches und Empirisches: Wie wird Punitivität erhoben - und was kommt dabei heraus?}

Analog zu der o.g. Dreiteilung (individuelle - gesellschaftliche - justizielle Punitivität) sollen auch die in der einschlägigen Forschung verwendeten Erhebungsmethoden klassifiziert werden. In empirischer Hinsicht liegt ein Schwergewicht bei der Erhebung individueller Strafeinstellungen, meist mithilfe von (regelmäßigen) schriftlichen Befragungen. Neben (nationalen und internationalen) Fremddaten (z.B. ICVS, Allensbach, US-Justizministerium) liegen hierzu eigene Datenquellen vor (Freiburg-Jena, vgl. Kury, Obergfell-Fuchs \& Würger, 2002; Obergfell-Fuchs \& Kury, im Druck; Kölner Rechtsanwaltsbefragung, vgl. Walter et al., 1999). Deutlich seltener werden dagegen qualitative Methoden (z.B. Einzel- bzw. Gruppeninterviews) bei der Untersuchung von Punitivität eigesetzt, wobei die Projektgruppe auch hier mit ersten eigenen Daten zu subjektiven Kriminalitätsvorstellungen der Bevölkerung aufwarten kann (vgl. dazu auch die Projektbeschreibung 3.7.2). Untersuchungen zur Punitivität mithilfe von (Feld- bzw. Labor-) Experimenten gibt es hingegen nur sehr selten (etwa Doob \& Roberts, 1988; oder - in methodenkritischer Absicht - Kury, 1995).

Einen zweiten methodischen Schwerpunkt der Forschungsliteratur bilden die Daten der Justiz- bzw. Sanktionierungspraxis (bspw. Rechtspflegestatistiken). Auf nationaler Ebene lässt sich anhand ausgewählter Deliktsbereiche die Entwicklung in der justiziellen Sanktionenstruktur (Art und Dauer der Sanktion) über die Zeit hinweg analysieren und im Hinblick auf Veränderungen der zugrunde liegenden Strafmentalität interpretieren. 
Die gesamtgesellschaftliche (oder Makro-)Punitivität, wird im Vergleich zu den anderen beiden Ebenen nur sehr selten empirisch untersucht. Da der öffentliche Diskurs hauptsächlich in den Medien stattfindet bzw. sich dort niederschlägt, sollten auch die Erhebungsmethoden an diesen Stellen ansetzen. Dabei ist insbesondere an differenzierte Medienanalysen (qualitativ und quantitativ) zu denken. Aus dem Gesagten ergeben sich (zumindest) die in Abbildung 3 dargestellten konzeptionellen und methodischen Facetten von Punitivität. Auf der konzeptionellen Ebene wird angenommen, dass "Punitivität" nicht als ein einheitliches und eindimensionales Konstrukt angesehen werden kann, sondern dass sich Strafmentalitäten vielmehr in verschiedenartigen Bereichen bzw. Domänen auffinden und analysieren lassen (vgl. 2.). Darüber soll die Abbildung auch verdeutlichen, dass zur Analyse dieser verschiedenen "Punitivitäten" auch ganz unterschiedliche Erhebungs- und Auswertungsmethoden zur Verfügung stehen. Damit soll allerdings keineswegs eine eindeutige Zuordnung von Punitivitätsebene und Methodik impliziert werden - vielmehr erscheint oft gerade die Kombination verschiedener methodischer Ansätze (Multimethodalität) besonders Erfolg versprechend (wenngleich sich sicherlich nicht alles mit allem sinnvoll kombinieren lässt).

\section{Abbildung 3: Inhaltliche und methodische Diversifizierung des Konstrukts "Punitivität"}

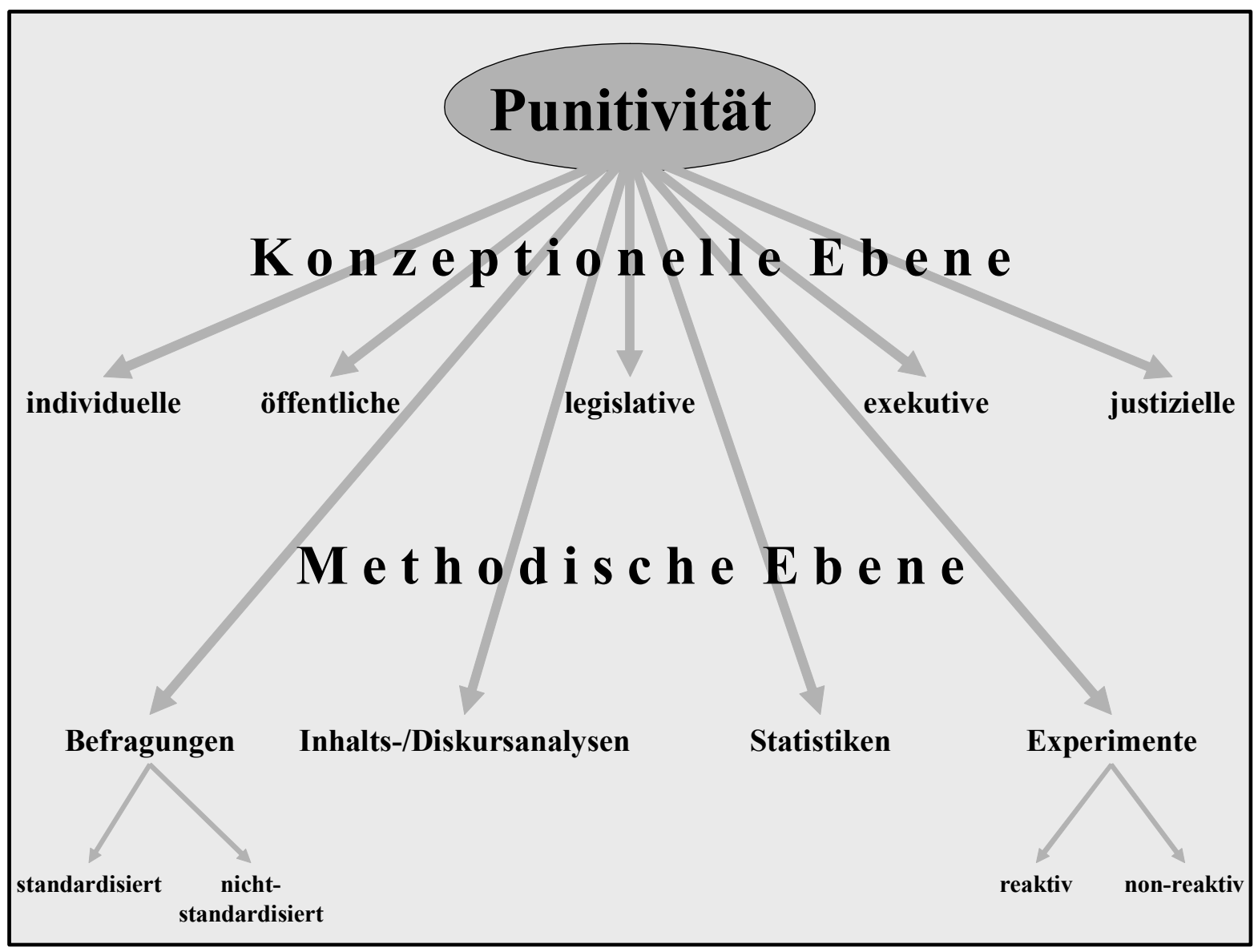

\section{Methodische Probleme: Was messen wir eigentlich, wenn wir "Punitivität" messen?}

In diesem Teilbereich des Projekts soll im Besonderen auf die Probleme der verschiedenen empirischen Methoden zur Erfassung von Punitivität eingegangen werden, wiederum (möglichst) geordnet nach den drei o.g. Punitivitätsebenen. 
Die auftretenden Probleme bzw. methodischen Einschränkungen können dabei durchaus von Fall zu Fall verschieden sein. Beispielsweise kann die Frage nach der Akzeptanz der Todesstrafe maßgeblich von den erhebungstechnischen Rahmenbedingungen (Sanktionsalternativen! Vgl. etwa Kury, 1995) oder der gesellschaftlich-rechtlichen Situation abhängen (wird die Todesstrafe tatsächlich durchgeführt?). In vielen Fällen weiß der Untersucher (bzw. der Leser) am Ende nicht, was eigentlich gemessen wurde (Problem der Validität der Erhebung). Weiterhin hängen die Ergebnisse auch von unkontrollierten Stichprobenschwankungen über die verschiedenen Erhebungszeitpunkte hinweg, unterschiedlichen (und v.a. nicht weiter hinterfragten) Informationen der Befragten zur Sanktionswirklichkeit oder auch von kurzfristigen "crime waves" bzw. "moral panics" ab, wodurch die Zuverlässigkeit bzw. die Replizierbarkeit der Ergebnisse gefährdet ist (Problem der Reliabilität der Erhebung).

Im Rahmen des Projekts soll versucht werden, die verschiedenen empirischen Herangehensweisen auf derartige methodische Schwächen hin abzuklopfen und - soweit möglich - Alternativen bzw. Kompensationsmöglichkeiten vorschlagen. In diesem Zusammenhang werden wir auch auf den (häufig verzerrenden) Einfluss der Medien auf das Kriminalitätswissen eingehen (Überrepräsentation bestimmter Delikte, insbesondere schwerer Gewalttaten, die oft zusätzlich auf unrealistische Art und Weise dargestellt werden (vgl. etwa Förster \& Schenk, 1984; Gerbner \& Gross, 1976; Kania, 2004; Reiner, 2002; Sheley \& Ashkins, 1981; Surette, 1998). Auch die von den Medien häufig geübte Praxis des Anbietens bestimmter Lösungen ("Paketlösung") - meist in Form von härteren Strafen - soll kritisch betrachtet werden.

\section{Zwischenfazit: Wo stehen wir aktuell?}

Auf der Basis der o.g. Befunde soll versucht werden, herauszufinden, ob die Punitivität (weltweit) zunimmt. Neben der Antwort auf diese Frage (die, soviel lässt sich schon jetzt vorwegnehmen, nicht in Form eines klaren "Ja" oder "Nein" beantwortet werden kann), soll auch auf das mögliche Interesse von Wissenschaft, Politik und Medien an steigender Punitivität eingegangen werden ("Cui bono"?).

In diesem Zusammenhang soll insbesondere die Rolle der (Kriminal-)Politik ausführlich betrachtet und mit einigen Beispielen der jüngeren nationalen Politikgeschichte illustriert werden (Schröders "Wegschließen ...", Sicherungsverwahrung, Fall "Mehmet", Wahlsieg Schill, Folter im Ermittlungsverfahren usw.). Dabei lässt sich insgesamt eine zunehmende Fokussierung auf bestimmte Delikte bzw. bestimmte Tätergruppen feststellen (im Wesentlichen Gewalt- und Sexualtäter sowie jugendliche Intensivtäter). Darüber hinaus soll aber auch hinterfragt werden, woran es liegt, dass immer mehr Politiker ihr Heil in einer punitiv-repressiven Kriminalpolitik suchen. Vergleichbare Trends lassen sich auch in internationaler Perspektive ausmachen, nicht zuletzt die seit geraumer Zeit feststellbare USamerikanische "Punitive Renaissance" ("War on Drugs", Kampf gegen den internationalen Terrorismus", "sportliche" Inhaftierungsregeln, neuartige Resozialisierungsversuche in sog. "Boot Camps", "Zero Tolerance" bzw. das "New Yorker Modell" usw.). Neben der Politik soll auch der Zusammenhang zur Medienpräsenz von Strafe ausführlich thematisiert werden (dazu aktuell Dowler, 2003).

\section{Ausblick: Wo wollen wir hin?}

Die zuvor beschriebenen Analysen bzw. die Aufarbeitung der bisherigen Forschungen sollen schließlich dabei helfen, Verbesserungsvorschläge insbesondere mit Bezug auf wünschenswerte Ergänzungen und Modifikationen der Operationalisierungen und Erhebungsmethoden geben zu können bzw. sinnvolle Methodenkombinationen vorzuschlagen. Dieses (Fern-)Ziel lässt sich mit der Kernfrage "Wie könnte die zukünftige (kriminologische) Forschung zur Punitivität aussehen?" umschreiben. Dabei wird es vor allem um Überlegungen zur Absicherung der Untersuchungsvalidität und -reliabilität gehen, und zwar sowohl innerhalb der einzelnen Punitivitäts- und Methodenbereiche als auch im Hinblick auf deren Verknüpfung. Neben Vorschlägen zu Verbesserungen insbesondere der üblichen Fra- 
gebogenuntersuchungen sollen ggf. aber auch Möglichkeiten zur Erfassung der (recht flüchtigen) gesellschaftlichen bzw. diskursiven Punitivität (insbesondere durch Medienanalysen) bedacht werden.

Ein weiterer, bislang kaum begangener methodischer Weg zur Erfassung individueller Punitivität führt über die sog. qualitative Methodik. Solche ausführlichen und nur wenig bis teilstrukturierten Interviews und Gruppendiskussionen ermöglichen es dem Untersucher, auch komplexere Zusammenhänge zu elaborieren bzw. Meinungen, Wissen und Einstellungen zu erheben, mit denen er bei der Untersuchungsplanung noch gar nicht gerechnet hat und die deshalb auch nicht in standardisierte Fragebögen aufgenommen werden können. Diesem Vorteil der Offenheit gegenüber dem Untersuchungsgegenstand und den Befragten stehen allerdings auch einige Nachteile gegenüber (geringe Stichprobenumfänge, keine Repräsentativität im eigentlichen Sinne, statistische Auswertungsverfahren sind üblicherweise nicht anwendbar; vgl. dazu auch die Projektbeschreibung 3.7.2).

Den dritten großen, in der bisherigen Punitivitätsforschung noch gar nicht verwendeten Methodenbereich stellen die experimentellen Untersuchungen dar. Hierbei geht es ausschließlich um die Erfassung von individueller Punitivität, durchaus aber kombinierbar mit dem Einfluss von Medienberichten. Der große Vorteil des Experiments liegt darin, - unter Berücksichtigung adäquater Versuchspläne - Ursache-Wirkungs-Zusammenhänge ("Kausalität") nachweisen zu können, d.h. Effekte eindeutig auf (wenige) willkürliche Variationen des Ausgangszustandes beziehen zu können (ceteris-paribus-Bedingungen). Ein Hauptanliegen dieses Projektes ist es, aus der großen Vielfalt experimenteller Möglichkeiten einige Versuchsanlagen herauszuarbeiten und diese (ggf. im Rahmen einer Drittmittelförderung) durchzuführen.

Neben den genannten empirischen und methodologischen Zielen, sollen - als weiteres Standbein des Projekts - aber auch die anfangs bereits kurz skizzierten konzeptionellen Gedanken zur "Punitivität" weiter vertieft bzw. elaboriert werden, so dass wir am Ende zu einer exakten und trotzdem aussagekräftigen Begriffskonzeption gelangen, idealerweise gleichsam unter Berücksichtigung von anderen, teilweise bislang ähnlich schwach bzw. unterdefinierten kriminologischen Konzepten wie "Vulnerabilität" (vgl. Killias, 1990; Reuband, 1999), "Verbrechensfurcht" (stellvertretend für viele: Boers, 1991; Hale, 1996) und "Deliktsschwereeinschätzung" (dazu grundlegend Sellin \& Wolfgang, 1964; aktuell Kania et al., 2003).

\section{- $\quad$ Arbeitsbericht 2002/2003:}

Die Initialzündung für dieses Projekt ging von einem Workshop am MPI im Oktober 2002 zur "Punitiven Gesellschaft" aus, in den Fritz Sack eingeleitet hat. In der Folge fanden regelmäßige Gespräche der o.g. Projektarbeitsgruppe am MPI statt, in deren Rahmen sich die inhaltlichen Rahmenbedingungen immer deutlicher herauskristallisierten. Die bisherigen empirischen Befunde und konzeptionellen Überlegungen wurden schließlich im September 2003 beim AJK-Symposium "Die neue Straflust" gemeinsam von allen drei Projektmitarbeitern vorgestellt (vgl. Kury, Obergfell-Fuchs \& Kania, 2004).

- $\quad$ Arbeitsplanung 2004:

Im kommenden Jahr sind weitere Ausarbeitungen auf allen drei Ebenen (konzeptionell, empirisch und methodenkritisch) geplant, verbunden mit der (möglichst auch internationalen) Veröffentlichung der Ergebnisse. Darüber hinaus wird derzeit die Beantragung von Drittmitteln zur Durchführung eigener, insbesondere experimenteller Untersuchungen geprüft.

- $\quad$ Projektbezogene Veröffentlichungen:

KANIA, H.: Kriminalitätsberichte und die Konstruktion von Kriminalitätswirklichkeit. In: M. Walter, H. Kania \& H.-J. Albrecht (Hrsg.): Alltagsvorstellungen von Kriminalität. Münster 2004 (im Druck). 
Kania, H., Brand, T., ZimmermanN, S. \& WAlter, M.: Die Einschätzung von Gewaltdelikten im europäischen Vergleich. Eine Fragebogenuntersuchung an Studierenden in zehn Ländern. In: Monatsschrift für Kriminologie und Strafrechtsreform 86, 247-264 (2003).

KURY, H.: Wie restitutiv eingestellt ist die Bevölkerung? Zum Einfluß der Frageformulierung auf die Ergebnisse von Opferstudien. In: Monatsschrift für Kriminologie und Strafrechtsreform 84, 84-98 (1995).

KURY, H.: Zur Sanktionseinstellung der Bevölkerung. In: H.-J. Albrecht, F. Dünkel, H.-J. Kerner, J., Kürzinger, H. Schöch, K. Sessar, B. Villmow (Hrsg.): Internationale Perspektiven in Kriminologie und Strafrecht. Festschrift für Günther Kaiser zum 70. Geburtstag. Berlin 1998, 237-267.

KuRY, H. \& Ferdinand, T.: Public Opinion and Punitivity. International Journal of Law and Psychiatry 22, 373-392 (1999).

KURY, H., OBERGFELl-FuCHS, J. \& KANIA, H.: Worüber sprechen wir eigentlich, wenn wir über "Punitivität" sprechen? In: Kriminologischen Journal, Beiheft 8 "Punitivität", 2004 (im Druck).

KURY, H., OBergfell-FuchS, J. \& WÜRGER, M.: Strafeinstellungen. Ein Vergleich zwischen Ostund Westdeutschland. Freiburg i.Br. 2002.

OBERGFELL-FuChS, J. \& KURY, H.: Strafeinstellungen der Bevölkerung. In: M. Walter, H. Kania \& H.-J. Albrecht (Hrsg.), Alltagsvorstellungen von Kriminalität. Münster 2004 (im Druck).

Walter, M., Brand, T., Geiter, H., Kania, H., Kremer, O. \& KreutZ, A.: Täter-Opfer-Ausgleich aus der Sicht von Rechtsanwälten. Einschätzungen, Ansichten und persönliche Erfahrungen (hrsg. vom BMJ). Mönchengladbach 1999.

\subsubsection{Gewalt- und Jugenddelinquenz im sozialökologischen Kontext}

- $\quad$ Bearbeiter: Dietrich Oberwittler (Sozialwiss., Projektleiter); Tilman Köllisch (Soziologe); Thomas Naplava (Soziologe); Dominic Kaltenbach (stud. soz.); Marc Wiesenhütter (stud. soz.).

- Zeitrahmen: 1998 bis 2003

- $\quad$ Projektstatus: abgeschlossen

- Projektbeschreibung:

(zugleich Promotions- und Habilitationsprojekt)

Das Projekt wurde im Frühjahr 2003 mit dem Ende der DFG-Förderung formell abgeschlossen. Die Auswertungen werden jedoch im Rahmen eines zweijährigen Intra-European Fellowships (Marie Curie FP6) des Projektleiters an der Universität Cambridge im internationalen Forschungsnetzwerk SCOPIC (Social Contexts of Pathways into Crime) sowie eines sechsmonatigen Marie-Curie Fellowships (FP5) von Tilman Köllisch an der University of Keele fortgeführt.

\section{Übersicht}

Das Ziel des Projekts liegt in der empirischen Analyse der urbanen Jugenddelinquenz und der sie bedingenden Einflussfaktoren am Beispiel zweier westdeutscher Städte (Köln und Freiburg) und - als Kontrastfolie - einer benachbarten ländlichen Region (Breisgau/Markgräfler Land). Der besondere theoretische und methodische Zugang der Studie liegt in der Einbeziehung des Raumes in die Deskription und Erklärung von delinquentem Verhalten und in der Verknüpfung verschiedener Datenquellen auf individueller und kollektiver Ebene im Rahmen von Mehrebenenmodellen. Die Fragestellung des Projekts knüpft an die aktuelle sozialwissenschaftliche Diskussion über eine Gefährdung des städtischen Zusammenlebens durch die Zunahme von sozialen Problemen im städtischen Raum an. Zwar spielen räumliche Kontexteinflüsse in soziologischen Erklärungsansätzen abweichenden Verhaltens 
seit langem eine wichtige Rolle, doch mangelt es bislang an entsprechenden empirischen Umsetzungen. Dies gilt sowohl für die klassischen Ansätze der sozialen Desorganisation, die die Bedeutung der informellen Sozialkontrolle über Jugendliche betont, und der Subkulturtheorie, die Prozesse der Delinquenzverstärkung durch differentielle Kontakte untersucht, als auch für neuere Ansätze wie routine activities approach und broken windows - Theorie. Allen Ansätzen ist die Überlegung gemein, dass delinquentes Verhalten nicht nur durch individuelle, sondern auch durch soziale Kontextfaktoren beeinflusst wird, die in der konkreten räumlichen Umgebung der Menschen zu finden sind. Dies können im Falle der Jugendlichen Wohnquartiere, aber auch Schulen als ein weiterer sozialökologischer Kontext sein. In der aktuellen Forschungsdiskussion, die sich vor allem auf die Verhältnisse in U.S.-amerikanischen Großstädten bezieht, werden vergröbert zwei wesentliche Wirkungsmechanismen solcher Kontexteinflüsse angenommen: Zum einen führen räumliche Konzentrationen sozial benachteiligter Bevölkerungsgruppen in bestimmten Wohnquartieren über die Zunahme von Kontakten zu gleichfalls benachteiligten Personen und die Verminderung von Sozialkapital zu einer zusätzlichen Benachteiligung und letztlich zu einer Ausbreitung devianter Einstellungen und Verhaltensmuster, zum anderen verlieren diese Wohnquartiere ihre "kollektive Selbstwirksamkeit", um der Ausbreitung von 'Disorder' und Delinquenz effektiv entgegenzuwirken. Die komplexen Wirkungszusammenhänge zischen individuellen Lebenslagen und Verhalten und ihren Wechselwirkungen mit kollektiven Faktoren legen einen breiten empirischen Zugang im Rahmen von lokalen Fallstudien und die Verknüpfung unterschiedlicher Perspektiven nahe.

Im Folgenden soll zunächst ein Überblick über diese unterschiedlichen Datenquellen gegeben werden, bevor anschließend die wesentlichen Projektziele und -ergebnisse des Projekts beschrieben werden.

\section{Datenquellen}

\section{1) Stadtviertelbezogene Sozial- und Polizeidaten (Aggregatdaten)}

Die kleinsten räumlichen Untersuchungseinheiten sind die amtlich definierten Stadtviertel der Städte Köln ( $\mathrm{n}=$ ca. 300, durchschnittlich ca. $3.500 \mathrm{EW})$ und Freiburg $(\mathrm{n}=$ ca. 40, durchschnittlich ca. 4.500 EW) sowie die ländlichen Gemeinden im Freiburger Umland $(\mathrm{n}=\mathrm{ca} .15)$. Diese Stadtviertel repräsentieren "natürliche" Siedlungseinheiten, ohne in sich wirklich homogen zu sein. Zu Analysezwecken werden diese kleinsten Einheiten teilweise zu größeren Gebietseinheiten zusammengelegt, wodurch sich die interne Heterogenität der Gebietseinheiten, aber auch die statistische Robustheit der Ergebnisse erhöht (siehe working paper No. 9. Für diese Einheiten liegen umfangreiche und sehr differenzierte Sozial- und Infrastrukturdaten vor, die als Einzelindikatoren oder verdichtete Faktoren eine sozialräumliche Beschreibung der Städte und ländlichen Gemeinden ermöglichen. Zu den Sozialdaten zählen neben alters- und nationalitätsspezifischen demographischen Informationen vor allem Indikatoren sozialer Ungleichheit und sozialer Probleme wie z.B. Soziahilfedaten und Wohnraumdaten. Für die Messung der städtischen Infrastruktur, die wir kriminologisch als Gelegenheitsstrukturen interpretieren, wurden Adressen von Geschäften, Arztpraxen und Gaststätten/Cafés geokodiert und den Stadtvierteln zugeordnet. Zusätzlich dienen die Fahrgastdaten des ÖPNV in Köln als Proxy-Variable der Aufenthaltsbevölkerung im Stadtgebiet. Für Köln bilden die Einzelfalldaten der polizeilichen Registrierungen aller Gewaltdelikte sowie aller Delikte von Personen unter 21 Jahren aus den Jahren 1994, 1998 und 1999 die Datenbasis. Durch die Geokodierung der Wohnsitzadressen von Tatverdächtigen und Opfern sowie der Tatortadressen sind kleinräumliche Auswertungen möglich. Zusätzlich konnten die vollständigen und bereits geokodierten Computerdaten der Einsatzleitzentrale der Kölner Polizei, die auch alle Notrufe enthalten, zur Auswertung herangezogen werden. In Freiburg und im Umland sind die Registrierungen von Tatverdächtigen unter 21 Jahre für den Zeitraum von ca. 1998/99 verfügbar. 
2) 'MPI-Schulbefragung 1999/2000' und 'MPI/FIFAS-Jugendbefragung 2000' zur selbstberichteten Delinquenz (Individualdaten)

Die Befragung von SchülerInnen der 8. bis 10. Klassen aller allgemeinbildenden Schulformen fand in Köln und Freiburg im Herbst 1999 und im Freiburger Umland im Herbst 2000 statt. Insgesamt wurden dabei ca. 6.500 Jugendliche überwiegend im Alter von 13 bis 16 Jahren schriftlich befragt. Die Ausschöpfungsrate beträgt auf der Schulebene ca. $86 \%$ und auf der Schülerebene (innerhalb der ausgewählten Klassen) ca. 85 \%. Der 16 Seiten umfassende Fragebogen war zunächst bei einer Pilotstudie an Emmendinger Schulen im Mai 1999 sowie bei einer Reihe weiterer kleiner Pretests an Freiburger und Kölner Schulen getestet worden. Ein ausführlicher Ergebnisbericht der Kölner und Freiburger Befragung liegt gedruckt und als PDF-Datei vor; über die Befragung im Landkreis BreisgauHochschwarzwald informiert ein separater Ergebnisbericht. Darüber hinaus sind ein Methodenbericht und eine Skalendokumentation verfügbar. Die Befragungsdaten stehen sowohl für 'konventionelle' Analysen auf der Individualdatenebene als auch für Mehrebenenanalysen zur Verfügung. Dazu war es von entscheidender Bedeutung, die Wohnadressen der SchülerInnen während der Befragung über ein Straßenverzeichnis den kleinräumlichen Stadtvierteln exakt zuzuordnen. Die als Methodenelement konzipierte zusätzliche 'MPI/FIFAS-Jugendbefragung 2000' wurde als mündliche Befragung von männlichen Jugendlichen in Freiburg in Zusammenarbeit mit FIFAS e.V. im Mai und Juni 2000 durchgeführt. Hier wurden 499 Jungen im Alter von 14 bis 17 Jahren mit dem gleichen Erhebungsinstrument wie bei der Schulbefragung interviewt. Bei ca. 300 Befragten konnte mit deren Einverständnis ein Abgleich ihrer selbstberichteten Delinquenz mit den tatsächlichen Polizeiregistrierungen durchgeführt werden.

\section{3) Bewohnerbefragung}

Die postalische Befragung der erwachsenen Wohnbevölkerung (Alter 25 bis 79 Jahre, deutsche und nicht-deutsche Nationalität) wurde im Frühjahr 2001 in den Stadtvierteln und Gemeinden durchgeführt, in der auch eine ausreichende Anzahl von jugendlichen Befragten vorhanden ist. Der Fragebogen wurde mit nur 8 Seiten sehr kurz gehalten. Die Nettostichprobe umfasst insgesamt ca. 2.500 Befragte, die Ausschöpfungsrate liegt insgesamt bei $49 \%$. Hierzu sind ein Methodenbericht und eine Skalendokumentation verfügbar. Die Bewohnerbefragung ergänzt die anderen Datenquellen v.a. in Hinblick auf die Wechselwirkungen zwischen sozialer Benachteiligung, Disorder und Delinquenz sowie den kollektiven Reaktionsformen im Wohnquartier. Das theoretische Konzept der Bewohnerbefragung lehnt sich an den erneuerten Ansatz der sozialen Desorganisation an, wie er im Projekt "Human Development in Chicago Neighborhoods" von Robert Sampson et al. operationalisiert wurde. Die Bewohner werden in erster Linie als Beobachter ihrer Wohnquartiere befragt; weniger ihre eigenen Einstellungen oder Verhaltensweisen, sondern das sich ergebene Bild überindividueller sozialer Eigenschaften des Wohnquartiers wie z.B. informelle Sozialkontrolle oder soziale Kohäsion zwischen Nachbarn sind hier von Interesse.

\section{Beschreibung der Projektziele und -ergebnisse}

Projektteil A: Kleinräumliche Verteilungen von registrierter Kriminalität und ihre sozial- und infrastrukturellen Korrelate

Analysen von innerstädtischen Verteilungen registrierter Kriminalität haben wiederholt eine starke Konzentration der Gewalttatorte in den Innenstädten und der Tatverdächtigen in den sozial besonders benachteiligten Stadtvierteln ergeben. Dies zeigt sich auch bei den Analysen, die mit den Kölner Polizeidaten durchgeführt wurden. Neben multiple Regressionen wurden hier auch kartographische Verfahren mithilfe von ArcView und des Programms CrimeStat 2.0 eingesetzt. Multiple Regressionsanalysen der wohnsitzbezogenen Tatverdächtigen- und Opferraten zeigen die überragende Bedeutung der Sozialhilfequote als dem zentralen Sozialindikator für niedrigen Sozialstatus und soziale Probleme für die Höhe der Deliktbelastung an. Die Varianzaufklärung ist für die Jugendkriminalitätsraten niedriger 
als für die altersübergreifenden Gewaltkriminalitätsraten, was vermutlich die stärkere soziale Streuung der registrierten Kriminalität im Jugendalter und die stärkere soziale Konzentration der registrierten Gewaltkriminalität reflektiert. Übliche Indikatoren der 'sozialen Desorganisation' wie z.B. Fluktuation oder Scheidungsrate sind dagegen für die Erklärung von Tatverdächtigenraten weniger relevant (siehe hierzu bislang Oberwittler 2001: Täter, Opfer, Tatorte). Bei der räumlichen Verteilung der Gewalttatorte im Stadtgebiet stellt sich zunächst die Frage des angemessenen Nenners für die Berechnung von Belastungsziffern. Weder die auf die Fläche noch die auf die Wohnbevölkerung bezogenen Raten spiegeln die Tatsache wider, dass sich in den Innenstädten eine ganz erhebliche Personenzahl zusätzlich zur Wohnbevölkerung aufhält, die das statistische Risiko von Gewaltereignissen relativiert. Eine zentrale Frage bei der Analyse von Gewaltverteilungen innerhalb des Stadtgebietes ist daher, welche sozialen und infrastrukturellen Einflussfaktoren unter Kontrolle der räumlichen Verteilung dieser empirisch gemessenen 'Aufenthaltsbevölkerung' bedeutsam bleiben, und welche Bedeutung den dahinter stehenden kriminologischen Erklärungsansätzen damit zukommt. Die Ergebnisse der Regressionsmodelle zeigen, dass dies - wie bei der Wohnsitzverteilung der Gewalttatverdächtigen auch - in erster Linie Indikatoren der sozialen Benachteiligung sind, während die Bedeutung der Gelegenheitsstrukturen und damit des routine activity approach weit geringer ist als in der gegenwärtigen Forschungsdiskussion über 'hot spots' angenommen wird. Dennoch, spezifische Gelegenheitsstrukturen, v.a. die Anzahl der Gaststätten, bleiben im multivariaten Modell als zweiter wesentlicher Einflussfaktor auf die Gewaltverteilung, insbesondere während der Abend- und Nachtstunden, bestehen (siehe hierzu Oberwittler/Wiesenhütter, The Risk of Violent Incidents; Oberwittler, im Erscheinen: Re-Balancing Routine Activity and Social Disorganization).

Projektteil B: Einflussfaktoren der polizeilichen Registrierung jugendlicher Delinquenz (siehe gesonderten Projektbericht 3.7.6 von Tilman Köllisch)

Projektteil C: Individual- und Mehrebenenanalysen zu den sozialen Einflussfaktoren von Jugenddelinquenz

\section{Validierung und Methodeneffekte}

Die Validität von Befragtenangaben zur selbstberichteten Delinquenz, insbesondere in Schulbefragungen, ist nicht unumstritten. Ein Ziel des Projekts lag daher in der Untersuchung möglicher Methodeneffekte des Erhebungs- und Interviewverfahrens auf das Antwortverhalten sowie in der externen Validierung selbstberichteter Delinquenz anhand der offiziellen polizeilichen Registrierungen der befragten Jugendlichen. Dies war aus Datenschutzgründen nur bei der haushaltsbasierten mündlichen Befragung, und nicht bei der Schulbefragung möglich.

Der Vergleich von haushaltsbasierter mündlicher Befragung und Schulbefragung zeigt einige bedeutsame Unterschiede. Die Ausschöpfungsrate der schulbasierten Befragung liegt erheblich höher als die der haushaltsbasierten Befragung, und insbesondere Jugendliche aus unteren sozialen Schichten werden besser erreicht. In der haushaltsbasierten Befragung liegen die Prävalenzraten der selbstberichteten Delinquenz ungefähr 20 bis 50 \% niedriger als in der schulbasierten Befragung. Während die unterschiedlichen Prävalenzraten eher mit den Selektionseffekten der Stichprobenverfahren erklärt werden können, deuten unterschiedlichen Korrelationsmuster mit relevanten Variablen möglicherweise auf Kontexteffekte der jeweiligen Erhebungssituationen hin. Insgesamt deutet sich ein Muster an, nach dem Zusammenhänge von Delinquenz mit familienbezogenen Variablen in der mündlichen Befragung stärker, und Zusammenhänge von Delinquenz mit schul- und peerbezogenen Variablen in der Schulbefragung stärker in Erscheinung treten. Dies gilt sowohl für strukturelle Variablen als auch noch stärker für Einstellungsvariablen wie etwa Schulmotivation und Freizeitorientierungen. Dies würde bedeuten, dass Jugendliche im Erhebungskontext der Schule den schulischen Faktoren sowie den Beziehungen zu den Gleichaltrigen eine höhere Wertigkeit beimessen als den familiären Faktoren, während diese familiären Faktoren für die Befragten im Erhebungskontext des elterlichen Haushalts eine größe- 
re Wertigkeit besitzen. Möglicherweise übt die Anwesenheit der anderen Jugendlichen während der Schulbefragung einen Druck der sozialen Erwünschtheit in der Art aus, das Antwortverhalten zu Fragen, die die Gleichaltrigen betreffen, an den jeweils gültigen Gruppennormen (ob deviant oder nichtdeviant) auszurichten.

Die Ergebnisse des Datenabgleichs der selbstberichteten Polizeikontakte bestätigen viele Erkenntnisse der bisherigen Forschung. Die überwiegende Mehrheit der Befragten hat - soweit diese dem Datenabgleich zugestimmt haben - auf die Frage nach Polizeikontakten ehrlich geantwortet. Auch die Resultate der differentiellen Validität bestätigen bereits vorliegende amerikanische und europäische Studien, die eine geringere Validität der Angaben von ethnischen Minderheiten und von Jugendlichen mit niedrigerem Sozial- und Bildungsstatus ergaben. In diesen Gruppen besteht eine klare Tendenz zum Verschweigen von Polizeikontakten. Wenn man berücksichtigt, dass Jugendliche aus ethnischen Minderheiten und unteren Bildungs- und Sozialschichten zudem höhere Verweigerungsquoten bei haushaltsbasierten Befragungen aufweisen und daher in der verwendeten Stichprobe unterrepräsentiert sind, so ist hier mit einer Unterschätzung von Zusammenhängen zwischen sozialstrukturellen Faktoren und Jugenddelinquenz zu rechnen.

Der Vergleich der beiden Befragungsstichproben zeigt, dass die höhere selbstberichtete Polizeikontakt-Rate der Schulbefragung unter Berücksichtigung der informellen Kontakte näher an dem 'wahren Wert' liegt als die niedrigere Rate der haushaltsbasierten mündlichen Befragung. Schulbefragungen sind daher vor allem wegen ihrer höheren Ausschöpfung von Befragten mit niedrigem Bildungs- und Sozialstatus gegenüber anderen Erhebungsformen grundsätzlich im Vorteil.

Allerdings deuten die weiteren Analysen darauf hin, dass die Validität der Selbstberichte in der Schulbefragung durch differentielle Effekte der sozialen Erwünschtheit auf das Antwortverhalten beeinträchtigt wird, die vermutlich zu einer Tendenz des Unterberichtens von Polizeikontakten bei Befragten mit hohem Bildungsstatus (Gymnasiasten und Waldorfschüler) führt. Auch hier könnte die Befragungssituation in Klassenräumen einen differentiellen Effekt der sozialen Erwünschtheit ausüben, der je nach normativem Kontext in unterschiedliche Richtungen wirkt und im Ergebnis eine deutliche Überschätzung von Zusammenhängen schul- und peerbezogener Variablen mit Polizeiauffälligkeit und Delinquenz zur Folge hat (siehe hierzu Köllisch/Oberwittler, eingereicht: Wie ehrlich berichten männliche Jugendliche; Naplava/Oberwittler 2002: Methodeneffekte; Oberwittler/Naplava 2002: Auswirkungen).

\section{Sozialräumliche Kontexteffekte}

In diesem Projektbereich werden Hypothesen zu den sozialen Verursachungsmechanismen von Jugenddelinquenz überprüft. Eine zentrale Fragestellung ist dabei, ob sozialräumliche Kontexteffekte (durch die Konzentration sozialer Benachteiligungen) als zusätzliche Einflussfaktoren neben individuellen Faktoren messbar sind, und wenn ja, wie die Wirkungsmechanismen solcher Kontexteffekte modelliert werden können. Einschränkend muss gesagt werden, dass wie bei konventionellen Analysen auch aufgrund des Querschnittscharakters der Daten keine Aussagen über Kausaleffekte möglich sind. Eine weitere Frage dabei ist, in welchem Verhältnis die Einflüsse des Wohnquartiers und der Schule zueinander stehen, die in der bisherigen Forschung fast ausschließlich isoliert voneinander untersucht wurden. Die Analysen mithilfe hierarchisch-linearer Modelle (Mehrebenenanalye) zeigen, dass Kontexteffekte des Wohnquartiers (gemessen an der Intraklassenkorrelation) nur für diejenigen Jugendlichen bestehen, die auch ihre Freunde überwiegend aus ihrem eigenen Wohnquartier wählen; wohnen die Freunde überwiegend in anderen Vierteln, ist kein Kontexteffekt nachweisbar. Darüber hinaus sind Kontexteffekte offenbar nur für deutsche, nicht aber für nicht-deutsche Jugendliche vorhanden. Demgegenüber zeigt die Intraklassenkorrelation eine durchweg größere Bedeutung der Schule als sozialer Kontext an. Dieses Ergebnis könnte als Bestätigung der Theorie der differentiellen Assoziation gewertet werden, da ein wesentlicher Mechanismus der sozialräumlichen Kontexteffekte offenbar über die Gleichaltrigen läuft. Allerdings dürfte ein Teil der Intraklassenkorrelation auf einen ho- 
mogenisierenden Effekt der Befragungssituation in Klassenzimmern auf das Antwortverhalten zurückzuführen sein (siehe Validierung und Methodeneffekte).

Für beide Kontexte (Stadtviertel und Schule) ergeben die Mehrebenenmodelle zur Erklärung der Delinquenz signifikante Effekte eines niedrigen durchschnittlichen Sozialstatus, die teilweise durch die devianten Orientierungen der Gleichaltrigen vermittelt werden. Dies zeigt an, dass der Effekt von niedrigem Sozialstatus oder 'Armut' auf Delinquenz, der ja in der kriminologischen Diskussion sehr umstritten ist, nicht nur auf der Individualdatenebene, sondern auch auf der üblicherweise vernachlässigten sozialökologischen Kontextebene wirksam wird, dort aber eher über subkulturelle Mechanismen vermittelt wird. Zusätzlich erweist sich auch das in der unabhängigen Bewohnerbefragung gemessene 'kindorientiere Sozialkapital' der Stadtviertel als signifikanter Prädiktor der Kontextebene auf die individuelle Delinquenz. Insgesamt haben sich die Hypothesen über die Existenz sozialräumlicher Kontexteffekte auf das abweichende Verhalten von Jugendlichen bestätigt (siehe dazu Oberwittler/Köllisch, Jugendkriminalität in Stadt und Land; Oberwittler, im Erscheinen, Jugenddelinquenz und Stadtstruktur; Oberwittler 2004: A Multilevel Analysis of Neighbourhood Contextual Effects; working paper No. 6).

Jugenddelinquenz im interethnischen Vergleich

(siehe gesonderten Projektbericht 3.7.7 von Thomas Naplava)

\section{Projektteil D: Kollektive Selbstwirksamkeit und soziale Desorganisation im Wohnquartier}

Im klassischen Ansatz der sozialen Desorganisation wird angenommen, dass die soziale Kohäsion und die informelle Sozialkontrolle in Wohnquartieren mit hoher Fluktuation, hohem Migrantenanteil und niedrigem durchschnittlichem Sozialstatus zu gering ist, um delinquentes Verhalten Jugendlicher effektiv zu verhindern. In die Definition dieser so genannten, kollektiven Selbstwirksamkeit' von Wohnquartieren wird heute auch das Sozialkapital der Bewohner, insbesondere die Kontakte zwischen Familien, einbezogen. Neuere Studien, die die relevanten Teilaspekte der kollektiven Selbstwirksamkeit von Wohnquartieren nicht nur aufgrund amtlicher Strukturdaten annehmen, sondern durch Bewohnerbefragungen zu messen versuchen, zeigen, dass Delinquenz und andere Disorder-Phänomene einerseits und soziale Desorganisation andererseits in einem reziproken Wechselverhältnis zueinander stehen. Desorganisation kann Delinquenz fördern, und Delinquenz kann Desorganisation fördern. Die Bewohnerbefragung dient dazu, diese Wechselwirkungen zwischen strukturellen Benachteiligungen, kollektiver Selbstwirksamkeit und Delinquenz zu untersuchen. Auch für die Perspektive der Bewohner werden Mehrebenenmodelle berechnet, um den relativen Einfluss individueller und kollektiver Faktoren in der Entstehung von sozialer Desorganisation einzuschätzen, wobei die Daten der Bewohnerbefragung mit den anderen Datenquellen verknüpft werden (siehe hierzu Oberwittler 2003: Messung und Qualitätskontrolle).

- $\quad$ Finanzierung:

Das Projekt wurde von April 2000 bis März 2003 von der Deutschen Forschungsgemeinschaft geför$\operatorname{dert}(\mathrm{Ob} 143 / 3-1,2)$.

- Zum Projekt vorliegende Veröffentlichungen:

KÖLLISCH, T. \& OBERWITTLER, D. (eingereicht bei Kölner Zeitschrift für Soziologie und Sozialpsychologie): Wie ehrlich berichten männliche Jugendliche über ihr delinquentes Verhalten? Ergebnisse einer externen Validierung.

OBERWITTLER, D. (im Erscheinen): Jugenddelinquenz und Stadtstruktur: Eine Mehrebenenanalyse zu sozialökologischen Kontexteffekten. In: Oberwittler, D./Karstedt, S. (Hrsg.), Soziologie der Kriminalität (Sonderheft 43 der Kölner Zeitschrift für Soziologie und Sozialpsychologie), Wiesbaden.

OBERWITTLER, D. (erscheint 2004): Re-Balancing Routine Activity and Social Disorganization Theories in the Explanation of Urban Violence: A New Approach to the Analysis of Spatial Crime Patterns 
Based on Population at Risk. In: Journal of Quantitative Criminology (special issue on European Criminology).

KÖLLISCH, T. \& OBERWitTLER, D. (erscheint 2004): Sozialer Wandel des Risikomanagements bei Kindern und Jugendlichen. Eine Replikationsstudie zur langfristigen Zunahme des Anzeigeverhaltens. In: Zeitschrift für Soziologie der Erziehung und Sozialisation 24(1), 2004.

OBERWITTLER, D. (erscheint 2004): A Multilevel Analysis of Neighbourhood Contextual Effects on Serious Juvenile Offending. The Role of Subcultural Values and Social Disorganization. In: European Journal of Criminology 1(2), 201-235 (2004).

OBERWITTLER, D.: Die Messung und Qualitätskontrolle kontextbezogener Befragungsdaten mithilfe der Mehrebenenanalyse - am Beispiel des Sozialkapitals von Stadtvierteln. ZA-Informationen 53, 1141 (2003).

OBERWITTLER, D.: Die Entwicklung von Kriminalität und Kriminalitätsfurcht in Deutschland - Konsequenzen für die Kriminalprävention. In: Deutsche Zeitschrift für Kommunalwissenschaften 3(1), (2003).

OBERWITTLER, D. (2003): Geschlecht, Ethnizität und sozialräumliche Benachteiligung - überraschende Interaktionen bei sozialen Bedingungsfaktoren von Gewalt und schwerer Eigentumsdelinquenz von Jugendlichen. In: Lamnek, S./Boatca. M. (Hrsg.), Geschlecht - Gewalt - Gesellschaft (Otto-vonFreising Tagungen der Katholischen Universität Eichstätt-Ingolstadt, Bd. 4), Opladen: Leske $+\mathrm{Bu}-$ drich, 269-294.

NAPLAVA, T. (2003): Selbstberichtete Delinquenz bei einheimischen und immigrierten Jugendlichen im Vergleich. Eine Sekundäranalyse von Schulbefragungen der Jahre 1995-2000. In: Soziale Probleme 14(1), 67-96.

OBerWitTler, D. \& KÖllisch, T. (2003): Jugendkriminalität in Stadt und Land. Sozialräumliche Unterschiede im Delinquenzverhalten und Registrierungsrisiko. In: Raithel, J. \& Mansel, J. (Hrsg.): Kriminalität und Gewalt im Jugendalter. Hell- und Dunkelfeldbefunde im Vergleich. Weinheim: Juventa, 135-160.

NAPLAVA, T. \& OBERWITTLER, D. (2002): Methodeneffekte bei der Messung selbstberichteter Delinquenz von männlichen Jugendlichen - Ein Vergleich zwischen schriftlicher Befragung in der Schule und mündlicher Befragung im Haushalt. In: Monatsschrift für Kriminologie und Strafrechtsreform 85(6), 401-423.

OBERWITTLER, D. \& NAPLAVA, T. (2002): Auswirkungen des Erhebungsverfahrens bei Jugendbefragungen zu 'heiklen' Themen - schulbasierte schriftliche Befragung und haushaltsbasierte mündliche Befragung im Vergleich. In: ZUMA-Nachrichten 51, 49-77.

OBerwitTLeR, D. \& WiesenhÜtTER, M. (2002). The Risk of Violent Incidents Relative to Population Density in Cologne Using the Dual Kernel Density Routine. In: Levine, N., CrimeStat II: A Spatial Statistics Program for the Analysis of Crime Incident Locations. Program Manual. Washington, D.C.: National Institute of Justice, 332.

OBERWitTler, D., KÖllisch, T. \& WÜRGER, M. (2002): Selbstberichtete Delinquenz bei Jugendlichen. In: Glöckner-Rist, A. (Hrsg.): ZUMA-Informationssystem. Elektronisches Handbuch sozialwissenschaftlicher Erhebungsinstrumente Version 6.0. Mannheim: Zentrum für Umfragen, Methoden und Analysen.

OBerwitTler, D., Blank, T., Köllisch, T. \& NAPlaVA, T. (2001): Soziale Lebenslagen und Delinquenz von Jugendlichen. Ergebnisse der MPI-Schulbefragung 1999 in Köln und Freiburg (Arbeitsberichte des Max-Planck-Instituts; Heft 1). Freiburg i. Br.: edition iuscrim.

OBERWITTLER, D. (2001): Täter, Opfer, Tatorte - Zu den innerstädtischen Verteilungsmustern der registrierten Kriminalität und ihren sozialen Korrelaten am Beispiel Kölns. In: Jehle, J.-M. (Hrsg.): Raum und Kriminalität: Sicherheit in der Stadt, Migrationsprobleme. Mönchengladbach: Forum Verlag, 121-146.

OBERWITTLER, D. (2000): Wird die Jugend immer gewalttätiger? Kriminologische Erkenntnisse über die Entwicklung jugendlicher Gewaltdelinquenz in Deutschland. In: Schimmel, K. (Hrsg.): Das macht doch jeder mal - Jugendkriminalität. Frankfurt/Main: IKO-Verlag, 14-37. 
OBerwitTler, D. (1999): Soziale Probleme, Gewalt und Jugendkriminalität in der Stadt. Ansätze einer sozialökologischen Forschung. In: Albrecht, H.-J. (Hrsg.): Forschungen zu Kriminalität und Kriminalitätskontrolle am Max-Planck-Institut für ausländisches und internationales Strafrecht in Freiburg i. Br. Freiburg i. Br.: edition iuscrim, 403-418.

OBERWITTLER, D. (1998): Social Problems, Violence and Juvenile Delinquency in the City - A SocioEcological, Multi-Level Approach. In: Albrecht, H.-J. \& Kury, H. (Eds.): Research on Crime and Criminal Justice at the Max Planck Institute (Summaries). Freiburg i.Br.: edition iuscrim.

Arbeitsberichte:

OBERWiTtLeR, D. (2003): Das stadtviertel- und gemeindebezogene Stichprobendesign. Anlage und empirische Ergebnisse (working paper / No. 9).

OBERwitTler, D., KÖllisch, T., NAPlaVa, TH. \& BlANK, T. (2002): MPI-Schulbefragung Breisgau / Markgräfler Land 2000 - Ergebnisbericht (working paper / No. 8).

KÖLLISCH, T. (2002): Wie ehrlich berichten Jugendliche über ihr delinquentes Verhalten? Ergebnisse einer externen Validierung selbstberichteter Delinquenz (working paper / No. 7).

OBERWITTLER, D. (2002): Ecological Context Effects on Juvenile Offending - Conditional Impacts of Neighborhoods and Schools (working paper / No. 6).

NAPLAVA, T. (2002): Delinquenz bei einheimischen und immigrierten Jugendlichen im Vergleich (working paper / No. 5).

OBERWitTler, D. \& NAPlaVA, T. (2001): Family Factors and Adolescents' Delinquency. Findings from Sociological Research in Germany (working paper / No. 4).

OBERWITTLER, D. (2001): Neighborhood Cohesion and Mistrust - Ecological Validity and Structural Conditions (working paper / No. 3).

OBERWITTLER, D. (2001): Juvenile Delinquency in Urban Neighborhoods - Do Community Contexts Matter? Paper Presented at the First Annual Meeting of the European Society of Criminology, Lausanne Sept. 2001 (working paper / No. 2).

OBERWITTLER, D. (1999): Sozialökologisch orientierte Analyse der Jugenddelinquenz und ihrer sozialstrukturellen Korrelate im urbanen Raum. DFG-Antrag auf Gewährung einer Sachbeihilfe (Auszüge) (working paper / No. 1).

OBERWITTLER, D. \& WÜRGER, M. (1999): Emmendinger Schülerbefragung zur Jugenddelinquenz 1999. Ergebnisbericht.

\subsubsection{Individuelle und strukturelle Determinanten von Anzeigeverhalten und Entdeckungs- risiko delinquenter Jugendlicher}

- $\quad$ Bearbeiter: Tilman Köllisch (Soziologe)

- Zeitrahmen: 2000 bis 2004

- $\quad$ Projektstatus: in Bearbeitung

- $\quad$ Projektbeschreibung: (zugleich Promotionsvorhaben)

Ziel der Untersuchung ist die Identifizierung sozialer und individueller Faktoren, die das Risiko eines Jugendlichen beeinflussen, wegen eines strafbaren Deliktes bei der Polizei registriert zu werden. Da die Arbeit Teil des umfangreicheren, von der DFG geförderten Projektes "Soziale Probleme und Jugenddelinquenz im sozialökologischen Kontext" ist, liegt ein Schwerpunkt in der Identifizierung und Untersuchung sozialökologischer Einflüsse auf das Anzeigeverhalten und Registrierungsrisiko der Jugendlichen. 
Ein Schlüsselmechanismus bei der Produktion von (registrierter) Kriminalität ist bei allen Delikten der Bringkriminalität das Anzeigeverhalten von betroffenen Opfern oder dritten Personen, die von dem Delikt Kenntnis erhalten. Wenn also bei Kriminalitätsopfern Diskriminierung im Anzeigeverhalten vorliegt, wird sich diese auch als Diskriminierung der Täter in den Polizeistatistiken niederschlagen. Ein weiterer Schlüsselmechanismus ist das Verfolgungsverhalten der Polizei. Dieses kann allerdings mit den zur Verfügung stehenden Daten nicht erfasst werden.

Die Relevanz der Arbeit ergibt sich auch aus der aktuellen kriminalpolitischen Diskussion in der BRD. Dabei stellt sich die entscheidende Frage, ob einem erheblichen Anstieg jugendlicher Gewaltkriminalität im Hellfeld auch ein Anstieg im Dunkelfeld des nicht kriminalisierten abweichenden Verhaltens entspricht, oder ob der Anstieg weitgehend auf eine Erhellung des Dunkelfeldes zurückzuführen ist. Eine Veränderung von Anzeigeverhalten und Registrierungsrisiko von Jugendlichen über die Zeit hinweg könnte den Hellfeldanstieg zum Teil erklären.

In den bereits vorliegenden Untersuchungen zu diesem Thema - die sich natürlich nicht immer auf das Registrierungsrisiko Jugendlicher beschränken - lassen sich zwei unterschiedlich orientierte Vorgehensweisen unterscheiden, die im folgenden als ergebnisorientiert und als prozessorientiert bezeichnet werden.

Die ergebnisorientierte Vorgehensweise zeichnet sich dadurch aus, dass in einem Modell gezeigt werden kann, anhand welcher Merkmale von Tätern und Taten sich die Dunkel- und Hellfeldpopulation unterscheiden bzw. welche Tätermerkmale dessen Entdeckungsrisiko steigern. Der Nachteil der ergebnisorientierten Vorgehensweise besteht darin, dass zwar eine Diskriminierung nach sozialen Merkmalen im Ergebnis (also der Registrierung) festgestellt werden kann. Über die sozialen Mechanismen, die zur Produktion dieses Ergebnisses führen, können aber nur Vermutungen aufgestellt werden.

Die zwischen der Tatbegehung und der Registrierung eines Jugendlichen bei der Polizei ablaufenden Prozesse sind allerdings keineswegs trivial, wie im Folgenden gezeigt werden soll. Die hauptsächlichen Determinanten des Anzeigeverhaltens sind folgende: Zunächst einmal muss das abweichende Verhalten von den Geschädigten oder Dritten überhaupt bemerkt werden (z.B. Ladendiebstahl, Diebstähle allgemein). Im Anschluss an seine Entdeckung muss ein wahrgenommenes Verhalten als abweichend definiert werden, bzw. das Opfer muss festlegen, für wie schwerwiegend es das Delikt hält. Allerdings muss der Geschädigte nicht nur definieren, ob er ein bestimmtes Verhalten als normabweichend beurteilt. Vielmehr muss er auch entscheiden, ob das Verhalten ihn so stark geschädigt hat, dass es sich lohnt, sich die Mühe einer Anzeige zu machen. Ein weiterer intervenierender Faktor zwischen Tatentdeckung und Anzeigeerstattung ist die informelle Einigung zwischen den Konfliktparteien. In diesem Zusammenhang ist auch auf die Möglichkeit von Selbstjustiz hinzuweisen. Ein weiterer Selektionsfaktor ist die Einstellung des betroffenen Opfers zu Bestrafung im allgemeinen und der Polizei im besonderen. Ein zentraler Faktor, der sich in zahlreichen Untersuchungen als relevant herausgestellt hat, ist weiterhin die Einschätzung des Erfolges einer Anzeige. Je schlechter die Erfolgsaussichten der Anzeige eingeschätzt werden, desto geringer ist die Anzeigeneigung. Ein weiterer Mechanismus, der vor allem für die Variation des Anzeigerisikos nach unterschiedlichen Deliktsarten sorgt, sind unterschiedliche institutionelle Rahmenbedingungen der Schadensregelung. Damit ist gemeint, dass beispielsweise Versicherungen Schäden aufgrund von Ein- oder Aufbrüchen oder auch Diebstahl in der Regel nur begleichen, wenn eine Anzeige erstattet wurde. Auch Ladendiebstähle werden bei vielen Unternehmen mittlerweile routinemäßig zur Anzeige gebracht. Das bedeutet, dass Täter von Diebstahlsdelikten ein größeres Basisrisiko tragen, von der Polizei registriert zu werden, als beispielsweise Gewalttäter.

Der letzte Selektionsmechanismus zwischen einer Tat und der Registrierung des Täters ist die Behandlung von Anzeigevorgängen durch die Polizei. Hier sind im Wesentlichen zwei Faktoren wirksam: Zum einen die "Eingangskontrolle" der Anzeigen durch die Polizei. Weiterhin können je nach organi- 
sationalen Rahmenbedingungen unterschiedliche Prioritäten bei der Verfolgung einzelner Delikte oder Deliktsarten gesetzt werden, um beispielsweise Erfolgsquoten anzupassen. Es könnte durchaus sein, dass diese Rahmenbedingungen polizeilichen Handelns sich auf den einzelnen Polizeiwachen unterscheiden und daher zusätzliche Streuung in der Registrierungswahrscheinlichkeit Jugendlicher auf Aggregatebene produzieren.

Der Nachteil der prozessorientierten Betrachtungsweise liegt auf der Hand. Aufgrund der Komplexität des Modells ist es (zumindest mit den vorliegenden Daten) unmöglich, alle Faktoren simultan zu prüfen. Werden dagegen ausschließlich einzelne Bereiche des Modells betrachtet, so ist nicht geklärt, welche Verzerrungen zwischen Hell- und Dunkelfeld sich letztlich ergeben.

Für den empirischen Teil der Dissertation bietet es sich daher an, eine kombinierte Strategie zu verfolgen und sowohl ein ergebnisorientiertes Modell zu berechnen als auch mehrere prozessorientierte.

- $\quad$ Arbeitsbericht bis 2003:

In den Jahren 2000 und 2001 wurden im Wesentlichen Vorleistungen erbracht, die sowohl dem Dissertationsprojekt als auch dem dieses einschließende Gesamtprojekt "Soziale Probleme und Jugenddelinquenz im sozialökologischen Kontext" zugute kommen. Dies beinhaltete u.a. die Vorbereitung und Durchführung einer Schülerbefragung, die Aufbereitung von Individualdaten, und Literaturrecherche. Darüber hinaus wurden Beiträge zu Veröffentlichungen erarbeitet. Im Jahr 2002 wurden die Untersuchung zur Validität von Dunkelfelddaten (selbstberichtete Delinquenz Jugendlicher) sowie die theoretische Aufarbeitung des Dissertationsthemas abgeschlossen. Im bisherigen Verlauf des Jahres 2003 wurden die Ergebnisse der Validitätsstudie zur Veröffentlichung aufbereitet. Weiterhin wurde eine Studie über die zeitliche Veränderung von Anzeigeverhalten und Registrierungsrisiko überarbeitet und zur Veröffentlichung eingereicht. Die Betrachtung der Bestimmungsgründe und Determinanten des Anzeigeverhaltens aus der Opferperspektive mittels bi- und multivariater Analysen (u.a. logistische Regressionen) wurde abgeschlossen. Darüber hinaus wurde mit der Untersuchung von Zusammenhängen zwischen Hell- und Dunkelfeld auf Aggregatsebene (Stadtviertel) begonnen.

- $\quad$ Arbeitsplanung 2004:

Mittels einer ökologischen Regression soll tiefergehend überprüft werden, welche Faktoren (insbesondere soziale Integration und soziales Kapital der Bewohner) das Registrierungsrisiko der Jugendlichen vermindern oder vergrößern. Die Berechnung eines ergebnisorientierten Modells (aus der Täterperspektive) mittels einer Logit-Analyse, bei der sozialräumliche Merkmale der Jugendlichen eingehen, soll einen Überblick darüber geben, welche Merkmale das Registrierungsrisiko eines Jugendlichen beeinflussen. Diese Arbeiten werden im Rahmen eines Marie-Curie-Stipendiums an der KeeleUniversity in England durchgeführt.

- $\quad$ Finanzierung:

Gefördert mit Mitteln der DFG.

- Zum Projekt vorliegende Veröffentlichungen:

OBERWitTLER, D. \& KöLlisCh, T.: Jugendkriminalität in Stadt und Land. Sozialräumliche Unterschiede im Delinquenzverhalten und Registrierungsrisiko. In: Kriminalität und Gewalt im Jugendalter. Hell- und Dunkelfeldbefunde im Vergleich. Hrsg. J. Raithel \& J. Mansel. Juventa, Weinheim 2003, 135-160.

OBERWITTLER, D., \& KÖLLISCH, T. \& WÜRGER, M.: Selbstberichtete Delinquenz bei Jugendlichen. In: ZUMA-Informationssystem. Elektronisches Handbuch sozialwissenschaftlicher Erhebungsinstrumente Version 6.0. Hrsg. A. Glöckner-Rist. Zentrum für Umfragen, Methoden und Analysen, Mannheim 2002: 


\subsubsection{Jugenddelinquenz im interethnischen Vergleich}

- $\quad$ Bearbeiter: Thomas Naplava (Soziologe)

- $\quad$ Zeitrahmen: 2001 bis 2003

- $\quad$ Projektstatus: abgeschlossen

- $\quad$ Projektbeschreibung: (zugleich Promotionsvorhaben)

Die Untersuchung beschäftigt sich mit der sozialen Lage von Jugendlichen ausländischer Herkunft und den sozialen Ursachen delinquenten Verhaltens Jugendlicher unterschiedlicher ethnischer Gruppen im Vergleich. Ziel ist es einerseits, die Verallgemeinerung theoretischer Ansätze zur Erklärung abweichenden Verhaltens über ethnische Gruppen hinweg zu prüfen, und daran anschließend andererseits spezifische Faktoren für einzelne ethnische Gruppen zu identifizieren, die mit delinquentem Verhalten der Jugendlichen in Beziehung stehen, indem die einzelnen theoretischen Ansätze hinsichtlich ihrer relativen Bedeutung für die Erklärung der Delinquenz für die ethnischen Gruppen bewertet werden. Darauf aufbauend sollen spezifische Zusammenhangsmuster zwischen Lebensbedingungen und Delinquenz innerhalb ethnischer Gruppen identifiziert werden. Die ethnischen Gruppen beinhalten deutsche, osteuropäische, türkische und Jugendliche aus Jugoslawien, Albanien und Kosovo. Die Arbeit ist Teil des Forschungsprojektes "Soziale Probleme und Jugenddelinquenz im sozialökologischen Kontext" unter der Leitung von D. Oberwittler. Die empirischen Auswertungen basieren auf den Schulbefragungen, die 1999 in Köln und Freiburg an allgemeinbildenden Schulen im Rahmen des Projektes durchgeführt wurden.

Die Forschung zum Zusammenhang zwischen Ethnie und Kriminalität konzentriert sich vorwiegend auf sozialstrukturelle Aspekte sowie als problematisch zu bewertende Integrationsprozesse ausländischer Personen, um die in offiziellen Statistiken ausgewiesene höhere Kriminalitätsbelastung vor allem ausländischer Jugendlicher zu erklären, obwohl über das genaue Ausmaß der Differenz in der Kriminalitätsbelastung zwischen autochthonen und ausländischen Personengruppen Unklarheit herrscht. Befunde zur Delinquenzbelastung Jugendlicher aus Befragungsstudien zeigen dagegen, dass zwar Unterschiede zwischen einzelnen ethnischen Gruppen vorhanden sind, diese aber nicht annähernd so dramatisch ausfallen wie in offiziellen Statistiken. Sofern Unterschiede erkennbar sind, beziehen sich diese auch hauptsächlich nur auf schwerere Formen der Delinquenz. Zudem ist auch in offiziellen Statistiken verschiedener Länder im Vergleich abzulesen, dass einzelne ethnische Gruppen nicht in allen Ländern die gleiche Delinquenzbelastung aufweisen, d.h. der Rückschluss von sozialstrukturellen Benachteiligungen auf höhere Kriminalitätsraten ausländischer Personen erscheint zu einfach.

Empirische Arbeiten zu dem Zusammenhang zwischen Ethnie und Kriminalität bestehen häufig allgemein darin, die Eigenschaft der Ethnie bzw. Rasse neben weiteren Variablen mit Kriminalität in Beziehung zu setzen, und zu prüfen, ob sich unter Kontrolle der anderen Eigenschaften die Differenz zwischen den ethnischen Gruppen aufhebt. Diesem Vorgehen liegt häufig die Annahme zugrunde, dass eine höhere Kriminalitätsbelastung von Ausländern auf den benachteiligten sozioökonomischen Status dieser Bevölkerungsgruppen zurückzuführen ist, so dass sich unter Kontrolle entsprechender Variablen die Differenz aufhebt. Ethnische Gruppen unterscheiden sich aber nicht nur in sozialstrukturellen Merkmalen, sondern auch in weiteren Lebensbereichen wie Einstellungen, Zukunftsorientierungen, sozialen Netzwerken und kulturellen Mustern. Die Komplexität der Unterschiede zwischen ethnischen Gruppen wird durch das nominale Merkmal der Ethnie bzw. der Rasse nicht ausreichend abgebildet. Um den vielfältigen Unterschieden ethnischer Gruppen und den sich möglicherweise daraus ergebenden Konsequenzen für die Ursachenzusammenhänge abweichenden Verhaltens Rechnung zu tragen, sind Gruppenvergleiche zwischen verschiedenen Ethnien erforderlich. Diese 
bieten die Möglichkeit, die Verallgemeinerung theoretischer Erklärungen über ethnische Gruppen hinweg zu prüfen, und auch spezielle Erklärungsmodelle für ethnische Minderheiten zu entwickeln.

Vor diesem Hintergrund sind bei der Erklärung von Delinquenz ausländischer Jugendlicher den Wechselwirkungen zwischen der Situation im Herkunftsland, dem Migrationsprozess sowie den Lebensumständen im Gastland Rechnung zu tragen. Die Prüfung der Erklärungsgüte von Theorien abweichenden Verhaltens innerhalb ethnischer Gruppen stellt einen Ansatz dar, das Zusammenspiel verschiedener Ursachenfaktoren zu berücksichtigen und auf diese Weise auch Grundlagen für präventive Maßnahmen zu entwickeln. Neben der individuellen Prüfung von Annahmen aus der sozialen Kontrolltheorie, der Anomie- bzw. Strain-Theorie und der Theorie Differentieller Assoziationen wird auch ein integriertes Modell zur Erklärung abweichenden Verhaltens zwischen ethnischen Gruppen entwickelt. Darüber hinaus werden auch Einflüsse des sozialräumlichen Kontextes auf das Verhalten geprüft, um Thesen über einen Zusammenhang zwischen räumlicher Segregation ethnischer Gruppen und Delinquenz zu testen.

- $\quad$ Arbeitsbericht 2002/2003:

Um die Angaben zur Delinquenzbelastung einheimischer und immigrierter Jugendlicher gegenüber den eigenen Daten zu validieren, konnten vier Jugendbefragungen der letzten Jahre sekundäranalytisch ausgewertet werden. Die Ergebnisse zu dem Vergleich wurden bei einer Fachzeitschrift zur Veröffentlichung eingereicht (siehe auch Arbeitsbericht Nr. 5).

Die ersten beiden Kapitel der Dissertation zu anomie- und kontrolltheoretischen Ansätzen wurden unter besonderer Berücksichtigung des Vergleiches einheimischer und immigrierter Jugendlicher bearbeitet. In Übereinstimmung mit bisherigen Befunden stehen sozialstrukturelle Merkmale nur schwach mit der selbst berichteten Delinquenz in Beziehung und sind zudem nicht in der Lage, Unterschiede in der Delinquenzbelastung zwischen einheimischen und immigrierten Jugendlichen zu erklären.

Das Ausmaß an sozialen Bindungen hingegen steht in starkem Zusammenhang mit der Delinquenz bei allen Jugendlichen. Allerdings erweist sich die Bedeutung der familiären Einbindung bei immigrierten Jugendlichen als schwächer. Dies ist vor der Beobachtung plausibel, dass die Orientierungen zugewanderter Jugendlicher außerhalb der Familie ausgeprägter sind.

Zwei weitere Kapitel, die die Analyse lerntheoretischer und sozialökologischer Einflüsse auf delinquentes Verhalten bei einheimischen und immigrierten Jugendlichen im Vergleich behandeln, wurden erarbeitet. Die Dissertation wurde zum Ende des Berichtszeitraums fertiggestellt.

- $\quad$ Finanzierung: Gefördert mit Mitteln der DFG. 


\section{Publikationen (Veröffentlichungen)}

\section{Zeitschriften}

\section{Auslandsrundschau der Zeitschrift für die gesamte Strafrechtswissenschaft (ZStW)}

114. Jg., Verlag Walter de Gruyter, Berlin 2002.

115. Jg., Verlag Walter de Gruyter, Berlin 2003.

Der Umfang der Auslandsrundschau, des Publikationsorgans des Instituts, betrug 2002232 Seiten, 2003208 Seiten.

\section{European Journal of Crime, Criminal Law and Criminal Justice}

10. Jg., Kluwer Law International, The Hague, London, Boston 2002.

11. Jg., Kluwer Law International, The Hague, London, Boston 2003.

Der Umfang des Journals betrug 2002342 Seiten, 2003420 Seiten.

\section{Monatsschrift für Kriminologie und Strafrechtsreform}

85. Jg., Carl Heymanns Verlag KG, Köln 2002.

86. Jg., Carl Heymanns Verlag KG, Köln 2003.

Der Umfang der Monatsschrift (12 Hefte) betrug 2002468 Seiten, 2003490 Seiten.

\section{Institutsreihen}

Im Berichtszeitraum 2002/2003 wurden bei der edition iuscrim insgesamt 36 Bände veröffentlicht. Im Einzelnen entfielen auf die "Beiträge und Materialien" 13 Bände mit 4.779 Seiten, auf die "Sammlung ausländischer Strafgesetzbücher in deutscher Übersetzung" 3 mit 1.341 Seiten, auf die "Kriminologischen Forschungsberichte" 14 mit 6.051 Seiten und auf die "Interdisziplinären Untersuchungen" 6 Bände mit 2.390 Seiten.

Vom 1.1.2002 bis 31.12.2003 wurden insgesamt (Strafrecht: 3.155, Kriminologie: 1.869) 5.024 Exemplare verkauft.

In der neuen Reihe "forschung aktuell/research in brief" erschienen 10 Hefte mit 311 Seiten. Von der ebenfalls neuen Serie "Arbeitsberichte" wurden 2 mit 264 Seiten publiziert. 


\section{Beiträge und Materialien aus dem Max-Planck-Institut für ausländisches und internationales Strafrecht Freiburg}

edition iuscrim, Freiburg i.Br.

2002

Band S 82.3 Eser, Albin/Arnold, Jörg (Hrsg.), Strafrecht in Reaktion auf Systemunrecht. Vergleichende Einblicke in Transitionsprozesse. Band 3: Argentinien. Freiburg i.Br. 2002, $444 \mathrm{~S}$.

Band S 82.5 Eser, Albin/Arnold, Jörg (Hrsg.), Strafrecht in Reaktion auf Systemunrecht. Vergleichende Einblicke in Transitionsprozesse. Band 5: Polen, Ungarn. Freiburg i.Br. 2002, $361 \mathrm{~S}$.

Band S 82.6 Eser, Albin/Arnold, Jörg (Hrsg.), Strafrecht in Reaktion auf Systemunrecht. Vergleichende Einblicke in Transitionsprozesse. Band 6: Mali, Ghana. Freiburg i.Br. 2002, $296 \mathrm{~S}$.

Band S 91 Richter, Thomas, Umweltstrafrecht in der Volksrepublik China. Freiburg i.Br. 2002, $296 \mathrm{~S}$.

Band S 93 Hamdorf, Kai, Beteiligungsmodelle im Strafrecht. Ein Vergleich von Teilnahme- und Einheitstätersystemen in Skandinavien, Österreich und Deutschland. Freiburg i.Br. 2002, $447 \mathrm{~S}$.

\section{2 (nachgedruckt)}

Band S 66 Swart, Bert/Klip, André (eds.), International Criminal Law in the Netherlands. Freiburg i.Br. 1997. $431 \mathrm{~S}$.

2003

Band S 82.7 Eser, Albin/Arnold, Jörg (Hrsg.), Strafrecht in Reaktion auf Systemunrecht. Vergleichende Einblicke in Transitionsprozesse. Band 7: Rußland, Weißrußland, Georgien, Estland, Litauen. Freiburg i.Br. 2003, 357 S.

Band S 92 Tellenbach, Silvia, Einführung in das türkische Strafrecht. Freiburg i.Br. 2003, $308 \mathrm{~S}$.

Band S 94 Heine, Günter/Huber, Barbara/Rose, Thomas O., Private Commercial Bribery. A Comparison of National and Supranational Legal Structures. Freiburg i.Br. 2003, $656 \mathrm{~S}$.

Band S 95.1 Eser, Albin/Kreicker, Helmut (Hrsg.), Nationale Strafverfolgung völkerrechtlicher Verbrechen. National Prosecution of International Crimes. Band 1: Deutschland. Freiburg i.Br. 2003, 552 S.

Band S 95.2 Eser, Albin/Kreicker, Helmut (Hrsg.), Nationale Strafverfolgung völkerrechtlicher Verbrechen. National Prosecution of International Crimes. Band 2: Finnland, Polen, Schweden. Freiburg i.Br. 2003, 304 S. 
Band S 97 Haeusermann, Axel, Der Verband als Straftäter und Strafprozßsubjekt. Freiburg i.Br. 2003, $464 \mathrm{~S}$.

Band S 98 Günther, Andreas M., Täterschaft und Teilnahme im südafrikanischen Recht. Eine rechtsvergleichende Studie unter besonderer Berücksichtigung der common purpose rule. Freiburg i.Br. 2003, 294 S.

\section{3 (nachgedruckt)}

Band S 66 Swart, Bert/Klip, André (eds.), International Criminal Law in the Netherlands. Freiburg i.Br. 1997. $431 \mathrm{~S}$.

\section{Kriminologische Forschungsberichte}

edition iuscrim, Freiburg i.Br.

2002

Band 92 Kury, Helmut, Obergfell-Fuchs, Joachim, Würger, Michael, Strafeinstellungen. Ein Vergleich zwischen Ost- und Westdeutschland. edition iuscrim, Freiburg i.Br. 2002, $201 \mathrm{~S}$.

Band 99 Kilchling, Michael, Die Praxis der Gewinnabschöpfung in Europa. Eine vergleichende Evaluationsstudie zur Gewinnabschöpfung in Fällen von Geldwäsche und anderen Formen Organisierter Kriminalität. Freiburg i.Br. 2002, $490 \mathrm{~S}$.

Band 100 Albrecht, Hans-Jörg/Kilchling, Michael (Hrsg.), Jugendstrafrecht in Europa. Freiburg i.Br. 2002, $535 \mathrm{~S}$.

Band 101 Albrecht, Hans-Jörg/van Kalmthout, Anton (eds.), Community Sanctions and Measures in Europe and North America. Freiburg i.Br. 2002, 600 S.

Band 102 Albrecht, Hans-Jörg/Kilchling, Michael/Braun, Elisabeth (eds.), Criminal Preventive Risk Assessment in the Law-Making Procedure. Freiburg i.Br. 2002, $302 \mathrm{~S}$.

Band 103 Ortmann, Rüdiger, Sozialtherapie im Strafvollzug. Freiburg i.Br. 2002, 681 S.

Band 104 Bleckmann, Frank, Strafrechtsdogmatik - wissenschaftstheoretisch, soziologisch, historisch. Das Beispiel des strafrechtlichen Vorsatzes. Freiburg i.Br. 2002, $371 \mathrm{~S}$.

Band 107 Haverkamp, Rita, Elektronisch überwachter Hausarrestvollzug: Ein Zukunftsmodell für den Anstaltsvollzug? Freiburg i.Br. 2002, 644 S.

Band 108 Albrecht, Hans-Jörg/Fijnaut, Cyrille (eds.), The Containment of Transnational Organized Crime. Comments on the UN Convention of December 2000. Freiburg i.Br. 2002, 278 S. 
2003

Band 106 Höfer, Sven, Sanktionskarrieren. Eine Analyse der Sanktionshärteentwicklung bei mehrfach registrierten Personen anhand von Daten der Freiburger Kohortenstudie. Freiburg i.Br. 2003, 198 S.

Band 109 Backmann, Ben, Sanktionseinstellungen und Delinquenz Jugendlicher. Eine vergleichende empirische Darstellung zur schweizerischen und deutschen Situation unter Berücksichtigung des jeweiligen Jugendstrafrechts. Freiburg i.Br. $2003,540 \mathrm{~S}$.

Band $110 \quad$ Mayer, Markus/Haverkamp, Rita/Lévy, René (eds.), Will Electronic Monitoring Have a Future in Europe? Contributions from a European Workshop, June 2002. Freiburg i.Br. 2003, 282 S.

Band 114 Shapland, Joanna/Albrecht, Hans-Jörg/Ditton, Jason/Godefroy, Thierry (eds.), The Informal Economy: Threat and Opportunity in the City. Freiburg i.Br. 2003, $436 \mathrm{~S}$.

Band 115 Albrecht, Hans-Jörg/Dorsch, Claudia/Krüpe, Christiane, Rechtswirklichkeit und Effizienz der Überwachung der Telekommunikation nach den $\S \S 100 \mathrm{a}$, $100 \mathrm{~b}$ StPO und anderer verdeckter Ermittlungsmaßnahmen. Eine rechtstatsächliche Untersuchung im Auftrag des Bundesministeriums der Justiz. Freiburg i.Br. 2003, $480 \mathrm{~S}$.

\section{Reihe "Sammlung ausländischer Strafgesetzbücher in deutscher Übersetzung"}

edition iuscrim, Freiburg i.Br.

2002

Bd. 111 Das spanische Strafgesetzbuch - Código Penal. Zweisprachige Ausgabe. Übersetzung von Markus Hoffmann und Manuel Cancio Meliá. Einführung von Enrique Bacigalupo. Freiburg i.Br. 2002, 376 S.

2003

Bd. 107 Das dänische Strafgesetz - Straffeloven. Zweisprachige Ausgabe. Aktualisierung auf den Stand 1.1.2003 von Karin Cornils und Vagn Greve. www.iuscrim.mpg.de/verlag/straf/daenStGB-Akt.pdf.

Bd. 113 Strafprozeßordnung der Niederlande - Wetboek van Strafvordering. Zweisprachige Ausgabe. Übersetzung und Einführung von Hans-Joseph Scholten. Freiburg i.Br. 2003, $545 \mathrm{~S}$.

Bd. 114 Das schwedische Kriminalgesetzbuch - Brottsbalken. Zweisprachige Ausgabe. Aktualisierung auf den Stand 1.1.2004 von Karin Cornils und Nils Jareborg. www.iuscrim.mpg.de/verlag/straf/schwedStGB-Akt.pdf.

Bd. 115 Die polnische Strafprozeßordnung - Kodeks postępowania karnego. Zweisprachige Ausgabe. Übersetzung und Einführung von Ewa Weigend. Freiburg i.Br. 2003, ca. $420 \mathrm{~S}$. 


\section{3 (nachgedruckt)}

Bd. 113 Strafprozeßordnung der Niederlande - Wetboek van Strafvordering. Zweisprachige Ausgabe. Übersetzung und Einführung von Hans-Joseph Scholten. Freiburg i.Br. 2003, 545 S.

\section{Reihe "Interdisziplinäre Untersuchungen aus Strafrecht und Kriminologie"}

2002

Band 6 Gleß, Sabine (Hrsg.), Auslieferungsrecht der Schengen-Vertragsstaaten. Neuere Entwicklungen. Freiburg i.Br. 2002, 633 S.

Band 7 Albrecht, Hans-Jörg/Chen Guangzhong (eds.), Non-Prosecution Policies. A Sino-German Comparison. Freiburg i.Br. 2002, 296 S.

Band $8 \quad$ Nemitz, Jan Christoph, Strafzumessung im Völkerstrafrecht. Ein Beitrag zur Strafzwecklehre und zur Strafzumessungsmethode unter besonderer Berücksichtigung des Römischen Statuts. Freiburg i.Br. 2002, 328 S.

\section{2 (nachgedruckt)}

Band 3/1 Militello, Vincenzo/Paoli, Letizia/Arnold, Jörg (curatori), Il crimine organizzato come fenomeno transnazionale. Forme di manifestazione, prevenzione e repressione in Italia, Germania e Spagna. Freiburg i.Br. 2000, 505 S.

2003

Band 9 Müller, Susanne, Sanktionen und Strafauswahl in Frankreich. Eine historische, rechtspolitische und dogmatische Analyse der Ermessensfreiheit des französischen Strafgerichts. Freiburg i.Br. 2003, 474 S.

Band $10 \quad V o ß$, Thomas, Europol: Polizei ohne Grenzen? Strafrechtliche Immunitätenregelungen und Kontrolle von Europol. Freiburg i.Br. 2003, 367 S.

Band 11 Ambos, Kai/Othman, Mohamed (eds.), New Approaches in International Criminal Justice: Kosovo, East Timor, Sierra Leone and Cambodia. Freiburg i.Br. 2003, $292 \mathrm{~S}$.

\section{3 (nachgedruckt)}

Band 5/1+2 Gleß, Sabine/Grote, Rainer/Heine, Günter (Hrsg.), Justitielle Einbindung und Kontrolle von Europol. Rechtsvergleichendes Gutachten im Auftrag des Bundesministeriums der Justiz. Band 1: Nationale und europäische Strafverfolgung. Band 2: Polizeiliche Ermittlungstätigkeit und Grundrechtsschutz. Freiburg i.Br. 2000, $694+638 \mathrm{~S}$. 


\section{Reihe "Rechtsvergleichende Untersuchungen zur gesamten Strafrechtswissenschaft"}

Verlag Nomos, Baden-Baden

2002

Band 25 Vest, Hans, Genozid durch organisatorische Machtapparate. An der Grenze von individueller und kollektiver Verantwortlichkeit. Baden-Baden 2002, $444 \mathrm{~S}$.

Band 26 Thomas, Herbert, Das Recht auf Einmaligkeit der Strafverfolgung. Vom nationalen zum internationalen ne bis in idem. Baden-Baden 2002, $365 \mathrm{~S}$.

Band 27 Eser, Albin/Lagodny, Otto/Blakesley, Christopher L. (eds.), The Individual as Subject of International Cooperation in Criminal Matters. A Comparative Study. Baden-Baden 2002, 770 S.

2003

Eser, Albin/Koch, Hans-Georg (Hrsg.), Schwangerschaftsabbruch und Recht: Vom internationalen Vergleich zur Rechtspolitik. Baden-Baden 2003, 361 S.

\section{Reihe "Ethik und Recht in der Medizin",}

Verlag Nomos, Baden-Baden

2003

Band 36 Maio, Giovanni/Just, Hanjörg (Hrsg.), Die Forschung an embryonalen Stammzellen in ethischer und rechtlicher Perspektive. Baden-Baden 2003.

\section{Reihe "Strafrecht und Kriminologie"}

Verlag Duncker \& Humblot, Berlin

2002

Band 16 Ambos, Kai, Der "Allgemeine Teil" des Völkerstrafrechts. Ansätze zu einer Dogmatisierung. Berlin 2002, 1058 S.

\section{"forschung aktuell / research in brief"}

2002

Heft 10 Eser, Albin/Lagodny, Otto/Blakesley, Christopher L., The Individual as Subject of International Cooperation in Criminal Matters. A Comparative Study. Freiburg i.Br. 2002, $28 \mathrm{~S}$. 
Heft 11 Walter, Michael/Albrecht, Hans-Jörg/Kania, Harald (Hrsg.), Alltagsvorstellungen von Kriminalität. Individuelle und gesellschaftliche Bedeutung für die Lebensgestaltung - Ein interdisziplinäres Symposion. Freiburg i.Br. 2002, $51 \mathrm{~S}$.

Heft 12 Gleß, Sabine, Auslieferungsrecht der Schengen-Vertragsstaaten. Neuere Entwicklungen. Freiburg i.Br. 2002, $20 \mathrm{~S}$.

Heft 13 Mayer, Markus, Modellprojekt Elektronische Fußfessel. Befunde der Begleitforschung - Zwischenbericht Mai 2002. Freiburg i.Br., 28 S.

Heft 14 Haverkamp, Rita, Implementing Electronic Monitoring. A comparative, empirical study on attitudes towards the measure in Lower Saxony/Germany and in Sweden. Freiburg i.Br., 24 S.

Heft 15 Eser, Albin/Arnold, Jörg/Kreicker, Helmut, Criminal Law in Reaction to State Crime. Comparative Insights into Transitional Processes. Freiburg i.Br. 2002, $17 \mathrm{~S}$.

2003

Heft 16 Heine, Günter/Rose, Thomas O., Private Commercial Bribery. A Comparison of National and Supranational Legal Structures. Freiburg i.Br. 2003, 21 S.

Heft 17 Albrecht, Hans-Jörg/Dorsch, Claudia/Krüpe, Christiane, Rechtswirklichkeit und Effizienz der Überwachung der Telekommunikation nach den $\S \S 100 \mathrm{a}$, 100b StPO und anderer verdeckter Ermittlungsmaßnahmen. Freiburg i.Br. 2003, $42 \mathrm{~S}$.

Heft 18 Moitra, Soumyo D., Analysis and Modelling of Cybercrime: Prospects and Potential. Freiburg i.Br., $44 \mathrm{~S}$.

Heft 20 Biehler, Anke/Kniebühler, Roland/Lelieur-Fischer, Juliette/Stein, Sibyl (eds.), Freiburg Proposal on Concurrent Jurisdictions and the Prohibition of Multiple Prosecutions in the European Union. Freiburg i.Br. 2003, 36 S.

\section{Reihe "Arbeitsberichte"}

2002

1 Grundies, Volker/Höfer, Sven/Tetal, Carina, Basisdaten der Freiburger Kohortenstudie. Prävalenz und Inzidenz polizeilicher Registrierung. Freiburg i.Br. 2002, $199 \mathrm{~S}$.

2

Wößner, Gunda, Behandlung, Behandelbarkeit und Typisierung von Sexualstraftätern. Ergebnisse einer bundesweiten Expertenbefragung. Freiburg i.Br. $2002,65 \mathrm{~S}$. 


\section{Veröffentlichungen}

Albrecht, Hans-Jörg La delincuencia organizada transnacional y los instrumentos internacionales de control. Regista Catalana de Seguretat Pública 8, 87-105 (2001) (Nachtrag).

u. Nogala, D., Police, Sociology of. In: International Encyclopaedia of Social and Behavioural Sciences, Vol. 17. Hrsg. P.B. Baltes, N.J. Smelser. Elsevier, Amsterdam 2001, 11532-11535 (Nachtrag).

(2002)

$u$. Hotter, I., Rundfunk und Pornographieverbot - Eine (auch rechtsvergleichende) Untersuchung zur Reichweite des Pornographieverbots im Rundfunk im weiteren Sinne. Rechtsgutachten, erstellt im Auftrag der Bayerischen Landeszentrale für neue Medien. BLM-Schriftenreihe, Bd. 68. R. Fischer, München $2002,181 \mathrm{~S}$.

Ist das deutsche Jugendstrafrecht noch zeitgemäß? Gutachten D Bd.1 zum 64. Deutschen Juristentag. Hrsg. Ständige Deputation des Deutschen Juristentages, Berlin 2002. C.H. Beck, München 2002, 172 S.

Entwicklungen im modernen Strafvollzug. In: Das Strafvollzugssystem - Fragen von Theorie und Praxis (griechisch). Hrsg. A. Chaidou. Juristische Bibliothek, Athen 2002, 191-232.

Immigration, Crime and Unsafety. In: Crime and Insecurity. The Governance of Safety in Europe. Hrsg. A. Crawford. Willan Publishing, Cullompton/UK, Portland/USA 2002, 159-185.

Ausländerkriminalität und die Entwicklung behördlicher Reaktionen. In: "Fremder, kommst Du nach Deutschland ...". Zum institutionellen Umgang mit Fremden in Staat und Gesellschaft. Hrsg. A. Graduszewski, J. Vettermann. Lit-Verlag, Münster 2002, 108-139.

The Death Penalty in China - Placing the Chinese Death Penalty Policies in International Perspectives (English and Chinese). In: EU-China Human Rights Dialogue. Working paper of the Third Seminar held in Lisbon 8-9 May 2000. Hrsg. Facultade de Direito, Universidad Nova de Lisboa, Lissabon 2002, 11-57.

Angehörige zwischen Strafzwecken des Staates und Integration des Täters. In: Mitgefangen: Die Gefangenen und ihre Angehörigen. Hrsg. F. Riklin. CaritasVerlag, Luzern 2002, 64-83.

Investigaciones sobre criminalidad económica en Europa: Conceptos y Comprobaciones Empíricas. In: Moderne Tendencias en la Ciencia del Derecho Penal y en la Criminología. Hrsg. Universidad Nacional de Educación a Distancia. Madrid 2002, 259-281.

Polizei, Diskriminierung und Fremdenfeindlichkeit in multi-ethnischen Gesellschaften. In: Strafrecht, Strafprozessrecht und Menschenrechte. Festschrift für Stefan Trechsel. Hrsg. A. Donatsch, M. Forster, C. Schwarzenegger. Schulthess, Zürich 2002, 355-372. 
Effizienter Jugendschutz im Rundfunk durch Ordnungswidrigkeiten- und Kriminalrecht? In: BLM-Symposion Medienrecht 2001. Zwischen Intendantenbefugnis und Zensurverbot: Jugendschutz in privaten Rundfunkangeboten in Bayern. Hrsg. Bayerische Landeszentrale für neue Medien (BLM). Fischer, München 2002, 87-105.

Xingshi susong zhong de biantong zhengce yiji jianchaguan zai fating shenli kaishi qian de zuoyong. In: Zhong-De di-3 jie, di-4 jie xingfaxue, fanzuixue yantaohui wenji (Drittes und viertes deutsch-chinesisches Kolloquium über Strafrecht und Kriminologie). Hrsg. Sifabu yufang fanzui yanjiusuo Bianyin (Institut für Verbrechensprävention beim Justizministerium der Volksrepublik China). Beijing 2002, 160-175.

Organisierte Wirtschaftskriminalität - Ein fassbarer Tatbestand? In: Rechtliche und strategische Aspekte der Kontrolle der organisierten Wirtschaftskriminalität. Seminar vom 5. bis 8. Juni 2001. Hrsg. Polizei-Führungsakademie Münster 2002, 123-144.

Eine kriminologische Einführung zu Menschenschmuggel und Schleuserkriminalität. In: Illegale Migration und Schleuserkriminalität. Hrsg. E. Minthe. Kriminologische Zentralstelle Wiesbaden 2002, 29-53.

A bünözésben mutatkozó változások, ezek okai és a kriminálpolitika szerepe. In: Belügyi Szemle - Külföldi Figyelö. Hrsg. L. Korinek. Innenministerium Ungarn, Budapest 2002, 3-42.

Juvenile Crime and Juvenile Law in the Federal Republic of Germany. In: Juvenile Justice Systems: International Perspectives. Hrsg. J.A. Winterdyk. Canadian Scholars' Press Inc., Toronto 2002, 171-205.

Kriminologische Erfahrungen und kriminalpräventive Räte. In: Wachsam und kooperativ? Der lokale Staat als Sicherheitsproduzent. Hrsg. R. Prätorius. Nomos Verlagsgesellschaft, Baden-Baden 2002, 22-40.

u. Chen Guangzhong (Hrsg.), Non-Prosecution Policies. A Sino-German Comparison. edition iuscrim, Freiburg i.Br. 2002, 286 S.

(als Autor) Comparative Perspectives on Public Prosecution and Non-Prosecution Policies in China and Germany, 203-229.

u. Fijnaut, C. (Hrsg.), The Containment of Transnational Organized Crime. Comments on the UN Convention of December 2000. edition iuscrim, Freiburg i.Br. 2002, $278 \mathrm{~S}$.

(als Autor) The UN Transnational Crime Convention - An Introduction, 1-18.

Die Todesstrafe in China. In: Zur Aktualität der Todesstrafe - Interdisziplinäre und globale Perspektiven. Hrsg. C. Boulanger, V. Heyes, P. Hanfling. Berlin Verlag, Berlin 2002, 165-192.

u. van Kalmthout, A. (Hrsg.), Community Sanctions and Measures in Europe and North America. edition iuscrim, Freiburg i.Br. 2002, 606 S.

(als Autor) Community Sanctions in the Federal Republic of Germany, 243270 .

u. Kilchling, M. (Hrsg.), Jugendstrafrecht in Europa. edition iuscrim, Freiburg i.Br. 2002, $535 \mathrm{~S}$. 
u. Kilchling, M., Braun, E. (Hrsg.), Criminal Preventive Risk Assessment in the Law-Making Procedure. edition iuscrim, Freiburg i.Br. 2002, $302 \mathrm{~S}$. (als Autor) Synthesis Report, 1-22.

u. Paoli, L., Cannabis Policies in Frankfurt. In: European City Conference on Cannabis Policy, 6, 7, 8 December 2001. Conference book. Hrsg. Ministry of Justice, The Netherlands, 75-89 [o.J. (2002)].

$u$. Walter, M., Kania, H. (Hrsg.), Alltagsvorstellungen von Kriminalität. forschung aktuell/research in brief, Nr. 11. edition iuscrim, Freiburg i.Br. 2002, $52 \mathrm{~S}$.

Fortress Europe? - Controlling Illegal Immigration. European Journal of Crime, Criminal Law and Criminal Justice, Jg. 10, Heft 1, 1-22 (2002).

Ist das deutsche Jugendstrafrecht noch zeitgemäß? Bedarf es- und wenn ja welcher - Veränderungen? Neue Juristische Wochenschrift, Beilage zu Heft 23, 26-22 (2002).

Terrorismus und kriminologische Forschung. Eine Bestandsaufnahme. Schweizerische Zeitschrift für Kriminologie 1, 5-17 (2002).

Antworten der Gesetzgeber auf den 11. September - eine Analyse internationaler Entwicklungen. Journal für Konflikt- und Gewaltforschung 4, 46-76 (2002).

Preliminary Remarks. European Journal of Crime, Criminal Law and Criminal Justice, Hefte 2-3, Special Issue on War-Victimization-Security: The Case of the Former Yugoslavia, 87-89 (2002).

Organisierte Kriminalität: Zur sozialen Konstruktion einer Gefahr. Ein Kommentar. In: Organisierte Kriminalität - oder gesellschaftliche Desorganisation? Angewandte Sozialforschung 22, 155-160 (2002).

Der elektronische Hausarrest. Das Potential für Freiheitsstrafenvermeidung, Rückfallverhütung und Rehabilitation. Monatsschrift für Kriminologie und Strafrechtsreform 85, 84-104 (2002).

$u$. Kilchling, M., Crime Risk Assessment, Legislation, and the Prevention of Serious Crime - Comparative Perspectives. Journal of Crime, Criminal Law and Criminal Justice, Vol. 10/1, 23-38 (2002).

u. Kilchling, M., Rechtsextremistische Gewalt, Strafrechtliche Sozialkontrolle, Täter-Opfer-Ausgleich und Wiedergutmachungsansätze. Recht der Jugend und des Bildungswesens 1, 82-93 (2002).

Arbeitslosigkeit: Exklusion aus dem Erwerbsleben und soziale Desintegration. In: Kriminalität und Gewalt im Jugendalter. Hell- und Dunkelfeldbefunde im Vergleich. Hrsg. J. Raithel, J. Mansel. Juventa Verlag, Weinheim und München 2003, 177-134.

Foreigners, migration, immigration and the development of criminal justice in Europe. In: Migrazioni, interazioni e conflitti nella costruzione di una democrazia europea. Hrsg. D. Melossi. Giuffrè Editore, Milano 2003, 787-819. 
Zusammenfassung und Resümee. In: Soziale Reflexivität und qualitative Methodik - Zum Selbstverständnis der Kriminologie in der Spätmoderne. Hrsg. K.-L. Kunz, C. Besozzi. Haupt Verlag, Bern u.a. 2003, 213-229.

The Role and Impact of Law and Enforcement in Reducing the Harms of IDU and HIV/AIDS. In: Reducing the Risks, Harms and Costs of HIV/AIDS and Injection Drug Use (IDU): A Synthesis of the Evidence Base for Development of Policies and Programs. Hrsg. International Affairs division of Health Canada/UNAIDS. Toronto 2003 (in print).

$u$. Chen Guangzhong (Hrsg.), Proceedings of the Sino-German Symposium on Compulsory Measures. Verlag der Chinese People's Public Security University. Beijing 2003, $205 \mathrm{~S}$.

(als Autor) Pretrial Detention in Germany - The Empirical Situation (englisch/chinesisch), 151-179.

u. Dorsch, C., Krüpe, Ch., Rechtswirklichkeit und Effizienz der Überwachung der Telekommunikation nach den $\S \S 100 \mathrm{a}, 100 \mathrm{~b}$ StPO und anderer verdeckter Ermittlungsmaßnahmen. edition iuscrim, Freiburg i.Br. 2003, $480 \mathrm{~S}$.

u. Dorsch, C., Krüpe, Ch., Rechtswirklichkeit und Effizienz der Überwachung der Telekommunikation nach den $\S \S 100 \mathrm{a}, 100 \mathrm{~b}$ StPO und anderer verdeckter Ermittlungsmaßnahmen. forschung aktuell/research in brief, Nr. 17. edition iuscrim, Freiburg i.Br. 2003, $42 \mathrm{~S}$.

u. Entorf, H. (Hrsg.), Kriminalität, Ökonomie und Europäischer Sozialstaat. Physica-Verlag, Heidelberg 2003, 273 S.

(als Autor) Einleitung, 1-5; Forschungen zur Wirtschaftskriminalität in Europa: Konzepte und empirische Befunde, 37-69.

u. Frisch, W., von Hirsch, A. (Hrsg.), Tatproportionalität. Normative und empirische Aspekte einer tatproportionalen Strafzumessung. C.F. Müller, Heidelberg 2003, $292 \mathrm{~S}$.

(als Autor) Tatproportionalität in der Strafzumessungspraxis, 215-242.

u. Kaiser, G. (Hrsg.), Will Electronic Monitoring have a future in Europe? edition iuscrim, Freiburg i.Br. 2003, 282 S.

(als Autor) The Place of Electronic Monitoring in the Development of Criminal Punishment and Systems of Sanctions, 249-264.

u. Shapland, J., Ditton, J., Godefroy, T. (Hrsg.), The Informal Economy: Threat and Opportunity in the City. edition iuscrim, Freiburg 2003, 426 S.

(als Autor) The Informal Economy - A Summary and Perspectives, 399-424.

The fortress of Europe? Control of illegal immigration (georgisch/englisch). In: "Law" Scientific-practical juridical journal 1-2, 41-50 (2003).

Forschungen zur Implementation und Evaluation jugendstrafrechtlicher Sanktionen. ZJJ (Zeitschrift für Jugendkriminalrecht und Jugendhilfe) 3, 224-232 (2003).

Verfassungsmäßigkeit des Jugendstrafvollzugs. RdJB (Recht der Jugend und des Bildungswesens) 51, 352-360 (2003).

u. Hotter, I., Jüngste Vorschläge zu Reformen im Bereich des Jugendstrafrechts. RdJB (Recht der Jugend und Bildungswesens) 51, 282-298 (2003). 
Ambos, Kai

\section{Veröffentlichungen auf CD-ROM}

Trafficking in Humans - Theory, Phenomenon and Criminal Law based responses. In: 7th Annual Conference and General Meeting of The International Association of Prosecutors, 8th to 12th September 2002 London, United Kingdom. Hrsg. International Association of Prosecutors. CPS, London 2002, CD-ROM.

Trafficking in Humans, Drugs and Money. In: 7th Annual Conference and General Meeting of The International Association of Prosecutors, 8th to 12th September 2002 London, United Kingdom. Hrsg. International Association of Prosecutors. CPS, London 2002, CD-ROM.

Der Allgemeine Teil des Völkerstrafrechts. Ansätze einer Dogmatisierung. Duncker \& Humblot, Berlin 2002, 1058 S.

(Hrsg.), La nueva justicia penal supranacional. Desarollos post-Roma. Tirant lo Blanch, Valencia 2002, $549 \mathrm{~S}$.

Nuevo derecho penal internacional. Instituto Nacional de Ciencias Penales, México 2002, $902 \mathrm{~S}$.

u. Choukr, F.H. (Hrsg.), Processo Penal e Estado de Direito. Campinas, São Paulo 2002.

Erscheinungsformen der impunidad und Gegenmaßnahmen. In: Politische Gewalt in Lateinamerika. Hrsg. Th. Fischer, M. Krennerich. Frankfurt a.M. 2000, 231-257; aktualisierte Fassung in: Korruption in Brasilien und Deutschland. Hrsg. W. Paul. Aachen 2002, 76-104.

El crimen organizado y la "Guerra contra las drogas" en Latinoamérica. In : Farmacodependencia y política de drogas. Coord. D. Schreck, E. Milanese. Bogotá (Caritas Internacional) 2002, 147-156.

Organisierte Kriminalität und "Drogenkrieg" in Lateinamerika. In: Drogenhilfe und Drogenpolitik. Hrsg. Deutscher Caritasverband. Freiburg i.Br. 2002, 179-189.

The Role of the Prosecutor. In: Towards A Procedural Regime For The International Criminal Court. Hrsg. St. Livingstone. Nottingham 2002, 11-21.

On the Rationale of Punishment at the Domestic and International Level. In: Le Droit Pénal à L'Épreuve de L'Internationalisation. Hrsg. M. Henzelin, R. Roth. Genève 2002, 305-323.

Superior Responsibility. In: The Rome Statute of the International Criminal Court: A Commentary. Hrsg. A. Cassese, P. Gaeta, J. Jones. 3 Vol. Oxford 2002, 823-872 (Vol. I); Other grounds for Excluding Criminal Responsibility, 1003-1048 (Vol. I).

Les pays d'Amérique latine. In: Juridictions Nationales et Crimes Internationaux. Hrsg. A. Cassese, M. Delmas-Marty. Paris 2002, 479-520.

u. Arnold, J., Meißner J., Nemitz, J.C., Wirth. S., Freiburger Juristen-Erklärung zur Achtung des Völkerrechts. In: Jahrbuch der Juristischen Zeitgeschichte, Bd. 3 (2001/2002). (Hrsg.) T. Vormbaum. Nomos Verlagsgesellschaft, Baden-Baden 2002, 99-101. 
u. Nemitz, J.C., Commentary. In: Annotated leading cases of International Criminal Tribunals. Hrsg. A. Klip, G. Sluiter. Vol. 4. The International Criminal Tribunal for Rwanda 1994-1999. Antwerpen et al. 2002, 469-475.

Annahme "bemakelten" Verteidigerhonorars als Geldwäsche? Juristenzeitung $57,70-82$ (2002).

Präterintentionalität und Erfolgsqualifikation. Rechtsvergleichende Überlegungen. Goltdammer's Archiv für Strafrecht, 455-482 (2002)

Internationalisierung des Strafrechts: das Beispiel "Geldwäsche". Zeitschrift für die gesamte Strafrechtswissenschaft 114, 236-256 (2002).

Straftäter oder Polizist - einerlei? In Lateinamerika ist die Polizei weit von rechtsstaatlichen Standards entfernt. Entwicklung und Zusammenarbeit 43, 51-53 (2002).

The Right of Non-Self-Incrimination of Witnesses before the ICC. Leiden Journal of International Law 15, 155-177 (2002).

La responsabilidad del superior en el Derecho penal internacional. Anuario de Derecho Penal y Ciencias Penales (Madrid) 52 (Januar-April 1999, veröffentlicht 2002), 527-593.

Control de la policía por el fiscal versus dominio policial de la instrucción. Tribunales de Justicia (Spanien) No. 3 (März 2002), 15-28; Derecho Penal Contemporáneo (Legis, Kolumbien) No. 1 (Octubre-Diciembre 2002), 149178; Ciencias Penales (Costa Rica) No. 20 (Octubre 2002), 21-35.

Delincuente y policía: ¿la misma cosa? En América Latina, la policía está aún lejos de cumplir con los estándares del Estado de Derecho. Desarollo y Cooperación 3/2002, 24-26.

Bedrohung. Das Weltstrafrecht hat seine Unschuld schon verloren. Süddeutsche Zeitung vom 16.7.2002, 13 (Feuilleton); in Spanisch: Amenaza. El Derecho Penal Internacional ya perdió su inocencia. Desarollo y Cooperación 5/2002, 7; Gaceta Jurídica, Santiago de Chile (Chile), 7/02, 18; La Gaceta Jurídica, La Paz (Bolivia), 16.8.2002, 11.

Europarechtliche Vorgaben für das (deutsche) Strafverfahren. Neue Zeitschrift für Strafrecht, 628 (2002) und 13 (2003).

u. Pastor, D., Rocha de Assis, M.T., Guzmán, J.L., Velásquez, F., Moreno, M., Caro, C., Modolell, J.L., Jurisdicción penal para crímenes internacionales en América Latina, Revista Penal (Spanien), No. 10, 130-160 (2002).

$u$. Wenning, T., Rechtsprechung zum internationalen Straf- und Strafverfahrensrecht. Neue Zeitschrift für Strafrecht-Rechtsprechungsreport, 289-296 (2002).

u. Wirth, S., The current law of crimes against humanity. An analysis of UNTAET Regulation 15/2000. Criminal Law Forum 13, 1-90 (2002). 
La Corte Penal Internacional. San José/Costa Rica 2003, 231 S.

u. Gómez Colomer, J.-L., Vogler, R., unter Mitarbeit von Malarino, E. (Hrsg.), La Policía en los Estados de Derecho Latinoamericanos. Un proyecto internacional de investigacíon. Ediciones Jurídicas Gustavo Ibáñez C. Ltd., Bogotá, D.C. $2003,629 \mathrm{~S}$.

u. Malarino, E. (Hrsg.), Persecución penal de crímenes internacionales en América Latina y España. Konrad-Adenauer-Stiftung und Max-PlanckInstitut für ausländisches und internationales Strafrecht, Montevideo 2003.

u. Malarino, E. (coord.), Persecução Penal International na América Latina e Espanha. Instituto Brasileiro de Ciências Criminais, São Paulo 2003.

Impunidade por violação dos direitos humanos e o direito penal internacional. In: Simpósio da Faculdade de Direito da Universidade de Coimbra e GoetheInstitut de Lisboa, Direito Penal Internacional para a protecção dos direitos humanos. Lissabon 2003, 129-165.

Some Preliminary Reflections on the Mens Rea Requirements of the Crimes of the ICC Statute and of the Elements of Crimes. In: Man's Inhumanity to Man. Essays in Honour of Antonio Cassese. Hrsg. L.C. Vohrah et al. The Hague 2003, 11-40.

$\S \S 3-7$ StGB. In: Münchener Kommentar zum StGB, Band I. Gesamghrsg. W. Joecks, K. Miebach. München 2003.

u. Gómez Colomer, J.L., Vogler, R. (Hrsg.), La policía en los Estados de Derecho Latinomericanos. Bogotá 2003 (editorial Gustavo Ibañez in Zusammenarbeit mit der Friedrich-Ebert-Stiftung und dem Max-Planck-Institut für ausländisches und internationales Strafrecht).

u. Othman, M. (Hrsg.), New Approaches in International Criminal Justice: Kosovo, East Timor, Sierra Leone and Cambodia. edition iuscrim, Freiburg i.Br. 2003, $282 \mathrm{~S}$.

u. Ruegenberg, G., §§ 8-9 StGB. In: Münchener Kommentar zum StGB, Band I. Gesamthrsg. W. Joecks, K. Miebach. München 2003.

Sobre los fines de la pena a niveles nacional y supranacional. Iter Criminis. Revista de Ciencias Penales (Instituto Nacional de Ciencias Penales), No. 6, México, 11-34 (2003); Revista de Derecho Penal y Criminología (Universidad Nacional de Educación a Distancia. Facultad de Derecho, Madrid). 2nda Epoca. No. 12, 191-211 (Julio 2003) [traduc. de JuS 2001].

$\mathrm{O}$ direito à não-auto-incriminação de testemunhas perante o Tribunal Penal Internacional. Revista de Estudos Criminais. Univ. Católica do Rio Grande do Sul, No. 8, 67-85 (2003).

Zur Strafbarkeit der Drittmittelakquisition, insbesondere gemäß $\S 331$ StGB. Juristenzeitung 58, 345-354 (2003).

Staatsanwaltschaftliche Kontrolle der Polizei, Verpolizeilichung des Ermittlungsverfahrens und organisierte Kriminalität. Juristische Ausbildung, Jg. 25, 674-682 (2003). 
Arnold, Jörg,
Art. 7 EMRK, common law und die Mauerschützen. Kritische Vierteljahresschrift 86, 31-43 (2003).

Zur Reform des strafprozessualen Vorverfahrens in Österreich. Österreichische Juristenzeitung 58, 661-669 (2003).

Der Europäische Gerichtshof für Menschenrechte und die Verfahrensrechte. Waffengleichheit, partizipatorisches Strafverfahren und Art. 6 EMRK. Zeitschrift für die gesamte Strafrechtswissenschaft 115, 583-637 (2003).

International Criminal Procedure: "Adversarial", "inquisitorial" or mixed? International Criminal Law Review 3, 1-37 (2003).

u. Grammer, Ch., Dominio del hecho por organización. La responsabildad de la conducción militar argentina por la muerte de Elisabeth Käsemann Cuadernos de Doctrina y Jurisprudencia Penal (Argentinien) 16, 163-196 (2003) = Revista Penal (Spanien), 27, 12 (2003) = Iter Criminis. Revista de Derecho y Ciencias Penales (Instituto Nacional de Ciencias Penales), No. 8. México 1141 (2003).

Strafrecht in Reaktion auf Systemunrecht. Vergangenheitspolitik bei europäischen Transformationen. In: Westnik. Nischegorodskowo Uniwersiteta, Ausgabe "Recht", 2(4) 2001, 91-108 (Nachtrag).

Geleitwort. In: Art. 7 EMRK und die Gewaltaten an der deutsch-deutschen Grenze. Zu den Urteilen des Europäischen Gerichtshofes für Menschenrechte. H. Kreicker. Nomos Verlagsgesellschaft, Baden-Baden 2002, IX-XII.

u. Eser, A. (Hrsg.), Strafrecht in Reaktion auf Systemunrecht. Vergleichende Einblicke in Transitionsprozesse. Bd. 3: Argentinien. edition iuscrim, Freiburg i.Br. 2002, 444 S.;

(als Autor mit Eser, A.) Einführung in das Gesamtprojekt, 1-25.

u. Eser, A. (Hrsg.), Strafrecht in Reaktion auf Systemunrecht. Vergleichende Einblicke in Transitionsprozesse. Bd. 5: Polen und Ungarn. edition iuscrim, Freiburg i.Br. 2002, $361 \mathrm{~S}$.

(als Autor mit Eser, A.) Einführung in das Gesamtprojekt, 1-18.

u. Eser, A. (Hrsg.), Strafrecht in Reaktion auf Systemunrecht. Vergleichende Einblicke in Transitionsprozesse. Bd. 6: Mali und Ghana. edition iuscrim, Freiburg i.Br. 2002, $296 \mathrm{~S}$.

(als Autor mit Eser, A.) Einführung in das Gesamtprojekt, 1-18.

u. Eser, A., Kreicker, H., Criminal Law in Reaction to State Crime. Comparative Insights into Transitional Processes. A Project Report. research in brief/forschung aktuell, Nr. 15. edition iuscrim, Freiburg i.Br. 2002, $17 \mathrm{~S}$.

u. Ambos, K., Meißner J., Nemitz, J.C., Wirth. S., Freiburger Juristen-Erklärung zur Achtung des Völkerrechts. In: Jahrbuch der Juristischen Zeitgeschichte, Bd. 3 (2001/2002). (Hrsg.) T. Vormbaum. Nomos Verlagsgesellschaft, Baden-Baden 2002, 99-101.

Strafrecht in Reaktion auf Systemunrecht. Vergangenheitspolitik bei europäischen Transformationen. In: Westnik. Nischegorodskowo Uniwersiteta, Ausgabe "Recht" 1(5), 207-217 (2002). 
(2003)

Aydin, Öykü Didem

Backmann, Ben
Die USA haben kein Recht auf vorsorgliches Töten. In: Die Stärke des Rechts gegen das Recht des Stärkeren. Politische und rechtliche Einwände gegen eine Rückkehr des Faustrechts in die internationalen Beziehungen. Hrsg. D.S. Lutz, H.J. Gießmann. Nomos Verlagsgesellschaft, Baden-Baden 2003, 326329.

u. Eser, A. (Hrsg.), Strafrecht in Reaktion auf Systemunrecht. Vergleichende Einblicke in Transitionsprozesse. Bd. 7: Rußland, Weißrußland, Georgien, Estland, Litauen. edition iuscrim, Freiburg i.Br. 2003, 357 S.

(als Autor mit Eser, A.) Einführung in das Gesamtprojekt, 1-18.

u. Eser, A., O Direito Penal como reacção às injustiças do sistema. In: Simpósio da Faculdade de Direito da Universidade de Coimbra e Goethe-Institut de Lisboa. Direito Penal Internacional Para a Protecção dos Direitos Humanos, Fin de Século, Lda. 2003, 21-42.

Neue Fragen an den Satz "nullum crimen, nulla poena sine lege". In: Die Bedeutung P.J.A. Feuerbachs (1775-1833) für die Gegenwart. Hrsg. R. Gröschner, G. Haney. ARSP-Beiheft 87. Franz Steiner Verlag, Stuttgart 2003, 107123.

Deutschland hilft beim verbotenen Angriffskrieg gegen Irak. In: Informationsbrief des Republikanischen Anwältinnen- und Anwältevereins e.V. 90, 10-13 (2003).

Verbrechensbegriff und völkerstrafrechtliche Tatbestände im neuen StGB Estlands. In: Juridica international. Law Review University of Tartu, VIII, 1115 (2003).

DDR-Recht im Zeitgeist des BGH. StraFo 4, 109-110 (2003).

u. Karsten, N., Kreicker, H., The German Border Guard Cases before the European Court of Human Rights. European Journal of Crime, Criminal Law and Criminal Justice, Jg. 11, Heft 1, 67-92 (2003).

u. Ambos, K., Kauß, U., Thun, K., Freiburger Juristenerklärung vom 10. Februar 2003: Eine deutsche Beteiligung am Krieg gegen Irak ist rechtswidrig. In: Jahrbuch der Juristischen Zeitgeschichte, Bd. 4 (2002/2003). Hrsg. Th. Vormbaum. Berliner Wissenschaftsverlag 2003, 279-281.

u. Ambos, K., Kauß, U., Thun, K., "Freiburg Lawyers' Declaration" of $10 \mathrm{Fe}-$ bruary 2003 - On German Participation in a War Against Iraq". German Law Journal, Vol. 4, No. 3-1 (2003).

u. Tellenbach, S., Länderbericht Türkei. In: Jugendstrafrecht in Europa. Hrsg. H.-J. Albrecht, M. Kilchling. edition iuscrim, Freiburg i.Br. 2002, 455-474.

u. Stump, B., Länderbericht Schweiz. In: Jugendstrafrecht in Europa. Hrsg. H.-J. Albrecht, M. Kilchling. edition iuscrim, Freiburg i.Br. 2002, 361-394.

Sanktionseinstellungen und abweichendes Verhalten Jugendlicher (Eine Projektdarstellung im Lichte des gegenwärtigen Forschungsstandes zur Jugendkriminalität). Deutsche Vereinigung für Jugendgerichte und Jugendgerichtshilfen (DVJJ)-Journal 1, 34-41 (2002).

Buchrezension: Zum Umgang mit kindlichen Auffälligkeiten (E.L. Pongratz). Monatsschrift für Kriminologie und Strafrechtsreform Heft 3, 294-295 (2002). 
Biehler, Anke

Braun, Elisabeth

Cornils, Karin u. Gleß, S., Parra, N., Zeitler, H.E., Analyse des Grünbuchs zum Schutz der finanziellen Interessen der EG und zur Schaffung einer europäischen Staatsanwaltschaft" im Auftrag des Haushaltskontrollausschusses des Europäischen Parlaments. Online:

$\mathrm{http} / /$ europa.eu.int/comm/anti_fraud/green_paper/contributions/pdf/gp_mpla nck_de.pdf

$u$. Gleß, Rechtsvergleichender Querschnitt. In: Auslieferungsrecht der Schengen Vertragsstaaten - Neuere Entwicklungen. Hrsg. S. Gleß. edition iuscrim, Freiburg i.Br. 2002, 547-611.

Die prozessualen Rechte des Angeklagten nach dem Grünbuch zur Europäischen Staatsanwaltschaft. ERA-Forum, 147-151 (2002).

u. Kniebühler, R., Lelieur-Fischer, J., Stein, S. (Hrsg.), Freiburg Proposal on Concurrent Jurisdictions and the Prohibition of Multiple Prosecutions in the European Union. research in brief/forschung aktuell, Nr. 20. edition iuscrim, Freiburg i.Br. 2003, $36 \mathrm{~S}$.

Book Review, Kelly Dawn Askin, War Crimes Against Women: Prosecution in International War Crimes Tribunals. Criminal Law Forum 13, 507-513 (2003).

u. Albrecht, H.-J., Kilchling, M. (Hrsg.), Criminal Preventive Risk Assessment in the Law-Making Procedure. edition iuscrim, Freiburg i.Br. 2002, $450 \mathrm{~S}$.

(als Autorin mit Kilchling, M.) Germany, 145-187.

u. Kilchling, M., Risk Assessment in der deutschen Gesetzgebung - Übertragbarkeit bisheriger Ansätze zur Gesetzeswirkungs- und Gesetzesfolgenabschätzung auf die OK-Prävention? Die Kriminalprävention 6, 12-18 (Heft 1), 45-56 (Heft 2) (2002).

Dopingrecht in Dänemark. In: Legal Comparison and Harmonisation of Doping Rules. Hrsg. K. Vieweg, R. Siekmann. European Commission Project No. C 116-15, CD-ROM.

Die Entwicklung des Sanktionensystems in Schweden und Deutschland. In: Flores juris et legum. Festskrift till Nils Jareborg. Hrsg. P. Asp, C.E. Herlitz, L. Holmqvist. Iustus Förlag, Uppsala 2002, 151-167.

Landesbericht Dänemark. In: Jugendstrafrecht in Europa. Hrsg. H.-J. Albrecht, M. Kilchling. edition iuscrim, Freiburg i.Br. 2002, 27-49.

Landesbericht Dänemark. In: Zeugnisverweigerungsrechte bei (verdeckten) Ermittlungsmaßnahmen. Hrsg. J. Wolter, W.-R. Schenke. Bundesministerium der Justiz, Berlin 2002, 379-390.

O Tópos Ektilessis Ton Eglimaton Ikfrassis Sto Diadvktio. Armenopoulos 56, 360-366 (2002).

Il luogo di commissione die reati di manifestazione del pensiero in Internet. Il diritto dell'informazione e dell'informatica XVIII, 891-901 (2002).

Neue Strafvollzugsgesetze in Dänemark und Norwegen, Zeitschrift für die gesamte Strafrechtswissenschaft 114, 683-695 (2002). 
Dorsch, Claudia

Eser, Albin

(2002)
Ein Nachruf auf die Vermögensstrafe. In: Rikosoikeudellisia Kirjoituksia VII. Pekka Koskiselle 1.1.2003 omistettu (Festschrift für Pekka Koskinen). Hrsg. R. Lahti, T. Lappi-Seppälä. Suomalainen Lakimiesyhdistys, Helsinki 2003, 15-29.

Grundlagen der Strafverfolgung völkerrechtlicher Verbrechen in Schweden. In: Nationale Strafverfolgung völkerrechtlicher Verbrechen. National Prosecution of International Crimes. Bd. 2: Finnland, Polen, Schweden. Hrsg. A. Eser, H. Kreicker. edition iuscrim, Freiburg i.Br. 2003, 183-278.

$u$. Greve, V., Aktualisierung der zweisprachigen Ausgabe des Dänischen Strafgesetzes - Straffeloven, auf den Stand 1.1.2003 in pdf-Format auf der Homepage des Instituts:

www.iuscrim.mpg.de/verlag/straf/daenStGB-Akt.pdf.

$u$. Jareborg, N., Aktualisierung der zweisprachigen Ausgabe des Schwedischen Kriminalgesetzbuchs - Brottsbalken auf den Stand 1.1.2004 in pdfForm auf der Homepage des Instituts:

www.iuscrim.mpg.de/verlag/straf/schwedStGB-Akt.pdf.

$u$. Greve, $V$., Aufenthalts- und Zutrittsverbote als kriminalpräventive Mittel im dänischen Recht. In: Maßnahmen gegen Organisierte Kriminalität im Rechtsstaat - Möglichkeiten und Grenzen. Hrsg. B. Öztürk, W. Gropp. Seçkin Yayincilik, Ankara 2003, 39-54.

u. Albrecht, H.-J., Krüpe, Ch., Rechtswirklichkeit und Effizienz der Überwachung der Telekommunikation nach $\S \S 100 \mathrm{a}, 100 \mathrm{~b}$ StPO und anderer verdeckter Ermittlungsmaßnahmen. edition iuscrim, Freiburg i.Br 2003, 480 S.

u. Albrecht, H.J., Krüpe, Ch., Rechtswirklichkeit und Effizienz der Überwachung der Telekommunikation nach $\S \S 100 \mathrm{a}, 100 \mathrm{~b}$ StPO und anderer verdeckter Ermittlungsmaßnahmen. forschung aktuell/research in brief, Nr. 17. edition iuscrim, Freiburg i.Br. 2003, 42 S.

Welches Strafrecht braucht und verträgt der Mensch? Einige Gedanken zu vernachlässigten Grundfragen. In: Festschrift für Klaus Lüderssen. Hrsg. C. Prittwitz u.a. Nomos Verlagsgesellschaft, Baden-Baden 2002, 195-204.

Brauchen wir ein Europäisches Strafgesetzbuch? In: Vorausbroschüre "Texte und Thesen der Referentinnen und Referenten" zum Rechtspolitischen Kongress 2002 in Karlsruhe "Recht schafft Zukunft". Hrsg. Friedrich-EbertStiftung. Nomos Verlagsgesellschaft, Baden-Baden 2002, 59-62.

Prefácio. In: Processo Penal e Estado de Direito. Hrsg. F.H. Choukr, K. Ambos. edicamp, São Paolo 2002, IX-X.

Deguo jingji xingfa de xin fazhan (Zur neuesten Entwicklung des deutschen Wirtschaftsstrafrechts). In: Zhongde disanjie, disijie xingfaxue, fanzuixue yantaohui wenji (Drittes und vierte deutsch-chinesische Kolloquien über Strafrecht und Kriminologie). Hrsg. Sifabu yufang fanzui yanjiusuo Bianyin (Institut für Verbrechensvorbeugung beim Justizministerium der Volksrepublik China). Beijing 2002, 111-120.

Auf der Suche nach dem mittleren Weg: Zwischen Fundamentalismus und Beliebigkeit. In: Unterwegs mit Visionen. Festschrift für Rita Süssmuth. Hrsg. M. Langer, A. Laschet. Verlag Herder, Freiburg i.Br. 2002, 117-139. 
Una justicia penal "a la medida del ser humano" en la época de la globalización ("Menschengerechte" Strafjustiz im Zeitalter von Europäisierung und Globalisierung). Übersetzung ins Spanische von Teresa Manso Porto. In: Tendencias del Derecho Penal y la Política Criminal del Tercer Milenio (Colección Memorias), Mexiko 2002, 39-66.

Internet und internationales Strafrecht. In: Rechtsfragen des Internet und der Informationsgesellschaft. Symposion der rechtswissenschaftlichen Fakultäten der Albert-Ludwigs-Universität Freiburg und der Städtischen Universität Osaka. Hrsg. D. Leipold. Verlag C.F. Müller, Heidelberg 2002, 303-326.

Stellungnahmen zur Stammzellforschung. In: Ethische Fragen zur Stammzellforschung: Import oder "Eigenbau". Hrsg. D. Groß, G. Keil, U.R. Rapp. Würzburger Kreis, Band 2, Würzburg 2002, 42, 44, 45, 47-49, 51, 52, 53, 54, 57, 58, 62 f., 64, 65, 69-70, 79-81, 83-84, 85, 86.

Individual Criminal Responsibility. In: The Rome Statute of the International Criminal Court: A Commentary. Hrsg. A. Cassese, P. Gaeta, J.R.W.D. Jones. Oxford University Press, New York 2002, 767-822.

Mental Elements - Mistake of Fact and Mistake of Law. In: The Rome Statute of the International Criminal Court: A Commentary. Hrsg. A. Cassese, P. Gaeta, J.R.W.D. Jones. Oxford University Press, New York 2002, 889-948.

Harmonisierte Universalität nationaler Strafgewalt: ein Desiderat internationaler Komplementarität bei Verfolgung von Völkerrechtsverbrechen. In: Strafrecht, Strafprozessrecht und Menschenrechte. Festschrift für Stefan Trechsel zum 65. Geburtstag. Hrsg. A. Donatsch, M. Forster, Ch. Schwarzenegger. Verlag Schulthess, Zürich u.a. 2002, 219-236.

Geleitwort. In: Auslieferungsrecht der Schengen-Vertragsstaaten. Neuere Entwicklungen. Hrsg. S. Gleß. edition iuscrim. Freiburg 2002, V-VI.

Intānetto to kokusaikeiho (Internet und internationales Strafrecht). Übersetzung ins Japanische von Kazushige Asada. In: Intānetto jōhōshakaito hō. Nishi-Doku Sinpojiumu (Internet und Informationsgesellschaft und Recht. Japanisch-deutsches Symposion) Freiburg 2001. Hrsg. H. Matsumoto, S. Nishitani, K. Moriya. ShinzanshaVerlag, Tokio 2002, 385-425.

u. Arnold, J. (Hrsg.), Strafrecht in Reaktion auf Systemunrecht. Vergleichende Einblicke in Transitionsprozesse. Bd. 5: Polen und Ungarn. edition iuscrim, Freiburg i.Br. 2002, 361 S.;

(als Autor mit Arnold J.) Einführung in das Gesamtprojekt, 1-18.

u. Arnold, J. (Hrsg.), Strafrecht in Reaktion auf Systemunrecht. Vergleichende Einblicke in Transitionsprozesse. Bd. 6: Mali und Ghana. edition iuscrim, Freiburg i.Br. 2002, 296 S.;

(als Autor mit Arnold, J.) Einführung in das Gesamtprojekt, 1-18.

u. Arnold, J., Kreicker, H., Criminal Law in Reaction to State Crime. Comparative Insights into Transitional Processes. A Project Report. research in brief/forschung aktuell, Nr. 15. edition iuscrim, Freiburg i.Br. 2002, 17 S. 
u. Baumann, J. (Hrsg.), Doitsu taian gurupu: Hanzai higaino kaifuku. Taian songai kaifuku. (Alternativ-Entwurf Wiedergutmachung. Entwurf eines Arbeitskreises deutscher, österreichischer und schweizerischer Strafrechtslehrer). München 1992, Seibundo, Tokyo 2002, 207 S.

(als Autor) Vorwort, i-vi.

u. Lagodny, O., Blakesley, Ch.L., The Individual as Subject of International Cooperation in Criminal Matters. A Comparative Study. Nomos Verlagsgesellschaft, Baden-Baden 2002, $770 \mathrm{~S}$.

(als Autor) Introduction (of the editors), V-VI.

u. Lagodny, O., Blakesley, Ch.L., The Individual as Subject of International Cooperation in Criminal Matters - A Comparative Study. A Summary by Otto Lagodny. research in brief/forschung aktuell, Nr. 10. edition iuscrim, Freiburg i.Br. 2002, $29 \mathrm{~S}$.

Verso una Corte Penale Internazionale: Nascita e Fondamenti dello Statuto di Roma. L'Indice Penale, Nuova Serie V/1, 279-305 (2002).

La "Adecuación Social": ¿Figura Legal Superflua o Necesaria? Reflexiones respecto a la concesión de ventajas socialmente habituales. ("Sozialadäquanz": eine überflüssige oder unverzichtbare Rechtsfigur? Überlegungen anhand sozialüblicher Vorteilsgewährungen). Übersetzung ins Spanische von María del Rosario Picasso und Pablo Lucero. Delitos culposos - I. Revista de Derecho Penal No. 1, 453-473 (2002).

Yoroppaka to Gurobarukano jidai niokeru "Hitonifusawashi" keji shiho. ("Menschengerechte" Strafjustiz im Zeitalter von Europäisierung und Globalisierung). Übersetzung ins Japanische von Masami Okaue. Hikaku Hogaku Vol. 36 No. 1, 275-302 (2002).

Funzioni, Metodi e Limiti della Ricerca in Diritto Penale Comparato (Funktionen, Methoden und Grenzen der Strafrechtsvergleichung). Übersetzung ins Italienische von Riccardo Ferrante. Diritto penale XXI secolo 1, 1-37 (2002).

Von der Konkurrenz zur Kongruenz nationaler Strafrechtsordnungen: Wege zur Rechtsannäherung in Europa. Poinikos Logos (zweimonatige Revue für Strafrecht und Kriminologie) 5, 2157-2170 (2002).

Sobre a mais recente Evolução do direito penal económico alemão (Zur neuesten Entwicklung des deutschen Wirtschaftsstrafrechts). Übersetzung ins Portugiesische von Marco Oliveira da Silva und Jorge de Figueiredo Dias. Revista Portuguesa de Ciência Criminal, No. 4, 531-547 (2002).

u. de la Cuesta, J.L., Les Compétences criminelles concurrentes nationales et internationales et le principe "ne bis in idem"(in französisch, englisch und spanisch). Revue Internationale de Droit Pénal 72, 739-777 (2002).

u. Koch, H.-G., Jinko ninshin chuzetsu no kokusaiteki hikaku. Shoken - dosatsu - teigen. (Schwangerschaftsabbruch im internationalen Vergleich. Meinungen- Einsichten - Vorschläge). Übersetzung ins Japanische von K. Kai/T. Matsuo. Jurist 1220, 68-75 (2002) und Jurist 1221, 134-144 (2002). 
u. Koch, H.-G., Jinko ninshin chuzetsu no kokusaiteki hikaku. Shoken - dosa$\mathrm{su}$ - teigen. (Schwangerschaftsabbruch im internationalen Vergleich: Befunde Einsichten - Vorschlag). Übersetzung ins Japanische von Kenji Ueda. The Doshisha Hogaku (The Doshisha Law Review), Nr. 287, 275-309 (2002).

u. Koch, H.-G., Hikakuteki kanten kara mita seibutsu igakuno shinpo ni kansura hoteki shomondai. Doitsu haihogoho o meguru kaisei rongi. (Rechtsprobleme biomedizinischer Fortschritte in vergleichender Perspektive - Zur Reformdiskussion um das deutsche Embyonenschutzgesetz). Übersetzung ins Japanische von Toshio Yoshida/Shiho Hitatsuka. The Hokkaigakuen Law Journal (38/2), 239-264 (2002).

(2003)

Diethnis kai Pankosmia Ethniki Poiniki Dikaiodosia/Internationale und Universale Nationale Strafgerichtsbarkeit. Zur Entstehung des Rom-Statuts für einen Internationalen Strafgerichtshof und seine Auswirkungen auf das nationale Strafrecht. Ant. N. Sakkoulas Verlag, Athen-Komotini 2003, 447 S.

Aktuelle Perspektiven transnationalen Strafrechts/Current perspectives of transnational criminal law. In: Rechtsraum Europa. Perspektiven für die Harmonisierung/The European Area of Justice. Perspectives for Harmonisation. Zweisprachige Broschüre der Konferenz aus Anlass der Einweihung des Bundesministeriums der Justiz in Berlin am 30.-31.5.2002. Hrsg. Bundesministerium der Justiz. Berlin 2003, 53-94.

u. Koch, H.-G., Schwangerschaftsabbruch und Recht. Vom internationalen Vergleich zur Rechtspolitik. Nomos Verlagsgesellschaft, Baden-Baden 2003, $360 \mathrm{~S}$.

National Jurisdiction over Extraterritorial Crimes within the Framework of International Complementarity: A Comparative Survey on Transnational Prosecution of Genocide According to the Principle of Universality. In: Man's Inhumanity to Man. Essays on International Law in Honour of Antonio Cassese. Hrsg. L.C. Vohrah et al. Kluwer Law International, The Hague u.a. 2003, 279-296.

Preface. In: Private Commercial Bribery. A Comparison of National and Supranational Legal Structures. Hrsg. G. Heine, B. Huber, Th.O. Rose. ICC/edition iuscrim, Freiburg i.Br. 2003, VII-VIII.

Brauchen wir ein Europäisches Strafgesetzbuch? In: Recht schafft Zukunft. Perspektiven der Rechtspolitik in einer globalisierten Welt. Dokumentation des Rechtspolitischen Kongresses 2002 in Karlsruhe. Hrsg. H. Däubler-Gmelin, I. Mohr. Verlag J.H.W. Dietz, Bonn 2003, 136-150.

Justizielle Rechte. In: Kommentar zur Charta der Grundrechte der Europäischen Union. Hrsg. J. Meyer. Nomos Verlagsgesellschaft, Baden-Baden 2003, 501-555.

Harmonization of Penal Sanctions in Europe: Comparative Typology of Convergences and Divergences. In: L'Harmonisation des sanctions pénales en Europe. Hrsg. M. Delmas-Marty, G. Giudicelli-Delage, E. Lambert-Abdelgawad. Société de Législation Comparée, Paris 2003, 379-442. 
Prólogo. In: La Policía en los Estados de Derecho Latinoamericanos. Un proyecto internacional de investigación. Hrsg. K. Ambos, J.-L. Gómez-Colomer; R. Vogler. Friedrich-Ebert Stiftung/Instituto Max Planck/Ediciones Jurídicas Gustavo Ibáñez, Bogotá 2003, IX-XI.

Prefacio e introducción al proyecto "Persecución penal nacional de crímenes internacionales". In: Persecución penal nacional de crímenes internacionales en América Latina y España. Hrsg. K. Ambos, E. Malarino. Konrad Adenauer-Stiftung/Instituto Max Planck de Derecho Penal Extranjero e Internacional, Uruguay 2003, 13-22.

Prefácio e Introdução ao Projeto "Persecução Penal Nacional de Crimes Internacionais". In: Persecução Penal Internacional na América Latina e Espanha. Coords. K. Ambos, E. Malarino. Instituto Brasileiro de Ciências Criminais (IBCCRIM), São Paolo 2003, 15-25.

Preface. In: Freiburg Proposal on Concurrent Jurisdictions and the Prohibition of Multiple Prosecutions in the European Union. research in brief/forschung aktuell, Nr. 20. Hrsg. A. Biehler, R. Kniebühler, J. Lelieur-Fischer, S. Stein. edition iuscrim, Freiburg i.Br. 2003, 1-5.

u. Arnold, J., O projecto "O Direito Penal como reacção às injustiças do sistema - visão comparativa da política de tratamento do passado do ponto de vista penal depois da mudança de sistema". In: Direito Penal Internacional para a Protecção dos Direitos Humanos. Simpósio da Faculdade de Direito da Universidade de Coimbra e Goethe-Instituto de Lisboa. Fim de Século Edições, Coimbra 2003, 21-42.

u. Koch, H.-G., Rechtsprobleme biomedizinischer Fortschritte in vergleichender Perspektive. Zur Reformdiskussion um das deutsche Embryonenschutzgesetz. In: Gedächtnisschrift für Rolf Keller. Hrsg. Strafrechtsprofessoren der Tübinger Juristenfakultät und Justizministerium BadenWürttemberg. Verlag Mohr Siebeck, Tübingen 2003, 15-36.

u. Koch, H.-G., Forschung mit humanen embryonalen Stammszellen im Inund Ausland. Rechtsgutachten zu den strafrechtlichen Grundlagen und Grenzen der Gewinnung, Verwendung und des Imports sowie der Beteiligung daran durch Veranlassung, Förderung und Beratung. In: Forschung mit humanen embryonalen Stammzellen. Strafrechtliche Grundlagen und Grenzen. Hrsg. Deutsche Forschungsgemeinschaft. WILEY-VCH Verlag, Weinheim 2003, 37-207.

u. Kreicker, H. (Hrsg.), Nationale Strafverfolgung völkerrechtlicher Verbrechen. National Prosecution of International Crimes. Bd. 1: Deutschland. edition iuscrim, Freiburg i.Br. 2003, 552 S.

(als Autor) Vorwort (des Projektinitiators), V-VIII.

u. Kreicker, H. (Hrsg.), Nationale Strafverfolgung völkerrechtlicher Verbrechen. National Prosecution of International Crimes. Bd. 2: Finnland, Polen, Schweden. edition iuscrim, Freiburg i.Br. 2003, 302 S.

(als Autor mit Kreicker, H.) Vorwort, V-VII, Einführung, 1-12.

Auf dem Weg zu einem internationalen Strafgerichtshof: Entstehung und Grundzüge des Rom-Statuts. Zeitschrift des Bernischen Juristenvereins 139/1, $1-42(2003)$. 
Ewald, Uwe

Gleß, Sabine
Na putu k Međunarodnom kaznenom sudu: Nastanak i temeljne crte Rimskog statuta (Auf dem Weg zu einem Internationalen Strafgerichtshof: Entstehung und Grundzüge des Rom-Statuts). Übersetzung ins Kroatische von Petar Novoselec. In: Hrvatski Ljetopis za Kazneno Pravo i Praksu (Kroatisches Jahrbuch für das Strafrecht und die Strafpraxis), Vol. 10/1, 133-163 (2003).

Recht im Rucksack - Interview zur Verwendung embryonaler humaner Stammzellen. Mit Susanne Keil. DUZ (Deutsche Universitäts-Zeitung) 17, 18-19 (2003).

"Shakaiteki Sotousei": Yokeina Hōkeisho ka Soretomo Hōkidekinai Hōkeisho ka ("Sozialadäquanz": eine überflüssige oder unverzichtbare Rechtsfigur? Überlegungen anhand sozialüblicher Vorteilsgewährungen). Übersetzung ins Japanische von Toshio Yoshida. The Hokkaiguken Law Journal 49/1, 85-102 (2003).

u. von Oppeln-Bronikowski, C., War - Victimization - Security: The Case of the Fromer Yugoslavia. European Journal of Crime, Criminal Law and Criminal Justice, Heft 1, 39-44 (2002).

(Hrsg.), Auslieferungsrecht der Schengen Vertragsstaaten - Neuere Entwicklungen. edition iuscrim, Freiburg i.Br. 2002, $633 \mathrm{~S}$.

(als Autorin mit Biehler, A.) Rechtsvergleichender Querschnitt, 547-611.

u. Biehler, A., Parra, N., Zeitler, H.E., Analyse des Grünbuchs zum Schutz der finanziellen Interessen der EG und zur Schaffung einer europäischen Staatsanwaltschaft" im Auftrag des Haushaltskontrollausschusses des Europäischen Parlaments. Online:

$\mathrm{http} / /$ europa.eu.int/comm/anti_fraud/green_paper/contributions/pdf/gp_mpla nck_de.pdf

Auslieferungsrecht der Schengen-Vertragsstaaten. forschung aktuell/research in brief, Nr. 12. edition iuscrim, Freiburg i.Br. 2002, 24 S.

What should be the Conditions for a European Corpus Juris Criminalis? In: Towards a European Ius Commune in Legal Education and Research. Hrsg. M. Faure, J. Smits, H. Schneider. Antwerpen u.a. 2002, 125-127.

Europe. In: The Individual as Subject of International Cooperation in Criminal Matters. A Comparative Study. Hrsg. A. Eser, O. Lagodny, Ch.L. Blakesley. Baden-Baden 2002, 31-130.

The Prominent Procedural Issues: Obtaining Evidence Abroad - a European Approach. In: The Containment of Transnational Organized Crime. Comments on the UN Convention of December 2000. Hrsg. H.-J. Albrecht, C. Fijnaut. Freiburg i.Br. 2002, 133-143.

What Kind of Judicial Control do the New Protagonists Need? The Accountability of the European Police Office (Europol). In: L'espace pénal européen: enjeux et perspectives. Hrsg. M. de Kerchove/A. Weyembergh. Bruxelles 2002, 31-45.

Brauchen neue Vollzugsräume neue Kontrollformen? Zur Ent-Rechtlichung europäischer Strafverfolgung. Zeitschrift für die gesamte Strafrechtswissenschaft 114, 636-656 (2002). 
$\S 247$ a StPO - (auch) eine Wohltat für den Angeklagten? Juristische Rundschau, 97-98 (2002).

Die "Verkehrsfähigkeit von Beweisen" im Strafverfahren. Zeitschrift für die gesamte Strafrechtswissenschaft 115, 131-150 (2003).

Covering the Entire English Criminal Justice System (Book Review: Blackstone's Criminal Practice 2003). 14 Criminal Law Forum, 101-109 (2003).

Examensklausur Strafrecht, "Geschäfte unter Gaunern". Juristische Ausbildung (JURA) 25, 496-502 (2003).

Rezension: Die Reglementierung von Prostitution in Deutschland, Duncker \& Humblot, Berlin 1999: - Soiné, M., Archiv für Kriminologie, Bd. 206 2001, 190-191 (Nachtrag)

Gropengießer, Helmut Bericht über das Internationale Kolloquium "Strafjustiz im Spannungsfeld von Fairness und Effizienz. Konvergente und divergente Entwicklungen im Strafprozessrecht" auf Schloss Ringberg/Tegernsee vom 8.-11. Mai 2002. Zeitschrift für die gesamte Strafrechtswissenschaft 114, 941-952 (2002).

u. Kreicker, H., Landesbericht Deutschland. In: Nationale Strafverfolgung völkerrechtlicher Verbrechen im internationalen Vergleich. National Prosecution of International Crimes. Bd. 1: Deutschland. Hrsg. A. Eser, H. Kreicker. edition iuscrim, Freiburg i.Br. 2003, 552 S.

u. Kohler, M., Übungsklausur Strafrecht: "Glück und Unglück eines römischen Feldherren". Juristische Ausbildung 25. Jahrg., Heft 4 , 277-282 (2003).

Rezension: Die Rechtswidrigkeit bei der Sachbeschädigung, Juristische Rundschau 1998, Heft 3, 89-95; besprochen von Masatsuna Morinaga, KansaiUniversität, Hogaku-Journal Nr. 72, 173-180 (2002).

Grundies, Volker

u. Höfer, S., Tetal, C., Basisdaten der Freiburger Kohortenstudie: Prävalenz und Inzidenz polizeilicher Registrierung. Arbeitsberichte aus dem MaxPlanck-Institut 2002/1. edition iuscrim, Freiburg i.Br. 2002, 199 S.

Hägele, Ralf

Besprechung von Laufs, A., Uhlenbruck W. (Hrsg.), Handbuch des Arztrechts (3. Aufl., C.H. Beck Verlag, München 2003). Forum DKG - Das offizielle Magazin der Deutschen Krebsgesellschaft e.V. 18/1, 50 (2003).

Werbung gegen Krebs: juristische Implikationen. Forum DKG - Das offizielle Magazin der Deutschen Krebsgesellschaft e.V. 18/5, 45-48 (2003).

Haverkamp, Rita Elektronisch überwachter Hausarrestvollzug: Ein Zukunftsmodell für den Anstaltsvollzug? Eine rechtsvergleichende, empirische Studie unter besonderer Berücksichtigung der Rechtslage in Schweden. edition iuscrim, Freiburg i.Br. 2002, $621 \mathrm{~S}$.

Implementing Electronic Monitoring. A comparative, empirical study on attitudes towards the measure in Lower Saxony/Germany and in Sweden. research in brief/forschung aktuell, Nr. 14. edition iuscrim, Freiburg i.Br. 2002, $23 \mathrm{~S}$.

u. Lévy, R., Mayer, M. (Hrsg.), Will Electronic Monitoring Have a Future in Europe? edition iuscrim, Freiburg i.Br. 2003, 292 S. 
Herz, Annette

Höfer, Sven

Hotter, Imke

Huber, Barbara u. Mayer, M., Die Zukunft der elektronischen Überwachung in Europa. Monatsschrift für Kriminologie und Strafrechtsreform 86, 216-220 (2003).

Jugendstrafrecht in England and Wales. In: Jugendstrafrecht in Europa. Hrsg. H.-J. Albrecht, M. Kilchling. edition iuscrim, Freiburg i.Br. 2002, 81-136.

$u$. Kania, H., Everyday Perceptions of Crime. European Journal of Crime, Criminal Law and Criminal Justice, Jg. 10, Heft 4, 276-285 (2002).

u. Grundies, V., Tetal, C., Basisdaten der Freiburger Kohortenstudie: Prävalenz und Inzidenz polizeilicher Registrierung. Arbeitsberichte aus dem Max-Planck-Institut 2002/1. edition iuscrim, Freiburg i.Br., 197 S.

Sanktionskarrieren. Eine Analyse der Sanktionshärteentwicklung bei mehrfach registrierten Personen anhand von Daten der Freiburger Kohortenstudie. edition iuscrim, Freiburg i.Br. 2003, $180 \mathrm{~S}$.

u. Kania, H., (2003, November) "Crime Time" zur Prime Time. Ein Kommentar zu vier Sendungen über Kriminalität in der ZDF-Reihe "Abenteuer Wissen" [21 Absätze]. Journascience.org - JSO: Informationsportal zum Thema Kriminalität [Online Dokument]. Verfügbar über:

http://www.journascience.org/de/mediensammlung/content/Journascience_ CrimeTime_neu.pdf [Datum des Zugriffs: 1.12.2003].

u. Albrecht, H.-J., Rundfunk und Pornographieverbot - Eine (auch rechtsvergleichende) Untersuchung zur Reichweite des Pornographieverbots im Rundfunk im weiteren Sinne. Rechtsgutachten, erstellt im Auftrag der Bayerischen Landeszentrale für neue Medien. BLM-Schriftenreihe, Bd. 68. R. Fischer, München 2002, $181 \mathrm{~S}$.

u. Albrecht, H.-J., Jüngste Vorschläge zu Reformen im Bereich des Jugendstrafrechts. RdJB (Recht der Jugend und Bildungswesens) 51, 282-298 (2003).

Sanctions against Bribery Offences in Criminal Law. In: Corruption, Integrity and Law Enforcement. Hrsg. C. Fijnaut, L. Huberts. Kluwer. The Hague 2002, 137-150.

$\S 12$ FAG und Überwachung der Telekommunikation: Ermittlungsmassnahmen im Strafprozess- und Polizeirecht unter besonderer Berücksichtigung der Zeugnisverweigerungsrechte - Rechtsvergleichender Überblick. In: Zeugnisverweigerungsrechte bei verdeckten Ermittlungshandlungen. Hrsg. J. Wolter, W.-R. Schenke. Bundesministerium der Justiz, Berlin 2002, 61-95.

Ermittlungsmaßnahmen und Zeugnisverweigerungsrechte im supranationalen Bereich. In: Zeugnisverweigerungsrechte bei verdeckten Ermittlungshandlungen. Hrsg. J. Wolter, W.-R. Schenke. Bundesministerium der Justiz, Berlin 2002, 371-377.

Landesbericht England und Wales. In: Zeugnisverweigerungsrechte bei verdeckten Ermittlungshandlungen. Hrsg. J. Wolter, W.-R. Schenke. Bundesministerium der Justiz, Berlin 2002, 391-403.

$\mathrm{Zu}$ Leon Radzinowicz' "Adventures in Criminology". In: Festschrift für Klaus Rolinski. Hrsg. H.-H. Kühne, H. Jung, A. Kreuzer, J. Wolter. Nomos Verlagsgesellschaft, Baden-Baden 2002, 335-347. 
(Hrsg.), Combating Corruption in the European Union/Korruptionsbekämpfung in der Europäischen Union/La lutte contre la corruption dans l'Union européenne. Bundesanzeiger, Köln 2002, 265 S.

El jurado - un órgano jurisdiccional eficiente? Ciencias Penales Contemporáneos. Revista de Derecho Penal, Procesal Penal y Criminología, Vol. 1, 213-247 (2002).

La lotta alla corruzione in prospettiva sovranazionale. Rivista Trimestrale di Diritto Penale dell'Economica, 467-489 XIV (2001) und in Ciencias Penales Contemporáneos, Revista de Derecho Penal, Procesal Penal y Criminología, Vol. 2, 364-405 (2002).

$u$. Gropp, $W$., Initiativas jurídicas contra la criminalidad organizada. Ciencias Penales Contemporáneos. Revista de Derecho Penal, Procesal Penal y Criminología, Vol. 2, 398-434 (2002).

Die polizeiliche und justitielle Zusammenarbeit in Europa - Ein Überblick. In: Datenübermittlung und Vorermittlungen. Festgabe für Hans Hilger. Hrsg. J. Wolter, W.-R. Schenke, P. Riess, M.A. Zöller. C.F. Müller Verlag, Heidelberg 2003, 135-152.

Introduzione. In: La corruzione tra privati. Hrsg. R. Acquaroli, L. Foffani. Guiffrè, Milano 2003, 31-42.

u. Heine, G., Rose, T.O. (Hrsg.), Private Commercial Bribery. A Comparison of National and Supranational Legal Structures. edition iuscrim \& International Chamber of Commerce, Freiburg i.Br. \& Paris 2003, 658 S.

(als Autorin) Supranational Measures, 559-601.

The Tribunal for Serious Fraud. Journal of Financial Crime, Vol. 11, no. 1, 28-37 (2003).

La lucha contra la corrupción desde una perspectiva supranacional. Annales de la Facultad de Derecho, La Laguna 2002, 95-115; Iter Crimines, Revista de Sciencias Penales, no. 7, 159-188 (2003); La Ley, Revista Penal, Vol. 11, 4152 (2003).

El delito de infanticidio. Revista de Derecho Penal, 135-148 (2003).

Statutory Interpretation: Zur Auslegung englischer Gesetze. Zeitschrift für die gesamte Strafrechtswissenschaft 115, 723-741 (2003).

Statutory Interpretation: Sobre la interpretación de las leyes inglesas. Revista Facultad de Derecho Universidad Granada 6, 101-118 (2003).

Jarvers, Konstanze

Zum Tatbestand der Verunglimpfung der Staatsreligion (Art. 412 it.StGB). In: Multireligiosität im vereinten Europa. Historische und juristische Aspekte. Hrsg. H. Lehmann. Wallstein, Göttingen 2003, 86-97.

Jescheck, Hans-Heinrich

Giuliano Vassalli visto dalla Germania. Rivista italiana di diritto e procedura penale. Bd. XL (2002). Giuffré Editore, Milano, 277-281.

Introduzione à: Gaetana Morgante, L'illiceità speziale nella teoria generale del reato. Ed, G. Giapichelli. Torino 2002, XIII-XVII. 
Einführung zum Strafgesetzbuch. Textausgabe mit ausführlichem Sachregister. DT-Taschenbuchverlag (Beck Texte im dtv), 37. Aufl. 2002, IX-XXXVI.

Einführung zum Strafgesetzbuch. Textausgabe mit ausführlichem Sachregister. DT-Taschenbuchverlag (Beck-Texte im dtv), 38. Aufl. 2002, VII-XXXVIII.

Erinnerungen an das Centre d'études pour prisonniers de guerre allemands in St. Denis 1946/47. In: Juristische Zeitgeschichte. Jahrbuch Bd. 3 (2001/2002), Hrsg. Th. Vormbaum. Nomos-Verlagsgesellschaft, Baden-Baden 2002, 6065 .

Neuere Entwicklungen im Strafrecht Deutschlands und Spaniens sowie im europäischen und internationalen Strafrecht. Informaciones, Zeitschrift für den deutsch-spanischen Rechtsverkehr, II, 71-76 (2002).

Der Internationale Strafgerichtshof nach der Resolution des Sicherheitsrats der Vereinten Nationen vom 12. Juli 2002. Festschrift für C.F. Rüter. Amsterdam University Press, Amsterdam 2003, 118-130.

Einführung zum Strafgesetzbuch (Beck-Texte im dtv). 38. Aufl. 2002. Russische Übersetzung von N.S. Rachkova unter Mitarbeit von D.A. Shestakov. Yuridichnesky Center Press, St. Petersburg 2003, 11-95.

Introduzione. In: Il Codice penale tedesco. Hrsg. Vinciguerra. Traduzione di G. Bonadio e altri. II. ed. Verlag Cedam, Padua 2003, 1-45.

u. Weigend, T., Tratado de Derecho Penal. Parte General. Traducción de Miguel Olmedo Cardenete. Quinta Edición, Verlag Comares, Granada 2003, XLIV/1066.

Evolución del concepto juridico penal de culpabilidad en Alemania y Austria. Actualidad Penal No. 6, La Ley, Madrid, 173-193 (2003). Übersetzung von Patricia Esquinaz Valverde, Granada, "Wandlungen des strafrechtlichen Schuldprinzips in Deutschland und Österreich", JB1. 1998, 609 (2003).

"Hans Schultz zum Gedächtnis". Zeitschrift für die gesamte Strafrechtswissenschaft 115, 460-468 (2003).

Gutachten "Zum Entwurf des Allgemeinen Teils des neuen Strafgesetzbuchs der Tschechischen Republik". Vollständiger Text in tschechischer Sprache in: "Trestní právo" (Strafrecht) 11/2003, S. 14-24 und 12/2003, S. 2-9. Verlag Nakladatelstvís Orag, Prag 2003.

$u$. Válková, $H$., K reformě českého trestniho práva hmotného svêtle stanoviska (Stellungnahme zum Entwurf des Allgemeinen Teils des neuen tschechischen Strafgesetzbuchs). Trestně právné revue, 269-272 (2003).

Kaiser, Günther

u. Schöch, H., Strafvollzug. Ein Lehr- und Handbuch. 5. Aufl. Heidelberg 2002, 563 und XXIV.

Sozialtherapie in Kriminalrecht und Strafvollzug - noch immer eine Herausforderung? In: Festschrift für Klaus Roliniski zum 70. Geburtstag am 11. Juli 2002. Hrsg. H.-H. Kühne, H. Jung, A. Kreuzer, J. Wolter. Nomos Verlagsgesellschaft, Baden-Baden 2002, 349-364. 
Strukturwandel des Strafvollzuges durch Privatisierung. In: Festschrift für Stefan Trechsel zum 65. Geburtstag. Hrsg. A. Donatsch, M. Forster, Ch. Schwarzenegger. Schulthess Verlag, Zürich 2002, 869-886.

Torture: Legal Perspectives. In: International Encyclopedia of the Social and Behavioral Sciences, Hrsg. N.J. Smelser, P.B. Baltes. Pergamon 2002, 1578315786 .

Besprechungsaufsatz: "Die Erfindung des Verbrechers" - zur Geschichte der Kriminologie in Deutschland. Monatschrift für Kriminologie und Strafrechtsreform 85, 451-460 (2002).

Rezension zu: Klaus Laubenthal, Sexualstraftaten. Die Delikte gegen die sexuelle Selbstbestimmung. Berlin-Heidelberg 2000. Goltdammer's Archiv für Strafrecht 149, Heft 7, 427 (2002).

$u$. Schöch, H., Strafvollzug: Eine Einführung in die Grundlagen. 5., neu bearbeitete Aufl. Heidelberg 2003, 391 und XXII. UTB 706.

Besprechungsaufsatz: Kriminologie im interdisziplinären Gespräch - zugleich eine Besprechung der wissenschaftshistorischen Studie Peter Beckers zur Kriminologiegeschichte im 19. Jahrhundert. Monatsschrift für Kriminologie und Strafrechtsreform 86, 478-485 (2003).

Folter, Misshandlung und krimineller Machtmissbrauch heute. Kriminologisches Journal, Heft 4, 243-259 (2003).

Zu: Franz von Liszt: Der Zweckgedanke im Strafrecht (1882/83). BadenBaden 2002. Goltdammer's Archiv für Strafrecht 150, 709 f. (2003).

$\mathrm{Zu}$ : David Garland, The culture of control. Crime and social order in contemporary society. Monatsschrift für Kriminologie und Strafrechtsreform 86, 234-240 (2003).

$\mathrm{Zu}$ : Michael Kubink, Strafen und Alternativen für den zeitlichen Wandel. Duncker \& Humblot, Berlin 2002, 848 S. Monatsschrift für Kriminologie und Strafrechtsreform 86, 323-327 (2003).

Kania, Harald

u. Walter, M., Albrecht, H.-J. (Hrsg.), Alltagsvorstellungen von Kriminalität . forschung aktuell/research in brief, Nr. 11. edition iuscrim, Freiburg i.Br. $2002,52 \mathrm{~S}$.

u. Herz, A., Everyday Perceptions of Crime. European Journal of Crime, Criminal Law and Criminal Justice 10, 276-285 (4/2002).

Kriminalitätsberichte im Fernsehen und die Konstruktion subjektiver Kriminalitätswirklichkeit. In: Berliner Forum Gewaltprävention, Nr. 12, Themenschwerpunkt: Kriminalitätsopfer. Hrsg. Landeskommission Berlin gegen Gewalt. Berlin 2003, 60-71.

u. Brand, T., Zimmermann, S., Walter, M., Die Einschätzung von Gewaltdelikten im europäischen Vergleich. Eine Fragebogenuntersuchung an Studierenden in zehn Ländern. Monatsschrift für Kriminologie und Strafrechtsreform 86, 247-264 (2003). 
u. Höfer, S. (2003, November), "Crime Time" zur Prime Time. Ein Kommentar zu vier Sendungen über Kriminalität in der ZDF-Reihe "Abenteuer Wissen" [21 Absätze]. Journascience.org - JSO: Informationsportal zum Thema Kriminalität [Online Dokument]. Verfügbar über:

http://www.journascience.org/de/mediensammlung/content/Journascience CrimeTime_neu.pdf [Datum des Zugriffs: 1.12.2003].

(Hrsg.), Die Praxis der Gewinnabschöpfung in Europa. edition iuscrim, Freiburg i.Br. 2002, $490 \mathrm{~S}$.

(als Autor) Einführung, 1-18; Deutschland, 19-81; Zusammenfassung und Ertrag, 429-451;

(als Autor mit Löschnig-Gspandl, M.) Österreich, 83-133.

Substantive Aspects of the U.N. Convention Against Transnational Organized Crime: A Step Towards an 'Organized Crime Code'? In: The Containment of Transnational Organized Crime. Comments on the UN Convention of December 2000. Hrsg. H.-J. Albrecht, C. Fijnaut. edition iuscrim, Freiburg i.Br. 2002, 83-96.

u. Albrecht, H.-J., Braun, E. (Hrsg.), Criminal Preventive Risk Assessment in the Law-Making Procedure. edition iuscrim, Freiburg i.Br. 2002, $450 \mathrm{~S}$.

(als Autor mit Braun, E.) Germany, 145-187.

u. Albrecht, H.-J. (Hrsg.), Jugendstrafrecht in Europa. edition iuscrim, Freiburg i.Br. 2002, $544 \mathrm{~S}$.

(als Autor) Vergleichende Perspektiven - Grundsätze des Jugendstrafrechts im europäischen Ausland und der Türkei, 475-532.

Grundlinien des Jugendstrafrechts in Europa. DVJJ-Journal, Nr. 178, 371-378 (2002).

Reformentwurf zum strafrechtlichen Sanktionenrecht: Opferfreundlich oder nicht? Neue Kriminalpolitik, Heft 1, 4-6 (2002).

Opferschutz und der Strafanspruch des Staates - ein Widerspruch? Neue Zeitschrift für Strafrecht 22, 57-63 (2002).

Beschleunigte Verfahren und Schlichtung als opferrelevante Optionen in Deutschland? ERA-Forum, Heft 1, 44-49 (2002).

Empirische Erkenntnisse aus Kriminologie und Viktimologie zur Lage von Opfern. DVJJ-Journal, Nr. 175, 14-23 (2002).

A Magic Formula which can do away with Terrorism? MaxPlanckResearch 2002, Issue 1, 16-20.

u. Albrecht, H.-J., Rechtsextremistische Gewalt, Strafrechliche Sozialkontrolle, Täter-Opfer-Ausgleich und Wiedergutmachungsansätze. Recht der Jugend und des Bildungswesens 50, 82-93 (2002).

u. Albrecht, H.-J., Crime Risk Assessment, Legislation, and the Prevention of Serious Crime - Comparative Perspectives. European Journal of Crime, Criminal Law and Criminal Justice 10, 23-38 (2002). 
u. Braun, E., Risk Assessment in der deutschen Gesetzgebung - Übertragbarkeit bisheriger Ansätze zur Gesetzeswirkungs- und Gesetzesfolgenabschätzung auf die OK-Prävention? Die Kriminalprävention 6, Heft 1, 12-18, Heft 2, 45-56 (2002).

Zukunftsperspektiven für das Jugendstrafrecht in der erweiterten Europäischen Union. Recht der Jugend und des Bildungswesens 51, 305-317 (2003).

Opferperspektiven der OK - Einige Gedanken zu Ohlemachers Untersuchungsergebnissen aus viktimologischer Sicht. Angewandte Sozialforschung $23,80-82$ (2003).

Ping "Xingshi susong zhong de biantong zhengce yiji jianchaguan zai fating shenli kaishi qian de zuoyong". In: Zhong-De di-3 jie, di-4 jie xingfaxue, fanzuixue yantaohui wenji (Drittes und viertes deutsch-chinesisches Kolloquium über Strafrecht und Kriminologie). Hrsg. Sifabu yufang fanzui yanjiusuo (Bianyin) (Institut für Verbrechensprävention beim Justizministerium der Volksrepublik China). 1. Aufl. Beijing 2002, 178-181.

"Zhongguo xingshi susong zhong de biantong zhengce yiji jianchaguan zai zhushen qian de zuoyong" de pinglun. In: Zhong-De di-3 ji, di-4 jie xingfaxue, fanzuixue yantaohui wenji (Drittes und viertes deutsch-chinesisches Kolloquium über Strafrecht und Kriminologie). Hrsg. Sifabu yufang fanzui yanjiusuo (Bianyin) (Institut für Verbrechensprävention beim Justizministerium der Volksrepublik China). 1. Aufl. Beijing 2002, 199-201.

u. Becker, M., Rechtsmittel im Strafrecht. Eine international vergleichende Untersuchung zur Rechtswirklichkeit und Effizienz (Nachdruck). In: Strafverteidigervereinigungen: Justizreform 2000 - kurzer Prozess mit neuen Mitteln? 24. Strafverteidigertag Würzburg, 1. Aufl. Berlin 2002, 234-255.

Das Gesetz zur Einführung der vorbehaltenen Sicherungsverwahrung. Neue Juristische Wochenschrift 55, 3204-3208 (2002).

Neues von der Sicherungsverwahrung - ein Überblick über den Stand der Gesetzgebung. Strafverteidiger 22, 500-504 (2002).

u. Luczak, A., Examensklausur StR. Verscherbeln, Abzocken und andere Geschäfte. Juristische Ausbildung 24, 493-500 (2002).

Die strafrechtliche Verfolgung organisierter Kriminalität - Eindrücke aus einem empirischen Forschungsvorhaben. In: Kriminologie zwischen Grundlagenwissenschaften und Praxis. Hrsg. V. Dittmann, J.-M. Jehle. Forum Verlag Godesberg 2003, 345-361.

Organisierte Kriminalität in Deutschland: Begriff - Rechtliche Maßnahmen empirische Erkenntnisse. Angewandte Sozialforschung 23, Heft 1/2, 27-40 (2003).

Erwiderung zu einer Anmerkung von Friedrich Schneider. Angewandte Sozialforschung 23, Heft 1/2, 44 (2003).

Verhältnismäßigkeit fraglich: Problematische Sanktion im Strafrecht. Frankfurter Rundschau vom 21.7.2003, 8. 
Kniebühler, Roland M. u. Biehler, A., Lelieur-Fischer, J., Stein, S. (Hrsg.), Freiburg Proposal on Concurrent Jurisdictions and the Prohibition of Multiple Prosecutions in the European Union. research in brief/forschung aktuell, Nr. 20. edition iuscrim, Freiburg i.Br. 2003, $36 \mathrm{~S}$.

Koch, Hans-Georg Zum Status des Embryos in vitro aus rechtlicher und rechtsvergleichender Sicht, in: Bernhard Moser/Reinhard Peter (Hrsg.) 1. Österreichische BioethikKonferenz, Report, Wien, 2001, 52-61 und 114-116 (57 f.):

http://www.modernpolitics.at/publikationen/bookshop/download/bioethik_report.pdf (Nachtrag).

Advance Directives in Germany. In: Autodeterminarsi Nonostante. Hrsg R. Dameno. Edizioni Angelo Guerini e Associati SpA, Mailand 2002, 67-76.

u. Vieweg, K., Siekmann, R. (Hrsg.), Legal Comparison and Harmonisation of Doping Rules. Final report within the framework of the pilot project for campaigns to combat doping in Sport in Europe (CD-ROM-Publikation).

(als Autor) Rechtsvergleichender Querschnitt.

Kosmetische Eingriffe: Anforderungen an die Aufklärung. Kosmetische Medizin 23 (2), 100-104 (2002).

u. Eser, A., Jinkō ninshin chūzetsu no kokusaiteki hikaku. Shoken - dōsatsu teigen (Schwangerschaftsabbruch im internationalen Vergleich. MeinungenEinsichten - Vorschläge). Übersetzung in die japanische Sprache von K. Kai, T. Matsuo. Jurist 1220, 68-75 und Jurist 1221, 134-144 (2002).

u. Eser, A., Hikakuteki kanten kara mita seibutsu igakuno shinpo ni kansura hōteki shomondai. Doitsu haihogohō o junru kaisei rongi (Rechtsprobleme biomedizinischer Fortschritte in vergleichender Perspektive - Zur Reformdiskussion um das deutsche Embryonenschutzgesetz). Übersetzung in die japanische Sprache von T. Yoshida, S. Hitatsuka. The Hokkaigakuen Law Journal (38:2002/2), 239-264 (2002).

u. Eser, A., Schwangerschaftsabbruch und Recht. Vom internationalen Vergleich zur Rechtspolitik. Nomos Verlagsgesellschaft, Baden-Baden 2003, $361 \mathrm{~S}$.

Vom Embryonenschutzgesetz zum Stammzellgesetz: Überlegungen zum Status des Embryos in vitro aus rechtlicher und rechtsvergleichender Sicht. In: Die Forschung an embryonalen Stammzellen in ethischer und rechtlicher Perspektive. Hrsg. G. Maio, H. Just. Nomos Verlagsgesellschaft, Baden-Baden 2003 (Medizin in Recht und Ethik, Bd. 36, 97-118).

$u$. Eser, A., Forschung mit humanen embryonalen Stammszellen im In- und Ausland. Rechtsgutachten zu den strafrechtlichen Grundlagen und Grenzen der Gewinnung, Verwendung und des Imports sowie der Beteiligung daran durch Veranlassung, Förderung und Beratung. In: Forschung mit humanen embryonalen Stammzellen. Strafrechtliche Grundlagen und Grenzen. Hrsg. Deutsche Forschungsgemeinschaft. WILEY-VCH Verlag, Weinheim 2003, 37-207. 
Köllisch, Tilman

Kreicker, Helmut
Rechtlicher Status des In-vitro-Embryos - Maßnahmen zur Effizienzsteigerung bei medizinisch unterstützter Fortpflanzung aus rechtlicher und rechtsvergleichender Sicht. gpk - Gesellschaftspolitische Kommentare 44, 27-32 (2003).

Besprechung von Igloffstein, Tobias, Regelwerke für die humanmedizinische Individualbehandlung. Eine Untersuchung der zivil-, straf- und berufsrechtlichen Bedeutung medizinischer Richt- und Leitlinien (Baden-Baden [Nomos Verlagsgesellschaft] 2003, 246 S.). Archiv für Kriminologie 212, 185-186 (2003).

Besprechung von Kullmann, Hans Josef/Bischoff, Rolf/Dressler, Wolf-Dieter/ Pauge, Burkhard (Hrsg.), Arzthaftpflicht-Rechtsprechung (AHRS), Teil II: Entscheidungen ab 1.1.1993 (Berlin [Erich Schmidt], Loseblattwerk Stand Mai 2003). Archiv für Kriminologie 212, 189-190 (2003).

u. Oberwittler, D., Würger, M., Selbstberichtete Delinquenz bei Jugendlichen. In: ZUMA-Informationssystem. Elektronisches Handbuch sozialwissenschaftlicher Erhebungsinstrumente Version 6.0. Hrsg. A. Glöckner-Rist. Zentrum für Umfragen, Methoden und Analysen, Mannheim 2002.

u. Oberwittler, D., Jugendkriminalität in Stadt und Land. Sozialräumliche Unterschiede im Delinquenzverhalten und Registrierungsrisiko. In: Kriminalität und Gewalt im Jugendalter. Hell- und Dunkelfeldbefunde im Vergleich. Hrsg. J. Raithel, J. Mansel. Juventa Verlag, Weinheim und München 2003, 135-160.

Art. 7 EMRK und die Gewalttaten an der deutsch-deutschen Grenze. Zu den Urteilen des Europäischen Gerichtshofs für Menschenrechte. Nomos Verlagsgesellschaft Baden-Baden 2002. XX, 127 S.

u. Arnold, J., Eser, A., Criminal Law in Reaction to State Crime. Comparative Insights into Transitional Processes. A Project Report. research in brief/ forschung aktuell, Nr. 15. edition iuscrim, Freiburg i.Br. 2002, $17 \mathrm{~S}$.

als Mitarbeiter mit Weigend, E., Zoll, A., Landesbericht Polen. In: Strafrecht in Reaktion auf Systemunrecht. Vergleichende Einblicke in Transitionsprozesse. Bd. 5: Polen, Ungarn. Hrsg. A. Eser; J. Arnold. edition iuscrim. Freiburg i.Br. 2002, 27-150.

als Mitarbeiter mit Vukor-Quarschie, N.G., Landesbericht Ghana. In: Strafrecht in Reaktion auf Systemunrecht. Vergleichende Einblicke in Transitionsprozesse. Bd. 6: Mali, Ghana. Hrsg. A. Eser; J. Arnold. edition iuscrim. Freiburg i.Br. 2002, 169-293.

Die völkerstrafrechtliche Unverjährbarkeit und die Regelung im Völkerstrafgesetzbuch. Neue Justiz, Heft 6, 281-286 (2002).

Auf dem Weg zu einem neuen Völkerstrafgesetzbuch (zu Andreas Zimmermann, ZRP 2002, 97). Zeitschrift für Rechtspolitik 8, 371 (2002).

u. Eser, A. (Hrsg.), Nationale Strafverfolgung völkerrechtlicher Verbrechen. National Prosecution of International Crimes. Bd. 1: Deutschland (zusammen mit Gropengießer, H.). edition iuscrim, Freiburg i.Br. 2003, $552 \mathrm{~S}$.

(als Autor mit Eser, A.) Einführung, 1-12. 
Krüpe, Christiane

Kury, Helmut

(2002) u. Eser, A. (Hrsg.), Nationale Strafverfolgung völkerrechtlicher Verbrechen. National Prosecution of International Crimes. Bd. 2: Finnland, Polen, Schweden. edition iuscrim, Freiburg i.Br. 2003, $304 \mathrm{~S}$.

(als Autor mit Eser, A.) Vorwort, V-VII und Einführung, 1-12.

u. Eser, A., Prefacio e introducción al proyecto "Persecución penal nacional de crímenes interncionales". In: Persecución penal nacional de crímenes internationales en América Latina y España. (Hrsg.) K. Ambos, E. Malarino. Montevideo/Uruguay) 2003, 13-22.

u. Arnold, J., Karsten, N., The German Border Guard Cases before the European Court of Human Rights. European Journal of Crime, Criminal Law and Criminal Justice 11, Heft 1, 67-92 (2003).

u. Albrecht, H.-J., Dorsch, C., Rechtswirklichkeit und Effizienz der Überwachung der Telekommunikation nach $\S \S 100 \mathrm{a}, 100 \mathrm{~b}$ StPO und anderer verdeckter Ermittlungsmaßnahmen. edition iuscrim, Freiburg i.Br 2003, $480 \mathrm{~S}$.

u. Albrecht, H.-J., Dorsch, C., Rechtswirklichkeit und Effizienz der Überwachung der Telekommunikation nach $\S \S 100 \mathrm{a}, 100 \mathrm{~b}$ StPO und anderer verdeckter Ermittlungsmaßnahmen. forschung aktuell/research in brief, Nr. 17. edition iuscrim, Freiburg i.Br. 2003, 42 S.

(Hrsg.), International Comparison of Crime and Victimization: The ICVS. de Sitter Publications, Willowdale/Ontario 2002 (gleichzeitig Sonderheft "IJCC International Journal of Comparative Criminology", Vol. 2 (2002).

(als Autor) Introduction, 1-9.;

(als Autor mit Obergfell-Fuchs, J., Würger, M.) Methodological problems in victim surveys: The example of the ICVS, 38-56;

(als Autor mit Obergfell-Fuchs, J., Smartt, U., Würger, M.), Attitudes to punishment: How reliable are international crime victim surveys?, 133-150.

Bearbeitung der folgenden Stichworte: Bundeskriminalamt (111-112), Freiheitlich-demokratische Grundordnung (231-323), R. Gehlen (245), H. Herold (287), John-Affäre (327-328), Jugendstrafrecht (Bundesrepublik) (330-331), Jugendstrafrecht (DDR) (331), Kriminalität (DDR) (373-374), Todesstrafe (Bundesrepublik) (596-597), Untersuchungsausschuß Freiheitlicher Juristen (609-610), Verfassungsbeschwerde (Bundesrepublik) (618), Verwaltungsgerichte (Bundesrepublik) (628-629). In: Lexikon der deutschen Geschichte von 1945 bis 1990. Ereignisse, Institutionen, Personen im geteilten Deutschland. Hrsg. M. Behnen. Kröner, Stuttgart 2002.

Das Sicherheitsgefühl der Bevölkerung. Hintergründe und Forderungen. In: Kommunalpolitisches Forum "Sicherheit als Wirtschafts- und Standortfaktor", 17. Okt. 2000. Hrsg. Landeshauptstadt Stuttgart. Stabsstelle des Oberbürgermeisters, Haus der Wirtschaft, Stuttgart 2002, 29-79.

Prisoners as victims of crime: The victimisation of (young) offenders in prison establishments - Recent results from Germany. In: Policing in Central and Eastern Europe: Deviance, violence, and victimization. Hrsg. M. Pagon. College of Police and Security Studies, Ljubljana 2002, 413-429. 
Das Freiburger Persönlichkeitsinventar und sein Einsatz bei kriminologischen Fragestellungen. Das Problem der Verfälschungstendenzen. In: Die Person im biologischen und sozialen Kontext. Hrsg. M. Myrtek. Hogrefe, Göttingen u.a. 2002, 249-270.

Überfüllung der Gefängnisse und Lösungsvorschläge. In: Drittes und viertes deutsch-chinesisches Kolloquium über Strafrecht und Kriminologie. Hrsg. Institut für Verbrechensprävention beim Justizministerium der Volksrepublik China. Institut für Verbrechensprävention, Peking 2002, 285-290.

u. Czapska, J. (Hrsg.), Mit represy jnosci albo o znaczeniu prewencji kryminalnej (The myth of Repression or: The importance of crime prevention). Zakamycze, Krakow 2002.

(als Autor) Wstep. Preface - Summary, 9-25;

Postawy punitywne i ich znaczenie - Punitive attitudes and their significance, 107-171.

(als Autor mit Obergfell-Fuchs, J.) Komunalna prewencja kryminalna w Europie - Community Crime Prevention in Europe, 343-434.

u. Chipounova, T., Viktimisierung von Gefangenen als Merkmal der Krise von Sanktionen (anhand vergleichender Untersuchungen). In: Komparativistika: Almanach der vergleichenden sozio-humanitären Forschungen. Hrsg. L.A. Verbizkaja, W.W. Vasilkova, W.W. Kozlowsky, N.G. Zkworzov. Soziologische Gemeinschaft von M.M. Kovalewski, St. Petersburg 2002, 119-133.

u. Obergfell-Fuchs, J., Würger, M., Strafeinstellungen. Ein Vergleich zwischen Ost- und Westdeutschland. edition iuscrim, Freiburg i.Br. 2002, $201 \mathrm{~S}$.

u. Obergfell-Fuchs, J., Ferdinand, T., The background of illegal drug abuse: A German view. In: Drugs and crime. Deviant pathways. Hrsg. S. Brochu, C. Da Agra, M.-M. Cousineau. Ashgate Publishing, 197-218.

u. Obergfell-Fuchs, J., Smartt, U., The evolution of public attitudes to punishment in Western and Eastern Europe. In: Changing attitudes to punishment. Public opinion, crime and justice. Hrsg. J.V. Roberts, M. Hough. Willan Publishing, Cullompton, Devon 2002, 93-114.

u. Obergfell-Fuchs, J., Wößner, G., Würger, M., Fear of crime and victimization. In: Crime victimization in comparative perspective. Results from the International Crime Victims Survey 1089-2000. Hrsg. P. Nieuwbeerta. Boom Juridische uitgevers, Den Haag 2002, 317-334.

u. Pagon, M., Lobnikar, B., How are victims of (sexual) crimes seen: The problem of stigmatization effects. In: Policing in Central and Eastern Europe: Deviance, violence, and victimization. Hrsg. M. Pagon. College of Police and Security Studies, Ljubljana 2002, 517-525.

u. Smartt, U., Germany. In: Encyclopedia of crime and punishment, Vol. 2. Hrsg. D. Levinson. Sage, Thousand Oaks 2002, 784-791.

u. Wößner, G., The impact of changed social structures on crime trends in modern societies. In: Development without disorders. Criminological viewpoints. Hrsg. G.S. Bajpai. Vishwavidyalaya Prakashan, Sagar, 67-106. 
u. Wößner, G., A família e os comportamentos desviantes dos jovens. In: Comportamento Anti-social e Família: Uma abordagem científica. Hrsg. A.C. Fonseca. Livraria Almedina, Coimbra 2002, 181-211.

$\mathrm{Zu}$ Sanktionseinstellungen und der präventiven Wirkung (harter) Sanktionen (Teil 2, Schluss). The Hokkaigakuen Law Journal 37, 271-340 (japanisch: 177-211) (2002).

$\mathrm{Zu}$ Situation, Fragestellungen und Vorgehensweisen der Rechtspsychologie in Deutschland. Socialinis Darbas - Mokslo Darbai. Lietuvos Teises Universitetas, Vilnius, No. 2 (2), 73-98 (2002).

Die Strafeinstellung der Bevölkerung - Zunahme der Punitivität. Criminology: Yesterday, Today, Tomorrow, No. 2 (3). St. Petersburg, 90-105 (2002).

u. Brandenstein, M., Zur Viktimisierung (jugendlicher) Strafgefangener. Zeitschrift für Strafvollzug und Straffälligenhilfe 51, 22-33 (2002).

u. Obergfell-Fuchs, J., Chouaf, S., Sexuelle Viktimisierung an Frauen. Kriminalistik 56(4), 241-247 (2002).

u. Pagon, M., Lobnikar, B., Wie werden Opfer von (Sexual-)Straftaten von der Polizei gesehen? Zum Problem der Stigmatisierung. Kriminalistik 56, 735-744 (2002).

u. Shestakov, D. (Hrsg.), Criminology: Yesterday, Today, Tomorrow (russisch), No. 1 (2). Herzen University Press, St. Petersburg (2002).

$u$. Smartt, $U$., The changing face of Germany's crime rate since unification. Cjm - Criminal Justice Matters 46, 46-47 (2002).

$u$. Smartt, U., Violence in prisons: The victimisation of (young) offenders in prison establishments - Recent results from Germany. Comparative Law Review 36, Heft 2, 1-37 (2002).

u. Smartt, U., Prisoner-on-prisoner violence: Victimization of young offenders in prison. Some German findings. Criminal Justice 2, 411-437 (2002).

$u$. Smartt, U., Gewalt an Strafgefangenen: Ergebnisse aus dem anglo-amerikanischen und deutschen Strafvollzug. Zeitschrift für Strafvollzug und Straffälligenhilfe 51, 323-339 (2002).

$u$. Wößner, G., The role of changed family structures and processes in juvenile delinquency. Criminology: Yesterday, Today, Tomorrow, No. 1 (2). St. Petersburg, 166-200 (2002).

u. Wößner, G., Comparative Analysis of Crime: The Background of Deviant Behavior. Psicothema 14, 78-89 (2002).

u. Zapletal, J., K postojum obyvatelstva ke kriminalite a k trestání: srovnání (predevsím) Nemecka a Ceské republiky (Zur Einstellung der Bevölkerung zur Kriminalität und deren Bestrafung: ein Vergleich (vor allem) zwischen der Bundesrepublik Deutschland und der Tschechischen Republik). Kriminalistika 35, 13-27 (2002). 
u. Zapletal, J., Kriminalita a její prezentace $\mathrm{v}$ médiích: Zkusenosti (predevsím) z Nemecka a Ceské republiky (Die Kriminalität und deren Präsentation in den Medien: Erfahrungen (vor allem) aus Deutschland und der Tschechischen Republik). Kriminalistika 35, 92-107 (2002).

Wie werden Opfer von Straftaten gesehen? Zur Stigmatisierung von Verbrechensopfern. In: Geschlecht - Gewalt - Gesellschaft. Hrsg. S. Lamnek, M. Boatca. Lese + Budrich, Opladen 2003, 418-443.

u. Dölling, D., Feltes, T., Heinz, W. (Hrsg.), Kommunale Kriminalprävention - Analyse und Perspektiven. Ergebnisse der Begleitforschung zu den Pilotprojekten in Baden-Württemberg. Felix Verlag. Holzkirchen/Obb. 2003.

(als Autor mit Obergfell-Fuchs, J.) Opfererfahrungen, Kriminalitätsfurcht und Vorstellungen zur Prävention von Kriminalität - Stand der Forschung, 32-55; Ergebnisse der Bevölkerungsbefragung in Freiburg i.Br., 84-140;

Standardinventar für Bevölkerungsbefragungen zu Kriminalität und Kriminalitätsfurcht - Ergebnisse von Pretests, 233-249.

$u$. Obergfell-Fuchs, J. (Hrsg.), Crime prevention - new approaches. Weisser Ring Verlags-GmbH, Mainz 2003.

(als Autor mit Obergfell-Fuchs, J.) Introduction, 5-7;

(als Autor mit Obergfell-Fuchs, J., Kloppenburg, V., Wößner, G.) New approaches of preventing sexual crimes in Germany, 277-320.

u. Smartt, U., O declínio da família tradicional - Justificacoes possíveis para a delinquencia na adolescencia e para a criminalidade juvenil? In: Comportamento anti-social: Escola e família. Hrsg. I. Alberto, A.C. Fonseca, C.P. Albuquerque, A.G. Ferreira, J. Regelo. Centro de Psicopedagogia da Universidade de Coimbra, Coimbra 2003, 83-128.

Zaporniki kot zrtve kaznivih dejanj: victimizacija (mladih) obsojencev $\mathrm{v}$ nemskih zaporih. Varstvoslovje (Prisoners as victims of crime: The victimization of (young) offenders in German prison establishments). Revija za teorijo in prakso varstvoslovja 5, 131-141 (2003).

Zum polizeilichen Umgang mit Angehörigen von Straftätern. Kriminalistik 57, 415-420 (2003).

$u$. Bandzeviciene, $R$., Erentaite, $R$., Seksualines prievartos auku Stigmatizacijos Tendencijos. Mokslo Darbai - Socialinis Darbas 2 (4), 76-89 (2003).

u. Ferdinand, T.N., Obergfell-Fuchs, J., Does severe punishment mean less criminality? International Criminal Justice Review 13, 110-148 (2003).

u. Kapanadze, K., Lammich, S., Strafverfolgung in Georgien - Zum Problem Korruption. Zeitschrift für Strafvollzug und Straffälligenhilfe 52, 163-165 (2003).

u. Kapanadze, K., Lammich, S., Einstellungen zu Strafvollzug und Sanktionen in Georgien - Ergebnisse einer Umfrage. Zeitschrift für Strafvollzug und Straffälligenhilfe 52, 24-31 (2003).

u. Kern, J., Frauen und Kinder von Inhaftierten. Eine vergessene Gruppe. Kriminologisches Journal 35, 97-110 (2003). 
Lammich, Siegfried

u. Kern, J., Angehörige von Inhaftierten - zu den Nebeneffekten des Strafvollzugs. Zeitschrift für Strafvollzug und Straffälligenhilfe 52, 269-278 (2003).

u. Obergfell-Fuchs, J., Robert, P., Zauberman, R., Pottier, M.-L. Opferbefragungen in Deutschland und Frankreich. Unterschiedliche Konzeptionen und Vorgehensweisen. Monatsschrift für Kriminologie und Strafrechtsreform 86, 59-73 (2003).

u. Obergfell-Fuchs, J., Kriminalitätsfurcht und ihre Ursachen. Der Bürger im Staat 53, Heft 1, 9-18 (2003).

u. Pagon, M., Lobnikar, B., Podoba zrtev (spolnih) deliktov in odnos do nasilja - problem stigmatizacije (Image of victims of (sexual) offences and the attitude towards violence - a problem of stigmatisation.). Revija za kriminalistiko in kriminologijo 54, 137-158 (2003).

u. Yoshida, T., Wie werden Opfer von Straftaten gesehen? Zur Stigmatisierung von Verbrechensopfern. The Hokkaigakuen Law Journal 38, 145-198 (2003).

Die russische Strafrechtswissenschaft in der Übergangsperiode - Betrachtungen eines ausländischen Beobachters (Russisch). In: Zivilgesellschaft sowie Staat und Recht in der Übergangsperiode (Russisch). Hrsg. Bildungsministerium der Russischen Föderation- Staatliche Universität in Niznyj Novgorod. Niznyj Novgorod 2002, 217-221.

Die neuen russischen Geldwäschebestimmungen. Kriminalistik 6, 363-365 (2002).

Neue russische Regelungen zur Bekämpfung der Geldwäsche. Berliner Anwaltsblatt 5, 220-224 (2002).

u. Khomitch, V., Landesbericht Weißrußland. In: Strafrecht in Reaktion auf Systemunrecht. Vergleichende Einblicke in Transitionsprozesse. Bd. 7: Rußland, Weißrußland, Georgien, Estland, Litauen. Hrsg. A. Eser, J. Arnold. edition iuscrim, Freiburg i.Br. 2003, 142-154, 235-249.

u. Gamkrelidze, O., Landesbericht Georgien. In: Strafrecht in Reaktion auf Systemunrecht. Vergleichende Einblicke in Transitionsprozesse. Bd. 7: Rußland, Weißrußland, Georgien, Estland, Litauen. Hrsg. A. Eser, J. Arnold. edition iuscrim, Freiburg i.Br. 2003, 155-167, 250-260.

u. Piesliakas, V., Landesbericht Litauen. In: Strafrecht in Reaktion auf Systemunrecht. Vergleichende Einblicke in Transitionsprozesse. Bd. 7: Rußland, Weißrußland, Georgien, Estland, Litauen. Hrsg. A. Eser, J. Arnold. edition iuscrim, Freiburg i.Br. 2003, 181-190, 279-298, 309-310.

u. Kury, H., Einstellungen zu Strafvollzug und Sanktionen in Georgien. Ergebnisse einer Umfrage. Zeitschrift für Strafvollzug und Straffälligenhilfe, 2431 (2003).

u. Kury, H., Strafverfolgung in Georgien - das Problem Korruption. Zeitschrift für Strafvollzug und Straffälligenhilfe, 163-165 (2003).

Lelieur-Fischer, 
Juliette

Luczak, Anna

Maguer, Azilis

Manso Porto, Teresa
Französische Übersetzung des Völkerstrafgesetzbuchs, Online Publikationen des Max-Planck-Instituts:

http://www.iuscrim.mpg.de/forsch/legatext/VStGBfrz.pdf, Freiburg 2002, 65 S.

Rezension zur Monographie von Eva Kohler, Beschleunigte Strafverfahren im deutschen und im französischen Recht (Duncker \& Humblot, Kölner Kriminalwissenschaftliche Schriften, Band 36, 2001). Revue de science criminelle et de droit pénal comparé 3, 701 (2002).

Bericht über das Kolloquium "Strafjustiz im Spannungsfeld von Fairness und Effizienz" (8.-11. Mai 2002, Schloss Ringberg/Tegernsee). Revue de science criminelle et de droit pénal comparé 4, 923-925 (2002).

u. Biehler, A., Kniebühler, R., Stein, S. (Hrsg.), Freiburg Proposal on Concurrent Jurisdictions and the Prohibition of Multiple Prosecutions in the European Union. research in brief/forschung aktuell, Nr. 20. edition iuscrim, Freiburg i.Br. 2003, 36 S..

Rezension zur Monographie von Jocelyne Leblois-Happe, Quelles réponses à la petite délinquance? Etude du droit répressif français sous l'éclairage comparé du droit répressif allemand (Presses universitaires d'Aix-Marseilles, 2002). Revue pénitentiaire et de droit pénal 2003-4, 609-610 (2003).

Mafiakraken. Die Konstruktion "organisierte Kriminalität". Forum Recht 2, 44-46 (2002).

u. Kinzig, J., Examensklausur StR. Verscherbeln, Abzocken und andere Geschäfte. Juristische Ausbildung 24, 493-500 (2002).

Keine Monopole im illegalen Markt. Die Fehldeutung des Drogenhandels. Forum Recht 2, 44-47 (2003).

u. Müller, S., Landesbericht Frankreich. In: Jugendstrafrecht in Europa. Hrsg. H.-J. Albrecht, M. Kilchling. edition iuscrim, Freiburg i.Br. 2002, 157-189.

Die Einstellung von ausländischen Polizistinnen und Polizisten in Deutschland: Ergebnisse einer Untersuchung. Monatsschrift für Kriminologie und Strafrechtsreform 4, 309-316 (2002).

Grenzüberschreitende polizeiliche Kooperation am Beispiel des Gemeinsamen Zentrums für Zoll-und Polizeiarbeit in Kehl, www.bka.de/kriminalwissenschaften/kiforum/kiforum2003.html (2003)

Der neue Kontrollraum der grenzüberschreitenden polizeilichen Kooperation. Eine politikwissenschaftliche Untersuchung zur deutsch-französischen Grenzregion. Zeitschrift für europäische Studien 3, 447-469 (2003).

Verfahren und Erfahrungen zur Einstellung ausländischer Mitbürger in den deutschen Polizeidienst. In: Aktuelle Entwicklungen des Beamten- und Disziplinarrechts. Polizei-Führungsakademie, Münster, 27-42 (2003).

La coopération policière transfrontalière, moteur de transformations dans l'appareil de sécurité français. Cultures et Conflits, 33-56 (2003).

El desconocimiento de la norma en el Código penal peruano. Revista Peruana de Ciencias Penales, Edición Especial sobre el Código Penal Peruano, 12. Band, 60-77 (2002). 
Mayer, Markus

Meyer, Jürgen

$(2002)$
La consumación en los delitos contra el medio ambiente: comparación de los modelos colombiano, español y alemán. In: El funcionalismo en Derecho Penal. Libro Homenaje al Profesor Günther Jakobs. Hrsg. E. Montealegre Lynett. Universidad Externado de Colombia, Bogotà 2003, 445-461.

Efectos jurídico-penales del error de prohibición en los sistemas colombiano, español y alemán. In: El funcionalismo en Derecho Penal. Libro Homenaje al Profesor Günther Jakobs. Hrsg. E. Montealegre Lynett. Universidad Externado de Colombia, Bogotà 2003, 307-321.

Modellprojekt Elektronische Fußfessel. Befunde der Begleitforschung - Zwischenbericht Mai 2002. forschung aktuell/research in brief, Nr. 13. edition iuscrim, Freiburg i.Br. 2002, 26 S.

u. Haverkamp, R., Lévy, R. (Hrsg.), Will Electronic Monitoring Have a Future in Europe? edition iuscrim, Freiburg i.Br. 2003, 292 S.

(als Autor) The German Pilot Project: Potentials and Risks.

Das Hessische Modellprojekt zur Überwachung mit Hilfe der elektronischen Fußfessel. In: Neues in der Kriminalpolitik. Hrsg. E. Minthe. Kriminologische Zentralstelle, Wiesbaden 2003, S. 115-123.

u. Haverkamp, R., Die Zukunft der elektronischen Überwachung in Europa. Monatsschrift für Kriminologie und Strafrechtsreform 86, 216-220 (2003).

Der Konvent zur Zukunft Europas - Aktueller Sachstand und Ausblick. Schleswig-Holsteinischer Landtag. Niederschrift der 38. Sitzung des Europaausschusses vom 26.11.2002, 4-12.

Menschenrechte und internationaler Strafgerichtshof. In: Recht schafft $\mathrm{Zu}$ kunft, Rechtspolitischer Kongress 2002, Karlsruhe 26.-28.4.2002. Hrsg. Friedrich-Ebert-Stiftung, 72-75.

Demokratie und Handlungsfähigkeit in einer erweiterten Europäischen Union. In: Sitzung der EU-Ausschüsse von Bundesrat und Deutschem Bundestag am 26.6.2002. Hrsg. Bundesrat. Berlin 2002, 28-30 und passim.

Konvent zur Zukunft Europas. In: Konvent zur Zukunft Europas. Öffentliche Anhörung des Ständigen Ausschusses des Landtags von Baden-Württemberg am 15.11.2002. Stuttgart 2002, 29-32 und 42-44.

Machtzuwachs für Brüssel. Interview in: Der Spiegel, Nr. 14 vom 30.3.2002, 79 (2002).

Die Problematik der neuen Regelung zur gewerbsmäßigen Steuerhinterziehung nach $\S 370 \mathrm{a}$ AO. Interview in: DStR 20-21, 879-884 (2002).

Von der Grundrechtecharta zum Verfassungskonvent. Vorwärts, Juni 2002, Regionalausgabe Baden-Württemberg, 46 (2002).

Steuerverkürzungsbekämpfungsgesetz - § 370a AO, Motive des Gesetzgebers - Folgen für die beratenden Berufe. Interview in: WirtschaftsprüferkammerMitteilungen, Mai 2002, 40. Jg., 90-95 (2002).

Der Schritt von der Wirtschaftsgemeinschaft zur Werteordnung, ZRPRechtsgespräch. Zeitschrift für Rechtspolitik, 272-274 (2002). 
Mit dem Europäischen Konvent zu mehr Demokratie. punkt, 11. Jg., Ausgabe 52, 3-5 (2002).

Konvent ohne Denkverbote. Europäische Zeitung, 10 (2002).

Die Europapolitik zu Zeiten des Europäischen Konvents. polunity.com vom 22.8.2002, 1-3 (2002).

Grundrechtecharta wird auch für Ungarn verbindlich. Der neue Pester Lloyd vom 10.9.2002, 13 (2002).

EU-Institutionen: Aktiv gestalten. Eine demokratischere Staatengemeinschaft braucht ein gestärktes EU-Parlament. Deutschland, Nr. 5, 34 (2002).

EU-Grundrechtecharta - Mitgliedsländer streiten um die Rechtsverbindlichkeit. Diakonie 6, 26-28 (2002).

u. Hartleif, S., Die Konventsidee. Zeitschrift für Parlamentsfragen (ZParl 2/2002), 368-376 (2002).

$u$. Hölscheidt, S., Die Verfassung der Föderation der europäischen Nationalstaaten. Recht und Politik 4, 195-200 (2002).

(2003)

(Hrsg.), Kommentar zur Charta der Grundrechte der Europäischen Union. Baden-Baden 2003, XXXII, 634 S.

Solidarität ist ein Auftrag. Diskussionsbeitrag. In: Wie solidarisch ist Europa? Dokumentation. Hrsg. Ver.di, 2003, 12-17.

Menschenrechte und Internationaler Strafgerichtshof. In: Recht schafft $\mathrm{Zu}-$ kunft. Hrsg. H. Däubler-Gmelin, I. Mohr (für die Friedrich-Ebert-Stiftung). Bonn 2003, 167-176.

Der Europäische Konvent entwirft die Föderation von 25 Nationalstaaten. In: Bewusstsein für ein Europa von morgen. Internationale Perspektiven der Erwachsenenbildung. Hrsg. H. Hinzen, J. Leyhe (für den DVV = Deutschen Volkshochschul-Verband). Bonn 2003, Heft 42, 37-40.

Religion in der zukünftigen EU-Verfassung. In: Die EU und die Religionen. Hrsg. Bundestagsfraktion Bündnis 90/Die Grünen. Berlin 2003, 5-7, 23-25.

Warum braucht Europa eine Verfassung? In: Jahrbuch der Juristischen Gesellschaft Bremen 2003, 7-16.

$u$. Hölscheidt, S., Towards a Constitution for Europe in: FES-ALERT on German Political Currents 4/2003 (interner Newsletter der Friedrich-EbertStiftung, Washington DC).

u. Kaufmann, B., Lamassoure, A. (Hrsg.), Transnational Democracy in the Making. IRI Europe Handbook 2004. Amsterdam 2003, 276 S.

(als Autor mit B. Kaufmann, A. Lamassoure) Welcome to the Future of European Democracy, Introduction, $11 \mathrm{f}$.

(als Autor mit S. Hölscheidt) The Europe-wide Constitution Referendum, 85.

Contra: Flexibilisierung des Stabilitätspakts? Zeitschrift für Rechtspolitik, 28 (2003).

Solidarität wird zum Kennzeichen der EU. Ver.di Publik 02, 4 (2003). 
Europa wird ein Staatenverbund sein. ZRP-Rechtsgespräch. Zeitschrift für Rechtspolitik, 104-106 (2003).

Die Rolle der nationalen Parlamente - einschließlich der Länderparlamente in der Europäischen Union. In: Interparlamentarische Arbeitsgemeinschaft, Protokoll Nr. 74 des Forums vom 25.11.2002, 10-14 und 18 f. Bonn 2003.

Kultur in der Europäischen Verfassung - Römische Herausforderungen. Kultur Austausch 1, 110-111 (2003).

Weniger oder mehr Grundrechtsschutz für Bürgerinnen und Bürger der Europäischen Union? Beilage zur Ergebnisniederschrift der EAK (Europäische Arbeitsgemeinschaft zur Betreuung der Kriegsdienstverweigerer) - Mitgliederversammlung in Straßburg vom 24.- 26.2.2003, 1-20.

Konvent auf Verfassungskurs. NJW-Editorial, Heft 20, III (2003).

Der Europäische Konvent und die Öffentlichkeit. PIN-Aufsatz aus dem Bereich der Politischen Theorie, http://www.politik-im-netz.com/pin_rl/rational/rat_aufsatz.lasso.

Auch in Deutschland sollen die Bürger selbst über die EU entscheiden. Frankfurter Rundschau Nr. 115 vom 19.5.2003, 7 (2003).

Echte Wertegemeinschaft. Interview. Badische Zeitung vom 16.6.2003.

EU-Grundrechte werden einklagbar. Interview. Schwäbische Zeitung vom 21.6.2003.

Raum der Freiheit, der Sicherheit und des Rechts. Mitteilungs-Blatt DAV Internationaler Rechtsverkehr 1, 89-93 (2003).

u. Hölscheidt, S., Die Europäische Verfassung des Europäischen Konvents. Europäische Zeitschrift für Wirtschaftsrecht (EuZW), 613-621 (2003).

u. Hölscheidt, S., Nach der Erweiterung: Die EU und ihre europäischen Nachbarn. Europe Russian language quarterly of the Polish Institute of International Affairs, Warschau, 31-38 (2003).

u. Hölscheidt, S., Wie der Konvent Europa verfasst hat . Zeitschrift für Staatsund Europawissenschaften (ZSE) 3, 336-346 (2003).

Mohr, Tilmann

Übersetzung des Landesberichts Finnland von D. Frände. In: Nationale Strafverfolgung völkerrechtlicher Verbrechen. National Prosecution of International Crimes. Bd. 2: Finnland, Polen, Schweden. Hrsg. A. Eser, H. Kreicker. edition iuscrim, Freiburg i.Br. 2003, 21-75.

u. Nemitz, J.C. (Hrsg.) Strafrecht aus nordischer Perspektive, Festschrift für Karin Cornils zum 25-jährigen Jubiläum als Referentin am Max-PlanckInstitut. Shaker Verlag, Aachen 2003, 336 S.

(als Autor) Strafrechtliche Verwicklungen eines Fußballabends, oder: Joint Criminal Ventures im Nordischen Referat? 183-194.

Opphold ved MaxPlanck-Instituttet som gjesteforsker (auf Norwegisch), http://www.nordstraff.net/dokument/mpi.pdf.

Naplava, Thomas u. Oberwittler, D., Factores familiares e delinquência juvenil - Resultados da investigação sociológica na Alemanha. In: Comportamento Anti-social e Família: Uma abordagem científica. Hrsg. A.C. Fonseca. Livraria Almedina, Coimbra 2002, 157-179. 
u. Oberwittler, D., Methodeneffekte bei der Messung selbstberichteter Delinquenz von männlichen Jugendlichen - Ein Vergleich zwischen schriftlicher Befragung in der Schule und mündlicher Befragung im Haushalt. Monatsschrift für Kriminologie und Strafrechtsreform 85, 401-423 (2002).

$u$. Oberwittler, D., Auswirkungen des Erhebungsverfahrens bei Jugendbefragungen zu 'heiklen' Themen - schulbasierte schriftliche Befragung und haushaltsbasierte mündliche Befragung im Vergleich. ZUMA-Nachrichten 51, 4977 (2002).

Nemitz, Jan Christoph Landesbericht Finnland. In: Jugendstrafrecht in Europa. Hrsg. H.-J. Albrecht, M. Kilchling. edition iuscrim, Freiburg i.Br. 2002, 137-156.

Nogala, Detlef $\quad$ Ordnung durch Beobachtung -Videoüberwachung als urbane Einrichtung. In: Jahrbuch StadtRegion 2002. Hrsg. N. Gestring, H. Glasauer, C. Hannemann, W. Petrowsky, J. Pohlan. Leske + Budrich, Opladen 2002, 32-54.

u. Albrecht, H.-J., Police, Sociology of. In: International Encyclopaedia of Social and Behavioural Sciences, Vol. 17. Hrsg. P.B. Baltes, N.J. Smelser. Elsevier, Amsterdam 2002, 11532-11535.

Des Erkennungsdienstes Kern - Gegenwart und Zukunft von genetischen Fingerabdrücken, Massengentests und polizeilichen DNA-Profil Dateien. In: Innere Sicherheit als Gefahr. Hrsg. Humanistische Union. Humanistische Union e.V., Berlin 2003, 286-302.

Obergfell-Fuchs, Joachim

KKP - Erfahrungen und Perspektiven. In: Dokumentation des Fachkongresses "Kommunale Kriminalprävention - Netzwerk der Zukunft". Hrsg. Innenministerium Baden-Württemberg. Landeskriminalamt Baden-Württemberg, Stuttgart 2002, 50-51.

u. Kury, H., Würger, M., Strafeinstellungen. Ein Vergleich zwischen Ost- und Westdeutschland. edition iuscrim, Freiburg i.Br. 2002, $201 \mathrm{~S}$.

O znaczeniu prywatnych firm ochrony osób i mienia w Niemczech, z uwzglednieniem aspektów integracji europejskiej (The role of private security services in Germany with a look at the united Europe). In: Mit represyjnosci albo o znaczeniu prewencji kryminalnej (The myth of repression or: the importance of crime prevention). Hrsg. J. Czapska, H. Kury. Kantor Wydawniczy Zakamycze, Kraków 2002, 679-716.

u. Kury, H., Komunalna prewencja kryminalna w Europie (Community crime prevention in Europe). In: In: Mit represyjnosci albo o znaczeniu prewencji kryminalnej (The myth of repression or: the importance of crime prevention). Hrsg. J. Czapska, H. Kury. Kantor Wydawniczy Zakamycze, Kraków 2002, 343-434.

u. Kury, H., Ferdinand, T., The background of illegal drug abuse: a German View. In: Drugs and crime deviant pathways. Hrsg. S. Brochu, C. da Agra, M.-M. Cousineau. Ashgate, Aldershot 2002, 197-218.

u. Kury, H., Smartt, U., The evolution of public attitudes to punishment in Western and Eastern Europe. In: Changing attitudes to punishment. Public opinion, crime and justice. Hrsg. J.V. Roberts, M. Hough. Willan Publishing, Cullompton, Devon 2002, 93-114. 
u. Kury, H., Wößner, G., Würger, M., Fear of crime and victimization. In: Crime victimization in comparative perspective. Hrsg. P. Nieuwbeerta. Boom Juridische uitgevers, Den Haag 2002, 317-334.

Das Auge des Gesetzes. Reader's Digest, Dezember 2002, 9-12.

u. Kury, H., Chouaf, S., Sexuelle Viktimisierung an Frauen. Kriminalistik 56(4), 241-247 (2002).

u. Kury, H., Würger, M., Methodological problems in victim surveys: The example of the ICVS. International Journal of Comparative Criminology 2(1), 38-56 (2002).

u. Kury, H., Smartt, U., Würger, M., Attitudes to punishment: How reliable are international crime victim surveys? International Journal of Comparative Criminology 2(1), 133-150 (2002).

(2003)

u. Kury, H. (Hrsg.), Crime prevention - new approaches. Weisser Ring, Mainz 2003, $492 \mathrm{~S}$.

u. Kury, H., Opfererfahrungen, Kriminalitätsfurcht und Vorstellungen zur Prävention von Kriminalität - Stand der Forschung. In: Kommunale Kriminalprävention - Analysen und Perspektiven. Hrsg. D. Dölling, T. Feltes, W. Heinz, H. Kury. Felix Verlag, Holzkirchen 2003, 32-55.

u. Kury, H., Ergebnisse der Bevölkerungsbefragung in Freiburg i.Br. In: Kommunale Kriminalprävention - Analysen und Perspektiven. Hrsg. D. Dölling, T. Feltes, W. Heinz, H. Kury. Felix Verlag, Holzkirchen 2003, 84-140.

$u$. Kury, $H$., Standardinventar für Bevölkerungsbefragungen zu Kriminalität und Kriminalitätsfurcht - Ergebnisse von Pretests. Hrsg. D. Dölling, T. Feltes, W. Heinz, H. Kury. Felix Verlag, Holzkirchen 2003, 233-249.

u. Kury, H., Introduction. In: Crime prevention - new approaches. Hrsg. H. Kury, J. Obergfell-Fuchs. Weisser Ring, Mainz 2003, 5-7.

u. Kury, H., Kloppenburg, V., Wößner, G., New approaches to preventing sexual crimes in Germany. In: Crime prevention - new approaches. Hrsg. H. Kury, J. Obergfell-Fuchs. Weisser Ring, Mainz 2003, 277-320.

Opferforschung zu Gewaltkriminalität. Public Health Forum 11, Nr. 39, 20-21 (2003).

Organisierte Kriminalität - nichts als nur Begriffsverwirrung? Angewandte Sozialforschung 23, 70-73 (2003).

u. Kury, H., Robert, P., Zauberman, R., Pottier, M.-L., Opferbefragungen in Deutschland und Frankreich. Monatsschrift für Kriminologie und Strafrechtsreform 86, 59-73 (2003).

u. Kury, H., Kriminalitätsfurcht und ihre Ursachen. Der Bürger im Staat 53, 918 (2003).

Rezensionen: Gordon Hughes, Eugene McLaughlin, John Muncie (Hrsg.): Crime Prevention and Community Safety - New Directions, London: Sage 2001. Kriminologisches Journal, 35(1), 69-71 (2003). 
Oberwittler, Dietrich Zusammenleben im Wohngebiet. Eine Skala zur Messung des sozialen Klimas in Wohnquartieren am Beispiel Freiburgs. Beiträge zur Statistik der Stadt Freiburg i.Br., Jahresheft 2000-2001, 17-28 (2002).

u. Naplava, Th., Factores familiares e delinquência juvenil - Resultados da investigação sociológica na Alemanha. In: Comportamento Anti-social e Família: Uma abordagem científica. Hrsg. A.C. Fonseca. Livraria Almedina, Coimbra 2002, 157-179.

u. Wiesenhütter, M., The Risk of Violent Incidents Relative to Population Density in Cologne Using the Dual Kernel Density Routine. In: CrimeStat II: A Spatial Statistics Program for the Analysis of Crime Incident Locations. Program Manual. Hrsg. N. Levine. National Institute of Justice, Washington. D.C. $2002,332$.

u. Köllisch, T., Würger, M., Selbstberichtete Delinquenz bei Jugendlichen. In: ZUMA-Informationssystem. Elektronisches Handbuch sozialwissenschaftlicher Erhebungsinstrumente Version 6.0. Hrsg. A. Glöckner-Rist. Zentrum für Umfragen, Methoden und Analysen, Mannheim 2002.

u. Naplava, Th., Auswirkungen des Erhebungsverfahrens bei Jugendbefragungen zu 'heiklen' Themen - schulbasierte schriftliche Befragung und haushaltsbasierte mündliche Befragung im Vergleich. ZUMA-Nachrichten 51, 49-77 (2002).

u. Naplava, Th., Methodeneffekte bei der Messung selbstberichteter Delinquenz von männlichen Jugendlichen - Ein Vergleich zwischen schriftlicher Befragung in der Schule und mündlicher Befragung im Haushalt. Monatsschrift für Kriminologie und Strafrechtsreform 85, 401-423 (2002).

Geschlecht, Ethnizität und sozialräumliche Benachteiligung - überraschende Interaktionen bei sozialen Bedingungsfaktoren von Gewalt und schwerer Eigentumsdelinquenz von Jugendlichen. In: Geschlecht - Gewalt - Gesellschaft (Otto-von-Freising-Tagungen der Katholischen Universität Eichstätt-Ingolstadt, Bd. 4). Hrsg. S. Lamnek, M. Boatca. Leske + Budrich Opladen 2003, 269-294.

u. Köllisch, T., Jugendkriminalität in Stadt und Land. Sozialräumliche Unterschiede im Delinquenzverhalten und Registrierungsrisiko. In: Kriminalität und Gewalt im Jugendalter. Hell- und Dunkelfeldbefunde im Vergleich. Hrsg. J. Raithel, J. Mansel. Juventa Verlag, Weinheim 2003, 135-160.

Die Messung und Qualitätskontrolle kontextbezogener Befragungsdaten mithilfe der Mehrebenenanalyse - am Beispiel des Sozialkapitals von Stadtvierteln. ZA-Informationen 53, 11-41 (2003).

Die Entwicklung von Kriminalität und Kriminalitätsfurcht in Deutschland Konsequenzen für die Kriminalprävention. Deutsche Zeitschrift für Kommunalwissenschaften 3 (2003).

von Oppeln-Bronikowski,

Viktimisierung in Konfliktgebieten - Der Fall des ehemaligen Jugoslawien. Internationaler Workshop "War - Victimization - Security: The Case of the Former Yugoslavia" vom 2. bis 4. November 2001 in Berlin. Monatsschrift für Kriminologie und Strafrechtsreform 6, 85. Jg., 445-447 (2002). 
Ortmann, Rüdiger

Paoli, Letizia

(2002)
Victims' Protection in International Law: The Normative Basis and a Look into the Practice. European Journal of Crime, Criminal Law and Criminal Justice 2-3, 233-252 (2002).

u. Ewald, U., War - Victimization - Security: The Case of the Fromer Yugoslavia. European Journal of Crime, Criminal Law and Criminal Justice 1, 3944 (2002).

Sozialtherapie im Strafvollzug - Eine experimentelle Längsschnittstudie zu den Wirkungen von Strafvollzugsmaßnahmen auf Legal- und Sozialbewährung. edition iuscrim, Freiburg i.Br. 2002, $681 \mathrm{~S}$.

The Implementation of the UN Convention against Transnational Organized Crime: Concepts and Actors. In: The Containment of Transnational Organized Crime. Comments on the UN Convention of December 2000. Hrsg. H.-J. Albrecht, C. Fijnaut. edition iuscrim, Freiburg i.Br. 2002, 207-233.

Il confronto tra Milano e Francoforte. In: Tossicodipendenze a Milano nel 2000. Hrsg. Ufficio Tossicodipendenze del Comune di Milano. Milano 2002, 156-158.

Italien. In: Die Praxis der Gewinnabschöpfung in Europa. Hrsg. M. Kilchling. edition iuscrim. Freiburg i.Br. 2002, 239-295.

Drug Trafficking. In: Encyclopedia of Crime and Punishment. Hrsg. D. Levinson. Vol. 1. Sage, Thousands Oaks, CA 2002, 569-576.

The Italian Mafia. In: Encyclopedia of Crime and Punishment. Hrsg. D. Levinson. Sage, Thousands Oaks, CA 2002, Vol. 2, 938-940.

u. Albrecht, H.-J., Cannabis Policies in Frankfurt. In: European City Conference on Cannabis Policy, 6, 7, 8 December 2001. Conference book. Hrsg. Ministry of Justice, The Netherlands, 75-89 [o.J. (2002)].

Flexible Hierarchies and Dynamic Disorder. The Drug Distribution System in Frankfurt and Milan. Drugs: Education, Prevention and Policy 9 (2), 143 (2002).

Rasvitie nesakonnogo rinka narkotikov: potreblenie i torgovla v postsovetskij Rossii. (The Development of an Illegal Drug Market: Drug Consumption and Trade in Post-Soviet Russia). Kriminologia: vchera, segodna, savtra (Criminology: Yesterday, Today, Tomorrow) 2(3), 52-75 (2002).

Javlajetsa li prestypnij oborot narkotikov formoj organisovannoj prestypnosti. (Is Illegal Drug Trafficking a Form of Organized Crime?). Kriminologia: vchera, segodna, savtra (Criminology: Yesterday, Today, Tomorrow) 4(5), 168-179 (2002).

The Price of Freedom: Illegal Drug Markets and Policies in Post-Soviet Russia. The Annals of the American Academy of Political Sciences (582), 167180 (2002).

The Development of an Illegal Market: Drug Consumption and Trade in PostSoviet Russia. British Journal of Criminology 42 (1), 21-39 (2002). 
Paulenz, Simon

u. Ciklauri-Lammich, E., Osnovnije Aspekti politiki Rossii po protivodejstvijy nesakonnomy oboroty i ypotreblenijy narkotikov. (The Fundamental Aspects of Russian Drug Policy'). Pravo i Politika (Law and Politics) 2 (26), 32-38 (2002).

Mafia Brotherhoods: Organized Crime, Italian Style. Oxford University Press, New York 2003, 289 S.

Broken Bonds: Mafia and Politics in Sicily. In: Menace to Society: Political Criminal Collaboration Around the World. Hrsg. R. Godson. Transaction, New Brunswick 2003, 27-70.

Das "pacchetto giudiziario" - Reformbedarf für die italienische Justiz. In: Italien im Aufbruch - eine Zwischenbilanz. Hrsg. Bernd Rill. Hanns-SeidelStiftung, München 2003, 155-168.

Il crimine organizzato. In: Rapporto sulla criminalità in Italia. Hrsg. Marzio Barbagli. Il Mulino, Bologna 2003, 275-300.

Il mercato delle droghe. In: Rapporto sulla criminalità in Italia. Hrsg. Marzio Barbagli. Il Mulino, Bologna 2003, 81-108.

The Invisible Hand of the Market: The Illegal Drugs Trade in Germany, Italy, and Russia. In: Criminal Finances and Organising Crime in Europe. Hrsg. P.C. van Duyne, K. van Lampe, J.L. Newell. Wolf, Nijmegen 2003, 19-40.

The Informal Economy and Organized Crime. In: The Informal Economy: Threat and Opportunity in the City. Hrsg. H.-J. Albrecht, J. Shapland, J. Ditton, T. Godefroy. edition iuscrim, Freiburg i.Br. 2003, 133-172.

Paulenz, Simon

Rezension: Gesellschaft und Staat in Afrika. Blätter des iz3w, Nr. 259, 54 f. (2002).

Ungerechte Gerechtigkeit. Blätter des iz3w Nr. 271, 26 ff. (2003).

Rabenstein, Christiane Doping - Legal Comparison and Harmonisation of Doping Rules - Landesbericht England und Wales. CD-ROM

Towards European Convergence in Penal Policy and Practice: Criminal Sanctions - Reform Proposals in Germany and England from a Comparative Perspective, Internet-Publikation

(http://www.iuscrim.mpg.de/forsch/onlinepub/rabenstein.pdf).

Richter, Thomas

Umweltstrafrecht in der Volksrepublik China. edition iuscrim, Freiburg i.Br. 2002, $296 \mathrm{~S}$.

Lun huanjing fanzui de xingwei bufa he jieguo bufa. In: Zhong-De di-3 jiedi4 jie xingfaxuefanzuixue yantaohui wenji. Hrsg. Sifabu yufang fanzui yanjiusuo. Beijing 2002, 151-155.

Guanyu Zhongguo de huanjing xingfa, youqi shi guanyu shetuan de kechufaxing. In: Zhong-De di-3 jiedi-4 jie xingfaxuefanzuixue yantaohui wenji. Hrsg. Sifabu yufang fanzui yanjiusuo. Beijing 2002, 156-159. 
Silverman, Emily

Simon, Jan-Michael $u$. Dernauer, M., Deguo xingshi susong chengxu zhong bu-qisu de lishi fazhan. In: Zhong-De bu-qisu zhidu bijiao yanjiu (Comparative Research on Sino-German Non-prosecution Policies). Hrsg. Chen Guangzhong, H.-J. Albrecht. Zhongguo Jiancha Chubanshe, Beijing 2002, 62-76.

u. Dernauer, M., Deguo qingzui yu zhengju wenti de bu-qisu. In: Zhong-De bu-qisu zhidu bijiao yanjiu (Comparative Research on Sino-German Nonprosecution Policies). Hrsg. Chen Guangzhong, H.-J. Albrecht. Zhongguo Jiancha Chubanshe, Beijing 2002, 115-123.

u. Dernauer, M., Historical Development of Non-Prosecution Policies in Germany. In: Non-Prosecution Policies. A Sino-German Comparison. Hrsg. H.-J. Albrecht, Chen Guangzhong. edition iuscrim, Freiburg i.Br. 2002, 19-39.

u. Dernauer, M., Dismissal of Cases because of Evidence Problems in Germany. In: Non-Prosecution Policies. A Sino-German Comparison. Hrsg. H.-J. Albrecht, Chen Guangzhong. Freiburg i.Br. 2002, 151-162.

Sifa jiguan de xuqiu suo mianlin de xianfa he chengxufa wenti. In: Zhong-De qiangzhi cuoshi guoji yantaohui lunwenji (Proceedings of Sino-German Symposium on Compulsory Measures). Hrsg. H.-J. Albrecht, Chen Guangzhong. Beijing 2003, 198-205.

u. Fan Jianhong, Strafrecht. In: Das große China-Lexikon. Hrsg. B. Staiger, F. Stefan, H.-W. Schütte. Darmstadt 2003, 724-727.

Country Report USA. In: Der Einsatz akustischer und visueller Dokumentationsverfahren im Strafverfahren: Eine vergleichende Studie im Auftrag des Bundesministeriums der Justiz. Hrsg. H.-J. Albrecht, M. Kilchling. edition iuscrim, Freiburg i.Br. 2002, 281-305.

The Role of Capacity in the Adjudication and Punishment of Youthful Offenders in Germany and the United States: A Legal Comparison. In: Konflikt der Rechtskulturen? Die USA und Deutschland im Vergleich. Hrsg. K. Krakau, F. Streng. Winter, Heidelberg. 2003, 127-142.

als Mitarbeiter mit Sancinetti, M.A., Ferrante, M., Argentinien. In: Strafrecht in Reaktion auf Systemunrecht. Vergleichende Einblicke in Transitionsprozesse, Bd. 3. Hrsg. A. Eser, J. Arnold. edition iuscrim, Freiburg i.Br. 2002, $444 \mathrm{~S}$.

Responsabilidad criminal y reconciliación. El Derecho Penal frente a la violencia política masiva en Sudáfrica, Ruanda y El Salvador. In: La Corte Penal Internacional. Instrumento de paz para Colombia, Bogotá. Hrsg. Fundación País Libre (im Erscheinen $)=$

www.altocomisionadoparalapaz.gov.co/opinion/articulo_\%20simon.doc.

Jurisdição Penal Internacional. In: Revista Brasileira de Ciências Criminais No. 40 (outubro-dezembro 2002). Hrsg. Instituto Brasileiro de Ciências Criminais. São Paulo/Brasil, 63-101 (2002).

Jurisdicción Universal. La Perspectiva del Derecho Internacional Público. In: Revista Judicial. Corte Suprema de Justicia, San José, Costa Rica, Año XXVII, No. 81 (octubre-diciembre 2002), 32-71 = Revista Electrónica de Estudios Internacionales, Vol. 4 (2002): www.reei.org/reei4/Simon.PDF = www.unifr.ch/derechopenal/articulos/pdf/ Simon1.pdf. 
Stein, Sibyl

Tellenbach, Silvia
Proceso de paz en Colombia y Corte Penal Internacional. Breves apuntes sobre el Proyecto de Ley No. 85/03 S. In: Justicia y reparación en el marco de procesos de paz. Hrsg. V. Guerrero, R. Mora. Bogotá (im Erscheinen).

La Comisión para el Esclarecimiento Histórico. In: Boletín Mexicano de Derecho Comparado No. 106 (enero-abril 2003). Hrsg. Instituto de Investigaciones Jurídicas de la UNAM. México D.F./México, 147-203 (2003).

Przemoc propierana przez państwo - Odpowiedzialność karna a pojednanie. In Ius et Lex 1. Fundacja Ius et Lex, Warszawa, Polska, 161-173 (2003).

u. Biehler, A., Kniebühler, R., Lelieur-Fischer (Hrsg.), Freiburg Proposal on Concurrent Jurisdictions and the Prohibition of Multiple Prosecutions in the European Union. research in brief/forschung aktuell, Nr. 20. edition iuscrim, Freiburg i.Br. 2003, $36 \mathrm{~S}$.

Buchbesprechung: Herbert Baumann/Gerhard Brehme/Matthias Ebert (Hrsg.), Die Verfassungen der anglophonen Staaten des subsaharischen Afrikas. Berlin, Recht in Afrika 5, 107-108 (2001) (Nachtrag).

Die Vielfalt der Rechtsmeinungen gilt dem Islam als Gnade. Max-PlanckForschung 4, 94-97 (2001) (Nachtrag).

u. Aydin, Ö.D., Türkei. In: Jugendstrafrecht in Europa. Hrsg. H.-J. Albrecht, M. Kilchling. edition iuscrim, Freiburg i.Br. 2002, 455-474.

u. Scholler, H. (Hrsg.), Rechtssprichwort und Erzählgut - Europäische und Afrikanische Beispiele. Diskussionsbericht. Berlin 2002.

In Islam, Diversity of Opinions is seen as a Divine Gift. MaxPlanckResearch 1, 90-95 (2002).

Buchbesprechung: Tilman Nagel, Einführung in das islamische Recht. Juristenzeitung 57, 708-709 (2002).

Tagungsbericht: 28. Tagung der Gesellschaft für Rechtsvergleichung vom 19.-22. September 2001 in Hamburg. VII. Fachgruppe für vergleichende Rechtsgeschichte, orientalische Rechte und ethnologische Rechtsforschung. Juristenzeitung 57, 285-287(2002).

Zum türkischen Strafrecht. Gestern - Heute - Morgen. Vestnik Nižegorodskogo Universiteta im. N.I. Lobačevskogo. Serija Pravo, Wypusk 1(5), 265-274 (2002).

Zur Änderung der türkischen Verfassung durch das Gesetz Nr. 4709 vom 3. Oktober 2001. Verfassung und Recht in Übersee 35 (2002), 532-547.

Einführung in das türkische Strafrecht. edition iuscrim, Freiburg i.Br. 2003, $308 \mathrm{~S}$.

Muslime im deutschen Strafvollzug. In: Multireligiosität im vereinten Europa - Historische und juristische Aspekte. Hrsg. H. Lehmann. Wallstein Verlag, Göttingen 2003, 135-144. 
Tetal, Carina

Tränkle, Stefanie

Trappe, Julie

Weber, Jonas Peter

Weigend, Ewa
Tagungsbericht: 28. Tagung der Gesellschaft für Rechtsvergleichung vom 19.-22. September 2001 in Hamburg. VI. Fachgruppe für vergleichende Rechtsgeschichte, orientalische Rechte und ethnologische Rechtsforschung. Mitteilungen der Gesellschaft für Rechtsvergleichung, Nr. 29, 36-39 (2003).

Ehrenmorde an Frauen in der arabischen Welt. wuquf 13, 74-89 (2003).

u. Grundies, V., Höfer, S., Basisdaten der Freiburger Kohortenstudie: Prävalenz und Inzidenz polizeilicher Registrierung. Arbeitsberichte aus dem MaxPlanck-Institut 2002/1. edition iuscrim, Freiburg i.Br., 197 S.

Die Rolle von Rechtfertigungen bei der Schuldaushandlung im Täter-OpferAusgleich. TOA-Infodienst, Nr. 16, 26-30 (2002).

Die Bedeutung einer gemeinsamen Situationsrahmung. Interaktionssoziologische Anmerkungen zum Täter-Opfer-Ausgleich. Monatsschrift für Kriminologie und Strafrechtsreform 4, 299-309 (2003).

als Mitarbeiterin mit Udvaros, J., Landesbericht Ungarn. In: Strafrecht in Reaktion auf Systemunrecht. Vergleichende Einblicke in Transitionsprozesse. Bd. 5: Polen, Ungarn. Hrsg. A. Eser, J. Arnold. edition iuscrim, Freiburg i.Br. 2002.

$u$. Karsten, $N$., Tagungsbericht über das Symposium "Strafrechtsentwicklung in Osteuropa: Zwischen bewältigten und neuen Herausforderungen". "MaxPlanck-Forschung", Heft 4 (2002).

$u$. Karsten, $N$., Strafrechtsentwicklung in Osteuropa: Zwischen bewältigten und neuen Herausforderungen. Tagungsbericht. Zeitschrift für die gesamte Strafrechtswissenschaft 115, 443-450 (2003).

Verhältnismäßigkeit der Sicherungsverwahrung. Ausblick auf die künftige Anwendung von Art. 64 EStGB. Schweizerische Zeitschrift für Strafrecht, Band 120, Heft 4, 398-409 (2002).

Das neue polnische StGB vom 6. Juni 1997. In: Kriminalität im Grenzgebiet. Band. 5/6: Das neue polnische Strafgesetzbuch (Kodeks karny). Hrsg. G. Wolf. Springer Verlag, Berlin 2002, 1-13.

$u$. Zoll, A., Landesbericht Polen. In: Strafrecht in Reaktion auf Systemunrecht. Vergleichende Einblicke in Transitionsprozesse. Bd. 5: Polen, Ungarn. Hrsg. A. Eser, J. Arnold. edition iuscrim, Freiburg i.Br. 2002, 29-150.

Übersetzung und Einführung von Die polnische Strafprozeßordnung - Kodeks postępowania karnego - Zweisprachige Ausgabe. Freiburg i.Br. 2003, 420 S.

Grundlagen der Strafverfolgung völkerrechtlicher Verbrechen in Polen. In: Nationale Strafverfolgung völkerrechtlicher Verbrechen. National Prosecution of International Crimes. Bd. 2: Finnland, Polen, Schweden. Hrsg. A. Eser, H. Kreicker. edition iuscrim, Freiburg i.Br. 2003, 77-181.

Grundzüge der neuen polnischen Strafprozessordnung von 1997. Zeitschrift für die gesamte Strafrechtswissenschaft 115, 153-174 (2003).

Die Vorbereitung auf den Anwaltsberuf vor dem Hintergrund der deutschen Juristenausbildung (polnisch). Palestra, Nr. 7/8, 273-277 (2003). 
Wenning, Tobias

Wößner, Gunda

Würger, Michael

Zerbes, Ingeborg u. Ambos, K., Rechtsprechung zum internationalen Straf- und Strafverfahrensrecht. Neue Zeitschrift für Strafrecht-Rechtsprechungsreport, 289-296 (2002).

Behandlung, Behandelbarkeit und Typisierung von Sexualstraftätern: Ergebnisse einer bundesweiten Expertenbefragung. Arbeitsberichte aus dem MaxPlanck-Institut 2/2002. edition iuscrim, Freiburg i.Br. 2002, 56 S.

Statement on the conduct of investigations into past cases of abuse (in children's homes) - Memorandum 73. In: House of Commons, Home Affairs Committee. The conduct of investigations into past cases of abuse in children's homes. Vol. II: Memoranda. The Stationary Office, London, EV 2002, 129-130.

u. Obergfell-Fuchs, J., Kury, H., Würger, M., Fear of crime and victimization. In: Crime victimization in comparative perspective. Hrsg. P. Nieuwbeerta. Boom Juridische uitgevers, Den Haag 2002, 317-334.

u. Kury, H., A familília e os comportamentos desviantes dos jovens. In: Compartamento Anti-social e Família: Uma abordagem científica. Hrsg. A.C. Fonseca. Livraria Almedina, Coimbra 2002, 181-211.

u. Kury, H., The Impact of Changed Social Structures on Crime Trends in Modern Societies. In: Development without Disorders. Hrsg. G.S. Bajpai. Vishwavidyala Prakashan, Sagar 2002, 67-106.

State of the Art of Sex Offender Treatment in Germany: Results of an Expert Survey. Forensische Psychiatrie und Psychotherapie (Supplement) 9, 151 (2002).

u. Kury, H., Comparative analysis of crime - The background of deviant behavior. Psycothema 14, 78-89 (2002).

u. Kury, H., Obergfell-Fuchs, J., Kloppenburg, V., New approaches of preventing sexual crimes in Germany. In: Crime Prevention - New Approaches. Hrsg. H. Kury, J. Obergfell-Fuchs. Weißer Ring, Mainz 2003, 277-320.

Review: Jutta Elz, Legalbewährung und kriminelle Karrieren von Sexualstraftätern - Sexuelle Gewaltdelikte (Wiesbaden: KrimZ). Monatsschrift für Kriminologie und Strafrechtsreform 86/2, 160-162 (2003).

u. Kury, H., Obergfell-Fuchs, J., Strafeinstellungen. Ein Vergleich zwischen Ost- und Westdeutschland. edition iuscrim, Freiburg i.Br. 2002, $201 \mathrm{~S}$.

u. Oberwittler, D., Köllisch, T., Selbstberichtete Delinquenz bei Jugendlichen. In: ZUMA-Informationssystem. Elektronisches Handbuch sozialwissenschaftlicher Erhebungsinstrumente Version 6.0. Hrsg. A. Glöckner-Rist. Zentrum für Umfragen, Methoden und Analysen, Mannheim 2002.

u. Obergfell-Fuchs, J., Kury, H., Wößner, G., Fear of crime and victimization. In: Crime victimization in comparative perspective. Hrsg. P. Nieuwbeerta. Boom Juridische uitgevers, Den Haag 2002, 317-334.

Anonyme Zeugen - Faires Verfahren in Österreich und der Schweiz? In: Information und Recht. Hrsg. M. Cottier, K. Sahlfeld, D. Rüetschi. Helbing und Luchterhand, Basel u.a. 2002, 379-403. 


\section{Wissenschaftliche Veranstaltungen des Instituts}

\section{Tagungen am oder in Zusammenarbeit mit dem Institut}

German-Sino Symposium: Questions of Evidence Law in an Intercultural Comparison/Deutsch-chinesisches Symposium: "Fragen des Beweisrechts in einem interkulturellen Vergleich". Freiburg i.Br., 14.-15.1.2002 (Albrecht als Veranstalter und Referent, Richter als Diskussionsteilnehmer).

Interdisziplinäres Symposion "Alltagsvorstellungen von Kriminalität - Individuelle und gesellschaftliche Bedeutung für die Lebensgestaltung". Universität Köln, 21.-23.2.2002 (Albrecht und Kania als Mitveranstalter und Referenten, Obergfell-Fuchs, Oberwittler, Paoli als Referent(in)en, Herz als Berichterstatterin).

Wissenschaftliches Kolloquium anlässlich der Sitzung des Fachbeirats und des Kuratoriums. Freiburg i.Br. 1.3.2002 (Gleß als Referentin).

Gemeinsame Tagung des Max-Planck-Instituts und des Kriminologischen Forschungsinstituts Niedersachsen. Freiburg i.Br., 20.3.2002 (Oberwittler als Referent).

Internationales Kolloquium "Strafjustiz im Spannungsfeld von Fairness und Effizienz - Konvergente und divergente Entwicklungen im Strafprozessrecht. Criminal Justice between Due Process and Crime Control - Convergence and Divergence in Criminal Procedure Systems". Tagungsstätte der Max-Planck-Gesellschaft "Schloss Ringberg", 8.-11.5.2002 (Veranstalter: Eser; Koordination und Organisation: Rabenstein; Ambos und Gleß als Referent(in); Bahrenberg, Bekou, Biehler, Gropengießer, Jarvers, Kerll, Lelieur-Fischer als Konferenzassistentinnen und -assistenten, Huber als Teilnehmerin).

European Workshop (LEA) "Will Electronic Monitoring Have a Future in Europe?" MaxPlanck-Institut für ausländisches und internationales Strafrecht, Freiburg i.Br., 13.-15.6.2002 (Albrecht als Mitveranstalter, M. Mayer als Koordinator und Referent, Nogala).

Internationales Kolloquium "Strafrechtsentwicklung in Osteuropa: Zwischen bewältigten und neuen Herausforderungen". Tagungsstätte der Max-Planck-Gesellschaft "Schloss Ringberg", 26.-29.6.2002 (wiss. Leitung: Eser und Arnold; organisatorische Betreuung: Kreicker, Röth, Schmidt, Illing, Karsten, Trappe; Teilnehmer: Lammich, Weigend).

First Working Conference: "Modeling the World Heroin Market: Assessing the Consequences of Changes in Afghanistan Production". Max-Planck-Institut für ausländisches und internationales Strafrecht, Freiburg i.Br., 13.9.2002 (Paoli als Referentin).

International Colloquium "Environmental Law and Criminal Penalties in EU Member States". Max Planck Institute for Foreign and International Criminal Law Freiburg i.Br., 16.17.9.2002 (Eser als Mitveranstalter).

Workshop "Interdisziplinäre Zusammenarbeit zwischen dem MPI für Strafrecht Freiburg und dem MPI für ethnologische Forschung Halle". MPI für ethnologische Forschung, Halle, 3.12.2002 (Arnold als Mitveranstalter; Kouassi, Simon, Tellenbach als Diskussionsteilnehmer). 
International Conference "Organized Crime in Europa: Conceptions, Patterns and Policies in the European Union and Beyond". Max-Planck-Institut für ausländisches und internationales Strafrecht Freiburg i.Br., 27.2.2003-1.3.2003 (Paoli als Mitveranstalterin und Referentin, Cornils, Kilchling, Kinzig, Luczak als Referenten).

Seminario Internacional "Persecución penal nacional de crímenes internacionales desde una perspectiva comparada". Konrad Adenauer Stiftung/Max Planck Institut für ausländisches und internationales Strafrecht. Montevideo/Uruguay, 27.-28.2.2003 (Eser und Ambos als Mitveranstalteer und Referenten).

Workshop "Reform des Strafrechts und des Strafprozeßrechts in Tadschikistan". Freiburg i.B., 17.-19.3.2003 (Arnold,Trappe als Veranstalter; Hünerfeld, Tellenbach, Lammich).

Workshop "Die Rolle der Ehre im Strafrecht". Freiburg i.Br., 24.-26.4.2003 (Koordination und Organisation: Tellenbach; Eser, Weigend).

Workshop "Grenzüberschreitendes ne bis in idem. Ein Regelungsvorschlag für die Europäische Union". 2 Seminare. Freiburg i.Br., 22.-24.5.2003 und 10.-12.7.2003 (Eser als Veranstalter, Sieber mit Grußwort und Einführung, Biehler, Kniebühler, Lelieur-Fischer, Stein).

Vorkolloquium der Association de Droit Pénal International (AIDP) über "Konkurrenzen nationaler und internationaler Strafgerichtsbarkeit und der Grundsatz ne bis in idem" zur IV. Sektion des XVII. Internationalen Strafrechtskongresses (2004 in Bejing). Berlin, 1.4.6.2003 (Eser als Veranstalter, Biehler, Kniebühler, Lelieur-Fischer, Stein).

Conferencia Internacional "El Estatuto de la Corte Penal Internacional y sus Implicaciones en el Derecho Nacional de los Países Latinoamericanos". Internationale Konferenz in Zusammenarbeit mit dem Centro de Estudios de Politíca Criminal y Ciencias Penales, des MaxPlanck-Instituts für ausländisches und internationals Strafrecht, dem Goethe-Institut Mexiko und der Rechtswissenschaftlichen Fakultät der Universidad La Salle. Mexiko-City, 18.22.8.2003 (Eser als Mitveranstalter, Referent und Diskussionsleiter).

17th International Conference of the International Society for the Reform of Criminal Law "Convergence of Criminal Justice Systems: Building Bridges - Bridging the Gaps". Den Haag, 24.-28.8.2003 (Eser als Mitveranstalter, Referent und Sitzungsleiter, Rabenstein als Referentin).

EU-China Legal and Judical Co-operation Programme, Max-Planck-Institut für ausländisches und internationales Strafrecht, Freiburg i.Br., 9.-11.9.2003 (Albrecht und Sieber als Veranstalter, Biehler, Kinzig, Luczak als Referenten).

"Colloquium on the International and Comparative Criminal Trial Project" mit der Nottingham Trent University/Nottingham Law School. Max-Planck-Institut für ausländisches und internationales Strafrecht, Freiburg i.Br., 17.9.2003 (Albrecht, Simon als Mitveranstalter).

Symposion über "Strafrecht im Islam und Recht im Iran". Jahrestagung der Gesellschaft für Arabisches und Islamisches Recht. Freiburg i.Br., 10.-11.10.2003 (Tellenbach als Veranstalterin und Referentin, Eser, Sieber). 
Deutsch-Amerikanischer Workshop "Current Issues in Criminal Law". A cooperative effort involving the Max Planck Institute and the Carl Schurz Haus (Freiburg), the Bavarian American Academy (Munich), and the Fulbright Senior Specialist Program (Washington, D.C.). Freiburg i.Br., 30.-31.10.2003 (Silverman als Veranstalterin; Eser, Sieber, Luczak, Mayer, Namgalies, Silverman als Referenten; Kury).

Deutsch-Serbisches Kolloquium. Max-Planck-Institut, Freiburg i.Br., 28.11.2003 (Organisation: Kiza, Rinceanu, Simon und Weigend; Sieber; Arnold, Dorsch, Jarvers, Krüpe, Kreicker, Paoli als Referenten).

Expertenseminar "Alternative Means to Retributive Justice in Violent Conflicts in the Middle East". Bahçeşehir-Universität Istanbul und Max-Planck-Institut für ausländisches und inteernationales Strafrecht, Freiburg i.Br. und Istanbul/Türkei, 4.-7.12.2003 (Albrecht, Rezai, Simon als Mitveranstalter und Referenten, Rohne als Referent).

Fortbildungsseminar für chinesische Staatsanwältinnen und Staatsanwälte. Max-PlanckInstitut für ausländisches und internationales Strafrecht, Freiburg i.Br., 6.-18.12.2003 (Kilchling als Veranstalter; Albrecht, Braun, Dorsch, Kilchling, Kinzig, Krüpe, Mayer, Sieber als Referenten; Winter).

\section{Kolloquien am Institut}

\subsection{Allgemeine Kolloquien am Institut}

Gastvortrag des Zeitzeugen Sally Perel, der als jüdischer Hitlerjunge das Hitler-Regime überlebt hat. Die Finanzierung übernahm die Konrad-Adenauer-Stiftung. Max-PlanckInstitut Freiburg i.Br., 6.11.2002 (Namgalies als Veranstalterin).

"A Comparative Look at Criminal Law Codification: the United States, Great Britain, and the Continent" (Stuart P. Green, Professor of Law an der Louisiana State University in Baton Rouge/USA, zur Zeit Visiting Research Fellow an der University of Glasgow). Freiburg i.Br., 8.11.2002.

\subsection{Wissenschaftliche Kolloquien der strafrechtlichen Forschungsgruppe}

"Zur Entwicklung des internationalen Anklagesystems - Ermittlungsbefugnis des Anklägers von internationalen Strafgerichtshöfen" ( $W u W e i$, Jiangsu/China). Freiburg i.Br., 7.6.2002.

"Atrocities in Afghanistan and International Criminal Law: Crimes against Humanity" (Gholam Haidar Allama, Mashad/Iran). Freiburg i.Br., 7.6.2002.

"Aspects of the Inter-Relationship between International Criminal Law and Domestic Jurisdictions" (Olympia Bekou, Nottingham/England). Freiburg i.Br., 7.6.2002.

"Impact of European Community Law on National Criminal Law" (Mari Leinonen, Helsinki/Finnland). Freiburg i.Br., 5.7.2002.

"Criminal Law and the Transformations of the Polish Political System in the Years 19902000" (Prof. Dr. Janusz Kochanowski, Warschau/Polen). Freiburg i.Br., 24.7.2002. 
"Strafrechtliche Fragen im Zusammenhang mit Methoden der alternativen Medizin" (Dr. Pedro J. Montano, Montevideo/Uruguay). Freiburg i.Br., 21.10.2002.

"Die künftige Europäische Verfassung und das Strafrecht" (Prof. Dr. Jürgen Meyer). Freiburg i.Br., 28.10.2003.

"Globalisation économique et droits de l'homme" (Prof. Dr. Mireille Delmas-Marty, Collège de France, Paris). Freiburg i.Br. 4.12.2003.

\subsection{Wissenschaftliche Kolloquien der kriminologischen Forschungsgruppe}

"Viktimisierte Unternehmen und ihre Vorstellungen über die Justiz in Québec" (Prof. JeanLuc Bacher, Montréal). Freiburg i.Br., 26.2.2002.

"Heroingestützte Behandlung bei Heroinabhängigen - Erfahrungen aus der Schweiz und ihre Folgen" (Ambros Uchtenhagen, Zürich). Freiburg i.Br., 12.3.2002.

"Recent Trends in Spanish Criminology" (Per Stangeland, Malaga). Freiburg i.Br., 17.5. 2002.

"Council of Europe Activities in the Field of Penology and Prisons" (Stephanos Stavros, Strasbourg). Freiburg i.Br., 28.5.2002.

"Legal and political challenges of money-laundering and proceeds of crime controls: a view from the Far Western side of Europe" (Prof. Michael Levi, Cardiff). Freiburg i.Br., 3.7.2002.

"Everything you need to know in order NOT to have a strong opinion about drug legalization" (Prof. Peter Reuter, Maryland). Freiburg i.Br., 12.9.2002.

"The Development of Parole in England and Wales and the Role of Research in its Reform" Prof. Stephen Shute, Birmingham). Freiburg i.Br., 16.1.2003.

Isabelle Mansuy, Universität Grenoble, "Der Schutz der Strafgefangenenrechte in Frankreich und Deutschland" (Isabelle Mansuy, Grenoble). Freiburg i.Br., 27.1.2003.

"Aspects of Punishment in International Criminal Law" (Prof. Dirk van Zyl Smit, Nottingham/Kapstadt). Freiburg i.Br., 9.5.2003.

"Organisierte Kriminalität im Südlichen Afrika: Neuere Trends" (Peter Gastrow, Cape Town). Freiburg i.Br., 21.5.2003.

"Special Legal Procedures for the Protection of Women from Violence" (Prof. Raymond Teske, Texas). Freiburg i.Br., 2.6.2003. 


\section{Doktorandensprecher/Doktorandentreffen}

Im Sommer 2002 wurden neue Doktorandensprecher gewählt: Christoph Grammer (Strafrechtliche Forschungsgruppe), Clivia Namgalies (Strafrechtliche Forschungsgruppe) und Scharie Tavcer (Kriminologische Forschungsgruppe).

Im Rahmen des monatlich am Institut stattfindenden Doktorandentreffens (IusCrimDocs-Treff) stellten folgende Doktoranden ihre Arbeiten vor:

- Harald Kania (Subjektive Kriminalitätstheorien - Alltagswissen und Vorstellungen über Kriminalität, Oktober 2003)

- Stefanie Tränkle ("Strategien für die EDV-gestützte Auswertung qualitativer Daten", September 2002)

- Anna Luczak ("Was ist organisierte Kriminalität? Bedeutung und Verwendung des Begriffs (Beispiel England)", Januar 2003)

- Scharie Tavcer ("Causal Factors of Trafficking of Women for Sexual Exploitation from Moldova", Februar 2003)

- Anke Biehler ("Vergewaltigung als Mittel der Kriegsführung", März 2003)

- Christoph Grammer ("Der Straftatbestand des zwangsweisen Verschwindenlassens", März 2003)

- Markus Mayer ("Die elektronische Fußfessel - Zwischenergebnisse der Evaluation des hessischen Modellprojekts", April 2003)

- Clivia Namgalies ("NS-Propagandaverbote im Strafrecht", Mai 2003)

- Ernesto Kiza ("Methods and Discourses of Empirical Description of Mass-Victimization", Juni 2003)

- Constanze von Oppeln-Bronikowski ("The transmittance of conflict-related victimization across generations", Juni 2003)

- Holger Rohne ("Alternative ways to cope with victimization resulting from the IsraeliPalestinian-Conflict", August 2003)

Im Sommer 2003 wurden Ernesto Kiza (Kriminologische Forschungsgruppe) und Verena Krenberger (Kriminologische Forschungsgruppe) zu den neuen Doktorandensprechern gewählt.

Im Rahmen der bisherigen Amtsperiode wurden fünf DoktorandInnentreffen durchgeführt, die jeweils einmal monatlich stattfanden.

Darüber hinaus wurde ein Mentorensystem eingeführt, ein Handout konzipiert sowie die Mailingliste der IusCrimDocs fortgesetzt, über die alle freiwillig angemeldeten DoktorandInnen zusätzliche Informationen zu Veranstaltungen, Diskussionen usw. austauschen können.

Im Rahmen der MPG-weiten Betätigung der DoktorandInnenvertretungen, fand auch 2003 ein bundesweites Treffen in Dresden statt, an dem Frau Krenberger und Maria Elena Zegada teilnahmen. Neben der Diskussion der für DoktorandInnen relevanten Themen innerhalb der MPG (z.B. Bezahlung ausländischer DoktorandInnen, Lehrtätigkeit von DoktorandInnen) und anschließende Stellungnahme durch den Präsidenten Prof. Gruss, wurde auch die weitere Vernetzung der Vertretungen vorangetrieben. Frau Krenberger vertritt das Institut im Arbeitskreis "Interdisziplinarität", während Frau Zegada der "Web-Group" beitrat.

Für das Jahr 2004 ist zunächst die Umsetzung von Seminarreihen, insbesondere zur Frage unterschiedlicher Forschungsmethoden, geplant. Darüber hinaus ist ein Ausflug zur JVA Freiburg vorgesehen und es wird eine Diskussionsrunde mit einem ortsansässigen Amtsrichter zum Thema "Strafzumessung in der amtsgerichtlichen Praxis" vorbereitet. 


\section{Wissenschaftliche Vorträge}

Albrecht,Hans-Jörg "Exclusion of Evidence: The European Perspective". German-Sino Symposium: "Questions of Evidence Law in an intercultural Comparison"/Deutschchinesisches Symposium: "Fragen des Beweisrechts in einem interkulturellen Vergleich". MPI für ausländisches und internationales Strafrecht. Freiburg i.Br., 14.1.2002.

"Beschleunigung des Strafverfahrens und beschleunigte Strafverfahren im europäischen Vergleich". Tagung 2b/2002 "Chancen und Grenzen des beschleunigten Strafverfahrens" der Deutschen Richterakademie Trier, 18.1.2002.

"Europäisierung des Strafrechts". Conference MPG 2000+: "Internationalization - New Modes of Regulations - Multiple Regulatory Structures". Max Planck Project Group Common Goods, Law, Politics and Economics. Bonn, 22.2.2002.

"Der gesellschaftliche Kontext von Gewalt, Kriminalität, Prävention und Disziplinierung". Interdisziplinäres Symposium "Alltagsvorstellungen von Kriminalität - Individuelle und gesellschaftliche Bedeutung für die Lebensgestaltung". Universität Köln, 23.2.2002.

"Versuch einer Synthese - Konsequenzen und Ausblick". Tagung "Soziale Reflexivität und qualitative Methodik. Zum Selbstverständnis der Kriminologie in der Spätmoderne"der ETH/Universität Zürich. Centro Stefano Franscini. Monte Verità, Ascona, 29.3.2002.

"Pornographieverbot im Rundfunk". Präsentation der gleichnamigen Studie. Forum der Bayerischen Landeszentrale für Neue Medien. München, 19.4.2002.

"Bedeutung von Schuld und Schuldfeststellung im europäischen Raum". Tagung 13b/2002 der Deutschen Richterakademie Trier, 24.4.2002.

"Festung Europa? - Die Kontrolle der Immigration". Symposium 2002 des Heidelberger Clubs für Wirtschaft und Kultur e.V. "Euro-Vision: United States of Europe?" Heidelberg, 27.4.2002.

"Developments in the Rule of Law Standards in Europe". International Conference on the Rule of Law and Legal Education. China University of Political Science and Law. Beijing, 6.5.2002.

"Evidence Law and New Technology". Sino-German Conference on Criminal Evidence Law, Evidence and Technology, China University of Political Science and Law, Beijing, 7.5.2002.

"Public Prosecution Services in the Federal Republic of Germany - The Legal Framework and Practice of Public Prosecution". Chief Public Prosecutor's Office. Wuhan, 8.5.2002.

"Immigration, der Fremde und Hassgewalt - Empirische Befunde und theoretische Erklärungen". Berichte aus den wissenschaftlichen Arbeiten der Sektionen der Max-Planck-Gesellschaft im Rahmen des Greifswald International Students Festivals im MPI für Plasmaphysik. Greifswald, 5.6.2002 
"Digitale und Informationstechnologie im Strafverfahren". Rechts- und Staatswissenschaftliche Fakultät der Ernst-Moritz-Arndt-Universität. Greifswald, 6.6.2002.

"What Place for Electronic Monitoring in the System of Criminal Sanctions?". European Workshop "Will Electronic Monitoring Have a Future in Europe?" Freiburg i.Br., 13.-15.6.2002.

"A Comparative Perspective on Will in Law". Symposium "On the Social Significance of the Will: Questioning Folkpsychology, Law, and Forensic Medicine". Max-Planck-Institut für Psychologische Forschung, München, 27.6. 2002.

"International and Comparative Perspectives on Sentencing - Making international sentencing and penal comparisons: What do we know and what do we still need to know?". Second International Conference on Sentencing and Society. The Centre for Sentencing Research, The University of Strathclyde/Großbritannien. Glasgow, 27.6.2002.

"Bewährungshilfe heute: Konzentration auf das Kerngeschäft?". Veranstaltung zur Einweihung der neuen Räume der Bewährungshilfe Freiburg i.Br., 12.7.2002.

"Trafficking in Humans, Drugs, and Money - Key Concepts". 7th Annual Conference and General Meeting of the International Association of Prosecutors. London, 9.9.2002.

"Ist das deutsche Jugendstrafrecht noch zeitgemäß? - Bedarf es und wenn ja welcher Veränderungen?" 64. Deutscher Juristentag, C, Abteilung Strafrecht. Berlin, 18.9.2002.

"The Law on Enforcement of Criminal Sanctions of Montenegro - An Assessment and Evaluation". Expert meeting on the Montenegrin Law on the Enforcement of Criminal Sanctions. Council of Europe co-operation programme to strengthen the rule of law.Montenegrin Institute for Enforcement of Criminal Sanctions, Ministry of Justice of Montenegro. Podgorica/ Yugoslavia, 27.9.2002.

"The System of Penal Sanctions and Sentencing in the Federal Republic of Germany". Séminaire européen de recherche "Sanctionner les infractions pénales en Europe: Allemagne". Faculté de Droit de l'Université de Genève et CDPC, UFR de Droit de l'Université Paris X-Nanterre. Genève, 4.10.2002.

"Strafrechtliche Sanktionen, Strafverfahren und Strafzumessung". Internationales Symposium und Estnische Juristentage zu "Estnische Strafrechtsreform und neues Strafrecht im europäischen Vergleich". Universität Tartu, Justizministerium der Estnischen Republik. Tartu/Estland, 11.10.2002.

"Ist das deutsche Jugendstrafrecht noch zeitgemäß?" Tagung "Jugendstrafrecht in der Diskussion - Aktuelle Reformfragen" der Friedrich Ebert Stiftung i.V.m. der DVJJ e.V. Regionalgruppe Mecklenburg-Vorpommern sowie dem Lehrstuhl für Kriminologie der Ernst-Moritz-Arndt Universität. Greifswald, 18.10.2002.

"Legislative responses to 9/11 - Comparative analysis of anti-terrorism legislation". Hongkong City University. Hongkong, 24.10.2002. 
"Transnational Organized Crime - New Challenges for Police and Policing". Law Faculty of the Macao University. Macao, 25.10.2002.

"Legislative responses to 9/11 - Comparative analysis of anti-terrorism legislation". Library Hall of the CUPL, Beijing, 28.10.2002.

"Trends in Research on Crime and Criminal Justice". Chinese People's Public Security University, Beijing, 30.10.2002.

"Developments in National and International Criminal Law". Chinese Academy of Social Sciences, Institute of Law. Beijing, 1.11.2002.

"Immigration, Transnational Communities and Shadow Economies - The Emergence of New Subcultures and Subcultural Norms". Conference "Mobile People, Mobile Law". MPI für ethnologische Forschung. Halle, 8.11.2002.

"International Public Prosecution Standards". Vietnamese Prosecutors Programme "Vietnam - Strengthening the Prosecutorial Capacity". The Danish Institute for Human Rights. Kopenhagen, 7.12.2002.

"Legislative Responses to 9/11". International Conference on Human Rights and Terrorism. University of Haifa. Haifa/Israel, 17.12.2002.

(2003)

(1) "Comparative Law Perspectives - Common Law and Continental Systems". (2) "Appointment and Training Standards for Judges, Prosecutors and Defense Counsel". Symposium on Afghanistan and the Rule of Law. United States Institute of Peace. Washington D.C., 3.2.2003.

"National Terrorism and International Terrorism". Tagung International Terrorism and World Governance. UNICRI in collaboration with EUROPOL. UNICRI Turin, 7.2.2003.

"Verfassungsrechtliche Aspekte von Pornographie und Jugendschutz". Abendforum der Katholischen Akademie in Bayern zu "Der PornographieBoom und seine Folgen". München, 12.2.2003.

"Rechtswirklichkeit und Effizienz der Überwachung der Telekommunikation nach den $\S \S 100 \mathrm{a}, 100 \mathrm{~b}$ sowie der akustischen Wohnraumüberwachung und anderer verdeckter Ermittlungsmaßnahmen". Vorstellung des Projekt-Zwischenberichts anlässlich der dritten Beiratssitzung im Bundesministerium der Justiz. Berlin, 20.2.2003.

"Detention: The Empirical Situation". Sino-German Conference on Coercive Measures during the Criminal Investigation. Beijing, 24.-25.2.2003.

"Anti-Terrorism legislation after 9/11". Lent Term 2003 Lecture Series, University of Cambridge, Institute of Criminology. Cambridge, 6.3.2003.

"Criminal Policy. Prisons and Alternatives to Imprisonment". 65th International Regional Seminar "New Tendencies in Crime and Criminal Policy in Central and Eastern Europe". Miskolc/Ungarn, 12.3.2003.

"International and European Standards and Requirements in Relation to the Prosecutorial Function". Course "Vietnam - Strengthening the Procuratorial Capacity". The Danish Institute for Human Rights. Kopenhagen, 26.3.2003. 
"Bedeutung von Schuld und Schuldfeststellung im europäischen Raum" und "Schuldstrafrecht und islamischer Kulturkreis". Tagung 15a/2003 "Schuld und Strafe" der Deutschen Richterakademie Trier, 8.5.2003.

"Trafficking in Humans - Theory, Phenomenon and Criminal Law based Responses". St. Petersburgischer Kriminologie-Klub, Juristische Fakultät, St. Petersburg/Russlans, 27.5.2003.

"Political Corruption and Corruption Control in the EU Countries". Juristische Gesellschaft Warschau, 9.6.2003.

"Die Entwicklung der Jugendkriminalität". Juristische Fakultät der Universität Lublin/Polen, 10.6.2003.

"Reformen des Strafrechts in Deutschland". Juristische Fakultät der Universität Lublin/Polen, 11.6.2003.

"International and European Standards and Requirements in Relation to the Prosecutorial Function". Seminar on "Strengthening the Procuratorial Capacity in Vietnam". The Danish Institute for Human Rights. Kopenhagen, 13.6.2003.

"Der erweiterte Sicherheitsbegriff und seine Folgen für die Innen- und Rechtspolitik auf europäischer Ebene". Konferenz "Reorganisation der europäischen Sicherheitsarchitektur". Anwälte für Demokratie und Menschenrechte (RAV) u.a. Berlin, 27.6.2003

"Grenzgänger - Internationale Adoption und Kinderhandel". Vortragsreihe zum internationalen Kinderschutz an der Universität Gießen, 8.7.2003.

"Delincuencia juvenil y la reforma en las leyes de menores". Congreso internacional "Las ciencias penales en el siglo XXI, 20.-27.8.2003. INACIPE, Mexiko", 26.8.2003.

"Principles and Standards of Evidence". Workshop with Senior Chinese officials from the Ministry of Justice, Ministry of Foreign Affairs, Supreme People's Court and Supreme Peoples Procuratorate at the MPI in the framework of the EU-China Legal and Judicial Co-operation Programme. Freiburg i.Br., 10.9.2003.

"The Right to Remain Silent - The Continental Example". International Conference" "The content of the right to remain silent in a developing constitutional jurisprudence". Justice College Pretoria/South Africa, 1.10.2003.

"International and European Standards and Requirements in Relation to the Prosecutorial Function". Vietnamese Prosecutors Programme "Vietnam Strengthening the Prosecutorial Capacity". The Danish Institute for Human Rights. Kopenhagen, 6.10.2003.

"Elektronische Fußfessel als Bewährungsauflage: Der hessische Modellversuch". Tagung der Neuen Kriminologischen Gesellschaft. München, 10.10. 2003.

"Death Penalty - International and Human Rights Perspectives on the Future of Capital Punishment". National Human Rights Training Course. Department of the Supreme Procuratorate. Beijing, 27.10.2003. 
"New Developments in Criminological and Criminal Law Research in Germany and Europe". Criminal Justice Institute. Beijing 28.10.2003.

"Standards of Public Prosecution". EU-China Legal and Judicial Co-operation Programme. The Danish Institute for Human Rights. Kopenhagen, 31.10.2003.

"Die Bekämpfung der Geldwäsche in der Kreditwirtschaft". Seminarreihe Europäisches Strafrecht. Bahçeşehir-Universität Istanbul, 4.-7.11.2003.

"Comparative report on Racist Violence: Final results". Meeting of RAXEN National Focal Points, European Monitoring Centre on Racism and Xenophobia. Wien, 11.11.2003.

"Rechtswirklichkeit und Effizienz der Telekommunikationsüberwachung aus wissenschaftlicher Sicht". 24. Triberger Symposium des Justizministeriums Baden-Württemberg zu "Die Überwachung der Telekommunikation - Ein strafprozessuales Instrument im Spannungsfeld zwischen Freiheit und Sicherheit. Triberg, 13.11.2003.

"Organized Environmental Crime: The State of Research". Conference "Environmental Crime in Europe 'Rules of Sanctions'". Brüssel 27.-28.11.2003.

"Introduction"; "A Summary and Conclusions". "Future prospects of an intercultural dialogue on justice". Experts' seminar on "Alternative Means to Retributive Justice in Violent Conflicts in the Middle East". Bahçeşehir-Universität Istanbul/MPI für ausländisches und internationales Strafrecht, Freiburg i.Br., Istanbul, 4. und 6.12.2003.

"Beweisstandards im Strafprozessrecht in vergleichender Perspektive". Besuch einer Delegation chinesischer Staatsanwälte am MPI für ausländisches und internationales Strafrecht, Freiburg i.Br., 8.12.2003.

"Anstaltsbeiräte in Recht und Praxis des Strafvollzugs in Deutschland". Japan Federation of Bar Associations. Tokio, 10.12.2003.

"Transnational Organized Crime - The German Response". Symposium "Transnational Organized Crimes and Human Security. Risumeikan Universität, Kyoto, 12.12.2003.

Ambos, Kai

"Das internationale Strafrecht und dessen Bedeutung für Art. $1 \mathrm{~F}$ und Art. 33 Abs. 2 Genfer Flüchtlingskonvention". UNHCR-Expertengespräch. Berlin, 14.3.2002.

"La internacionalización de la Justicia penal". Podiumsveranstaltung "La globalización de los derechos humanos". ILDIS (Friedrich-Ebert-Stiftung)/ Goethe Institut-Inter Nationes. La Paz/Bolivien, 8.4.2002.

"Derecho Penal Internacional". 20-stündiger Kurs im Rahmen des Masterprogramms der Universidad Salamanca/Spanien in Mar del Plata/Argentinien), 10.-13.4.2002.

"Transatlantische Irritationen. The Dispute on the ICC and the Fight against Terrorism". Diskussion mit Prof. Jutta Limbach, Prof. Ruth Wedgwood und Prof. Bruno Simma. Goethe Forum, München, 21.4.2002. 
Comment on the topic "International Criminal Procedure: 'adversarial', 'inquisitorial' or mixed?" International Colloquium of the Max Planck Institute for Foreign and International Criminal Law "Criminal Justice between Due Process and Crime Control". 1. session. "Overview of different types of procedure". Ringberg Castle (Tegernsee, Bavaria), 8.-11.5.2002.

"El mandamiento de detención y entrega europeo". Congreso Internacional. Instituto Universitario Alonso Martínez de Justicia y Litigación. Universidad Carlos III de Madrid. Teilnahme an der mesa redonda "La persecución internacional de la delincuencia". Sevilla 23.-24.5.2002.

"Der Europäische Gerichtshof für Menschenrechte und Verfahrensrechte". Strafrechtslehrertagung Bayreuth, 28.5.-1.6.2003.

"Schutz der Menschenrechte durch das Völkerstrafrecht?" Juristische Gesellschaft Augsburg e.V. Augsburg, 12.6.2002.

"The ICC and International Relations". Podiumsdiskussion im Rahmen der Konferenz "Justice without borders: The Yugoslavia Tribunal in The Hague Model for an International Criminal Court?" Friedrich-Ebert-Stiftung/Bundeszentrale für politische Bildung. Berlin, 16.-18.6.2002.

"Proceso penal, policía y seguridad en Alemania". Vortrag für mexikanische Senatoren im Rahmen des incoming Programms "Innere Sicherheit" der Friedrich-Ebert-Stiftung. Bonn, 24.6.2002.

"Polícia, Ministério Público e criminalidada organizada na Alemanha". Vortrag bei der Associação Mineira do Ministério Público. Belo Horizonte, Minas Gerais/Brasil, 8.8.2002.

"Investigação preliminar". Vortrag 1. Congresso sobre as Reformas do Código do Processo Penal e Estado Democrático de Direito, Pontifícia Universidade Católica do Paraná/Universidade Federal do Paraná, Curitiba/ Brasilien, 19.-22.8.2002.

"Corte Penal Internacional". 8-stündiger Fortbildungskurs. Poder Judicial de la Província de Neuquén/Colégio de Abogados, Neuquén/Argentina, 20.8.2002.

"Polícia e Ministério Público na Alemanha". Vortrag an der Polizeiakademie (Academia dos Delegados Policiais). Curitiba (Paraná, Brasilien), 22.8.2002.

"Direito processual penal comparado e internacional". 15-stündiger Kurs in der "Especialização em Direito Processual Penal 2002". Pontifícia Universidade Católica do Paraná, (Curitiba/Brasilien), 23.-24.8.2002.

"Tribunal Penal Internacional". Vortrag bei UNIME, Faculdade de Ciências Jurídicas, Salvador (Bahia, Brasilien), 2.9.2002.

"Nuevo Derecho Penal Internacional". Instituto Nacional de Ciencias Penales, Vortragreihe "Temas selectos de derecho penal contemporáneo". Ciudad de México, 10.10.2002.

"The principle of complementarity: Difficulties regarding harmonisation of domestic legislation with the ICC Statute". International Conference "International Criminal Court". Organisation for Security and Cooperation in Europe. Belgrad (FR Yugoslavia), 15.11.2002. 
"Derecho Penal Internacional". 2 mal 15-stündiger Kurs im Rahmen des Masterprogramm der Universidad Autonoma de Mexico (UAM) i.V.m. der Universität Barcelona (Spanien). Ciudad de Mexico, 7.-9.10. und 10.-12.10.2002.

"Selected Issues of the Core Crimes in International Criminal Law". International Conference "International Criminal Law: Quo vadis?" International Institute for Higher Studies in Criminal Science (ISISC). Panel 3: International Crimes: Criteria for their identification and classification and future developments. Siracusa/Italy, 28.11.-4.12.2002.

"La Corte Penal Internacional y los derechos nacionales". Mesa redonda. Conferencia "Corte Penal Internacional". Generalitat de Catalunya, Centre d'Estudis Jurídics i Formació Especializada. Barcelona, 30.-31.1.2003.

"Obligación y modelos de implementación del Estatuto de Roma". Seminario Internacional "Persecución penal nacional de crímenes internacionales desde una perspectiva comparada"(Konrad Adenauer Stiftung/Max Planck Institut für ausländisches und internationales Strafrecht). Montevideo/Uruguay), 27.28.2.2003.

"Autoría y participación: responsabilidad de los jefes en organizaciones jerárquicas". Colegio de Abogados de Rosario (Argentina), Instituto de Ciencias Penales, 3.3.2003 und Universidad Austral, Buenos Aires/Argentina, 4.3.2003.

"Autoría y participación en derecho penal internacional". Universidad Católica de Rosario/Argentina, 4.3.2003.

"Cooperación de los Estados con la CPI y Persecución Penal de los Delitos". Seminario Internacional "La Corte Penal Internacional" (Universidad de Chile/Goethe Institut Chile/Konrad Adenauer Stiftung). Santiago de Chile, 2.3.4.2003.

"La internacionalización del derecho penal y América Latina". Internationales Humboldt-Kolloquium/Coloquio Internacional Humboldt "La función mediadora del derecho como ciencia universal en una época de globalización y de lucha contra el terrorismo". Montevideo/Uruguay, 3.-6.4.2003.

Der Europäische Gerichtshof für Menschenrechte und Verfahrensrechte. Strafrechtslehrertagung Bayreuth 28.5.-1.6.2003.

"Der internationale Strafgerichtshofs und das Jugoslawien-Tribunal in Den Haag - Welche Zukunft?" Osteuropa Zentrum - Vortragsreihe. Abschlusskonferenz im Berliner Rathaus. Berlin, 29.7.2003.

"La reforma procesal penal en Latinoamérica". Conversatorio Internacional sobre Experiencias de Reforma de la Administración de Justicia (Poder Judicial, Banco Mundial, USAID et al.). Lima/Peru, 21.-22.8.2003.

"La Policía en los Estados de Derecho Latinoamericanos. Un enfoque comparativo". Presentación del Libro, Fescol (Fundación Ebert). Bogotá, 11.9.2003.

"La Corte Penal Internacional y el conflicta armado en Colombia". Universidad Eafit, Medellín, 12.9.2003; Universidad Nacional de Colombia, Bogotá, 15.9.2003; Universidad Santiago de Cali, 16.9.2003. 
"Impunidad y Corte Penal Internacional". Seminario "Corte Penal Internacional. Instrumento de Paz para Colombia". Fundación País Libre/Konrad Adenauer Stiftung. Bogotá, 16.-17.9.2003.

"Derechos Humanos, Justicia Internacional y la Corte Penal Internacional". XIII Seminario Eduardo García Máynez, Itam/Escuela Libre de Derecho/ Universidad Autonoma Metropolitana/Inacipe. Mexico D.F., 3.-4.10.2003.

"La Corte Penal Internacional y Mexico". Tribunal Superior de Justicia del Estado de Oaxaca (Mexico), 6.10.2003.

Presentación del libro "La Policía en los Estados de Derecho Latinoamericanos". Academía Nacional de Seguridad Pública. Mexico D.F., 7.10.2003.

"La Corte Penal Internacional y Mexico". Partido de Acción Nacional (PAN), Camará de Diputados. Mexico D.F., 8.10.2003.

"Derecho Penal Internacional". 15-stündiger Kurs im Rahmen des Masterprogramm der Universidad Autonoma de Mexico (UAM) i.V.m. der Universität Barcelona (Spanien). Ciudad de Mexico, 9.-11.10.2003.

"Rechtsstaat und Staatskriminalität in Lateinamerika - Transformationsprozesse im Vergleich". Kolloquium "Estado de Derecho y delincuencia de Estado en América Latina. Procesos de transformación comparados". Hotel Maksoud Plaza, São Paulo/Brasilien, 23.2.2002.

Schlussbetrachtendes Referat. Kolloquium "Estado de Derecho y delincuencia de Estado en América Latina. Procesos de transformación comparados". Hotel Maksoud Plaza, São Paulo/Brasilien, 24.2.2002.

"Neue Fragen an den Satz 'Nullum crimen, nulla poena sine lege"'. Tagung der Internationalen Vereinigung für Rechts- und Sozialphilosophie (IVR) "Die Bedeutung P.J.A. Feuerbachs (1775-1833) für die Gegenwart". Jena, 16.3.2002.

Strafrecht in Reaktion auf Systemunrecht. Vergangenheitspolitik bei europäischen Transformationen. Tagung "Recht und Politik". Universität Nishnij Novgorod/Russland, 26.4.2002.

"Rache und Vergeltung oder Versöhnung und Amnestie". Schulvortrag im Rahmen der Jahresversammlung der Max-Planck-Gesellschaft. Halle, 11.6.2002.

"Verbrechensbegriff und völkerstrafrechtliche Tatbestände im neuen StGB Estlands". Tagung "Reform des Strafrechts in Estland". Universität Tartu/ Estland, 10.10.2002.

"Internationaler Strafgerichtshof - Instanz weltweiter Gerechtigkeit oder Instrument zur Durchsetzung politischer Interessen?" Vortrag zur Schlussdiskussion des 27. Strafverteidigertages "Internationalisierung des Strafrechts Fortschritt oder Verlust an Rechtsstaatlichkeit?" Hotel Bellevue, Dresden, 16.3.2003.

"Rache und Vergeltung oder Versöhnung und Amnestie". Schulvortrag im Rahmen der Jahresversammlung der Max-Planck-Gesellschaft. Hamburg, 3.6. 2003. 
Biehler, Anke

Cornils, Karin

Dorsch, Claudia
"Das Rückwirkungsverbot und der deutsch-deutsche Fall". Deutsch-Serbisches Kolloquium des Max-Planck-Instituts für ausländisches und internationales Strafrecht, Freiburg i.Br., 28.11.2003.

"Täter mit gutem Gewissen". Tagung "Explaining away the past". Norwegian Academy of Science, Oslo, 19.12.2003 (gemeinsam mit Julie Trappe).

"Eurojust und Europäischer Haftbefehl". Vortrag im Rahmen der Tagung "Eurocops". Evangelische Akademie Hofgeismar, 12.3.2002.

"Vergewaltigung als Mittel der Kriegsführung". Vortrag beim Deutschen Juristinnenbund, Freiburg i.Br., 9.4.2002.

Vorstellung des Gutachtens zum Grünbuch, Teilnahme an der Sitzung des Haushaltskontrollausschusses des Europäischen Parlaments. Straßburg, 13.5. 2002.

"Prozessuale Rechte des Angeklagten". Tagung über die Europäische Staatsanwaltschaft. Europäische Rechtsakademie Trier, 24.6.2002.

"La sécurité intérieure: une menace pour les libertés individuelles?" Vortrag im Rahmen der Europawoche zum Thema "L'Europe: un éspace de liberté, de sécurité et de justice?" des Institut d'études politiques de Strasbourg, des Europäischen Parlaments und des Centre des études européennes de Strasbourg, 21.3.2003.

"Perspectives for European Criminal Law". EU-China Legal and Judicial Cooperating Programme. Max-Planck-Institut für ausländisches und internationales Strafrecht, Freiburg i.Br., 10.9.2003.

"Gözütok und darüber hinaus: Die Entwicklung des Prinzips ne bis in idem in der Europäischen Union". Verbrechensbekämpfung in der EU: Die Unionspolitik nach dem Konvent. Europäische Rechtsakademie Trier, 24.10.2003.

"Juridiska personers straffansvar i tysk rätt". Strafferetslærerseminar 2002. Dänische Strafrechtslehrertagung. Sostrup, 29.8.2002.

"Organized Crime Policies in Denmark". International Conference "Organized Crime in Europe: Conceptions, Patterns and Policies in the European Union and Beyond". Freiburg i.Br., 1.3.2003.

"Komparativ straffrättsforskning". Nordisk workshop i strafferett 2003. Gesamtnordisches Doktorandenseminar. Skanderborg, 11.5.2003.

"Farliga sinnessjuka i tysk straffrätt". Strafferetslærerseminar 2003. Dänische Strafrechtslehrertagung. Rørvig, 28.8.2003.

u. Krüpe, Ch., "Rechtswirklichkeit und Effizienz der Überwachung der Telekommunikation nach den $\S \S 100 a, 100 b$ StPO". Vortrag im Rahmen des Seminars "Rechtliche und kriminalistische Probleme bei der Überwachung der Telekommunikation". Polizei-Führungsakademie Münster, 4.11.2003.

u. Krüpe, Ch., "Rechtswirklichkeit und Effizienz der Überwachung der Telekommunikation nach den $\S \S 100 a, 100 \mathrm{~b}$ StPO". Vortrag im Rahmen des Besuchs der serbischen Delegation hoher und höchster Richter, "Deutschserbisches Kolloquium". Max-Planck-Institut für ausländisches und internationales Strafrecht, Freiburg i.Br., 28.11.2003. 
Eser, Albin

(2002) u. Krüpe, Ch., "Praxis der Telefonüberwachung in Deutschland". Besuch einer Delegation chinesischer Staatsanwälte am MPI für ausländisches und internationales Strafrecht, Freiburg i.Br., 12.12.2003.

"Abortion in International Perspective". University of Texas School of Law, Austin/USA, 11.2.2002.

"Misconduct in Science: A German Lesson". Institute for the Medical Humanities, University of Texas Medical Branch, Galveston/USA, 12.2.2002.

"Abortion. An International Perspective: Report on a Comparative Research Project and Discussion of Legal Policy Issues". University of Houston Health Law \& Policy Institute in Zusammenarbeit mit der Health Law Organization, Houston/USA, 20.2.2002.

"The Status of the Embryo in Comparative Perspective. New Challenges to Law and Ethics by Modern Biomedical Techniques". Townsend Memorial Lecture at the University of Texas Medical Branch, Galveston/USA, 21.2. 2002.

"The Relationship between National and International Criminal Jurisdiction". Panel on the International Criminal Court at the University of Houston Law Center, Houston/USA, 22.2.2002.

"Perspectivas do Direito (Penal) Médico". Colóquio de Homenagem da Faculdade de Direito de Coimbra ao Professor Albin Eser "Novas Tarefas e Fronteiras do Direito (Penal) Médico" (Neue Aufgaben und Grenzen des Medizin(straf)rechts). Coimbra, 20.3.2002.

"La Nueva Evolución del Derecho Penal Económico". Abschlussvortrag im Rahmen des portugiesisch-brasilianischen Magisterkurses an der Universidade de Coimbra, 22.3.2002.

"The Lay Participation in Criminal Justice in Germany and in other Countries". Kolloquium der Athens Bar Association, der Marangopoulos Foundation for Human Rights und der Greek Association on Criminology über "Lay Participation in Criminal Justice in Europe (Prospects at the beginning of the 21st Century)". Athen, 15.4.2002.

"Brauchen wir ein europäisches Strafgesetzbuch?" Rechtspolitischer Kongress 2002 der Friedrich-Ebert-Stiftung "Recht schafft Zukunft. Gemeinsame Werte globales Recht". Karlsruhe, 27.4.2002.

Eröffnungsansprache und Schlußbetrachtungen zum Internationalen Kolloquium "Strafjustiz im Spannungsfeld von Fairness und Effizienz - Konvergente und divergente Entwicklungen im Strafprozeßrecht. Criminal Justice between Due Process and Crime Control - Convergence and Divergence in Criminal Procedure Systems". Tagungsstätte der Max-Planck-Gesellschaft, Schloss Ringberg, 8.-11.5.2002.

"Aktuelle Perspektiven transnationalen Strafrechts". "Rechtsraum Europa Perspektiven für die Harmonisierung" aus Anlass der Einweihung des Bundesministeriums der Justiz. Berlin 31.5.2002.

"Auf dem Weg zu einem neuen internationalen Strafgerichtshof: Entstehung und Grundzüge des Rom-Statuts". Universität Bern, 11.6.2002. 
"National Sovereignty and International Criminal Law". Training Course of the International Criminal Law Network (ICLN) and Science Alliance to ICTY and ICC. Den Haag, 17.6.2002.

Eröffnungsansprache und Schlußbetrachtungen zum Internationalen Kolloquium "Strafrechtsentwicklung in Osteuropa: Zwischen bewältigten und neuen Herausforderungen". Tagungsstätte der Max-Planck-Gesellschaft, Schloss Ringberg, 26.-29.6.2002.

"Der Internationale Strafgerichtshof. Seine Entstehungsgeschichte und die Grundzüge des Rom-Status". Nürnberger Menschenrechtszentrum aus Anlaß der Errichtung des IStGH am 1.7.2002. Nürnberg, 1.7.2002.

"Wahrheit und Wahrhaftigkeit in der Wissenschaft". Wissenschafts- und Publizistikpreisverleihung der GlaxoSmithKline Stiftung. München, 10.7.2002.

Eröffnungsansprache zum International Colloquium "Environmental Law and Criminal Penalties in EU Member States". Max-Planck-Institut für ausländisches und internationales Strafrecht, Freiburg i.Br., 16.-17.9.2002.

"Auf der Suche nach dem mittleren Weg: Zwischen Fundamentalismus und Beliebigkeit". Symposion der Philosophisch-Theologischen Hochschule in Vallendar/Rhein über "Bioethische Herausforderung" zum 70. Geburtstag von Prof. Rudolf Hasenstab. Vallendar, 4.10.2002.

"Harmonization of Penal Sanctions in Europe. Comparative Typology of Convergences and Divergences". Colloque International "L'harmonisation des sanctions pénales en Europe". Paris, 10.-11.10.2002.

"European Network on International Criminal Justice". Conference "European Research 2002" der European Commission - Community Research, Brüssel, 12.11.2002.

"Recommendations of GRECO's First Evaluation Round - An Assessment". Joint GRECO and MONEYVAL Seminar for Evaluators. Paphos/Zypern, 21.11.2002.

"The International Criminal Justice System: Complementarity between International and National Institutions". International Conference on "International Criminal Law: Quo vadis?" Istituto Superiore Internazionale di Science Criminali (ISISC), Siracusa/Italien, 29.11.2002.

"Wahrheit und Wahrhaftigkeit in der Wissenschaft". Studium Generale der Universität Lübeck, 5.12.2002.

(2003)

"Abortion Law in Comparative Perspective". Saint Louis University. Saint Louis/Missouri, 21.2.2003.

"Introducción". Seminario Internacional "Persecución penal nacional de crímenes internacionales desde una perspectiva comparada". Montevideo/ Uruguay, 27.2.2003.

"Counselling: A Third Way in Meeting Abortion". Columbia University, School of Law, New York, 4.3.2003.

"Between 'Pro Life' and 'Pro Choice': Findings of a Comparative Project on Abortion". Hastings Centre for Bioethics. Garrison/New York, 10.3.2003. 
"Towards International Criminal Justice: The Genesis and Main Features of the Rome Statute". Center of International Human Rights at the Yale Law School. New Haven/Connecticut, 26.3.2003.

"War Crimes - Genocide - Crimes Against Humanity: Challenges for International Criminal Justice". Oxford University European Affairs Society. Oxford/England, 14.5.2003.

"Vom Nürnberger Tribunal zum Internationalen Strafgerichtshof". Ökumenischer Kirchentag, Themenbereich "Wer die Vergangenheit vergisst, ist zu ihrer Wiederholung verurteilt". Ökumenischer Kirchentag, Berlin, 29.5.2003.

"Internationale Strafgerichtsbarkeit. Zu Vorgeschichte und Grundzügen des Rom-Statuts". III. Deutsch-Türkischer Juristentag über "Das Strafrecht der Europäischen Union". Goethe-Institut, Istanbul, 16.6.2003.

"En el camino hacia una Corte Penal Internacional: Formación y estructura del Estatuto de Roma". Conferencia Internacional "El Estatuto de la Corte Penal Internacional y sus Implicaciones en el Derecho Nacional de los Países Latinoamericanos". Ciudad de México, 18.8.2003.

"La interrupción del embarazo, análisis de derecho comparado". Congreso Internacional "Las Ciencias Penales en el siglo XXI", veranstaltet vom Instituto Nacional de Ciencias Penales (INACIPE) und der Mexican Academy of Criminal Sciences. Ciudad de México, 21.8.2003.

"Basic Functions and Structures of Criminal Proceedings from a Comparative Perspective". 17th International Conference of the International Society for the Reform of Criminal Law "Convergence of Criminal Justice Systems: Building Bridges - Bridging the Gaps". Den Haag, 25.8.2003.

"Research with Human Embryos and Stamcells: The Development in Germany in Comparative Perspective". Universität Warschau, 25.9.2003.

"Das Rom-Statut für einen internationalen Strafgerichtshof: Eine Herausforderung für die nationale Strafrechtspflege, exemplifiziert durch das deutsche Völkerstrafgesetzbuch". Universität Athen, 21.11.2003.

"General Concepts and Principles of International Criminal Law". Conference on The International Criminal Court and the Advent of International Criminal Justice. Jerusalem, 15.12.2003.

Gleß, Sabine

"Bleibt die größere EU sicher?" Perspektiven der EU-Erweiterung im Bereich der Zusammenarbeit Justiz und Inneres. Expertengespräch in der Stiftung Wissenschaft und Politik, Berlin 21.1.2002.

"Brauchen neue Vollzugsräume neue Kontrollformen? - zur Entrechtlichung europäischer Strafverfolgung". Vortrag anlässlich der Sitzung des Fachbeirats und des Kuratoriums, Freiburg i.Br. 1.3.2002.

"Wer kontrolliert die Kontrolleure?" Konferenz "Eurojust" der Europäischen Rechtsakademie (ERA), Trier, 22.3.2002.

"Funktion des 'Gerichts' im Ermittlungs- und Hauptverfahren". RingbergKolloquium: Strafjustiz im Spannungsfeld von Fairness und Effizienz, Schloss Ringberg, 9.5.2002. 
"Relations Between the European Prosecutor and the European Police Office (Europol)". Criminal Law Protection of the Financial interests of the Community and the Role of a European Public Prosecutor. Budapest, 31.5.2002.

"Analyse des Grünbuchs und der Anhörung". Kolloquium "Die Zusammenarbeit der Gemeinschaft und der Mitgliedstaaten zum Schutz der Finanzen Europas". Heidelberg, 5.10.2002.

"Conclusions". The Law of Evidence and Judicial Cooperation in the European Union. Europäische Rechtsakademie Trier, 26.11.2002.

"Zum Prinzip der gegenseitigen Anerkennung". Koreferat auf der außerordentlichen Strafrechtslehrertagung in Dresden, 7.-8.11.2003.

Großengießer, Helmut "Rule of Law - Einfluß der Strafrechtswissenschaft auf den ICC bzw. das Völkerstrafrecht". Tagung "Rule of Law - Herrschaft des Rechts - Ein Jahr Internationaler Strafgerichtshof"der Evangelischen Akademie Westfalen, Iserlohn, 5.7.2003.

Herz, Annette

"Menschenhandel in der Bundesrepublik Deutschland". Tagung "Prostitution - ein anerkannter Beruf? Perspektiven zur Bekämpfung der Menschenhandels als Geschäftsfeld der Organisierten Kriminalität". Katholische Akademie Trier, 12.-14.11.2003.

"Results of an Empirical Study: Criminal Prosecution of Trafficking in Human Beings". Conference "Traffing in Persons: Theory and Practice in Regional and International Cooperation". Vereinte Nationen, Office on Drugs and Crime. Bogotá, 19.-21.11.2003.

Hetz, Silke

"Der Status des extrakorporalen Embryos - Rechtliche Aspekte des Klonens". Fortbildungsseminar für Ärzte (Humangenetik). Freiburg i.Br., 25.6.2003

"Klonen". Zentrum für Ethik und Recht in der Medizin (ZERM). Freiburg i.Br., 16.7.2003

Huber, Barbara

"La lucha contra la corrupción desde una perspectiva supra-nazional". XIV. Congreso Universatorio de Alumnos de derecho penal. Salamanca/Spanien, 13.-15.3.2002.

"La lotta alla corruzione in prospettiva sopranazionale". Universität Macerata, 12.4.2002.

"Legal Measures to Curb Bribery in the Private Sector - Results of a Legal Study". International Chamber of Commerce, Paris 22.4.2002.

"Gli standards europei di tipo premediale - Collaboratori di giustizia ed agenti infiltrate". Centro Studi Giuridici: Criminalitá transnazionale fra esperienze europee e risposte penali globali. Lucca/Italien, 24.5.2002.

"The Tribunal for Serious Fraud - the European Experience". Tagung: Roskill revisited: Fraud Trials re-assessed. London, 5.10.2002.

"La lucha contra la corrupción desde una perspectiva supra-nazional". Universidad La Laguna, Tenerifa/Spanien, 28.10.2002.

"La cooperación judicial y policial en Europa - Una vision general". Universidad de Granada, Facultad de Derecho, Granada/Spanien, 12.5.2003. 
Jarvers, Konstanze

Jescheck,

Hans-Heinrich

Kaiser, Günther

Kania, Harald
"The Fight against Commercial Bribery by Supra-National Measures". Global Forum III on Fighting Corruption and Safeguarding Integrity. Seoul, 30.5. 2003

"La cooperación judicial y policial en Europa - Una vision general". Congresso Internacional "Las ciencias penales en el siglo XXI". Mexico City 22.8. 2003.

"La Responsibilità da reato delle persone giuridiche - El contesto sovranazionale europeo". Università degli Studi di Palermo, Facoltà di Giurispudenza, Palermo 10.10.2003.

"Rechtliche Rahmenbedingungen der Korruptionsbekämpfung in Europa". Internationale Fachtagung "Europäische Zusammenarbeit bei der Bekämpfung der Korruption". Landespolizeischule Rheinland-Pfalz, 15.12.2003.

"Profili generali dell'ordinamento giudiziario penale tedesco". Vorlesung "Organizzazione di polizia e ordinamento giudiziario". Universität Ferrara, 27.2.2002.

"Reati sessuali - I modelli sanzionatori previsti nel sistema tedesco". Meeting internazionale "Le libertà delle donne in Europa e nel mediterraneo". Baia della zagare/Italien, 7.6.2003.

"Zeugenschutz in Italien". Deutsch-Serbisches Kolloquium. Max-Planck-Institut für ausländisches und internationales Strafrecht, Freiburg i.Br., 28.11.2003.

Nuovi sviluppi nel diritto penale italiano, nel diritto penale europeo e nel diritto penale internazionale. Veranstaltung: Departamento di diritto penale dell'Università di Modena, Senatssaal, Modena, 12.10.2002.

Der Internationale Strafgerichtshof nach der Resolution des Sicherheitsrats der Vereinten Nationen vom 12.7.2002. Veranstaltung: Wiss. Reihe im Gemeindesaal der ev. Christuskirche in Freiburg i.Br., 23.2.2003.

Entstehung, Gründung und Aufbauphase des Instituts für Kriminologie der Universität Tübingen. Vortrag im Rahmen eines wissenschaftlichen Kolloquiums am Institut für Kriminologie der Universität Tübingen, 14.9.2002.

"'Das ist ja abscheulich!' - Wertvorstellungen, Kriminalitätsvorstellungen und (kriminelles) Handeln. Interdisziplinäres Symposion "Alltagsvorstellungen von Kriminalität". Universität zu Köln, 23.2.2002.

"Über die Darstellung von Kriminalität in den Massenmedien - oder: Wo findet eigentlich die 'wirkliche Kriminalität' statt?" Schulvortrag im Rahmen der 53. Jahreshauptversammlung der Max-Planck-Gesellschaft in Halle, 11.6.2002.

"Subjektive Kriminalitätstheorien - Alltagswissen und Vorstellungen über Kriminalität in der Bevölkerung". 43. Kongress der Deutschen Gesellschaft für Psychologie (DGPs). Humboldt-Universität Berlin, 25.9.2002.

"Alltagsvorstellungen über Kriminalität". Vortrag im Rahmen des Doktoranden-Kolloquiums am MPI für Strafrecht, Freiburg i.Br., 28.11.2002. 
Kilchling, Michael
"TV Crime Reports and the Construction of Individual Reality". Convegno internazionale "La rappresentazione televisiva del crimine". International Conference "The TV presentation of crime". Mailand, 15.5.2003.

u. Kury, H., Obergfell-Fuchs, J., "Worüber sprechen wir eigentlich, wenn wir über 'Punitivität' sprechen?". Symposion "Die neue Straflust" des Arbeitskreise Junger Kriminologen (AJK). Hamburg, 11.-13.9.2003.

"Empirische Erkenntnisse aus Kriminologie bzw. Viktimologie zur Lage von Opfern". Evangelische Akademie Bad Boll, 26.1.2002.

"Financial Counterterrorism Initiatives in Europe". International Conference: Legal Instruments in the Fight Against International Terrorism - A Transatlantic Dialogue. European Parliament, Brussels, 7.5. 2002.

"Comparative Review of the English, French and German Criminal Justice Systems". EU-China Legal and Judicial Programme. Academy of European Law Trier, 17.5.2002.

"Trends und Entwicklungen der deutschsprachigen Rechtstatsachenforschung im Bereich des Strafrechts seit Beginn der neunziger Jahre". Bundeskriminalamt, Wiesbaden, 13.6.2002.

"Potentieller und tatsächlicher Mehrwert von TOA und Wiedergutmachung in thematischer und empirischer Perspektive". Universität Saarbrücken, 14.6. 2002.

"Opferschutz und Strafrecht". Weisser Ring Baden-Württemberg. Gernsbach, 3.8. 2002.

"Praxis der Vermögensabschöpfung in Europa". Wiesbaden, 20.8.2002.

"Gewinnabschöpfung im europäischen Vergleich". Justizakademie NRW, Bad Münstereifel, 9.9.2002.

"Jugendstrafrecht in Europa". 64. Deutscher Juristentag, Berlin, 17.9.2002.

"Proofing of Policy and Legislative Proposals as a Tool to Counter Opportunities for the Financing of Terrorism". EU Forum on the Prevention of Organised Crime. Brussels, 29.10.2002.

"Vermögensbezogene Bekämpfungsstrategien in Europa - Organisierte Kriminalität und Terrorismus". Polizei-Führungsakademie Münster, 3.12.2002.

"Rechtsvergleichende Aspekte der Geldwäsche". Anti-Korruptionsseminar für chinesische Staatsanwältinnen und Staatsanwälte. Wiesbaden, 4.12.2002.

"Comparative Review of the English, French and German Criminal Justice Systems". EU-China Legal and Judicial Programme. Europäische Rechtsakademie Trier, 5.12.2002.

"Judicial Co-Operation in Criminal Matters in the EU". EU-China Legal and Judicial Programme. Europäische Rechtsakademie Trier, 6.12.2002.

"The Fights against Terrorism in the EU". EU-China Legal and Judicial Programme. Europäische Rechtsakademie Trier, 6.12.2002. 
"Vermögensbezogene Bekämpfungsstrategien in Europa - Organisierte Kriminalität und Terrorismus". Katholische Akademie Trier, 13.12.2002.

"Jugendstrafrecht in der Europäischen Union - heute", "Jugendstrafrecht in der Europäischen Union - morgen". Europäische Konferenz des österr. Bundesministeriums für Justiz zur Jugendstrafrechtspflege in Europa. Klagenfurt, 16.-17.1.2003.

Gewinnabschöpfung im europäischen Vergleich". Justizakademie NRW, Recklinghausen, 3.2.2003.

"Organized Crime Policies in Germany". International Conference: Organized Crime in Europe: Conceptions, Patterns and Policies in the European Union and Beyond. Freiburg i.Br., 27.2.2003.

"Profitorientierte Bekämpfung der Wirtschaftskriminalität". Katholische Akademie Trier, 11.4.2003.

"Opferschutz und der Strafanspruch des Staates - ein Widerspruch?" Deutsche Richterakademie Wustrau, 15.9.2003.

"Comparative Review of the English, French and German Criminal Justice Systems". EU-China Legal and Judicial Programme. Europäische Rechtsakademie Trier, 16.10.2003.

"Judicial Co-Operation in Criminal Matters in the EU". EU-China Legal and Judicial Programme. Europäische Rechtsakademie Trier, 17.10.2003.

"The Fights against Terrorism in the EU". EU-China Legal and Judicial Programme. Europäische Rechtsakademie Trier, 17.10.2003.

"Comparative Perspectives on Juvenile Justice Law in the European Union", Symposium on Juvenile Offending in Bosnia and Herzegovina, Jahorina, 29.10.2003.

"Non-Governmental Organisations and their Influence on Public Perceptions of Crime and its Control". 22nd Council of Europe Criminological Research Conference "Opinions, Attitudes and Images of Crime and its Control". Strasbourg, 25.11.2003.

"Finanzermittlungen als vermögensbezogene Strafverfolgungsstrategie bei Organisierter Kriminalität und Terrorismus". Fortbildungsseminar für chinesische Staatsanwältinnen und Staatsanwälte. Freiburg i.Br., 8.12.2003.

"Geldwäschekontrolle in Europa - von der Organisierten Kriminalität zum Terrorismus". Kongress "Bekämpfung der Geldwäsche 2003". Ueberreuter Managerakademie/Ostdeutsche Sparkassenakademie. Potsdam, 11.12.2003.

Kinzig, Jörg

"Nachträgliche" oder "vorbehaltene Sicherungsverwahrung - Tragfähiges Konzept oder populärer Aktionismus? 26. Strafverteidigertag. Mainz, 9.3.2002.

"Wohin mit den gefährlichen Kriminellen? Zur strafrechtlichen Behandlung 'unverbesserlicher Gewohnheitstäter'." Zwei Vorträge an weiterführenden Schulen in Sachsen-Anhalt (Halle, Hattstedt) anlässlich der Hauptversammlung der Max-Planck-Gesellschaft in Halle, 11. und 13.6.2002. 
Koch, Hans-Georg u. Luczak, A., "Organized Crime Today: Germany" International Conference "Organized Crime in Europe: Conceptions, Patterns and Policies in the European Union and Beyond". Freiburg i.Br., 28.2.2003.

"Not kennt kein Gebot? - Die strafrechtlichen Konsequenzen von Folterhandlungen an Tatverdächtigen durch Polizeibeamte mit präventiver Zielsetzung". Habilitationsvortrag an der Universität Freiburg i.Br., 17.7.2003.

"La situación del crimen organizado en Europa especialmente in Alemania". Congreso Internacional Las Ciencias Penales en el Siglo XXI. Mexico-City, 21.8.2003.

u. Luczak, A., "Organized Crime: Forfeiture and Confiscation of Criminal Assets in Germany". Vortrag anlässlich des Besuchs einer chinesischen Delegation im Rahmen des "EU-China Legal and Judicial Co-operation Programme". Freiburg i.Br., 10.9.2003.

"Die rechtliche Bewältigung von Erscheinungsformen organisierter Kriminalität". Vortrag vor der Staatsanwaltschaft Freiburg i.Br., 14.11.2003.

"Organisierte Kriminalität in Deutschland". Vortrag anlässlich des Besuches einer Delegation chinesischer Staatsanwältinnen und Staatsanwälte. Freiburg i.Br., 8.12.2003.

"Die Neuregelung des Schwangerschaftsabbruchs." Seminar "Grundlagen der Sozial- und Konfliktberatung bei Schwangerschaft". Pro Familia Bundesverband. Frankfurt, 15.2.2002.

"Juristische Probleme im Kontext der Stammzellforschung." Tagung "Menschenoptimierung?" Akademie für politische und soziale Bildung der Diözese Mainz in Kooperation mit dem Institut für Theologie und Sozialethik der TU Darmstadt. Heppenheim, 18.2.2002.

"Rechtsfragen des Schwangerschaftsabbruchs." Fortbildungsveranstaltung "Schwangerschaftskonfliktberatung". Akademie für ärztliche Fortbildung und Weiterbildung der Landesärztekammer Hessen. Bad Nauheim, 10.3.2002.

"Besondere rechtliche Aspekte des Schwangerschaftsabbruchs beim Erkennen von Missbildungen nach der 12. Schwangerschaftswoche." Fortbildungsveranstaltung "Schwangerschaftskonfliktberatung". Akademie für ärztliche Fortbildung und Weiterbildung der Landesärztekammer Hessen. Bad Nauheim, 10.3.2002.

"Zur rechtlichen Problematik von sogenannten Ersatzdrogen." 11. Medizinisch-Juristisches Kolloquium "Allgemeine Fragen aus Recht und Medizin". Akademie für ärztliche Fort- und Weiterbildung der Landesärztekammer Thüringen/Institut für Rechtsmedizin der Friedrich-Schiller-Universität Jena, 16.3.2002.

"Obhutspflicht im Krankenhaus - Haftungsrechtliche Aspekte." 11. Medizinisch-Juristisches Kolloquium "Allgemeine Fragen aus Recht und Medizin". Akademie für ärztliche Fort- und Weiterbildung der Landesärztekammer Thüringen/Institut für Rechtsmedizin der Friedrich-Schiller-Universität Jena., 16.3.2002. 
"Lebensbeginn und Lebensende als Probleme des Medizin(straf-)rechts". Kolloquium "Novas Tarefas e Frenteiras do Diereito (Penal) Médico", Faculdade de Direito da Universidade de Coimbra/Portugal, 21.3.2002.

"Patientenverfügung - Medizinrechtliche Aspekte." Fortbildungsreihe "Ethik in der Medizin". Ärztekammer Sachsen-Anhalt. Magdeburg, 27.4.2002.

"Doping im Rechtsvergleich." Seminar "Sport und Recht", el§a - The European Law Student's Association. Freiburg i.Br., 31.5.2002.

"Rechtsfragen von Lebensbeginn und Lebensende". Schulvortrag im Rahmen der Hauptversammlung der Max-Planck-Gesellschaft. Wolfen, 12.6.2002.

"Rechtliche Aspekte des Lebensbeginns." Fortbildungsveranstaltung des profamilia Landesverbands Sachsen. Leipzig, 13.6.2002.

"Sterbehilfe und Patientenverfügungen unter rechtlichen Aspekten". Seminar "Weiterbildung Psychosoziale Onkologie", Aufbaukurs Block 1. Freiburg i.Br., 21.6.2002.

"Rechtliche Problemfelder der Forschung mit nicht einwilligungsfähigen Personen in der Notfallmedizin". 3. Sommertagung des Arbeitkreises Medizinischer Ethik-Kommissionen in der Bundesrepublik Deutschland. Mainz, 29.6.2002.

"The patient's right to have easy access to healthcare." Seminar "Choices in Health Care". European Master in Bioethics. Freiburg i.Br., 24.9.2002.

"Aktuelle Rechtsfragen im Zusammenhang mit dem Schwangerschaftsabbruch." Fortbildungsveranstaltung "Schwangerschaftskonfliktberatung" (2. Teil: Erfahrungsaustausch). Akademie für ärztliche Fortbildung und Weiterbildung der Landesärztekammer Hessen. Bad Nauheim, 9.11.2002.

"Rechtsfragen der ärztlichen Schweigepflicht". Veranstaltungsreihe des Medizinisch-juristischen Arbeitkreises am LG Ulm. Ulm, 18.11.2002.

"Aktuelle Rechtsfragen im Zusammenhang mit genetischer Beratung". 17. Freiburger Tagung "Ethische und psychologische Grundlagen genetischer Beratung". Freiburg i.Br., 29.11.2002.

"Rechtliche Regelungen und Erfahrungen in Deutschland". Kolloquium "Natürliches Sterben oder verfügter Tod?" Kolloquium mit dem Beirat des ZERM. Freiburg i.Br., 30.11.2002.

"Gibt es ein Recht auf Sterbehilfe?" Presseintensivseminar "Die Sterbehilfe als gesellschaftliche Herausforderung: Kann die klinische Ethikberatung eine Hilfe sein?" Zentrum für Ethik und Recht in der Medizin. Freiburg i.Br., 5.12.2002.

"Rechtsfragen der Therapiebegrenzung." Tagung "Ethische Probleme in der Intensivtherapie". Landesärztekammer Thüringen. Jena, 7.12.2002.

"Moderne Medizin zwischen Prävention und Selektion - rechtliche Überlegungen." Vortragsreihe "Ethik - Molekulare Medizin - Behinderung". Ludwig-Maximilians-Universität München, 11.12.2002. 
"Rechtliche Aspekte der pränatalen Diagnostik". Institut für Humangenetik und Anthropologie, Albert-Ludwigs-Universität Freiburg i.Br., 18.12.2002.

"Der rechtliche Rahmen für Therapieverzicht in der Neonatologie". Arbeitsgemeinschaft südbadischer Neonatologen, Zentrum für Kinderheilkunde und Jugendmedizin im Universitäts-Klinikum Freiburg. Freiburg i.Br., 23.1.2003.

"Strafbarer und straffreier Schwangerschaftsabbruch nach dem SFHG". Seminar "Grundlagen der Sozial- und Konfliktberatung bei Schwangerschaft". Pro Familia Bundesverband, Eppenhain/Taunus, 14.2.2003 sowie Remagen/ Rolandseck, 5.9.2003.

"Sterbebegleitung zwischen Fürsorge und Selbstbestimmung aus rechtlicher Perspektive". Interdisziplinärer Kurs zur Medizinethik "Selbstbestimmung und Fürsorge am Lebensende". Katholische Akademie Mülheim/Ruhr, 12.3. 2003 .

"Ethikkonsile als Entscheidungshilfe?" Interdisziplinärer Kurs zur Medizinethik "Selbstbestimmung und Fürsorge am Lebensende". Katholische Akademie Mülheim/Ruhr, 12.3.2003.

"Rechtliche Fragen im Umgang mit Sterbenden". Interdisziplinärer Kurs zur Medizinethik "Selbstbestimmung und Fürsorge am Lebensende". Katholische Akademie Mülheim/Ruhr, 12.3.2003.

"Ist das Embryonenschutzgesetz noch zeitgemäß? - Medizinisch unterstützte Fortpflanzung aus rechtlicher Sicht". 12. Medizinisch-Juristisches Kolloquium der Akademie für ärztliche Fort- und Weiterbildung der Landesärztekammer Thüringen und des Instituts für Rechtsmedizin der FriedrichSchiller-Universität Jena. Jena, 15.3.2003.

"Ist eine Revision des Gesetzes zum Schwangerschaftsabbruch sinnvoll?" Arbeitskreis "Ärzte und Juristen" der AWMF. Frühjahrstagung. Würzburg, 5.4.2003.

"Aufklärungs- und Einwilligungsfragen bei neonatologischen Patienten". Arbeitskreis Südbadischer Neonatologen. Lörrach, 10.4.2003.

"Rechtsproblematik der Lebendorganspende in Deutschland". Klausurtagung der Ständigen Kommission Organtransplantation der Bundesärztekammer. Wildbad-Kreuth, 8.9.2003.

"Sterbehilfe zwischen Tun und Unterlassen - Überlegungen aus rechtlicher Sicht". Expertengespräch der DGHS. Düsseldorf, 19.9.2003.

"Sterbehilfe und Patientenverfügung unter medizinrechtlichen Aspekten". Hospiztage 2003. Freiburg i.Br., 15.10.2003 und Müllheim, 22.10.2003.

"Ethische und rechtliche Probleme in der Palliativmedizin". Fortbildungsveranstaltung "Palliativmedizin" der Bezirksärztekammer Südbaden. Freiburg i.Br., 22.10.2003.

"Therapeutische und nichttherapeutische Forschung bei Nichteinwilligungsfähigen: Rechtliche Voraussetzungen und Grenzen". 5. Jahreskongress für Klinische Pharmakologie. Rostock-Warnemünde, 31.10.2003. 
Kreicker, Helmut

Krüpe, Christiane

Kury, Helmut
"Rechtliche Aspekte der Organtransplantation". Fachtagung "Ersatzteillager Mensch - Hirntod und Organspende in der Diskussion". Caritas-Akademie Freiburg i.Br., 7.11.2003.

"Der kommerzielle Erwerb von Nieren". Ethische Gesprächsrunde. 16. Berliner Dialyseseminar. Berlin, 6.12.2003.

"Nationale Strafverfolgung von Kriegsverbrechen - Völkerrechtliche Pflichten und staatliche Möglichkeiten". Kriegsverbrechen. Kritische Bilanz der Ahndung von Kriegsverbrechen in den europäischen Rechtsordnungen. Genf, 17.5.2003.

"Das Projekt 'Nationale Strafverfolgung völkerrechtlicher Verbrechen' - Forschungskonzeption und erste Ergebnisse". Deutsch-Serbisches Kolloquium. Max-Planck-Institut, Freiburg i.Br., 28.11.2003.

u. Dorsch, C., "Rechtswirklichkeit und Effizienz der Überwachung der Telekommunikation nach den $\S \S 100 \mathrm{a}, 100 \mathrm{~b}$ StPO". Vortrag im Rahmen des Seminars "Rechtliche und kriminalistische Probleme bei der Überwachung der Telekommunikation". Polizei-Führungsakademie Münster, 4.11.2003.

u. Dorsch, C., "Rechtswirklichkeit und Effizienz der Überwachung der Telekommunikation nach den $\S \S 100 a, 100 b$ StPO". Vortrag im Rahmen des Besuchs der serbischen Delegation hoher und höchster Richter. "DeutschSerbisches Kolloquium". Max-Planck-Institut, Freiburg i.Br., 28.11.2003.

u. Dorsch, C., "Praxis der Telefonüberwachung in Deutschland". Besuch einer Delegation chinesischer Staatsanwälte am MPI für ausländisches und internationales Strafrecht, Freiburg i.Br., 12.12.2003.

"Kriminalitätsentwicklung in Ost- und Westdeutschland: Ursachen und Hintergründe" (Schulvortrag). 53. Jahreshauptversammlung der Max-PlanckGesellschaft. Halle/Saale, 11.-14.6.2002.

"Legislation, penal practice and attitudes to punishment in Germany". 2nd Conference of the European Society of Criminology. Toledo/Spanien, 4.7.9.2002.

"Sexual misuse as part of domestic violence: International results and methodological discussion". 64th International Course of Criminology der International Society of Criminology. Siena, Certosa di Pontignano/Italien, 7.9.11.2002.

"Victim Surveys. Registered Crime and Hidden Criminality. Research Methods and Findings about Crime. Impact of Social and Political Changes at the Traditional Criminality". 65th International Regional Seminar "New Tendencies in Crime and Criminal Policy in Central and Eastern Europe" of the International Society for Criminology. Miskolc/Ungarn, 11.-14.3.2003.

"Media and crime: Results from Germany on the influence of media on crimilnal behaviour". Internationale Konferenz zu "The TV presentation of crime", durchgeführt von der Universitá Cattolica del S.C. und der Universitá degli studie-Bicocca. Mailand, 14.-16.5.2003. 
"Wie werden Opfer von* (Sexual)Straftaten gesehen? - Zur Problematik der sekundären Viktimisierung". Tagung zu dem Thema "Geschlecht - Gewalt Gesellschaft" der Katholischen Universität Eichstätt-Ingolstadt, 3.-5.7.2003.

"Sexual Victimization of Female Students". 3rd Annual Conference of the European Society of Criminology. Helsinki, 27.-30.8.2003.

"Das Gesicht der Freiheitsstrafe - zur Insassenkultur im geschlossenen Strafvollzug für Männer". Vortrag bei der Richterakademie Wustrau, 8.9.2003:

"Was erfassen wir, wenn wir die Sanktionseinstellung messen? Wie aussagekräftig sind die Ergebnisse zur Punitivität?" Symposion "Die neue Straflust" des Arbeitskreise Junger Kriminologen (AJK). Hamburg, 11.-13.9.2003.

"Die Erschließung des Dunkelfeldes bei häuslicher Gewalt in Forschung und Prävention". Philipps-Universität Marburg, Fachbereich Medizin, Zentrum für Methodenwissenschaften und Gesundheitsforschung, Institut für Medizinische Soziologie und Sozialmedizin, Marburg, 5.11.2003.

"Evaluation - Woher wissen wir, was wirkt?" Fachwoche Straffälligenhilfe, organisiert vom Deutschen Caritasverband. Bergisch Gladbach, 25.11.2003:

"Das deutsche Recht der internationalen Rechtshilfe in Strafsachen". Justizministerium, Minsk, 12.6.2002.

"Entwicklung des strafrechtlichen Umweltschutzes in den osteuropäischen Ländern seit der politischen Wende". Tagung der Fachgruppe Recht der Deutschen Gesellschaft für Osteuropakunde. Salzburg, 3.10.2002.

"Probleme in Zusammenhang mit der deutschen Praxis im Bereich der internationalen Zusammenarbeit in Strafsachen". Justizministerium, Sofia, 18.10. 2002.

"Neue Tendenzen der internationalen rechtlichen Zusammenarbeit in Strafsachen". Oberstes Gericht der Republik Kroatien, Zagreb, 22.11.2002.

"Migration und Kriminalität in Deutschland". Polizeiakademie der Tschechischen Republik, Prag, 15.4.2003.

"Neue Tendenzen im Bereich der internationalen rechtlichen Zusammenarbeit in Strafsachen". Deutsch-transkaukasische Tagung über Kriminalität und Kriminalitätsprävention. Tbilissi, 19.5.2003.

"Aktuelle strafrechtliche Entwicklungen in Deutschland in bezug auf die Bekämpfung der OK, der Korruption und des Terrorismus". Internationale Tagung in der Generalstaatsanwaltschaft der Republik Bulgarien zum Thema Bekämpfung der OK, der Korruption und des Terrorismus. Sofia, 29.5.2003.

"Juristenausbildung in Deutschland und Aserbaidschan - ein Vergleich". Staatliche Universität, Baku, 29.9.2003.

"Aktuelle Entwicklungen im Bereich der internationalen Rechtshilfe in Strafsachen". Aserbaidschanische Internationale Universität, Baku, 1.10.2003.

Luczak, Anna

"Was ist organisierte Kriminalität? Bedeutung und Verwendung des Begriffs Beispiel England". Vortrag im Rahmen des Doktorandenkolloquiums. MaxPlanck-Institut, Freiburg i.Br., 29.1.2003. 
Maguer, Azilis

Manso Porto, Theresa modelos colombiano, español y alemán." Tagung: "III Seminario sobre Filosofía y Derecho Contemporáneo". Homenaje al Prof. Günther Jakobs. Universidad Externado de Colombia, 20.-23.3.2002.

"Efectos jurídico-penales del error de prohibición en los sistemas colombiano, español y alemán." Tagung: "III Seminario sobre Filosofía y Derecho Contemporáneo". Homenaje al Prof. Günther Jakobs. Universidad Externado de Colombia, 20.-23.3.2002.

"El 'blanqueo' como comportamiento delictivo. Modelos de regulación español y alemán; delimitación de las conductas punibles". Tagung "Las ciencias penales en el siglo XXI". Instituto Nacional de Ciencias Penales (INACIPE), Mexiko D.F., 22.8.2003.

Mayer, Markus

deutschen Polizeidienst". Seminar "Aktuelle Entwicklungen des Beamtenund Disziplinarrechts". Polizei-Führungsakademie Münster, 8.-10.1.2003.

"Modellprojekt zur Erprobung der elektronischen Überwachung - For- u. Kinzig, J., "Organized Crime Today - Germany". Vortrag bei der International Conference "Organized Crime in Europa: Conceptions, Patterns and Policies in the European Union and Beyond". Max-Planck-Institut, Freiburg 1.Br., 27.2.2003.

u. Kinzig, J., "Treatment of Assets: Money Laundering, Confiscation, Restitution and Repatriation of Funds". Vortrag im Rahmen des EU-China Legal and Judical Co-operation Programme. Max-Planck-Institut, Freiburg i.Br., 10.9.

"Economic and Organized Crime: Forfeiture and Confiscation of Unlawfully Workshop "Current Issues in Criminal Law". Max-Planck-Institut, Freiburg i.Br., 30.10.2003. schungskonzeption". Vortrag im Rahmen der Einführung in die empirische Sozialforschung (Methoden I). Institut für Soziologie, Universität Freiburg i.Br., 16.1.2002.

"Benefits and Problems of Electronic Monitoring". Vortrag im Rahmen des European Workshop "Will Electronic Monitoring Have a Future in Europe?" Freiburg i.Br., 13.-15.6.2002.

"Ergebnisse der Begleitforschung zum Modellprojekt Elektronische Fußfessel". Podiumsdiskussion der Bewährungshilfe bei dem Landgericht Darmstadt, 18.10.2002.

"Das Hessische Modellprojekt zur Erprobung der elektronischen Überwachung - Forschungskonzeption und erste Befunde". Vortrag im Rahmen der Einführung in die empirische Sozialforschung (Methoden I). Institut für Soziologie, Universität Freiburg i.Br., 3.12.2002.

"Der hessische Modellversuch zur Anwendung der 'elektronischen Fußfessel"". Vortrag im Rahmen der Fachtagung "Neue Konzepte der Kriminalpolitik" der Kriminologischen Zentralstelle, Wiesbaden, 7.-9.5.2003. 
Meyer, Jürgen

Mohr, Tilmann

Namgalies, Clivia

Nogala, Detlef
"Electronic Monitoring in Germany" Vortrag im Rahmen des deutschamerikanischen Workshops "Current Issues in Criminal Law". A cooperative effort involving the Max Planck Institute, the Carl Schurz Haus (Freiburg), the Bavarian American Academy (Munich), and the Fulbright Senior Specialist Program (Washington, D.C.). Freiburg i.Br., 30.10.2003.

"Das Hessische Modellprojekt zur Erprobung der elektronischen Überwachung - Pädagogische Fragen". Vortrag im Rahmen einer Fortbildungsveranstaltung für die Bewährungshilfe Offenburg und Baden-Baden. Offenburg, 6.11.2003.

"Das Hessische Modellprojekt zur Erprobung der elektronischen Überwachung - Befunde der Begleitforschung". Vortrag im Rahmen der Einführung in die empirische Sozialforschung (Methoden I). Institut für Soziologie, Universität Freiburg i.Br., 3.12.2003.

"Modellversuch elektronische Fußfessel in Hessen". Besuch einer Delegation chinesischer Staatsanwälte am MPI für ausländisches und internationales Strafrecht, Freiburg i.Br., 10.12.2003

"Die künftige Europäische Verfassung und das Strafrecht". Max-PlanckInstitut für ausländisches und internationales Strafrecht, Freiburg i.Br., 28.10. 2003.

"Opphold ved Max-Planck-Instituttet som gjesteforsker". Nordisk workshop i strafferet. Gesamtnordisches Doktorandenseminar. Skanderborg, 11.5.2003 (auf Norwegisch).

"System Crime/Transitional Justice" Vortrag im Rahmen des deutsch-amerikanischen Workshops "Current Issues in Criminal Law" - A cooperative effort involving the Max Planck Institute, the Carl Schurz Haus (Freiburg), the Bavarian American Academy (Munich), and the Fulbright Senior Specialist Program (Washington, D.C.). Freiburg i.Br., 30.10.2003.

"Die neue Verpolizeilichung der Gesellschaft - Sicherheitsarbeit in der neoliberalen Ordnung". 13. AKIS-Workshop: "Kustodalisierung der Inneren Sicherheit - Wachen, kontrollieren, patrouillieren". Universität Osnabrück, 16.2. 2002.

"Sudden Precipitations of Risk Flows: Virtuality and the Hot Emergency Society". ESRC Seminar "Immaterial Crimes, Policing Immateriality". University of Leeds, 12.4.2002.

"Die Polizei und das Polizieren - Über Ordnung in kleinen und großen Welten". Institut für Konflikt- und Gewaltforschung. Universität Bielefeld, 22.4. 2002.

"Horst Herold and his philosophy of police prevention". 2nd European Society of Criminology Conference. Toledo/Spanien, 6.9.2002.

"Policing in Europe and European Policing - What do Criminologists really know?" 2nd European Society of Criminology Conference. Toledo/Spanien, 7.9.2002. 
Obergfell-Fuchs, $J$.

Oberwittler, Dietrich
"Overcoming the Barriers of Policing - Civil liberties as collateral damage of transnational crime fighting?" 3. Tagung der Arbeitsgemeinschaft europäischer Rechtsethnologen (READ-AGERE): Reorganisation oder Ende der Rechtsstaatlichkeit? Universität Rostock, 15.11.2002.

"State, Market, Civil Society: Mixing the Economy of Policing Anew? - Observations from Germany and Continental Europe". In Search of Security: An international conference on policing and security. Montreal, 21.2.2003.

"To be on someone's side - Kriminologische Wissenschaft zwischen Ordnung und Interesse". Tagung der Gesellschaft für interdisziplinäre wissenschaftliche Kriminologie (GIWK). Wien, 13.3.2003.

"Outline of the CEPOL Research and Science Database". CEPOL - Research and Science Committee Meeting with the National Contact Persons. Kopenhagen, 11.6.2003.

"For Security's Sake: Diversification and Centralisation - Pillars and Layers of Policing in Post-Welfare Germany". International Workshop: Policing: Comparative Perspectives. Université de Grenoble, 20.6.2003.

"Soziohysterie und Punitivität - sozial-und massenpsychologische Aspekte einer kriminologischen Konzeption". AJK-Tagung "Neue Straflust". Rissen bei Hamburg, 11.9.2003.

"Structure of CEPOL's Research \& Science Database". European Police Research Conference "Interplay between Research - Education - Practice". Solna/Schweden, 3.12.2003.

"Behandlung und Prognose bei Sexualstraftätern". Schulvortrag anlässlich der 53. Jahresversammlung der Max-Planck-Gesellschaft". Wolfen, 16.6.2002.

"Viktimologie". Seminar "Professioneller Umgang mit Opfern" der Akademie der Polizei Baden-Württemberg, Freiburg i.Br., 4.6.2002 und 26.6.2002.

"Erstellung von Kriminalitätsprognosen". Seminar "Strategische Kriminalitätsanalyse" der Akademie der Polizei Baden-Württemberg. Freiburg i.Br., 26.7.2002.

"Treatment and instruction of social and vocational skills in prisons". Seminar on activities for prisoners of the Council of Europe. Istanbul, 6.3.2003.

u. Albrecht, H.-J., "Gewalt, Delinquenz und Sucht". 15. Internationaler Suchtkongress "Traumatisierung und Sucht". Hamburg, 11.9.2003.

u. Kury, H., Kania, H., "Worüber sprechen wir eigentlich, wenn wir über 'Punitivität' sprechen?" AJK-Symposium "Neue Straflust". Hamburg, 12.9.2003.

"Recovering from sexual victimization - the role of victim services". "The challenge of practice, the benefits of theory". Annual Conference of the American Society of Criminology. Denver, 21.11.2003.

"Was bringt die Einbeziehung des Raumes in kriminologische Erklärungsmodelle?" Gemeinsame Tagung des Max-Planck-Instituts und des Kriminologischen Forschungsinstituts Niedersachsen. Freiburg i.Br., 20.3.2002. 
Ortmann, Rüdiger

Paoli, Letizia
"Perspektiven der Kriminalprävention und ihrer Vernetzung". Sicherheit und Ordnung. Aufgabe von Staat, Kommunen und Bürgern. Seminar des Deutschen Instituts für Urbanistik, Berlin, 12.6.2002.

"Ecological Context Effects on Juvenile Offending - Conditional Impacts of Neighborhoods and Schools." American Society of Criminology Annual Meeting. Chicago, 15.11.2002.

"Arbeitslosigkeit und ihre Auswirkungen auf die Kriminalitätsgefährdung Jugendlicher mit Migrationshintergrund". 8. Deutscher Präventionstag. Hannover, 28.4.2003.

"Interaktionen von Geschlecht, Ethnizität und sozialräumlicher Benachteiligung bei Gewalt und schwerer Delinquenz von Jugendlichen." Geschlecht Gewalt - Gesellschaft. Gegenwartsdiagnosen (Otto-von-Freising-Tagung der Katholischen Universität Eichstätt-Ingolstadt). Eichstätt, 10.7.2003.

"The Common Good: A multilevel analysis of social capital and collective efficacy in urban and rural communities". 5th Conference of the International Society for Quality-of-Life Studies. Frankfurt, 23.7.2003.

"Armut macht Angst: Soziale Probleme, Kriminalitätsfurcht und 'kollektive Wirksamkeit' in Wohnquartieren". Sicherheit und soziale Kontrolle in Städten. Gemeinsame Tagung der DGS-Sektionen Soziale Probleme und soziale Kontrolle und Stadt- und Regionalsoziologie. Universität Oldenburg, 24.10. 2003.

"Jugenddelinquenz und Stadtstruktur: Eine Mehrebenenanalyse zu sozialökologischen Kontexteffekten". Forschungskolloquium am Institut für Soziologie der Universität Bielefeld, 9.12.2003.

"Hauptaufgaben der Forschung in der Anlage und Durchführung einer Evaluationsstudie zur Sozialtherapie bei Sexualstraftätern". Vortrag vor dem Arbeitskreis der Psychologen der sozialtherapeutischen Abteilungen und Vertretern des Justizministeriums des Freistaates Sachsen. JVA Waldheim, 23.8.2002.

"Auswahl und Diagnose kriminogener Merkmale als Hauptaufgabe einer theoriegestützten sozialtherapeutischen Behandlung von Sexualstraftätern und einer Evaluation der Behandlung". Workshop des Arbeitskreises der Psychologen der sozialtherapeutischen Abteilungen des Freistaates Sachsen, Tagungsstätte des JM Sachsen. Dresden, 3.-4.9.2002 (3.9.2001).

"Verbrechensfurcht und organisierte Kriminalität: 'Die Russen-Mafia'". Symposion: "Alltagsvorstellungen von Kriminalität". Universität Köln, 23.2.2002.

"The Mafia in Italy and the United States". Law School, University of New York, 21.3.2002.

"Mafia and Organized Crime". "G. Beto Lecture". Criminal Justice Center, Sam Houston State University, Huntsville, 27.3.2002.

"The Fight Against the Mafia in Italy: Lessons for the United States". Criminal Justice Center, Sam Houston State University, Huntsville, 28.3.2002

"The Price of Freedom: Illegal Drug Markets and Drug Policies in Post-Soviet Russia". Criminal Justice Center, Sam Houston State University, Huntsville, 1.4.2002. 
"'The Invisible Hand of the Market': Illegal Drug Trade in Germany, Italy, and Russia". Criminal Justice Center, Sam Houston State University, Huntsville, 2.4.2002.

"The Mafiosi as Rational Entrepreneurs?" Department of Sociology, Sam Houston State University, Huntsville, 3.4.2002.

"Cannabis - Entpönalisierung?" Fachtagung: "Cannabispolitik im europäischen Vergleich". Grüne Bundestagsfraktion. Berlin, 3.6.2002.

"Il 'pacchetto giudiziario' - Reformbedarf für die italienische Justiz". Expertentagung der Hanns-Seidel-Stiftung: "'Tra un anno faremo una verifica' - Das erste Jahr der Berlusconi-Regierung". Wildbad Kreuth, 13.6.2002.

"Modeling the World Heroin Market: Project Rationale and Conference Goals". First Working Conference: "Modeling the World Heroin Market: Assessing the Consequences of Changes in Afghanistan Production". Freiburg i.Br., 13.9.2002.

"Moving into Terra Incognita: Knowledge Gaps and Makeshift Research Methods". First Working Conference: "Modeling the World Heroin Market: Assessing the Consequences of Changes in Afghanistan Production". Freiburg i.Br., 13.9.2002.

"Mafia and Organised Crime in Italy". International Conference: "Organised Crime in Europe: Conceptions, Patterns and Policies in the European Union and Beyond". Freiburg i.Br., 28.2.2003.

"Modeling the World Heroin Market: Project Rationale and Conference Goals". Second Working Conference: "Modeling the World Heroin Market: Assessing the Consequences of Changes in Afghanistan Production". Istanbul, 24.6.2003.

"What We Do Not Know and How We Might Learn It". Second Working Conference: "Modeling the World Heroin Market: Assessing the Consequences of Changes in Afghanistan Production". Istanbul, 24.6.2003.

"Organisierte Kriminalität in Italien". Deutsch-Serbisches Kolloquium. MaxPlanck-Institut, Freiburg i.Br., 28.11.2003.

Rabenstein, Christiane "Criminal Sanctions - Reform Proposals in Germany and England from a Comparative Perspective". Konferenz "Sentencing and Society". Centre for Sentencing Research. University of Strathclyde, Glasgow/Schottland, 27.29.6.2002.

"Deprivation of Liberty and Life Sentences". Konferenz der International Society for the Reform of Criminal Law "Convergence of Criminal Justice Systems: Building Bridges - Bridging the Gaps". Den Haag, 24.-28.8.2003.

Richter, Thomas

"Freiheit der Meinungen und ihre (grundrechtliche) Absicherung in der Volksrepublik China". Göttingen, 7.11.2002.

Constitutional and Procedural Questions about the Requirement of Judicial Authority in Germany and China. Sino-German Symposium on Compulsory Measures. Beijing 25.2.2003. 
Rohne, Holger-Ch. "Intracultural approaches to violent conflicts and their victimological significance - A research in the context of the Israeli-Palestinian Conflict". Präsentation am Expertenseminar "Alternative Means to Retributive Justice in Violent Conflicts in the Middle East". Istanbul, 6.12.2003.

Sieber, Ulrich

Silverman, Emily

"Criminality and Non-Prosecution Policies". European Science for Japanese Students. Albert-Ludwigs-Universität, Freiburg i.Br., 20.3.2003.

"Deguo xingfa lilun tixi de jieshao". Fanzui lilun tixi guoji yantaohui. Shandong University/China. 15.11.2003.

"Deguo he Zhongguo de xingfa jiegou zhi bijiao". Shandong University/ China. 19.11.2003.

"Rechtliche Risiken und rechtliche Bewertung". Fachkonferenz "Sicherheit und Schutz in der Informationsgesellschaft des Münchner Kreises". München, 18.9.2003.

"Rechtsinformatik". Vortrag an der Ludwig-Maximilians-Universität München, 15.10.2003.

"Ein passendes Strafrecht für den Raum der Freiheit, der Sicherheit und des Rechts: Aufgaben für die Rechtswissenschaft". Vortrag auf Einladung der "Europäischen Rechtsakademie Trier" über "Verbrechensbekämpfung in der Europäischen Union: Die Unionspolitik nach dem Konvent". Trier, 23.-24.10. 2003 (23.10.).

Erstattung eines mündlichen Sachverständigengutachtens in dem laufenden Nicolic-Verfahren beim internationalen Strafgerichtshof für das ehemalige Jugoslawien (ICTY) über "The Punishment of Serious Crimes". Den Haag, 4.5.11.2003 (5.11.).

"Legal Compliance im Jugendschutzrecht". Vortrag anlässlich des Round Table Gesprächs "Jugendschutzrichtlinien für Seitenbetreiber und Suchmaschinen" der Coolspot AG Düsseldorf. Frankfurt, 14.11.2003.

"Internetkriminalität". Vortrag anlässlich des Besuchs chinesischer Staatsanwälte im Max-Planck-Institut für ausländisches und internationales Strafrecht. Freiburg i.Br., 16.12.2003.

"Strafzumessungsrichtlinien in den Vereinigten Staaten". Drei-Länder Seminar: Strafrechtliche Sanktionensysteme im Vergleich. Universität Freiburg i.Br., Strobl/Österreich, 31.5.2002.

"Restitution und Victim-Offender-Mediation im US-Amerikanischen Recht". Neue Wege der Haftvermeidung. Universität des Saarlandes, Saarbrücken, 15.6.2002.

"What is the Max Planck Institute: A Brief Overview". Current Issues in Criminal Law: A German-American Workshop. Max-Planck-Institut, Freiburg i.Br., 30.10.2003. 
Simon, Jan-Michael
"Las reacciones del Derecho Penal frente a crimines del Estado en Guatemala" (1. Vortrag) und "La Comisión para el Esclarecimiento Histórico" (2. Vortrag). Kolloquium "Estado de Derecho y Delincuencia de Estado en América Latina. Procesos de Transformación Comparados". Hotel Maksoud Plaza, São Paulo/Brasilien, 22.-24.2.2002. =

www.iuscrim.mpg.de/forsch/straf/docs/Simon_Lectures_4x.pdf www.iuscrim.mpg.de/forsch/straf/docs/Simon_Lectures_5x.pdf.

"State-sponsored violence". Konferenz "European Criminology: sharing borders, sharing a discipline". Annual Conference of the European Society of Criminology. Universität Castilla-La Mancha, Toledo/Spanien, 5.-7.9.2002 = www.iuscrim.mpg.de/forsch/straf/docs/Simon_Lectures_\%206_7x.pdf.

"State-sponsored mass violence: criminal accountability and 'reconciliation"'. Konferenz "Penal responsibility in liberal democratic systems". Foundation IUS ET LEX, Universität von Warschau, Warschau/Polen, 27.-29.9.2002.

"Jurisdição penal internacional". Seminar "VIII Seminário Internacional do Instituto Brasileiro de Ciências Criminais". Hotel Maksoud Plaza, São Paulo/ Brasilien, 8.-11.10.2002.

"Das Weltrechtsprinzip. Nationale Verfolgung völkerrechtlicher Verbrechen". Tagung "Ende der Straflosigkeit? Erwartungen an den Internationalen Strafgerichtshof". Haus Schwanenwerder/Adam-von-Trott-Haus, Berlin-Nikolassee, 8.-9.11.2002

= www.iuscrim.mpg.de/forsch/straf/docs/Simon_Lectures_8x.pdf.

"Violencia masiva patrocinada por el Estado: Responsabilidad criminal y 'reconciliación'". Seminar "Teoría y práctica en juicios penales por genocidio y delitos de lesa humanidad en México y en el mundo". Senat der Republik. Mexiko D.F., 28.1.2003

=www.iuscrim.mpg.de/forsch/straf/docs/Simon_Lectures_9x.pdf.

"Strafrechtliche Verantwortlichkeit und Versöhnung. Erfahrungen zum Umgang mit politischer Massengewalt". Tagungsreihe "Internationale Gerichtsbarkeit gegen Kriegsverbrechen? Der Strafgerichtshof in Den Haag und das Jugoslawien-Tribunal". Berliner Rathaus, Berlin, 3.7.2003

= www.iuscrim.mpg.de/forsch/straf/docs/Simon_Lectures_11.pdf.

"Violencia y reconciliación. El papel del Derecho Penal en situaciones extremas" (1. Vortrag) und Kommentar "Las reformas procesales sucedidas a lo largo de la década de los noventa en América Latina" (2. Vortrag). Kongress "Las Ciencias Penales en el Siglo XXI". Hotel Radisson Paraíso, Mexiko D.F., 20.-27.8.2003.

"Responsabilidad Criminal y Reconciliación. El Derecho Penal frente a la violencia política masiva en Sudáfrica, Ruanda y El Salvador". Seminar "La Corte Penal Internacional. Instrumento de paz para Colombia". Hotel Dann Carlton, Bogotá/Kolumbien, 16.-17.9.2003.

"Procesos de paz en Colombia y Corte Penal Internacional. Breves apuntes sobre el Proyecto de Ley No. 85/03 S". Tagung "Justicia y reparación en el marco de procesos de paz". Universität Javeriana, Bogotá/Kolumbien, 18.11.2003 = www.iuscrim.mpg.de/forsch/straf/docs/Simon_Lectures_12.pdf. 
Tellenbach, Silvia

Tränkle, Stefanie
"The semantics of reconciliation and criminal responsibility: a case study". Seminar "Experts' Seminar on alternative means to retributive justice in violent conflicts in the Middle East". Hotel La Martine/ Bahçeşehir-Universität Istanbul, 4.-7.12.2003.

"Islamisches Recht und deutsches Umfeld. Streiflichter auf ein bisweilen schwieriges Verhältnis." Vortragsreihe des deutsch-türkischen Freundeskreises e.V. Freiburg i.Br. 22.3.2002.

"Islam Hukukunda Terörle Mücadele"(Terrorbekämpfung im islamischen Recht). Tagung Terör, Örgütlü Suçla Mücadele ve İnsan Hakları (Terror, Kampf gegen die OK und Menschenrechte), veranstaltet von der Universität İzmir u.a. Çeşme 18.4.2002.

"Zur Änderung der türkischen Verfassung von 1982 durch das Gesetz Nr. 4709 vom 3.10.2001". Jahrestagung des Arbeitskreises für Überseeische Verfassungsvergleichung. Halle, 29.6.2002.

"Das Religionsprivileg im Vereinsrecht und seine Streichung". Koexistenz und Konflikt von Religionen in Europa (Tagung im Rahmen der Projektreihe MPG 2000+). Halle, 29.11.2002.

"Die Strafe im islamischen Recht". Internationale Vereinigung für Rechtsphilosophie - Untersektion Bayern. München, 23.1.2003.

"Rechtsverständnis und politischer Alltag in der Türkei". 8. Bundeskongress der Bundeszentrale für politische Bildung, Dialog der Kulturen, Ethnien und Religionen - Herausforderungen an die politische Bildung. Braunschweig 6.8.3. (7.3.2003).

"La riparazione del danno da reato nel diritto penale islamico". Universität Teramo, 10.3.2003.

"Zur Strafrechtspflege in der Islamischen Republik Iran". Symposion über "Strafrecht im Islam und Recht im Iran". Jahrestagung der Gesellschaft für Arabisches und Islamisches Recht. Freiburg i.Br., 10.10.2003.

"Fundamental Principles of Islamic and Western Criminal Law - A Comparative Analysis", Tagung zum Thema Islamic Law and Contemporary issues in International Law: The Use of Force, veranstaltet von der Middle East Association of International Law. Amman, 2.12.2003.

"Islamic Criminal Law Unveiled". K.U.Leuven, 8.12.2003.

"Konfliktbearbeitung in der Strafrechts-Mediation". Tagung Angewandte Gesprächsforschung. Arbeitskreis Angewandte Gesprächsforschung. Zürich, 23.11.2002.

"La médiation pénale en Allemagne et en France". Centre d'Études Sociologique sur le Droit et les Institutions Pénales (CESDIP), Paris, 25.2.2003.

Leitung einer Datensitzung. Arbeitstagung zur Gesprächsforschung. Institut für Deutsche Sprache. Mannheim, 3.4.2003.

"Victim-Offender Mediation in Germany: Ideals meet Reality". Weltkongress der International Society of Criminology. Rio de Janeiro, 14.8.2003. 
Trappe, Julie

Weigend, Ewa

Wößner, Gunda

Zerbes, Ingeborg
"La médiation pénale en Allemagne: le paradoxe de la gestion d'une procédure pénale hors du cadre judiciaire". "Médiation(s) et politique(s)", organisiert von Jacques Faget, CERVL-CNRS. Universität Bordeaux, 16.10.2003.

"Normativität und Kontextualität des Rechts - strafrechtliche Vergangenheitsaufarbeitung in Rumänien nach 1989". Tagung "Rechtsforschung als disziplinübergreifende Herausforderung". Max-Planck-Institut für ethnologische Forschung, Halle, 2.-3.6.2003.

"Die neuesten Entwicklungen im deutschen und polnischen Strafprozessrecht". Universität Ljubljana/Slowenien, 16.6.2003.

"Die neuesten Entwicklungstendenzen im deutschen Strafprozess am Beispiel des Vorverfahrens" (polnisch). Universität Warschau, 26.6.2003.

"Die Vorbereitung auf den Anwaltsberuf vor dem Hintergrund der deutschen Juristenausbildung" (polnisch). Sitzung des polnischen Obersten Anwaltsrats, Warschau, 30.6.2003.

"Strafbarkeit der Kollektivsubjekte im deutschen Recht" (polnisch). Konferenz "Strafbarkeit von Kollektivsubjekten". Jastrzębia Góra/Polen, 13.10.2003.

"Teilnahme der Medien im deutschen Strafprozess" (polnisch). Konferenz "Das Recht auf Privatheit und die Medien" der polnischen Datenschutzbeauftragten. Warschau, 20.10.2003.

"Erste Ergebnisse empirischer Forschungen zu Tätertypen". Kommerzielle sexuelle Ausbeutung von Kindern. Katholische Akademie Trier, 14.3.2002.

"Treatment, Treatability and Typologies of Sex Offenders - an Expert Survey" (Poster). 7th Conference of the International Association for the Treatment of Sexual Offenders. Wien, 11.-14.9.2002.

"Differentialdiagnostische Typisierung von Sexualstraftätern". 10. Arbeitstagung der Fachgruppe Rechtspsychologie der Deutschen Gesellschaft für Psychologie. Berlin, 26.9.2003.

"Die OECD-Konvention gegen transnationale Bestechung im internationalen Geschäftsverkehr". Studientagung "Korruption" für Polizeibeamte, Richter und Staatsanwälte. Katholische Akademie Trier, 24.9.2003. 


\section{Beteiligung an der Lehre}

\section{- Lehrveranstaltungen}

Albrecht: WS 2001/02, Vorlesung "Kriminologie I", Universität Freiburg; Kriminologisches Blockseminar "Cybercrime and Cybercrime-Kontrolle", MPI Freiburg, 25.1. 2002.

SS 2002, Vorlesung "Kriminologie II" Universität Freiburg, Kriminologisches Blockseminar "Innere Sicherheit und Kriminalitätsentwicklung: Neuere Untersuchungen zu Tendenzen in Kriminalität und Kriminalitätskontrolle", MPI Freiburg, 3.7.2002.

WS 2002/03, Vorlesung "Strafvollzugsrecht" Universität Freiburg, Kriminologisches Blockseminar "Informationstechnologie, Strafrecht und Strafverfahrensrecht", MPI Freiburg, 17.1.2003.

SS 2003, Vorlesung "Jugendstrafrecht" Universität Freiburg; Kriminologisches Blockseminar "Terrorismus: Entwicklung, Erklärung und rechtspolitische Antworten", MPI Freiburg, 11.7.2003.

"Die Bekämpfung der Geldwäsche in der Kreditwirtschaft". Seminarreihe Europäisches Strafrecht. Bahçeşehir-Universität Istanbul, 4.-7.11.2003.

Ambos: SS 2003: Vorlesung Strafrecht II, 5-stündig; Vorlesung "Einführung in das internationale Strafrecht", 1-stündig; Seminar "Europäisches Strafrecht", Blockveranstaltung;

WS 2003/04: Vorlesung Strafrecht I, 5-stündig; Vorlesung "Europäisches Strafrecht", 1stündig; Seminar "Strafrecht vor neuen gesellschaftlichen Herausforderungen, alle Universität Göttingen.

"Derecho Penal Internacional". 20-stündiger Kurs im Rahmen des Masterprogramms der Universidad Salamanca/Spanien in Mar del Plata/Argentinien), 10.-13.4.2002.

"Corte Penal Internacional". 8-stündiger Fortbildungskurs. Poder Judicial de la Província de Neuquén/Colégio de Abogados, Neuquén/Argentina, 20.8.2002.

"Direito processual penal comparado e internacional". 15-stündiger Kurs in der "Especialização em Direito Processual Penal 2002". Pontifícia Universidade Católica do Paraná, (Curitiba/Brasil), 23.-24.8.2002.

"Derecho Penal Internacional". 2mal 15-stündiger Kurs im Rahmen des Masterprogramm der Universidad Autonoma de Mexico (UAM) i.V.m. der Universität Barcelona (Spanien). Ciudad de Mexico, 7.-9.10. und 10.-12.10.2002.

"Derecho Penal Internacional". 15-stündiger Kurs im Rahmen des Masterprogramm der Universidad Autonoma de Mexico (UAM) i.V.m. der Universität Barcelona (Spanien). Ciudad de Mexico, 9.-11.10.2003.

Arnold: WS 2001/02: Seminar "Wirtschaftsstrafrecht und Wirtschaftskriminologie" mit Prof. Nelles und Prof. Boers (2-stündig).

SS 2002: Seminar "Jugend- und Drogenkriminalität" mit Prof. Boers (2-stündig).

WS 2002/03: Seminar "Wirtschaft, Kriminalität und Strafrecht" mit Prof. Nelles und Prof. Boers (2-stündig).

SS 2003: Vorlesung und Übung im Strafvollzug (2-stündig) sowie Seminar "Rechtliche Bekämpfung des Terrorismus" mit Prof. Nelles und Prof. Welp (2-stündig).

WS 2003/04: Seminar "Wirtschaftsstrafrecht und Wirtschaftskriminologie" mit Prof. Nelles und Prof. Boers (2-stündig) - jeweils an der Westfälischen Wilhelms- Universität Münster.

SS 2002: Seminar "Das Recht auf Verteidigung im internationalen Vergleich" (2-stündig); WS 2003/04: Seminar "Makrokriminalität und Krieg" (2-stündig) - jeweils an der HumboldtUniversität zu Berlin. 
Eser: Adjunct Professor an der Columbia University School of Law in the City of New York: Vorlesungen über Comparative and International Criminal Law, spring term 2003.

Gleß: WS 2002/2003: Internationale Rechtshilfe und Zusammenarbeit in Strafsachen, Vorlesung.

WS 2002/2003: Strafrechtsklausur im Examensklausurenkurs.

WS 2003/2004: Strafrechtsklausur im Examensklausurenkurs, jeweils Westfälische WilhelmsUniversität Münster; Europäisches Strafrecht - und die Schweiz? Gastvorlesung in der Ringvorlesung: Internationale Kriminalpolitik, Universität Bern, 16.12.2003.

"The Law of Evidence and Judicial Cooperation in the European Union". Europäische Rechtsakademie, Trier, 25.-26.11.2002.

Höfer: WS 2003/2004: Arbeitsgemeinschaft Strafrecht Allgemeiner Teil, Universität Konstanz.

Kilchling: Winter-Semesterferien 2002 (12.4.2002): Ferienklausurenkurs an der AlbertLudwigs-Universität Freiburg i.Br., Strafrechtsklausur.

Korrektor und Prüfer im Rahmen des M.A.-Studienganges "Master in European Criminology" der Katholischen Universität Leuven (B), Verteidigungstermine 25./26. Juni 2002, 10. September 2002, 9./10 September 2003.

Kinzig: WS 2001/2002: Stellen und Besprechung einer strafrechtlichen Klausur im Examensklausurenkurs der Assistenten an der Albert-Ludwigs-Universität Freiburg.

Koch: WS 2001/02, SS 2002, WS 2002/03, SS 2003, WS 2003/04: Vorlesungen zu medizinrechtlichen Grundfragen im Rahmen des rechtsmedizinischen Teils des "Ökologischen Kurses" für MedizinstudentInnen.

WS 2001/02, WS 2002/03, WS 2003/04: Vorlesung "Medizinrecht" (auch für MedizinstudentInnen).

SS 2002: Medizinrechtliches Seminar zu "Kontrolle medizinischer Tätigkeit durch EthikGremien und verwandte Einrichtungen - Legitimationsrituale oder wirksame Mechanismen zur Entscheidungsoptimierung?".

SS 2003: Medizinrechtliches Seminar zu "Aktuelle Entwicklungen des Arztrechts". Alle Veranstaltungen an der Universität Freiburg i.Br.

Kreicker: SS 2003: Zwei Übungen im Strafrecht für Anfänger I an der Universität Freiburg i.Br.

Kury: WS 2001/2002, SS 2002, WS 2002/2003; SS 2003: 3-stündiges Seminar "Forensische Psychologie I und II" am Psychologischen Institut der Universität Freiburg i.Br. (zusammen mit Obergfell-Fuchs).

Lelieur-Fischer: Leitung von zwei Arbeitsgemeinschaften (travaux dirigés) + Deutschfranzösischer Studiengang ("Magistère Droit franco-allemand des affaires") an der Université Robert Schuman, Strasbourg. Französisches Sachenrecht (5. Semester) und Bürgschaftsrecht (6. Semester), Oktober 2002 bis Juni 2003.

Oktober 2003 bis Juni 2004: Leitung von vier Arbeitsgemeinschaften (travaux dirigés) an der Université Robert Schuman, Strasbourg. Französisches Strafrecht - Allgemeiner Teil (3. Semester) und Strafprozessrecht (4. Semester), Oktober 2003 bis Juni 2004.

Mayer, M., WS 2001/2002: Seminar "Normen und Sanktionen".

WS 2002/2003: "Zur Soziologie elektronischer Überwachung". Seminar, beide Institut für Soziologie, Universität Freiburg i.Br. 
Nogala: WS 2002/3, WS 2003/4: Lehraufträge "Kriminologie" am Fachbereich Polizei der Fachhochschule für Öffentliche Verwaltung, Hamburg. WS 2003/4: Lehrauftrag "Polizeitheorie" am Institut für kriminologische Sozialforschung, Universität Hamburg.

Obergfell-Fuchs: WS 2001/2002, SS 2002, WS 2002/2003, SS 2003, WS 2003/2004: "Forensische Psychologie (3-stündig), Institut für Psychologie an der Albert-Ludwigs-Universität Freiburg (zusammen mit Kury).

SS 2002, SS 2003, WS2003/2004: "Kriminalpolitische Konzeptionen" (2-stündig), Evangelische Fachhochschule für Sozialwesen, Religionspädagogik und Gemeindediakonie, Freiburg i.Br.

Oberwittler: SS 2002: Theorien abweichenden Verhaltens (Hauptseminar); WS 2002/2003: Einführung in die Bildungssoziologie (Proseminar), Universität Freiburg i.Br., Institut für Soziologie.

Paoli: WS 2001/02: Seminar "The Sociology of Crime and Deviance - An Introduction", Fachbereich Geschichte und Soziologie, Universität Konstanz.

Tellenbach: Türkisches Straf-und Strafprozeßrecht, Seminar für Einzelentscheider des Bundesamts für Flüchtlinge, Bern, 18.3.2002.

Türkisches Straf-und Strafprozeßrecht, Seminar für Einzelentscheider des Bundesamts für die Anerkennung ausländischer Flüchtlinge, Berlin 19.6.2002.

"Strafe und Menschenwürde im Islam", Graduiertenkolleg Anthropologische Grundlagen und Entwicklungen im Christentum und im Islam, Bamberg, 8.6.2002.

Zerbes: WS 2002/2003, SS 2003, WS 2003/2004: Arbeitsgemeinschaften; seit WS 2002/ 2003 fallweise Vorlesungsvertretungen und gemeinsame Seminare mit Prof. Fuchs, Universität Wien; WS 2000 bis SS 2002: fallweise Vorlesungsvertretungen und gemeinsame Seminare mit Prof. Pieth, Universität Basel. 


\section{Studienaufenthalte, Vortragsreisen, Kontakt- und Informationsreisen}

2002

Forschungsaufenthalt als Visiting Professor am Institute for the Medical Humanities. University of Texas, Medical Branch, Galveston/Texas, 6.1.-28.2.2002 (Eser).

Gastprofessur am Criminal Justice Center, Sam Houston State University, Huntsville, 23.3.7.4.2002 (Paoli).

Forschungsaufenthalt in Berkeley/Californien, 19.8.-6.9.2002 (Silverman).

Forschungsaufenthalt als Marie-Curie-Stipendiatin der Europäischen Union am CESDIP, Paris, 1.12.2002-28.2.2003 (Tränkle).

2003

Visiting Professorship at Clare Hall College, Cambridge University, 1.2.-30.4.2003 (Albrecht).

Forschungsaufenthalt als Adjunct Professor an der Columbia University School of Law in the City of New York, 1.2.-30.3.2003 (Eser).

Studienaufenthalt an der Peking-Universität und der Qinghua-Universität vom 1.3.-7.3.2003 (Richter).

Marie Curie Fellowship der Europäischen Union an der Keele University, England, seit 8.10.2003 (Köllisch).

Vortragsreise in der VR China 24.-29.10.2003 (Albrecht).

Einmonatiger Aufenthalt im Oktober 2003 in Benin zur Erforschung von Selbstjustiz und für Literaturrecherche hinsichtlich des außerstaatlichen und staatlichen Strafrechts in Benin (Paulenz). 


\section{Zusammenarbeit mit anderen Forschungseinrichtungen des In- und Auslands}

Das Max-Planck-Institut verfolgt eine Politik der engen Zusammenarbeit mit anderen Forschungseinrichtungen des In- und Auslandes, die sowohl im Rahmen der gemeinsamen Projekte der beiden Forschungsgruppen als auch in den gemeinschaftlichen Projekten auf dem Gebiet des Strafrechts, in den Schwerpunktbereichen der kriminologischen Forschungsgruppe wie auch in den jeweiligen Einzelprojekten eine variantenreiche und unterschiedliche Ausgestaltung erfahren und im übrigen mit unterschiedlichen Zielen versehen sind. Die Ziele beziehen sich auf die Steigerung von Innovation und Effizienz in der Durchführung vergleichender und interdisziplinärer Forschung durch die Schaffung eines verlässlichen Netzwerkes von Forschungseinrichtungen, auf die systematische Erweiterung und Zentrierung von Informationen zu ausländischem Strafrecht und internationalem Strafrecht sowie interkulturell vergleichender Forschung am Institut, auf die Belebung und Intensivierung des kritischen wissenschaftlichen Diskurses über europäische und internationale Strafrechtsreformen und Kriminalitätskontrolle durch regelmäßigen wissenschaftlichen Austausch und Kontakt mit anderen inund ausländischen Forschern und durch die aktive Beteiligung und Förderung der Schaffung europäischer Foren wissenschaftlicher Veröffentlichungen sowie die Teilnahme am Aufbau europäischer Ausbildungsgänge im Bereich von Strafrecht und Kriminologie. $\mathrm{Zu}$ diesen Zielen gehören auch die Unterstützung von Übergangsländern im Prozess der Schaffung moderner, rechtsstaatlicher und an internationalen Standards orientierter Strafjustizsysteme. Das Gerüst der wissenschaftlichen Kooperation bilden die einzelnen Länderreferate, die Einbindung des Instituts in interdisziplinäre und empirische vergleichende Untersuchungen sowie zu einem gewissen Teil förmliche Kooperationsverträge (beispielsweise mit der Universität Montreal, der China University of Political Sciences and Law Beijing oder mit dem Institute of Crime Prevention am Chinesischen Justizministerium Beijing).

In der Umsetzung des angedeuteten Programms nimmt das Institut zunächst an verschiedenen europäischen und internationalen Forschungsnetzwerken teil. Beispielhaft sei die Teilnahme an der "Groupe de Recherches sur les Normativites" genannt, in dessen Rahmen regelmäßige workshops und Seminare zu Erträgen europäischer Forschung zu Strafjustizsystemen organisiert werden.

Den Kern der Zusammenarbeit bilden freilich vergleichende interdisziplinäre, normative und empirische Untersuchungen, die aus unterschiedlichen Programmen und Initiativen resultieren.

Verschiedene Projekte sind im Rahmen des Falcone-Programms der Europäischen Union zustande gekommen. Sie wurden in Kooperation mit Universitäten des europäischen Auslands durchgeführt. Genannt werden sollen die Forschungsaktivitäten zur Organisierten Kriminalität, welche die Universitäten Palermo und Madrid eingeschlossen haben. Zu nennen ist dann die Untersuchung der Geldwäsche und der Geldwäschekontrolle, in die Forschungseinrichtungen aus England (Cardiff), Holland (Tilburg), Frankreich (Paris), Ungarn (Budapest), Österreich (Graz) und Schweiz (Basel) einbezogen waren. Die Untersuchung zur Risikoabschätzung im Gesetzgebungsverfahren war auf die Zusammenarbeit mit Universitäten und Forschungseinrichtungen aus elf europäischen Ländern gegründet. Die nunmehr begonnene Evaluation der sozialtherapeutischen Behandlung von Sexualstraftätern beruht auf einer Zusammenarbeit mit der Technischen Universität Dresden.

Weiterhin zu nennen ist aus dem Bereich "Recht und Medizin" die Beteiligung an mehreren internationalen Projekten im Rahmen verschiedener EU-BIOMED-Programme. Diese besteht teils in koordinierender und projektleitender Form (wie - in Zusammenarbeit mit der Akademie für Ethik in der Medizin - beim Projekt "Informed Consent in Psychiatry"), teils findet sie ihren Ausdruck neben der fachlichen Kooperation in der Mitarbeit auf der Ebene der "Project Management Group" (wie beim vom Centre of Medical Law and Ethics am King's College London organisierten Projekt "The Moral and Legal Issues Surrounding the Treatment and Care of Patients in Persistent Vegetative State"), teils äußert sie sich in der Wahrnehmung einer Landesberichterstattern vergleichbaren Rolle (wie im Rah- 
men des "European Network for Biomedical Ethics", des Projekts "Therapeutic Research in Assisted Conception" sowie - beantragt - des Projekts "Consensus autour de la recherche sur l'embryon humain). Auf lokaler Ebene ergeben sich vielfältige Aktivitäten im Grenzbereich von Recht und Medizin vor allem daraus, dass das MPI mit seinem Referat "Recht und Medizin" als Mitträger des "Zentrums für Ethik und Recht in der Medizin" (ZERM) am Klinikum der Universität Freiburg fungiert.

Schließlich hat sich eine Zusammenarbeit mit der RAND Corporation ergeben, in der Fragestellungen des weltweiten Heroinmarktes und der Kontrolle von Cannabismärkten thematisiert werden. Zusammen mit der Sam Houston State University/Texas ist ein Projekt in Angriff genommen worden, das die Untersuchung der polizeilichen und justiziellen Bewältigung von Hassgewalt zum Gegenstand hat. Ferner wurde zusammen mit Forschern der Sam Houston State University eine vergleichende Untersuchung der Tötungskriminalität im Zusammenhang mit der Kohortenstudie begonnen.

Die Forschungen zu Europol und den Schengen-Verträgen sind ebenfalls auf die Europäische Union bezogen und enthalten eine enge Kooperation mit dem MPI für ausländisches öffentliches Recht und Völkerrecht in Heidelberg.

Seit Ende der siebziger Jahre hat das Institut ein System bilateraler wissenschaftlicher Kooperation mit Universitäten der ehemals sozialistischen Staaten entwickelt, aus dem Veranstaltungen wie deutsch-sowjetische, deutsch-polnische, deutsch-ungarische Kolloquien zu Strafrecht und Kriminologie samt nachfolgenden Veröffentlichungen der Erträge entstanden sind. Dieses System der Kooperation hat sich sodann weiterentwickelt in eine eher inhaltlich denn bilateral bestimmte ad-hoc Kooperation zu beispielsweise "Rechtfertigungs- und Entschuldigungsgründe", "Intermediate Sanctions In Europe", "Tatproportionalität in der Strafzumessung" oder "Systems and Developments of Penal Sanctions in Western and Central Europe". Im Unterschied zu den bilateral ausgelegten Kooperationen ist die Zusammenarbeit mit dieser Strategie von teils durchgehenden Forschungsthemen bestimmt.

Der wissenschaftliche Austausch in der kriminologischen Forschung wird ferner durch regelmäßige workshops mit Forschungseinrichtungen des In- und Auslands sichergestellt, anlässlich derer laufende Untersuchungen vorgestellt und diskutiert werden. Zu nennen sind hier beispw. workshops, die zusammen mit dem Kriminologischen Forschungsinstitut Niedersachsen (Freiburg), dem kriminologischen Institut der Universität zu Köln (Köln) sowie dem CESDIP (Freiburg) durchgeführt worden sind.

Aus einer auf regelmäßige gemeinsame Seminare angelegten Kooperation mit dem Institute for Crime Prevention am Chinesischen Justizministerium/Beijing hat sich seit 1996 eine nunmehr auf die Durchführung gemeinsamer Untersuchungen erweiterte intensive Zusammenarbeit mit der Volksrepublik China ergeben, die auf chinesischer Seite ganz wesentlich durch die China University of Political Sciences and Law getragen wird. Aus dieser Zusammenarbeit entstanden Forschungsberichte zu "NonProsecution Policies" (China University of Political Sciences and Law), zu "Zwangsmaßnahmen im Ermittlungsverfahren" (China University of Political Sciences and Law) sowie Publikationen zur Geldwäsche und Geldwäschekontrolle (University of Wuhan). Fortgeführt werden gemeinsame SinoDeutsche Kolloquien zu Strafrecht und Kriminologie sowie gemeinsame workshops beispw. mit der Sichuan University zu verschiedenen kriminologischen und strafrechtlichen Fragestellungen. In der Implementation dieser Kooperation kommen dem DAAD sowie dem Büro des DAAD in Beijing im Übrigen herausragende Bedeutung zu. In Zusammenarbeit mit der Universität Freiburg sowie der Juristischen Fakultät der Universität Freiburg und im Rahmen des Deutsch-Chinesischen Rechtsstaatsdialogs wird die Gründung eines Instituts für Deutsches Recht an der China University of Political Sciences and Law in Beijing geplant. Das Vorhaben wurde zu Beginn des Jahres 2004 anlässlich eines vom Institut, der Rechtswissenschaftlichen Fakultät der Universität Freiburg und der China University of Political Sciences and Law gemeinsam organisierten Kolloquium zu "Globalisierung, Ökonomie und Menschenrechte" weiter konkretisiert. 
Die Zusammenarbeit mit Universitäten und Forschungseinrichtungen des In- und Auslands äußert sich ferner in regelmäßigen wissenschaftlichen Kolloquien am Institut, zu denen in- und ausländische Forscherinnen und Forscher eingeladen werden.

Auf der Basis eines Vertrags zwischen MPG und CNRS ist das Institut seit 1998 Teil eines Laboratoire Européen Associé (LEA); darin arbeiten das CESDIP (Centre d'Etudes Sur le Droit et Les Institutions Pénales/Paris) sowie das IFRESI/Lille) mit. Die hier entwickelten und in deutsch-französischen Forscherteams bearbeiteten Schwerpunkte betreffen die Innere Sicherheit, die Immigration, Viktimisierung und Verbrechensangst, Drogenmärkte sowie Strafrechtliche Sanktionen und Strafzumessung.

Ferner ist auf die Teilnahme an der Entwicklung und Umsetzung europäischer Ausbildungsgänge hinzuweisen. So ist das Institut in das Masters Programm der Universität Leuven einbezogen.

Nicht zuletzt bildet auch die Mitgliedschaft des MPI und der Mitarbeiterinnen und Mitarbeiter in wissenschaftlichen Gesellschaften des In- und Auslandes, wie namentlich in der Association Internationale de Droit Pénal (AIDP) und der International Society for the Reform of Criminal Law nicht zu unterschätzende Plattformen für Forschungsanstöße und Kooperation. 


\section{Beziehungen zu Wirtschaft, Politik und Gesellschaft}

Die Beziehungen des Instituts zu Wirtschaft, Politik und Gesellschaft lassen sich in vier Schwerpunktbereiche unterteilen. Es handelt sich dabei einmal um die aus Grundlagenforschung oder Auftragsforschung fließende Beratung von Rechts- und Innenpolitik sowie Gesetzgebung. Daneben stellt das Gutachtenreferat ein wichtiges Bindeglied zur Justizpraxis, zur Anwaltschaft sowie zur Wirtschaft her. Ferner ist das Institut über beratende und organisierende Tätigkeit in unterschiedlicher Art und Weise in die Entwicklungs- und Außenpolitik der Bundesrepublik Deutschland sowie der Europäischen Union eingebunden. Schließlich wirkt das Institut an Fort- und Weiterbildungsveranstaltungen - insbesondere im Justizbereich - mit. Naheliegenderweise sind die Beziehungen des MaxPlanck-Instituts für ausländisches und internationales Strafrecht mit der Rechts- und Innenpolitik sowie mit den Parlamenten in besonderer Weise ausgebaut.

Die beratende und sachverständige Tätigkeit für Rechts-, Innenpolitik und Parlamente lässt sich in große Projekte der Grundlagen- und Auftragsforschung sowie die individuelle Beratung von Einzelprojekten, Kommissionen etc. unterscheiden. Die am Institut betriebene Grundlagenforschung ist in mancher Hinsicht Ausdruck der besonderen Beziehungen zwischen Institut und Rechts- und Innenpolitik. Dasselbe gilt für die Auftragsforschung, die das Institut ebenfalls mit Justiz- und Innenministerien sowie dem Bundeskriminalamt verbindet. Zur systematischen Vorbereitung von Reformvorhaben im Bereich des Strafrechts auf nationaler (Bundes- oder auch Landesebene) wie auch supraund internationaler Ebene wird in immer stärkerem Umfang auf Untersuchungen zurückgegriffen, die als Grundlagenprojekte am Institut betrieben werden oder auf Aufträge von Ministerien zurückzuführen sind. Hierzu zählen beispielsweise das vom Bundesministerium der Justiz in Auftrag gegebene Projekt "Rechtswirklichkeit und Effizienz des deutschen Rechtsmittelsystems im Strafrecht unter Berücksichtigung des internationalen Standards" sowie das gleichfalls vom Bundesministerium der Justiz veranlasste Projekt zur "Evaluation der Telefonüberwachung". Hierzu gehören auch Forschungen zur Behandlung der Gewalt in der Ehe und Untersuchungen zu "Möglichkeiten der Privatisierung polizeilicher Aufgabenbereiche". Die individuelle Beratertätigkeit umfasst gutachtliche Stellungnahmen zu Einzelvorhaben der Politik wie das "Strafrechtliche Sanktionensystem", ebenso wie die Reform des Schwangerschaftsabbruchsrechts oder die Mitwirkung an der Begutachtung des wissenschaftlichen Begleitmodells zur heroingestützten Behandlung Opiatabhängiger, aber auch die Mitarbeit in EthikKommissionen zur Prüfung von Forschungsvorhaben sowie in Gremien zur praktischen Handhabung des neuen Transplantationsgesetzes. Im Übrigen ist auf regelmäßige Anhörungen von Institutsangehörigen zu den unterschiedlichsten Fragen des Strafrechts und der Inneren Sicherheit im Rahmen der Parlaments- und Fraktionsarbeiten zu verweisen.

Mit den im Gutachtenreferat zusammengefassten und gebündelten Aktivitäten sind vor allem Beziehungen zu Justizpraxis, Anwaltschaft und Wirtschaft bzw. zum privaten Bereich verbunden. Hier wird die beständig zunehmende Nachfrage nach Informationen und sachverständigem Wissen zu Fragen des ausländischen Strafrechts, des internationalen Strafrechts sowie komplexer strafrechtlicher Materien sichtbar.

Die entwicklungs- und außenpolitischen Komponenten in den Beziehungen begründen sich aus der zunehmenden Bedeutung des "legal capacity building", der Sicherheit und des menschenrechtlichen Dialogs für Schwellenländer und Übergangsgesellschaften; sie verweisen auch auf die immer stärker werdende Bedeutung der Ausgestaltung des Strafrechts für die erfolgreiche Abwicklung des schnellen wirtschaftlichen und politischen Wandels in Übergangsgesellschaften sowie die exponierte Stellung des Strafrechts und vor allem strafrechtlicher Sanktionen, darüber hinaus von Kriminalitätsproblemen (Drogen, Geldwäsche) in der Außenpolitik und damit für stabile Verhältnisse zwischen Staaten. Strafrechtliche Sozialkontrolle weist im Übrigen besondere Bezüge zu den Menschenrechten auf. In diesem Bereich ist auf die Beteiligung von Institutsangehörigen an Projekten der Gesellschaft für Technische Zusammenarbeit zur Strafrechtsreform in Afrika und in Südamerika zu verweisen, im übrigen auf die 
Einbindung des Instituts in den fortlaufenden Menschenrechtsdialog zwischen der Europäischen Union und China. Das Institut war unter österreichischer Ratspräsidentschaft aktiv an dem 1. EU-China Dialog beteiligt, hat unter deutscher Ratspräsidentschaft den 2. Dialog organisiert und inhaltlich mitbestritten und hat auch unter portugiesischer, französischer, schwedischer und belgischer Ratspräsidentschaft wiederum aktiv am wissenschaftlichen und politischen Menschenrechtsdialog mitgewirkt. Ferner ist das Institut auch im Dialog zwischen der Europäischen Union und Iran vertreten.

Nicht zu vernachlässigen ist dann die Beziehung des Instituts zu den Ausbildungssystemen der Justiz und justiznaher Berufe. Hiervon legt die Mitwirkung an Veranstaltungen der Deutschen Richterakademie ebenso Zeugnis ab wie die Teilnahme an einer Vielzahl von weiteren Fort- und Weiterbildungsveranstaltungen. 


\section{X. Öffentlichkeitsarbeit}

Die Öffentlichkeitsarbeit des Instituts beruht neben den klassischen Formen der Forschungsberichte (in internen und externen Veröffentlichungsreihen) und anderer Druckdarstellungen von Forschungsbefunden ganz wesentlich auf der differenzierten Präsentation und Verbreitung von Forschungsergebnissen im Rahmen der Homepage des Instituts (www.iuscrim.mpg.de). Ferner ist die Öffentlichkeitsarbeit in die Vortragstätigkeit anlässlich öffentlicher Veranstaltungen oder Fortbildungsveranstaltungen relevanter Berufsgruppen sowie in die Präsentation von Forschungsbefunden und Sachwissen in Rundfunk- und Fernsehsendungen bzw. -interviews eingebunden. Die Öffentlichkeitsarbeit besteht aus aktiven und aus reaktiven Komponenten. Zu den aktiven Komponenten zählen die erwähnten Formen der Veröffentlichung und des Angebots an Informationen über das Institut und Forschungsergebnisse. Hierzu gehört auch die nunmehr systematische Information der Medien über wissenschaftliche Veranstaltungen und Forschungsergebnisse des Instituts. Die reaktive Seite betrifft vor allem die fortlaufende Beantwortung von Anfragen der Medien, die im Wesentlichen tagespolitische Themen betreffen. Hierzu gehören Interviews und die Mitwirkung in Sendungen. Neben die herkömmlichen Medien tritt nunmehr verstärkt die Vorstellung der strafrechtswissenschaftlichen und der empirisch-kriminologischen Forschung im Internet. Ein Öffentlichkeitsreferat hat die Aufgabe, strategische Überlegungen zur öffentlichkeitswirksamen Verbreitung der wissenschaftlichen Befunde zu entwickeln und damit die aktive Öffentlichkeitsarbeit zu organisieren; jedoch beruht die Öffentlichkeitsarbeit auch auf den Aktivitäten der einzelnen Mitarbeiterinnen und Mitarbeiter. Im Einzelnen ergaben sich im Berichtszeitraum folgende Entwicklungen:

- Die Forschungsreihe "Interdisziplinäre Untersuchungen aus Strafrecht und Kriminologie", mit der die Resultate übergreifender und gemeinsamer Planung und Durchführung der strafrechtlichen und kriminologischen Forschungsgruppen dargestellt wird, hat sich bewährt.

- Die Homepage des Instituts wurde erweitert und an Benutzerbedürfnisse angepasst. Allgemeine Informationen über das Institut werden ebenso präsentiert wie Angaben zu einzelnen Projekten, Länder- und Sachreferaten. Im Übrigen wird unter dem Stichwort "Aktuelles" laufend über neue Entwicklungen in der Forschung berichtet. Unter "online publication and resources" können Forschungsberichte und adhoc Veröffentlichungen im pdf Format abgerufen werden.

- Die Veröffentlichungsform des "Forschung Aktuell" bzw. "research in brief" ermöglicht eine schnelle und weite Verbreitung von Forschungsergebnissen.

- Die "Arbeitsberichte" haben sich ebenfalls bewährt.

- Auf das Programm des Institutsverlags (edition iuscrim) wird die Öffentlichkeit durch regelmäßig erscheinende Gesamtverzeichnisse sowie durch spezielle Informationen über Neuerscheinungen hingewiesen. Das Programm ist im Übrigen auch auf der Homepage repräsentiert.

- Die Interessen der Medien waren im Berichtszeitraum sehr stark bestimmt durch Organisierte Kriminalität, Drogen und Drogenkontrolle, die Telefonüberwachung und den Grossen Lauschangriff, das Internationale Tribunal (ehemaliges Jugoslawien) und hier durch den Fall Milosevic sowie die Errichtung eines permanenten Internationalen Strafgerichtshofes nach dem Rom-Statut, die elektronische Fußfessel, internationalen Terrorismus und Geldwäsche. 


\section{Sonstige wissenschaftliche Tätigkeiten}

Albrecht, Hans-Jörg Gutachten für den Europarat zum Law on Enforcement of Criminal Sanctions of Montenegro, January 2002.

Gutachten für den 64. Deutschen Juristentag am 18.-19.9.2002 in Berlin "Ist das deutsche Jugendstrafrecht noch zeitgemäß? - Bedarf es und wenn ja welcher Veränderungen?", September 2002.

Gutachten für den Europarat zum Law on the Execution of Penal Sanctions of the Republic of Serbia, September 2003.

Eser, Albin

Mitwirkung an den Plenarsitzungen der beim Europarat angesiedelten GRECO (Groupe d'Etats contre la Corruption) im Jahr 2002 vom 1.-8.3., 13.-17.5., 8.-12.7., 14.-18.10. und 9.-13.12. sowie im Jahr 2003 vom 7.-11.7., 13.-17.10. und 8.-12.12. in seiner Eigenschaft als "Scientific Expert".

Erstellung eines rechtsvergleichenden Querschnitts für das von der Europäischen Kommission geförderte Projekt "L'hamonisation des sanctions pénales en Europe".

Jescheck, Hans-Heinrich

Kilchling, Michael

Beratung des Justizministeriums der Tschechischen Republik bei dem Entwurf für den Allgemeinen Teil des neuen tschechischen Strafgesetzbuchs mit Vorlage des schriftlichen Gutachtens in deutscher Sprache und tschechischer Übersetzung. Einladung des Justizministers zu einem Referat vor dem Legislativrat der Regierung am 8.12.2003 über eine grundlegende Streitfrage des Entwurfs.

Deutscher Delegierter im Management Committee der COST Action A 21 "Restorative Justice Developments in Europe" der European Science Foundation (seit 2002).

Mitglied der Crime Proofing Steering Group der EU-Kommission, DG Justice and Home Affairs (seit 2002).

Mitglied der Steering Group zu dem AGIS-Projekt "Method and Assessment of Vulnerability of Sectors (MAVUS)" des Institute for International Research on Criminal Policy (IRCP) der Universität Gent (seit 2003).

Kinzig, Jörg

2002: Sachverständiger vor dem Verfassungs- und Rechtsausschuss des Sächsischen Landtages in Dresden zum "Gesetz über die Unterbringung besonders rückfallgefährdeter Straftäter (Straftäter-Unterbringungsgesetz-StrUBG)".

2002: Sachverständiger vor dem Rechtsausschuss des Deutschen Bundestages in Berlin zu den Gesetzentwürfen des Bundesrates BT-Drs. 14/1125 sowie BT-Drs. 14/6709.

2002: Sachverständiger vor dem Rechtsausschuss des Deutschen Bundestages in Berlin zum Gesetzentwurf BT-Drs. 14/8586.

2003: Gutachter vor dem Bundesverfassungsgericht in den Verfahren 1 BvR 2378/98 und 1 BvR 1084/99 (so genannter Großer Lauschangriff). 
Lammich, Siegfried Beteiligung an den "Gesprächen des Runden Tisches" über den Entwurf des AT für ein neues bulgarisches StGB. Justizministerium Sofia 11.-15.9.2002.

Beteiligung an den "Gesprächen des Runden Tisches" zum Entwurf eines belarussischen Gesetzes über die internationale rechtliche Zusammenarbeit in Strafsachen. Minsk, 12.-16.6.2002.

Sieber, Ulrich

Erstellung einer Studie "The Punishment of Serious Crimes" für den internationalen Strafgerichtshof für das ehemalige Jugoslawien (ICTY) sowie Erstattung eines mündlichen Sachverständigengutachtens hierzu in dem laufenden Nicolic-Verfahren vor dem ICTY.

Tellenbach, Silvia Anhörung im Bundestagsausschuss für Menschenrechte und humanitäre Hilfe zum Thema "Islamisches Recht und Menschenrechte". Berlin, 22.10.2003.

Gutachten über den Entwurf eines Türkischen Strafgesetzbuchs und über den Entwurf einer türkischen Strafprozessordnung für den Europarat. 


\section{Rufe und wissenschaftliche Auszeichnungen}

\section{- Auszeichnungen}

Höfer wurde am 4.6.2003 die Otto-Hahn-Medaille 2002 für den wissenschaftlichen Nachwuchs in der Max-Planck-Gesellschaft verliehen. Die Verleihung fand statt auf der 54. Hauptversammlung der Max-Planck-Gesellschaft in Hamburg. Höfer wurde für seine Dissertation zum Thema "Sanktionskarrieren - Eine Analyse der Sanktionshärteentwicklung bei mehrfach registrierten Personen anhand von Daten der Freiburger Kohortenstudie" ausgezeichnet. Die Arbeit ist im April 2003 in der edition iuscrim als Band 106 der Kriminologischen Forschungsberichte aus dem Max-Planck-Institut für ausländisches und internationales Strafrecht erschienen.

Professor Kaiser wurde am 9.10.2003 die Beccaria-Medaille in Gold der Neuen Kriminologischen Gesellschaft verliehen.

- Ernennungen/Wahlen/Mitgliedschaften

Professor Eser ist zum Mitglied des Stiftungsrates der ScheringStiftung BBerlin gewählt worden (2003).

\section{- Habilitationen/Lehrstuhlvertretungen/Rufe/Lehrbeaufträge}

J. Arnold ist seit 2001 Lehrbeauftragter an der Universität Münster.

Ambos erhielt im Februar 2003 den Ruf auf einen Lehrstuhl für "Strafrecht und Strafprozessrecht" an die Universität Göttingen.

Kinzig ist seit Juli 2003 Privatdozent für die Fächer Strafrecht, Strafprozessrecht, Kriminologie, Jugendstrafrecht und Strafvollzug. 


\section{Ausländische Wissenschaftler am Institut und Entwick- lungen im Bereich des wissenschaftlichen Nachwuchses}

\section{Ausländische Wissenschaftler am Institut}

Große Bedeutung für die wissenschaftliche Zusammenarbeit des Instituts mit Forschungseinrichtungen des Auslands haben die zahlreichen ausländischen Wissenschaftler, die teilweise in die Forschungsprojekte am Institut einbezogen sind, teilweise eigenständige Untersuchungen verfolgen. Die Forschungstätigkeit ausländischer Wissenschaftler soll sich in Zukunft stärker in Publikationen des Instituts niederschlagen und im Übrigen in Kooperationsvorhaben am Institut eingebettet werden. Forschungsergebnisse werden insbesondere in den "online publications and resources" sowie in der Reihe "research in brief" dokumentiert werden.

Die Zahl der ausländischer Wissenschaftler, die mindestens einen Monat am Institut bleiben, liegt bei durchschnittlich etwas über 100 pro Jahr. Vom beruflichen Status können die Wissenschaftler in drei Gruppen eingeteilt werden. So gehören beispw. von den 107 Wissenschaftlern im Jahr 200235 in die Gruppe der Professoren, 40 in die Gruppe der Postdocs und 32 in die Gruppe der Doktoranden. Für 2003 lauten die Zahlen bei 112 Wissenschaftlern: 27,57 und 28. Die durchschnittliche Aufenthaltsdauer liegt bei etwa 4 Monaten. Sie fällt erwartungsgemäß kürzer aus für Professoren, aber auch bei Postdocs, mit 2-3 Monaten (mit Ausnahme der Humboldt-Stipendiaten). Der Aufenthalt ausländischer Wissenschaftler konzentriert sich - auch dies erwartungsgemäß - auf die Universitätsferien, wobei es durchaus zu Kapazitätsproblemen im Hinblick auf Arbeitsplätze und Bibliotheksnutzung kommen kann. Doktoranden verweilen häufig ein Jahr oder länger; auch Humboldt-Stipendiaten müssen bei ihrem Erstaufenthalt nach den Regeln der Humboldt-Stiftung mindestens 6 Monate bleiben, tun dies aber häufig ein Jahr und länger. Gerade diese längeren Aufenthalte sind für den Aufbau von Beziehungen zum Institut sowie zur deutschen Sprache, Wissenschaft und Kultur sehr wichtig.

Die Finanzierung der Gastaufenthalte erfolgt nur zu einem begrenzten Teil durch Max-Planck-Stipendien. Von erheblicher Bedeutung für die Förderung des wissenschaftlichen Austauschs sind der DAAD und dann vor allem auch die Humboldt-Stiftung. Ferner sind Stipendien der parteinnahen Stiftungen zu nennen, mit denen insbesondere die Durchführung von Promotionen ausländischer Forscherinnen und Forscher gewährleistet wird. Schließlich sind in den vergangenen Jahren Forschungsaufenthalte am Institut auch über Mittel der Europäischen Union gefördert worden (beispw. Marie-CurieProgramm). In manchen Ländern (z.B. Spanien) findet sich ein großes Angebot von Stipendiengebern für Forschungsaufenthalte; ausländische Wissenschaftler finanzieren ihren Aufenthalt aber auch aus eigenen Mitteln. Der Anteil der Wissenschaftler, die durch Max-Planck-Stipendien gefördert werden, beträgt im Jahre 2003 etwa $35 \%$. Dies unterstreicht die große Bedeutung der Forschungsförderung für die wissenschaftliche Kooperation mit dem Ausland durch Humboldt-Stiftung, DAAD sowie die parteinahen Stiftungen.

Die Struktur der Herkunftsländer ausländischer Wissenschaftler reflektiert natürlich eine gewisse Tradition in der Rezeption der deutschen Strafrechtsdogmatik im Ausland und Länder wie Spanien, Italien und Korea stehen immer wieder im Vordergrund. Die Schwerpunkte der wissenschaftlichen Kontakte mit dem Ausland liegen - gemessen an der Zahl ausländischer Wissenschaftler am Institut und für den Berichtszeitraum 2002-2003 (219) - demnach in Westeuropa (78) und hier insbesondere in der Europäischen Union (70). Osteuropa (einschließlich der GUS-Staaten) ist mit 50 Aufenthalten vertreten; auf den Nahen Osten, einschließlich Türkei entfallen 15 Aufenthalte. Ostasien ist mit 29, Südamerika mit 26, Nordamerika mit 8, Afrika mit 12 Aufenthalten und Australien mit einem Aufenthalt vertreten.

In den beiden Berichtsjahren hielten sich 107 (2002) bzw. 112 (2003) ausländische Gäste aus jeweils 38 Staaten am Institut auf. 2002 kamen aus Italien 10 Gäste, aus Südkorea 9, aus Polen 8 und aus Spa- 
nien 7, aus China und Georgien je 5, aus Griechenland, Iran, Russland, Schweiz und USA je 4, aus Brasilien, Japan, Mexiko, Schweden, Südafrika je 3, aus Argentinien, Chile, Finnland, Kroatien, der Türkei und Uruguay je 2, aus Australien, Benin, Bolivien, Elfenbeinküste, Estland, Frankreich, Island, Israel, Kanada, Litauen, Niederlande, Österreich, Peru, Portugal, Swaziland und Tschechien je 1 Gast. - 2003 bestand die Spitzengruppe wiederum aus Italien(17), Spanien (12), Polen(10) und Südkorea(6). Je 5 Gäste kamen aus Argentinien, Griechenland und Russland, je 4 aus China, der Türkei und Ungarn, 3 aus Iran, je 2 aus Georgien, Großbritannien, Japan, Kolumbien, der Schweiz, Schweden, Slowenien, Südafrika, Tschechien, Uruguay und USA, je 1 Gast aus Belgien, Brasilien, Chile, Dänemark, Elfenbeinküste, Finnland, Israel, Jugoslawien, Kamerun, Kanada, Kroatien, Norwegen, Peru, Senegal, Tanzania und Weißrussland.

\section{Entwicklungen im Bereich des wissenschaftlichen Nachwuchses (Doktoranden/Habilitanden)}

\subsection{Strafrechtliche Forschungsgruppe}

Mit dem Rigorosum wurden in den Jahren 2002/2003 folgende Promotionsverfahren abgeschlossen:

Günther, Andreas M. Täterschaft und Teilnahme im südafrikanischen Recht. Eine rechtsvergleichende Studie unter besonderer Berücksichtigung der common purpose rule (Rigorosum: 31.1.2003) (Eser).

Haeusermann, Axel Der Verband als Straftäter und Strafprozeßsubjekt (Rigorosum: 31.1.2003) (Eser).

Hägele, Rolf Grundstrukturen des Rechts der Arzneimittelprüfung am Menschen in Deutschland, Österreich und der Schweiz unter besonderer Berücksichtigung strafrechtlicher Gesichtspunkte (Rigorosum: 7.5.2002) (Eser).

Hamdorf, Kai

Beteiligungsmodelle im Strafrecht. Ein Vergleich von Teilnahme- und Einheitstätersystemen in Skandinavien, Österreich und Deutschland (Rigorosum: 19.6.2002) (Eser).

Tallroth, Paulina Informationsrechte des Beschuldigten im Vorverfahren. Eine rechtsvergleichende Studie zur Verwirklichung strafprozessualer Garantien im Verfahrensrecht Deutschlands und der nordischen Länder unter Berücksichtigung der Europäischen Menschenrechtskonvention (Rigorosum: 27.5.2003) (Eser).

Weik, Beate

Objektive und subjektive Verbrechenselemente im US-amerikanischen Strafrecht. Eine Annäherung an das Unrechtsverständnis (Rigorosum: 27.11.2002) (Eser).

Weltz, Kerstin

Die Unterlassungshaftung im Völkerstrafrecht aus dem Blickwinkel des französischen, US-amerikanischen und deutschen Recht (Rigorosum: 31.1.2003) (Eser). 
Neu begonnen wurden in den Jahren 2002/2003 folgende Dissertationsvorhaben:

Rinceanu, Johanna Völkerstrafrechtliche Verbrechen und ihre Erfassung durch die rumänische Strafgewalt - Ein Vergleich des rumänischen Strafgesetzbuchs mit dem Römischen Statut und dem deutschen Völkerstrafgesetzbuch (Arnold).

Simon, Jan-Michael Strafrecht in Postkonfliktsituationen - eine komparative Untersuchung zum Einsatz von Strafrecht in der Internationalen Gemeinschaft (Tomuschat).

Trappe, Julie $\quad$ Strafrechtliche Reaktion auf Systemunrecht in Rumänien nach 1989 im Vergleich zu anderen osteuropäischen Staaten (Arnold).

\subsection{Kriminologische Forschungsgruppe}

Mit dem Rigorosum wurden in den Jahren 2002/2003 folgende Promotionsverfahren abgeschlossen:

Backmann, Ben

Sanktions- und Wertvorstellungen Jugendlicher im internationalen Vergleich zwischen Baden-Württemberg und der Nordwestschweiz (Rigorosum: 4.1. 2002) (Albrecht).

Bareinske, Christian Sanktion und Legalbewährung im Jugendstrafverfahren in Baden-Württemberg - Eine Analyse der Legalbewährung von jugendlichen Straftätern nach einer formellen bzw. informellen Erledigung des Verfahrens anhand der Freiburger Kohortenstudie (Rigorosum: 25.11.2003) (Albrecht).

Haverkamp, Rita Der elektronisch überwachte Hausarrest. Eine rechtsvergleichende und empirische Untersuchung in Schweden und Deutschland (Rigorosum: 5.2.2002) (Albrecht).

Höfer, Sven

Sanktionskarrieren - Eine Analyse der Sanktionshärteentwicklung bei mehrfach registrierten Personen anhand von Daten der Freiburger Kohortenstudie (Rigorosum: 4.2.2002) (Albrecht).

Lang, Bettina

Strafrechtsbezogene Vergangenheitspolitik - "Politischer Wille" und "Strafrechtsrealität" im Spannungsverhältnis am Beispiel von Deutschland und Südafrika (Rigorosum: 25.11.2003) (Albrecht).

Maguer, Azilis $\quad$ Grenzüberschreitende polizeiliche Kooperation - Praktiken, Institutionen und Strukturen entlang der deutsch-französischen Grenze (Verteidigung: 19.12. 2002) (Albrecht).

Müller, Susanne Rechtliche und tatsächliche Kriterien der Strafzumessung im deutsch-französischen Vergleich - ein Beitrag zur Sanktionsforschung im Rahmen des Laboratoire Européen Associé (Rigorosum: 4.11.2002) (Albrecht).

Nemitz, Jan Christoph Strafzumessung im Völkerstrafrecht - ein Beitrag zur Strafzwecklehre und zur Strafzumessungsmethode unter besonderer Berücksichtigung des römischen Status (Rigorosum: 4.2.2002) (Albrecht).

Schäfer-Vogel, Gundula

Gewalttätige Jugendkulturen - Symptom der Erosion kommunikativer Strukturen (Rigorosum: 25.11.2003) (Albrecht). 
Neu begonnen wurden in den Jahren 2002/2003 folgende Dissertationsvorhaben:

Dorsch, Claudia

Fröhmcke, Vigor

Herz, Annette Louise

Hotter, Imke

Jessen, Daniela

Kafatou, Maria

Kiza, Ernesto

Krüpe, Christiane

Latsiou, Charikleia

Laule, Juliane

Lukas, Tim

Meyer-Wieck, Hannes

Mirimovitsch, Irina

Palacios Huerta, Alfonso

Park, Hee Young

Rathgeber, Corene

Rebmann, Christoph

Rehaag, Constantin
Effizienz der Überwachung der Telekommunikation nach $\S \S 100 \mathrm{a}, 100 \mathrm{~b}$ StPO (Albrecht).

Muslime im Strafvollzug - Die Rechtsstellung von Strafgefangenen muslimischer Religionszugehörigkeit in Deutschland (Albrecht).

Strafverfolgung von Menschenhandel - unter besonderer Berücksichtigung des neuen Prostitutionsgesetzes (Albrecht).

Untersuchungshaftvermeidung bei Jugendlichen und Heranwachsenden in Baden-Württemberg aus Sicht der Praxis (Albrecht).

Die Implementation der Fußfessel in Hessen - Eine Evaluation des Einführungsprozesses anhand empirischer Analyse der Rechtswirklichkeit und Effizienz des elektronisch überwachten Hausarrests (Albrecht).

Verbrechen, Risiko und Strafjustiz in der postmodernen Medienlandschaft über den Zusammenhang zwischen den Kriminalitätsdarstellungen in den Massenmedien und der ideologischen Funktion des Strafjustizsystems (Albrecht).

Methoden und Diskurse empirischer Beschreibung von Massen-Viktimisierungen. Eine Untersuchung am Beispiel der Opferwerdung im ehemaligen Jugoslawien und an EU-Außengrenzen (Albrecht).

Rechtswirklichkeit der Überwachung der Telekommunikation nach den $\S \S 100 \mathrm{a}, 100 \mathrm{~b}$ StPO (Albrecht).

Kriminologische und strafrechtliche Gesichtspunkte moderner Reproduktionstechnologie unter besonderer Berücksichtigung bioethischer Fragestellungen (Albrecht).

Berücksichtigung von Angehörigen bei der Auswahl und Vollstreckung von Sanktionen (Albrecht).

Bauliche Sanierung als Kriminalprävention (Albrecht).

Rechtswirklichkeit und Effizienz der akustischen Wohnraumüberwachung ("großer Lauschangriff") nach $\S 100$ c I Nr. 3 StPO (Albrecht).

Migrationserfahrungen und Kriminalisierung von jugendlichen Spätaussiedlern im nationalstaatlichen Kontext (Albrecht).

Organisierten Kriminalität als strafrechtlich eigenständiger Tatbestand (Albrecht).

Cybercrime und strafrechtliche Kontrolle (Albrecht).

Makroviktimologische Perspektiven bei der Aufarbeitung des jugoslawischen Bürgerkrieges (Albrecht).

Implementation und Evaluation von Finanzermittlungen (Albrecht).

Prinzipien von Täterschaft und Teilnahme im englischen Strafrecht (Albrecht). 
Rohne, Holger-C. Gesellschaftsspezifische Reaktionen auf Viktimisierungen und ihre Bedeutung im interkulturellen Kontext - eine viktimologische Untersuchung im Kontext des israelisch-palästinensischen Konflikts (Albrecht).

Saux, Maria Soledad Terrorismusbekämpfung in der E.U.: Auswirkungen auf das Asyl- und Einwanderungsrecht (am Beispiel Spaniens und Deutschlands) (Albrecht).

Schäfer, Carsten Drogenkonsum und Strafverfolgungspraxis (Albrecht).

Tavcer, Scharie Causal Factors in the Crime of Trafficking of Women for Sexual Exploitation from Moldova (Albrecht).

von Oppeln-Bronikowski,

Constanze Die Übertragung konfliktbedingten Opfererlebens auf die zweite Generation am Beispiel der Kriegsopfer im ehemaligen Jugoslawien (Albrecht).

Wang, Ying Vergleichende Untersuchung des deutschen und chinesischen Medizinstrafrechts (Albrecht).

Wen, Fan Kriminelle Karrieren und Kriminalprävention - Eine vergleichende empirische Studie aus der Perspektive von Straftäter und Justiz (Albrecht).

Winterer, Heidi Strafverfolgung bei Gewalt im sozialen Nahbereich - Entwicklungen und Tendenzen am Beispiel der Staatsanwaltschaft Freiburg (Albrecht).

Zimmerling, Diana Gewaltkriminalität im Lebenslauf - Eine Längsschnittanalyse von Gewalttätern anhand der Daten der Freiburger Kohortenstudie (Albrecht).

Folgendes Habilitationsverfahren wurde im Jahr 2003 abgeschlossen:

Kinzig, Jörg

"Die rechtliche Bewältigung von Erscheinungsformen organisierter Kriminalität". Verleihung der "venia legendi" für die Fächer Strafrecht, Strafprozessrecht, Kriminologie, Jugendstrafrecht und Strafvollzug (17.7.2003). 


\section{EDV und BIBLIOTHEK}

\section{EDV}

\subsection{Interne und externe Informationsdienste, Internet-Repräsentation, Angebote, Informationsmanagement}

\section{Internet-Repräsentation}

Der steigende Trend in der Nachfrage nach Informationen auf den Web-Seiten des Institutes setzte sich fort. So stieg die durchschnittliche Anzahl an Besuchen pro Tag von 403 im November 2001 über 692 (November 2002) auf 823 (November 2003). Hier spiegelt sich sicher der allgemeine Anstieg in der Nutzung des Internets wieder. Die leichte Abflachung des Trends liegt vermutlich auch am - inzwischen leicht veralteten - Design der Seiten und der relativ "tiefen" Verschachtelung derselben. Im Frühjahr 2004 ist eine Umstellung auf eine modernere, am Web-Design der MPG angelehnte Gestaltung geplant. Hierbei wird das in der Startphase befindliche Projekt "Content Management System für die juristischen Institute in der MPG" (s.u.) wertvolle Dienste leisten. Die Abbildungen ${ }^{1} 1$ und 2 zeigendie Anzahl der Zugriffe für das jeweilige Jahr. In den Detailstatistiken (die im Intranet verfügbar sind) zeigt sich ein hohes Interesse an den Online-Publikationen und an konkreten Forschungsinhalten. Insbesondere kurze Abstracts und andere Publikationen finden sich regelmäßig unter den "Top Ten" der abgefragten Seiten.

\section{Domains}

Um die Auffindbarkeit des Instituts im WWW zu verbessern, wurden mehrere Domänen reserviert. So führen zum Beispiel die URLs www.mpi-kriminologie.de und www.strafrecht.de auf die allgemeine Homepage des Instituts. Unter dem Link www.mpi-freiburg.de befindet sich die von unserem Institut zur Verfügung gestellte gemeinsame Homepage der Max-Planck-Institute in Freiburg. Diese URL führt auch zu den Web-Kameras (Webcams) des Instituts. Diese zeigen den Blick vom Dach des Instituts über die Dächer des Stadtteils Wiehre bis zum Freiburger Münster und zum Schlossberg. Die Bilder werden im Abstand von 5 Minuten aktualisiert.

Für das Projekt "Association of Institutes for the Development of an Organised and Economic Crime Agenda in Europe (AIDA)" wurde eine eigene Homepage (www.aida-eu.org) mit einer Datenbank als Prototyp eingerichtet. Im Rahmen des aktuellen CEPOL-Projekts, in dessen Rahmen im Auftrag der Europäischen Polizeiakademie eine wissenschaftliche Datenbank zu polizeirelevanten Forschungen konzipiert und implementiert wird, konnte der in der MPG entwickelte e-DOC-Server modifiziert und für die Zwecke der Kooperation der europäischen Polizei angepasst werden. Der e-DOC-Server dient der Verwaltung und Veröffentlichung von digitalen Dokumenten und stellt im Prinzip eine Mischung zwischen einem Publikations- und Redaktionswerkzeug und einer digitalen Bibliothek dar. Die im Rahmen dieser beiden Projkete erworbenen Kenntnisse flossen direkt in die weitere Entwicklung der Software und ermöglichen deren Einsatz für weitere Projekte am MPI.

1 Bitte beachten Sie, dass die Grafiken nicht dieselbe Skala besitzen. Auffällig ist der Rückgang der Zugriffe im Juli und August 2003 (Abb. 2). Man könnte spekulieren, dass der heiße Sommer möglicherweise der Grund war. 


\section{Informationsmanagement}

Der hauptsächlich von der Bibliothek übernommene Bereich des Informationsmanagements wurde von der EDV-Abteilung im technischen Bereich aktiv unterstützt. Besonders erwähnt sei hier neben den externen Literaturdatenbanken eine von zwei Mitarbeitern gepflegte Literaturdatenbank mit Artikeln aus kriminologischen Zeitschriften. Diese Datenbank enthält inzwischen annähernd 3000 Artikel aus diesen Zeitschriften und ist intern im Haus recherchierbar. Weiterhin im Mittelpunkt des institutsinternen Informtionssystems steht freilich auch weiterhin der im Jahr 2000 eingeführte Web-OPAC. Dieser wurde kontinuierlich weiterentwickelt und wird - obwohl er mit der Einführung der neuen Bibliothekssoftware obsolet wird - möglicherweise beibehalten, da er eine "unscharfe" Suche und somit einen anderen, wertvollen Blick auf die Bestände der Bibliothek ermöglicht. Dieser Suchservice hat sich insbesondere für schnelle ad-hoc-Suchläufe vom Arbeitsplatz der Mitarbeiter aus als überaus nützliche Arbeitshilfe erwiesen, die oftmals schneller zu den gewünschten Ergebnissen führt als andere, aufwändigere Suchstrategien.

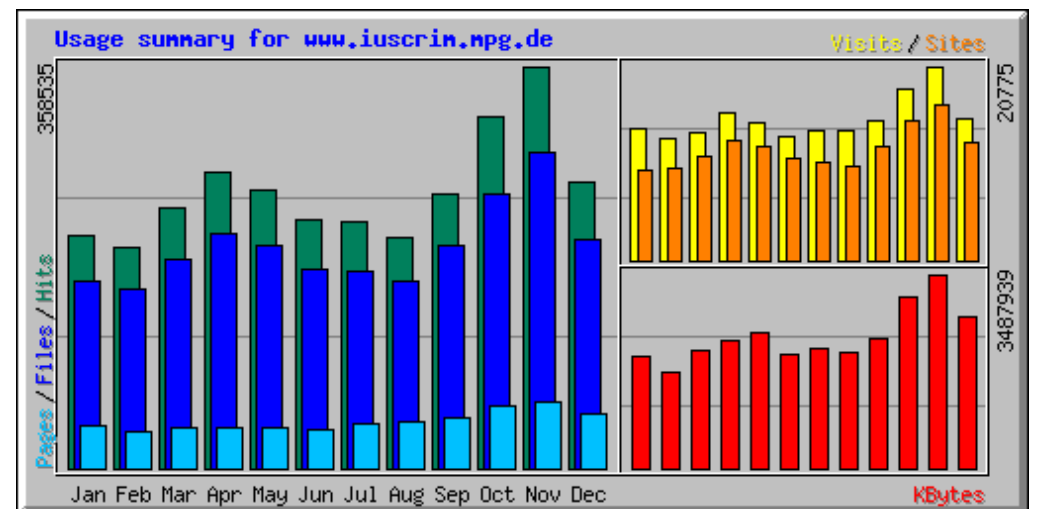

Abb. 1: Nutzung von ,iuscrim.mpg.de“ im Jahr 2002

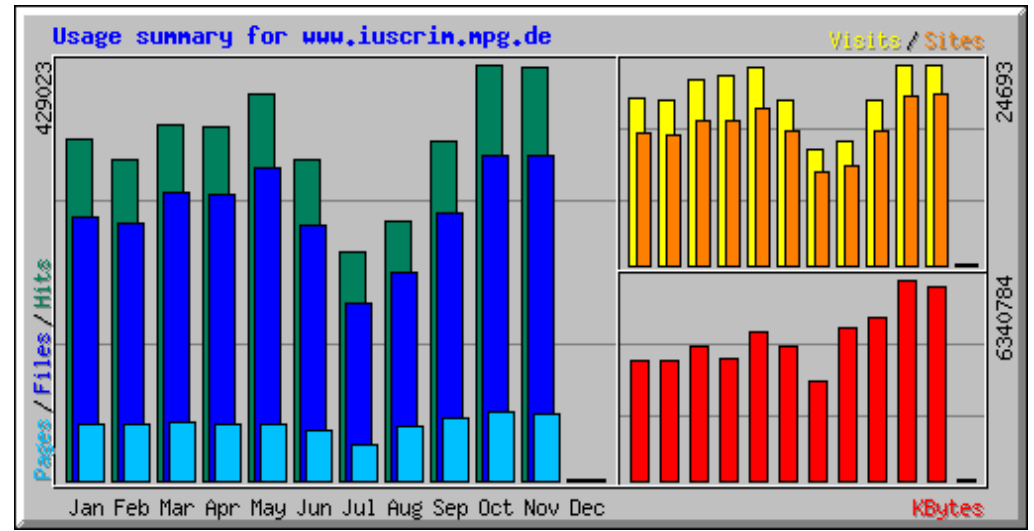

Abb. 2: Nutzung von "iuscrim.mpg.de" im Jahr 2003 


\subsection{Beschaffung, Umbau}

Neben dem Austausch von ca. 120 Arbeitsplatzrechnern gab es eine Reihe größerer Beschaffungen, die im Falle der Backup- und der SAN-Lösung im Zusammenhang mit einem erfolgreichen BAR ${ }^{2}$ Antrag standen. Ende des Jahres 2002 wurde dem Institut der Antrag auf eine Backup-Lösung mit der Software "Tivoli Storage Manager" genehmigt. Dieses System ging - nach anfänglichen Schwierigkeiten, da die von IBM angekündigte Software erst ein halbes Jahr später zur Verfügung stand - im August 2003 in Betrieb. Es besteht aus zwei getrennten Backup-Servern, einem für das allgemeine Netzwerk und einem für das abgeschottete Netzwerk der Kriminologie. Beide Server sind mit Bandrobotern (so genannte "Tape-Libraries") verbunden, die eine Kapazität von über 10 Terabyte besitzen. Für die Organisation der wiederkehrenden Abläufe wurde eine "Backup-Policy" entworfen, die im Moment noch modifiziert wird. Diese Policy soll, wenn genug Erfahrungen mit dem System gesammelt wurden, festgeschrieben werden. Im Moment werden 5 Versionen von aktiven und 2 Versionen von gelöschten Dateien vorgehalten, so dass irrtümlich überschriebene oder gelöschte Dateien wiederhergestellt werden können. Nach der Einführung der zentralen File-Server, die es den Mitarbeitern ermöglichen, von jedem beliebigen PC aus zu arbeiten, stellte sich leider heraus, dass die Technik zwar wie projektiert funktionierte, aber nicht stabil genug war. Da bei einem Ausfall der Server alle Mitarbeiter an den PC nicht weiterarbeiten können, wurde ein Antrag auf ein "Storage-Area-Network" (SAN) gestellt. In der beantragten Lösung sind sämtliche Ressourcen redundant angelegt und bei einem Ausfall kann sehr schnell umgeschaltet werden. Die entsprechende Hardware wurde Ende 2003 geliefert und soll so schnell wie möglich in Betrieb genommen werden. Auch dieses Projekt konnte mit BAR-Mitteln finanziert werden.

Bereits im Jahr 2002 wurde mit der Einführung der Terminalserver eine Möglichkeit gefunden, teuere, aber selten benötigte Software-Lizenzen allen Mitarbeitern am Arbeitsplatz zur Verfügung zu stellen. Das System und die damit verbundene Lizenzkontrolle hat sich sehr gut bewährt und soll weiter ausgebaut werden. Im Zuge der Inbetriebnahme der Web-Cams wurde der Glasfaser-Backbone installiert. Die wichtigsten EDV-Verteiler sind nun auch noch durch Glasfaser verbunden, die eine sehr viel höhere Bandbreite ermöglicht als die bereits installierte Kupferverkabelung.

\subsection{Konsolidierung und Umstrukturierung}

Die bereits in den früheren Jahren angestrebte Konsolidierung zur Vereinfachung und Rationalisierung der Arbeitsabläufe wurde weiter vorangebracht. Die Verteilung von Anwendungs-Software erfolgt nun automatisch auf Anforderung der Nutzer. Dadurch werden die EDV-Mitarbeiter stark entlastet und die Kontrolle der Lizenzen sowie die Aktualität der Programme ist gewährleistet. Mit der Migration der letzten Arbeitsplätze konnte das alte Netz abgeschaltet werden. Alle Arbeitsstationen im Haus befinden sich jetzt hinter der Firewall.

Durch die zentralen Netzwerkdrucker konnte der Aufwand zur Druckerwartung reduziert werden. Allerdings ist diese Lösung noch unbefriedigend bei vertraulichen Ausdrucken; die beabsichtigte Kostenkontrolle bereitet ebenfalls noch Probleme. Zur Lösung dieser Probleme wurde im Laufe des Jahres 2003 eine spezielle Software ausgiebig getestet, die im Zusammenhang mit den Ausweisen der Zugangskontrolle das vertrauliche Drucken und eine Abrechnung des individuellen Druckvolumens ermöglicht. Diese Software kann aus finanziellen Gründen leider erst im nächsten Jahr eingeführt werden und wird sich - bei sehr konservativer Schätzung - innerhalb von höchstens 2 Jahren amortisieren.

2 Der BAR ist der Beratende Ausschuss für Rechenanlagen in der MPG, er wird vom Präsidenten berufen und berät diesen. Er entscheidet über die Vergabe von EDV-Mitteln über $50 \mathrm{~T} €$. 


\subsection{Sicherheit}

Die Sicherheit im Bereich der EDV war auch in den letzten zwei Jahren ein beherrschendes Thema. In vielen Bereichen wurde das Sicherheitskonzept weiter optimiert. Auf diese Anstrengungen ist sicherlich auch zurückzuführen, dass es im Berichtszeitraum keinerlei sicherheitsrelevante Vorkommnisse gab. Die PIX Firewall der Firma Cisco, die seit Ende 2001 in Betrieb ist, hat sich nach kleineren Anlaufschwierigkeiten sehr gut bewährt. Besonders der Betrieb im "Failovermode", bei dem beim Ausfall der primären Maschine eine zweite die Funktion übernimmt, ist sehr erfolgreich.

Durch die Einführung eines "Software Update Servers" kann gewährleistet werden, dass sich alle Computer im Haus auf dem neuesten Softwarestand befinden. Hierdurch wird verhindert, dass schlecht gewartete Maschinen, wie es in der Vergangenheit im Internet immer wieder beobachtet wurde, als Verteiler von Viren bzw. Würmern oder als Einfallstore für Hacker dienen. Nachdem die zentrale Virenscanner-Lizenz der MPG für McAfee abgelaufen war, wurde dieser mit einer eigenen Lizenz nur noch auf dem zentralen Mailserver eingesetzt. Auf sämtlichen anderen Rechnern im Haus ist hingegen der neue Sophos Virenscanner aktiv. Auch hier sorgt eine zentrale Verwaltung der Updates für die entsprechende Aktualität. Allein im Jahr 2003 wurden über zehntausend (!) Viren erfolgreich abgewiesen. Seit mehreren Jahren trat hausintern keine Vireninfektion mehr auf. Um der wachsenden Flut von "Spam"-mails Herr zu werden, installierte die EDV das Programm "Spamassassin" auf dem zentralen Mailserver. Dadurch kann ein großer Anteil von "Spam" bereits im Vorfeld markiert und von den Empfängern dann automatisch ausgesondert werden. Leider ist die Erkennungsrate noch nicht so hoch wie es wünschenswert wäre, sodass eine weitere Verfeinerung der Filter notwendig ist.

Vom 7. bis zum 9.5.2003 wurde der zweite Workshop zur Computersicherheit in der MPG im Hause durchgeführt. Die über 50 Teilnehmern aus der gesamten MPG und anderen Forschungseinrichtungen sowie aus der Industrie nahmen an Diskussionen, Vorführungen und 25 verschiedenen Vorträgen über relevante Themen teil. Das Treffen erwies sich wie schon die erste derartige Veranstaltungals großer Erfolg. Von denTeilnehmern wurde daher der Wunsch geäußert, den Workshop mit einem Schwerpunkt zum Computerrecht zu wiederholen.

Um eine schnelle Reaktion bei Ausfällen von Angeboten wie Serverdiensten, Internetanbindung und Druckern zu gewährleisten wurden mehrere Formen zur Überwachung dieser Ressourcen installiert. Die Benachrichtigung der zuständigen EDV-Mitarbeiter erfolgt per e-mail bzw. per sms auf das jeweilige Mobiltelefon. Die Software "what's up" überwacht in der Hauptsache Serverdienste, die Internetanbindung und Netzwerkverteiler und löst die Benachrichtigung aus. Mit der Software "MRTG" (multi router traffic grapher) wird der Datenverkehr zwischen den einzelnen Komponenten und auch mit dem Internet überwacht. Hier können Unregelmäßigkeiten im Datenaufkommen erkannt und teilweise diagnostiziert werden.

\subsection{Sonstiges}

Auch in den Jahren 2002/2003 gehörten interne Schulungen von Mitarbeitern zu den regelmäßigen Angeboten der EDV-Abteilung. Hierzu zählen insbesondere Einführungen in das Arbeiten und Präsentieren mit Power Point und die Erstellung von Graphiken mit Excel. Diese Programme werden von den Wissenschaftlern immer häufiger genutzt.

Die Kooperation mit anderen MPI im EDV-Bereich ist ein weiterer Arbeitsschwerpunkt. Neben der Teilnahme an den sehr aufwändigen Planung des gemeinsamen Content Management Systems der juristischen Institute, der Mitarbeit am e-Doc Projekt und der Teilnahme und Organisation an und von mehreren Workshops istin Kooperation mit der Generalverwaltung, dem MPI für Immunbiologie und 
der GWDG die Organisation und Durchführung der DV-Treffen der MPG mit über 200 Teilnehmern in den nächsten zwei Jahren geplant.

\subsection{Planung}

Aufgrund fehlender Personalressourcen bzw. Investitionsmittel konnten diverse Projekte bisher nicht in Angriff genommen werden. Notwendig erscheinen insbesondere die folgenden Vorhaben:

Überwachung von Temperatur und Umweltbedingungen in den Netzwerk- und Serverschränken. Im Sommer kam es zu einer starken Temperaturerhöhung und dadurch wurde eine USV beschädigt. Um solche Ausfälle und andere Schäden zu verhindern, bzw. die Komponenten überwachen zu können, ist die Integration in das bestehende Überwachungssystem geplant.

Der weitere Ausbau des Netzwerks im Haus wird durch die Aufstellung von Computern in den Lesesälen und im Freihandbereich der Bibliothek erforderlich, da es hier bislang zu Engpässen kommt. Im Zuge der Einführung des SAN wird eine Erhöhung der Bandbreite zwischen zentralen Netzwerkkomponenten von $100 \mathrm{Mbit} / \mathrm{s}$ auf $1 \mathrm{Gbit} / \mathrm{s}$ möglich sein.

Das bereits seit mehreren Jahren angestrebte "Haus-Informations-System", eine Datenbank zur Verwaltung von Mitarbeitern, Gästen, Ressourcen und Adressen kann - die Freigabe der nötigen Mittel vorausgesetzt - im nächsten Jahr durchgeführt werden. Diese Datenbank ist eine Modifikation eines Systems, das beim Institut für Informatik der Universität Freiburg eingesetzt und betrieben wird.

Mit der Einführung eines VPN-Gateway (Virtual Private Network) soll ein verschlüsselter Zugang vom Internet auf die Ressourcen des Instituts ermöglicht werden. Dies ist vor allem für den Zugriff von Mitarbeitern von Heimarbeitsplätzen oder für die Anbindung der reisenden Wissenschaftler gedacht.

Durch das hohe Sicherheitsbedürfnis im Hause wurde die Einführung eines Funk-LAN (Local Area Network), das einen relativ hohes Sicherheitsrisiko mit sich bringt, bisher verzögert, da andere Projekte eine höhere Priorität hatten. Es steht zu hoffen, dass dies zusammen mit dem VPN-Gateway durchgeführt werden kann.

Nach wie vor ist eine der Hauptherausforderungen die Rationalisierung und Automatisierung von wiederkehrenden Abläufen, sowohl im Bereich der EDV-Organisation als auch im Arbeitsablauf des Hauses. Es ist sicherlich möglich durch geeignete Investition in bestimmte Bereiche in anderen Geld zu sparen (vgl. oben: Follow-Me-Printing). Auch können einige Projekte aufgeschoben und so die erforderlichen Mittel reduziert werden. Jedoch ist ein Verzicht auf langfristige, wohldurchdachte Investitionen im Bereich der EDV auf Dauer nicht ratsam, um einigermaßen auf dem Stand der Technik zu bleiben und nicht ins Hintertreffen zu geraten. Solange diese Voraussetzungen erfüllt werden, steht einer weiteren positiven Entwicklung nichts im Wege. 


\section{Bibliothek}

\section{$2.1 \quad$ Überblick}

Im Berichtszeitraum überstieg der Bestand unserer Bibliothek die runde Zahl von 350.000 Bänden. Die Bibliothek hat sich damit als eine der weltweit umfangreichsten Sammlungen strafrechtlicher und kriminologischer Literatur behaupten können.

Diese Stellung der Bibliothek in der internationalen Forschungslandschaft verdanken wir maßgeblich Herrn Professor Dr. Josef Kürzinger, der zum 30. Juni 2003 in den Ruhestand getreten ist. Seit seinem Amtsantritt am 1. August 1976 baute er die Bibliothek von 120.000 Bänden auf die jetzige Größe aus.

Seine Nachfolge in der Leitung der Bibliothek trat zum 1. Juli 2003 Frau Elisabeth Wynhoff an.

In der Bibliothek ist in den Jahren 2002 und 2003 als neuer Tätigkeitsschwerpunkt das Sammeln und Bereitstellen von Informationen, die in elektronischer Form vorliegen, neben den "klassischen" Bestandsaufbau (Erwerbung von Monographien) getreten. In engem Zusammenhang dazu steht die Einführung des neuen Bibliothekssystems ALEPH, mit dessen integriertem OPAC die Daten der Bibliothek erstmals laufend aktualisiert im Internet zur Verfügung gestellt werden können.

\subsection{Personal}

In der Bibliothek waren am 31. Dezember 2003 beschäftigt: 1 wiss. Mitarbeiterin (Leitung der Bibliothek), 5 Diplombibliothekarinnen (davon 3 Ganztags- und 2 Halbtagskräfte), 1 Bibliothekarin, 1 Buchhändlerin, 1 Angestellte, 1 Zeithilfe (halbtags).

Insgesamt waren beschäftigt: 6 Personen ganztags (100\%), 3 Personen halbtags (50 \%) und 1 Person zu 80,52 \%. Hinzu kommen studentische Hilfskräfte (stundenweise).

Die Personallage gestaltete sich im Berichtszeitraum zunehmend schwierig: Zwar konnten größere krankheitsbedingte Ausfälle durch Überstunden sowie durch Straffung der Arbeitsabläufe aufgefangen werden. Nicht ausgeglichen werden konnte aber der Wegfall der Planstelle "Schlußstelle/Magazin" zum September 2003. Übergangsweise - zunächst bis zum 30. Juli 2004 - werden die in diesem Bereich anfallenden und für den laufenden Betrieb der Bibliothek notwendigen Arbeiten durch eine Zeithilfe (halbtags) sowie durch studentische Hilfskräfte (40 h/Monat) erledigt. Für die Zeit nach dem 30. Juli 2004 muss eine dauerhafte und praktikable Lösung aber noch gefunden werden.

\subsection{Etat und Verteilung der Mittel}

Für Erwerbungen und Einband wurden im Berichtszeitraum verwendet:

$\underline{2002}$

$\underline{2003}$

Im Haushaltsplan veranschlagt:

537.000,00 EUR

604.000,00 EUR

Kürzungen:

$-17.312,00$ EUR $\quad-54.211,00$ EUR

519.688,00 EUR $549.789,00$ EUR 
Davon wurden ausgegeben

$\underline{2002}$

für Bücher und Fortsetzungen:

für Periodika:
241.842,00 EUR

262,631,00 EUR $\underline{2003}$

256.501,00 EUR

280.398,00 EUR

für die Benutzung von OnlineDatenbanken und Bibliothekssoftware:

\begin{tabular}{rr}
$15.215,00 \mathrm{EUR}$ & $12.890,00 \mathrm{EUR}$ \\
\hline $519.688,00 \mathrm{EUR}$ & $549.789,00 \mathrm{EUR}$
\end{tabular}

Im Jahr 2003 (2002) wurden für strafrechtliche Literatur 426.685,00 EUR (392.241,00 EUR) und für kriminologische Literatur 110.214 EUR (112.132,00 EUR) aufgewendet. Dies entspricht einer prozentualen Verteilung von 79 (78) \% zu 21 (22) \%. Die Ausgaben für den Einband betrugen 25.685,00 EUR (26.630,00 EUR).

\subsection{Bestand und Zuwachs}

Zum 31.12.2003 beläuft sich der Gesamtbestand der Bibliothek auf ca. 364.600 Bände, davon sind ca. 88.400 Bände Zeitschriftenbände.

Der Zuwachs der Bibliothek betrug im Jahre 2003 (2002) 7.993 (7.603) Bände. Hiervon sind 4.956 (4.546) Bände Monographien und Fortsetzungen und 3.037 (3.057) Bände Zeitschriftenbände.

Die Neuerwerbungen verteilen sich wie folgt auf die fachlichen Gruppen:

$\underline{2002} \underline{\mathbf{2 0 0 3}}$

\begin{tabular}{lrr} 
Strafrecht & 4.945 Bände $(65 \%)$ & 5.388 Bände $(67 \%)$ \\
Strafrecht, allg. & 171 Bände $(2 \%)$ & 190 Bände $(2 \%)$ \\
Kriminologie & 1.825 Bände $(24 \%)$ & 1.813 Bände $(23 \%)$ \\
Kriminologie allg. & 662 Bände $(9 \%)$ & 602 Bände $(8 \%)$ \\
\hline Gesamt: & 7.603 Bände (100 & 7.993 Bände $(100$ \\
$\%)$ & $\%)$
\end{tabular}

\subsection{Digitale Informationsversorgung und Internet}

Die Bestände und Informationen der Bibliothek, die in elektronischer Form vorgehalten werden, sind den Benutzern über Intranet und Internet zugänglich. Im Berichtszeitraum 2002 und 2003 wurde das Angebot an digitalen juristischen Informationen und Volltexten stark erweitert. $\mathrm{Zu}$ nennen sind hier insbesondere der Zugang zu Beck-online (mit Volltexten der NJW, NStZ, und NStZ-RR etc. sowie den Volltexten vom Schönke/Schröder, KK-StPO und KK-OWiG) und der Online-Zugang zu LexisNexis. LexisNexis ergänzt als internationale, schwerpunktmäßig den nordamerikanischen und britischen Bereich abdeckende juristische Datenbank das am Institut vorhandene Angebot an Datenbanken und CD-ROMs zum deutschen Recht (u.a. JurisWeb, BGH-Nack, BGHE/Strafsachen, BGHSt auf CD$\mathrm{ROM})$. 
Der Zugriff auf die rechtwissenschaftlichen Online-Datenbanken, auf die von der Bibliothek abonnierten CD-ROMs und auf die e-journals erfolgt über die Intranetseiten der Bibliothek ("Serviceangebote der Bibliothek"; Einstiegsseite: http://www.iuscrim.mpg.de/intranet/infoman/infostart.html).

Die Bibliothek hat im Berichtszeitraum begonnen, eine Sammlung mit kriminologischen Links aufzubauen, deren Gliederung der Bibliothekssystematik entspricht. Neben externen Links werden auch die (kriminologischen) Online-Publikationen des Instituts in die Linksammlung aufgenommen. Die Start-Version dieser Linksammlung ist im Intranet zugänglich.

Neu eingerichtet wurde die Rubrik "Gesetzgebung aktuell" mit einer Auflistung der aktuellen Anfragen, Anträge, Gesetzentwürfe und Verhandlungen des Bundestags und Bundesrat sowie des Landtags Baden-Württemberg, die einen Bezug zum Strafrecht, Strafvollzug, Polizeirecht und anderen einschlägigen Gebieten aufweisen. Dazu werden die Papierausgaben der Bundestags-Drucksachen, der Bundesrats-Drucksachen, der stenographischen Berichte des Bundestags sowie des Bundesrats und der Landtags-Drucksachen von Baden-Württemberg laufend ausgewertet. Sofern die Materialien zum Zeitpunkt ihres Eingangs bereits in den Datenbanken des Bundestages und Bundesrates sowie des Landtags Baden-Württemberg im Volltext vorgehalten werden, werden die Angaben von uns entsprechend verlinkt.

Mitte 2002 wurde die Bibliothekssystematik, nachdem der Text der einzelnen Systematikstellen mit dem Text der entsprechenden Suchanfrage im Web-OPAC (http://opac.iuscrim.mpg.de/) hinterlegt und mit dem Web-OPAC verlinkt worden war, als Html-Dokument ins Internet gestellt

(http://www.iuscrim.mpg.de/bib/systematik.html). Nunmehr ist anhand der Bibliothekssystematik eine direkte sachliche Suche im Web-OPAC möglich.

Die Internetseiten der Bibliothek (Startseite: http://www.iuscrim.mpg.de/bib/bibliothek.html) wurden im Layout umfassend neu gestaltet.

\subsection{Benutzung}

Im Jahr 2003 (2002) wurde die Bibliothek von 799 (868) externen Benutzern in Anspruch genommen. Im Vergleich zu den Vorjahren ist die Anzahl der Benutzer deutlich angestiegen und erreichte den höchsten Stand seit 1997.

Im Frühjahr 2003 wurden weitere 10 Lesesaal-Arbeitsplätze mit PCs und Internet-Zugang ausgestattet, so dass nunmehr an 20 der insgesamt 40 Lesesaal-Arbeitsplätze auf das Internet und auf die von der Bibliothek angebotenen Datenbanken und CD-ROMs zugegriffen werden kann. Zusätzlich wurden $\mathbf{5}$ Tagesgast-Plätze mit PCs und Rollwägen zur Aufbewahrung der ausgeliehenen Bücher ausgestattet. Diese Arbeitsplätze bieten seitdem die gleiche Ausstattung wie die Lesesaal-Arbeitsplätze und werden von den Institutsgästen bei starker Belegung der Lesesäle gut angenommen. In den Sommermonaten, in denen die Zahl der Institutsgäste stark anzusteigen pflegt, konnte dadurch eine Überbelegung der Lesesaal-Plätze vermieden werden.

Eine wichtige Ergänzung zur persönlichen Betreuung durch das bibliothekarische Fachpersonal stellt unsere Faltblatt-Reihe BibInfo dar, in der wir unseren Benutzern Bedienungsanleitungen und Benutzungshilfen anbieten. 2002 und 2003 brachten wir neu heraus:

- $\quad$ Einführung in die Bibliotheksbenutzung (BibInfo 02)

- $\quad$ Library Guide for Visitors to the Institute (BibInfo 02E)

- $\quad$ Map of the Institute (BibInfo 01E)

- $\quad$ Systematik der Bibliothek (BibInfo 05).

Im Jahr 2003 (2002) wurden 224 (199) Fernleihbestellungen positiv erledigt. 


\subsection{Projekte}

\subsubsection{Umstellung auf ein neues EDV-System der Bibliothek (Aleph)}

Im Berichtszeitraum wurde die Umstellung auf das neue EDV-System der Bibliothek (Aleph) vorbereitet. Der Wechsel des Bibliothekssystems war notwendig geworden, weil das seit 1993 in der Bibliothek eingesetzte und inzwischen veraltete Bibliothekssystem BIS den Anforderungen des Internet nicht gewachsen war. So waren für die Anzeige unserer Bibliotheksdaten im WWW zeitraubende Arbeitsschritte notwendig, und nur einmal wöchentlich konnte der Datenbestand auf den neuesten Stand gebracht werden. Darüber hinaus wird das BIS vom Hersteller in naher Zukunft nicht weiter gepflegt.

Die besondere Stärke des neuen Bibliothekssystems Aleph liegt in der Aufbereitung der Bibliotheksdaten in einem integrierten OPAC. Unmittelbar nach der Titeleingabe neuer Bücher stehen die Daten "worldwide" im Web zur Verfügung.

Die Vorbereitung der Systemumstellung erfolgte im Rahmen eines zentralen Projekts der Max-PlanckGesellschaft. Dank der hervorragenden Zusammenarbeit mit den Bibliotheken des Max-PlanckInstituts für ausländisches öffentliches Recht und Völkerrecht in Heidelberg und des Max-PlanckInstituts für ausländisches und internationales Privatrecht in Hamburg sowie der GWDG in Göttingen verliefen die vorbereitenden Arbeiten zur Implementierung des neuen Bibliothekssystems weitgehend reibungslos.

Die Arbeiten waren zu Jahresende soweit fortgeschritten, dass der Betrieb von Aleph in den Bereichen Erwerbung und Katalogisierung im Januar 2004 aufgenommen werden kann.

\subsubsection{Retrospektive Katalogisierung}

Zug um Zug soll der Kartenkatalog, der die bis 1992 angeschaffte Literatur nachweist, in den elektronischen Katalog (Web-OPAC) umgeschrieben werden. Im Berichtszeitraum wurde diese so genannte "retrospektive Katalogisierung" fortgeführt und deutlich forciert: Insgesamt konnten 9.129 Buchtitel aus den Altbeständen im elektronischen Bibliothekssystem katalogisiert werden, während es in den Jahren 2000 und 2001 noch 5.350 Titelaufnahmen gewesen waren (plus $71 \%$ ).

Seit Aufnahme der retrospektiven Katalogisierung bis zum 31.12.2003 wurden die Bestände der Notationsgruppen Deutschland, Frankreich, Großbritannien, Italien, Liechtenstein, Österreich, "Recht und Medizin" sowie Schweden erfaßt.

Darüber hinaus wurde im Berichtszeitraum das 1993 begonnene Konversionsprojekt des kriminologischen Altbestandes ("RetroKrim-Projekt") aufgegriffen und erfolgreich beendet. Die 1993 von einer Fremdfirma erfassten Datensätze des kriminologischen Bestandes (35.925 Datensätze) waren der Bibliothek auf Magnetbändern in einem fehlerhaften Datenformat geliefert worden und konnten zunächst nicht in die BIS-Datenbank integriert werden. Das Projekt kam daher 1994 zum Stillstand. Im Herbst 2002 wurde das Projekt in Zusammenarbeit mit der EDV-Abteilung wieder aufgenommen, und die Daten wurden durch die Firma ExLibris eingespielt. Die anschließende Datenanalyse ergab allerdings, dass jeder einzelne Datensatz noch bibliothekarisch nachbearbeitet werden musste. Im 1. Halbjahr 2003 wurden daher in einer Sonderaktion, die mit hohem Engagement vom gesamten Personal der Bibliothek durchgeführt wurde, sämtliche Datensätze nachbearbeitet. Die in der Bibliothek vorhandene kriminologische Literatur ist seitdem vollständig im Web-OPAC nachgewiesen.

Die retrospektive Erfassung der Altbestände ist die Grundvoraussetzung für den mittelfristig geplanten Einsatz der elektronischen Buchausleihe. Obwohl im Berichtszeitraum durch Optimierung der Arbeitsabläufe beachtliche Zuwachszahlen bei der retrospektiven Konversion erzielt werden konnten, 
kann die Erfassung des Altbestandes (noch ca. 170.000 Karteikarten) mit dem vorhandenen Personal in absehbarer Zeit nicht beendet werden. Wir regen daher für 2004/2005 die Durchführung eines Sonderprojektes an.

\subsubsection{Zusammenführung des Sonderbestandes "Recht und Medizin"}

Die Altbestände der rechtsmedizinischen Literatur (Erscheinungsjahr vor 1999), die bisher getrennt nach Ländern unter vier Systematikstellen aufgestellt waren, wurden im Jahr 2002 in den seit 1999 bestehenden Sonderbestand "Recht und Medizin" eingegliedert. Für den Benutzer ist damit die gesamte Literatur zum Thema leicht greifbar. Gleichzeitig wurde mit der Zusammenführung der Bücher dringend benötigter Stellplatz im Länderteil Deutschland frei.

Insgesamt wurden 1.770 Bücher umsigniert, neu beschriftet und am neuen Standort aufgestellt. Rund $20 \%$ (368) der Bücher waren zuvor nur im Kartenkatalog verzeichnet gewesen. Diese Bücher wurden während des Projektes retrospektiv katalogisiert, so dass der Bibliotheksbestand an rechtsmedizinischer Literatur nun auch vollständig im Web-OPAC nachgewiesen ist. Darüber hinaus war mit dem Projekt eine Inventur des rechtsmedizinischen Bestandes verbunden.

\subsubsection{Bibliographie "New Criminological Literature in Europe"}

Die Bibliotheksleitung redigiert weiterhin die in der Zeitschrift "European Journal of Crime, Criminal Law and Criminal Justice" erscheinende Bibliographie neuer kriminologischer Literatur in Europa. 